\title{
Galicia no tempo de Afonso X
}

EDITORES

José M. Andrade Cernadas Simon R. Doubleday 





\section{Galicia no tempo de Afonso X}

Ed. José M. Andrade Cernadas e Simon R. Doubleday 


\section{Edita}

(c) CONSELLO DA CULTURA GALEGA, 2021

Pazo de Raxoi, 2 a andar

Praza do Obradoiro

15705 Santiago de Compostela

T 981957202 - F 981957205

correo@consellodacultura.gal

www.coonsellodacultura.gal

\section{Imprime}

Grafisant SL

\section{Deseño e maquetación}

Ekinocio

Depósito Legal: C 1911-2021

ISBN 978-84-17802-35-6

DOI: $10.17075 /$ gtax.2021

(c) dos textos

Os autores e autoras

(c) das imaxes

Archivo Histórico Nacional (Madrid); Arquivo Histórico Provincial de Ourense; Biblioteca Nacional de España; Biblioteca Nacional de Portugal; Biblioteca Nazionale Centrale di Firenze; Fundación Catedral de Santiago de Compostela; Real Monasterio de Santa Clara de Allariz; Real Biblioteca del Monasterio de El Escorial; SAMI Catedral de Santiago de Compostela: Arquivo da Catedral e Museo da Catedral 
Introdución

Repensando o paradigma do declive da Galicia medieval

José M. Andrade Cernadas e Simon R. Doubleday

Rethinking the paradigm of medieval Galician 'decline' $\quad$ P 25

Diplomatario galego de Afonso X

Francisco Javier Pérez Rodríguez

La piel del leopardo: Galicia y el ordenamiento territorial alfonsí

Francisco J. Hernández

Pontevedra, a cidade que floreceu na Baixa Idade Media: aden-

trándonos na dieta medieval a través dos restos humanos

Olalla López-Costas

Facerse presentes. As mulleres da familia real castelá e o reino de Galicia na culminación plenomedieval

Diana Pelaz Flores

Cara e cruz: conflito político, territorio e padroado rexio en Galicia durante o reinado de Afonso X e Violante de Aragón

Rosa Maㅡ Rodríguez Porto

Santa Clara de Allariz, historia dunha fundación real (ss. XIII-XV)

Mạ Beatriz Vaquero Díaz

Sabean quantos este liuro virem... A recepción galega do legado historiográfico e haxiográfico do Rei Sabio na primeira metade século XIV

Ricardo Pichel

As Antigüidades da Gallaecia na obra historiográfica de Afonso X

Helena de Carlos Villamarín

Afonso o Sabio na lírica trobadoresca galego-portuguesa: da historia literaria á política cultural

Henrique Monteagudo 



\section{Introdución Repensando o paradigma do declive da Galicia medieval}

José M. Andrade Cernadas e Simon R. Doubleday

DOI: $10.17075 /$ gtax.2021.001 

O paradigma tradicional da historia de Galicia na Baixa Idade Media é o do seu declive político e cultural: un declinar que, se ben non foi tan precipitado como a decadencia, derrota e desaparición de al-Andalus, comparte cando menos algunhas características en común. Gil Anidjar sinalou a existencia dunha preocupación historiográfica obsesiva coa fin de al-Andalus, subliñando a súa finitude e mais a súa pretendida excepcionalidade dun xeito que escurece os modos en que sobrevive e persiste a cultura andalusí en Iberia e máis alá. É un feito rechamante, escribe Anidjar, que «with al-Andalus, it is mostly to an irrevocable end and a catastrophic past that we are summoned and told we must bear witness»' ${ }^{1}$. De maneira semellante, unha ostensible recesión nos éxitos políticos da Galicia dos séculos XII e XIII é considerada xeralmente como un chanzo nun proceso de declive de longa duración, que culminaría inevitablemente nos chamados «séculos escuros». Este proceso, en principio, non remataría até o Rexurdimento do século XIX, case fatalmente interrompido pola ditadura de Franco ${ }^{2}$.

Esta suposta decadencia medieval en Galicia asóciase cos mesmos eventos que se perciben tradicionalmente como cruciais no comezo da fin de al-Andalus: entre outros, a conquista de Toledo, a unión definitiva das Coroas de Castela e León e a ocupación de Córdoba, Sevilla e outras partes de Andalucía nos últimos anos do reinado de Fernando III (m. 1252) e nos primeiros dos do seu fillo Afonso X (1252-1284). Porén, as narrativas teleolóxicas que suxiren a inestabilidade da «reconquista» cristiá non reflicten a viva realidade dese período, ou a incerteza que acompañaba as repetidas invasións dos imperios almorábide e marinida. E do mesmo modo que debemos desmitificar o ano 1492 como o derradeiro final das culturas andalusís, e cuestionalo como marcador dunha ruptura absoluta co pasado, tamén debemos interrogar as narrativas convencionais do declive galego por esas datas. Ben polo contrario, debemos estar alerta aos sinais que mostran a continuada importancia de Galicia na Iberia medieval, en termos políticos, económicos e culturais.

Hai un consenso xeral arredor da idea de que Galicia ocupou un papel central nos reinos cristiáns ibéricos entre os séculos IX e finais do XI. A inventio, no século IX, do sartego de Santiago polo bispo de Iria Flavia, Teodomiro, deulle a Galicia un papel central no imaxinario relixioso da cristiandade medieval, tanto na Península 
Ibérica como fóra dela ${ }^{3}$. No reino ás veces coñecido polos investigadores modernos como de Asturias-León e posteriormente de León, Galicia tiña un claro protagonismo tanto na política, como na economía ou no eido eclesiástico. Esta realidade é ben visible até o reinado de Fernando I e Sancha (1037-1065). Tanto o territorio ao norte do Miño, como as partes máis setentrionais do que hoxe en día é Portugal, eran o escenario privilexiado da actividade monárquica e eclesiástica e das loitas polo poder. A pesar de que o reinado de Fernando I foi considerado, en ocasións, como de xiro cara ao sur-leste, é dicir, cara á fronteira con Castela, o certo é que o rei centrou boa parte das súas enerxías na consolidación da súa autoridade en Asturias, León e Galicia, ao tempo que espallaba o territorio do seu dominio en Portugal ${ }^{4}$. A importancia de Galicia faise patente no Mapamundi do Beato de Burgo de Osma, elaborado - probablemente no mosteiro de Sahagún- no ano 1086 e no que Galicia ocupa un espazo ben prominente, que se corresponde coa meirande parte da Península Ibérica. Tanto a Torre de Hércules na actual cidade da Coruña, un punto de referencia na navegación atlántica, como a igrexa de Santiago son puntos destacados deste Mapamundi; o templo xacobeo debúxase, de feito, como o máis grande do mundo. Pola súa parte, a igrexa do recentemente conquistado Toledo ten unha representación claramente menor, semellando máis un castelo ou fortificación que unha igrexa 5 .

A toma de Toledo por Afonso VI no ano 1085 foi percibida tradicionalmente como unha data clave na historia ibérica, a partir da cal a fronteira sur se vai facendo cada vez máis importante e o extremo noroeste, Galicia incluída, tería perdido boa parte do seu peso específico no conxunto do reino de León-Castela. Temos sobradas evidencias de que a Coroa experimentou dificultades no control de Galicia ao longo deste período. Como sinalou Francisco Prado-Vilar, a última década do século XI foi unha época de tensións arredor da sucesión dinástica, que veu acompañada da inestabilidade provocada pola expansión territorial e mais polo cambio de rito relixioso. O rei centrou os seus esforzos na promoción á sucesión do seu fillo natural Sancho (nacido da súa relación coa súa amante musulmá Zaida) e tivo que confrontarse co partido borgoñón, particularmente cos seus xenros, os condes Raimundo e Henri$q^{2} e^{6}$. A decisión de Afonso VI de delegar responsabilidades no conxunto dos territorios previamente rexidos polo rei García (1065-1072), unha Gallaecia posromana que chegaba polo sur até o río Douro, tivo as súas consecuencias. Raimundo comezou a se intitular como Dei gratia comes et totius Galletie dominus sen facer referencia ningunha a Afonso; probablemente isto foi a causa que levou o rei Afonso a tomar a decisión de dividir estas terras usando o río Miño como fronteira xeográfica, e de conceder o

\footnotetext{
3 D’Emilio 2015b: 7.

4 Reilly/Doubleday (no prelo).

5 López Carreira/Andrade Cernadas 2020: 113-116.

6 Prado-Vilar 2009.
} 
condado de Portugal e mais o territorio de Coimbra ao conde Henrique, que estaba casado coa infanta Tareixa, filla ilexítima do rei

En calquera caso, é posible esaxerar o prolongado efecto destas dificultades, a progresiva marxinación de Galicia no século XII, e mesmo aínda a estratéxica división de responsabilidades por parte de Afonso VI, que á fin había de resultar permanente polo feito de que Portugal emerxeu dende entón como un reino independente. En termos culturais, o período que abrangue os séculos XI ao XIII foi definido por James D’Emilio como un dos máis dinámicos na historia de Galicia. A construción dunha nova basílica en Santiago veu acompañada por una inmensa onda construtiva conforme o estilo románico cara a finais do século XII: «an astounding technical, economic, and cultural feat for a pre-industrial society» ${ }^{8}$. En termos políticos, é certo que Afonso VII (1126-1157), tocius Hispaniae imperator, centrou a súa xestión en varias frontes: consolidar a unión das Coroas de Castela e León, as súas aspiracións á Coroa de Aragón e a ocupación de Almería e outras partes do sur da Península. Aínda así, este rei nacido e criado en Galicia manifestou o seu desexo de ser soterrado en Santiago, como fixera seu pai, e de crear un panteón rexio na cidade, malia que, finalmente, só a súa dona, a raíña Berenguela, ficou soterrada en Compostela9.

Galicia desempeñou un importante papel na conquista de Almería, a xulgar polo que din a Chronica Adefonsi Imperatoris e mais o Prefatio Almeriae, nos que se sinala que os galegos foron os primeiros en entrar no campo de batalla. É neste contexto no que a idea de Santiago Matamouros vai collendo forma a mediados do século XII, no Privilexio dos votos elaborado polo cóengo compostelán Pedro Marcio, ou nas crónicas como a Historia Silense e, posteriormente, nos traballos de Lucas de Tui ${ }^{10}$. Tras a decisión de Afonso VII de dividir os reinos de León e Castela en 1157, Galicia continuou tendo un peso considerable no conxunto do reino de León ou, máis propiamente, de León-Galicia, coa aristocracia galega (sinaladamente o grupo dos Traba) mantendo unha forte hexemonía. Tanto Fernando II (1157-1188) como Afonso IX (1188-1230) foron soterrados en Santiago, e ambos figuran adoito nos diplomas das súas chancelarías como reis de León e Galicia. Aínda que Fernando II só visitou Galicia esporadicamente despois de 1172, o seu fillo Afonso IX fíxoo moi frecuentemente e mesmo creou o cargo de meiriño maior do reino de Galicia ${ }^{11}$. Fundou varias cidades, entre elas A Coruña, e apoiou con entusiasmo a peregrinación a Santiago; de feito, morreu o 24 de setembro de 1230 en Sarria, mentres ía de camiño a Compostela como romeiro.

É precisamente este ano, 1230, o que é máis veces invocado como un punto crucial na historia de Galicia. Certo é que, tal como argumentou Francisco García Fitz, a vitoria cristiá na batalla das Navas de Tolosa, dezaoito anos antes, puido

\footnotetext{
7 Portela 2015.

8 D’Emilio 2015b: 22, 64.

9 Yzquierdo Peiró 2019.

10 Falque 2015.

11 Pérez Rodríguez 2015: 431-438.
} 
non ser a «batalla decisiva» nos termos do proceso de longo percorrido da chamada Reconquista. Cómpre recordar, sen ir máis lonxe, o estalido dunha crise dinástica no imperio almohade tras a morte do califa Abu Iacub en 1224, o que propiciou unha nova fase de expansionismo cristián na fronteira andalusi ${ }^{12}$. Porén, a unión dinástica de León e Castela significaba que Galicia pasaba a ter unha función algo máis marxinal no conxunto dun novo reino moito máis extenso, tras as conquistas de Córdoba, Sevilla e o reino de Murcia. Ademais, a importancia económica da principal ruta de peregrinación cara a Santiago, de traxectoria leste-oeste, íase ver ameazada polas novas rutas do norte ao sur. Por outra banda, no que queda de século, houbo só tres visitas reais a Galicia e o mesmo Afonso X nunca chegou a vir. Cando, eventualmente, o seu fillo Sancho IV (1284-1295) fixo a súa primeira visita a Galicia no ano 1286, deixou claro que «auia mas de L annos que non entrara en Gallizia otro Rey, si non yo agora» ${ }^{13}$. Afonso X, o derradeiro califa almohade segundo a definición de Maribel Fierro, demostrou unha rotunda preferencia polo sur da Península e por Sevilla en particular, o que puxo de manifesto coa súa preocupación pola fronteira andalusí e o seu fecho del Imperio na procura do título de Emperador do Sacro Imperio Romano. De acordo co paradigma convencional, a Coroa de Castela tiña pouco interese en Galicia, considerada como territorio dominado pola Igrexa e a vella aristocracia, xustamente os dous poderes que o rei Afonso X tentaba desafiar.

Porén, os académicos galegos cuestionaron de modo progresivo este paradigma. Xa a mediados dos oitenta, con motivo do sétimo centenario da morte de Afonso X, un breve pero moi suxestivo traballo de Santiago Jiménez Gómez (1984-1985) sinalaba que a imaxe dun rei que estaba politicamente distanciado de Galicia - ou que era considerado directamente antigalego- non era axeitada. A nobreza galega estivo implicada de cheo tanto nas campañas militares na fronteira andalusí como no proceso de reorganización social e colonización. Por exemplo, argumentaba este autor, sabemos da presenza na fronteira andalusí de Estevo Fernández de Castro, quen foi xenerosamente compensado no repartimento de Sevilla, do mesmo xeito que o foi o arcebispo compostelán, Xoán Arias, que tamén participara canda outros cabaleiros no servizo real en varias campañas preto de Sevilla. Jiménez Gómez tamén suxire que Galicia fora tamén unha importante fonte de rendas destinadas a sufragar a candidatura do rei ao título imperial. Sinaladamente, entre 1272 e 1274, os diplomas casteláns refírense, a miúdo, ás taxas cobradas para o fecho del Imperio. En terceiro lugar, Galicia estaba cada vez máis suxeita ao marco lexislativo afonsino, como queda de manifesto no Espéculo, nas Partidas e no Fuero Real. Iso supuxo, por exemplo, a creación de alfándegas en moitos portos de Galicia, así como a creación de burgos reais como Pontedeume en 1270. Cómpre ter en conta, tamén, as intervencións xudi-

12 García Fitz 2012.

13 López Ferreiro 1895, 1: 375. Estes argumentos foron desenvolvidos por Pérez Rodríguez 2015: 441-448, no contexto dunha reformulación deste tópico historiográfico. 
ciais nos preitos entre os concellos galegos e os seus señores, incluíndo os bispos de Ourense e, moi especialmente, os arcebispos de Santiago. Finalmente, para Jiménez Gómez, o vínculo máis estreito entre Afonso X e Galicia reside no ámbito da cultura, sinaladamente na súa produción lírica, tan ben representada nas Cantigas de Santa María e nas súas composicións profanas. A influencia da tradición literaria e lingüística galego-portuguesa na produción cultural afonsí, conclúe Jiménez Gómez, formula unha serie de interrogantes, por exemplo se o rei falaba galego, a partir de que momento e se o galego funcionaba como lingua franca na corte.

A conexión galega de Afonso X puido comezar na súa infancia. O seu aio, o burgalés García Fernández de Villamayor, estaba casado con dona Maior Arias, unha nobre galega que podería pertencer á familia Arias da Limia. García Fernández recibiu a tenza da vila de Maceda, preto de Ourense, de mans de Fernando III. $\mathrm{O}$ infante Afonso puido ter, moi probablemente, o seu primeiro contacto coas cortes nobiliarias da rexión do Miño en 1232, cando seu pai, Fernando III, visitou, entre outros lugares, Lugo, Santiago (que era para entón o principal centro de eclosión da lírica trobadoresca en lingua galega), A Coruña, Ourense e Tui; un contacto co reino de Galicia que ben puido terse intensificado nos vindeiros anos. É moi debatida a teoría de que Afonso pasase algún tempo en Maceda cando mozo, cuestión que, hoxe en día, non ten referendo documental ${ }^{14}$.

En calquera caso, estivese ou non nesta vila ourensá, o que si puido producirse nalgún punto de Galicia foi o comezo da relación de Afonso con María Afonso, filla de seu avó Afonso IX e de Teresa Gil de Soverosa. Parece, por outra banda, que chegado á súa maioría de idade, arredor de 1240, Afonso recibiu importantes vilas en Galicia e mais en León ${ }^{15}$. Mesmo sendo infante, Afonso —segundo apunta Pérez Rodríguez-recibira un rol significativo en Galicia e León, exercendo unha autoridade de tipo xudicial en nome de seu pai. Isto é un primeiro indicio de que non debemos reducir a «monarquía» á figura individual do rei, argumento sobre o que volveremos decontado. Xunto cunha serie de territorios leoneses, o infante Afonso foi investido coa tenza de Ribadavia dende 1240 e, posiblemente, da de Lemos, entre outras. Ribadavia estaba gobernada por Andrés Fernández de Castro, no nome de Afonso, en 1245 e 1249, o que suxire que a súa función aí era de longa duración ${ }^{16}$.

A ausencia física do rei en Galicia dende a súa coroación en 1252 é un feito indiscutible, pero dende os primeiros meses do seu reinado a chancelaría real continuou confirmando privilexios en favor dos mosteiros galegos. É ben certo que non eran novos privilexios pero, deste modo, mantívose unha tendencia confirmatoria ben visible xa dende os reinados de Afonso IX e mais Fernando III. Tal como expón Jiménez Gómez, o reino de Galicia continuou a ser vital economicamente para

14 González Jiménez 2004: 18.

15 Monteagudo 2014: 123-124.

16 Monteagudo 2014: 149, Pérez Rodríguez 2015: 441-448. 
a Coroa, en particular como fonte de ingresos das rendas derivadas da actividade mercantil dunha serie de portos marítimos, e dez deses portos (dun total de vinte e catro) estaban en Galicia: Ribadeo, Viveiro, Ortigueira, Cedeira, Ferrol, Betanzos, A Coruña, Baiona, A Guarda e Tui, así como tres portos pesqueiros secundarios: Noia, Padrón e Pontevedra. Afonso X era perfectamente consciente da necesidade de defender as costas galegas; a Orde de Santa María de España fora fundada coa finalidade de defender a fronte litoral do reino. Mentres tanto, os galegos continuaron a participar nas campañas militares do rei e a conquista de Sevilla foi, con toda seguridade, un estímulo importante para o desenvolvemento económico dos portos galegos ${ }^{17}$.

Para Pérez Rodríguez e outros, Afonso X encarnaba unha tendencia espallada amplamente pola Europa occidental neste tempo consistente no reforzo da autoridade rexia ${ }^{18}$. Ademais de resolver as disputas entre os concellos e os señoríos episcopais de Galicia, Afonso tomou o control da sé arcebispal de Santiago, que quedara vacante tras a morte de Xoán Arias en 1266. O seu rexeitamento a recoñecer o candidato papal, Gonzalo Gómez, significou que Santiago permanecese como unha cidade baixo o señorío real até a fin do reinado e, máis aínda, até o comezo do século XIV. Polas mesmas razóns, a sé de Ourense ficou vacante unha década despois de 1276. Estas estratexias tiveron un efecto politicamente polarizador e o rei gañou a animadversión da Igrexa galega, ao mesmo tempo que se ía mergullando nun crecente enfrontamento cos integrantes da vella aristocracia. Houbo, por exemplo, unha vigorosa reacción contra a vaga de fundacións urbanas promovida polo rei en territorio galego. Pero o mesmo Afonso X e a monarquía no seu conxunto, entendida de modo máis amplo como estrutura corporativa e colectiva, estaban seriamente comprometidos con Galicia, en contra do que comunmente se tende a pensar. Polo mesmo, Galicia seguiu operando como un territorio vibrante no económico e no cultural, e continuou sendo calquera cousa menos periférico no conxunto da Coroa de Castela e León. O mito da marxinación é, de feito, o resultado dunha operación de apagado histórico, un proceso que parte do século XVI en diante. Foi entón cando Galicia comezou, baixo as dinastías dos Habsburgo primeiro e dos Borbóns despois, a ser máis dependente economicamente e cada vez máis suxeita aos penetrantes clixés centralistas do atraso $^{19}$. Pero aínda neste momento tardío, como veremos máis adiante, temos motivos para cuestionar o tópico do declive.

Agora que Galicia rexorde outra vez, no século XXI, cunha significativa importancia económica, e cando a situación xeograficamente periférica lle dá, de modo paradoxal, un renovado papel central en España e no eido atlántico, parece oportuno rever os vellos tópicos do atraso e da marxinación ${ }^{20}$. Así pois, os colaboradores deste volume volven avaliar os variados vieiros polos que Galicia desempeñou

17 Pérez Rodríguez 2015: 452-456.

18 Doubleday 2001: esp. cap. 4.

19 López Carreira/Andrade Cernadas 2020: esp. 29-58 e 121-182.

20 Colmeiro 2009. 
un papel sobranceiro no marco da Península no século XIII, nomeadamente durante o reinado de Afonso X. O capítulo 1 deste libro, a cargo de Francisco Javier Pérez Rodríguez e titulado «Diplomatario galego de Afonso X», ofrece un punto de partida para este novo achegamento, similar ao que fixera Manuel González Jiménez no «Diplomatario andaluz de Alfonso X» (1991). A pesar de que o capítulo non inclúe a edición dos documentos orixinais, confiamos en que esta compilación de fontes sirva como un recurso esencial para investigacións futuras. $\mathrm{O}$ «Diplomatario» corrobora o argumento de que existía unha forte implicación real en Galicia durante o reinado de Afonso X. Dá conta tamén dunha serie de concesións de terras no Aljarafe de Sevilla en favor da nobreza galega e do cabido compostelán, por volta do ano 1260, e que forman parte do repartimento dese territorio (docs. 11, 16, 99, 123). Fornece, tamén, moitas evidencias sobre o feito de que Galicia continuaba a ser unha importante fonte de ingresos para o financiamento das campañas militares en Andalucía; nese sentido, vemos a Afonso $\mathrm{X}$ enviando o seu «alcalde» Domingo Eanes para recadar cartos cos que custear a frota de Cádiz en 1258 (doc. 100; cf. doc. 151). Así mesmo testemuña que, entre os oficiais reais, o meiriño maior Rodrigo García de Traba estivo particularmente activo na resolución de casos xudiciais en Galicia (docs. 114-115, 118, 127), e que polo xeral houbo unha tensión constante despois de 1268 entre os mosteiros galegos e varios oficiais da monarquía, incluíndo o meiriño maior e o adiantado de Galicia (docs. 160-163, 184, 203, 214, 222).

Algúns dos máis duradeiros funcionarios de Afonso X foron galegos, como o propio Gómez García de Soutomaior. Moitos destes oficiais estiveron estreitamente unidos ao rei, en especial nas últimas fases do reinado, por fortes vencellos de lealdade persoal; máis tamén, por esta mesma razón, esa rede vai ser logo desmantelada polo seu sucesor Sancho $\mathrm{IV}^{21}$. O «Diplomatario» tamén evidencia a maneira en que o goberno real era, como sinalou Theresa Earenfight, «a family affair» ou un asunto de familia. Isto reforza a idea de que a monarquía debe ser entendida, até a Baixa Idade Media, non como unha forma de goberno en solitario por parte dun único dirixente, senón, pola contra, como unha empresa colectiva e corporativa que involucraba moitos integrantes da familia real e achegados, tanto homes como mulleres ${ }^{22}$. Afonso X refírese a un dos seus meiriños en Galicia, Xoán Fernández, como «mio sobrino» en xullo de 1277 (doc. 205). O seu fillo primoxénito, Fernando de la Cerda, estivera moi implicado como axente da xustiza real en Galicia dende xullo de 1270, cando está documentada a súa presenza en Santiago, do mesmo modo que fixera o propio Afonso cando fora infante (docs. 169, 185, 205). Igualmente, o infante Sancho está presente en Santiago na súa condición de alférez e almirante da confraría de Santa María

21 Este proceso é estudado detidamente por Hernández 2021.

22 Earenfight 2016, Pick 2017. Coincidindo coa visión de Earenfight da monarquía como un asunto de familia, Pick sinala que «The king was at the apex of that family, but his security and ability to exert his authority depended not only on networks of relationship with nobles, rivals, and members of the Church but also on relationships within the family» (238). 
de España o 16 de novembro de 1272 (doc. 180), e estivo en Allariz o 24 de novembro do mesmo ano, lugar onde a súa nai confirmaría o mecenado dun convento de clarisas (doc. 183). Para o ano 1274 estaba gobernando as terras reais (reguengo) galegas dende Burgos, por medio do seu oficial Xoán Gato (doc. 193; cf. doc. 194). A súa función en Galicia consolidouse máis despois da morte de Fernando de la Cerda en 1275 (docs. 198, 207, 208, 223), e nos últimos anos da década de 1270 comezaba a exercer o que Francisco J. Hernández definiu como «un papel cuasi virreinal» no noroeste da Península, coas funcións dun correxente (212) ${ }^{23}$. Sancho visitou Galicia en 1276 e outra vez en 1278, e axiña volveu despois do seu ascenso ao trono en 1286.

$\mathrm{O}$ «Diplomatario» tamén revela o activo papel da monarquía en apoio das vilas e cidades de Galicia, por exemplo na protección dos privilexios mercantís e fiscais da cidade da Coruña, que recibira o monopolio do comercio do sal (doc. 87; cf. 92, 195), ou na anterior tenza de Afonso en Ribadavia (doc. 97) ou en Pontevedra (doc. 151) - que revelaba unha economía vibrante, tal como argumenta Olalla López-Costas no capítulo 3 desde volume- pero tamén a cidade de Lugo e, mesmo, Vilafranca do Bierzo (doc. 191). O 15 de febreiro de 1268, Afonso X liberou os cidadáns de Lugo de ser arrestados ou encarcerados por causa de ter débedas co bispo (doc. 158). Medidas deste tipo reflicten unha xestión real manifestamente hostil cara ao poder das sés episcopais de Galicia. Isto contrasta coas políticas desenvolvidas polo mesmo Afonso X nos primeiros anos do seu reinado (1252-1256), cando ratificara unha longa relación de privilexios previamente concedidos á Igrexa de Santiago e protexera os seus intereses económicos e espirituais. O 6 de novembro de 1254 concedeu a protección real para todos os peregrinos de camiño a Compostela (doc. 20); e o 29 do mesmo mes regularizou o modo en que os peregrinos debían facer as súas últimas vontades e testamento (doc. 21). Dous anos máis tarde, o 3 de novembro de 1256, concedeulle ao arcebispo de Santiago, Xoán Arias, o dereito de ter un mercado cada martes en Aldeanueva [de Figueroa], nun punto lonxe de Compostela, entre Toro e Salamanca; e ao día seguinte entregoulle ao mesmo arcebispado a vila galega de Xallas (docs. 74-75).

Así e todo, mesmo nestes primeiros anos pódense detectar sinais de crecente desconfianza por parte do cabido catedralicio, reflectindo tensións que se desenvolverían nunha constante actitude anticompostelá pola parte do rei de Castela. Neste clima de desconfianza, en Covarrubias, o 10 de novembro de 1255, Afonso concedeu que fose o cabido de Compostela quen controlase as rendas da sé durante o tempo que estivese vacante (doc. 78); e en Vitoria, o 10 de xaneiro de 1256, fixo explícito que o préstamo financeiro que a Igrexa de Santiago lle concedera a seu pai, Fernando III, fose feito libremente e, polo tanto, sen teren a necesidade de devolvelo (doc. 90). Durante os primeiros anos da década de 1260, Afonso interveu en moitos dos conflitos 
de intereses que enfrontaban a catedral co consello da cidade, e resolveu en favor deste nunha decisión crucial tomada o 30 de xuño de 1264 en Sevilla (doc. 137).

A firme proxección do poder real en Galicia no reinado de Afonso X é o tema principal do traballo de Francisco J. Hernández, «La piel del leopardo: Galicia y el ordenamiento territorial alfonsí», que conforma o capítulo 2 deste volume. O reguengo, argumenta Hernández, era aínda unha parte importante da paisaxe galega a mediados do século xIII; malia ser tamén terra de cregos e monxes, o dominio da Igrexa distaba moito por estas datas do que chegaría a ser no século XVII. Este argumento reforza consideracións parecidas no sentido de que o control da Igrexa era máis limitado do que poderiamos imaxinar en varias áreas de Galicia, incluíndo as zonas montañosas do leste; aínda que podemos asumir que a Igrexa tiña menos interese nas terras pouco produtivas, había nesta rexión terras extremadamente fecundas (incluíndo o Ribeiro de Avia) sobre as que o control real foi significativo ${ }^{24}$.

Hernández, pola súa parte, defende que esta presenza real era especialmente forte na terra chá (os territorios baixo xurisdición real) ${ }^{25}$; neste sentido, a delegación de poder real nos eidos xudicial e administrativo en tenzas estaba ben asentado, en territorios como Trastámara, Montenegro, Monterroso, Sarria, Lemos, Toroño ou A Limia. A historia destas tenzas rotatorias reflicte o poder da Coroa para escoller os tenentes, xa que estes nomeamentos non eran hereditarios, nin simples concesións ás dinámicas locais de poder. Entre estes tenentes estaba un fillo natural de Afonso X, Afonso Fernández, quen, ao igual que seu pai, pasou a maior parte da súa vida en Sevilla. Este mesmo Afonso Fernández foi enviado como xefe dunha forza militar dirixida contra Santiago de Compostela co fin de asegurar os dereitos reais. Hernández fai constar que, mentres que as cinco sés episcopais galegas foron excluídas do pago das taxas ordinarias, non o foron do pago dos servizos extraordinarios, unha fonte principal de ingresos para as arcas reais. Afonso $\mathrm{X}$ tentou por todos os medios limitar o poder dos señoríos laicos e eclesiásticos, e beneficiouse de xeito considerable da vacante na sé de Compostela que se produciu tras a morte do arcebispo en 1266.

En moi boa medida, a continua afirmación do poder rexio en Galicia era só unha mostra do valor económico e comercial deste territorio para a Coroa de Castela e León. No capítulo 3, «Pontevedra, a cidade que floreceu na Baixa Idade Media: adentrándonos na dieta medieval a través dos restos humanos», Olalla López-Costas ofrécenos unha nova perspectiva arqueobiolóxica sobre estas cuestións. Argumenta que o século XIII, lonxe de ser un período de declive, foi unha época decisiva no desenvolvemento da economía de Galicia e, sinaladamente, nas fortunas comerciais de Pontevedra coa súa preeminencia adquirida na pesca atlántica. A autora suxire que

24 Andrade Cernadas 2016.

25 Non se debe confundir este termo coa Terra Chá, un territorio moderno do norte da provincia de Lugo. 
isto se debeu principalmente ás intervencións dos reis de León (Fernando II e Afonso IX) e de Castela-León (Fernando III e Afonso X), o que favoreceu que Pontevedra adquirise un papel principal no comercio do peixe, dentro e fóra da Península. Sobre a base das prospeccións arqueolóxicas levadas a cabo entre 2007 e 2010 nos cemiterios das igrexas da vila, e adoptando innovadoras metodoloxías científicas, López-Costas analiza en detalle a dieta dos veciños de Pontevedra no século XIII. Chega á conclusión de que era unha dieta rica e diversa en produtos do mar, e establece, deste modo, relacións entre pautas de consumo e status socioeconómico.

Repensando a relación da Coroa con Galicia no tempo de Afonso X, é moi importante evitar focalizalo todo na figura singular do rei. Tal como observou Lucy Pick, «the old master narrative of the sovereign king and the fantasy of uncomplicated male lordship have proven extremely resistant to a more nuanced understanding of how power was construed, held, and wielded in the Middle Ages» ${ }^{26}$. Malia que o «xiro de xénero» nos estudos sobre a realeza se produciu moi lentamente, unha nova e poderosa xeira de estudos sobre a «rexinalidade», poder e xénero na Europa medieval, acaba de salientar a importancia das mulleres das elites, incluíndo aquelas que formaban parte da corte e da familia real entendida dun modo amplo ${ }^{27}$. En León e mais en Galicia, as raínas foron recoñecidas por moito tempo como gardiás espirituais da familia real, exercendo autoridade a través da propiedade de casas relixiosas ${ }^{28}$. Non de menor importancia era o seu papel de intercesión e mediación no amplo contexto da monarquía corporativa, un medio que lles permitía ás mulleres da familia real manexar unha parte significativa do «poder brando». A correxencia estaba sorprendentemente espallada pola Europa medieval, dende Bizancio ou Noruega até Polonia, e, tal como estudou Miriam Shadis, este poder foi exercido en Castela e León pola raíña Berenguela xunto co seu fillo Fernando III ${ }^{29}$.

Esta nova visión da monarquía medieval como unha entidade corporativa na que as mulleres da familia real, á par que os homes, eran pezas vitais, explórase no traballo de Diana Pelaz, «Facerse presentes. As mulleres da familia real e o reino de Galicia na culminación plenomedieval», que constitúe o capítulo 4 deste volume. Tomando como punto de partida a fundación do convento de clarisas de Allariz pola raíña Violante, Pelaz subliña tanto o papel espiritual desempeñado polas mulleres da realeza na Castela e León do século XIII, como a súa actividade política e diplomática. Conclúe que a monarquía era «unha institución complexa, que supera os límites do corpo físico do monarca». A multiplicidade de figuras reais con presenza na Corte, máis alá da raíña e das infantas, que quedou testemuñada nos diplomas rexios, sen dúbida contribuía a amplificar o alcance da Coroa. A figura da raíña é entendida «como enlace entre pai e fillo/s pero tamén por si mesma, como figura polí-

26 Pick 2017: 246.

27 Véxase, por exemplo, Bianchini 2012, Earenfight 2014, Pelaz Flores 2015.

28 Pick 2011.

29 Shadis 2009. 
tica autónoma e independente». Segundo confirma Pelaz, esta función reflíctese nas artes visuais, sinaladamente nas imaxes do tombo do mosteiro cisterciense de Toxos Outos, no cal se representan once raíñas. O papel administrativo das infantas reais foi tamén significativo: Pelaz apunta á súa función como tenentes de importantes territorios, incluíndo portos comercialmente relevantes como A Coruña, para alén dunha serie de espazos situados ao longo da fronteira con Portugal. Conclúe observando que o reino de Galicia «continuaría a formar unha parte fundamental tras a reunión de León e Castela baixo o mandato de Fernando III e de vital importancia para a estabilidade do conxunto territorial durante o reinado de Alfonso X»; tanto para as mulleres da realeza como para os seus equivalentes masculinos, os territorios de Galicia continuaron representando un espazo esencial de acción.

O papel das mulleres da familia real é igualmente central no capítulo 5, de Rosa Ma Rodríguez Porto, «Cara e cruz: conflito político, territorio e padroado rexio en Galicia durante o reinado de Afonso X e Violante de Aragón». Afonso desenvolveu unha política que, se ben non se podería considerar antigalega, si chegou a ser anticompostelá. As institucións eclesiásticas galegas, como o cabido catedralicio de Santiago, procuraron na raíña Violante unha fonte alternativa de apoio real. É posible, como suxire Porto, que Violante, a diferenza de Afonso, viaxase persoalmente a Compostela nos primeiros anos da década de 1260; certamente sabemos que estivo no reino de León-Galicia en 1264-1265. Do mesmo xeito que Pelaz, Rodríguez Porto apunta cara a modelos longamente establecidos nos que as mulleres da realeza despregaron axendas políticas no noroeste peninsular; o convento de Santa Clara de Allariz puido ser fundado dentro dun «triángulo imaxinario», formado por Xunqueira de Ambía, Porqueira e Celanova, que tradicionalmente pertencera ás infantas de León. Como unha proxección franciscana da fundación real de Las Huelgas - en si unha reinvención das institucións vencelladas ao Infantado-, Allariz foi tamén a inspiración da fundación de Santa Clara de Coimbra pola raíña Isabel de Portugal, reflectindo as implicacións xeopolíticas dos fortes lazos dinásticos existentes entre dona Violante e a súa sobriña Isabel. Este desexo de acollerse á protección e padroado das mulleres da familia real pode verse corroborado pola centralidade que teñen as imaxes das raíñas no Tombo Colorado e, de novo, no tombo de Toxos Outos. Para o seu descontento, o papel da raíña Violante como padroeira do convento e favorecedora do seu desenvolvemento económico foi drasticamente minorado polo seu fillo o infante Sancho. Este quitoulle á nai importantes tenzas e foi o responsable do nomeamento do bispo de Ourense, Pedro Eanes de Nóvoa, quen podería ser considerado como unha némese dos franciscanos en Galicia, nun momento en que Violante estaba tentando establecer o convento de clarisas de Allariz. Isto combinábase coa desafección que xa existía cara a Sancho, por parte da nobreza e o clero de Galicia, nun momento, sinala a autora deste capítulo, no que Galicia estaba a piques de se converter nun reino independente. Porén, aínda así, a raíña continuou a ser un firme padroeiro, tal como 
pon de manifesto o dispar rexistro documental, malia a escaseza das obras artísticas que poden realmente asociarse coa iniciativa de Violante; neste sentido, as páxinas finais do capítulo de Rodríguez Porto están dedicadas a unha análise do papel de Violante en relación cunha serie de obxectos materiais convencionalmente asociados á súa figura.

O traballo de Beatriz Vaquero, «Santa Clara de Allariz, historia dunha fundación real (ss. XIII-XV)», conforma o capítulo 6 do libro e baséase na inminente edición dos 376 documentos sobre o convento que chegaron até os nosos días, trazando a súa historia dende os seus primordios en 1282 e a incorporación da súa primeira abadesa, Sancha Eanes, até finais do século Xv. Para Violante este foi, en parte, un proxecto persoal: o convento ía ser un lugar de refuxio na súa viuvez, despois do falecemento de Afonso X en 1284, e no seu testamento deixou por escrito a súa intención de ser soterrada alí. Porén, reforzando a liña de interpretación que é un dos eixes centrais deste libro, Vaquero acepta o argumento de que a fundación de Santa Clara de Allariz foi tamén un movemento político pensado coa intención de reafirmar o poder real como contrapeso do poder da Igrexa, neste caso o poder do bispo de Ourense; un feito, por outra banda, do que o prelado parecía ser un bo coñecedor. Tanto é así que o convento foi despois apoiado por Sancho IV, polo seu fillo o infante Felipe e por outros membros da familia real nas décadas seguintes, tamén por Afonso XI, ao tempo que continuaba sendo «un importante centro de poder feminino».

O convento de Allariz, daquela, estivo estreitamente entrelazado coas redes de poder real. Como sinala Ricardo Pichel na súa contribución, «Sabean quantos este liuro virem... A recepción galega do legado historiográfico e haxiográfico do Rei Sabio na primeira metade século XIV», que conforma o capítulo 7, desempeñou un papel importante na recepción e difusión da obra haxiográfica de Bernardo de Brihuega, pouco despois da súa composición na corte afonsina. Centrándose na difusión transfronteiriza da produción historiográfica e haxiográfica da corte de Afonso X, tanto en Galicia como en Portugal, o estudo de Pichel subliña a importancia dos grandes fogares nobres - entre outras, as poderosas liñaxes dos Lima-Batisela, dos Riba de Vizela, dos Andrade e dos Castro de Lemos-como centros de mecenado e nós nunha rede transpeninsular de poder cultural da elite nobiliaria desde finais do século XIII e durante o XIV. Nestas coordenadas, o eco das grandes producións históricas (post)afonsinas como a General Estoria, a Estoria de España ou a Crónica de Castilla dá boa conta do interese destes núcleos señoriais por transmitir e difundir o legado historiográfico de Afonso X a través de diferentes copias, traducións, compilacións e refundicións aquén e alén do Miño ao longo do trescentos.

Se ben debemos entender a monarquía como un fenómeno corporativo que implica complexas redes culturais e políticas, isto certamente podería reflectirse atendendo á axenda e as aspiracións específicas dos reis individuais. Afonso X aspiraba a ter o control de todos os seus reinos, tamén o de Galicia e aínda máis alá, como parte 
do seu intento de ser coroado emperador do Sacro Imperio Romano. Tal como escribiu Kristin Kennedy, «Even after Pope Gregory had definitively quashed his imperial ambition, Alfonso styled himself "by the grace of God king of the Romans" in documents issued in connection with the weddings of two of his sons at Burgos in 1281»; cando se abriu o sartego de Afonso X, en 1571, comprobouse que estaba cheo de insignias imperiais. Kennedy subliñou o programa ideolóxico desenvolvido pola súa produción textual, insistindo no feito de que os destinatarios prioritarios destes textos eran os membros da elite da súa propia corte, e non necesariamente un público máis amplo ${ }^{30}$. Outros apuntaron cara ao reiterado intento de centralizar o control político nos reinos de León e Castela, e o xeito en que esta axenda política quedou reflectida na súa produción cultural, como é o caso das Cantigas de Santa María ou da súa lírica profana.

Neste contexto, o estudo de Helena de Carlos, «As Antigüidades da Gallaecia na obra historiográfica de Afonso X», capítulo 8 do libro, é unha suxestiva reflexión sobre o clima ideolóxico na corte real. De Carlos pregúntase polo modo en que a «protohistoria» de Galicia era vista polos historiadores que traballaban na corte, centrándose sinaladamente na historia de Xerión. Segundo a historiografía tradicional, que posiblemente recollía procesos coloniais na Península antes da invasión romana, a riqueza de Xerión en gando fora cobizada pola figura mítica do mesmo Hércules: «ese culto a Xerión podería ser un eco da lembranza de depredacións de gando no seo dunha loita entre o elemento colonial pregrego, representado por Heracles, contra os reis indíxenas». A figura de Hércules era de particular interese para a corte de Afonso X nos comezos da expansión castelá por Andalucía, onde, segundo argumenta De Carlos, o legado romano e mais o legado andalusí figuraban de modo omnipresente. Na corte castelá do século XIII, Hércules era considerado como un emblema dunha cultura civilizadora anterior, e no novo contexto imperial a historia de Hércules e a de Xerión foron transformadas e adaptadas.

$\mathrm{Na}$ fonte latina orixinal fornecida por Xustino, un historiador do século III, Hércules aparecía representado como un depredador agresivo. Agora, na tradición auspiciada por Afonso X, debúxase, pola contra, como unha figura xusta e nobre. Xerión, pola súa parte, represéntase como un monstro de sete cabezas a quen Hércules decapita heroicamente nunha batalla. Hércules, segundo os historiadores do contorno real, fora o fundador dunha cidade no lugar da batalla, que viría sendo A Coruña, e mandaría construír unha gran torre nese mesmo sitio, labor que completaría o seu sobriño, o rei Espan, señor de «España». Foi tamén Hércules, segundo a Estoria de España, o primeiro en localizar o terreo onde ía ser erixida a gran cidade romana de Sevilla. De Carlos conclúe suxerindo que o compromiso do rei Afonso X co estudo da historiografía e as fontes romanas pode ser considerado como un precursor do humanismo renacentista italiano, un século e medio máis cedo, reforzando a idea compartida por outros investigadores de que as orixes do Renacemento non poden

30 Kennedy 2019: esp. 24 e 44. 
ser vistas como un fenómeno intrinsecamente italiano, senón máis ben como un proceso multifocal no que o mundo ibérico desempeñou un papel vital ${ }^{31}$.

A forte ligazón de Galicia coa monarquía de Castela no século XIII reflectiuse no eido da produción lírica ${ }^{32}$. Tal como observou Pérez Rodríguez, «Galician influence at the Castilian courts of Alfonso X and Sancho IV is [...] highlighted by the success there of Galician-Portuguese troubadours and the embrace of their language for courtly verse, both in the cantigas de amigo or de loor and the cantigas de escarnio and de maldizer» ${ }^{33}$. No capítulo final deste volume, o número 9, «Afonso o Sabio na lírica trobadoresca galego-portuguesa: da historia literaria á política cultural», Henrique Monteagudo salienta particularmente a vibrante tradición trobadoresca compostelá e a influencia que exerceu na corte do Rei Sabio. Para Monteagudo, o uso do galego por Afonso $\mathrm{X}$ responde en parte ao avanzado estadio de desenvolvemento que os xéneros líricos acadaran en Galicia e tamén a un intento de minorar a autoridade política e cultural da Igrexa. Considérao, igualmente, como algo natural nunha Península plurilingüe na que múltiples formas dos romances vernáculos eran vistos como complementarios, e a imposición dunha única lingua nacional era considerada como anatema ${ }^{34}$. Afonso asumiu a función de patrón literario, desafiando dese xeito o papel cultural que viñera desenvolvendo a aristocracia na produción lírica, e promoveu ao mesmo tempo o labor de xograres galegos de orixe relativamente humilde. Porén, este padroado centralizado non ten por que ser, dende logo, un proxecto que venerar de maneira acrítica, en tanto que puido ter contribuído á debilidade da produción lírica dentro da propia Galicia.

O capítulo de Monteagudo ofrece unha lectura autobiográfica dunha serie de cantigas atribuídas ao propio Afonso $\mathrm{X}^{35}$; ao mesmo tempo subliña a promoción por parte do rei da poesía satírica, un xénero cunha longa traxectoria na cultura galego-portuguesa, como un instrumento de control ideolóxico ${ }^{36}$. Tamén sinala o valor das Cantigas de Santa María como un modo de forxar unha espiritualidade monárquica distintiva, que servise para reducir o monopolio espiritual da Igrexa. A par doutros investigadores, por exemplo o mesmo Kennedy, Monteagudo salienta o carácter marcadamente cortesán do público das Cantigas de Santa María; segundo el, a súa composición estivo moi influída pola batalla ideolóxica mantida cos arcebispos

31 Doubleday 2015: 228-229.

32 Jiménez Gómez 1984-1985: 160-163.

33 Pérez Rodríguez 2015: 456.

34 Pode ser interesante comparar este aspecto coa insistencia de Roger Wright na tardía distinción conceptual entre diferentes dialectos do «romance» ou «ibero-romance», e na inseparabilidade do galego-portugués (Wright 2015). Véxase tamén Mariño Paz / Varela Barreiro (2010) e Mariño Paz (2020).

35 Esta aproximación, que tamén é mantida por Doubleday 2015, distingue parcialmente a súa interpretación da doutros estudosos. Kennedy 2019: 89-90, por exemplo, argumenta que mentres que moitos dos poemas atribuídos ao rei parecían reflectir os seus sentimentos máis íntimos, outros son motivados en moi boa medida pola tradición literaria.

36 Véxase Doubleday 2004. 
composteláns, que o levaría a marxinar o culto a Santiago nas cantigas en favor do culto mariano e doutros santuarios como o de Villasirga.

As evidencias fornecidas polos ensaios que forman parte deste volu-

me poñen de manifesto que a Galicia do século XIII non iniciara o seu declive, que a monarquía castelá non se afastara de Galicia, de ningún modo, no tempo de Afonso $\mathrm{X}$, e que existía unha fluída interacción entre Galicia e Castela en termos económicos, políticos e culturais. E así continuou sendo en etapas posteriores No seu estudo de dous privilexios rodados concedidos a receptores galegos por Xoán II de Castela (1406-1454) en 1419 e 1420, Miguel García-Fernández, Diana Pelaz e Ricardo Pichel (2020) insisten en que a distancia física dende Galicia non significaba, necesariamente, que os gobernantes baixomedievais estivesen desinteresados no noroeste peninsular. Estes autores argumentan que os historiadores ignoraron por moito tempo a historia do poder real na Galicia da Baixa Idade Media, e reclaman que se poña maior atención aos modos máis indirectos nos que o poder real era exercido nese período, dende a distancia, mantendo unha relación próxima, complexa e bidireccional cos concellos e a nobreza de Galicia, así como coas institucións eclesiásticas. Neste sentido, xulgan de grande interese o desenvolvemento dun corpus de documentación real referida ao reino de Galicia.

Galicia era periférica só nun sentido estritamente xeográfico, mentres que desempeñou un papel clave no mapa cultural e lingüístico dunha Península híbrida nese momento histórico, e na que o eventual dominio de Castela e do castelán estaba lonxe de se consolidar. Este paradigma revisado, e en especial a negación do status «periférico», merece ser comparado cos argumentos defendidos por Ma Carmen Saavedra Vázquez para a España dos séculos XVI e XVII, un período que convencionalmente é coñecido como os «séculos escuros». Galicia non era periférica para os intereses de Carlos V, insiste Saavedra, contrariamente ao que se adoita afirmar. Entre outras políticas desenvolvidas nese momento, Carlos V creou a Real Audiencia de Galicia, un tribunal xurídico pero tamén un órgano de goberno que podía intervir en diversos aspectos da vida local, exercendo unha arbitraxe entre os nobres ao tempo que defendía os intereses da poboación contra os poderes locais. Aínda que Felipe II só visitou Galicia nunha ocasión, a Coroa continuou afirmando os seus intereses na segunda metade do século XV, por exemplo coa creación da Inquisición en Santiago en 1574. Ao mesmo tempo, as dinámicas do poder nunca foron unidireccionais aínda no período dos Habsburgos: as ordes que chegaban da capital tiñan que afrontar os retos da distancia e a xeografía, e a Coroa seguía necesitando negociar o poder coas elites locais, tal como acontecera no século xiII. De acordo co que sinala Henrique Monteagudo, malia que a lingua galega puido verse eclipsada na cultura impresa, nin el nin Saavedra consideran axeitado o termo de «séculos escuros»; así pois, non pode- 
mos proxectar a escasa presenza da lingua galega nos textos publicados sobre todos os acontecementos do período, ou aplicalo ao conxunto da realidade galega ${ }^{37}$.

Rematamos, polo tanto, coa sensación de que o clixé historiográfico da decadencia de Galicia a partir do século XIII, do mesmo modo que acontece coa obsesión da fin de al-Andalus que xa sinalara Gil Anidjar, pode ser máis ben unha percepción ilusoria, un invento que en realidade se corresponde coas particulares preocupacións dos séculos XIX e XX. Monteagudo suxire que, igual que sucede co termo inglés dos «Dark Ages», o dos «séculos escuros» de Galicia evoca un período comprendido entre dúas fases superiores de claridade, neste caso a Idade Media e o Rexurdimento. Consideramos que xa chegou a hora, polo tanto, de cuestionar o tópico da decadencia de Galicia na Baixa Idade Media, dende o século XIII en diante. Coidamos que os traballos contidos neste libro poden axudar a continuar este importante debate histórico.

O volume xorde como unha das iniciativas que, co gallo do oitavo centenario do nacemento de Afonso X, promoveu o Consello da Cultura Galega para celebrar a mencionada efeméride. Os editores queremos agradecer a participación de todos os colaboradores, tanto os que publican neste libro como os que, por motivos de axenda ou outras dificultades, non figuran finalmente entre os autores da obra. A todos eles o noso agradecemento máis sincero ${ }^{38}$.

37 Saavedra Vázquez 2016.

38 A contribución a este volume de Simon R. Doubleday foi posible en parte pola xenerosa bolsa que lle foi concedida pola National Endowment for the Humanities, para o curso académico 2020-2021. Esta introdución beneficiouse moito dos comentarios de varios contribuíntes do libro, especialmente Ricardo Pichel e Henrique Monteagudo. 


\title{
Rethinking the paradigm of medieval Galician 'decline'
}

\author{
José M. Andrade Cernadas and Simon R. Doubleday
}

The traditional paradigm of later medieval Galician history is one of political and cultural decline: a decline that, if not as precipitous as the decline, defeat, and disappearance of Al-Andalus, shares at least some features in common. Gil Anidjar has pointed to the obsessive historiographical concern with the end of al-Andalus, with underscoring its finitude and its supposed historical uniqueness, in a manner that obscures the ways in which Andalusi culture survives and persisted in Iberia and beyond. It is a striking fact, Anidjar writes, that "with al-Andalus, it is mostly to an irrevocable end and a catastrophic past that we are summoned and told we must bear witness"'. Similarly, an ostensible downturn in the political fortunes of Galicia in the twelfth and thirteenth century is widely seen as a step in a long process of decline, culminating inevitably in the so-called 'séculos escuros'. This process was allegedly not reversed until the nineteenth-century Rexurdimento, which was, in turn, almost fatally interrupted by the Franco dictatorship². The supposed medieval downturn, curiously, is associated with some of the very same events that are often perceived as turning points marking the beginning of the end of al-Andalus: among them, the conquest of Toledo, the definitive union of the crowns of Castile and León, and the occupation of Córdoba, Sevilla, and other parts of Andalusia in the last years of the reign of Fernando III (d. 1252) and the first years of his son, Alfonso X (1252-84). But teleological narratives that suggest the inevitability of the Christian 'reconquest' do not reflect the lived reality of this period, or the uncertainty that accompanied repeated invasions by the Almohad and Marinid empires. And just as we must demythologize the year 1492 as the emphatic 'end' of Andalusi cultures, a clean, perfect, and absolute break with the past, so it is worth interrogating conventional narratives of Galician decline. Instead, we should be alert to signs of the enduring importance of Galicia in medieval Iberia, in political, economic, and cultural terms.

By universal consensus, Galicia had occupied a pivotal role in the Christian realms of Iberia between the ninth and late eleventh centuries. The ninthcentury inventio of the tomb of the St. James by Bishop Teodomiro of Iria Flavia had given Galicia centrality in the spiritual imagination of medieval Christians across Iberia and western Europe ${ }^{3}$. In the realm sometimes known to modern scholars as the kingdom of “Asturias-León”, and later “León”, Galicia exerted a great deal of economic, political, and ecclesiastical weight, as late as the mid-eleventh century reigns of Fernando

\footnotetext{
1 Anidjar 2008: 182.

2 Monteagudo 2016.

3 D’Emilio 2015b: 7.
} 
I and Sancha. Both the territory north of the Miño and the northern sectors of what is now Portugal would be a primary sphere for royal and ecclesiastical activity, and for power struggles, in this period. Although Fernando I's reign has sometimes been seen as marking a turn to the southeast, to the Castilian frontier, he would focus his energies on the consolidation of his authority in Asturias, León, and Galicia, as well attempting to expand his dominion in northern Portugal ${ }^{4}$. The importance of Galicia is reflected in the Mappa Mundi of the Beatus of Burgo de Osma, produced-probably at Sahagún-in 1086. Here, Galicia is given an extremely prominent space (the majority of the Iberian Peninsula). Both the Torre de Hércules in A Coruña, a navigational point of reference, and the church of Santiago are given protagonism; the church in fact appears as the largest in the world. The Castilian church of newly conquered Toledo, for its part, is given only a very minor representation, and as a fortress rather than a church ${ }^{5}$.

Alfonso VI's occupation of Toledo in 1085 has sometimes been perceived as marking a new stage in Iberian history in which the southern frontier would become increasingly significant and the far northwest, including Galicia, would lose its relative weight in the kingdom of León-Castile. There is certainly evidence that the crown experienced some difficulty in controlling Galicia during this period. As Francisco Prado-Vilar has observed, the last decade of the eleventh century was one of intense maneuvering around the dynastic succession, accompanying the instability caused by territorial expansion and the change of religious rite. One camp, focused on the king's efforts to promote the succession of his natural son Sancho (born to his liaison with his Muslim lover Zaida), was pitted against the Burgundian party and in particular Alfonso's Burgundian sons-in-law counts Raymond and Henry ${ }^{6}$. Alfonso's decision to delegate responsibility for the broad territories previously ruled by King García (1065-72) - a post-Roman Gallaecia stretching as far south as the Douro/Duero-seems to have come at a cost; Raymond began to style himself Dei gratia comes et totius Galletie dominus, without reference to Alfonso; it was this that led to Alfonso's decision to divide these lands along the Miño, and to entrust the county of Portugal and the territory of Coimbra to Count Henry, who was married to Alfonso's illegitimate daughter the infanta Teresa7.

However,itmaybepossibletoexaggeratethelong-termimpactofthese difficulties, the marginalization of Galicia in the twelfth century, and even Alfonso VI's strategic division of responsibilities, which would prove to be permanent as the kingdom of Portugal emerged as an autonomous realm. In cultural terms, the period between the eleventh and thirteenth centuries has been described by James D'Emilio as among the most dynamic periods the history of Galicia; the building of the new ba-

\footnotetext{
4 Reilly and Doubleday, forthcoming.

5 López Carreira and Andrade Cernadas 2020: 113-16.

6 Prado-Vilar 2009.

7 Portela 2015.
} 
silica in Santiago itself was accompanied by a broader wave of Romanesque construction in the late twelfth century, "an astounding technical, economic, and cultural feat for a pre-industrial society”. In political terms, it's true that Alfonso VII of León-Castile (1126-57), tocius Hispaniae imperator, focused primarily on consolidating the union of the crowns of Castile and León, his claims to the crown of Aragon, and the occupation of Almería and other parts of the southern peninsula. Still, he wished to be buried in Santiago, as his father had been, and to create a royal pantheon there, although in the end, only his wife Berenguela was buried in Compostela9. Galicia played an important role in Alfonso VII's conquest of Almería, to judge from the Chronica Adefonsi Imperatoris and the Poema de Almería, which is attached to the chronicle and which indicates mentions that the Galicians were the first to enter battle. This is the context in which the idea of Santiago 'Matamoros' takes shape, in the mid-twelfth century Privilegio de los votos forged by the Galician canon Pedro Marcio, in the visual arts, in the Historia Silense, and later in the work of Lucas Tuy ${ }^{10}$. In the wake of Alfonso VII's division of the realms of León and Castile in 1157, Galicia continued to exert considerable weight within the kingdom of León-more properly, León-Galicia-with the Galician nobility (including particularly the Traba clan) proving particularly influential. Both Fernando II (1157-88) and Alfonso IX (1188-1230) would be buried in Santiago, and both kings were referred to in their diplomas as rulers of León and Galicia. Although Fernando rarely visited Galicia in person after 1172, Alfonso IX did so frequently, and also created the position of meiriño maior of Galicia ${ }^{11}$. He founded a number of cities, including A Coruña, and supported pilgrimage to Santiago; indeed, he died on September 24, 1230, in the town of Sarria, while on pilgrimage there.

It is precisely this year, 1230, that is most often invoked as a pivotal point in the history of Galicia. As Francisco García Fitz has argued, the Christian victory at Las Navas de Tolosa, eighteen years earlier, may not have been a 'decisive battle' in terms of the long-term trajectory of the Christian kingdoms, a turning point in the so-called Reconquista; instead, a dynastic crisis in the Almohad empire after the death of the caliph Abū Yaqūb in 1224, had ushered in a new phase of Christian expansionism on the Andalusi frontier ${ }^{12}$. Nevertheless, so the argument goes, the dynastic reunification of León and Castile meant that Galicia now found itself relatively marginal within a much larger kingdom, which further expanded with the conquests of Córdoba, Sevilla, and the kingdom of Murcia. The economic importance of the eastwest pilgrimage route to Santiago was now challenged by north-south routes. For the rest of the century, there would be only three visits by a king to Galicia; and Alfonso X himself would never go there. When, eventually, his son Sancho IV (1284-95) visited

8 D’Emilio, 2015b: 22, 64.

9 Yzquierdo Peiró 2019.

10 Falque 2015.

11 Pérez Rodríguez 2015: 431-38.

12 García Fitz 2012. 
Galicia in 1286, he recalled that "it had been more than fifty years since a king had visited Galicia”"13. Alfonso, the last Almohad caliph', as Maribel Fierro has termed him, demonstrated an overwhelming preference for the south of the peninsula and for Seville in particular, while being preoccupied with the Andalusian frontier and with the fecho del Imperio, his search for the title of Holy Roman Emperor. According to the conventional paradigm, the Castilian crown had little interest in Galicia, the heartland of the church and the old nobility whose power he was desperate to challenge.

Yet Galician scholars have increasingly questioned this paradigm. Already in the mid-1980s, in the wake of the seven hundredth anniversary of Alfonso X's death, a brief but highly suggestive essay by Santiago Jiménez Gómez (1984-85) indicated that the view of a king who was politically distanced from Galicia-if not positively anti-Galician-was misleading on a number of levels. Galician noblemen (and others from Galicia) were significantly involved both in the military campaigns on the Andalusian frontier and in the process of resettlement and colonization. For instance, he argued, we know about the presence in the Andalusian frontier of Estevo Fernández de Castro, who was compensated in the repartimiento of Seville, as was the archbishop of Santiago himself, Xoan Arias, who had also participated with a number of knights in his service in several campaigns near Seville. Galicia was also an important source of revenues destined to support his candidacy for the imperial title, Jiménez Gómez suggested; particularly between 1272 and 1274, Castilian diplomas referred constantly to taxes raised for the fecho del Imperio. Thirdly, Galicia was increasingly subject to the Alfonsine legislative framework, as established in the Espéculo, the Partidas, and the Fuero Real. This meant, for instance, the creation of customs houses (alfándegas) in numerous Galician ports, as well as the creation of royal towns such as Pontedeume in 1270; and judicial intervention in cases which pitted Galician municipalities against their lords, including the bishops of Ourense and-more dramatically-the archbishops of Santiago. Finally, for Jiménez Gómez, the closest link between Alfonso X and Galicia was in the realm of culture, notably in his lyrical output, culminating in the Cantigas de Santa María. The influence of the Galician-Portuguese literary and linguistic tradition in Alfonsine cultural production, Jiménez Gómez concluded, raised a number of intriguing questions: for instance, whether the king spoke the language, for how long, and whether it was a lingua franca at court.

Alfonso X's Galician connection may in fact have dated from his early childhood. His guardian García Fernández de Villamayor (who was from Burgos) was married to Doña Mayor Arias, probably a Galician noblewoman who may have come from the Arias family of Limia. García Fernández received the tenancy of the town of Maceda, near Ourense, from Fernando III. The young infante Alfonso had probably

13 López Ferreiro 1895, 1: 375: “auia mas de L annos que non entrara en Gallizia otro Rey, si non yo agora”. These arguments are acknowledged by Pérez Rodríguez 2015: 438-41, within the frame of an attempt to rethink this conventional paradigm. 
had his first contact with the noble courts of the Miño region - in which troubadour lyric was being cultivated - in 1232, when his father Fernando III visited Lugo, Coruña, Santiago, Tui and Orense, this contact probably intensified in the following years. The claim that Alfonso himself spent time in Maceda, for which there is no documentary evidence at present, is contested ${ }^{14}$. Be that as it may, it may have been somewhere in Galicia that he initiated his relationship with his barragana Maria Afonso, daughter of his grandfather Alfonso IX and Teresa Gil de Soverosa. He would have received important towns in Galicia-León when he reached his majority around $1240^{15}$. As infante, Alfonso-Pérez Rodríguez has suggested-was granted a significant role in Galicia and León, exercising judicial authority on behalf of his father, Fernando III. This is the first indication that we should not reduce 'monarchy' to the singular figure of the king-an argument to which we will return shortly. Along with a number of Leonese territories, the infante Alfonso was entrusted with the tenancy of Ribadavia, from 1240, and possibly Lemos; it's possible that other Galician tenancies were in his hands too. Ribadavia was governed by Andrés Fernández de Castro, in Alfonso’s name, in 1245 and 1249, suggesting that his role there was long-lasting ${ }^{16}$.

The king's physical absence from Galicia after his accession to the throne in 1252 is undisputed; but from the earliest months of the reign, the royal chancery continued to issue confirmations of privileges to Galician monasteries; not new privileges, but this emphasis on confirmations had begun already under Alfonso IX and Fernando III. As Jiménez Gómez argued, the region continued to be vital for the crown for economic reasons, with particular value as a source of customs revenues from key maritime ports, ten out of twenty-four of which were in Galicia: Ribadeo, Viveiro, Ortigueira, Cedeira, Ferrol, Betanzos, A Coruña, Baiona, A Guarda, and Tui, as well as “three secondary fishing ports” (Noia, Padrón, and Pontevedra). Alfonso X was keenly conscious of the need to defend the Galician coasts; the Order of Santa María de España was dedicated to defending the shoreline of his kingdoms. Meanwhile, Galicians did indeed continue to participate in royal military campaigns, and equally the conquest of Seville was probably an important stimulus for Galician ports ${ }^{17}$.

For Pérez Rodríguez and others, Alfonso X embodied a widespread western European tendency to assert royal authority more strongly in this period ${ }^{18}$. Apart from adjudicating over disputes between Galician consellos and bishops, Alfonso took control of the vacant archbishopric of Santiago after the death of Juan Arias in 1266; his refusal to recognize the papal candidate, Gonzalo Gómez, would mean that Santiago remained under royal lordship until the end of the reign, and into the early fourteenth century. For the same reasons, the see of Ourense remained vacant

14 González Jiménez 2004: 18.

15 Monteagudo 2014: 123-24.

16 Monteagudo 2014: 149, Pérez Rodríguez 2015: 441-48.

17 Jiménez Gómez 1984-85, Pérez Rodríguez 2015: 452-56.

18 Doubleday 2001: esp. ch. 4. 
for a decade after 1276. These strategies were of course politically polarizing, earning Alfonso the hostility of the Galician church, just as he found himself in an increasingly conflictive relationship with members of the old aristocracy.

There was vigorous opposition to Alfonso's building of new towns across Galicia. But Alfonso X personally, and the monarchy more broadly-understood as a collective, corporate phenomenon-were far more deeply engaged in Galicia than we have conventionally been led to believe. Galicia, equally, remained an economically vibrant and culturally influential region, anything but "peripheral" within the kingdom of Castile and León. The myth of marginality is, in fact, a result of historical erasure, a process that developed from the sixteenth century onwards. It was then at the earliest, under the new Habsburg and Bourbon dynasties, that Galicia became more economically dependent and increasingly subject to pervasive centralist clichés of backwardness ${ }^{19}$. But even at this later stage, as we will see, there are reasons to question the motif of decline.

As Galicia re-emerges again, in the twenty-first century, as a significant economic force whose geographically peripheral status paradoxically gives it renewed centrality in Spain and in the Iberian Atlantic, it is time for us to revisit clichés of decline and marginality ${ }^{20}$. The contributors to this volume reassess the many ways in which Galicia played a significant role within the frame of thirteenth-century Iberia, particularly during the reign of Alfonso X. Chapter 1, Francisco Javier Pérez Rodríguez's “Diplomatario galego de Afonso X” offers a foundation stone for this reappraisal, paralleling the Diplomatario andaluz de Alfonso X of Manuel González Jiménez (1991). Although, as Pérez Rodríguez explains, it does not include transcriptions of the original documents, our expectation is that this edition of sources will be an invaluable resource for future research. The "Diplomatario" confirms the impression of intensive royal involvement in Galicia during the reign of the Wise King. It includes a number of royal land grants in the Aljarafe de Sevilla, in the years up to 1260, to members of the Galician nobility and to the cathedral chapter of Compostela, in the Repartimiento of that territory (docs 11, 16, 99, 123). It provides further evidence for claims that Galicia was an important source of income for royal campaigns on the Andalusian frontier; we see Alfonso X sending his alcalde Domingo Eanes to collect monies for the fleet in Cadiz in 1258 (doc. 100; cf. 151). It also offers evidence that, among royal officials, the meiriño maior Rodrigo García was particularly active in adjudicating Galician legal cases (docs. 114-15, 118, 127); and that more generally, after 1268, there was endemic tension between Galician monasteries and a number of monarchical officials, including the meiriños maiores and the adelantado de Galicia (docs. 160-163, 184, 203, 214, 222). 
Some of Alfonso's most longstanding officials were indeed Galicians: men like Gómez García de Sotomaior. Many of these officials were, particularly in the latter stages of the reign, closely tied to the king by close bonds of personal loyalty, and for this very reason, the apparatus would later be dismantled by Sancho IV ${ }^{21}$. The "Diplomatario" further indicates the degree to which royal government was-as Theresa Earenfight has argued-a family affair. This strengthens the argument that monarchy in the High Middle Ages should be understood not as rule by a single figure but rather as a corporate and collective enterprise involving many family members, both male and female ${ }^{22}$. Alfonso X refers to one of his meiriños in Galicia, Xoán Fernández, as mio sobrino, in July 1277 (doc. 205). His eldest son, Fernando de la Cerda, became actively involved as an agent of royal justice in Galicia from July 1270-when he was present in Santiago de Compostela-just as Alfonso himself had been involved as infante (docs. 169, 185, 205). Equally, the infante Sancho is present in Santiago in his capacity as alférez e almirante da cofradía de Santa María de España on 16 November 1272 (doc. 180), and-interestingly in view of his mother's later patronage of a Clarissan monastery there-Sancho was in Allariz by 24 November that year (doc. 183). By 1274 , he was actively managing the royal lands (reguengo) in Galicia from Burgos through his official Xoán Gato (doc 193; cf. doc. 194). His role in Galicia was then consolidated after Fernando de la Cerda's death in 1275 (docs. 198, 207, 208, 223), and by the late 1270s, he was beginning to exert what Francisco J. Hernández has elsewhere called "un papel cuasi virreinal" in the northwest of the peninsula, acting as "co-regente" (212) ${ }^{23}$. Sancho visited Galicia in both 1276 and 1278, and as Hernández points out in chapter 2, he would soon return there after his accession to the throne in 1286.

The "Diplomatario" also reveals active royal intervention in regard to the towns of Galicia, including protection of the commercial and tax privileges of the city of A Coruña, which was given a monopoly of the salt trade (doc. 87; cf. 92, 195) and Alfonso's former tenancy of Ribadavia (doc. 97), as well as Pontevedra (doc. 151) - whose vibrant economy is studied by Olalla López-Costas in chapter 3-and the towns of Lugo including Villafranca del Bierzo (doc. 191). On 15 February 1268, Alfonso $\mathrm{X}$ exempted the citizens of Lugo from being arrested or imprisoned for debts owed to the bishop (doc. 158). Policies of this kind reflect an increasingly assertive royal policy towards the power of the Galician episcopal sees. This contrasts with Alfonsine policy in the first years of the reign (1252-56), when he had confirmed a large number of prior privileges granted to the cathedral church of Santiago de Compostela and had protected the spiritual and economic interests of the church. On 6 November 1254 he

21 This process is studied in depth by Hernández 2021.

22 Earenfight, 2016. See also Pick 2017. Agreeing with Earenfight's view of monarchy as a family affair, Pick asserts that "The king was at the apex of that family, but his security and ability to exert his authority depended not only on networks of relationship with nobles, rivals, and members of the Church but also on relationships within the family" (238).

23 Hernández 2021. 
had granted royal protection to all pilgrims traveling to Santiago (doc. 20); and on the $29^{\text {th }}$ of the same month, had regularized the manner in which pilgrims to Santiago could make their last will and testament (doc 21). Two years later, on 3 November 1256, he had granted the archbishop of Santiago, Xoán Arias, the right to hold a market every Tuesday in Aldeanueva [de Figueroa], located far from Compostela between Toro and Salamanca; the following day he granted the archbishopric the Galician town of Xallas (docs. 74-75).

Nevertheless, even in these early years, there had been signs of mounting mistrust on the part of the cathedral chapter, revealing tensions that would evolve into a consistently ‘anti-Compostelan’ policy on the part of the Castilian king. In Covarrubias, on 10 November 1255, reflecting this mistrust, Alfonso concedes that it will be the chapter of Compostela which controls the revenue of the see during such time as it is vacant (doc. 78); and in Vitoria, on 10 January 1256, he makes explicit that the financial grant which the Church of Santiago had made to his father, Fernando III, had been made freely-and was not, by implication, necessarily to be repeated (doc. 90). During the early 1260s, Alfonso frequently adjudicated the competing interests of the cathedral and the urban consello, finding in favor of the latter in a key decision of 30 January 1264 in Seville (doc. 137).

The determined projection of royal power in Galicia in the reign of Alfonso $\mathrm{X}$ is the principal theme of Francisco J. Hernández's “La piel del leopardo: Galicia y el ordenamiento territorial alfonsí” (chapter 2). The reguengo was still an important part of the Galician landscape in the mid-thirteenth century, Hernández argues; although this was also 'a land of clerics and monks', the dominance of the church was far from what it would become in the seventeenth century. This argument reinforces similar claims that the control of the church was more limited than we might imagine in a number of areas in Galicia, including the eastern mountain ranges; and that while we might assume this reflects the church's lack of interest in less productive land, there were other territories too that were extremely productive (including Ribeiro de Avia) in which royal control was significant ${ }^{24}$.

Hernández, for his part, asserts that this royal presence was especially strong in the terra chá (the territories under royal jurisdiction)25; the delegation of royal judicial and administrative powers as 'tenancies' was well-established in places like Trastámara, Montenegro, Monterroso, Sarria, Lemos, Toroño and Limia. The history of these rotating tenancies, in his view, reflects the power of Crown to choose tenants-these positions were not hereditary, nor simple concessions to local power dynamics. Among the tenants was Alfonso X’s natural son Alfonso Fernández el Niño (who like his father, spent most of his time in Sevilla); it was Alfonso Fernández who

24 Andrade Cernadas 2016.

25 This term is not to be confused with the Terra Chá, a modern Galician territory in the north of the province of Lugo. 
was sent at the head of a military force against Santiago de Compostela to assert royal rights. Hernández emphasizes that while the five episcopal sees in Galicia-Santiago, Tui, Ourense, Lugo and Mondoñedo-were excluded from ordinary tax obligations, they were not exempt from the 'extraordinary' servicios, which provided the crown with an essential source of revenue. Alfonso X, he concludes, attempted consistently to restrain the power of ecclesiastical and lay lordships, and benefitted substantially from the vacancy in the see of Santiago de Compostela which followed the death of the archbishop in 1266.

To a considerable degree, the continuing assertion of royal power in Galicia reflected the territory's economic and commercial value for the kingdom of Castile-León. In chapter 3, "Pontevedra, a cidade que floreceu na Baixa Idade Media: adentrándonos na dieta medieval a través dos restos humanos”, Olalla López-Costas offers us a new archaeobiological perspective on these questions. She argues that, far from marking a period of decline, the thirteenth century was decisive in the development of the Galician economy, and specifically in the commercial fortunes of Pontevedra, which acquired prominence in Atlantic fishing. This owed a good deal, she suggests, to the intervention of the kings of León (Fernando II and Alfonso IX) and Castile-León (Fernando III and Alfonso X), allowing Pontevedra to acquire a privileged role in the fish trade, within and beyond the peninsula. On the basis of excavations carried out between 2007 and 2010 in church cemeteries in Pontevedra, and adopting cutting-edge scientific methodologies, López-Costas analyzes in detail the thirteenth-century diet of the city's inhabitants, coming to the conclusion that this diet was rich and diverse in seafood. She carefully relates patterns of consumption to socioeconomic status.

In rethinking the crown's relationship to Galicia, in the age of Alfonso $\mathrm{X}$, it's important to avoid a focus on the singular figure of the king. As Lucy Pick has observed, "the old master narrative of the sovereign king and the fantasy of uncomplicated male lordship have proven extremely resistant to a more nuanced understanding of how power was construed, held, and wielded in the Middle Ages”26. Although the 'gender turn' in royal studies has been painfully slow, a wealth of new scholarship on queenship, gender, and power in medieval Europe underscores the importance of elite women, including those who formed part of the court and the extended royal family ${ }^{27}$. In León and Galicia, queens had long been recognized as spiritual guardians for the royal family, exerting authority through their ownership of religious houses ${ }^{28}$. No less important was their intercessory role within the broader framework of corporate monarchy, a context that allowed royal women a significant degree of 'soft power', as well as their direct agency within this framework. Co-rulership was surprisingly

26 Pick 2017: 246.

27 See, for instance, Bianchini 2012, Earenfight 2014, Pelaz Flores 2015.

28 Pick 2011. 
widespread across medieval Europe, including Byzantium, Norway, and Poland, and as Miriam Shadis has shown, had been exercised in Castile and León by Queen Berenguela along with her son, Fernando III ${ }^{29}$.

This new vision of medieval monarchy as a corporate body in which royal women, as well as men, were vital players, is explored in Diana Pelaz's essay, "Facerse presentes. As mulleres da familia real e o reino de Galicia na culminación plenomedieval” (chapter 4). Using as a point of departure Queen Violante's foundation of the Clarissan convent of Allariz, Pelaz underscores both the spiritual role of royal women in thirteenth-century Castile and León and their political and diplomatic agency. She concludes that monarchy was "unha institución complexa, que supera os límites do corpo físico do monarca”. The multiplicity of royal figures whose presence at court is cited in royal diplomas-including the queen and the infantas-amplified the reach of the crown. The figure of the queen is understood "como enlace entre pai e fillo/s pero tamén por si mesma, como figura política autónoma e independente”. For Pelaz, this role is reflected in the visual arts, notably in the images of the tombo of the Cistercian monastery of Toxos Outos, in which eleven queens are represented. The administrative role of royal infantas was also significant: Pelaz points to their role as tenentes of important territories, including commercially important ports like A Coruña and territories on the Portuguese frontier. She concludes by observing that the kingdom of Galicia "continuaría a formar unha parte fundamental tras a reunión de León e Castela baixo o mandato de Fernando III e de vital importancia para a estabilidade do conxunto territorial durante o reinado de Alfonso X;" and that for royal women, as well as their male counterparts, the Galician territories remained an essential sphere of action.

The role of royal women is similarly central to Rosa María Rodríguez Porto's study, “Cara e cruz: conflito político, territorio y padroado rexio en Galicia durante o reinado de Afonso X e Violante de Aragón” (chapter 5). Alfonso was committed to a policy which, while not anti-Galician, certainly came to be anti-Compostelan. Galician ecclesiastical institutions like the cathedral chapter of Compostela therefore looked to Queen Violante as an alternative source of royal support. It's possible, Porto suggests, that Violante, unlike Alfonso, had traveled in person to Compostela in the early 1260s; she had certainly visited the kingdom of León-Galicia in 1264-65. Like Pelaz, Porto points to longer-standing patterns whereby royal women had exerted political agency in the Iberian northwest; the convent of Santa Clara de Allariz would be founded within an 'imaginary triangle' formed by Xunqueira de Ambía, Porqueira and Celanova, which had traditionally belonged to the infantas of León. As a Franciscan re-iteration of the royal foundation of Las Huelgas-itself a reinvention of the female institutions linked to the Infantazgo-Allariz was also the inspiration for the foundation of Santa Clara de Coimbra by Queen Isabel of Portugal, reflecting the geo-political

29 Shadis 2009. 
implications of the close dynastic links between Violante and her niece Isabel. The aspiration to female royal protection and patronage was reflected in the centrality given to images of royal queens in the Tumbo Colorado and, again, the Tumbo de Toxos

Outos. To her chagrin, Queen Violante's role as patron and her economic agency were undercut by her son the infante Sancho, who relieved her of important tenancies and who was responsible for the appointment of the bishop of Ourense, Pero Eanes de Nóvoa, who was the nemesis of the Franciscans in Galicia when Violante was attempting to establish a Clarissan convent at Allariz. This was coupled by disaffection with Sancho among Galicia nobles and clerics; Galicia, she indicates, was "on the point of becoming an independent kingdom". Yet the queen remained an important patron, as the disparate documentary record attests, despite the paucity of the artistic works that can actually be associated to Violante's initiative; in this regard, the closing pages of Porto's chapter are dedicated to an analysis of Violante's role in relation to material objects with which she has been conventionally associated.

Beatriz Vaquero’s essay, "Santa Clara de Allariz, historia dunha fundación real (ss. XIII-XV)" (chapter 6), draws on the evidence of a forthcoming edition of 376 extant documents relating to the convent in order to pursue the story of Allariz from its origins in 1282 and its first abbess Sancha Eanes all the way to the end of the fifteenth century. For Violante, this was in part a personal project: the convent was to be a place of refuge in her widowhood, after Alfonso X's death in 1284, and in her testament, she announced her intention to be buried there. However, reinforcing a line of interpretation that is a leitmotif of this book, Vaquero accepts the argument that the foundation of Santa Clara de Allariz was also a political move designed to reassert royal power as a counterbalance to the power of the church-in this case, the power of the bishop of Ourense (a fact of which the bishop appears to have been keenly aware). As such, the convent was later supported by Sancho IV, his son the infante Felipe, and other members of the royal family in the decades that followed, notably Alfonso XI, while remaining "un importante centro de poder feminino”.

The convent of Allariz, then, was closely entwined in networks of royal power. As Ricardo Pichel explains in his contribution, "Sabean quantos este liuro virem... A difusión do legado historiográfico e haxiográfico do Rei Sabio na Galicia baixomedieval” (chapter 7), it played an important role in the reception of the hagiographical work of Bernardo de Brihuega, soon after its composition at the Alfonsine court. Focusing in depth on the cross-frontier diffusion of Alfonsine historiographical and hagiographical production in both Galicia and Portugal, Pichel's chapter underscores the importance of great noble households-among others, the powerful lineages of Lima-Batisela, Riba de Vizela, Andrade, and Castro de Lemos-as centers of patronage and nodes in a trans-peninsular network of elite cultural power in the late thirteenth and fourteenth centuries. The trajectory of the great Alfonsine (and post-Alfonsine) historical projects-including the General Estoria, the Estoria de Es- 
paña, and the Crónica de Castilla-provides ample testimony of the interest of these seigneurial households in transmitting and diffusing the historiographical and hagiographical legacy of Alfonso X through copying, translation, compilation, and re-editing on both sides of the River Miño, throughout the fourteenth century.

While we must indeed understand monarchy as a corporate phenomenon involving complex cultural and political networks, it could certainly be imprinted by the specific agenda and aspirations of individual kings. Alfonso X aspired to control across the whole expanse of his realms, including Galicia, and indeed beyond, as he pursued the title of Holy Roman Emperor. As Kristin Kennedy has written, "Even after Pope Gregory had definitively quashed his imperial ambition Alfonso styled himself 'by the grace of God king of the Romans' in documents issued in connection with the weddings of two of his sons at Burgos in 1281”. When Alfonso's coffin was opened in 1579, it was found to contain a number of imperial insignia. Kennedy has underscored the ideological work performed by his textual production, insisting that the primary audience was comprised of elite members of his own court circles rather than a broader public ${ }^{30}$. Others have pointed to the sustained attempt to centralize political control within the kingdoms of León and Castile, and the ways in which this ideological agenda is reflected in cultural production, including the Cantigas de Santa María and the Cantigas de escarnio y de maldezir.

In this context, Helena de Carlos's study of "As Antigüidades da Gallaecia na obra historiográfica de Afonso X" (chapter 8) is suggestive as a reflection of the ideological climate of the royal court. De Carlos asks how the 'protohistory' of pre-Roman Galicia was represented by the historians working at Alfonso's court, focusing particularly on the Alfonsine recasting of the story of the western Iberian ruler Xerión. According to narrative tradition, possibly refracting pre-classical colonial processes in the peninsula, Xerión's wealth in cattle had been coveted by the mythical Roman figure Hercules: "ese culto a Xerión podería ser un eco da lembranza de depredacións de gando no seo dunha loita entre o elemento colonial pregrego, representado por Heracles, contra os reis indíxenas”. The figure of Hercules was of particular interest to the Alfonsine court in the wake of Castilian expansion into Andalusia, where (De Carlos argues) the Roman legacy—as well as the Andalusi legacy-was ubiquitous and pervasive. In the thirteenth century Castilian court, Hercules was seen as an emblem of a previous civilizing culture, and in the new, imperializing context, the story of Xerión and Hercules was transformed.

In the original third-century Latin source, Xustino, Hercules had been represented as an aggressive predator. Now, in the Alfonsine tradition, he was instead depicted as a just and noble figure. Xerión, in contrast, was represented as a seven-headed monster whom Hercules bravely decapitates in battle. Hercules, according to the royal historians, had founded a city on the site of that battle-A Coruña- 
and ordered a great tower to be built there, a task which was completed by Hercules' nephew King Espan, lord of “España”. It had also been Hercules who, according to the Estoria de Espanna, first located the site where the great Roman city of Seville would later be built. De Carlos concludes by suggesting that the Alfonsine commitment to the study of ancient Roman sources was shared with earliest Renaissance Italian humanism, sometimes predating it by half a century, reinforcing the idea-which has been explored elsewhere-that origins of the Renaissance should be seen not as an intrinsically Italian development but rather as a multipolar phenomenon in which Iberia also played a vital role ${ }^{31}$.

The close enmeshment of Galicia and the Castilian monarchy in the thirteenth century was also reflected in the realm of lyrical production ${ }^{32}$. As Pérez Rodríguez has observed, “Galician influence at the Castilian courts of Alfonso X and Sancho IV is [...] highlighted by the success there of Galician-Portuguese troubadours and the embrace of their language for courtly verse, both in the cantigas de amigo or de loor and the cantigas de escarnio and de maldizer" 33 . In the final essay in this volume, chapter 9, "Afonso o Sabio na lírica trobadoresca galego-portuguesa: da historia literaria á política cultural”, Henrique Monteagudo emphasizes in particular the vibrancy of the Compostelan troubadour tradition, and the influence it exerted at the Alfonsine court. For Monteagudo, the use of galego by Alfonso X responded in part to the advanced development of lyric genres in Galicia (as well as to an attempt to undercut the cultural and political authority of the church). He also sees it as a natural move in a plurilingual peninsula in which multiple forms of romance vernacular were seen as complementary, and the imposition of a single national language was anathema. ${ }^{34}$ Alfonso assumed a principal role as literary patron, in a way that increasingly challenged the older cultural role of the aristocracy and promoted Galician xograres of relatively humble origin. His centralization of patronage is not self-evidently a project which we should venerate uncritically, since to some degree it may have weakened lyric production within Galicia itself.

Monteagudo's chapter favors an autobiographical reading of a number of cantigas attributed to AX himself f5; $^{35}$ at the same time, he underscores the king's promotion of satirical poetry (a genre with a longstanding Galician-Portuguese precedent) as an instrument of ideological control $^{36}$ and the value of the Cantigas

31 Doubleday 2015: 228-29.

32 Jiménez Gómez 1984-85: 160-63.

33 Pérez Rodríguez 2015: 456.

34 The point is worth comparing with Roger Wright's insistence on the very late conceptual distinction between different dialects of 'Romance' or 'Ibero-Romance'; and the continuing inseparability of Galician-Portuguese (Wright 2015). See also Mariño Paz and Varela Barreiro (2010) and Mariño Paz (2020).

35 This approach, which is also adopted in Doubleday 2015, partially distinguishes his reading from that of some other scholars. Kennedy 2019, 89-90, argues-for instance-that while many of the poems attributed to Alfonso appear to reflect the king's inner feelings and emotional states, others owe a great deal to literary tradition.

36 See Doubleday 2004. 
de Santa María as a means of forging a distinctive royal spirituality, undercutting the spiritual monopoly of the Church. Like other scholars, including Kennedy, Monteagudo emphasizes the very specific nature of the courtly audience for the Cantigas de Santa María; in his view, these were not a broadly propagandistic tool aimed at a wide public. Nonetheless, he argues, their composition was certainly inflected by the ideological battle against the archbishops of Santiago de Compostela, leading to a marginalization of the cult of St. James in the cantigas in favor of the Marian cult and other sacred sites such as Villasirga.

The evidence of the essays in this volume strongly suggests that thirteenth-century Galicia was not yet in decline; that Galicia, by no means peripheral other than in a geological sense, played a key role in a culturally and linguistically hybrid peninsula in this period; that the Castilian monarchy had in no way 'withdrawn' from Galicia in the age of Alfonso X; and that there was a fluid interaction between Galicia and Castile, in economic, political, and cultural terms. This would long remain the case. In their study of two privilegios rodados granted to Galician recipients by Juan II of Castile (1406-54) in 1419 and 1420, Miguel García-Fernández, Diana Pelaz Flores, and Ricardo Pichel (2020) have reiterated that physical distance from Galicia did not necessarily mean that late medieval rulers were unconcerned with the Iberian north-west; historians have largely overlooked the history of royal power in Galicia in the later Middle Ages, they argue, calling for historians to pay closer attention to the ways in which royal power was exerted in less direct ways during the later Middle Ages, from a distance, encompassing close, complex, and bidirectional relationships with the Galician municipalities and nobility, as well as with its ecclesiastical institutions. It would be wise, they conclude, to contemplate developing a corpus of medieval royal documents relating to the kingdom of Galicia ${ }^{37}$.

This revised paradigm, and in particular the denial of Galicia's “peripheral" status, may be worth comparing with the arguments articulated by María del Carmen Saavedra Vázquez for sixteenth- and seventeenth-century Spain: a period which has conventionally been known as the 'séculos escuros'. Galicia was not peripheral to Carlos V's interests, Saavedra insists, contrary to what is typically affirmed. Among other policies, Carlos V created a Real Audiencia for Galicia: a judicial tribunal but also an organ of government which could intervene in many aspects of local life, arbitrating between lords while also defending the interests of the population against local powers. Although Philip II visited Galicia only once, the crown continued to attempt to assert its interest there in the later part of the century, for instance with the creation of the Inquisition in Santiago in 1574. At the same time, power dynamics were not unidirectional even in the Habsburg period: orders from Madrid had to confront the challenges of distance and geography, and the crown continued to need to negotiate power with local elites, as had been the case in the thirteenth century.

37 García-Fernández, Pelaz Flores and Pichel 2020: 175. 
Although, as Henrique Monteagudo has also observed, Galician language may have been eclipsed in the printed medium, neither he nor Saavedra finds the term 'séculos escuros' to be sustainable; we cannot project the 'decline' of Galician language in published texts onto the events of this period or apply it to Galicia as a whole ${ }^{38}$.

One is left with the sense that the historiographical motif of Galician decline, like the obsession with the 'end' of al-Andalus to which Gil Anidjar has drawn attention, may to a considerable degree be illusory, an 'invention' that in fact speaks to the particular concerns of the nineteenth and twentieth centuries. Monteagudo has suggested that, like the English term 'Dark Ages', the term 'séculos escuros' evokes a period between two superior phases of 'light', in this case the Middle Ages and the Rexurdimento ${ }^{39}$. Equally, it is time to interrogate the cliché of late medieval decadence in the status of Galicia, from the thirteenth century onwards; it is our hope that the essays in this book will stimulate ongoing discussion and debate.

This volume arises as one of the initiatives promoted by the Consello da Cultura Galega to commemorate the eighth centenary of the birth of Alfonso X in 1221. The editors wish to thank all those who have contributed to this volume and those who, by virtue of other professional commitments or other difficulties, are not, in the end, among the list of contributors. Our most sincere gratitude to all those who have shaped the book ${ }^{40}$.

38 Saavedra Vázquez 2016.

39 Monteagudo, “A invención dos ‘séculos escuros”, 149-53.

40 Simon R Doubleday's contribution to this volume was made posible in part due to the generous scholarship granted by the National Endowment for the Humanities, for the academic year 2020-21. This introduction has benefitted greatly from invaluable feedback from a number of contributors to the book, including particularly Ricardo Pichel and Henrique Monteagudo. 


\section{REFERENCIAS BIBLIOGRÁFICAS}

- ANDRADE CERnadas (2016): «Algunhas historias por tratar da historia medieval de Galicia», en Isidro Dubert (ed.), Historia das historias de Galicia, Vigo, Xerais, 119$-147$.

- ANIDJAR, Gil (2008): «Postscript: Futures of Al-Andalus», en Simon R. Doubleday/ David Coleman (eds.), In the Light of Medieval Spain: Islam, the West, and the Relevance of the Past, Nova York, Palgrave, 181-200.

- Bianchini, Janna Bianchini (2012): The Queen's Hand: Power and Authority in the Reign of Berenguela of Castile, Philadelphia, University of Pennsylvania Press.

- Colmeiro, José (2009): «Peripheral Visions, Global Positions: Remapping Galician Culture», Bulletin of Hispanic Studies, 86, 213-230.

- D’Emilio, James (ed. e trad.) (2015a): Culture and Society in Medieval Galicia: A Cultural Crossroads at the Edge of Europe, Leiden, Brill.

- D'Emilio, James (2015b): «The Paradox of Galicia: A Cultural Crossroads at the Edge of Europe», en James D'Emilio (ed. e trad.), Culture and Society in Medieval Galicia: A Cultural Crossroads at the Edge of Europe, Leiden, Brill, 3-125.

- Doubleday, Simon R. (2001): The Lara Family: Crown and Nobility in Medieval Spain, Cambridge, Mass., Harvard University Press.

- Doubleday, Simon R. (2004): «O que foi passar a serra: Frontier-crossing and the thirteenth-century nobility in the cantigas de escarnio e maldizer», en Martin Aurell (ed.), Le médiéviste et la monographie familiale: sources, méthodes et problematiques, Turnhout, Brepols, 189-200.

- Doubleday, Simon R. (2015): The Wise King: A Christian Prince, Muslim Spain, and the Birth of the Renaissance, Nova York, Basic Books.

- Earenfight, Theresa (2014): Queenship in Medieval Europe, Nova York, Palgrave Macmillan.

- EARENFight, Theresa (2016): «Where do we go from here? Some thoughts on power and gender in the Middle Ages», Medieval Feminist Forum: A Journal of Gender and Sexuality, 51, 16-31.

- FaLQue, Emma (2015): «Galicia and Galicians in the Latin Chronicles of the Twelfth and Thirteenth Centuries», en James D'Emilio (ed. e trad.), Culture and Society in Medieval Galicia: A Cultural Crossroads at the Edge of Europe, Leiden, Brill, 400-428.

- FiERro, Maribel (2009): «Alfonso X 'the Wise’: The Last Almohad Caliph?», Medieval Encounters, 15, 175-198.

- García-Fernández, Miguel/Diana Pelaz Flores/Ricardo Pichel (2020): «Galicia e El-Rei ou como reinar desde a distancia: comunicación política arredor de dous 
novos privilexios rodados de Xoán II», Madrygal. Revista de Estudios Gallegos, 23, 139-180.

- GARCía FITZ, Francisco (2012): «Was Las Navas a decisive battle?», Journal of Medieval Iberian Studies, 4, 5-9.

- González JimÉnEZ, Manuel (2004): Alfonso X el Sabio, Barcelona, Ariel.

- HeRnándeZ, Francisco J. (2021): Los hombres del rey: la transición de Alfonso X a Sancho IV (1276-1286), Salamanca, Universidad.

- JimÉnez GómEz, Santiago (1984-1985): «Afonso o Sabio e Galicia: ¿diverxencia ou extrañamento?», Cuadernos de Estudios Galegos, 35, 147-165.

- Kennedy, Kirstin (2019): Alfonso X of Castile-León: Royal Patronage, Self-Promotion and Manuscripts in Thirteenth-Century Spain, Amsterdam, Amsterdam University Press.

- López CARreira, Anselmo/Xosé Miguel Andrade Cernadas (2020): O Reino Medieval de Galicia: Crónica dunha desmemoria, Vigo, Xerais.

- López FERREIRO, Antonio (1895): Fueros municipales de Santiago y su tierra, Santiago de Compostela, 2 vols., repr. Madrid 1975.

- Mariño PAZ, Ramón/Xavier VARELA BARreiro (2010): «Linguas do Camiño en territorio ibérico durante a Idade Media», en Esther Corral (ed.), In marsupiis peregrinorum. Circulación de textos e imágenes alrededor del Camino de Santiago en la Edad Media, Firenze, Edizioni del Galuzzo - Sismel, 59-82.

- MARiño PAZ, Ramón (2020): «O uso escrito do romance nos reinos de Afonso X o Sabio e no reino de Portugal desde o século XII ata finais do XIII. Estado da cuestión», Labor Histórico, 6:1, 246-271 (https://revistas.ufrj.br/index.php/lh/article/ view/32294).

- Monteagudo, Henrique (2014): A nobreza miñota e a lírica trobadoresca na Galicia da primeira metade do século XIII: a personalidade histórica do trobador Johan Soayrez Somesso. Os trobadores Afonso Soarez Sarraça e Estevan Fayan, Noia, Editorial Toxosoutos.

- Monteagudo, Henrique (2016): «A invención dos ‘séculos escuros’», en Isidro Dubert (ed.), Historia das historias de Galicia, Vigo, Xerais, 149-179.

- Pelaz Flores, Diana (2015): Reinas consortes. Las Reinas de Castilla en la Edad Media (siglos XI al XV), Madrid, Sílex.

- PÉrez Rodríguez, Francisco Javier (2015): «The Kingdom of Galicia and the Monarchy of Castile-León in the Twelfth and Thirteenth Centuries», en James D’Emilio, (ed. e trad.), Culture and Society in Medieval Galicia: A Cultural Crossroads at the Edge of Europe, Leiden, Brill, 429-462.

- PICK, Lucy K. (2011): «Sacred Queens and Warrior Kings in the Royal Portraits of the Liber Testamentorum of Oviedo», Viator, 2, 49-82. 
- PIск, Lucy K. (2017): Her Father's Daughter: Gender, Power, and Religion in the Early Spanish Kingdoms, Ithaca/London, Cornell University Press.

- Portela, Ermelindo (2015): «The Making of Galicia in Feudal Spain (1065-1157), en James D'Emilio (ed. e trad.), Culture and Society in Medieval Galicia: A Cultural Crossroads at the Edge of Europe, Leiden, Brill, 367-399.

- PRADO-VILAR, Francisco (2009): «Lacrimae rerum: San Isidoro de León y la memoria del padre», Goya, 328, 195-221.

- Reilly, Bernard F./Simon R. Doubleday (no prelo): Christian Spain Before the Crusades: Power and pragmatism in eleventh-century Iberia, Philadelphia, University of Pennsylvania Press.

- SaAvedra Vázquez, María del Carmen (2016): «A realidade política de Galicia nos 'séculos escuros'», en Isidro Dubert (ed.), Historia das historias de Galicia, Vigo, Xerais, 211-240.

- SHADIS, Miriam (2009): Berenguela of Castile (1180-1246) and Political Women in the High Middle Ages, Nova York, Palgrave Macmillan.

- Wright, Roger (2015): «Galician Before 1250», en James D’Emilio (ed. e trad.), Culture and Society in Medieval Galicia. A Cultural Crossroads at the Edge of Europe, Leiden, Brill, 843-861.

- YZQUIERDo PeIRó, Ramón (2019): «Unha catedral para os reis de Galicia: O Panteón Real de Santiago de Compostela», en Anselmo López Carreira/Manuel Vilar Álvarez/Ramón Yzquierdo Peiró/Ma del Pilar Rodríguez Suárez/Mercedes Vázquez Bertomeu, O Panteón Real, Santiago de Compostela, Concello de Santiago, 15-47. 


\title{
Diplomatario galego de Afonso X
}

\author{
Francisco Javier Pérez Rodríguez
}

Universidade de Vigo

DOI: 10.17075/gtax.2021.002 



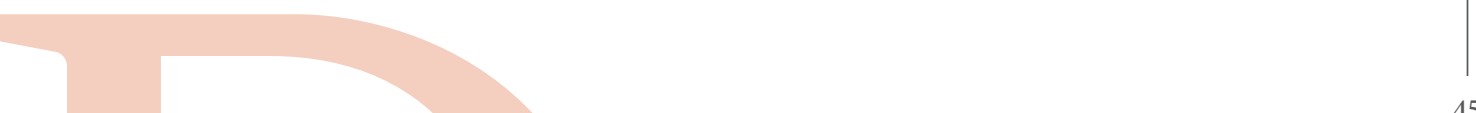

Fronte ás coleccións documentais dos monarcas inmediatamente anteriores, tanto no reino de León como no de Castela -Fernando II (1943), Sancho III (1980) e Afonso VIII (1960), Afonso IX (1944) e Fernando III (1980)-, editadas por Julio González, a de Afonso X aínda está por facer. O intento máis ambicioso sobre a súa documentación é a Documentación e itinerario de Alfonso X el Sabio, de Manuel González Jiménez e María Antonia Carmona Ruiz (2012), que sucede á recompilación feita décadas antes por Antonio Ballesteros Beretta, en 1963. Nelas, e especialmente na primeira, ofrécese o rexesto dos diplomas emanados da chancelaría rexia, se ben con certas incorreccións no que se refire, cando menos, á documentación galega. En canto á edición documental cabe destacar os Textos y concordancias de Documentos castellanos de Alfonso X, obra de María Teresa Herrera, María Nieves Sánchez, María Estela González de Fauve e María Purificación Zabia, publicada en CD-ROM en 1999, así como o Diplomatario andaluz de Alfonso X de Manuel González Jiménez (1991), obra de importancia capital ao compilar o enorme número de documentos do reinado que fan referencia a Andalucía.

Recollendo o título dado por González Jiménez, a nosa intención é bastante menos ampla porque neste traballo non se presentan as transcricións documentais, senón só os rexestos dos diplomas dirixidos por don Afonso ao reino de Galicia ou, nalgún caso, a galegos que reciben bens fóra dela. Trátase de presentar dun xeito ordenado este conxunto documental, pois os erros e as incorreccións son relativamente frecuentes á hora de citalos en diversas obras que, directa ou indirectamente, tratan sobre o reinado de Afonso X en Galicia. A meirande parte deles están editados, se ben non todos publicados, como ocorre, por exemplo, cos correspondentes ao mosteiro de Santa María de Melón, transcritos en 1957 na tese de doutoramento de Segundo Cambón Suárez, aínda inédita. Teño comprobado a maior parte das citas arquivísticas dos documentos citados, como pode comprobarse no aparato crítico correspondente, se ben hai algúns diplomas dos que non se sabe onde se atopan na actualidade, como os correspondentes ao antigo arquivo do mosteiro de San Vicente de Monforte, recollidos por Ballesteros. Por outra banda, e para facilitar a consulta, inclúo o rexesto de certos documentos que, citados en certas obras, non son tales senón que nelas se errou na data ou non foi dado pola chancelaría do Sabio; para evitar contabilizalos como documentos propios desta, inclúense no lugar que cronoloxicamente lles corresponde pero numerándoos como bis. Si que foron numerados os dous que considero falsos. 
Ademais, recóllense neste diplomatario os documentos expedidos polos infantes don Fernando e don Sancho, aínda que deste último só ata antes da súa revolta contra o seu pai en 1282. Deste ano só recollo o n.․2 223, doazón do infante a don Paio Gómez Chariño que se datou en febreiro dese ano, co que sería anterior ao levantamento de don Sancho, cando, en realidade, debe ser posterior ${ }^{1}$.

Volvendo á documentación, e no que a Galicia se refire, a chancelaría do Rei Sabio ten un claro parecido respecto ao acontecido no reinado anterior, o do seu pai Fernando III. Os gráficos 1 e 2 demostran como foi nos cinco primeiros anos de ambos os dous reinados cando se concentra o maior número de documentos².

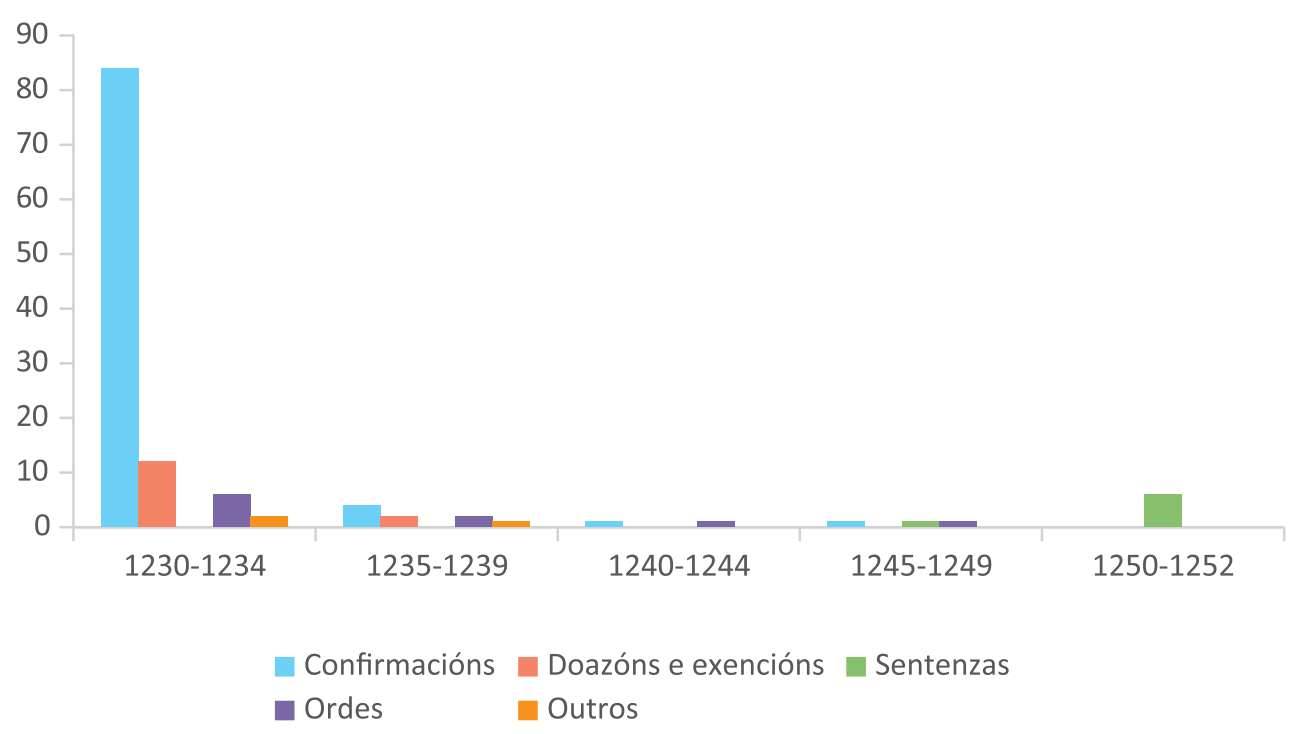

Gráfico 1: Tipo de documentos emitidos pola chancelaría de Fernando III (1230-1252) referentes ao reino de Galicia.

1 Quero agradecer aos coordinadores deste volume, así como ao Consello da Cultura Galega, que me permitisen publicar este traballo, que coido que é importante para establecer os documentos expedidos por Afonso X que fan referencia a Galicia ou aos galegos. Todo o meu agradecemento tamén a Francisco J. Hernández polas súas anotacións ás versións previas deste traballo.

2 Nos gráficos non se teñen en conta os documentos da etapa de don Afonso como infante nin os emitidos polos seus fillos Fernando e Sancho, e tampouco os n.․1ㄴ, 141, 150, 172, 215 e 217 por non afectar directamente a Galicia, aínda que teñen relación con ela; así, por exemplo, os n.ํำ 141 e 150 tratan da fixación da fronteira entre os reinos de León e Galicia co de Portugal. 


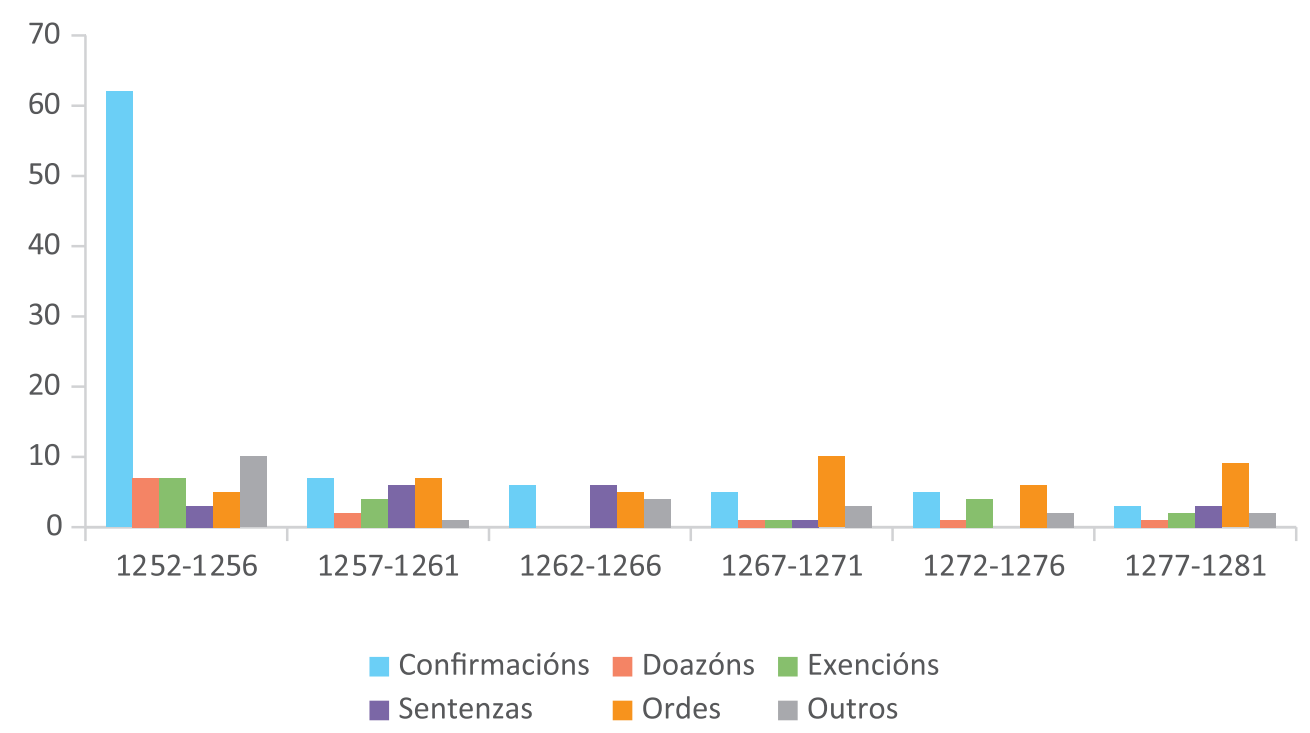

Gráfico 2: Tipo de documentos emitidos pola chancelaría de Afonso X (1230-1252) referentes ao reino de Galicia.

Tal concentración débese ao enorme número de confirmacións feito, sobre todo a entidades eclesiásticas, particularmente mosteiros. Trátase dun fenómeno que non afecta só a Galicia senón ao conxunto da Coroa e que, como estudou M. Kleine (2015: 162-163), se ben estas confirmacións adoitan facerse ao principio dos reinados, no caso de Afonso X atrásase ata 1255 por mor, sobre todo, da necesidade de rematar o repartimento de Sevilla.

Por outra banda, o reinado de don Afonso aparece como continuidade do de Fernando III na esfera xudicial. Unha vez conquistada Sevilla, en 1248, don Fernando emitiu unha serie de sentenzas que van ser capitais, sobre todo para as relacións de certas cidades coas catedrais que eran as súas señoras, en concreto Tui e Santiago de Compostela. O Sabio acabaría con longos procesos xudiciais abertos en tempos do seu pai, aínda que participará como xuíz en bastantes máis que se prolongan durante o seu goberno. Hai tamén que sinalar que don Afonso non emitiu ningún documento a persoas ou entidades galegas unha vez que o infante don Sancho se rebelou a mediados de 1282.

A documentación conservada é maioritariamente eclesiástica, sendo os arquivos catedralicios e monásticos onde permaneceron a gran maioría dos diplomas. Só unha pequena porcentaxe é municipal, destacando os forais concedidos a Santa Marta de Ortigueira e a Pontedeume. 


\section{SIGLAS}

AA: Arquivo do Mosteiro de San Paio de Antealtares. Santiago de Compostela. ACLe: Arquivo da Catedral de León. León.

ACLu: Arquivo da Catedral de Lugo. Lugo.

ACMd: Arquivo da Catedral de Mondoñedo. Mondoñedo.

ACOu: Arquivo da Catedral de Ourense. Ourense.

ACSC: Arquivo da Catedral de Santiago de Compostela. Santiago de Compostela.

ACT: Arquivo da Catedral de Tui. Tui.

ADA: Arquivo Diocesano de Astorga, Astorga.

AHMAC: Arquivo Histórico Municipal da Coruña. A Coruña.

AHPL: Arquivo Histórico Provincial de Lugo. Lugo.

AHPOu: Arquivo Histórico Provincial de Ourense. Ourense.

AHUSC: Arquivo Histórico Universitario de Santiago de Compostela. Santiago de Compostela.

AMOv: Arquivo Municipal de Oviedo. Oviedo.

AMSCS: Arquivo do Mosteiro de San Clemente de Sevilla. Sevilla.

ANTT: Arquivo Nacional da Torre do Tombo. Lisboa.

ARCV: Arquivo da Real Chancelaría de Valladolid. Valladolid.

ARG: Arquivo do Reino de Galicia. A Coruña.

BCPMHAO: Boletín de la Comisión Provincial de Monumentos Históricos y Artísticos de Orense. 


\section{REXESTOS DOCUMENTAIS}

1

1246, agosto, 15. Zamora.

O infante don Afonso [X] doa á Orde de San Xoán do Hospital a terra de Páramo, na «honor» de Sarria, «como la tovo siempre ricomme».

B. AHN, Órdenes Militares, Carp. 568, n.o18-R. En confirmación de Afonso X, xa rei, de 14 de outubro de 1255. Rex.: Ballesteros Beretta 1984: 1061 (n.․2); González Jiménez/Carmona Ruiz 2012: 98 (n.․22).

Ed.: García Tato 2004: 180 (n. 79$)$.

[1252-1284]

A petición do seu abade, Afonso X concede ao mosteiro de Santa María de Monfero as peitas reais dos vasalos do cenobio para a obra do mosteiro, salvo os do ano en curso, que serán recadados por dous homes bos nomeados polo abade, e ordena a Nuno Pérez, xuíz de Pruzos, e a Men Rodríguez de Pontedeume que supervisen o cobro do imposto e o seu gasto na obra da igrexa.

B. AHN, Clero, Carpeta 505, n.․⒓ En confirmación de Sancho IV de 9 de febreiro de 1285 en confirmación deste mesmo monarca de 9 de febreiro de 1285 e novamente en 1 de maio de 1293 en confirmación de Fernando IV de 26 de xullo de 1306 en confirmación de Afonso XI de 25 de xuño de 1313; en traslado desta última confirmación realizado o 9 de xaneiro de 1316 por García Pérez, notario dos coutos de Monfero.

Rex.: Sánchez Belda 1953: 355 (n.요 822).

Ed.: Gaibrois de Ballesteros 1922-1928: t. 3, 31-32 (n. 49).

Na primeira confirmación da doazón e orde, a realizada por Sancho IV en 1285, resúmese, sen datala, e dun xeito algo confuso posto que pode entenderse que o que se atribúe a Afonso X pode ter sido obra de Fernando III pois, se ben parece indubidable que o diploma que se confirma é obra de Afonso X, que nel se diga que o abade de Monfero mostróme una carta del rey don Alffonso, mío padre, permite pensar que un dos numerosos copistas das sucesivas confirmacións cambiara Fernando por Afonso. Sería necesario datar ao xuíz de Pruzos, Nuno Pérez, e a Men Rodríguez de Pontedeume para datar correctamente a carta e confirmar a súa autoría.

[1252-1284]

Afonso X exime de pedido ao mosteiro de San Salvador de Lérez porque este estaba «muy pobre e mucho endebdado». 
B. AHN, Clero, Carpeta 1787, n.o 13. En confirmación de Sancho IV de 20 de novembro, sen ano, en confirmación de Fernando IV de 1299 en confirmación de Afonso XI de 8 de novembro de 1329.

50 Rex.: Sánchez Belda 1953: 355 (n.․ 821).

\title{
4
}

[1252-1284]

Afonso X ordena pescudar para descubrir se o mosteiro de Santa María de Xunqueira de Ambía debe pagar xantar ao rei.

Ed.: Crespo Pozo 1964-1966: 258-259 e 447-448.

\section{5}

[1252-1284]

\begin{abstract}
Afonso $X$, tras ordenar a investigación e recibila, confirma os privilexios do Concello da terra de Dozón.
\end{abstract}

B. Museo de Pontevedra, Col. Sampedro, C. 29-12. En confirmacións de Fernando IV, Xoán II, Enrique IV e os Reis Católicos recollidas na feita por Carlos III o 6 de marzo de 1767.

Rex.: Miramontes Castro 1996: 120 (n.. 15).

Ed.: Fernández de Viana y Vieites 2009: 101 (n. 79).

Fóra da confirmación de 1767, dá noticia desta confirmación Pedro Pérez de Lama de Dozón, primeira testemuña na investigación realizada polo xuíz de Búbal e Castela no preito que enfronta ao mosteiro de Vilanova co Concello de Dozón, quen conta como, tras romper os portugueses a arca na que se gardaban os documentos do Concello, custodiada na igrexa de Santa María de Dozón, en tempos de Fernando II, os do couto paresceran con el-Vasco López- ante el rey don Afonso, a quien Dios perdone, padre del don Sancho, e que el rey lo mando inquerir se obiera y tal previllejo [...] e dis que vista el rey la pesquisa que les confirmó estas cosas como sobredicho es por otro previllejo.

\section{6}

1252, outubro, 15. Sevilla.

Afonso X confirma ao mosteiro de Santa María de Sobrado a confirmación xenérica dos seus privilexios realizada por Fernando III o 24 de novembro de 1230, que inclúe.

B. AHN, Clero, Carpeta 542, n.ํㅜ 1 . En traslado notarial realizado no século XIV.

Rex.: Sánchez Belda 1953: 308-309 (n.ํ 717); Ballesteros Beretta 1984: 1062 (n.o 46); González Jiménez/Carmona Ruiz 2012: 104 (n. 으 65). 
1252, novembro, 16. Badajoz.

Afonso X confirma as sentenzas dadas por Fernando III o 12 de xullo de 1250 en: 1) o preito entre o arcebispo de Santiago de Compostela e os homes da terra que se negaban a pagar «maniadgo», ditaminando a favor do primeiro e ordenando que se pague salvo naqueles lugares que poidan demostrar a súa exención; e 2) o preito entre a Igrexa de Santiago de Compostela e varios carniceiros da cidade de Santiago sobre a renda que a primeira esixe aos segundos de varias mesas na carnizaría, resolvendo a favor da Igrexa e ordenando que os carniceiros paguen a renda esixida.

B. ACSC, Tumbo B, ff. 120v-121r. En traslado realizado por André Pérez e Afonso Eanes, notarios de Santiago de Compostela.

Rex.: González Vázquez 1996: 307; González Jiménez/Carmona Ruiz 2012: 105 (n.․72).

Ed.: González Balasch 2004: 322 (n.․160).

\section{8}

1252, novembro, 18. Badajoz.

Afonso X sentencia que o mosteiro de San Lourenzo de Carboeiro non debe entregar a El-Rei o animal de carga que o seu pai, Fernando III, lle demandara, segundo demostrou a investigación feita ao respecto polo bispo de Lugo don Miguel.

A. AHN, Clero, Carpeta 1784, n. ⒔ Orixinal. Pergameo, 204 x 193 mm.

Rex.: Sánchez Belda 1953: 309 (n.ํ718); Buján Rodríguez 1996: 304 (n.ํ 236); Lucas Álvarez 1999: 944 (n.ํㅡ 102); González Jiménez/Carmona Ruiz 2012: 105 (n.o 71).

Ed.: Lucas Álvarez 1958: 562-563 (n.ํ75); Herrera/Sánchez/González de Fauve/Zabia 1999: AGA 1r.

\section{9}

[1252, novembro, 26]. Badajoz.

Afonso X confirma ao mosteiro de Santa María de Montederramo a orde dada por Fernando III o 11 de agosto de [1241], que inclúe, de que non se cobre imposto ningún aos bens que sexan para sustento do cenobio.

B. ACOu, Monacais, n.ํ6ㄱ. En confirmación de Fernando IV de 1 de abril de 1302.

Rex.: Leirós Fernández 1951: 59 (n. 679); Duro Peña 1972: 96 (n. 321).

Ed.: Lorenzo 2016: 737 (n. 6ㅜ). 


\section{0}

1252, decembro, 3. Mérida.

Afonso X confirma á Igrexa de Santiago de Compostela os diplomas seguintes de Afonso IX, que inclúe; 1) decreto sobre os «iuniores» que poden ir poboar unha vila real, sen data; 2) sentenza que obriga aos homes de Bama a dar ao arcebispo compostelán o mesmo foro de froito que de pan, de 3 de maio de 1225; 3) orde aos habitantes da Terra de Santiago de dar «vida» e cebada aos tenentes da terra, sen data; 4) procuracións que deben pagarse ao pertegueiro e aos cabaleiros da Terra de Santiago, sen data; 5) orde de que os habitantes da Terra de Santiago dean colleita ao arcebispo compostelán cuando vaia por ela, de 14 de xuño de 1229; e 6) decreto sobre o tránsito de veciños entre as terras de reguengo e as de señorío compostelán, de 22 de marzo de 1215.

B. ACSC, Tumbo B, ff. 77r-78v. En traslado realizado por André Pérez e Afonso Eanes, notarios de Santiago de Compostela.

Rex.: González Vázquez 1996: 307; González Jiménez/Carmona Ruiz 2012: 106 (n.ํ76).

Ed.: González Balasch 2004: 230-231 (n.ํ109).

\section{1}

1253.

Afonso X concede a don Fernando Rodríguez de Castro a aldea de Villanueva Nogachet, rebautizada «Castro», no Aljarafe de Sevilla, cos seus muíños de aceite, salvo a trintena debida a El-Rei, e coa obriga de manter un home con cabalo e armas.

B. AHN, Clero, Carpeta 3441, n.ํ 8. En confirmación de Sancho IV de 3 de xuño de 1287 en confirmación de Fernando IV de 22 de novembro de 1304.

Rex.: González Jiménez 1991: 107 (n.ํ109bis); González Jiménez/Carmona Ruiz 2012: 107 (n. 86).

\section{2}

1253, xaneiro, 26. Sevilla

Alfonso X, «por le fazer bien e por le fazer en ello gran merced», retira a don Munio Fernández de Rodeiro da meirindade maior de Galicia, que desempeñara nos tempos do seu pai, Fernando III, e del mesmo ata agora, ordenando que ninguén demande nada ao cabaleiro por mor dese cargo, pois don Munio deu por fiadores a don Nuno González, ao pertegueiro de Santiago don André Fernández, a don Gonzalo Eanes de Nóvoa e a si mesmo, co que «quantas malfetrias yo fallare por uerdat que fiço el et los sus merinos en Gallicia» serán xulgadas polo mesmo rei. 
Reg.: González Jiménez/Carmona Ruiz 2012: 108 (n.o 96).

Ed.: López Ferreiro 1895: 358.

López Ferreiro remite ao AHN, ao fondo procedente do mosteiro de Santa María de Ferreira de Pallares, onde non se atopa na actualidade ou, cando menos, non foi recollido por Rey Caíña 1985.

13

1253, febreiro, 15. Sevilla.

Afonso X envía ao arcebispo de Santiago de Compostela e aos homes e cabaleiros da Terra de Santiago o caderno das Cortes de Sevilla de 1253.

B. ACSC, Tumbo B, ff. 97r-101r. En traslado realizado por André Pérez e Afonso Eanes, notarios de Santiago de Compostela.

Rex.: González Vázquez 1996: 307; González Jiménez/Carmona Ruiz 2012: 110 (n.․105).

Ed.: López Ferreiro 1895: 363-388; González Balasch 2004: 271-285 (n.․127).

14

1253, xullo, 7. Sevilla.

Afonso X confirma o privilexio concedido polo seu pai, Fernando III, o 3 de novembro de 1238 a don Xoán Arias, electo de Santiago de Compostela, polo que, durante súa vida, exime do pago de todo tributo real a todos os seus vasalos que vivan desde o Esla ata a Transerra.

B. ACSC, Tumbo B, f. 42rv. En traslado realizado por André Pérez e Afonso Eanes, notarios de Santiago de Compostela.

Rex.: González Vázquez 1996: 307; González Jiménez/Carmona Ruiz 2012: 118 (n.o 160).

Ed.: González Balasch 2004: 161 (n.o 56).

15

1253, setembro, 8. Sevilla.

Afonso X sentencia no preito entre a Igrexa compostelá e o Concello de Santiago de Compostela, respondendo a cada unha das denuncias interpostas, deixando algunha delas pendente ata que se achegue a documentación requirida.

B. ACSC, Tumbillo de Concordias, ff. 21v-27r. Copia simple.

Rex.: González Vázquez 1996: 307-308; González Jiménez/Carmona Ruiz 2012: 121 (n.ํ183).

Ed.: López Ferreiro 1895: 251-260. 


\section{6}

1253, setembro, 26. Sevilla.

Afonso X doa a don Xoán Arias, arcebispo de Santiago de Compostela, a aldea de Yugar, rebautizada como Santiago, cos seus muíños de aceite, mais vinte xugadas en Otier, no termo de Facialcázar.

B. ACSC, Tumbo B, ff. 73r-74r. En traslado realizado por André Pérez e Afonso Eanes, notarios de Santiago de Compostela.

Rex.: González González 1951: II, 313; Ballesteros Beretta 1984: 1063 (n.. 72); González Vázquez 1996: 308-309; González Jiménez/Carmona Ruiz 2012: 121-122 (n.․188).

Ed.: González Jiménez 1991: 63-64 (n.․6); González Balasch 2004: 223-225 (n.․106).

17

1253, outubro, 23. Sevilla.

Alfonso $X$ ordena a don Ponce de Vale que non se cobren terzas ás igrexas de Asturias, León e Galicia que non as pagaban en tempos do seu pai, Fernando III.

A. AHN, Carpeta 1577, n. $\mathrm{o} 11$ bis.

Rex.: González Jiménez/Carmona Ruiz 2012: 122 (n.o 195).

18

1254, febreiro, 10. Toledo.

Afonso X confirma ao Concello da Coruña a confirmación de Fernando III de 1 de novembro de 1231, que inclúe, da concesión de Afonso IX do foral de Benavente e de dúas leguas de termo á vila de xuño de 1208.

B. AHMAC, Privilexios Reales, n.ำ 1 [Desaparecido]. En confirmación de Sancho IV de 3 de setembro de 1286. Ed.: González Garcés 2008: 466-467; Barral Rivadulla 1998: 387-388 (n.ํ1).

[18bis]

1254, marzo, 12. Toledo.

«Carta de Afonso X á catedral de Santiago de Compostela». 
Rexestado por González Jiménez/Carmona Ruiz 2012: 133 (n.. 271), no ACSC, Tumbillo de Concordias, f. 35, trátase da orde aos recadadores do reino de León para que respecten o costume existente en tempos de Afonso IX en Toro e nas súas aldeas para pagar a moeda foreira; é, pois, o mesmo documento que rexestan como n.o 272. No Tumbillo esténdese entre os folios 35r e 36r.

\section{9}

1254, marzo, 18. Toledo.

Afonso X ordena aos colledores da moeda no bispado lucense que cobren o dito tributo en Lugo e na súa meirindade do xeito en que adoitaba facerse en tempos de Afonso IX.

A. ACLu, Atado 5, n. 83 . Orixinal. Pergameo.

Rex.: Sánchez Belda 1953: 309 (n. 721); González Jiménez/Carmona Ruiz 2012: 134 (n.o 282).

Ed.: Herrera/Sánchez/González de Fauve/Zabia 1999: AGA 1v; Cañizares del Rey 2015: 252 (n.o 421).

\section{0}

1254, novembro, 6. Burgos.

Afonso $X$ concede a súa protección a todos os peregrinos que viaxen polos seus reinos, en especial aos que van a Santiago de Compostela, e dita certas disposicións sobre eles, como a posibilidade de que fagan testamento.

A. ACLe, Pergaminos, n. .9280 . Orixinal. Pergameo, 220 x 240 mm.

B. ACSC, Tumbo B, f. 37rv. En traslado realizado por Andrés Pérez e Alfonso Eanes, notarios de Santiago de Compostela.

Rex.: González Vázquez 1996: 309; González Jiménez/Carmona Ruiz 2012: 147 (n. 369 e 370).

Ed.: Ruiz Asencio 1993: 217-218; González Balasch 2004: 151-152 (n.o 48).

\section{1}

1254, novembro, 29. Burgos.

Afonso X comunica ás distintas autoridades do Camiño de Santiago que estableceu a forma en que os peregrinos a Santiago de Compostela poden realizar os seus testamentos-facendo referencia ao seu estatuto de 6 de novembro de 1254- e que enviou tres cartas chumbadas ás catedrais de Burgos, León e Santiago de Compostela, e ordena que cumpran o nelas establecido. 
B. ACSC, Tumbo B, f. 111rv. En traslado realizado por André Pérez e Afonso Eanes, notarios de Santiago de Compostela.

56 Rex.: González Vázquez 1996: 309; González Jiménez/Carmona Ruiz 2012: 148 (n.o 375).

Ed.: González Balasch 2004: 306-307 (n.․148).

\section{2}

1254, decembro, 8. Burgos.

Afonso X confirma á Igrexa de Santiago de Compostela a confirmación de Fernando III de 8 de agosto de 1218 da exención á vila de Ledigos, de señorío compostelán, de todo tributo rexio, que se entregará á Igrexa de Santiago de Compostela, tal e como lle fora concedido por Afonso VIII.

B. ACSC, Tumbo B, f. 111rv. En traslado realizado por André Pérez e Afonso Eanes, notarios de Santiago de Compostela, da confirmación de Sancho IV de 28 de decembro de 1284.

Rex.: González Vázquez 1996: 309; González Jiménez/Carmona Ruiz 2012: 149 (n. 386).

Ed.: González Balasch 2004: 316 (n.ํ156).

\section{3}

1254, decembro, 11. Burgos.

Afonso X confirma á Igrexa de Santiago de Compostela a confirmación de Fernando III de 2 de novembro de 1238, que inclúe, da exención do pago de portádego no reino de Castela aos veciños de Ledigos, tal e como lle fora concedido por Afonso VIII.

B. ACSC, Tumbo B, f. 111rv. En traslado realizado por André Pérez e Afonso Eanes, notarios de Santiago de Compostela, da confirmación de Sancho IV de 28 de decembro de 1284.

Rex.: González Vázquez 1996: 309; González Jiménez/Carmona Ruiz 2012: 150 (n.o 395).

Ed.: González Balasch 2004: 316-317 (n. 156).

\section{4}

1254, decembro, 14. Burgos.

Afonso X doa a mosteiro de Santa María de Meira o reguengo de Ribas de Sor.

B. AHN, Carpeta 1135, n. ․ En traslado notarial de 1362.

Rex.: Sánchez Belda 1953: 310 (n.ำ 720); González Jiménez/Carmona Ruiz 2012: 151 (n. 397). 


\section{5}

1255, xaneiro, 9. Burgos.

Afonso X confirma ao mosteiro de Santa María de Melón a confirmación de Fernando III de 2 de abril de 1232, que inclúe, da doazón de Afonso IX do termo e reguengo entre o mosteiro e o río Brul coa metade do dito río e coas pesqueiras de Reza, no Miño, de novembro de 1200.

A. AHN, Clero, Carpeta 1447, n.o 3. Orixinal. Pergameo, 635 x 635 mm.

B. AHN, Códices, L. 323, ff. 56v-58r. Copia simple.

C. AHPOu, Tumbo Dourado, ff. 72v-74r. Copia simple.

Rex.: Sánchez Belda 1953: 310 (n.ํ721); González Jiménez/Carmona Ruiz 2012: 166 (n.o 514).

Ed.: Cambón Suárez 1957: n.으 520.

\section{6}

1255, xaneiro, 10. Burgos.

Afonso X confirma ao mosteiro de Santa María de Melón a confirmación de Fernando III de 4 de abril de 1232, que inclúe, da doazón de Afonso IX do couto de Tielas, de 28 de abril de 1230.

A. AHN, Sigilografía, C. 11, n. 2. Orixinal. Pergameo, 544 x 648 mm.

B. AHN, Códices, L. 325, ff. 143r-144r. Copia simple.

C. AHPOu, Tumbo Dourado, ff. 72v-74r. Copia simple.

D. AHPOu, Tumbo de frei Lourenzo Pérez de 1611, f. 278v. Copia simple.

Rex.: Sánchez Belda 1953: 311 (n.o 722); González Jiménez/Carmona Ruiz 2012: 166 (n.o 516).

Ed.: Cambón Suárez 1957: n.o 526.

27

1255, xaneiro, 10. Burgos.

Afonso X confirma ao mosteiro de Santa María de Melón a confirmación de Afonso IX de 25 de xuño de 1228, que inclúe, da confirmación que este mesmo monarca concedera o 23 de xuño de 1223 dos reguengos entregados ao cenobio por Afonso VII e Fernando II.

B. AHN, Códices, L. 323, f. 49rv. Copia simple.

Rex.: Sánchez Belda 1953: 311 (n.o 723); González Jiménez/Carmona Ruiz 2012: 166 (n.o 517).

Ed.: Cambón Suárez 1957: n. 522. 


\section{8}

1255, xaneiro, 10. Burgos.

Afonso X confirma ao mosteiro de Santa María de Melón a confirmación de Fernando III de 28 de maio de 1231, que inclúe, da confirmación realizada por Afonso IX o [23 de xuño de 1223] -sen copiar a data-dos reguengos concedidos ao cenobio por Afonso VII e Fernando II.

A. ACOu, Monacais, Melón, n.. 728 . Orixinal. Pergameo, 510 x 670 mm.

B. AHN, Códices, L. 323, f. 50rv. Copia simple.

C. AHPOu, Tumbo Dourado, ff. 56rv. Copia simple.

Rex.: Leirós Fernández 1951: 64 (n.․728); Sánchez Belda 1953: 312 (n.․724); Duro Peña 1972: 97-98 (n.․ 325); González Jiménez/Carmona Ruiz 2012: 167 (n.․518).

Ed.: Cambón Suárez 1957: n.․523.

29

1255, xaneiro, 10. Burgos.

Afonso X confirma ao mosteiro de Santa María de Melón a doazón do reguengo de Francelos, que inclúe, realizada por Fernando II en xullo de 1176.

A. ACOu, Monacais, Melón, n.ํ6ㅇ. Orixinal. Pergameo, 470 x 660 mm.

B. ACOu, Monacais, Melón, n.․2 2150. Pergameo, 345 x 453 mm. En traslado realizado o 7 de setembro de 1329 por Estevo Martíz, notario de Tui.

C. AHN, Códices, L. 323, ff. 125r-126r. Copia simple.

D. AHPOu, Tumbo de frei Lourenzo Pérez de 1611, f. 61rv. Copia simple.

Rex.: Leirós Fernández 1951: 60 (n.․685) [datándoo en 1252] e 191 (n.․2 2150); Sánchez Belda 1953: 312 (n.․725);

Duro Peña 1972: 96-97 (n.o 322); González Jiménez/Carmona Ruiz 2012: 167 (n.o 519).

Ed.: Cambón Suárez 1957: n.․524.

30

1255, xaneiro, 10. Burgos.

Afonso X confirma ao mosteiro de Santa María de Melón a confirmación de Afonso IX de 28 de xuño de 1228, que inclúe, da doazón do monte Veduego e de Baíste feita por Afonso VII ao mosteiro de Santa María de Barcia o 28 de decembro de 1155.

A. AHN, Clero, Carpeta 1447, n.으 4. Orixinal, Pergameo, 467 x 575 mm.

B. AHN, Códices, L. 324, ff. 164r-165r. Copia simple.

C. AHPOu, Tumbo Dourado, ff. 461v-463r. Copia simple. 
D. AHPOu, Tumbo de frei Lourenzo Pérez de 1611, f. 148v-149r. Copia simple.

Rex.: Sánchez Belda 1953: 312-313 (n.o 726); González Jiménez/Carmona Ruiz 2012: 166-167 (n.o 515 e 520)

[Trátase do mesmo documento].

Ed.: Cambón Suárez 1957: n.o 525.

\section{1}

1255, xaneiro, 10. Burgos.

Afonso X confirma ao mosteiro de Santa María de Melón a confirmación de Afonso IX de xuño de 1228, que inclúe, da doazón de San Cibrao de Monterrei, Barcia, Cans e Santa Uxía de Vigo feita por Fernando II o 28 de decembro de [1159].

A. ACOu, Monacais, Melón, n. 730. Orixinal. Pergameo, 595 x 576 mm.

B. AHN, Códices, L. 325, ff. 342r-343r. Copia simple.

C. AHPOu, Tumbo de frei Lourenzo Pérez de 1611, f. 285rv. Copia simple.

Rex.: Leirós Fernández 1951: 64 (n. 730); Sánchez Belda 1953: 313 (n. 727); Duro Peña 1972: 97 (n. 323); González Jiménez/Carmona Ruiz 2012: 167 (n. 521).

Ed.: Cambón Suárez 1957: n.은.

32

1255, xaneiro, 10. Burgos.

Afonso X confirma ao mosteiro de Santa María de Melón a confirmación de Afonso IX de 25 de xuño de 1228, que inclúe, da doazón da décima parte das rendas reais do burgo de Ribadavia (Bonbou) realizada por Fernando II o 2 de novembro de 1172.

A. ACOu, Monacais, Melón, n.ํ729. Orixinal. Pergameo, 525 x 640 mm.

B. AHN, Códices, L. 323, ff. 32r-33r. Copia simple.

Rex.: Leirós Fernández 1951: 64 (n. 729); Sánchez Belda 1953: 313-314 (n. 728); Duro Peña 1972: 97 (n.o 324$)$;

González Jiménez/Carmona Ruiz 2012: 167 (n.o 518).

Ed.: Cambón Suárez 1957: n.o 521.

33

1255, xaneiro, 10. Burgos.

Afonso X confirma ao mosteiro de Santa María de Melón a confirmación de Afonso IX de 26 de xuño de 1228, que inclúe, da doazón do monte de Bugariña realizada por Fernando II o 30 de outubro de 1185. 
B. AHPOu, Tumbo de frei Lourenzo Pérez de 1611, f. 279rv. Copia simple.

Ed.: Cambón Suárez 1957: n.․528.

1255, xaneiro, 12. Burgos.

Afonso X confirma ao mosteiro de Santa María de Melón a confirmación de Fernando III de 20 de abril de 1232, que inclúe, da doazón da metade do décimo do celeiro de Castrelo de Miño realizada por Afonso IX, de 10 de xaneiro de 1202, na que o monarca toma así mesmo baixo a súa comenda e acouta todos os bens do cenobio.

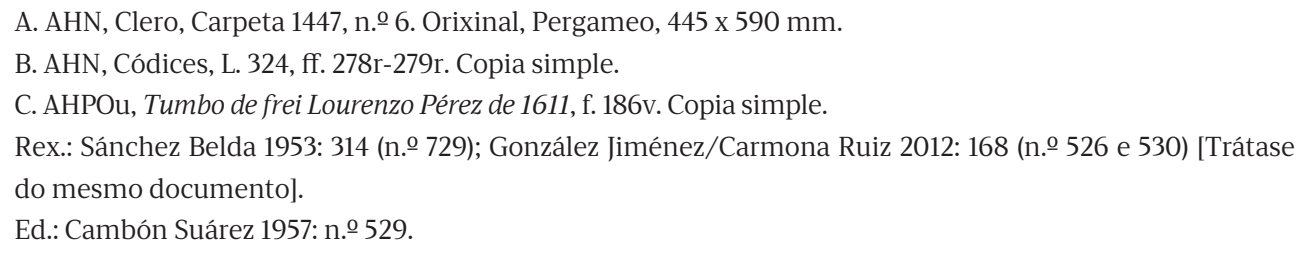

\section{5}

1255, xaneiro, 18. Burgos.

Afonso X confirma ao mosteiro de Santa María de Melón a confirmación de Afonso IX de 26 de xuño de 1228, que inclúe, da doazón da metade da igrexa de Santa María de Arbo e o casal de Soutelo realizada por este mesmo monarca o 15 de abril de 1201.

A. AHN, Clero, Carpeta 1447, n. 7. Orixinal, Pergameo, 438 x 496 mm.

B. AHN, Códices, L. 325, ff. 105r-106r. Copia simple.

C. AHPOu, Tumbo de frei Lourenzo Pérez de 1611, f. 315v-316r. Copia simple.

Rex.: Sánchez Belda 1953: 314-315 (n.o 730); González Jiménez/Carmona Ruiz 2012: 170 (n.o 547).

Ed.: Cambón Suárez 1957: n.ํㅗㄴ 531.

\section{6}

1255, xaneiro, 18. Burgos.

Afonso X confirma ao mosteiro de Santa María de Melón a confirmación de Afonso IX de 24 de xuño de 1228, que inclúe, da renuncia que este mesmo monarca fixo a favor do mosteiro das viñas de Sanín o 26 de outubro de 1219. 
A. AHN, Sigilografía, C. 11, n.ํㅜ 1. Orixinal, Pergameo, 438 x $608 \mathrm{~mm}$. O fragmento que lle falta a este pergameo -a súa esquina superior esquerda- consérvase no ACOu, Monacais, Melón, no 6143.

B. AHN, Códices, L. 324, ff. 240v-241v. Copia simple.

C. AHPOu, Tumbo de frei Lourenzo Pérez de 1611, f. 125rv. Copia simple.

Rex.: Sánchez Belda 1953: 315-316 (n.․ 731); Duro Peña 1972: 98 (n.. 326); González Jiménez/Carmona Ruiz 2012: 171 (n.. 548).

Ed.: Cambón Suárez 1957: n.․5 530.

37

1255, xaneiro, 18. Burgos.

Afonso X confirma ao mosteiro de Santa María de Melón a confirmación de Afonso IX de 24 de xuño de 1228, que inclúe, da doazón dun casal en San Pedro de Retorta feita por este mesmo monarca o 20 de agosto de 1221.

A. AHN, Clero, Carpeta 1447, n. o 10. Orixinal, Pergameo, 548 x 570 mm.

B. AHN, Códices, L. 325, ff. 325r-326v. Copia simple.

C. AHPOu, Tumbo de frei Lourenzo Pérez de 1611, f. 322rv. Copia simple.

Rex.: Sánchez Belda 1953: 316 (n. 732); González Jiménez/Carmona Ruiz 2012: 171 (n.o 549).

Ed.: Cambón Suárez 1957: n.o 533.

38

1255, xaneiro, 18. Burgos.

Afonso X confirma ao mosteiro de Santa María de Melón a doazón da herdade de Barciademera, que inclúe, realizada por Afonso IX o 5 de febreiro de 1193.

A. AHN, Clero, Carpeta 1447, n. ․ Orixinal, Pergameo, 400 x 505 mm.

B. AHN, Códices, L. 325, f. 151rv. Copia simple.

C. AHPOu, Tumbo de frei Lourenzo Pérez de 1611, f. 286rv. Copia simple.

Rex.: Sánchez Belda 1953: 316-317 (n.o 733); González Jiménez/Carmona Ruiz 2012: 171 (n.o 550).

Ed.: Cambón Suárez 1957: n.은 532.

39

1255, xaneiro, 19. Burgos.

Afonso X confirma ao mosteiro de Santa María de Melón a confirmación de Afonso IX de 25 de xuño de 1228, que inclúe, da doazón da metade da igrexa de Santa María de Couso feita por este mesmo monarca o 8 de xaneiro de 1227. 
A. AHN, Clero, Carpeta 1447, n.․ 11. Orixinal, Pergameo, 498 x 590 mm.

B. AHN, Códices, L. 324, ff. 186v-198r. Copia simple.

62 C. AHPOu, Tumbo de frei Lourenzo Pérez de 1611, f. 150v. Copia simple. Rex.: Sánchez Belda 1953: 317 (n. 734); González Jiménez/Carmona Ruiz 2012: 171 (n.o 551).

Ed.: Cambón Suárez 1957: n.․534.

40

1255, xaneiro, 20. Burgos.

Afonso X confirma ao mosteiro de Santa María de Melón a confirmación de Afonso IX de 28 de xuño de 1228, que inclúe, da doazón do reguengo de San Pedro de Arbo e da pesqueira de Guisande feita por Fernando II o 19 de novembro de 1184.

A. AHN, Clero, Carpeta 1447, n. 13 . Orixinal, Pergameo, 420 x 535 mm.

B. AHN, Clero, Carpeta 1447, n. 12. Pergameo, 338 x 405 mm. En traslado realizado o 9 de marzo de 1294 por Afonso Raimúndez, notario de Ribadavia.

C. AHN, Códices, L. 325, ff. 102r-103v. Copia simple.

D. AHPOu, Tumbo de frei Lourenzo Pérez de 1611, f. 316rv. Copia simple.

Rex.: Sánchez Belda 1953: 317-318 (n.ํ735); González Jiménez/Carmona Ruiz 2012: 171 (n.ํ553).

Ed.: Cambón Suárez 1957: n.o 535.

\section{1}

1255, xaneiro, 22. Burgos.

Afonso X confirma ao mosteiro de Santa María de Melón a confirmación de Afonso IX de 26 de xuño de 1228, que inclúe, da doazón da veiga de Francelos e da metade de Reza feita por Fernando II en marzo de 1166.
A. AHN, Sigilografía, C. 9, n.요 8. Orixinal, Pergameo, 455 x 640 mm.
B. AHN, Códices, L. 323, ff. 148r-149r. Copia simple.
C. AHPOu, Tumbo Dourado, f. 261rv. Copia simple.
D. AHPOu, Tumbo de frei Lourenzo Pérez de 1611, ff. 59v-60v. Copia simple.
Rex.: Sánchez Belda 1953: 318-319 (n.ำ 736); Ballesteros Beretta 1984: 1068 (n. 168); González Jiménez/Car- mona Ruiz 2012: 172 (n.o 558).
Ed.: Cambón Suárez 1957: n.으 536. 


\section{2}

1255, xaneiro, 28. [Burgos].

Afonso X ordena a Pedro Nunes de Santiago e Pedro Fernández de Pontevedra, os seus investigadores no bispado de Astorga e terra de Aliste, que envien as pescudas que fagan sobre diversos crimes e delitos ao meiriño maior de León, Gonzalo Morán, e queden eles cun traslado notarial.

B. ACSC, Tumbillo de Concordias, f. 59rv. Copia simple.

Rex.: Ballesteros Beretta 1984: 1061 (n.o 25) [Datándoo en 1253]; González Vázquez 1996: 309; González Jiménez/Carmona Ruiz 2012: 176 (n.. 584).

\section{3}

1255, xaneiro, 28. Burgos.

Afonso $X$ confirma á Orde do Temple o acordo realizado entre Afonso IX e esta mesma orde o 29 de abril de 1211, no que se fai referencia a bens nas terras galegas de Limia, Lemos e Faro.

A. AHN, Órdenes Militares, Carp. 568, n.ํㅜ 17-R. Orixinal. Pergameo, 500 x 605 mm.

Rex.: González Jiménez/Carmona Ruiz 2012: 176 (n.․583).

Ed.: García Tato 2004: 177-179 (n.․78).

\section{4}

1255, marzo, 10. Aguilar de Campoo.

Afonso X confirma á Igrexa e Concello de Ourense a exención de portádego e de calquera outra carga para todo viño ou produto que se leve desa cidade cara a Santiago de Compostela concedida por Afonso IX o 17 de novembro de 1188.

A. ACOu, Privilexios 3, n. ⒉ Orixinal. Pergameo, 387 x 445 mm.

Rex.: Duro Peña 1972: 42 (n.ํ 117); González Jiménez/Carmona Ruiz 2012: 194 (n.o 723$).$

Ed.: DACO 1917: 73-74; Vaquero Díaz/Pérez Rodríguez 2010: 221-222 (n.o 413). 


\section{5}

1255, marzo, 20. Carrión.

Afonso X confirma ao mosteiro de San Xulián de Moraime a posta baixo comenda e defensa do cenobio e dos seus bens, que acouta, feita por Fernando III o 5 de febreiro de 1232, e a confirmación xenérica dos privilexios do cenobio concedida por este mesmo monarca o 23 de xullo de 1238, incluíndo ambas as dúas.

B. AHUSC, Clero, Moraime, n. ⒒ En confirmación de Afonso XI de 10 de abril de 1335.

C. AHUSC, Clero, Moraime, n.o 13. En confirmación de Pedro I de 15 de setembro de 1351.

D. AHUSC, Clero, Moraime, n.ํㅜ 16. En confirmación de Xoán I de 20 de setembro de 1380.

E. AHUSC, Clero, Moraime, n.ํ2 26. En confirmación de Xoán II de 19 de maio de 1434.

Rex.: Buján Rodríguez 1996: 304 (n.o 238); Lucas Álvarez 1999: 1103 (n.o 13); González Jiménez/Carmona Ruiz 2012: 195 (n.․ 726).

Ed.: Lucas Álvarez 1975: 634-635 (n.ํㅜ 10).

\section{6}

1255, marzo, 23. Carrión.

Afonso X confirma, romanceándoas, as concesións feitas ao burgo de Belesar por Afonso IX en 1208.

B. AHN, Clero, Carpeta 1067, n. ․ En traslado realizado en marzo de 1380 por Vasco Rodríguez, notario de Chantada.

Rex.: Sánchez Belda 1953: 319 (n. 737); Ballesteros Beretta 1984: 1069 (n.o 204); González Jiménez/Carmona Ruiz 2012: 195 (n.o 729 e 730) [Trátase do mesmo documento].

Ed.: Méndez Pérez/Otero Piñeyro Maseda/Romaní Martínez 2016: 198-199 (n.o 13).

47

1255, marzo, 28. Sahagún.

Afonso $X$ confirma ao priorado de Santa Comba de Naves a confirmación de Fernando III de 15 de febreiro de 1231, que inclúe, da exención do xantar e outros pagos inxustamente impostos ao cenobio polo casteleiro de Alba de Búbal dada por Afonso IX o 12 de setembro de 1229.

B. AHN, Clero, Carpeta 1506, n.ํㅜ 10. En traslado realizado o 12 de novembro de 1325 por Domingo Nunes, notario de Ourense.

Rex.: Sánchez Belda 1953: 319-320 (n.o 738); González Jiménez/Carmona Ruiz 2012: 196 (n.o 734).

Ed.: Dono Lopez 2010: 241-243 (n.ํ 100). 


\section{8}

1255, marzo, 29. Sahagún.

Afonso X confirma ao mosteiro de San Salvador de Celanova a confirmación de Fernando III de 13 de abril de 1233, que inclúe, da doazón de Afonso IX do lugar de Mixós nos termos en que llo entregara Afonso VII, feita o 12 de abril de 1215.

A. AHN, Sigilografía, C. 11, n. 9 4. Orixinal. Pergameo, 463 x 507 mm.

Rex.: Sánchez Belda 1953: 320 (n.ํ 739); Ballesteros Beretta 1984: 1068 (n.․168) [Datándoo o 25 de marzo]; González Jiménez/Carmona Ruiz 2012: 195 (n. 728) e 196 (n. 735) [Trátase do mesmo documento]. Ed.: Vaquero Díaz 2004: 91-93 (n.. 54).

49

1255, abril, 4. Sahagún.

Afonso X confirma ao mosteiro de San Salvador de Celanova a confirmación de Fernando III de 8 de xaneiro de 1231, que inclúe, da entrega por Afonso IX da comenda do mosteiro a este mesmo e a prohibición de que ningún saión ou meiriño entre no cenobio, de 31 de maio de 1216.

A. AHN, Clero, Carpeta 1432, n. ․ Orixinal. Pergameo, 454 x 620 mm.

B. AHN, Clero, Carpeta 1432, n.o 6. Traslado notarial sen data.

C. AHN, Clero, Carpeta 1434, n. ⒚ En confirmación dos Reis Católicos de 20 de setembro de 1480.

D. AHN, Clero, Carpeta 1435, n.ํㅜ 14. En confirmación de Filipe III de 30 de xaneiro de 1604.

Rex.: Sánchez Belda 1953: 320-321 (n. 740); González Jiménez/Carmona Ruiz 2012: 198 (n.ํ749).

Ed.: Vaquero Díaz 2004: 93-95 (n. 55).

50

1255, abril, 12. Sahagún.

Afonso X confirma ao mosteiro de Santa María de Penamaior a confirmación de Fernando III de 28 de decembro de 1231, que inclúe, do mandato de Afonso IX ao seu meiriño sobre os xugueiros do cenobio dado o 28 de decembro de 1223.

B. AHN, Clero, Carpeta 1219, n.o 8. En confirmación de Sancho IV de 9 de xuño de 1290.

Rex.: Sánchez Belda 1953: 321 (n. 741); González Jiménez/Carmona Ruiz 2012: 202 (n.ํ 776). 
51

1255, abril, 28. Sahagún.

66

Afonso X confirma xenericamente os privilexios do priorado de San Salvador de Pedroso, ordenando que se lles manteñan segundo os tiña en tempos de Afonso IX e Fernando III, e acouta as súas heredades.

B. ACM, Pedroso. En traslado da confirmación de Sancho IV de 21 de setembro de 1286 realizado por Pedro Martínez, notario de Neda.

Rex.: Cal Pardo 1990: 113-114 (n.․11).

Ed.: Cal Pardo 1984: 245 (n. $\underline{0} 11)$.

52

1255, abril, 28. Villada.

Afonso X confirma ao mosteiro de Santo Estebo de Ribas de Sil a confirmación de Fernando III de 5 de xullo de 1232, que inclúe, da sentenza dada por Afonso IX o 7 de agosto de 1214 no preito mantido entre o cenobio e Diego Eanes, no que establece que ningún cabaleiro poida ter como vasalo a quen o debe ser do mosteiro.

A. AHN, Sigilografía, C. 11, n.ํ⒉ Orixinal. Pergameo, 520 x 635.

Rex.: Sánchez Belda 1953: 321-322 (n. 742); Ballesteros Beretta 1984: 1070 (n.o 221) [Datándoo o día 8 de abril]; González Jiménez/Carmona Ruiz 2012: 207 (n.o 814).

Ed.: Duro Peña 1977: 284-285 (n.o 46).

53

1255, xuño, 2. Palencia.

Afonso X confirma ao mosteiro de Santa María de Oseira a confirmación de Fernando III dada o 5 de novembro de 1231, que inclúe, na que confirma pola súa vez a de Afonso IX de todas as propiedades do cenobio, con prohibición de adquirir novas posesións reguengas salvo nos arredores do mosteiro ou cando conte co expreso permiso do monarca, e con acoutamento de todos os seus servizais, feita o 22 de outubro de 1228.

A. AHN, Clero, Carpeta 1526, n.․ㅜ 16. Orixinal. Pergameo, 590 x 665 mm.

B. AHN, Códices, L. 1008 B, ff. 7r-8v. Copia simple.

C. AHN, Códices. L. B-15, ff. 96v-97r. Copia simple.

Rex.: Sánchez Belda 1953: 322 (n.o 743); Duro Peña 1972: 98 (n. 327); González Jiménez/Carmona Ruiz 2012: 212 (n.․ 849).

Ed.: Romaní Martínez 1989: 698-700 (n.ํ739). 
1255, xuño, 2. Palencia.

Afonso X confirma ao mosteiro de Santa María de Oseira a confirmación xenérica dos seus privilexios realizada por Fernando III o 20 de decembro de 1230, que inclúe.

B. AHN, Clero, Carpeta 1526, n.․ㅡ 20. En traslado realizado o 23 de febreiro de 1345 por Pedro Eanes, notario de Castela, Búbal e Bolo de Senda.

Rex.: Sánchez Belda 1953: 322-323 (n. 744); González Jiménez/Carmona Ruiz 2012: 212 (n.요 850).

Ed.: Romaní Martínez 1989: 700-702 (n.ํ740).

55

1255, xuño, 10.

Afonso X confirma ao priorado de Santa María de Xunqueira de Ambía a orde de Fernando III de 3 de marzo de 1237, que inclúe, aos ricoshomes e oficiais reais da terra de Limia que ninguén tome nada dos bens e vasalos do cenobio.

Ed.: Crespo Pozo 1964-1966: 261 e 445.

\section{6}

1255, xuño, 11. Palencia.

Afonso X confirma ao priorado de Santa María de Xunqueira de Ambía o acordo subscrito ante Afonso IX o 8 de abril de 1227, que inclúe, entre o cenobio e varios cabaleiros sobre os vasalos do couto monástico.

B. ACOu, Papeis de Xunqueira de Ambía. Copia simple do século XvIII.

57

1255, xuño, 12.

Afonso X confirma ao mosteiro de San Lourenzo de Carboeiro a confirmación xenérica dos seus privilexios realizada por Fernando III en outubro de 1232, que inclúe. 
A. AHUSC, San Martiño, Pergameos, n.ํ56 . Orixinal. Pergameo.

B. AHUSC, San Martiño, Pergameos, n. ํ 66. En confirmación de Afonso XI de 5 de xullo de 1335.

C. AHUSC, San Martiño, Pergameos, n. 67 . En confirmación de Afonso XI de 5 de xullo de 1335. Rex.: Lucas Álvarez 1999: 944-945 (n. 103); González Jiménez/Carmona Ruiz 2012: 214 (n.요 861). Ed.: Lucas Álvarez 1958: 564 (n.. 78).

\section{8}

1255, xuño, 14.

Afonso X confirma ao mosteiro de San Lourenzo de Carboeiro o mandato de Fernando III de 13 abril de 1232, que inclúe, no que ordena que ninguén teña amos nin vasalos no couto monástico sen permiso do abade e convento.

A. AHN, Clero, Carpeta 1784, n.․⒕ Orixinal. Pergameo, 240 x 245 mm.

B. AHUSC, San Martiño, Pergameos, n. 66. En confirmación de Afonso XI de 5 de xullo de 1335.

C. AHUSC, San Martiño, Pergameos, n. 67. En confirmación de Afonso XI de 5 de xullo de 1335.

Rex.: Sánchez Belda 1953: 323 (n. 745); Buján Rodríguez 1996: 304 (n. 237); Lucas Álvarez 1999: $944-945$ (n.ํㅡ 103); González Jiménez/Carmona Ruiz 2012: 214 (n.ㅇ 863).

Ed.: Lucas Álvarez 1958: 563-564 (n.ํ 76); Cañizares del Rey 2002: 306 (n.ํ127).

59

1255, xuño, 16. Palencia.

Afonso X confirma ao mosteiro de Santa María de Penamaior a confirmación de Fernando III de 13 de abril de 1232, que inclúe, na que confirma, pola súa vez, a confirmación de Afonso IX do couto e igrexa de San Salvador de Furco, de 30 de abril de 1227, adquirida polo mosteiro a García Rodríguez de Neira, así como a posesión de varias herdades do cenobio que se especifican.

A. AHN, Clero, Carpeta 1216, n.․⒗ Orixinal. Pergameo, 513 x $680 \mathrm{~mm}$.

Rex.: Sánchez Belda 1953: 323-324 (n.․746); Ballesteros Beretta 1984: 1071 (n.ำ 235); González Jiménez/Carmona Ruiz 2012: 215 (n.․ 867).

\section{0}

1255, abril, 5. Castromonte.

Afonso X concede á Orde do Temple a contribución da terra de Alba de Aliste e de Alcañices e Sahagún a cambio de todo o que a Orde posuía en Betanzos. 
A. Archivo Municipal de Alcañices, Atado 14, n.. 25.

Rex.: González Jiménez/Carmona Ruiz 2012: 216 (n.․ 877).

61

1255, [xullo], 12.

Afonso X confirma ao mosteiro de Santa María de Castro de Rei a confirmación de Fernando III de 29 de outubro de 1231, que inclúe, na que confirma ao cenobio catro cartas de Afonso IX: 1) exención de xantar, de maio de 1210; 2) doazón do monte de «Vilar Papi», de 20 de marzo de 1221; 3) mandato sobre que as herdades do mosteiro están acoutadas, de 20 de xuño de 1215; e 4) confirmación da doazón da herdade de «Auercere», de 19 de agosto de 1219.

A. AHN, Clero, Carpeta 1484, n.ํ⒌ Orixinal. Pergameo, 520 x 625 mm.

Rex.: Sánchez Belda 1953: 324 (n. 747); González Jiménez/Carmona Ruiz 2012: 217 (n.․885).

\section{2}

1255, xullo, 17. Valladolid.

Afonso X confirma ao mosteiro de Santa María de Montederramo a confirmación de Fernando III de 13 de xullo de 1232, que inclúe, na que confirma varias doazóns feitas polos monarcas anteriores, que especifica, así como calquera outra doazón ou privilexio concedido polos seus antecesores ao mosteiro.

A. AHN, Clero, Carpeta 1484, n.․ 2. Orixinal. Pergameo, 475 x 415 mm.

Rex.: Sánchez Belda 1953: 324-325 (n.․ 748); González Jiménez/Carmona Ruiz 2012: 218 (n.o 887).

Ed.: Lorenzo 2016: 368-370 (n.․ㅜ 189).

\section{3}

1255, xullo, 18. Valladolid.

Afonso X confirma ao mosteiro de Santa María de Montederramo a notificación de Afonso IX de 14 de agosto de 1227, que inclúe, na que confirma que, entre outros, o lugar de Piñeira e a metade do de Trasmonte son do cenobio por doazón de Afonso VII, ordenando que se lle respeten e que o comendador do Courel e Elvira López partan Trasmonte co abade de Montederramo. 
Rex.: Sánchez Belda 1953: 325 (n.․749); González Jiménez/Carmona Ruiz 2012: 218 (n.o 889) e, probablemente, 219 (n. 895), datado en 22 de xullo de 1255.

70 Ed.: Lorenzo 2016: 891 (n.. 719).

\section{4}

1255, xullo, 23. Valladolid.

Afonso X confirma ao mosteiro de Santa María de San Clodio a exención de pedido feita ao mosteiro por Afonso IX o 12 de marzo de 1218, que inclúe.

B. AHN, Códices, L. 424 B, f. 25rv. En copia simple de confirmación de Afonso XI de 5 de xuño de 1335. Rex.: Sánchez Belda 1953: 325 (n.o 750); González Jiménez/Carmona Ruiz 2012: 219 (n.o 896). Ed.: Lucas Álvarez e Lucas Domínguez 1996: 310 (n.ํ75).

\section{5}

1255, setembro, 18. Valladolid.

Afonso X confirma ao mosteiro de San Salvador de Celanova a confirmación de Fernando III de 15 de abril de 1232, que inclúe, da promesa de Afonso IX de 3 de maio de 1223 de non facer pobra no castro de Verín.

A. AHN, Clero, Carpeta 1432, n.․ 7. Orixinal. Pergameo, 460 x 470 mm.

B. AHN, Clero, Carpeta 1433, n.ำ 9. En confirmación de Afonso XI de 18 de agosto de 1316. Rex.: Sánchez Belda 1953: 326 (n. 751); González Jiménez/Carmona Ruiz 2012: 225 (n. 942). Ed.: Vaquero Díaz 2004: 96-98 (n. 57).

\section{6}

1255, setembro, 18. Valladolid.

Afonso X confirma ao mosteiro de San Salvador de Celanova a confirmación de Fernando III de 15 de abril de 1232, que inclúe, na que Afonso IX prohibe mercar herdades en Pazos e Verín e sacar pedido de Atás, sen data.

A. AHN, Sigilografía, C. 10, n.o 3. Orixinal. Pergameo, 300 x 237 mm.

B. AHN, Clero, Carpeta 1433, n.ํㅜ 9. En confirmación de Afonso XI de 18 de agosto de 1316.

C. AHN, Clero, Carpeta 1432, n. 9. En traslado realizado o 27 de novembro de 1347 polo notario Rui Fernández. Rex.: Sánchez Belda 1953: 326-327 (n.ำ 752); González Jiménez/Carmona Ruiz 2012: 227 (n.o 943).

Ed.: Vaquero Díaz 2004: 95-96 (n.ํ56). 


\section{7}

1255, setembro, 20. Valladolid.

Afonso X concede á Pobra de Ortigueira o foral de Benavente.

Rex.: González Jiménez/Carmona Ruiz 2012: 226 (n.o 944).

Ed.: Maciñeira Pardo de Lama 1892: 269-273.

\section{8}

1255, outubro, 14. Valladolid.

Afonso X confirma á Orde de San Xoán do Hospital a súa propia doazón da terra de Páramo, na «honor» de Sarria, realizada o 15 de agosto de 1246, sendo aínda infante.

A. AHN, Órdenes Militares, Carp. 568, n.ํㅜ 18-R. Orixinal. Pergameo, 170 x 290 mm.

Rex.: González Jiménez/Carmona Ruiz 2012: 161 (n. 474).

Ed.: García Tato 2004: 179 (n.ํㅜㄱ).

\section{9}

1255, outubro, 19. Burgos.

Afonso X promete que o servizo que lle fan o bispo, cabido e clerecía de Lugo para pagar as débedas de Fernando III co papa non debe volverlle ser solicitado.

A. ACLu.. Orixinal. Pergameo.

Rex.: Sánchez Belda 1953: 327 (n. 753); González Jiménez/Carmona Ruiz 2012: 232 (n. 991).

Ed.: Herrera/Sánchez/González de Fauve/Zabia 1999: AGA 2r; Cañizares del Rey 2015: 254 (n.o 423).

\section{0}

1255, outubro, 22. Burgos.

Afonso X confirma ao mosteiro de Santa María de Melón a autorización de Afonso IX a Paio Arias e á súa muller, María Pérez, de 30 de xaneiro de 1229, que inclúe, para vender ao dito cenobio a herdade de Vimieiros e as condicións que o mosteiro terá para co monarca con ela; seguido pola confirmación das herdades de Melón en Castrelo de Miño e Ribadavia. 
A. AHN, Clero, Carpeta 1448, n. 3. Orixinal. Pergameo, 580 x 630 mm.

B. AHN, Códices, L. 324, ff. 291v-292r. Copia simple.

72 C. AHPOu, Tumbo de frei Lourenzo Pérez de 1611, f. 190v. Copia simple.

Rex.: Sánchez Belda 1953: 327 (n. 754); González Jiménez/Carmona Ruiz 2012: 232 (n.o 994).

Ed.: Cambón Suárez 1957: n.․554.

\section{1}

1255, outubro, 23. Burgos.

Afonso X confirma ao mosteiro de Santa María de Melón as exencións de portádego concedidas por Fernando II en marzo de 1170 e por Afonso IX o 11 de agosto de 1201, incluíndo ambas as dúas.

A. AHN, Sigilografía, C. 5, n. 7. Orixinal. Pergameo, 230 x 235 mm.

B. AHN, Códices, L. 323, ff. 62v-63r. Copia simple.

C. AHPOu, Tumbo de frei Lourenzo Pérez de 1611, f. 18r. Copia simple.

Rex.: Sánchez Belda 1953: 328 (n.․755); González Jiménez/Carmona Ruiz 2012: 233 (n.ํ 996).

Ed.: Cambón Suárez 1957: n.․5 555.

72

1255, outubro, 28. Burgos.

Afonso $X$ confirma ao mosteiro de San Vicente do Pino a confirmación de Afonso IX de 29 de marzo de 1191 da terceira parte da poboación do Pino -futuro Monforte de Lemos-e das súas rendas, así como o couto monástico e outras propiedades segundo llas concederan Raimundo de Borgoña e Afonso VII.

Rex.: Ballesteros Beretta 1984: 1072 (n.․ 266); González Jiménez/Carmona Ruiz 2012: 233 (n.․ 1001).

73

1255, outubro, 29. Burgos.

Afonso X confirma ao mosteiro de San Vicente do Pino o documento de Afonso IX de 29 de outubro de 1204 no que o monarca confirma o acordo feito polo cenobio co Concello de Monforte de Lemos e doa a mosteiro parte das rendas da vila en compensación por fundar a poboación, engadindo varias igrexas e a exención de xantar, consistente en 150 soldos que anualmente adoitaba darlle o mosteiro. 
B. BN, Ms. 834, ff. 162r-164r. Copia simple do século XVIII.

B. BRAH, Col. Salazar y Castro, O-24, ff. 149-151. Copia simple do século XVIII.

Rex.: González Jiménez/Carmona Ruiz 2012: 234 (n.ํㅜ 1003).

Ed.: Rodríguez Fernández 1990: 258-261 (n.․ 15); Díaz Martín 1997-1999: n.o 165.

74

1255, novembro, 3. Burgos.

Afonso X concede ao arcebispo de Santiago de Compostela que poida celebrarse mercado todos os martes no seu lugar de Aldeanueva, entre Toro e Salamanca.

B. ACSC, Tumbo C, f. 4r. Copia simple.

Rex.: González Vázquez 1996: 309; González Jiménez/Carmona Ruiz 2012: 235 (n.․1011).

75

1255, novembro, 4. Burgos.

Afonso X concede a don Xoán Arias, arcebispo de Santiago de Compostela, e aos seus sucesores "por muchos servicios buenos e grandes que me fizo», «e porque fallé siempre en él lealtat e uerdat», a vila e alfoz de Xallas.

B. ACSC, Tumbo B, ff. 2r-3v. En traslado realizado por André Pérez e Afonso Eanes, notarios de Santiago de Compostela.

C. ACSC, Tumbo A, ff. 70v-71v. Copia simple.

D. ACSC, Tumbillo de Concordias, ff. 41r-43r. Copia simple.

Rex.: González Vázquez 1996: 309; González Jiménez/Carmona Ruiz 2012: 235 (n. 1013).

Ed.: Lucas Álvarez 1998: 316-319 (n.․165); González Balasch 2004: 74-76 (n.․2).

76

1255, novembro, 9. Covarrubias.

Afonso X doa á Igrexa de Santiago de Compostela as herdades que en Terra de Santiago tivesen os cabaleiros e escudeiros «que se salieron con don Enrricque, mio hermano, o se fueron o se fueren para él».

B. ACSC, Tumbo B, f. 6r. En traslado realizado por André Pérez e Afonso Eanes, notarios de Santiago de Compostela.

Rex.: González Vázquez 1996: 309; González Jiménez/Carmona Ruiz 2012: 236 (n.o 1018).

Ed.: González Balasch 2004: 82 (n.․7). 
77

1255, novembro, 10. Covarrubias.

Afonso X exime do pago de moeda foreira ao bispo, cabido e clerecía menor da catedral de Santiago de Compostela.

B. ACSC, Tumbo B, ff. 74v-75v. En traslado realizado por André Pérez e Afonso Eanes, notarios de Santiago de Compostela.

Rex.: González Vázquez 1996: 309; González Jiménez/Carmona Ruiz 2012: 236 (n.o 1020).

Ed.: González Balasch 2004: 225-227 (n.o 107).

\section{8}

1255, novembro, 10. Covarrubias.

Afonso X establece que á morte do arcebispo de Santiago de Compostela será o cabido compostelán o que se faga cargo dos seus bens mentres estea vacante a sé, e ordena que non sexa tomado por un representante do rei, quen debe axudar e defender ao delegado do cabido que administre os ditos bens.

B. ACSC, Tumbo B, ff. 86r-87v. En traslado realizado por André Pérez e Afonso Eanes, notarios de Santiago de Compostela.

C. ACSC, Tumbillo de Concordias, ff. 92v-93r. Copia simple.

Rex.: González Vázquez 1996: 310; González Jiménez/Carmona Ruiz 2012: 236 (n.ํ1021).

Ed.: González Balasch 2004: 249-251 (n.o 115).

79

1255, novembro, 10 . Covarrubias.

Afonso $X$ diríxese a todos os concellos e aldeas do arcebispado de Santiago de Compostela comunicándolles as normas para o pago do décimo.

B. ACSC, Tumbillo de Concordias, ff. 54v-56r. Copia simple.

Rex.: González Vázquez 1996: 309; González Jiménez/Carmona Ruiz 2012: 236 (n.o 1022).

Ed.: López Ferreiro 1901: 409-411 (n. 92). 


\section{0}

1255, novembro, 13. Santo Domingo de Silos.

Afonso X confirma á igrexa de Santa María de Iria e á vila de Padrón a confirmación de Fernando III de 22 de febreiro de 1232 da confirmación dos seus privilexios e exencións por Fernando II, sen datar, que inclúe.

B. Colección particular. En confirmación de Sancho IV de 29 de novembro de 1284 en confirmación de Fernando IV de 8 de marzo de 1312 en confirmación de Afonso XI de 12 de agosto de 1332; en traslado realizado o 5 de maio de 1393 por Lopo Afonso, notario de Padrón; confirmado polos Reis Católicos o 11 de maio de 1476. C. Arquivo Municipal de Padrón. En confirmación de Sancho IV de 29 de novembro de 1284 en confirmación de Fernando IV de 8 de marzo de 1312 en confirmación de Afonso XI de 12 de agosto de 1332; en traslado realizado o 5 de maio de 1393 por Lopo Afonso, notario de Padrón; confirmado por Xoana I o 28 de maio de 1510. Rex.: González Jiménez/Carmona Ruiz 2012: 237 (n.ํ1028).

Ed.: Rodríguez Carbia e Beiró Piñeiro 2003): $54-57$ e $72-76$ (n.. 3 e 4).

Os documentos que se confirman, supostamente concedidos por Fernando II, deben estar interpolados, como deixa entrevelo a mención aos 28 santos bispos que rexeron a sé de Iria antes da inventio do sepulcro de Santiago en Compostela, sen estar claro a quen corresponde algunha das confirmacións, mesturándose a Afonso IX con Fernando III, se ben se sinalan soamente as datas recollidas no rexesto.

81

1255, novembro, 13. Santo Domingo de Silos.

Afonso X confirma ao mosteiro de San Xusto de Toxos Outos a confirmación de Fernando III de 20 de febreiro de 1232, que inclúe, na que se confirman: 1) o acoutamento do mosteiro e exención de portádego dadas por Fernando II o 2 de decembro de 1177; 2) a doazón do reguengo de Cando, por Fernando II, de 11 de decembro de 1167; 3) a toma da comenda do cenobio, exención de portádego e confirmación por Afonso IX de 20 de febreiro de 1198 de todos os acoutamentos feitos por Afonso VII e Fernando II; 4) doazón da igrexa e vila de San Xián da Pereiriña, por Afonso IX o 15 de xuño de 1219; e 5) doazón da cuarta parte da viña de Forno Telleiro, en Ribadavia, de 17 de abril de 1213.

B. AHN, Clero, Carpeta 556, n.․ 12. En confirmación de Sancho IV de 29 de novembro de 1284.

Rex.: Sánchez Belda 1953: 328 (n. 756); Ballesteros Beretta 1984: 1073 (n.o 277); González Jiménez/Carmona Ruiz 2012: 238 (n.․1032). 


\section{2}

1255, novembro, 13. Santo Domingo de Silos.

Afonso X confirma ao mosteiro de San Xusto de Toxos Outos a confirmación de Fernando III de 19 de febreiro de 1232, que inclúe, na que se confirman: 1) o acoutamento do mosteiro e exención de portádego dados por Fernando II o 2 de decembro de 1177; e 2) a doazón do reguengo de Cando, por Fernando II, de 11 de decembro de 1167.

A. AHN, Clero, Carpeta 556, n.․ 11. Orixinal. Pergameo, 550 x 655 mm.

B. AHN, Códices, L. 1002 B, ff. 22v-23r.

Rex.: Sánchez Belda 1953: 328-329 (n.․757); González Jiménez/Carmona Ruiz 2012: 233 (n.․1031).

Ed.: Pérez Rodríguez 2004: 69-72 (n.o 37).

\section{3}

1255, novembro, 13. Santo Domingo de Silos.

Afonso X confirma ao mosteiro de San Xusto de Toxos Outos: 1) a concesión do couto monástico, acoutamento de todas as herdades do cenobio e exención de portádego, dadas por Afonso VII o 5 de decembro de 1135; 2) concesión do couto de San Cristovo de Arzón, dada por Afonso VII o 10 de maio de 1138; 3) doazón e acoutamento das igrexas de San Salvador e San Martiño de Duio feita por Afonso VII o 5 de decembro de 1135; e 4) doazón de varias herdades nas terras do Ribeiro de Avia, Salnés e Carnota feita por Afonso VII o 7 de maio de 1138.

B. AHN, Clero, Carpeta 556, n.․ 8. En confirmación de Sancho IV de 29 de novembro de 1284 en confirmación de Fernando IV de 8 de marzo de 1312.

C. AHN, Clero, Carpeta 556, n.ํㅜ 17. En confirmación de Sancho IV de 29 de novembro de 1284 en confirmación de Fernando IV de 8 de marzo de 1312, en confirmación de Afonso XI de 12 de agosto de 1332, en confirmación de Pedro I de 14 de setembro de 1351

Rex.: Sánchez Belda 1953: 329 (n.․758); González Jiménez/Carmona Ruiz 2012: 237-238 (n.ํ1030).

84

1255, novembro, 13. Santo Domingo de Silos.

Afonso X confirma ao mosteiro de San Xusto de Toxos Outos a confirmación de Fernando III de 17 de febreiro de 1232, que inclúe, na que se confirman: 1) a concesión do couto monástico, acoutamento de todas as herdades do cenobio e exención de portádego, por Afonso VII o 5 de decembro de 1135; e 2) a concesión do couto de San Cristovo de Arzón, por Afonso VII o 10 de maio de 1138. 
B. AHN, Códices, L. 1002 B, ff. 21r-22r.

Rex.: Sánchez Belda 1953: 330 (n.. 759); González Jiménez/Carmona Ruiz 2012: 237-238 (n.․1030).

Ed.: Pérez Rodríguez 2004: 66-69 (n.우 36).

\section{5}

1255, novembro, 13. Santo Domingo de Silos.

Afonso X confirma ao mosteiro de San Xusto de Toxos Outos a confirmación de Fernando III de 17 de febreiro de 1232, que inclúe, na que se confirman: 1) a doazón e acoutamento das igrexas de San Salvador e San Martiño de Duio, por Afonso VII o 5 de maio de 1135; e 2) a doazón de varias herdades nas terras do Ribeiro de Avia, Salnés e Carnota, por Afonso VII o 7 de maio de 1138.

B. AHN, Códices, L. 1002 B, ff. 23r-25r.

Rex.: Sánchez Belda 1953: 330 (n.o 760); González Jiménez/Carmona Ruiz 2012: 237-238 (n.o 1030).

Ed.: Pérez Rodríguez 2004: 72-75 (n.o 38).

\section{6}

1255, novembro, 17. Santo Domingo de Silos.

Afonso $X$ ordena a todos os que leven mercancías por mar á Coruña suxeitas ao pago de portádego que paguen a parte que deste corresponde ao mosteiro de Santa María de Sobrado, incluso os mercadores de Santander e Castro Urdiales, aos que escusara o propio monarca, aclarando que a súa intención ao eximirlles dese pago foi a de «les quitar el mio derecho e non más».

A. AHN, Clero, Carpeta 542, n. 8. Orixinal. Pergameo, 164 x 203 mm.

Rex.: Sánchez Belda 1953: 331 (n.ํ761); González Jiménez/Carmona Ruiz 2012: 239 (n.o 1038).

Ed.: Herrera/Sánchez/González de Fauve/Zabia 1999: AGA 2v.

87

1255, decembro, 2. Vitoria.

Afonso X autoriza á vila da Coruña a proverse e vender sal libremente, prohibindo que ningún barco a leve a Betanzos, cuxos veciños deben mercala na Coruña.

B. AHMAC, Privilexios, no 12 . En confirmación de Sancho IV de 4 de setembro de 1286.

C. AHMAC, Privilexios, no 5 . Traslado realizado por Juan Mariño, notario do Concello da Coruña. 
Rex.: Ballesteros Beretta 1984: 1073 (n.․282); González Jiménez/Carmona Ruiz 2012: 240 (n.ํ1048).

Ed.: González Garcés 2008: 490-494.

88

1255, decembro, 14. Vitoria.

Afonso X comunica ao Concello de Ourense a voda da súa primoxénita, dona Berenguela, co primoxénito e herdeiro do rei de Francia, e ordénalle que nomee tres procuradores para que se presenten ante el o día da Candelaria para facer homenaxe tanto a ela como ao seu marido así como que poñan o seu selo na carta que sobre ese asunto redactou o seu porteiro, Gonzalo Yáñez, e que, selada, lle sexa levada polos representantes municipais.

B. ACOu, Escrituras 12, no 115. En protesta da Igrexa auriense ante o monarca por solicitar ao Concello de Ourense que preste homenaxe e xuramento como herdeira do reino á súa primoxénita, dona Berenguela, de 31 de xaneiro de 1256.

Rex.: Duro Peña 1972: 42 (n.․18); González Jiménez/Carmona Ruiz 2012: 241 (n.․1053).

Ed.: DACO 1917: 174-175; Vaquero Díaz/Pérez Rodríguez 2010: 225-226 (n.o 416).

89

[1256, xaneiro], 10. Vitoria.

O Concello de Ourense presta homenaxe e xura como herdeira dos reinos de Afonso X á súa filla primoxénita, dona Berenguela, acabada de casar con don Luís, primoxénito e herdeiro do rei de Francia.

B. ACOu, Escrituras 12, no 115. En protesta da Igrexa auriense ante o monarca por solicitar ao Concello de Ourense que preste homenaxe e xuramento como herdeira do reino á súa primoxénita, dona Berenguela, de 31 de xaneiro de 1256.

Ed.: DACO 1917: 176-177; Vaquero Díaz/Pérez Rodríguez 2010: 229-230 (n.․416).

Moi deteriorado, o pergameo deixa ver que este documento foi feito en Vitoria, onde Afonso $\mathrm{X}$ permaneceu ata o 24 de xaneiro de 1256 (González Jiménez/Carmona Ruiz 2012: 27). A súa redacción debeu facerse, pois, nese mes e ano, co que o «decima» que se conserva da datación leva a datalo o día 10. 


\section{0}

1256, xaneiro, 10. Vitoria.

Afonso X recoñece a don Xoán Arias, arcebispo de Santiago de Compostela, que a axuda que a súa Igrexa lle prestou para saldar as débedas do seu pai, Fernando III, foi feita libremente.

B. ACSC, Tumbillo de Concordias, f. 39rv. Copia simple.

Rex.: González Vázquez 1996: 310; González Jiménez/Carmona Ruiz 2012: 243 (n.o 1075).

91

1256, xaneiro, 10. Vitoria.

Afonso X autoriza a don Rodrigo Gómez de Galicia a vender á Orde de Calatrava a masía de Cerrajas, vinte xugadas de herdade en Noblas, no termo de Facialcázar, e as casas en Sevilla que, como as herdades anteriores, lle doara a don Rodrigo.

B. AHN, Órdenes Militares, Registro III, f. 129.

Rex.: González González 1951: II, 327; González Jiménez/Carmona Ruiz 2012: 243 (n.ํ1074).

Ed.: González Jiménez 1991: 188-189 (n.ํ170).

\section{2}

1256, febreiro, 9. San Esteban de Gormaz.

Afonso X, por denuncia do Concello da Coruña dos préstamos forzosos requiridos tanto polo seu pai, Fernando III, como polo mesmo Afonso X, exime aos veciños e aos mercadores da Coruña de todo préstamo forzado polos reis de Castela e León.

A. AHMAC. Privilexios, n. 7. Orixinal. Pergameo.

Rex.: Ballesteros Beretta 1984: 1074 (n.o 301); González Jiménez/Carmona Ruiz 2012: 246 (n.ํ1095).

Ed.: Herrera/Sánchez/González de Fauve/Zabia 1999: AGA 3r; González Garcés 2008: 494-498.

93

1256, febreiro, 10. San Esteban de Gormaz.

Afonso X agradece ao arcebispo e ao cabido de Santiago de Compostela que prestasen homenaxe á infanta dona Berenguela, co gallo do seu compromiso matrimonial con don Luís, primoxénito e herdeiro do rei de Francia, como herdeira dos reinos de Castela e León. Inclúese o nomeamento dos procuradores da Igrexa, de 2 de febreiro 
de 1256, en Santiago de Compostela, os cóengos Fernando Afonso e o mestre Fernando, representantes da Igrexa compostelá, dos concellos de Santiago, de Pontevedra e de toda a Terra de Santiago, así como o xuramento prestado polos ditos procuradores o mesmo 10 de febreiro de 1256.

B. ACSC, Tumbo B, f. 42rv. En traslado realizado por André Pérez e Afonso Eanes, notarios de Santiago de Compostela.

Rex.: González Vázquez 1996: 310; González Jiménez/Carmona Ruiz 2012: 246 e 721 (n.․ 1097 e 3860). Ed.: López Ferreiro 1902: 91-93 (n.ํ31); González Balasch 2004: 207-209 (n.․ 94).

\section{4}

1256, febreiro, 14. San Esteban de Gormaz.

Ante a protesta do bispo e do cabido aurienses por recibir a homenaxe do Concello de Ourense, Afonso X manifesta que con iso non pretendeu nin pretende danar o dereito e señorío da Igrexa auriense.

A. ACOu, Privilexios 4, no 40. Orixinal. Pergameo, 160 x 150 mm.

Rex.: Duro Peña 1972: $42-43$ (n.o 119); González Jiménez/Carmona Ruiz 2012: 247 (n.o 1101).

Ed.: DACO 1917: 178; Vaquero Díaz/Pérez Rodríguez 2010: 233-234 (n.o 423).

\section{5}

1256, marzo, 22. Soria.

Afonso X confirma ao mosteiro de San Martiño Pinario a confirmación xenérica dos seus privilexios realizada por Fernando III o 25 de febreiro de 1232, que inclúe.

B. AHN, Clero, Carpeta 515, n.ํ 6. En traslado notarial de confirmación de Fernando IV de 1 de xuño de 1305 en confirmación de Afonso XI de 10 de xaneiro de 1332.

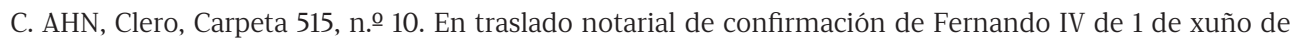
1305 en confirmación de Afonso XI de 10 de xaneiro de 1332 en confirmación de Afonso XI de 15 de marzo de 1344.

D. AHUSC, San Martiño, Pergameos, n. ⒈ En confirmación de Pedro I de 12 de outubro de 1365.

E. AHN, Clero, Carpeta 517, n.o 17. En traslado notarial da confirmación de Pedro I de 15 de setembro de 1351. F. AHN, Clero, Carpeta 516, n.․ㅗ 5. En traslado notarial da confirmación de Fernando IV de 1 de xuño de 1305 en confirmación de Afonso XI de 10 de xaneiro de 1332 en confirmación de Afonso XI de 15 de marzo de 1344 en confirmación de Xoán I de 20 de setembro de 1380 en confirmación de Enrique III de 25 de abril de 1391. G. AHN, Clero, Carpeta 516, n.․ㅜ 10. En traslado notarial de confirmación de Fernando IV de 1 de xuño de 1305 en confirmación de Afonso XI de 10 de xaneiro de 1332 en confirmación de Afonso XI de 15 de marzo de 1344 en confirmación de Xoán I de 20 de setembro de 1380 en confirmación de Enrique III de 22 de xuño de 1401. 
Rex.: Sánchez Belda 1953: 331 (n.․762); Buján Rodríguez 1996: 304 (n.․238); Lucas Álvarez 1999: 164 (n.․ 128); González Jiménez/Carmona Ruiz 2012: 249 (n.ํㅜ 1113).

\section{6}

1256, xuño, 18. Brihuega.

Afonso X comunica a don Mateo, xuíz de Lugo, que os homes de San Vicente dos Muros -San Vicente do Burgo-e Santiago de Prógalo, que recorreran ante El-Rei a sentenza dada por don Mateo no preito que mantiñan co bispo de Lugo sobre o pago de facendeira, non se presentaron na corte no prazo sinalado, polo que ratifica a sentenza e condena, polas custas, aos homes das ditas parroquias en 46 soldos.

Rex.: Sánchez Belda 1953: 331-332 (n.․763).

Ed.: Cañizares del Rey 2015: 256-257 (n.․4 425).

\section{7}

1256, xuño, 30. Segovia.

Afonso $X$, por denuncia dos mercadores de Ribadavia dos préstamos forzosos requiridos tanto polo seu pai, Fernando III, como polo mesmo Afonso X, exime a veciños e mercadores de Ribadavia de todo préstamo forzado polos reis de Castela e León.

B. Biblioteca de Catalunya, Pergameos, 343. En confirmación de Xoán II de 17 de abril de 1420.

Rex.: Ballesteros Beretta 1984: 1074 (n. 315); González Jiménez/Carmona Ruiz 2012: 253 (n.ํ1144).

Ed.: Meruéndano 1908: 196-199, e 1909: 379-380; García-Fernández/Pelaz Flores/Pichel 2020: 171-172.

\section{8}

1256, setembro, 16. Segovia.

Afonso X confirma ao mosteiro de Santa María de Oseira a confirmación de Fernando III de [19 de febreiro] de 1232, que inclúe, do acoutamento e exención de todo preito real dos servizais do cenobio feita por Afonso IX o 18 de febreiro de 1222.
A. AHN, Sigilografía, C. 11, n. 6. Orixinal. Pergameo, 505 x 596 mm.
B. AHN, Códices, L. 1008 B, ff. 6r-7r. Copia simple.
C. AHN, Códices. L. B-15, ff. 98r-99v. Copia simple. 
Rex.: Sánchez Belda 1953: 322 (n.. 764); Duro Peña 1972: 98 (n.. 328); González Jiménez/Carmona Ruiz 2012: 262 (n. 1202$)$.

82 Ed.: Romaní Martínez 1989: $722-725$ (n.․ 761).

\section{9}

1257, marzo, 18. Lorca.

Afonso $X$ doa a don Fernando Eanes Batisela a aldea de Algavalí, no termo de Aznalfarache.

B. AHN, Órdenes Militares, Registro III, f. 129.

Rex.: González Jiménez/Carmona Ruiz 2012: 268 (n.ํ1245).

Ed.: González Jiménez 1991: 211 (n. 190).

Como amosa M. González Jiménez no seu Diplomatario, a data parece excesivamente tardía para a concesión dun donadío en Sevilla, co que debe pensarse nunha confirmación, ou ben nun erro do rexistro alcantarino, que ten ao seu favor datar o documento en Lorca. O donadío que recibiu don Fernando en Sevilla estaba formado pola aldea de Algavalí, rebautizada como «Lobarzana» polo monarca, que constaba de 150 aranzadas con cinco mil pés de oliveiral e figueiral, mais quince xugadas para pan en Alcázar, termo de Facialcázar (González González 1951: II, 24-25).

\section{0}

1258, febreiro, 1. Valladolid.

Afonso $X$ diríxese aos concellos de Galicia e Asturias anunciándolles o envío de Domingo Eanes, «mio alcalde sobrel fecho de la Cruziada», encargado de que as naves e «galeas» estean preparadas en Cádiz o vindeiro 1 de maio así como de recadar o préstamo en diñeiro para iso, roga que se lle entregue e ordena a alcalde que as cantidades dadas polos concellos se sitúen, para a súa restitución, na moeda foreira dos lugares destinados para iso.

B. AMOv, Tomo I, n.ํㅡ 22. En recibo da entrega por parte do Concello de Oviedo de 1200 marabedís ao alcalde real Domingo Eanes, en cumprimento da orde que se inclúe.

Reg.: González Jiménez/Carmona Ruiz 2012: 283 (n.ํ1343).

Ed.: Miguel Vigil 1889: 46 (n.․ㅡ 22).

\section{1}

1258, febreiro, 19. Valladolid.

Afonso X, á vista da doazón feita por Afonso IX a dona Estefanía de Xinzo e Vilamaior da Xironda en xuño de 1211, así como a posterior doazón feita por esta 
ao mosteiro de Santa María de Melón en xaneiro de 1249 -incluíndose ambas as dúasdevolve a este cenobio a aldea de Vilamaior, da que se incautara crendo que o mosteiro non tiña títulos para posuíla.

A. AHN, Sigilografía, C. 12, n.․․ 3.550 x $400 \mathrm{~mm}$.

B. ACOu, Monacais, Melón, n.ํ 785. En traslado realizado por Pedro Rodríguez, notario de Ribadavia.

C. ACOu, Monacais, Melón, n. 3810 . En traslado realizado por Rodrigo Eanes, notario de Ribadavia, o 1 de outubro de 1424.

D. AHPOu, Tumbo de frei Lourenzo Pérez de 1611, f. 222r. Copia simple.

Rex.: Leirós Fernández 1951: 69 (n.o 785); Sánchez Belda 1953: 332-323 (n.o 765) [Datándoo en marzo]; Duro Peña 1972: 99 (n.․ 329); González Jiménez/Carmona Ruiz 2012: 287 (n. 1369) [Datándoo en marzo].

Ed.: Cambón Suárez 1957: n.o 588.

\section{2}

1258, marzo, 1. Valladolid.

Afonso X exime do pago de moeda foreira ao bispo, cabido e clerecía menor da catedral de Ourense.

A. ACOu, Privilexios 3, no 22. Orixinal. Pergameo, 550 x 486 mm.

B. ACOu, Privilexios 4, no 18. En confirmación de Afonso XI de 25 de febreiro de 1339.

Rex.: Duro Peña 1972: 43 (n. 120); González Jiménez/Carmona Ruiz 2012: 285 (n.․1356).

Ed.: DACO 1917: 188-190; Herrera Sánchez González de Fauve/Zabia 1999: AGA 4r; Vaquero Díaz/Pérez Rodríguez 2010: 259-262 (n.․449).

\section{3}

1258, marzo, 1. Valladolid.

Afonso X establece que, á morte do bispo de Ourense, será o cabido auriense o que se faga cargo dos seus bens mentres a sé estea vacante, e ordena que non sexa tomado por un representante do rei, quen debe axudar e defender ao delegado do cabido que administre os devanditos bens.

A. ACOu, Privilexios 3, no 24. Orixinal. Pergameo, 515 x 317 mm.

B. ACOu, Libro Grande, ff. 16v-17r. Copia simple.

Rex.: Duro Peña 1972: 43 (n. 121); González Jiménez/Carmona Ruiz 2012: 285 (n.o 1355).

Ed.: DACO 1917: 191; Vaquero Díaz/Pérez Rodríguez 2010: 262-264 (n.o 450). 
1258, marzo, 4. Valladolid.

Afonso $X$ diríxese a todos os concellos e aldeas do bispado de Ourense lembrando a obrigatoriedade universal do pago do décimo.

A. ACOu, Privilexios 3, no 23. Orixinal. Pergameo, 300 x 317 mm.

Rex.: Duro Peña 1972: 43-44 (n. 122); González Jiménez/Carmona Ruiz 2012: 286 (n.o 1362).

Ed.: DACO 1917: 186-188; Herrera/Sánchez/González de Fauve/Zabia 1999: AGA 4v; Vaquero Díaz/Pérez Rodríguez 2010: 264-266 (n. 451).

\section{5}

1258, abril, 12. Valladolid.

Afonso X exime do pago da novena que lle concedeu o papa ao bispo auriense e a todas as igrexas da súa diocese durante tres anos, e ordena a Ponce de Vale e aos demais recadadores da taxa que non llela cobren.

A. ACOu, Escrituras 12, nํㅜㄹ. Orixinal. Pergameo, 97 x 33 mm.

Rex.: Duro Peña 1972: 44 (n. 123); González Jiménez/Carmona Ruiz 2012: 288 (n.o 1377).

Ed.: Herrera/Sánchez/González de Fauve/Zabia 1999: AGA 5r; Vaquero Díaz/Pérez Rodríguez 2010: 266 (n.ㅇ 452 ).

\section{6}

1258, abril, 13. Valladolid.

Afonso X confirma ao mosteiro de San Xulián de Samos a orde de Fernando III de 4 de xaneiro de 1232, que inclúe, para que ninguén cobre portádego nin tome nada por débedas ás bestas que leven pan, viño ou peixe ao mosteiro.

B. AHN, Sigilografía, C. 10, n. ⒈ En confirmación de Fernando IV de 22 de agosto de 1308.

Rex.: Sánchez Belda 1953: 333 (n.․766); Ballesteros Beretta 1984: 1078 (n.․384); González Jiménez/Carmona Ruiz 2012: 288 (n.. 1378).

\section{7}

1258, abril, 20. Valladolid.

Afonso X confirma ao mosteiro de Santa María de Monfero a orde de Fernando III de 28 de xaneiro de 1232, que inclúe, para que ninguén peñore as bestas que leven cargas ao mosteiro. 
B. AHN, Clero, Carpeta 506, n.․ 9. En confirmación de Sancho IV de 2 de maio de 1293 en confirmación de Afonso XI de 20 de marzo de 1331.

C. AHN, Clero, Carpeta 510, n.․․ 2. En confirmación de Sancho IV de 2 de maio de 1293 en confirmación de Afonso XI de 20 de marzo de 1331 en confirmación de Xoán II de 24 de maio de 1432.

D. AHN, Clero, Carpeta 506, n.․ 10. En traslado notarial realizado en 1348 da confirmación de Afonso XI de 20 de marzo de 1331.

E. AHN, Clero, Carpeta 503, n.․⒐ Copia simple coetánea.

Rex.: Sánchez Belda 1953: 333-334 (n. 767); López Sangil 2002: 683; González Jiménez/Carmona Ruiz 2012: 288 (n.․1381).

\section{8}

1258, abril, 20. Valladolid.

Afonso X confirma ao mosteiro de Santa María de Monfero a exención para os vasalos do cenobio e toma de comenda deste de Fernando III de 28 de xaneiro de 1232, que inclúe.

B. AHN, Clero, Carpeta 506, n.․ 9. En confirmación de Sancho IV de 2 de maio de 1293 en confirmación de Afonso XI de 20 de marzo de 1331.

C. AHN, Clero, Carpeta 510, n.․ 2. En confirmación de Sancho IV de 2 de maio de 1293 en confirmación de Afonso XI de 20 de marzo de 1331 en confirmación de Xoán II de 24 de maio de 1432.

D. AHN, Clero, Carpeta 506, n.․ 10. En traslado notarial realizado en 1348 da confirmación de Afonso XI de 20 de marzo de 1331.

E. AHN, Clero, Carpeta 503, n. 9. Copia simple coetánea.

Rex.: Sánchez Belda 1953: 334 (n.․768); López Sangil 2002: 683; González Jiménez/Carmona Ruiz 2012: 289 (n.o 1382).

\section{9}

1258, abril, 21. Valladolid.

FALSO.

Afonso X confirma ao mosteiro de Santa María de Monfero o acoutamento do mosteiro e das súas herdades dada por Afonso VII o 5 de decembro de 1135.

B. AHN, Clero, Carpeta 501, n.․․ 2. En traslado realizado o 9 de agosto de 1317 por Francisco Domínguez, notario de Betanzos.

C. AHN, Clero, Carpeta 501, n.. 1. Copia imitativa.

Rex.: Sánchez Belda 1953: 334-335 (n.o 769); Ballesteros Beretta 1984: 1078 (n.o 385); López Sangil 2002: 684; González Jiménez/Carmona Ruiz 2012: 289 (n. 1383).

O privilexio de Afonso VII de 5 de decembro de 1135 é claramente falso, como coido ter demostrado en Pérez Rodríguez 2019: 843-850, onde se pon de manifesto que o seu modelo foi tomado da concesión de couto a San Xusto de Toxos Outos, concedido nesa data polo Emperador. Tomando este diploma como modelo, e 
adaptándoo ás condicións de Monfero, a principios do XIV elaborouse esta falsa confirmación, para o que só houbo que adaptar as das concedidas a este mesmo mosteiro o día 20 de abril de 1258, sen que poida explicarse por que se decidiu datala ao día seguinte, 21. O traslado realizado en 1317 é, ademais, unha copia imitativa, como o seu irmán, coa actual sinatura n.. 1, que pode ter sido outro traslado-copia imitativa, como opina Sánchez Belda, «á que posteriormente cortáronselle as súas subscricións, para dar visos de orixinal», ou pode tamén pensarse que foi a que puxeron diante do notario de Betanzos para pór baixo ela a súa sinatura e fe. A favor da súa falsidade está así mesmo que, a diferenza dos dous privilexios anteriores, do día 20, confirmados posteriormente en 1293, 1331 e 1432, este do día 21 non o foi nunca, a pesar de conter unha concesión de moita maior transcendencia.

\section{0}

1258, xuño, 3. Medina del Campo.

Afonso $X$, no preito entre a Igrexa de Mondoñedo e os habitantes das freguesías de Santa María de Chavín, San Pedro de Viveiro e Santo Estevo de Valcarría, sentencia que estes deben pagar a martinega na forma en que o facían en tempos de Afonso IX e como o fan os da vila de Viveiro.

A. ACMd. Orixinal. Pergameo, 348 x $330 \mathrm{~mm}$.

Rex.: Ballesteros Beretta 1984: 1078 (n.․ 391); Cal Pardo 1990: 28 (n.. 36); González Jiménez/Carmona Ruiz 2012: 290 (n.. 1391$).$

Ed.: Cal Pardo 1999: $91-93$ (n.․36); Herrera/Sánchez/González de Fauve Zabia 1999: AGA 5v.

\section{1}

1258, xullo, 15. Arévalo.

Afonso X confirma ao Concello de Allariz a orde dada ao Concello de Ribadavia por Afonso IX, de 25 de xaneiro de 1226, para que non se cobre portádego en Ribadavia aos homes de Allariz.

Rex.: González Jiménez/Carmona Ruiz 2012: 293 (n.․1408).

Ed.: BCPMHAO 1908: 332 (n.ํ 78).

\section{2}

1258, xullo, 16. Arévalo.

Afonso $X$, no preito entre a Igrexa de Santiago de Compostela e os homes do couto de San Vicente de Caamouco sobre o pago destes de «fogazas» a aquela, sentencia que os couteiros deben pagalas posto que non presentan documento ningún 
para demostrar a súa exención do pagamento, e condénaos a pagar as custas do preito, que estima en 52 marabedís leoneses.

B. ACSC, Tumbillo de Concordias, f. 44rv. Copia simple.

Rex.: González Vázquez 1996: 310; González Jiménez/Carmona Ruiz 2012: 293 (n.ํ1410).

Ed.: López Ferreiro 1895: 357.

\section{3}

1258, outubro, 9. Madrid.

Afonso X ordena aos concellos de Viveiro e Ribadeo que cobren o portádego debido aos de Castro Urdiales «et a otros de los mios regnos» aos que non llelo cobran.

B. ACMd. Pergameos, n.․ 42. En traslado realizado por orde do mesmo Afonso X para pasalo de papel a pergameo de 17 de decembro de 1271.

Rex.: Ballesteros Beretta 1984: 1079 (n.o 414) [Datándoo o 9 de decembro]; Cal Pardo 1990: 30 (n.. 42); González Jiménez/Carmona Ruiz 2012: 297 e 299 (n. 1437 e 1454) [Trátase do mesmo documento, que datan tamén, e erradamente, o 9 de outubro de 1258].

Ed.: Cal Pardo 1991: 84; Cal Pardo 1999: 100 (n.․4).

\section{4}

1258, novembro, 24. Madrid.

Afonso X ordena ao seu meiriño maior en Galicia, don Rodrigo García, por mor da denuncia do abade de Santa María de Monfero, que pescude sobre se don Rodrigo Gómez e outros cabaleiros derribaron os mollóns que delimitan o couto do mosteiro de Monfero e que, de ser iso certo, os mande levantar e que, así mesmo, revise os privilexios do cenobio e que obrigue a gardalos.

B. ARG. Pergameos, n.․117. En sentenza dada por Xoán Pérez, xuíz de terra de Pruzos, de 8 de decembro de 1261. Rex.: González Jiménez/Carmona Ruiz 2012: 298 (n.o 1449) [Datándoo o 8 de novembro].

\section{5}

1258, decembro, 4. Toledo.

Afonso X ordena ao adiantado maior de León, don García Xil, e ao meiriño maior de Galicia, don Rodrigo García, que garden e fagan gardar os privilexios do mosteiro de Santa María de Carracedo. 
R. ADA, Ms. R-4, Cartulario de Santa María de Carracedo, f. 23. Rex.: González Jiménez/Carmona Ruiz 2012: 299 (n.ํ1452).

\section{6}

[1258], decembro, 17. Madrid.

\section{FALSO.}

Afonso X, a petición do prior de San Xoán de Caaveiro, confirma todos os seus privilexios, ordena que nin meiriño nin prestameiro entre nos seus coutos nin igrexas nin, «porque es mi capilla», cobre foro ou xantar, libera tamén de todo imposto aos servizais e homes do priorado e, por último, «mando al prior haga comendero en sus cotos que haga la justicia».

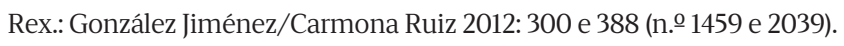

Ed.: González 1830: 182-183 (n. 56).

Este privilexio é, sen dúbida, atípico nas concesións afonsinas a mosteiros galegos, como pon en evidencia a mención a mi capilla ou a orde para que o prior nomee comendeiro. Chama tamén a atención a referencia a Afonso VII, «el Emperador, mio abuelo», quen «heredolo, e cotolo, e bienfecholo», ao priorado. Por outra banda, o Sabio confirma o 19 de marzo de 1281 a doazón de Santa María de Ribadeume e Santiago de Bermui de 1164 por Fernando II, así como o acoutamento -moi probablemente falso- de Caaveiro por parte de Alfonso VII, datado en 1135. Destes dous diplomas Sancho IV confirmou só a doazón de Ribadeume e Bermui o 2 de setembro de 1286 (Sánchez Belda 1953: 365 [n.o 847]; Fernández de Viana y Vieites e González Balasch 2002: 358 [n. 21]), o que permite supor ou, polo menos, pon en dúbida tanto a confirmación afonsina do couto como este atípico documento de 1258 que, por certo e incrementando a sospeita de falsidade, está mal datado en 1267. A súa primeira confirmación foi dada por Xoán II en 1420 (González 1830: 183), e converteuse entón no diploma sucesivamente presentado ante a corte para a súa confirmación, esquecéndose doutros privilexios, tanto auténticos como sospeitosos, así como da confirmación xenérica dos privilexios, usos e costumes do priorado concedida por Xoán I o 18 de setembro de 1380, confirmada por Enrique III en 1406 (Fernández de Viana y Vieites e González Balasch 2002: 374-375 e 384 (n.o 36 e 45).

117

1259, febreiro, 5. Toledo.

Afonso $X$ dita sentenza no preito que mantén o Concello de Ourense contra a Igrexa auriense; inclúese o memorial de agravios presentado polo Concello e as querelas da catedral.

A. ACOu, Privilexios 3, no 25. Orixinal. Pergameo, 575 x 590 mm.

Rex.: Duro Peña 1972: 44 (n. 124); González Jiménez/Carmona Ruiz 2012: 286 (n.o 1468 e 1469).

Ed.: DACO 1917: 179-184; Herrera/Sánchez/González de Fauve/Zabia 1999: AGA 6r; Vaquero Díaz/Pérez Rodríguez 2010: 284-289 (n.ㅇ 471). 


\section{[117bis]}

1259, agosto, 27. Toledo.

«Afonso X aproba a composición feita entre García Fernández, mestre de Alcántara, e Gonzalo Eanes de Nóvoa».

Rexestado por González Jiménez/Carmona Ruiz 2012: 305 (n. 1498), no documento, que publica B. Palacios Martín, non intervén Afonso X. Trátase dun rexesto que, na edición citada, di exactamente: «Gonzalo Ibáñez de Novoa reconoce la propiedad de Alcántara sobre diferentes cotos situados en Galicia que la orden había cedido de manera vitalicia a su padre, Juan Pérez, durante el maestrazgo de su hermano Pedro Ibáñez» (Palacios Martín [dir.] 2000: 189 [n. 199]).

\section{8}

1259, setembro, 26. Toledo.

Afonso $X$, ante a queixa do abade electo do mosteiro de San Xulián de Samos, que lle presentou a orde de Afonso IX de 28 de outubro de 1195, que inclúe, para que ninguén que non sexa o mosteiro teña vasalos nos coutos do cenobio, ordena a don Rodrigo García, meiriño maior de Galicia, que cumpra a dita orde.

B. AHN, Clero, Carpeta 1244, n. $\stackrel{0}{1}$. En copia do seu traslado de papel a pergameo realizada en Ciudad Real o 1 de febreiro de 1266.

Rex.: Sánchez Belda 1953: 335-336 (n.o 771); Pérez-Bustamante 1976: 14 (n.ํ13); Ballesteros Beretta 1984: 1080 (n. 0 431).

\section{9}

1259, setembro, 26. Toledo.

Afonso X confirma ao mosteiro de San Salvador de Chantada a confirmación de Fernando III de 27 de outubro de 1231, que inclúe, que confirma xenericamente os bens e privilexios que o cenobio tiña á morte de Afonso IX.

A. AHN, Clero, Carpeta 1067, n. 10 . Orixinal. Pergameo, 457 x 905 mm.

A'. AHN, Clero, Carpeta 1067, n. ํㅜㄴ. Orixinal. Pergameo, 480 x 640 mm.

B. AHN, Clero, Carpeta 1068, n.ํㅜ 20. En confirmación de Afonso XI de 25 de marzo de 1331.

C. AHN, Clero, Carpeta 1068, n.ํㅜ 20. En traslado da confirmación de Afonso XI de 25 de marzo de 1331 realizado o 8 de decembro de 1345 por Pedro Fernández, notario de Chantada.

Rex.: Sánchez Belda 1953: 335 (n.o 770); González Jiménez/Carmona Ruiz 2012: 307 (n.o 1510).

Ed.: Méndez Pérez/Otero Piñeyro Maseda/Romaní Martínez 2016: 200-203 (n.ํ15). 


\section{0}

Afonso X dá privilexio ao mosteiro de San Salvador de Chantada no que: 1) acouta e concede exención de entrada dos oficiales reais en todas as herdades do cenobio: 2) confirma a metade do portádego da feira de Chantada, segundo o mosteiro a tiña desde época de Afonso IX; 3) confirma os usos e costumes que ten o cenobio desde época de Afonso VII; 4) en caso de que os oficiais monásticos non fagan cumprir a xustiza nos homes do mosteiro, farao o meiriño real, se ben o que confisque ou tome ao reo será entregado ao cenobio; e 5) por mor da súa pobreza, concédelle exención de xantar e pedido.

B. AHN, Clero, Carpeta 1067, n.․ㅜ 12. En traslado realizado o 11 de xullo de 1330 por Lourenzo Eanes, notario de Orcellón.

C. AHN, Clero, Carpeta 1067, n.․1․ En traslado realizado por Xoán Domínguez, notario do rei don Sancho en terras de Asma e Monterroso.

Rex.: Sánchez Belda 1953: 336 (n.ํ 772); Ballesteros Beretta 1984: 1080 (n.․432) [Datándoo o 23 de setembro]; González Jiménez/Carmona Ruiz 2012: 306 e 307 (n.o 1503 e 1511) [Trátase do mesmo documento, que datan en días distintos, 6 e 26 de setembro].

Ed.: Méndez Pérez/Otero Piñeyro Maseda/Romaní Martínez 2016: 203-206 (n.․16).

Ballesteros Beretta 1984: 1080, dátao o 23 de setembro, mentres que González Jiménez/Carmona Ruiz 2012: 306 e 307 (n.. 1503 e 1511) dan dúas datas ao mesmo documento: a errónea do día 6 (n.․1503) e a correcta, 26 de setembro (n.․1511).

\section{1}

1260, xaneiro, 25. Toledo.

Afonso X, por denuncia da Igrexa de Santiago de Compostela, ordena aos concellos «en el Camino de Santiago desde Logronno fasta León», ao adiantado maior de Castela e aos meiriños que vexan a carta que prohiban a fabricación e venda das «señales de Santiago» de estaño e chumbo, pois soamente poden facerse e venderse na cidade de Santiago ou onde o arcebispo compostelán ordene.

B. ACSC, Tumbo B, f. 154rv. En traslado realizado por André Pérez e Afonso Eanes, notarios de Santiago de Compostela.

Rex.: González Vázquez 1996: 310; González Jiménez/Carmona Ruiz 2012: 309-310 (n.ํ1525).

Ed.: González Balasch 2004: 384-385 (n.o 201). 


\section{2}

1260, agosto, 24. Sevilla.

Afonso $X$ desbota as acusacións que contra o bispo de Mondoñedo presenta o Concello de Viveiro e rexéitaas para que vaian a xuizo. O Concello esixía reparación polos roubos e danos cometidos por Pedro Fernández, a entrega do portádego que se lle arrebatara en Portocelo, San Cibrao e Bares, así como que se obrigue aos de Ribadeo a obedecelo como homes do seu termo.

A. ACMd. Pergameos, n.o 37. Orixinal. Pergameo, 250 x 260 mm.

Rex.: Ballesteros Beretta 1984: 1097 (n. 770) [Datándoo o 24 de agosto de 1270]; Cal Pardo 1990: 28 (n.․ 37); González Jiménez/Carmona Ruiz 2012: 318 e 427 (n.o 1581 e 2285) [Datando o n.o 2285 o 24 de agosto de 1270]. Ed.: Cal Pardo 1991: 85-86; Cal Pardo 1999: $93-95$ (n. 37); Herrera/Sánchez/González de Fauve/Zabia 1999: AGA 7r.

\section{3}

1260, decembro, 20. Sevilla.

Afonso X doa ao cabaleiro Martiño Chapela unha casa no barrio da Abadía de Sevilla.

Rex.: González Jiménez 1991: 259 (n.ํ 235); González Jiménez/Carmona Ruiz 2012: 319 (n.ํ1590).

Documento perdido, do Arquivo do Mosteiro de San Clemente de Sevilla.

\section{B}

1261, xaneiro, 11. Sevilla.

Afonso X doa á abadesa e monxas de San Clemente de Córdoba a horta que, na Axerquía, fora de don Lourenzo Suárez Gallinato para que fagan mosteiro nela.

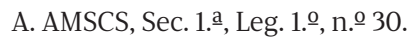

Rex.: González Jiménez/Carmona Ruiz 2012: 320 (n. 1594).

Ed.: González Jiménez 1991: 260-261 (n.o 237); Herrera/Sánchez/González de Fauve/Zabia 1999: AAN 51v. 
124

1261, febreiro, 21. Sevilla.

Afonso X sentencia no preito entre a Igrexa compostelá e o Concello de Santiago de Compostela aprobando a sentenza dada por Fernando III en 1250 e emitindo veredicto aos diferentes agravios presentados tanto polo Concello como pola Igrexa.

B. ACSC, Tumbo B, f. 17v-23r. En traslado realizado por André Pérez e Afonso Eanes, notarios de Santiago de Compostela.

C. ACSC, Tumbillo de Concordias, ff. 7r-21v. Copia simple.

Rex.: González Vázquez 1996: 311-312; González Jiménez/Carmona Ruiz 2012: 321 (n.․1599).

Ed.: López Ferreiro 1895: 264-277; González Balasch 2004: 109-121 (n.ํ28).

\section{5}

1261, febreiro, 23. Sevilla.

Afonso X confirma ao mosteiro de San Paio de Antealtares a confirmación xenérica de todos os seus bens e privilexios feita por Fernando III o 25 de febreiro de 1232, que inclúe.

B. AHUSC, San Martiño, Privilexios, n.ํ 63. En copia simple de confirmación de Sancho IV de 5 de maio de 1286 en confirmación de Afonso XI de 24 de xaneiro de 1332.

C. AHUSC, San Martiño, Privilexios, n. 64. En traslado notarial de 1335 de confirmación de Sancho IV de 5 de maio de 1286 en confirmación de Afonso XI de 24 de xaneiro de 1332.

Rex.: González Jiménez/Carmona Ruiz 2012: 321 (n.ํㅜ 1600).

Ed.: Lucas Álvarez 2001: 199-200 (n.o 21).

\section{6}

1261, marzo, 23. Sevilla.

Afonso X confirma a concesión por Afonso IX do foral de Benavente á Pobra de Ouro e a confirmación do alfoz que lle dera o bispo de Mondoñedo don Martiño de 10 de abril de 1220, que inclúe.

B. ACMd. Pergameos, n.ํ 38. En traslado realizado por Martín Suárez, notario de Castrodouro, o 26 de novembro de 1293.

Rex.: Cal Pardo 1990: 29-30 (n. 38); Ballesteros Beretta 1984: 1083 (n. 488) [Datándoo o 14 de maio]; González Jiménez/Carmona Ruiz 2012: 324 (n.ํㅜ 1617).

Ed.: Cal Pardo 1999: 95-96 (n. 38). 


\section{7}

1261, outubro, 13. Sevilla.

Afonso X ordena ao seu meiriño maior en Galicia, don Rodrigo García, por mor da denuncia do abade de Santa María de Monfero, que, en función da pescuda xa realizada sobre o couto do dito mosteiro, obrigue a Gonzalo Fernández de Sanxurxo, a Pedro Pardo e ao mordomo de dona Moor Afonso en terra de Ambroa a devolver a Monfero os vasalos do seu couto; obriga, así mesmo, ao primeiro que levante os mollóns que derribou. Para todo iso o meiriño conta coa pescuda sobre o couto monástico realizada - a raíz da orde de 24 de novembro de 1258 polo mesmo monarca-e lembra que non debe valer a prohibición rexia de que terra reguenga pase a abadengo, na que se escusan os anteditos, aos que El-Rei entregou a terra que estivera en mans de don Rodrigo Gómez, pois con esa prohibición «non queremos que por esta razon façan forçia nen torto a nenguno».

B. ARG. Pergameos, n.ํㅜ 117. En sentenza dada por Xoán Pérez, xuíz de terra de Pruzos, de 8 de decembro de 1261.

\section{[127bis]}

1262, xaneiro, 1. Sevilla.

«Privilexio de Afonso X a don Nuno, bispo de Mondoñedo».

Rexestado por González Jiménez/Carmona Ruiz 2012: 332 (n. 1665), que tomarían de Flórez (1764), no seu capítulo 7, se ben neste, con tal data, só figuran os estatutos outorgados polo bispo don Nuno ao seu cabido 3 .

\section{8}

1263, xaneiro, 12. Sevilla.

Afonso X, a petición do Concello de Allariz, ordena que os seus xuíces xulguen segundo os forais dados polo emperador Afonso VII á vila e, en caso de haber recurso, que non sexa alzado á vila de Sahagún, como ordenara o Emperador, senón que sexa levado ante El-Rei.

Rex.: González Jiménez/Carmona Ruiz 2012: 339 (n.․1717).

Ed.: BCPMHAO 1908: 208 (n.ํㅜ 75).

3 «a cuyo fin dispuso unos estatutos -o bispo don Nuno- conservados en pergamino antiguo del cabildo, firmados a primero de enero del año 1262» (Flórez 1764: 160). 


\section{9}

94

1263, febreiro, 1 . Sevilla.

Afonso X nomea como os seus procuradores a don Martín, bispo de León, a don García, bispo de Silves, a mestre don Xoán Afonso, arcediago compostelán, e ao notario real mestre Rodolfo de Podio para que, no seu nome, soliciten a Urbano IV e aos cardeais a coroa imperial e defendan os seus intereses neste asunto.

Rex.: Mansilla Reoyo 1956: 323-324 (n. 90); González Vázquez 1996: 312; González Jiménez/Carmona Ruiz 2012: 340 (n. o 1719).

\section{0}

1263, maio, 9. Sevilla.

Afonso $X$ sentencia no preito que manteñen a Igrexa de Santiago de Compostela co Concello da cidade sobre a interpretación da sentenza dada por Fernando III en 1250 e confirmada por el mesmo o 21 de febreiro de 1261, así como sobre novas denuncias que presenta o Concello compostelán contra o proceder da Igrexa xacobea.

B. ACSC, Tumbillo de Concordias, ff. 27r-30v. Copia simple.

Rex.: González Vázquez 1996: 312-313; González Jiménez/Carmona Ruiz 2012: 342 (n.o 1734).

Ed.: López Ferreiro 1895: 282-289.

\section{1}

1263, maio, 9. Sevilla.

Afonso X ordena aos seus alcaldes Pedro Rodríguez e Pedro Cordeiro que investiguen sobre o preito entre a Igrexa de Santiago de Compostela e o Concello da cidade sobre se, segundo o acordo feito en tempos de Fernando III, as herdades que os composteláns adquiriron despois do dito acordo estaban obrigadas a facer o foro que nel se ordena.

B. ACSC, Tumbillo de Concordias, ff. 31r-32r. Copia simple. Rex.: González Jiménez/Carmona Ruiz 2012: 342 (n.ํ1735). Ed.: López Ferreiro 1895: 279-280. 


\section{2}

1263, xullo, 6. Sevilla.

Afonso $X$ rexeita as reclamacións do Concello de Ourense contra o bispo e cabido aurienses sobre o foro que deben facer os cidadáns polo froito das árbores plantadas nos viñedos e pola auga coa que se regan as viñas.

A. ACOu, Privilexios 3, no 26. Orixinal. Pergameo, 207 x 213 mm.

Rex.: Duro Peña 1972: 44 (n.o 125); González Jiménez/Carmona Ruiz 2012: 343 (n.. 1745).

Ed.: DACO 1917: 195-196; Herrera/Sánchez/González de Fauve/Zabia 1999: AGA 7v; Vaquero Díaz/Pérez Rodríguez 2010: 329-330 (n.․513).

\section{3}

1263, novembro, 14. Sevilla.

Afonso $X$, recibida a investigación previamente encargada, sentencia no preito que manteñen Concello e Igrexa de Ourense sobre os escusados que deben ter na cidade o bispo e o cabido e sobre as «cuchares» do pan. O monarca establece que serán escusados todos os «paniaguados»-quen viva con eles nas súas casas-do bispo, dignidades e cóengos, correspondéndolle ao prelado seis artesáns máis na cidade; e que o produto das «cuchares» debe repartirse a medias entre Concello e Igrexa.

A. ACOu, Privilexios 3, no 26. Orixinal. Pergameo, 207 x 213 mm.

Rex.: Duro Peña 1972: 44 (n. 126); González Jiménez/Carmona Ruiz 2012: 347 (n. 1768).

Ed.: DACO 1917: 196-198; Herrera/Sánchez/González de Fauve/Zabia 1999: AGA 8r; Vaquero Díaz/Pérez Rodríguez 2010: 332-333 (n.ㅇ 516).

\section{4}

1264, xaneiro, 30. Sevilla.

Afonso X comunica á Igrexa de Santiago de Compostela as denuncias postas contra ela polo Concello compostelán, e dá prazo ás partes para que se presenten ante el o próximo día de santo André.

B. ACSC, Tumbillo de Concordias, ff. 36r-37r. Copia simple.

Rex.: González Jiménez/Carmona Ruiz 2012: 349-350 (n.o 1785).

Ed.: López Ferreiro 1895: 292-293. 


\section{5}

1264, xaneiro, 30. Sevilla.

Afonso X comunica ao arcebispo de Santiago de Compostela a denuncia posta contra el polo Concello compostelán, que o acusa de terlle obrigado a entregarlle 4200 marabedís, que piden que se lles devolvan aumentados, por mor do mal feito, dándolle prazo para presentarse ante el a xuízo o vindeiro día de santo André.

B. ACSC, Tumbillo de Concordias, ff. 37v-38r. Copia simple.

Rex.: Ballesteros Beretta 1984: 1086 (n.․546); González Vázquez 1996: 313; González Jiménez/Carmona Ruiz 2012: 349 (n.. 1783).

Ed.: López Ferreiro 1895: 293-294.

\section{6}

1264, xaneiro, 30. Sevilla.

Afonso X comunica ao Concello de Santiago de Compostela que ante a corte acudiron tanto os seus procuradores como os da Igrexa compostelá, que solicitaron que se publicasen as investigacións realizadas polos alcaldes reais Pedro Rodríguez e Pedro Cordeiro sobre os viláns reguengos e a realizada polo alcalde real Martiño López co obxecto de que as partes preparasen a súa defensa. Entregadas ás partes, a Igrexa pretende que a primeira pescuda non é válida, mentres que o Concello di o mesmo da segunda. O monarca empraza ás partes para o vindeiro día de santo André.

B. ACSC, Tumbo B, ff. 71r-72r. En traslado realizado por André Pérez e Afonso Eanes, notarios de Santiago de Compostela.

C. ACSC, Tumbillo de Concordias, ff. 36r-37r. Copia simple.

Rex.: González Vázquez 1996: 313; González Jiménez/Carmona Ruiz 2012: 350 (n.ํ1786).

Ed.: López Ferreiro 1895: 294-296; González Balasch 2004: 218-219 (n.o 103).

\section{7}

1264, xaneiro, 30. Sevilla.

Afonso $X$ sentencia no preito entre a Igrexa compostelá e o Concello de Santiago de Compostela ordenando que nin o pertegueiro maior nin outros pertegueiros interveñan nas compras e rendas dos veciños da cidade, que nas investigacións se poña o nome das testemuñas, ditaminando así a favor do Concello, que os xuíces cregos reciban «alçada de uoz assy como dis la nostra sentençia» mentres que deixa en suspenso o asunto sobre os homes bos que debe nomear a Igrexa nos preitos cos cidadáns, que corresponde a outro preito. 
B. ACSC, Tumbo B, f. 16rv. En traslado realizado por André Pérez e Afonso Eanes, notarios de Santiago de Compostela.

C. ACSC, Tumbillo de Concordias, f. 37rv. Copia simple.

Rex.: González Vázquez 1996: 313; González Jiménez/Carmona Ruiz 2012: 349 (n.o 1784).

Ed.: López Ferreiro 1895: 290-291; González Balasch 2004: 106-107 (n.. 25).

\section{8}

1264, febreiro, 6. Sevilla.

Afonso X ordena ao arcebispo de Santiago de Compostela que obrigue a repartir as herdades que os veciños da cidade de Santiago teñen fóra dela e advirte que algúns que teñen parte nelas non as queren dividir.

B. ACSC, Tumbillo de Concordias, f. 36r. Copia simple.

Rex.: Ballesteros Beretta 1984: 1086 (n.o 547); González Vázquez 1996: 313; González Jiménez/Carmona Ruiz 2012: 350 (n.. 1788).

Ed.: López Ferreiro 1895: 296-297.

\section{9}

1264, febreiro, 25. Sevilla.

Afonso X ordena aos seus alcaldes Pedro Rodríguez e Pedro Cordeiro a forma en que deben actuar para establecer as herdades que son propiedade dos veciños da cidade de Santiago de Compostela.

B. ACSC, Tumbillo de Concordias, ff. 32rv e 39v-40r. Copia simple.

Rex.: Ballesteros Beretta 1984: 1086 (n. 550); González Vázquez 1996: 313; González Jiménez/Carmona Ruiz 2012: 351 (n.o 1794).

Ed.: López Ferreiro 1895: 280-281.

\section{0}

1264, febreiro, 25. Sevilla.

Afonso X ordena aos seus alcaldes Pedro Rodríguez e Pedro Cordeiro que tomen declaración ás testemuñas que dean razón sobre as herdades que son propiedade dos veciños da cidade de Santiago de Compostela.

B. ACSC, Tumbillo de Concordias, ff. 32v-33r e 40r. Copia simple. 
Rex.: Ballesteros Beretta 1984: 1086 (n.o 551); González Vázquez 1996: 313; González Jiménez/Carmona Ruiz 2012: 351 (n. 1794).

98 Ed.: López Ferreiro 1895: 281-282.

\section{1}

1264, xuño, 5. Sevilla.

Afonso X e Afonso III de Portugal acordan nomear «partidores» que delimiten as fronteiras dos seus reinos. O primeiro, para marcar a fronteira «de Sauugal ata en Mino» nomea aos bispos de Lugo e de Ourense, a don Afonso Fernández e a don Gutierre Suárez, dos que irán soamente dous, que deben reunirse cos seus colegas portugueses en Bragança oito días despois do día de Pascua de Resurrección do vindeiro ano.

B. ANTT, Chancelaría de Afonso III, Liv. III, ff. 14v-15r.

Rex.: Ballesteros Beretta 1984: 1086 (n.o 559) [Datándoo o día 15]; González Jiménez/Carmona Ruiz 2012: 355 (n.․ 1825).

Ed.: González Jiménez 1991: 312-313 (n. 285).

\section{2}

1264, xuño, 22. Sevilla.

Afonso X confirma ao mosteiro de San Cibrán de Bribes a confirmación de Fernando III de 6 de febreiro de 1232, que inclúe, na que se confirman: 1) a doazón feita por Fernando II o 12 de xuño de 1186; 2) a doazón do reguengo de Santa María de Chantada, por Afonso IX, sen data; e 3) o privilexio de acoutamento para todas as súas herdades e exención de peitas para os seus vasalos, por Afonso IX, sen data.

B. AHN, Clero, Carpeta 490, n.ํ 4. En confirmación de Xoán I de 20 de setembro de 1380.

Rex.: Sánchez Belda 1953: 336-337 (n. 773); Lucas Álvarez 1999: 909 (n. 8); González Jiménez/Carmona Ruiz 2012: 356 (n.․1829).

\section{3}

1264, agosto, 5. Sevilla.

Alfonso X, a petición do Concello de Pontevedra, «porque este priuilegio non era seellado e por mala guarda fuera dañado de agua», confirma o foral de Pontevedra concedido por Fernando II en decembro de 1169, que inclúe. 
Museo de Pontevedra, Orixinal. Pergameo, 555 x $575 \mathrm{~mm}$.

Reg.: Ballesteros Beretta 1984: 1086 (n.ํ5ㄱ e 558); González Jiménez e Carmona Ruiz (2012): 355 (n.o 1823 e 1824). Ed.: Fernández-Villamil Alegre 1942: 138-141.

Tanto Ballesteros como González Jiménez e Carmona Ruiz fan dous documentos do que é soamente un, esta confirmación do foral pontevedrés de 1169.

\section{4}

1265, xaneiro, 22. Burgos.

Afonso X confirma ao mosteiro de Santa María de Melón a doazón de tres casais na vila de Rabal feita ao mosteiro por dona Tareixa Xil.

B. ACOu, Monacais, Melón, n.ํㅜ 1822. En traslado realizado por Xoán Airas, notario de Ribadavia, de 28 de abril de 1304.

C. AHN, Códices, L. 325, f. 26rv. Copia simple dun traslado notarial de 1274.

D. AHPOu, Tumbo de frei Lourenzo Pérez de 1611, f. 237rv. Copia simple dun traslado notarial de 1274.

Rex.: Leirós Fernández 1951: 161 (n. 1822); Sánchez Belda 1953: 337 (n.ํ774); Duro Peña 1972: 99 (n.o 330 ); González Jiménez/Carmona Ruiz 2012: 361 (n.ํ1859).

Ed.: Cambón Suárez 1957: n.ํㅜ 655.

\section{5}

1265, abril, 30. Sevilla.

Afonso $X$, vistas as probas presentadas no preito sobre a igrexa de [Santa María del Cereixido de Valdeorras, sentencia que pertencía á Igrexa de Astorga, e ordena que nin Xoán Gato, nin o seu procurador, nin outra persoa a molesten sobre a dita propiedade.

B. BN, Ms. 712 , f. $138 v$.

C. BN, Ms. 4357 (Tumbo Blanco de Astorga), f. 85r.

Rex.: Cavero Domínguez/Martín López 2000: 490 (n.․1339); González Jiménez/Carmona Ruiz 2012: 364 (n.․1882).

\section{6}

1265, maio, 6. Sevilla.

Afonso X confirma ao mosteiro de Santa Comba de Órrea a exención de todo imposto real, salvo moeda, concedida ás súas monxas por Afonso IX o 3 de marzo de 1213, que inclúe. 
B. ACMd. Pergameos, n.o 90. En confirmación de Fernando IV de 9 de xuño de 1304 en confirmación de Afonso XI de 20 de abril de 1317 en confirmación deste mesmo monarca de 29 de xuño de 1332.

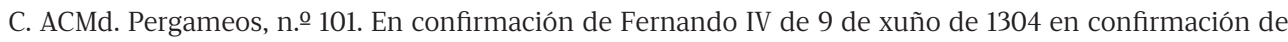
Afonso XI de 20 de abril de 1317 en confirmación deste mesmo monarca de 29 de xuño de 1332 en confirmación de Pedro I de 15 de decembro de 1351.

Rex.: Cal Pardo 1990: 49 (n.o 90); González Jiménez/Carmona Ruiz 2012: 365 (n.o 1886).

Ed.: Cal Pardo 1985: 50-61 (n.․ 2); Cal Pardo 1999: 212 e 254-255 (n.o 90 e 101).

\section{7}

1265, xuño, 4. Valladolid.

Afonso X confirma ao mosteiro de Santa Cristina de Ribas de Sil a confirmación do couto e concesión de exencións dadas por Fernando III, previa investigación, o 10 de xuño de 1231, que inclúe.

A. ACOu, Monacais, n.. 941. Orixinal. Pergameo, 480 x $387 \mathrm{~mm}$.

B. ACOu, Monacais, n.ํ 2164. En traslado realizado o 7 de maio de 1330 por Xoán de Rabal, notario de Caldelas e Trives.

Rex.: Leirós Fernández 1951: 83 (n.o 941); Duro Peña 1972: 99-100 (n.․31); Fernández Suárez 1974: n.o 13.

Ed.: Rodríguez Muñiz 2010: 114-115 (n.․15).

\section{8}

1266, febreiro, 1. Ciudad Real.

A petición do abade de San Xulián de Samos, Afonso X ordena trasladar a pergameo a súa orde de 26 de setembro de 1259 na que manda que se respecte a orde de Afonso IX de 28 de outubro de 1195, que inclúe, para que ninguén que non sexa o mosteiro teña vasalos nos coutos do cenobio.

B. AHN, Clero, Carpeta 1247, n. 4. En confirmación de Sancho IV de 3 de xullo de 1287.

C. AHN, Clero, Carpeta 1244, n.ํㅜ 1. Copia simple coetánea.

Rex.: Sánchez Belda 1953: 337 (n. 775); Ballesteros Beretta 1984: 1088 (n.o 593).

\section{9}

1266, marzo, 15. Sevilla.

Afonso X confirma ao mosteiro de Santa María de Meira a doazón de Fernando III da terra de Ribeira de Piquín e o que nela pertence ao monarca de 16 de xaneiro de 1232. 
A. AHN, Clero, Carpeta 1136, n.․ 18. Orixinal. Pergameo, 464 x 584 mm.

Rex.: Sánchez Belda 1953: 337-338 (n. 776); Ballesteros Beretta 1984: 1088 (n. 596); González Jiménez/Carmona Ruiz 2012: 368 (n.. 1908).

\section{0}

1267, febreiro, 16. Badajoz.

Afonso X de Castela, León e Andalucía e Afonso III de Portugal acordan as fronteiras entre os seus reinos.

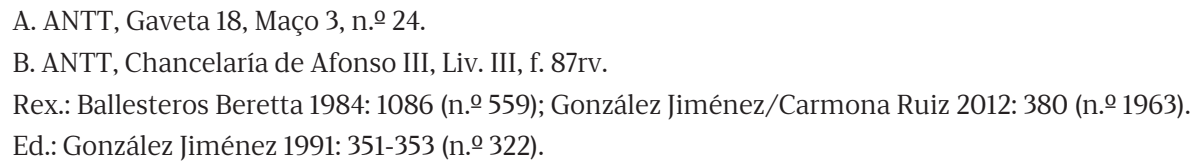

\section{1}

1267, abril, 1. Sevilla.

Afonso X, a quen os concellos de Pontevedra e doutras vilas do arcebispado de Santiago de Compostela fixeron servizo «para ayuda desta guerra», ordena que non sexan diminuídos os seus privilexios senón que se lles garden.

B. ACSC, Tumbo B, f. 111r. En traslado realizado por André Pérez e Afonso Eanes, notarios de Santiago de Compostela.

Rex.: Ballesteros Beretta 1984: 1090 (n.․ 630); González Vázquez 1996: 314; González Jiménez/Carmona Ruiz 2012: 381 (n.․․ 1990 e 1992).

Ed.: López Ferreiro 1895: 302; González Balasch 2004: 305-306 (n.․147).

\section{2}

1267, abril, 1. Sevilla.

Afonso X prohibe ao Concello de Santiago de Compostela facer «uizindades et aiuntamientos con cabaleyros et con outros omes que non son uuestros uizinos nem moran en uuestra uilla nen en uuestro lugar».

B. ACSC, Tumbillo de Concordias, ff. 44v-45r. Copia simple.

Rex.: González Vázquez 1996: 314; González Jiménez/Carmona Ruiz 2012: 381 e 387 (n.․1991 e 2037) [Datando o segundo rexesto o 1 de decembro].

Ed.: López Ferreiro 1895: 299. 


\title{
153
}

102

\author{
1267, abril, 2. Sevilla.
}

Afonso X ordena ao Concello de Santiago de Compostela que non faga xustiza salvo na maneira que se establece nos acordos e sentenzas dadas por Fernando III en 1250 e por el mesmo o 21 de febreiro de 1261 e o 9 de maio de 1263, e ordena así mesmo que obvie o mandato que lle enviou para que mantivese seguros os camiños que levan á cidade, onde «andauan muchos ladrones et robadores et malfechores» sen que os pertegueiros e meiriños o impedisen.

B. ACSC, Tumbillo de Concordias, f. 45r. Copia simple.

Rex.: Ballesteros Beretta 1984: 1090 (n. 629); González Vázquez 1996: 314; González Jiménez/Carmona Ruiz 2012: 381 (n.o 1993).

Ed.: López Ferreiro 1895: 300.

\section{4}

1267, abril, 2. Cantillana.

Afonso X ordena ao Concello de Santiago de Compostela que non inclúa nos seus «pechos» a quen fose escusado do arcebispo e do cabido.

B. ACSC, Tumbillo de Concordias, f. 45rv. Copia simple.

Rex.: Ballesteros Beretta 1984: 1091 (n.ํ 650) [Datándoo o 18 de decembro]; González Vázquez 1996: 314; González Jiménez/Carmona Ruiz 2012: 382 (n. 2001).

Ed.: López Ferreiro 1895: 300-301.

\section{5}

1267, abril, 12. Sevilla.

Afonso $X$, por denuncia da Igrexa de Lugo, ordena aos meiriños de Monforte, Sarria, Castroverde e outras vilas do bispado lucense que non demanden tributo ningún aos servizais do bispo e cóengos e que, de telos tomado, llelos devolvan.

A. ACLu, Libro 10, n. 24. Orixinal. Pergameo.

B. ACLu, Libro 10, n.ํㅗ 8. En confirmación de Sancho IV de 19 de abril de 1285 en confirmación de Xoán I de 20 de setembro de 1380.

C. ACLu, Libro 10, n.ํ 61. En confirmación de Sancho IV de 19 de abril de 1285 en confirmación de Xoán I de 20 de setembro de 1380 en confirmación de Enrique III de 12 de xullo de 1401.

D. ACLu, Atado N. ․ 5n confirmación de Sancho IV de 19 de abril de 1285 en confirmación de Xoán I de 20 de setembro de 1380 en confirmación de Enrique III de 12 de xullo de 1401 en confirmación de Xoán II de 7 de xullo de 1408. 
Rex.: Sánchez Belda 1953: 338 (n.․777); Ballesteros Beretta 1984: 1090 (n.․ 631); González Jiménez/Carmona Ruiz 2012: 379 e 382 (n. 1977 e 1998).

Ed.: Risco 1798: 374 (n.o 37); Herrera/Sánchez/González de Fauve/Zabia 1999: AGA 8v; Cañizares del Rey 2015: 278 (n. 441$)$.

\section{6}

1267, xullo, 28. Sevilla.

Afonso X ordena aos xustizas e Concello de Santiago de Compostela que non fagan xustiza salvo na maneira que se establece nos acordos e sentenzas dadas por Fernando III en 1250 e por el mesmo o 21 de febreiro de 1261 e o 9 de maio de 1263, que non ameacen aos cabaleiros, fidalgos e homes da Terra de Santiago e que, de ter algunha demanda que facerlles, a presenten aos vigairos e xuíces que corresponde.

B. ACSC, Tumbillo de Concordias, ff. 45v-46r. Copia simple.

Rex.: Ballesteros Beretta 1984: 1090 (n.o 637); González Vázquez 1996: 314; González Jiménez/Carmona Ruiz 2012: 415 (n.o 2016).

Ed.: López Ferreiro 1895: 301.

\section{7}

1267, outubro, 19. Jerez de la Frontera.

Afonso X confirma ao mosteiro de Santa María de Meira a exención de portádego outorgada por Fernando II o 27 de maio de 1159, que inclúe.

B. AHN, Clero, Carpeta 1146, n.․⒓ En confirmación de Sancho IV de 22 de febreiro de 1287 en confirmación de Afonso XI de 18 de decembro de 1331.

Rex.: Sánchez Belda 1953: 338 (n.ํ778); González Jiménez/Carmona Ruiz 2012: 386 (n.․ 2026 e 2027).

\section{8}

1268, febreiro, 15. Jerez de la Frontera.

Afonso X exime aos veciños de Lugo de ser peñorados ou encarcerados por débedas do pago do xantar ao bispo lucense.

R. AHPL, Fondo Muncipal, Resumo en Inventario dos privilexios do Concello de finais do século xIV. Rex.: García Oro 1991: 78; González Jiménez/Carmona Ruiz 2012: 391 (n.․ 2060).

Cit.: García Oro 1991: 54; Portela Silva/García Oro 1997: 265. 
1268, abril, 4. Jerez de la Frontera.

Afonso X confirma ao mosteiro de San Martiño Pinario a confirmación de Fernando III de 2 de outubro de 1232, que inclúe, do mandato polo que Afonso IX ordena que aos servizais do cenobio non se lles tomen pedidos nin marabedís, de 16 de abril de 1218 .

B. AHN, Clero, Carpeta 515, n.ํㅜ 10. En confirmación de Fernando IV de 1 de xuño de 1305 en confirmación de Afonso XI de 10 de xaneiro de 1332 en confirmación do mesmo Afonso XI de 15 de marzo de 1344.

C. AHN, Clero, Carpeta 515, n. ⒘ En traslado notarial da confirmación de Fernando IV de 1 de xuño de 1305 en confirmación de Afonso XI de 10 de xaneiro de 1332 en confirmación de Pedro I de 12 de outubro de 1365. D. AHN, Clero, Carpeta 516, n. ․ En confirmación de Fernando IV de 1 de xuño de 1305 en confirmación de Afonso XI de 10 de xaneiro de 1332 en confirmación do mesmo Afonso XI de 15 de marzo de 1344 en confirmación de Xoán I de 20 de setembro de 1380 en confirmación de Enrique III de 25 de abril de 1391.

E. AHN, Clero, Carpeta 516, n.ํㅜ 10. En confirmación de Fernando IV de 1 de xuño de 1305 en confirmación de Afonso XI de 10 de xaneiro de 1332 en confirmación do mesmo Afonso XI de 15 de marzo de 1344 en confirmación de Xoán I de 20 de setembro de 1380 en confirmación de Enrique III de 22 de xuño de 1401. F. AHN, Clero, Carpeta 515, n.ํ 6. En copia coetánea da confirmación de Afonso XI de 10 de xaneiro de 1332.

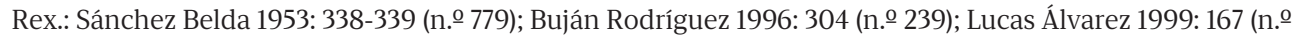
145); González Jiménez/Carmona Ruiz 2012: 394 (n.ํ 2082 e 2083).

Ed.: Lucas Álvarez 2003: 283-284 (n. 127).

\section{0}

1268, abril, 26. Jerez de la Frontera.

Afonso X, a petición e demanda dos mosteiros de Oseira, Melón, Sobrado, Meira, Montederramo, Armenteira, Oia, Monfero, Fiães, Penamaior e Xunqueira de Espadanedo, que protestan porque os concellos onde teñen propiedades lles fan pagar nas súas peitas e porque os oficiales reais lles toman así mesmo peitas e pedidos aos homes que viven nas súas herdades e coutos, ordena ao adiantado maior de Galicia que chame aos persoeiros dos concellos demandados e que, de recoñecer as acusacións dos cenobios, lles devolvan o tomado e, de non recoñecelas, que os emprace ante a corte; ordena así mesmo que os oficiais reais non tomen peitas nin pedidos aos vasalos dos mosteiros senón só como se facía en tempos de Afonso IX.

A. AHN, Clero, Carpeta 1451, n.․1․ Orixinal. Pergameo, 207 x 325 mm.

B. AHN, Clero, Carpeta 1545, n.ํㅜ 19. En confirmación de Sancho IV de 19 de abril de 1290 en confirmación de Afonso XI de 12 de marzo de 1335.

C. AHN, Clero, Carpeta 1531, n.ํㅜ 19. En traslado realizado por Xoán Domínguez, notario de Caldelas e Trives, o 26 de abril de 1281, con erro na súa data, pois dá o día 16 de abril. 
D. AHN, Clero, Carpeta 1808, n.o 16. En traslado realizado polos notarios Vidal Domínguez e Martiño Pérez, do Concello de Baiona, Xiraldo Domínguez, do Concello da Guarda, e Pedro González, escusador de Pedro Cousido, de Tui, da confirmación de Sancho IV de 9 de xuño de 1290.

E. AHN, Códices, L. 323, ff. 33v-34r. Copia simple.

Rex.: Sánchez Belda 1953: 339-341 (n. 781, 782 e 784); Pérez-Bustamante 1976: 15-16 (n.o 15, 16 e 17); Ballesteros Beretta 1984: 1092 (n.o 609 e 672); González Jiménez/Carmona Ruiz 2012: 397 (n.o 2099 e 2101).

Ed.: Cambón Suárez 1957: n.․ 695; Romaní Martínez 1989: 913-914 (n. 960).

Os tres rexestos redactados por Sánchez Belda corresponden, en realidade, a un só documento conservado nos fondos de Melón, Oia e Oseira, sendo o que corresponde a este último o rexestado como n.․784, que fai referencia aos n.. 781 e 782, non ao n.․․ 783 segundo indica o autor.

\section{1}

1268, abril, 26. Jerez de la Frontera.

Afonso X, a petición e demanda dos mosteiros de Oseira, Melón, Sobrado, Meira, Montederramo, Armenteira, Oia, Monfero, Fiães, Penamaior e Xunqueira de Espadanedo, que se queixan dos meiriños da terra e dos nobres, que quebrantaban os seus dereitos, ordena ao adiantado maior de Galicia: 1) que non esixa aos citados mosteiros en concepto de xantar máis de vinte marabedis anuais, cando fose persoalmente a cada un deles, segundo se acostumaba anteriormente; 2) que prohiba aos meiriños e mordomos dos ricoshomes esixir prestacións nos abadengos; e 3) que impida aos nobres os abusos de poder cos que forzaban os coutos dos mosteiros nos casos citados na carta.

B. AHN, Clero, Carpeta 1803, n. ․ En traslado realizado por Durán Pérez, notario de Tui, o 14 de xaneiro de 1276. Rex.: Sánchez Belda 1953: 340-341 (n.ํ783); González Jiménez/Carmona Ruiz 2012: 397 (n.ํ2100).

\section{2}

1268, agosto, 6. Sevilla.

Afonso X sentencia o preito que mantén o mosteiro de Santa María de Ferreira de Pallares cos veciños das freguesías de San Pedro de Vilaxuste, San Cibrao de Nespereira e San Salvador de Guntín sobre os deberes destes para co cenobio, no que estipula o seguinte: 1) o mosteiro recibirá dous soldos de cada habitante por razón de xantar, e un de cada viúva, e tres carneiros anuais por freguesía por razón de hospedaxe; 2) o mosteiro tomará baixo a súa protección e amparo aos fregueses; 3) que os veciños «non les uayan a boz nin querelloso nin les fagan responder a ella sinon en muerte o en feridas de omme o en furto o en casa quemada o en quebrantamiento della o en robo o en rosso o en fuerça de mujer»; 4) que tampouco acudan «en assonada» salvo para amparar ao mosteiro; 5) condena ao abade nas custas do xuízo; e 6) ordena ao adiantado don Estevo Fernández que devolva ao mosteiro os bens tomados en peñor polo xuízo. 
A. AHN, Clero, Carpeta 1091, n. 3. Orixinal. Pergameo, 335 x 233 mm.

B. AHN, Clero, Carpeta 1102, n. o 8. En confirmación de Pedro I de 20 de marzo de 1353.

C. AHN, Clero, Carpeta 1091, n.․5 5. En traslado realizado por Pedro Martínez, notario en terra de Pallares, o 16 de xuño de 1307.

D. AHN, Clero, Carpeta 1101, n. 3. En traslado realizado o 13 de xuño de 1341 por Fernando Pérez, notario de Lugo, da confirmación dada por Afonso XI o 5 de xuño de 1336.

E. AHN, Clero, Carpeta 1091, n. 4. Copia simple coetánea.

Rex.: Sánchez Belda 1953: 341-342 (n. 785); Ballesteros Beretta 1984: 1092 (n. 681); González Jiménez/Carmona Ruiz 2012: 399 (n. 2112).

Ed.: Rey Caíña 1985: 600-603 (n. 229); Herrera/Sánchez/González de Fauve/Zabia 1999: AGA 9r.

\section{3}

1269, febreiro, 10. Valladolid.

Afonso X ordena a Lope Díaz de Rojas e a Xoán Hurtado de Mendoza, os seus meiriños maiores no reino de Galicia, que non esixan preitos nin pedidos aos vasalos do mosteiro de Santa María de Monfero.

B. AHN, Clero, Carpeta 501, n.요 8. En traslado notarial realizado no século XIV.

Rex.: Sánchez Belda 1953: 342 (n.․ 786); López Sangil 2002: 686; González Jiménez/Carmona Ruiz 2012: 402 (ก.․ㅡ 2133).

\section{4}

1269, agosto, 8. Toledo.

Afonso X confirma á Igrexa e ao bispo de Lugo a confirmación xenérica dos seus privilexios realizada por Fernando III o 10 de marzo de 1231, que inclúe.

A. ACLu, Atado 5. Orixinal. Pergameo.

B. ACLu, Atado 2, n. 10 . En traslado notarial do século XIII.

C. ACLu, Libro 10, n. 26. En traslado notarial de 1313.

Rex.: Sánchez Belda 1953: 342 (n. 787); Ballesteros Beretta 1984: 1094 (n.o 709); González Jiménez/Carmona Ruiz 2012: 407 (n. 2165).

Ed.: Cañizares del Rey 2015: 285-287 (n. 446). 


\section{5}

1270, marzo, 17. Sevilla.

Afonso X confirma ao mosteiro de Santo Antoniño de Toques a confirmación xenérica de todos os seus bens e privilexios feita por Fernando III o 5 de novembro de 1231, que inclúe.

Rex.: Lucas Álvarez 2001: 285 (n.. 7).

\section{6}

1270, maio, 12. Burgos.

Afonso $X$ dá á Igrexa de Lugo o reguengo de Santa Mariña de Ramil, con catro servizais para que o labren, a cambio das propiedades da Igrexa no lugar de Santa María de Valonga, onde fundou a Pobra de Luaces a petición dos homes da terra; doa tamén á catedral lucense a igrexa da vila e de calquera outra igrexa que se levantase nela, así como un soar para o bispo e outro para o cabido.

A. ACLu, Libro 10, n.ํㅜ 25. Orixinal. Pergameo.

Rex.: Sánchez Belda 1953: 342-343 (n.ํ 788); Ballesteros Beretta 1984: 1096 (n.ํ744); González Jiménez/Carmona Ruiz 2012: 419 (n.. 2238).

Ed.: Risco 1798: 375-376 (n. 38); CDH-RAG 1915: 153-154 (n. 47); Herrera/Sánchez/González de Fauve/Zabia 1999: AGA 6v [Datándoo en 1260].

\section{7}

1270, maio, 13. Burgos.

Afonso X confirma ao mosteiro de Santo Estebo de Chouzán a confirmación de Fernando III de 21 de abril de 1232, que inclúe, da exención de entrada de calquera oficial rexio no couto monástico así como de pedido real aos homes do mosteiro concedida por Afonso IX o 11 de febreiro de 1213.

A. AHUSC, Clero, Pergameos, Col. Blanco Cicerón, n. 126. Orixinal. Pergameo, 460 x 570 mm.

B. AHN, Clero, Carpeta 521, n. 19. En traslado realizado polo notario Rodrigo Pérez.

C. AA, Pergameos, Santo Estevo de Chouzán, Mazo 1A, n.우 9. En traslado realizado polo notario [...] Fernández en 1271.

Rex.: Sánchez Belda 1953: 343 (n.․ 789); Buján Rodríguez 1996: 20 e 223 (n.․ 17 e 303); González Jiménez/ Carmona Ruiz 2012: 419 (n.․2 2239).

Ed.: Pichel Gotérrez 2009: 182-188 (n.․44). 


\section{8}

1270, xullo, 15. A Proba de Burón.

108

Don Fernando de la Cerda ordena aos concellos e meiriños de Galicia e Asturias que garden os privilexios do mosteiro de Santa María de Villanueva de Oscos.

A. AHN, Clero, Carpeta 1635, n. 20. Orixinal. Pergameo, 2340 x 140 mm.

Rex.: Ballesteros Beretta 1984: 1097 (n. 765); Álvarez Castrillón 2007: 394 (n.o 171); González Jiménez/Carmona Ruiz 2012: 614 (n. 3406).

Ed.: Ruiz de la Peña Solar 2007: 350-351 (n. 2); Pardo Rodríguez 2009: 142-143 (n.o 8).

\section{9}

1270, xullo, 24. Santiago de Compostela.

Don Fernando de la Cerda, no preito que mantén o mosteiro de San Xulián de Samos con Fernando Pérez, fillo de Rodrigo Rodríguez de Sarria, e Pedro Rodríguez de Sarria, que pretendian ter dereito a ter amos e vasalos nos habitantes do couto monástico, ditamina a favor do mosteiro.

A. AHN, Clero, Carpeta 1244, n. ⒖ Orixinal. Pergameo, 195 x 210 mm.

Rex.: Sánchez Belda 1953: 343-344 (n. 790); Ballesteros Beretta 1984: 1097 (n.ํ 767); González Jiménez/Carmona Ruiz 2012: 615 e 625 (n.o 3407 e 3469) [Datando o segundo o 4 de xullo de 1275 e dando como unha das partes a don Fernando Pérez de Castro].

Ed.: Pardo Rodríguez 2009: 143-144 (n.ㅇ 9).

\section{0}

1270, decembro, 30. Guadalajara.

Afonso $X$, a petición dos homes das terras de Pruzos e Bezoucos, funda a vila de Pontedeume, á que dá o foral de Benavente, e demarca o seu termo.

En confirmación de Fernando IV de 5 de marzo de 1306 en confirmación de Afonso XI de 24 de xullo de 1345. Rex.: González Jiménez/Carmona Ruiz 2012: 430 (n. 2307).

Ed.: López Ferreiro 1901: 161-169 (n. 34). 


\section{1}

1271, xuño, 19. Murcia.

Afonso X comunica ao bispo de Mondoñedo que o Concello do Castro de Ouro presentou contra el unha demanda por usurpar as herdades de Trasrío, Vilabona e a que pertenceu a Osorio Díaz, e dálle prazo para nomear un procurador que compareza ante os alcaldes da corte.

Rex.: Sánchez Belda 1953: 344 (n.o 791); Mayán Fernández (1994): 100; González Jiménez/Carmona Ruiz 2012: 435 (n.․ 2238 e 2239).

Este documento atópase nun dos cartularios da catedral de Mondoñedo que hoxe se custodian no AHN en dúas copias, das cales, segundo Sánchez Belda, polo menos unha é do século XV, tendo datas distintas: 17 e 19 de xuño de 1271. A primeira é a tomada por Mayán e a segunda por Sánchez Belda, e deron así orixe aos dous rexestos do mesmo documento ofertados por González Jiménez e Carmona Ruiz.

\section{2}

1271, agosto, 10. Murcia.

Relación de bens, lugares e rendas recibidos pola Orde de San Xoán do Hospital de Afonso X a cambio das vilas de Serpa, Moura e Mourão, entre os que se inclúen, en Galicia, a igrexa de Santa María de Castrelo de Miño e o portádego e os dereitos da terra de Quiroga, salvo moeda e xantar.

B. ANTT, Gaveta 14, Maço 1, n.․ 9. Inserto no cambio entre Afonso X e a Orde de San Xoán do Hospital de 11 de marzo de 1281.

Ed.: González Jiménez 1991: $402-403$ (n.. 382); De Ayala Martínez (ed.) 1995: 564-566 (n.o 345); García Tato 2004: 182-183 (n. 0 83).

\section{3}

1271, decembro, 17. Murcia.

Afonso $X$, a petición do bispo de Mondoñedo, traslada a pergameo a súa orde de 9 de outubro de 1258 sobre o pago de portádego aos concellos de Viveiro e Ribadeo.

B. ACMd. Pergameos, n.o 42. Orixinal. Pergameo, 172 x 270 mm.

Rex.: Ballesteros Beretta 1984: 1099 (n. 810); Cal Pardo 1990: 30 (n. 42); González Jiménez/Carmona Ruiz 2012: 441 (n.․2 2379).

Ed.: Cal Pardo 1999: 100 (n.․42). 


\section{4}

110

1271, decembro, 25. Murcia.

Afonso X, por denuncia do bispo de Mondoñedo, ordena ao adiantado maior de Galicia, don Estevo Fernández, e a todos os seus meiriños que obriguen a pagar a martiñega a todos aqueles homes do bispo mindoniense que deben facelo.

B. ACMd. Pergameos, n. 43 . En traslado realizado por orde do mesmo Afonso X para pasalo de papel a pergameo de 13 de febreiro de 1274.

Rex.: Ballesteros Beretta 1984: 1099 (n. 813); Cal Pardo 1990: 31 (n. 43); González Jiménez/Carmona Ruiz 2012: 441 (n. $\underline{\text { 2377)}}$.

Ed.: Cal Pardo 1991: 84; Cal Pardo 1999: 101 (n.o 43); Herrera/Sánchez González de Fauve/Zabia 1999: AGA 10v. Todas as edicións e rexestos datan este documento o día 25 de decembro a pesar de que, nas primeiras, se transcribe: Dada en Murçia veynt e çinco dias de deçembre.

\section{5}

1272, xaneiro, 18. Murcia.

Afonso X, por denuncia da Igrexa de Mondoñedo, ordena ao adiantado maior de Galicia, don Estevo Fernández, que prohiba a calquera meiriño real tomar tributo nos lugares da Igrexa mindoniense, excepto cando o mesmo adiantado se presente neles, unha vez por ano, a facer xustiza, así como que fagan pescudas xerais nos ditos lugares e que entren neles, salvo aos catro casos de corte.

B. ACMd. Pergameos, n.ํㅜ 59. En confirmación de Sancho IV de 27 de agosto de 1278 en traslado ordenado polo mesmo Sancho IV para pasar o diploma de papel a pergameo de 13 de maio de 1282 en confirmación de Fernando IV de 8 de febreiro de 1305.

C. ACMd. Pergameos, n.ํ 88. En confirmación de Sancho IV de 27 de agosto de 1278 en traslado ordenado polo propio Sancho IV para pasar o diploma de papel a pergameo de 13 de maio de 1282 en confirmación de Fernando IV de 8 de febreiro de 1305 en confirmación de Afonso XI de 20 de setembro de 1329.

D. ACMd. En traslado en papel da confirmación de Fernando IV realizado o 19 de outubro de 1308 por Afonso Eanes, notario de Mondoñedo.

Rex.: Cal Pardo 1990: 36 (n.․5); González Jiménez/Carmona Ruiz 2012: 473 (n.o 2601).

Ed.: Cal Pardo 1999: 132-133 (n. 59) e 206-208 (n.o 88).

Moi probablemente este documento se trate así mesmo do rexestado por González Jiménez/Carmona Ruiz 2012: 442 (n. 2386), que datan o 21, sen mes, de 1272. 


\section{6}

1272, febreiro, 24. Murcia.

Afonso X confirma a sentenza de Fernando III de 17 de febreiro de 1251 sobre o foral da freguesía de San Cristovo de Lestedo e os impostos que deben pagar.

A. AHN, San Marcos, Carpeta 375, n.o 61.

Ed.: Novo Cazón 1986: 250-251 (n. 46).

\section{7}

1272, setembro, 15. Burgos.

Afonso X confirma a mosteiro de Santa María de Oia a exención de portádego e de todo pago que deberan pagar as barcas que leven pan, viño, sal e outras vituallas ao dito mosteiro concedida por Afonso IX o 16 de xaneiro de 1213, que inclúe.

Ed.: Herrera/Sánchez/González de Fauve/Zabia 1999: AGA 9v.

Este documento que, segundo as editoras, se conserva no Arquivo da Catedral de Tui, no Fondo de Curia Diocesana, non se cita en ningún outro lugar, e tampouco o diploma que confirma, dado no mesmo mosteiro de Oia, que encaixa ben no itinerario de Afonso IX, quen concede o 8 de xaneiro unha doazón en Santiago de Compostela e o día 29 outra na vila de Milmanda (González González 1944, t. 2, 385-386).

\section{8}

1272, setembro, 21. Burgos.

Afonso X confirma a mosteiro de Santa María de Oia, a petición do seu abade, o privilexio de nomear xuíces nos seus coutos que xulguen os preitos aos seus habitantes, privilexio do que gozaba o mosteiro desde tempos de Afonso IX.
A. AHN, Clero, Carpeta 1803, n.․⒔ Orixinal. Pergameo, 185 x 197 mm.
B. AHN, Clero, Carpeta 1821, n.ํㅜ 11. En confirmación de Afonso XI de 25 de outubro de 1318.
C. AHN, Clero, Carpeta 1803, n.ํㅜ 14. En traslado realizado por Francisco Fernández, notario de Baiona e Val de Miñor.
Rex.: Sánchez Belda 1953: 344 (n.o 792); Ballesteros Beretta 1984: 1101 (n.o 854); González Jiménez/Carmona

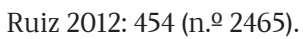
Ed.: Herrera/Sánchez/González de Fauve/Zabia 1999: AGA 10r. 
Afonso X confirma ao mosteiro de Santa María de Oia a doazón de Afonso IX de 15 de agosto de 1219, que inclúe, da aldea de Burgueira.

ARCV, Pergameos, Carpeta 98, n.으.

Ed.: Herrero Jiménez 2004: n.ำ 73.

\section{0}

1272, novembro, 16. Santiago de Compostela.

O infante don Sancho, alférez e almirante da confraría de Santa María de España, ordena aos que teñan por el os celeiros de Laias, Chamosiños, Raposeira e Vimieiros, sobre os que o cabido compostelán debe recibir anualmente douscentos marabedís e segundo o seu pai lle mandou pagarlle, que satisfagan esa cantidade e que lla entreguen anualmente, a partir de agora, o día de Pascua de Resurrección.

B. ACSC, Tumbo B, f. 282r. En traslado realizado por André Pérez e Afonso Eanes, notarios de Santiago de Compostela.

Rex.: Ballesteros Beretta 1984: 1102 (n. 871); González Vázquez 1996: 315; González Jiménez/Carmona Ruiz 2012: 653 (n. 3469); Hernández 2021: v. 2, n. 3.

Ed.: López Ferreiro 1902: 110 (n. 40); Torres Fontes 1977: 96 (n.ํ 1); González Balasch 2004: $643-644$ (n.o 358 ).

\section{1}

1272, decembro, 18. Madrid.

Afonso X comunica ao bispo de Mondoñedo ter recibido a denuncia do abade de San Salvador de Vilanova de Lourenzá acusando a don Manrique Xil de expulsalos, a el e aos seus monxes, do mosteiro, usurpando as súas propiedades, e ordena ao citado bispo que restitúa ao abade e monxes na posesión do mosteiro.

B. AHN, Códices, L. 6622, ff. 156-159. Inserto na orde do bispo de Mondoñedo a don Marique Xil de 11 de febreiro de 1273 .

Rex.: Sánchez Belda 1953: 344-345 (n. 793); Ballesteros Beretta 1984: 1102 (n.o 874); González Jiménez/Carmona Ruiz 2012: 459-460 (n.․2 2502). 


\section{2}

1272, decembro, 20. Madrid.

Afonso $X$ ordena aos seus oficiais no reino de León que axuden ao escudeiro Sancho Suárez, enviado do rei de Aragón, e ao seu porteiro, Xoán Fernández, a recibir os bens que a falecida dona Berenguela Afonso tiña en León e Galicia á hora da súa morte.

B. ACOu, Monacais, n. 2086. En entrega do casal de Santa Cristina de Quiroga polo escudeiro Sancho Suárez realizada o 16 de marzo de 1273 no Burgo de Caldelas.

Rex.: Leirós Fernández 1951: 95 (n.․1086); Duro Peña 1972: 100 (n.․ 332).

Ed.: Lorenzo 2016: 473-474 (n.. 303).

\section{3}

1272, decembro, 24. Allariz.

O infante don Sancho sentencia o preito entre o mosteiro de Santa María de Melón e Estevo Rodríguez, veciño de Ribadavia, pola posesión dun casal no couto de Domaio, vendido por este ao abade e do que non puido tomar posesión por telo usurpado Rodrigo Arias. Condénase a Estevo Rodríguez a entregar o casal, a pagar oito moios pola renda non cobrada polo abade durante os catro anos que duraba o preito e a indemnizalo, polas custas, con sesenta marabedís da guerra.

A. AHN, Clero, Carpeta 1451, n.․ㅜ 19. Orixinal. Pergameo, 165 x 380 mm.

B. AHN, Códices, L. 325, ff. 519r-520r. Copia simple.

Rex.: Sánchez Belda 1953: 345 (n.o 794); Ballesteros Beretta 1984: 1102 (n. 877); González Jiménez/Carmona Ruiz 2012: 653 (n. 3470); Hernández 2021, v. 2, n.o․ 4.

Ed.: Cambón Suárez 1957: n.o 729; Torres Fontes 1977: 97-98 (n.․ 2).

\section{[183bis]}

1273, febreiro, 6. Villamayor.

«Carta do infante don Fernando, fillo de Afonso X, aos meiriños para que se respecte o privilexio que ten o mosteiro de Santa María de Meira dado por El-Rei don Fernando».

Rexestado por Ballesteros Beretta 1984: 1102 (n. 80), é a única mención que coñezo deste diploma, do que non dan noticia nin Pardo Rodríguez 2009 nin González Jiménez/Carmona Ruiz 2012. Segundo Ballesteros, conservaríase no AHN, no fondo documental correspondente a Santa María de Meira. 


\section{4}

114

1273, abril, 6. Burgos.

Afonso X ordena ao adiantado maior de Galicia que faga respectar o dereito do mosteiro de Santa María de Oia a nomear xuíces nos seus coutos, seguindo o ditado polo mesmo monarca o 21 de setembro de 1272.

B. AHN, Clero, Carpeta 1803, n.ํㅜ 18. Copia simple realizada no século XIV.

Rex.: Sánchez Belda 1953: 345-346 (n. 795); Pérez-Bustamante 1976: 17 (n. 21); Ballesteros Beretta $1984: 1103$ (n.o 886); González Jiménez/Carmona Ruiz 2012: 463 (n.․2526).

Ed.: Fernández Rodríguez 2004: 231 (n.ํㅜ 12).

\section{5}

[1274].

O infante don Fernando de la Cerda, por denuncia de dona Moor Afonso, ordena aos abades de Santa María de Ferreira de Pallares e Santa María de Aciveiro investigar sobre o roubo de pan e gando realizado nas propiedades da dona por Ares González, fillo de Gonzalo Pérez de Borraxeiros, e os seus homes o 1 de decembro de 1273. Á vista da pescuda, o infante ditamina a favor de doña Moor, ordenando que Ares González lle devolva o valor do roubado.

Noticia na sentenza definitiva do preito dada por Afonso X o 18 de xullo de 1277.

Rex.: Sánchez Belda 1953: 349 (n.o 805); Pardo Rodríguez 2009: 231 (n.․57); González Jiménez/Carmona Ruiz 2012: 625 (ก.․ 3465).

\section{6}

1274, febreiro, 13. Burgos.

Afonso X, a petición do bispo de Mondoñedo, traslada a pergameo a súa orde de 25 de decembro de 1271 sobre o pago do tributo dos homes do bispo de Mondoñedo.

A. ACMd. Pergameos, n.ํ 43. Orixinal. Pergameo, 205 x 235 mm.

Rex.: Ballesteros Beretta 1984: 1104 (n.o 919); Cal Pardo 1990: 31 (n.o 43); González Jiménez/Carmona Ruiz 2012: 473 (n. $\underline{0}$ 2601).

Ed.: Cal Pardo 1991: 84; Cal Pardo 1999: 101-102 (n. 43); Herrera/Sánchez/González de Fauve/Zabia 1999: AGA 10v. 


\section{7}

1274, abril, 13. Palencia.

Afonso X, a petición do mosteiro de Santa María de Montederramo, ordena que non lle sexan peñoradas as vacas «que andaren cerca de su monesterio para su guarda et para adobo de su conuento».

A. ACOu, Monacais, n.ำ 1133. Orixinal. Pergameo, 185 x 140 mm.

Rex.: Leirós Fernández 1951: 99 (n. 1133); Duro Peña 1972: 100 (n. 333).

Ed.: Lorenzo 2016: 496-497 (n. 326$)$.

\section{8}

1274, abril, 15. Palencia.

Afonso X, por prometerlle o Concello de Tui, coma outros concellos do reino de León, darlle cada ano un servizo «que montasse tanto como una moneda», e por comprometerse a entregarlle o servizo de dous anos, «de lo que auemos mucho mester para fecho del Imperio», exímeo para sempre do pago de servizos.

\section{A. ACT. Pergameos 5, n.o 9. Orixinal. Pergameo.}

Rex.: Ballesteros Beretta 1984: 1105 (n.o 932); González Jiménez/Carmona Ruiz 2012: 478-479 (n. 2639).

Ed.: Ballesteros Beretta 1918: 74; Herrera/Sánchez/González de Fauve/Zabia 1999: AGA 11r.

Este documento é tamén o rexestado por González Jiménez/Carmona Ruiz: 478 (n.o 2638), pero como concedido ao Concello de Pontevedra. Segundo estes autores, trátase dun orixinal do Arquivo da Catedral de Tui, «Libro 5. de privilexios reais», mentres que o do Concello tudense é, como se recolle, o n. 9 da carpeta n. 5 de Pergameos.

\section{9}

1274, abril, 16. Palencia.

Afonso $X$ doa ao mosteiro de San Salvador de Celanova a metade da igrexa que «agora nuevamente mandé fazer en la mi puebla» de Monterrei, e reserva a presentación da outra metade.

B. AHN, Clero, Carpeta 1431, n.o 16. En traslado autorizado o 25 de xaneiro de 1338 por Rodrigo Afonso, alcalde de El-Rei no adiantamento de Galicia, de confirmación de Sancho IV de 1 de maio de 1291. C. AHN, Clero, Carpeta 1433, n.o 1. En confirmación de Fernando IV de 25 de maio de 1300. Rex.: Sánchez Belda 1953: 346 (n.. 796); Ballesteros Beretta 1984: 1105 (n.․ 933); González Jiménez/Carmona Ruiz 2012: 479 (n.. 2641).

Ed.: Ballesteros Beretta 1918: 74-75; Vaquero Díaz 2004: 107-108 (n. 67). 


\section{0}

116

1274, abril, 17. Palencia.

Afonso X exime para sempre ao mosteiro de Santa María de Monfero do servizo que debía pagarlle anualmente, en recoñecemento por prometerlle dar un servizo «que montasse tanto como una moneda», e que lle pagaría dunha vez o servizo de dous anos, «que era cosa que aviamos mucho mester para fecho del Imperio».

A. AHN, Clero, Carpeta 501, n. ํㅜ 10. Orixinal. Pergameo, 200 x 220 mm.

Rex.: Sánchez Belda 1953: 346 (n.o 797); Ballesteros Beretta 1984: 1105 (n. 934); López Sangil 2002: 686; González Jiménez/Carmona Ruiz 2012: 479 (n.ํ264).

Ed.: Herrera/Sánchez/González de Fauve/Zabia 1999: AGA 11v.

\section{1}

1274, abril, 21. Palencia.

Afonso $X$ exime aos veciños de Lugo do pago de portádego nos reinos de Castela e León, en especial en Vilafranca do Bierzo e nos portos do Cantábrico.

Rex.: González Jiménez/Carmona Ruiz 2012: 480 (n.․2 2645).

Cit.: García Oro 1991: 54; Portela Silva/García Oro 1997: 266.

\section{2}

12[74], abril, 23. Palencia.

Afonso X exime para sempre ao mosteiro de Santa María de Oseira do servizo que debía pagarlle anualmente, en recoñecemento por prometerlle dar un servizo «que montasse tanto como una moneda», e que lle pagaría dunha vez o servizo de dous anos, «que era cosa que aviamos mucho mester para fecho del Imperio».

B. AHN, Códices, L. 1008 B, f. 9rv. Copia simple.

Rex.: Sánchez Belda 1953: 346-347 (n.o 798); Ballesteros Beretta 1984: 1106 (n. 946) [Datándoo no mes de maio]; González Jiménez/Carmona Ruiz 2012: 483 (n.․ 2666).

Ed.: Ballesteros Beretta 1918: 76-77; Romaní Martínez 1989: 1013 (n. 1064). 


\section{[192bis]}

1274, xuño, 26. Santo Estevo de Chantada.

décimos».

«Carta de don Afonso X ao cóengo de Lugo sobre a recadación de

Así rexestado por Ballesteros Beretta 1984: 1106 (n.ํ 949), debe tratarse en realidade da concesión ante o cóengo lucense Fernando Afonso, vigairo do deádego, por parte de dous párrocos a un racioneiro do mosteiro de Chantada do décimo do casal de Centulle, con data de 16 de xuño de 1274 (Méndez Pérez/Otero Piñeyro Maseda/Romaní Martínez 2016: 207 (n. 18).

\section{3}

1274, outubro, 25. Burgos.

O infante don Sancho ordena ao seu home Xoán Gato que afore os casais reguengos e ermos que haxa na terra que ten por El-Rei en Galicia.

B. ACOu, Monacais, n.ํㅜ 1239. En foro realizado por Xoán Gato, por orde do infante don Sancho e de El-Rei Afonso X, ao mosteiro de Montederramo do monte dos Eirós, na freguesía de Santa María de Cesuris, o 20 de marzo de 1276 .

Rex.: Leirós Fernández 1951: 109 (n. 1239); Duro Peña 1972: 100 (n. 334); Hernández 2021, v. 2, n.o 5.

Ed.: Lorenzo 2016: 543 (n. 373 ).

\section{4}

1275, marzo, 19. Perpiñán.

Afonso X, a solicitude do infante don Sancho, ordena a Xoán Gato, home do infante, que afore os casais reguengos e ermos que haxa na terra que don Sancho ten por el en Galicia.

B. ACOu, Monacais, n.ํㅜ 1239. En foro realizado por Xoán Gato, por orde do infante don Sancho e de El-Rei Afonso X, ao mosteiro de Montederramo do monte dos Eirós, na freguesía de Santa María de Cesuris, o 20 de marzo de 1276.

Rex.: Leirós Fernández 1951: 109 (n. 1239); Duro Peña 1972: 100 (n. 335); Hernández 2021, v. 2, n.o 7.

Ed.: Lorenzo 2016: 543 (n. $\underline{\text { o } 373) . ~}$ 


\section{5}

118

Alfonso X confirma á vila da Coruña a orde de Fernando III de 29 de xuño de 1249 na que manda que non entre meiriño ningún nin na vila nin no seu alfoz, incluído don Munio Fernández.

B. AHMAC, Privilexios, no 3. En confirmación de Sancho IV de 4 de setembro de 1286.

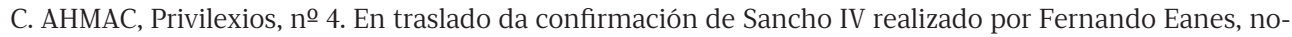
tario da Coruña.

Ed.: González Garcés 2008: 487-490.

González Garcés data o documento o 16 de marzo de 1281 por ler era de mill et CCC et XVIIII anos cando, na miña opinión e grazas á reprodución do documento que inclúe na edición, pode lerse mill e CCC e XIIII, isto é, 1276, data que se adecúa ao itinerario do monarca, quen pasou o mes de marzo de 1276 en Valladolid, pois o de 1281 estivo por terras sorianas (González Jiménez/Carmona Ruiz 2012: 79 e 86).

\section{6}

1276, abril, 20. Burgos.

Afonso X, a petición do mosteiro de Santa María de Montederramo e previa investigación feita por Xoán Gato, home do infante don Sancho, cambia catro «yuguerías» cerca do cenobio -dúas en Nogueira, unha en Retorta e outra en Escuadro-por cinco do mosteiro nos lugares de Casar do Mato, Sas do Monte, Bustelos, Resoio e Quintela.

A. ACOu, Monacais, n. $\underline{0}$ 6248. Orixinal. Pergameo, 180 x $215 \mathrm{~mm}$.

Rex.: Leirós Fernández 1951: 550 (n.o 6248); Duro Peña 1972: 101 (n. 336); González Jiménez/Carmona Ruiz 2012: 499 (n.․ 2771).

Ed.: Herrera/Sánchez/González de Fauve/Zabia 1999: AGA 12r; Lorenzo 2016: 544-545 (n.o 374).

\section{7}

1276, novembro, 14. Pobra de Valdeorras.

O infante don Sancho confirma ao mosteiro de Santa María de Melón a vixésima parte dos froitos e rendas do celeiro real de Castrelo de Miño, tal e como llo concedera Afonso IX e confirmado despois tanto Fernando III como Afonso X, e recibe ao mosteiro «en mi guarda e en mi comenda segund dize en una carta abierta que de mi tienen sobre esta razon».

A. ACOu, Monacais, n. 1249 . Orixinal. Pergameo, 232 x $260 \mathrm{~mm}$.

B. AHN, Clero, Carpeta 1452, n.․ㅜ 12. En traslado realizado o 5 de xullo de 1278 por Pedro Rodríguez, notario de Ribadavia. 
C. AHN, Códices, L. 324, ff. 265v-266r e 279rv. Copia simple.

D. AHPOu, Tumbo de frei Lourenzo Pérez de 1611, f. 187rv. Copia simple.

Rex.: Leirós Fernández 1951: 110 (n.o 1249); Sánchez Belda 1953: $347-348$ (n.o 801); Duro Peña 1972: 101 (n.o 338); Ballesteros Beretta 1984: 1110 (n.․1028); González Jiménez/Carmona Ruiz 2012: 654 (n.o 3477); Hernández 2021, v. 2, n. 15 .

Ed.: Cambón Suárez 1957: n.․․ 768.

\section{8}

1276, novembro, 28. Astorga.

O infante don Sancho, á vista da confirmación de Afonso X da doazón de Afonso IX á Igrexa de Astorga de varias igrexas reguengas na súa diocese, así como a sentenza emitida por Afonso X, favorable á dita Igrexa, de 30 de abril de 1265, sobre a igrexa de Santa María de Cereixido de Valdeorras, que tomara o infante, devólvea á Igrexa asturicense.

A. ACAst.: 1-24. Orixinal. Pergameo, 185 x $250 \mathrm{~mm}$.

B. BN, Ms. 713, f. 247.

Rex.: González Jiménez/Carmona Ruiz 2012: 654-655 (n. 3478); Hernández 2021, v. 2, n.o 16.

Ed.: Cavero Domínguez/Martín López 2000: $511-512$ (n. 1385).

\section{9}

1277, abril, 13. Burgos.

Afonso X intervén nun preito entre o mosteiro de San Vicente de Monforte e os homes do couto de Ande. Ordena que os que teñen herdades no couto as manteñan pero que non as poidan vender senón a homes do dito couto. Ademais, deben dar ao mosteiro martiñega, tres xantares de seis soldos «della bona moneda», fonsadeira «cuando el rey la echare», loitosa e «raysa», e os outros foros que daban en tempos de Afonso VIII e Fernando III.

Rex.: Ballesteros Beretta 1984: 1111 (n. 1043); González Jiménez/Carmona Ruiz 2012: 513 (n.․2 2863).

Copio exactamente o rexesto, traducíndoo ao galego, ofertado por González Jiménez e Carmona Ruiz, que din que a carta de El-Rei está copiada na sentenza do xuíz Xoán Díaz de 18 de agosto de 1285, remitindo, como fai tamén Ballesteros, a un Arquivo do Mosteiro de San Vicente de Monforte actualmente inexistente. 
Afonso $X$ ordena que no se tomen tributos reais aos monxes e aos vasalos do mosteiro de Santa María de Montederramo.

B. AHN, Clero, Carpeta 1493, n.o 5. En confirmación de Sancho IV de 4 de febreiro de 1291 en confirmación de Afonso XI de 16 de decembro de 1311.

Rex.: Sánchez Belda 1953: 348 (n.o 802); González Jiménez/Carmona Ruiz 2012: 513 (n. 2864).

R. Lorenzo 2016: 1263-1264 (n. o 1015) edita a confirmación de Afonso XI de 1311, se ben o resumo que presenta deste documento non se corresponde co texto que se confirma, que se refire exclusivamente ao mosteiro de Montederramo, e non ao conxunto de mosteiros cistercienses galegos. O dito resumo tómao do que se fai o 12 de xuño de 1334, cando o abade de Montederramo presentou un documento de Afonso X confirmado por Sancho IV (Lorenzo 2016: 1332 (n. 1077), que debe tratarse do concedido polo Rei Sabio aos mosteiros cistercienses galegos de 26 de abril de 1268 en relación cos concellos do reino galego.

\section{1}

1277, abril, 23. Burgos.

Afonso X, a petición dos abades cistercienses de Galicia, ordena aos colledores das peitas reais en terra de León e Galicia que non arrenden esa función a persoas subalternas polo que respecta aos vasalos e lugares dos citados mosteiros para evitar os danos e perdas que a estes se lles producía con tal sistema.

B. AHN, Clero, Carpeta 544, n.ํㅜ 3. En copia simple coetánea de confirmación de Sancho IV de 12 de febreiro de 1286.

C. AHN, Clero, Carpeta 544, n.․ 4. En traslado da confirmación de Sancho IV de 12 de febreiro de 1286 realizado polo notario Pedro Martínez (século XIV).

Rex.: Sánchez Belda 1953: 348-349 (n.o 803); Ballesteros Beretta 1984: 1111 (n.․1044); González Jiménez/Carmona Ruiz 2012: 513 (n. 2865).

\section{2}

1277, abril, 23. Burgos.

Afonso X, a petición dos abades cistercienses de Galicia, ordena aos concellos das pobras de Galicia e Asturias que non esixan tributos rexios nin municipais aos vasalos deses cenobios.

B. AHN, Clero, Carpeta 1627, n.․ 12-1. En traslado realizado polo escusador do notario de Ribadeo o 21 de decembro de 1289.

Rex.: Duro Peña 1972: 101 (n. 337); Álvarez Castrillón (2007): 398 (n.o 193). 
Ed.: Ruiz de la Peña Solar 2007: 354-355 (n. 5).

Baseándose nunha noticia que aparece nun testemuño de 1313, Duro Peña establece a existencia dunha orde que coincide con esta e que el data, sen excesivo convencemento, o 20 de abril de 1276.

\section{3}

1277, abril, 28. Burgos.

Afonso X, a petición dos abades cistercienses de Galicia, ordena a don Xoán Fernández, meiriño maior de Galicia, que non lles esixa diñeiro ningún en concepto de xantar senón soamente a «vianda» cando se presente persoalmente neles, que non lles cobre colleita se non é nas mesmas circunstancias e que non lles esixa unha mula por mosteiro, ou a súa equivalencia en diñeiro, como viña facendo.

B. AHN, Clero, Carpeta 544, n.ํㅜ 3. En copia simple coetánea de confirmación de Sancho IV de 12 de febreiro de 1286.

C. AHN, Clero, Carpeta 544, n. ․ En traslado da confirmación de Sancho IV de 12 de febreiro de 1286 realizado polo notario Pedro Martíz (século XIV).

Rex.: Sánchez Belda 1953: 349 (n.o 804); Pérez-Bustamante 1976: 18-19 (n.ํ24, 26 e 28) [datando o n.ํ 24 o día 23 de abril]; Ballesteros Beretta 1984: 1111 (n.o 1045); González Jiménez/Carmona Ruiz 2012: 513 (n.o 2866).

\section{4}

1277, xuño, 28. Burgos.

Afonso $X$, a cambio das terzas reais dos arciprestados de Roa, Aza e San Esteban de Gormaz, que tomou para entregarllas a don Simón Ruiz de los Cameros, entrega a dona Urraca Afonso, a súa tía, durante a vida dela, a vila da Coruña, os dereitos e propiedades adquiridos en Oímbra, Ganade e outros lugares en León e Asturias, as terzas dos arciprestados de Pineda e Aranda de Duero, e 500 marabedís situados na «martiniega» de Berlanga de Duero.

A. AHN, Clero, Carpeta 344, n.․ㅡ 11.

Rex.: González Jiménez/Carmona Ruiz 2012: 519 (n.ํ2901).

\section{5}

1277, xullo, 18. Burgos.

Afonso X comunica a don Xoán Fernández, «mio sobrino», meiriño maior de Galicia, a sentenza do preito incoado por dona Moor Afonso contra Ares González, fillo de Gonzalo Pérez de Borraxeiros, ao que acusa de roubarlle pan e gando. 
O preito foi presentado en primeira instancia ante don Fernando de la Cerda, que ordenou aos abades de Ferreira de Pallares e de Aciveiro investigar sobre os feitos, tras o que o infante ditaminou a favor de dona Moor. Ares González apeou a El-Rei, negando que a pescuda fose feita sen dereito e que o infante don Fernando non escoitase á súa parte. Xa en xuízo, El-Rei recoñece a legalidade da investigación, pero dá novo prazo ás partes, para o día primeiro de xullo, a solicitude de don Lope Díaz, de quen Ares González é vasalo. Ante a incomparecencia deste ou do seu procurador, El-Rei dita sentenza a favor de dona Moor e considera probado que o 1 de decembro de 1273 Ares González ou os seus homes lle roubaron cento cincuenta moios de pan, cento cincuenta armentios e cento cincuenta cabezas de gando menor, ovellas e cabras, polo que ordena que se lle pague o seu valor, descontando o xa devolto, e condena a Ares González nas custas.

A. AHN, Carpeta 1245, n.o 20. Orixinal. Pergameo, 250 x 433 mm.

Rex.: Sánchez Belda 1953: 350 (n. 807); Pérez-Bustamante 1976: $19-20$ (n.ํ 29 e 30) [datando o n.o 29 o día 10 de xullo]; Ballesteros Beretta 1984: 1112 (n.o 1068); González Jiménez/Carmona Ruiz 2012: 523 (n.o 2924).

Ed.: Grassotti 1981: 287-289.

Sánchez Belda recolle a noticia, dada neste documento, da orde dada a don Xoán Fernández para que comunique a dona Moor Afonso o prazo para que se presente na corte para o proceso, así como para que lle envíen os resultados da investigación sobre o asunto (Sánchez Belda 1953: 349-350 (n.o 806); Pérez-Bustamante 1976: 20 (n.o 32).

\section{6}

1278, xuño, 8. Segovia.

Afonso $X$ comunica ás autoridades do bispado de Ourense que enviou a don Abraham aben Xuxén, xenro do almoxarife 4 don Moyr, para recadar «todas llas sacas de llas cosas uedadas que sacaron de mío rregno contra mío deffendimiento, e los priuillegios quebrantados e las cartas mías e de llos otros rreys e las cosas descaminadas e llos bienes de aquellos que muriron sin herederos e el mostrenco», tal e como se di nas outras cartas que envía, así como o envío do seu porteiro Pedro Martínez para facer as entregas e tomar os peñores por todo o anterior, e ordena a esas autoridades que os axuden a cumprir a súa tarefa.

B. AHN, Clero, Carpeta 1506, n.o 11. Incluído na entrega que Pedro Martínez, porteiro de El-Rei, e Fernando López, porteiro de don Estevo Fernández, meiriño maior de Galicia, fan ao mosteiro de Santa Comba de Naves do couto de Mende e do lugar de San Cibrao.

Rex.: Sánchez Belda 1953: 350 (n.o 808); Ballesteros Beretta 1984: 1114 (n. 1111) [Datándoo no mes de maio]; González Jiménez/Carmona Ruiz 2012: 539-540 (n. 3032).

Ed.: Dono Lopez 2010: 241-243 (n.. 100).

4. O almoxarife era un funcionario encargado do cobro das rendas reais. 


\section{7}

1278, agosto, 6. Caldas de Reis.

O infante don Sancho confirma aos mestres e canteiros da Obra de Santiago os privilexios que gozan dos reis, os seus antecesores, confirmados por Fernando III e Afonso X, tomándoos baixo a súa garda e defensa.

A. ACSC, Documentos Soltos, Carpeta 7, n. .016.

Rex.: Ballesteros Beretta 1984: 1115 (n.ํ1137); González Vázquez 1996: 315 [datándoo en 1268]; González Jiménez/Carmona Ruiz 2012: 657 (n.․ 3495); Hernández 2021, v. 2, n. 39.

Ed.: López Ferreiro 1895: 482-483.

\section{8}

1278, agosto, 18. Tui.

$O$ infante don Sancho confirma a orde de Afonso $X$ de 18 de xaneiro de 1272 na que lle manda ao adiantado maior de Galicia, don Estevo Fernández, que prohiba diversas actuacións dos meiriños reais nos lugares da Igrexa de Mondoñedo.

B. ACMd. Pergameos, n.ํ5 59. En traslado ordenado polo propio Sancho IV para pasar o diploma de papel a pergameo de 13 de maio de 1282 en confirmación de Fernando IV de 8 de febreiro de 1305.

C. ACMd. Pergameos, n.요 88. En traslado ordenado polo propio Sancho IV para pasar o diploma de papel a pergameo de 13 de maio de 1282 en confirmación de Fernando IV de 8 de febreiro de 1305 en confirmación de Afonso XI de 20 de setembro de 1329.

D. ACMd. En traslado en papel da confirmación de Fernando IV realizado o 19 de outubro de 1308 por Afonso Eanes, notario de Mondoñedo.

Rex.: Cal Pardo 1990: 36 (n.o 59); González Jiménez/Carmona Ruiz 2012: 473 (n.o 2601); Hernández 2021, v. 2, n. 90 .

Ed.: Cal Pardo 1999: 131-133 (n. 9) e 206-208 (n.․ 88).

\section{9}

1278, outubro, 26. Toledo.

Afonso X ordena ao su meiriño maior de Galicia, don Estevo Fernández, e aos meiriños deste nas terras de Monterroso e Ulloa que devolvan á Orde de Santiago e ao seu mestre, don Pedro Muñiz, as herdades usurpadas aos priores e comendadores da Orde por cabaleiros, donas e outras persoas do reino de Galicia.

B. AHN, San Marcos, Carpeta 375, n. 64. En traslado realizado por Lourenzo Freire, notario das terras de Monterroso e Ulloa. 
Rex.: Sánchez Belda 1953: 350 (n.. 807); Pérez-Bustamante 1976: 21 (n.. 37); Ballesteros Beretta 1984: 1116 (n.. 1153); González Jiménez/Carmona Ruiz 2012: 545 (n.․3068).

124 Ed.: Novo Cazón 1986: 260-261 (n. 55).

\section{0}

1279, xullo, 28. Sevilla.

Afonso X exime ao bispo e ao cabido de Tui da obriga de albergar a ninguén nas casas da súa propiedade tanto na cidade como no resto do bispado.

B. ACT. Pergameos 3, n.ํㅜ 11. En confirmación de Sancho IV de 20 de maio de 1282.

Rex.: Galindo Romeo 1923: 45; Ballesteros Beretta 1984: 1117 (n. 1181); González Jiménez/Carmona Ruiz 2012: 553 (n. $\underline{0} 3125)$.

\section{1}

1279, agosto, 5. Sevilla.

Afonso X confirma á Igrexa de Tui a confirmación de Afonso VII de 1 de decembro de 1156 na que confirma a división dos bens da catedral entre bispo e cabido, e ordena que valga «salvo ende en aquellas cosas que pertenesçen al señorio da villa de Tuy», para o que debe observarse a sentenza dada sobre o señorío da cidade por Fernando III de 4 de xullo de 1250.

A. ACT. Pergameos 1, n.․ㅜ 12. En traslado notarial de 1325.

Rex.: Galindo Romeo 1923: 40; González Jiménez/Carmona Ruiz 2012: 554 (n. 3130).

\section{2}

[1279], novembro, 14. Sevilla.

Afonso X, por denuncia do mosteiro de Santa Cristina de Ribas de Sil, que se queixa de que os meiriños da terra de Caldelas e o Concello do Burgo de Caldelas demandan fonsadeira aos homes do couto monástico, e tendo mostrado o mosteiro privilexio de Afonso VII, confirmado por Afonso IX e Fernando III, no que se entregaba a Santa Cristina todas as peitas reais, salvo moeda, privilexio que, por «pobreza nunca me lo vinieron mostrar», ordena que non se tome colleita nin fonsadeira aos moradores do couto do mosteiro, que cobrará o cenobio, e prohibe así mesmo que acudan á hoste que sexa convocada polo Concello do Burgo de Caldelas ou por calquera rico-home ou cabaleiro. 
B. ACOu, Monacais, n. 1777. En confirmación de Fernando IV de 3 de xullo de 1304.

C. ACOu, Monacais, n.o 1867. En traslado realizado en decembro de 1310 por Xoán Fernández, notario do couto e mosteiro de Santa Cristina de Ribas de Sil, da confirmación de Fernando IV de 3 de xullo de 1304. Rex.: Duro Peña 1972: 101-102 (n. 339); Fernández Suárez (1974): n.o 17.

Ed.: Rodríguez Muñiz 2010: 117-118 (n.․19).

A data que figura na confirmación de Fernando IV é: Dada en Seuilla, XIII dias de nouenbro, era de mill e CCC e catorçe anos. Así pois, tanto o seu editor como os que o rexestaron datan o documento en decembro de 1276, se ben neses momentos o Rei Sabio non se atopaba en Sevilla senón en Vitoria (González Jiménez/ Carmona Ruiz 2012: 80). O redactor da carta foi Alfonso Pérez de la Cámara, quen traballa na chancelaría real entre 1278 e 1282, facendo unha a favor do cabido de Salamanca en Sevilla o 15 de outubro de 1279 (Kleine 2015: 303), co que considero que foi este ano cando se redactou este diploma, cuxa data foi mal copiada na confirmación de 1304 (XVI tería sido transcrito por catorçe), podendo ser tamén que estivese errada no orixinal (poñendo XIV en lugar de $X V I$ ).

\section{3}

1280, outubro, 6. Sevilla.

Afonso X exime aos veciños de Lugo de ser peñorados ou encarcerados por débeda coa cámara real.

Rex.: González Jiménez/Carmona Ruiz 2012: 565 (n. 3206).

Cit.: García Oro 1991: 54; Portela Silva/García Oro 1997: 266.

\section{4}

1281, febreiro, 21.

Afonso X, por denuncia do mosteiro de San Salvador de Celanova, ordena aos recadadores de tributos reais en Galicia que non cobren fonsadeira nas terras do dito cenobio posto que nunca a pagaran antes e, de tela cobrado, que lla devolvan.

B. AHN, Clero, Carpeta 1432, n.ํㅜ 15. En confirmación de Sancho IV de 25 de abril de 1291.

Rex.: Sánchez Belda 1953: 351 (n.․ 809); Ballesteros Beretta 1984: 1120 (n.ํ1243); González Jiménez/Carmona Ruiz 2012: 569 (n.o 3227).

Ed.: Vaquero Díaz 2004: 111 (n. 72).

\section{5}

1281, marzo, 10. San Esteban de Gormaz.

Afonso X, a cambio das vilas de Serpa, Moura e Mourão, entrega á Orde de San Xoán do Hospital a igrexa de Santa María de Castrelo de Miño. 
Rex.: Ballesteros Beretta 1984: 1120 (n.o 1251); González Jiménez/Carmona Ruiz 2012: 570 (n. 3238).

Ed.: CDH-RAG 1915: 134-135 (n.o 37); González Jiménez 1991: 501-502 (n.. 478); De Ayala Martínez (ed.) 1995: 577-578 (n.. 356); García Tato 2004: 185 (n.․ 86).

\section{6}

1281, marzo, 10. San Esteban de Gormaz.

Afonso X comunica aos habitantes da terra de Quiroga que doou esta á Orde de San Xoán do Hospital, con todo o seu señorío, os seus portádegos e todos os impostos rexios, salvo xantar e moeda foreira, e ordénalles que llelos entreguen aos freires da Orde a partir de agora.

B. ARG, Real Audiencia - Ejecutorias, Atado 7980, ff. 131r-133r. En traslado realizado polo notario Antonio López. Ed.: García Tato 2004: 181-182 (n.o 82) [Datándoo en 1271] e 186 (n. 87).

\section{7}

1281, marzo, 10. San Esteban de Gormaz.

Afonso X, vendo que os castelos de Serpa, Moura e Mourão eran da Orde do San Xoán do Hospital pero que cumprían ao señorío real, así como a relación de bens que lle entregara á dita Orde, de 10 de agosto de 1271, que inclúe, e o nomeamento de procuradores por parte da Orde, de 10 de outubro de 1280, que tamén inclúe, formaliza o cambio dos ditos castelos aos sanxoanistas por, entre outros lugares, bens e rendas, a igrexa de Santa María de Castrelo de Miño e a terra de Quiroga, salvo xantar e moeda nela.

B. ANTT, Gaveta 14, Maço 1, n. 9. En confirmación de Sancho IV de 15 de marzo de 1285.

Rex.: González Jiménez/Carmona Ruiz 2012: 571 (n.o 3242).

Ed.: González Jiménez 1991: 502-508 (n. 479); De Ayala Martínez (ed.) 1995: 578-581 (n.o 357); García Tato 2004: 186-188 (n. $\underline{\text { 8 } 8)}$ ).

\section{8}

1281, marzo, 19. Ágreda.

Afonso X confirma ao priorado de San Xoán de Caaveiro a carta de couto a favor do cenobio realizada por Afonso VII o 6 de maio de 1135, que inclúe.

Ed.: Fernández de Viana y Vieites/González Balasch 2002: 355 (n.o17). 
Afonso X confirma ao priorado de San Xoán de Caaveiro a doazón de Fernando II da igrexa de Santa María de Ribadeume e do lugar de Bermui de 23 de outubro de 1164, que inclúe.

B. AHN, Clero, Carpeta 491, n.ํ⒑ En copia simple de confirmación de Sancho IV de 21 de setembro de 1286. Rex.: Sánchez Belda 1953: 351 (n.o 810); González Jiménez/Carmona Ruiz 2012: 572 (n.. 3245).

Ed.: Fernández de Viana y Vieites/González Balasch 2002: 355 (n.․18).

\section{0}

1281, marzo, 28. Ágreda.

Afonso X ordena a Gutierre Pérez, «mio omme», que obrigue ao Concello de Monterrei a respectar os dereitos do mosteiro de Santa María de Melón en Vilamaior da Xironda, que o cenobio posúe por doazón de dona Estefanía.

B. AHN, Clero, Carpeta 1453, n. 3. En traslado realizado por Pedro Rodríguez, notario de Ribadavia. Rex.: Sánchez Belda 1953: 351 (n. 810); Ballesteros Beretta 1984: 1121 (n. 1259); González Jiménez/Carmona Ruiz 2012: 573 (n. 3258).

Ed.: Ruiz de la Peña Solar 2007: 355 (n.ํㅜ 6).

A sentenza que tanto Sánchez Belda 1953: 352 (n. 812) como Ballesteros Beretta 1984: 1121 (n.ํ1268) atribúen a Afonso X dáa, en realidade, o seu omme, Gutierre Pérez, a quen o monarca dirixe esta carta. A sentenza foi emitida a favor do mosteiro na mesma vila de Monterrei o 15 de maio de 1281, e ordena que os habitantes de Vilamaior da Xironda deben ser vasalos de Santa María de Melón e non veciños de Monterrei.

\section{1}

1281, agosto, 20. Sevilla.

Afonso $X$ ordena que os obreiros da Obra de Santiago queden exentos do pago de toda peita, servizo e moeda, segundo o están por privilexio concedido por Afonso IX e confirmado por Fernando III.

A. ACSC, Documentos Soltos, Carpeta 7, n.․ㅜ 16.

Rex.: Ballesteros Beretta 1984: 1122 (n.ํ1276); González Vázquez 1996: 315; González Jiménez/Carmona Ruiz 2012: 437 e 577 (n. 2355, 3281 e 3282) [Os tres rexestos son do mesmo documento, datando o primeiro (n.o 2355) en 1271].

Ed.: López Ferreiro 1895: 481-482. 


\section{2}

1281, setembro, 23. Sevilla.

Afonso X ordena ao seu home Gutierre Pérez, «o aquel que andare por mi en Gallizia», que devolva ao mosteiro de Santa María de Ferreira de Pallares o que lle tomaran don Estevo Fernández, adiantado maior de Galicia, e os seus meiriños de Monterroso e Pallares, e que se respecten os privilexios do cenobio.

A. AHN, Clero, Carpeta 1094, n. 7. Orixinal. Pergameo, 170 x 227 mm.

Rex.: Sánchez Belda 1953: 352 (n. 813); Pérez-Bustamante 1976: 23 (n.o 42); Ballesteros Beretta 1984: 1099 (n.o 807) [Datándoo en 1271]; González Jiménez/Carmona Ruiz 2012: 578-579 (n.o 3285 e 3284) [Datándoos respectivamente o 28 de setembro e o 23 de decembro].

Ed.: Rey Caíña 1985: 710-711 (n.o 313); Herrera/Sánchez/González de Fauve/Zabia 1999: AGA 12v.

\section{3}

1282, [outubro], 13. Córdoba.

O infante don Sancho concede a don Paio Gómez Chariño os dereitos que posuía na aldea de Riego del Camino, salvo xustiza e moeda foreira.

Rex.: González Jiménez/Carmona Ruiz 2012: 669 (n.o 3571); Hernández 2021, v. 2, n.o 240.

Ed.: De Ayala Martínez (ed.) 1995: 581-582 (n.o 358).

O mes de febreiro de 1282 o infante don Sancho non estaba en Córdoba senón en terras do reino de León: o día 9 estaba en Toro, e ese mesmo 13 dátase outro documento en Benavente, o 16 en Béjar e o 19 en Toledo, como amosan González Jiménez/Carmona Ruiz 2012: 669-670, se ben estes autores consideran que don Sancho estaba entón en Córdoba, baseándose na data deste diploma. Máis conveniente parece datalo no mes de outubro, cando o infante estivo na cidade andaluza, como fai F. J. Hernández, quen considera, ademais, que «o nomeamento de Pai Gómez Chariño como almirante polo infante Sancho carece de sentido antes de abril de 1292». Por outra banda, o lugar concedido é Riego del Camino, na actual provincia de Zamora, segundo consta nas contas de don Sancho, xa rei, de 1292: Riego, çerca de Çamora [...] tiénelos, por heredamiento, don Pay Gomez (Hernández 1993: I, 191). 


\section{ÍNDICE TOPONÍMICO}

Indícanse cos números en cursiva os topónimos dos lugares nos que foron emitidas as cartas reais recollidas no índice.

\section{A}

Aciveiro, Santa María de: antigo mosteiro no lugar de Mosteiro, freguesía de Santa María de Aciveiro, concello de Forcarei, provincia de Pontevedra: $185,205$.

Ágreda: vila cabeza do concello do seu nome, provincia de Soria: 218, 219, 220.

Aguilar de Campoo: vila cabeza do concello do seu nome, provincia de Palencia: 44. Alba de Aliste: antiga terra na actual provincia de Zamora, con cabeza no castelo de Castelo de Alba, concello de Losacino: 60.

Alba de Búbal: antigo castelo na freguesía de San Pedro de Trasalba, concello de Amoeiro, provincia de Ourense: 47.

Alcañices: vila cabeza do concello do seu nome, provincia de Zamora: 60 .

Aldeanueva de Figueroa: vila cabeza do concello do seu nome, provincia de Salamanca: 74.

Algavalí: aldea desaparecida do termo de San Juan de Aznalfarache, provincia de Sevilla: 99.

Aliste: antiga terra na actual provincia de Zamora, con cabeza na vila de Alcañices: 42. Aljarafe: rexión do antigo alfoz de Sevilla, na actual provincia de Sevilla: 11. Allariz: vila cabeza do concello do seu nome, provincia de Ourense: 111, 183. -Concello de: 128.

Ambroa: freguesía de San Tirso de Ambroa, concello de Irixoa, provincia da Coruña: 127. Antealtares, San Paio de: antigo mosteiro na rúa do seu nome, na cidade de Santiago de Compostela, concello de Santiago de Compostela, provincia da Coruña: 124.

Aragón, reino de: 182.

Aranda: antigo arciprestado da diocese de Osma, con centro na vila de Aranda de Duero, concello de Aranda de Duero, provincia de Burgos: 204.

Arbo, San Pedro de: lugar desaparecido na freguesía de Santa María de Arbo, concello de Arbo, provincia de Pontevedra: 40.

Arbo, Santa María de: freguesía do concello de Arbo, provincia de Pontevedra: 35. Arévalo: vila cabeza do concello do seu nome, provincia de Ávila: 111, 112.

Armenteira, Santa María de: antigo mosteiro no lugar de Vilar, freguesía de Santa María de Armenteira, concello de Meis, provincia de Pontevedra: 160, 161.

Arzón, San Cristovo de: freguesía do concello de Negreira, provincia da Coruña: 83, 84 . Astorga: cidade cabeza do concello do seu nome, provincia de León: 198.

-Bispado de: 42. 
-Igrexa de: 145, 198.

Asturias: 17, 100, 168, 202, 204.

130 Atás: lugar da freguesía de Santa María de Atás, concello de Cualedro, provincia de Ourense: 66.

Auercere: sine loc.: 61.

Axerquía: antigo barrio da cidade de Córdoba: 123.

Aza: antigo arciprestado da diocese de Osma, con centro na vila de Aza, concello de Aza, provincia de Burgos: 204.

Aznalfarache (99): vide San Juan de Aznalfarache.

\section{B}

Badajoz: cidade cabeza do concello e provincia do seu nome: 7, 8, 9, 150.

Baíste: actual freguesía de Santa María de Baíste, concello de Avión, provincia de Ourense: 30 .

Bama: antiga terra e arciprestado do arcebispado de Santiago que se estendía, cando menos e en todo ou en parte, polos actuais concellos do Pino, Arzúa e Touro, provincia da Coruña: 10.

Barcia: lugar da freguesía de Santa María de Quins, concello de Melón, provincia de Ourense: 31 .

-Santa María de: antigo mosteiro supostamente antecesor do de Santa María de Melón: 30.

Barciademera: actual freguesía de San Martiño de Barcia de Mera, concello de Covelo, provincia de Pontevedra: 38.

Bares: actual lugar de Porto de Bares, freguesía de Santa María de Bares, concello de Mañón, provincia da Coruña: 122.

Belesar: lugar da freguesía de San Bartolomeu de Belesar, concello de Chantada, provincia de Lugo: 46.

Benavente: cidade cabeza do concello do seu nome, provincia de Zamora.

-Foral de: 18, 67, 126, 170.

Berlanga de Duero: vila cabeza do concello do seu nome, provincia de Soria.

-Martiniega de: 204.

Bermui, Santiago de: freguesía do concello das Pontes de García Rodríguez, provincia da Coruña: 116, 219.

Betanzos: vila cabeza do concello do seu nome, provincia da Coruña: 60, 87, 109.

Bezoucos: antiga terra que se estendería aproximadamente polos actuais concellos de Mugardos, Ares, Fene, Cabanas, A Capela e As Pontes de García Rodríguez, provincia da Coruña: 170.

Bragança: cidade cabeza do concello e do distrito do seu nome (Portugal): 141.

Bribes, San Cibrán de: antigo mosteiro no lugar do Mosteiro, freguesía de San Cibrán de Bribes, concello de Cambre, provincia da Coruña: 142. 
Brihuega: vila cabeza do concello do seu nome, provincia de Guadalajara: 96.

Brul: regato afluente do río Miño pola dereita, tamén chamado de Outeiro, que decorre polos concellos de Melón e Ribadavia: 25.

Búbal: antiga terra na actual provincia de Ourense, entre os ríos Búbal, Miño e Barbantiño.

-Xuíz de: 5.

Bugariña: monte na actual freguesía de San Salvador de Prado, concello de Covelo, provincia de Pontevedra: 33.

Burgo de Caldelas: hoxe lugar do Burgo, freguesía de San Pedro do Burgo, concello de Castro Caldelas, provincia de Ourense.

-Concello de: 212.

Burgo, San Vicente do: freguesía do concello de Lugo, provincia de Lugo: 96.

Burgos: cidade cabeza do concello e provincia do seu nome: 20, 21, 22, 23, 24, 25, 26, $27,28,29,30,31,32,33,34,35,36,37,38,39,40,41,42,43,69,70,71$, 72, 73, 74, 75, 166, 167, 177, 178, 179, 184, 186, 193, 196, 199, 200, 201, 202, 203, 204, 205.

-Catedral de: 21.

Burgueira: actual freguesía de San Pedro de Burgueira, concello de Oia, provincia de Pontevedra: 179.

Bustelos: lugar da freguesía de Santiago da Medorra, concello de Montederramo, provincia de Ourense: 196.

\section{C}

Caamouco, San Vicente de: freguesía do concello de Ares, provincia da Coruña: 112.

Caaveiro, San Xoán de: antigo priorado agostiño no lugar do Coto, freguesía de Santiago da Capela, concello da Capela, provincia da Coruña: 116, 218, 219.

Cádiz: cidade cabeza do concello e provincia do seu nome: 100.

Caldas de Reis: vila cabeza do concello do seu nome, provincia de Pontevedra: 207.

Caldelas: antiga terra que se estendía, en todo ou en parte, polos actuais concellos da Teixeira, Castro Caldelas, San Xoán de Río, Chandrexa de Queixa, Montederramo e Parada de Sil, provincia de Ourense: 212.

Cando: freguesía de San Tirso de Cando, concello de Outes, provincia da Coruña: 81, 82. Cans: actual freguesía de Santo Estevo de Cans, concello do Porriño, provincia de Pontevedra: 31 .

Cantábrico, mar. -Portos do: 191.

Cantillana: vila cabeza do concello do seu nome, provincia de Sevilla: 154.

Carboeiro, San Lourenzo de: antigo mosteiro no lugar do Mosteiro, freguesía de Santa María de Carboeiro, concello de Silleda, provincia de Pontevedra: 8, 57, 58. 
Carnota: antiga terra que se estendía polos actuais concellos de Mazaricos, Carnota, Muros e Outes, provincia da Coruña, tendo a súa cabeza no castelo de San Xurxo: 83, 85.

Carracedo, Santa María de: antigo mosteiro no lugar de Carracedo del Monasterio, concello de Carracedelo, provincia de León: 115.

Carrión: vila, hoxe Carrión de los Condes, cabeza do concello do seu nome, provincia de Palencia: 45, 46.

Casar do Mato: lugar da freguesía de Santa María de Cristosende, concello da Teixeira, provincia de Ourense: 196.

Castela, reino de: 23, 191.

-Adiantado maior de: 121.

Castela: antiga terra na actual provincia de Ourense, ao oeste do río Barbantiño. -Xuíz de: 5 .

Castrelo de Miño: antiga demarcación que comprendería o actual termo municipal de Castrelo de Miño e talvez a freguesía de San Paio de Ventosela, concello de Ribadavia, provincia de Ourense: 70.

-Celeiro real: na freguesía de Santa María de Castrelo de Miño, concello de Castrelo de Miño, ou na de San Paio de Ventosela, concello de Ribadavia, provincia de Ourense: 34, 197.

Castrelo de Miño, Santa María de: freguesía do concello de Castrelo de Miño, provincia de Ourense: 172, 215, 217.

Castro de Ouro: lugar da freguesía de San Salvador do Castro de Ouro, concello de Alfoz, provincia de Lugo: 126.

-Concello de: 171.

Castro de Rei, Santa María de: antigo mosteiro no lugar da Enxamea, freguesía de Santa María de Castro de Rei de Lemos, concello de Paradela, provincia de Lugo: 61.

Castro Urdiales: vila cabeza do concello do seu nome, C. A. de Cantabria: 86, 113.

Castromonte: vila cabeza do concello do seu nome, provincia de Valladolid: 60 .

Castroverde: vila cabeza do concello do seu nome, provincia de Lugo.

-Meiriño de: 155.

Celanova, San Salvador de: antigo mosteiro na vila de Celanova, freguesía de San Rosendo de Celanova, concello de Celanova, provincia de Ourense: 48, 49, 65, 189, 214.

Centulle: lugar da freguesía de San Xurxo de Asma, concello de Chantada, provincia de Lugo: 192bis.

Cereixido de Valdeorras, Santa María de: freguesía do concello de Quiroga, provincia de Lugo: 145, 198.

Cerrajas: alquería sine loc. no antigo termo de Facialcázar: 91. 
Chamosiños: lugar da freguesía de Santa Baia de Chamosiños, concello de Trasmiras, provincia de Ourense.

-Celeiro real de: 180.

Chantada: vila cabeza do concello do seu nome, provincia de Lugo.

-Feira de: 120 .

Chantada, San Salvador de: antigo mosteiro no lugar da Portada, freguesía de San Salvador de Asma, concello de Chantada, provincia de Lugo: 119, 120, 192bis.

Chantada, Santa María de: actual Santa María de Regueira, freguesía do concello de Oza dos Ríos, provincia da Coruña: 142.

Chantada, Santo Estevo de: lugar da freguesía de San Salvador de Asma, concello de Chantada, provincia de Lugo: 192bis.

Chavín, Santa María de: freguesía do concello de Viveiro, provincia de Lugo: 110.

Chouzán, Santo Estevo de: antigo mosteiro no lugar de Chouzán, freguesía de Santo Estevo de Chouzán, concello de Carballedo, provincia de Lugo: 167.

Ciudad Real: cidade cabeza do concello e provincia do seu nome: 148 .

Córdoba: cidade cabeza do concello e provincia do seu nome: 223.

-Axerquía: 123B.

-Convento de San Clemente de: 123B.

Coruña, A: cidade cabeza do concello e provincia do seu nome: 86, 87, 92, 195, 204.

-Concello de: 18, 92.

Courel: antiga terra e encomenda da Orde de Santiago que comprendería o actual concello de Folgoso do Courel, provincia de Lugo.

-Comendador de: 63.

Couso, Santa María de: freguesía do concello de Avión, provincia de Ourense: 39.

Covarrubias: vila cabeza do concello do seu nome, provincia de Burgos: 76, 77, 78, 79.

\section{D}

Domaio: freguesía de San Pedro de Domaio, concello de Moaña, provincia de Pontevedra: 183.

Dozón, terra de: antiga terra que se estendería aproximadamente polo actual concello de Dozón, provincia de Pontevedra.

-Concello de: 5 .

Dozón, Santa María de: freguesía do concello de Dozón, provincia de Pontevedra: 5.

Duio, San Martiño de: freguesía do concello de Fisterra, provincia da Coruña: 83, 85.

Duio, San Salvador de: antiga freguesía, hoxe incluída na de San Martiño de Duio, concello de Fisterra, provincia da Coruña: 83, 85. 


\section{E}

Escuadro: lugar da freguesía de Santa Baia de Castro de Escuadro, concello de Maceda, provincia de Ourense: 196.

Esla: río afluente do río Douro, pola súa dereita, que rega as provincias de León e Zamora: 14.

\section{$\mathbf{F}$}

Facialcázar: antigo lugar do alfoz da cidade de Sevilla, entre Utrera e El Coronil, provincia de Sevilla; 16, 91, 99.

Faro: antiga terra na actual provincia da Coruña que tiña a súa cabeza no castelo de Faro, actual Torre de Hércules: 43.

Ferreira de Pallares, Santa María de: antigo mosteiro no lugar de Ferreira, freguesía de Santa María de Ferreira de Pallares, concello de Guntín, provincia de Lugo: 12, 162, 185, 205, 222.

Fiães, Santa María de: antigo mosteiro na freguesía de Santa María de Fiães, concello de Melgaço, distrito de Viana do Castelo (Portugal): 160, 161.

Forno Telleiro: viña sine loc. nas proximidades da vila de Ribadavia, concello de Ribadavia, provincia de Ourense: 81 .

Francelos: lugar da freguesía de San María Madanela de Francelos, concello de Ribadavia, provincia de Ourense: 29, 41.

Francia, reino de: 88, 89.

Furco, San Salvador de: freguesía hoxe desaparecida, no concello de Becerreá, provincia de Lugo: 59.

\section{G}

Galicia: reino de: 16, 100, 168, 172, 182, 193, 194, 201, 202, 203, 209, 214, 222.

-Adiantado maior de: 160, 161, 162, 174, 175, 184, 208, 222.

-Meiriño maior de: 12, 114, 115, 118, 127, 163, 203, 205, 209.

Ganade: lugar da freguesía de San Bartolomeu de Ganade, concello de Xinzo de Limia, provincia de Ourense: 204.

Guadalajara: cidade cabeza do concello e provincia do seu nome: 170 .

Guisande: pesqueira no río Miño, na freguesía de Santa María de Arbo, concello de Arbo, provincia de Pontevedra: 40.

Guntín, San Salvador de: freguesía do concello de Guntín, provincia de Lugo: 162.

\section{I}

Iria, Santa María de: antiga colexiata no lugar de Iria Flavia, freguesía de Santa María de Iria Flavia, concello de Padrón, provincia da Coruña: 80. 


\section{J}

Jerez de la Frontera: cidade cabeza do concello do seu nome, provincia de Cádiz: 157, 158, 159, 160, 161.

$\mathbf{L}$

Laias: lugar da freguesía de Santa Baia de Laias, concello de Cenlle, provincia de Ourense.

-Celeiro real de: 180 .

Lama de Dozón (5): vide Lama, A.

Lama, A: lugar da freguesía de Santiago de Saa, concello de Dozón, provincia de Pontevedra: 5 .

Lédigos: vila cabeza do concello do seu nome, provincia de Palencia: 22, 23.

Lemos: antiga terra na actual provincia de Lugo que tiña a súa cabeza na vila de Monforte de Lemos: 43.

León, reino de: 17, 18 bis, 182, 188, 191, 201, 204.

-Meiriño maior de: 42, 115.

León: cidade cabeza do concello e provincia do seu nome: 121.

-Catedral de: 21.

Lérez, San Salvador de: antigo mosteiro no lugar de Porta do Sol, freguesía de San Salvador de Lérez, concello e provincia de Pontevedra: 3.

Lestedo, San Cibrao de: actual Santiago de Lestedo, freguesía do concello de Palas de Rei, provincia de Lugo: 176.

Limia: antiga terra na actual provincia de Ourense que tiña a súa cabeza na vila de Allariz: 43, 55.

Logroño: cidade cabeza do concello do seu nome e capital da C. A. da Rioxa: 121.

Lorca: cidade cabeza do concello do seu nome, C. A. de Murcia: 99.

Lugo: cidade cabeza do concello e provincia do seu nome: 19, 158, 191, 192bis, 213.

-Bispado de: 19, 155.

-Bispo de: 8, 69, 96, 141, 155, 158, 164, 166.

-Igrexa de: 69, 155, 164, 166.

-Xuíz de: 96.

\section{M}

Madrid: cidade cabeza do concello do seu nome e capital da C. A. de Madrid: 113, 114, 116, 181, 182.

Medina del Campo: vila cabeza do concello do seu nome, provincia de Valladolid: 110. Meira, Santa María de: antigo mosteiro na vila de Meira, freguesía de Santa María de Meira, concello de Meira, provincia de Lugo: 24, 149, 157, 160, 161, 183bis. 
Melón, Santa María de: antigo mosteiro na vila de Melón, freguesía de Santa María de Melón, concello de Melón, provincia de Ourense: 25, 26, 27, 28, 29, $30,31,32,33,34,35,36,37,38,39,40,41,70,71,101,144,160,161,183$, 197, 220.

Mérida: cidade cabeza do concello do seu nome, provincia de Badajoz, capital da C. A. de Estremadura: 10.

Milmanda: antiga vila, hoxe lugar de Vila, freguesía de Santa María de Alcázar de Milmanda, concello de Celanova, provincia de Ourense: 177.

Miño, río: 25, 141.

Mixós: lugar da freguesía de San Mamede de Estevesiños, concello de Monterrei, provincia de Ourense: 48.

Mondoñedo: cidade cabeza do concello do seu nome, provincia de Lugo.

-Bispo de: 122, 126, 127bis, 171, 173, 174, 175, 181, 186.

-Igrexa de: 110, 175, 208.

Monfero, Santa María de: antigo mosteiro no lugar do Convento, freguesía de Santa María de Monfero, concello de Monfero, provincia da Coruña: 2, 107, $108,109,114,127,160,161,163,190$.

Monforte de Lemos: vila cabeza do concello do seu nome, provincia de Lugo: 72, 73.

-Concello de: 73.

-Meiriño de: 155.

Montederramo, Santa María de: antigo mosteiro no lugar de Montederramo, freguesía de Santa María de Montederramo, concello de Montederramo, provincia de Ourense: 9, 62, 63, 160, 161, 187, 196, 200.

Monterrei: antiga vila na freguesía de Santa María de Monterrei, concello de Monterrei, provincia de Ourense: 65, 189, 220.

-Concello de: 220.

Monterrei, San Cibrao de: antiga granxa do mosteiro de Santa María de Melón, hoxe desaparecida, na freguesía de San Pedro de Sanín, concello de Ribadavia, ou na veciña de San Xoán de Sadurnín, concello de Cenlle, provincia de Ourense: 31.

Monterroso: antiga terra que se estendía, cando menos, polo actual concello de Monterroso, provincia de Lugo: 209.

-Meiriño de: 212.

Moraime, San Xulián de: antigo mosteiro no lugar de Moraime, freguesía de San Xulián de Moraime, concello de Muxía, provincia da Coruña: 45.

Moura: vila cabeza do concello do seu nome, distrito de Beja (Portugal): 172, 215, 217.

Mourão: vila cabeza do concello do seu nome, distrito de Évora (Portugal): 172, 215, 217.

Murcia: cidade cabeza do concello do seu nome e capital da C. A. de Murcia: 171, 172, 173, 174, 175, 176 .

Muros, San Vicente dos (96): vide Burgo, San Vicente do. 


\section{$\mathbf{N}$}

Naves, Santa Comba de: antigo priorado no lugar de Naves, freguesía de San Mamede de Palmés, concello de Ourense, provincia de Ourense: 47.

Nespereira, San Cibrao de: freguesía do concello de Portomarín, provincia de Lugo: 162. Noblas: herdade sine loc. no antigo termo de Facialcázar: 91.

Nogueira: lugar da freguesía de Santa María de Nogueira, concello de Montederramo, provincia de Ourense: 196.

\section{o}

Oia, Santa María de: antigo mosteiro no lugar do Arrabal, freguesía de Santa María de Oia, concello de Oia, provincia de Pontevedra: 160, 161, 177, 178, 179, 184.

Oímbra: vila cabeza do concello do seu nome, provincia de Ourense: 204.

Órrea, Santa Comba de: antigo mosteiro no lugar da Eirexa, freguesía de Santa Comba de Órrea, concello de Riotorto, provincia de Lugo: 146.

Ortigueira: vila cabeza do concello do seu nome, provincia da Coruña: 67.

Oseira, Santa María de: mosteiro no lugar de Oseira, freguesía de Santa María de Oseira, concello de San Cristovo de Cea, provincia de Ourense: 53, 54, 98, 160, 161, 192.

Ourense: cidade cabeza do concello e provincia do seu nome.

-Bispado de: 104, 105, 206.

-Bispo de: 103, 105, 141.

-Concello de: 44, 88, 89, 94, 117, 132, 133.

-Igrexa de: 44, 94, 102, 103, 117, 132, 133.

\section{P}

Padrón: vila cabeza do concello do seu nome, provincia da Coruña: 80 .

Palencia: cidade cabeza do concello e provincia do seu nome: 53, 54, 56, 59, 187, 188, 189, 190, 191, 192.

Pallares: antiga terra que se estendía, cando menos, por parte do actual concello de Guntín, provincia de Lugo.

-Meiriño de: 212.

Páramo, terra de: antiga terra que se estendería aproximadamente polo actual concello do Páramo, provincia de Lugo: 1, 68.

Pazos: lugar da freguesía de San Fiz de Pazos, concello de Verín, provincia de Ourense: 66.

Pedroso, San Salvador de: antigo priorado agostiño no lugar do Carballo, freguesía de San Salvador de Pedroso, concello de Narón, provincia da Coruña: 51.

Penamaior, Santa María de: antigo mosteiro no lugar do Convento, freguesía de Santa María de San Lourenzo de Penamaior, concello de Becerreá, provincia de Lugo: 50, 59, 160, 161. 
Pereiriña, San Xián da: freguesía do concello de Cee, provincia da Coruña: 81.

Perpiñán: cidade capital do departamento dos Pireneos Orientais (Francia): 194.

Pinario, San Martiño de: antigo mosteiro na praza da Inmaculada da cidade de Santiago de Compostela, concello de Santiago de Compostela, provincia da Coruña: 95, 159.

Pineda: antigo arciprestado da diocese de Burgos, con centro na vila de Pineda de la Sierra, concello de Pineda de la Sierra, provincia de Burgos: 204.

Pino, San Vicente do: antigo mosteiro na praza de Luis de Góngora, na vila de Monforte de Lemos, concello de Monforte de Lemos, provincia de Lugo: 72, 73, 199.

Piñeira: lugar desaparecido, na freguesía de San Mamede de Vilachá, concello da Pobra do Brollón, provincia de Lugo: 63.

Pobra de Luaces: actual lugar de Valonga, freguesía de Santa María de Valonga, concello de Pol, provincia de Lugo: 166.

Pobra de Ortigueira: actual vila de Ortigueira, concello de Ortigueira, provincia da Coruña: 67.

Pobra de Ouro: hoxe lugar do Castro de Ouro, freguesía de San Salvador do Castro de Ouro, concello de Alfoz, provincia de Lugo: 126.

Pobra de Valdeorras: hoxe lugar da Proba, freguesía de Santa María da Proba, concello do Barco de Valdeorras, provincia de Ourense: 197.

Pontedeume: vila cabeza do concello do seu nome, provincia da Coruña: 2, 170.

Pontevedra: cidade cabeza do concello e provincia do seu nome.

-Concello de: 93, 143, 151, 188.

-Foral de: 143

Portocelo: lugar da freguesía de San Tirso de Portocelo, concello de Xove, provincia de Lugo: 122.

Proba de Burón, A: hoxe lugar da freguesía de Santa María Madanela da Pobra de Burón, concello da Fonsagrada, provincia de Lugo: 168.

Prógalo, Santiago de: freguesía do concello de Lugo, provincia de Lugo: 96.

Pruzos: antiga terra que se estendería aproximadamente polos actuais concellos de Pontedeume, Miño, Vilarmaior e Monfero, provincia da Coruña: 2, 170.

\section{Q}

Quintela: lugar hoxe dividido en Quintela de Arriba e de Abaixo, freguesía de San Martiño de Pedrafita, concello da Teixeira, provincia de Ourense: 196.

Quiroga: antiga terra que se estendía polo actual concello do mesmo nome, provincia de Lugo: 172, 216, 217.

\section{$\mathbf{R}$}

Rabal: lugar da freguesía de Santo André de Rabal, concello de Oímbra, provincia de Ourense: 144. 
Ramil, Santa Mariña de: freguesía do concello de Castro de Rei, provincia de Lugo: 166. Raposeira: celeiro real sine loc.: 180.

Resoio: lugar sine loc., probablemente no termo municipal da Teixeira ou no de Montederramo, provincia de Ourense: 196.

Retorta: lugar da freguesía de San Xoán das Chás, concello de Montederramo, provincia de Ourense: 196.

Retorta, San Pedro de: probablemente actual freguesía de San Pedro de Arantei, concello de Salvaterra de Miño, provincia de Pontevedra: 37.

Reza: antigo lugar que se dividía ás dúas beiras do río Miño, con pesqueiras nelas, queda na actualidade o da marxe esquerda, lugar da freguesía de San Salvador da Arnoia, concello da Arnoia, provincia de Ourense: 25, 41.

Ribadavia: vila cabeza do concello do seu nome, provincia de Ourense: 32, 70, 81, 97, $111,183$.

Ribadeo: vila cabeza do concello do seu nome, provincia de Lugo: 120.

-Concello de: 113, 173.

Ribadeume, Santa María de: freguesía do concello das Pontes de García Rodríguez, provincia da Coruña: 116, 219.

Ribas de Sil, Santa Cristina de: antigo mosteiro no lugar de Santa Cristina, freguesía de Santa Cristina de Caxide, concello de Parada de Sil, provincia de Ourense: 157, 212.

Ribas de Sil, Santo Estevo de: antigo mosteiro no lugar de Santo Estevo de Ribas de Sil, freguesía de Santo Estevo de Ribas de Sil, concello de Nogueira de Ramuín, provincia de Ourense: 52.

Ribas de Sor: probablemente freguesía de Santa María de Mañón, concello de Mañón, provincia da Coruña: 24.

Ribeira de Piquín: terra que comprendía, aproximadamente, o actual termo municipal de Ribeira de Piquín, provincia de Lugo: 149.

Ribeiro de Avia: antiga terra que se estendía entre os ríos Avia, Miño e a Serra do Suído, provincia de Ourense: 83, 85.

Riego del Camino: localidade do concello de Manganeses de la Lampreana, provincia de Zamora: 223.

Roa: antigo arciprestado da diocese de Osma, con centro na vila de Roa de Duero, concello de Roa de Duero, provincia de Burgos: 204.

\section{S}

Sabugal: vila cabeza do concello do seu nome, distrito de Guarda (Portugal): 141.

Sahagún: vila cabeza do concello do seu nome, provincia de León: 47, 48, 49, 50, 51, $60,118$.

Salamanca: cidade cabeza do concello e provincia do seu nome: 74, 212. 
Salnés: antiga terra que se estendía pola península do mesmo nome, provincia de Pontevedra: 83, 85.

Samos, San Xulián de: mosteiro no lugar de Samos, freguesía de Santa Xertrude de Samos, concello de Samos, provincia de Lugo: 106, 118, 148, 169.

San Cibrao: lugar da freguesía de Santa María de Lieiro, concello de Cervo, provincia de Lugo: 122.

San Clodio, Santa María de: antigo mosteiro no lugar de San Clodio, freguesía de Santa María de San Clodio, concello de Leiro, provincia de Ourense: 64.

San Esteban de Gormaz: vila cabeza do concello do seu nome, provincia de Soria: 92, 93, 94, 215, 216, 217.

-antigo arciprestado da diocese de Osma, con centro nesta vila: 204.

San Juan de Aznalfarache: vila cabeza do concello do seu nome, provincia de Sevilla: 99.

Sanín: lugar da freguesía de San Pedro de Sanín, concello de Ribadavia, provincia de Ourense: 26.

Santander: cidade cabeza do concello do seu nome e capital da C. A. de Cantabria: 86. Santiago de Compostela, cidade cabeza do concello do seu nome, provincia da Coruña, e capital da C. A. de Galicia: 7, 20, 44, 121, 138, 139, 140, 153, 169, 177, 180. -Arcebispado de: 79, 151.

-Arcebispo de: 7, 10, 13, 14, 16, 74, 75, 78, 90, 93, 121, 135, 138, 154.

-Cabido da catedral de: 77, 78, 93, 154.

-Camiño de: 21, 121.

-Carnizaría de: 7.

-Concello de: 15, 93, 123, 130, 131, 134, 135, 136, 137, 152, 153, 154, 156.

-Igrexa de: 7, 10, 15, 18bis, 21, 22, 23, 76, 77, 90, 93, 112, 121, 123, 130, 131, 134, 136, 137, 154.

-Obra de: 207, 221.

-Peregrinos a: 20, 21.

-Pertegueiro de: 10, 12, 137.

-Terra de: 7, 10, 13, 76, 93, 156.

Santo Domingo de Silos: vila cabeza do concello do seu nome, provincia de Burgos: $80,81,82,82,84,85,86$.

Santo Estevo de Chantada: lugar da freguesía de San Salvador de Asma, concello de Chantada, provincia de Lugo: 192bis.

Sarria: vila cabeza do concello do seu nome, provincia de Lugo.

-Honor de: antiga terra que na plena Idade Media se estendería aproximadamente polos actuais concellos de Castroverde, O Corgo, O Páramo, Paradela, Sarria, Samos, Triacastela, As Nogais, Cervantes, Becerreá, Baralla, Láncara, e talvez os de Navia de Suarna e Baleira, provincia de Lugo: 1, 68.

-Meiriño de: 155. 
Sas do Monte: lugar da freguesía de San Pedro de Sas do Monte, concello de Montederramo, provincia de Ourense: 196.

Sauugal (141): vide Sabugal.

Segovia: cidade cabeza do concello e provincia do seu nome: 97, 98, 205.

Serpa: vila cabeza do concello do seu nome, distrito de Beja (Portugal): 172, 215, 217.

Sevilla: cidade cabeza do concello do seu nome, provincia de Sevilla, e capital da C. A. de Andalucía: $6,11,12,13,14,15,16,17,91,122,123,123,124,125,126$, 127, 127bis, 128, 129, 130,131,132,133,134,135, 136, 137, 138, 139, 140, $141,142,143,145,146,148,149,151,152,153,155,156,162,165,210$, 211, 212, 213, 221, 222.

-Cortes de: 13.

Sobrado, Santa María de: antigo mosteiro no lugar de Sobrado, freguesía de San Pedro da Porta, concello de Sobrado dos Monxes, provincia da Coruña: 6, $86,160,161$.

Soria: cidade cabeza do concello e provincia do seu nome: 95.

Soutelo: probablemente o lugar dese nome na freguesía de Santa Cristina de Valeixe, concello da Cañiza, provincia de Pontevedra: 35.

\section{$\mathbf{T}$}

Tielas: antigo couto que comprendía as freguesías de Santa María do Campo, San Salvador de Prado, San Bernabé da Graña, San Miguel de Fofe e San María de Godóns, no actual concello de Covelo, provincia de Pontevedra: 26.

Toledo: cidade cabeza do concello e provincia do seu nome, capital da C. A. de Castela-A Mancha: 18, 18bis, 19, 115, 117, 117bis, 118, 119, 120, 121, 164, 209.

Toques, Santo Antoniño de: antigo mosteiro no lugar dos Curros, freguesía de Santa María da Capela, concello de Toques, provincia da Coruña: 165.

Toro: cidade cabeza do concello do seu nome, provincia de Zamora: 18bis, 73.

Toxos Outos, San Xusto de: antigo mosteiro no lugar de San Xusto, freguesía de San

Xusto de Toxos Outos, concello de Lousame, provincia da Coruña: 81, $82,83,84,85,109$.

Transerra: antiga demarcación do reino de León que comprendía, no século XIII, os te-

rritorios do sur da provincia de Salamanca e actual Estremadura: 14.

Trasmonte: lugar da freguesía de San Mamede de Vilachá, concello da Pobra do Brollón, provincia de Lugo: 63.

Trasrío: herdade sine loc., probablemente no concello de Alfoz, provincia de Lugo: 171. Tui: cidade cabeza do concello do seu nome, provincia de Pontevedra: 208, 211.

-Bispado de: 210.

-Bispo de: 210, 211.

-Concello de: 188.

-Igrexa de: 210, 211. 
$\mathbf{U}$

Ulloa: antiga terra que se estendía, cando menos, polo actual concello de Antas de Ulla, provincia de Lugo: 209.

V

Valcarría, Santo Estevo de: freguesía do concello de Viveiro, provincia de Lugo: 110. Valladolid: cidade cabeza do concello e provincia do seu nome, capital da C. A. de Castela e León: 62, 63, 64, 65, 66, 67, 68, 100, 101,102,103, 104,105, 106, 107, 108, 109, 147, 163, 195.

Valonga, Santa María de: freguesía do concello de Pol, provincia de Lugo: 166. Veduego: monte sine loc., no actual concello de Avión, provincia de Ourense: 30. Verín: vila cabeza do concello do seu nome, provincia de Ourense: 66. -Castro de (65): vide Monterrei.

Vigo, Santa Uxía de: antigo lugar hoxe integrado na cidade de Vigo, concello de Vigo, provincia de Pontevedra: 31 .

Vilabona: herdade sine loc., probablemente no concello de Alfoz, provincia de Lugo: 171. Vilafranca do Bierzo: cidade cabeza do concello do seu nome, provincia de León. -Portádego en: 191.

Vilamaior: hoxe lugar da Xironda, freguesía de San Salvador da Xironda, concello de Cualedro, provincia de Ourense: 101.

Vilamaior da Xironda: freguesía de San Salvador da Xironda, concello de Cualedro, provincia de Ourense: 101, 220.

Vilanova de Dozón, San Pedro: antigo mosteiro no lugar do Mosteiro, freguesía de Santa María de Dozón, concello de Dozón, provincia de Pontevedra: 5.

Vilanova de Lourenzá, San Salvador de: antigo mosteiro na vila de Vilanova, freguesía de Santa María de Lourenzá, concello de Lourenzá, provincia de Lugo: 181.

Vilar Papi, monte: talvez lugar de Vilalpape, freguesía de San Bartolomeu de Vilalpape, concello de Bóveda, provincia de Lugo: 61.

Vilaxuste, San Pedro de: freguesía do concello de Portomarín, provincia de Lugo: 162.

Villada: vila cabeza do concello do seu nome, provincia de Palencia: 52.

Villamayor: sine loc.: 183bis.

Villanueva de Oscos, Santa María de: antigo mosteiro na vila de Villanueva de Oscos, concello de Villanueva de Oscos, C.A. de Asturias: 168.

Vimieiros: celeiro real sine loc.: 180.

Vimieiros: lugar desaparecido na freguesía de San Paio de Ventosela, concello de Ribadavia, provincia de Ourense: 70 .

Vitoria: cidade cabeza do concello do seu nome, provincia de Álava, e capital da C. A. de Euskadi: 87, 88, 89, 90, 91, 212.

Viveiro, San Pedro de: freguesía do concello de Viveiro, provincia de Lugo: 110. 
Viveiro: vila cabeza do concello do seu nome, provincia de Lugo: 110, 113.

-Concello de: 122, 173.

$\mathbf{X}$

Xallas: antiga terra na actual provincia da Coruña que se estendería polo actual concello de Santa Comba, con cabeza na Pobra do seu nome: 75.

Xinzo: antigo lugar, hoxe vila de Xinzo de Limia, cabeza do concello do seu nome, provincia de Ourense: 101.

Xunqueira de Ambía, Santa María de: antigo priorado agostiño na praza de San Rosendo, freguesía de Santa María a Real de Xunqueira de Ambía, concello de Xunqueira de Ambía, provincia de Ourense: 4, 55, 56.

Xunqueira de Espadanedo, Santa María de: antigo mosteiro no lugar de Xunqueira de Espadanedo, freguesía de Santa María de Xunqueira de Espadanedo, concello de Xunqueira de Espadanedo, provincia de Ourense: 160, 161.

$\mathbf{Y}$

Yugar: aldea sine loc. no alfoz da cidade de Sevilla: 16.

$\mathbf{Z}$

Zamora: cidade cabeza do concello e provincia do seu nome: 1 .

\section{ÍNDICE DE PERSOAS}

A

Abraham aben Xuxén, xenro do almoxarife don Moyr: 206.

Afonso VII, rei de León e Castela: 27, 28, 30, 48, 72, 81, 83, 84, 85, 109, 116, 120, 128, 211, 212, 218.

Afonso VIII, rei de Castela e Toledo: 22.

Afonso IX, rei de León e Galicia: 18, 18bis, 19, 25, 26, 27, 28, 30, 31, 32, 33, 34, 35, 36, 37 , $38,39,40,41,43,44,46,47,48,49,50,51,52,53,56,59,61,63,64,65$, $65,70,71,72,73,80,81,98,101,110,111,118,119,120,126,142,146,148$, 159, 160, 167, 177, 178, 179, 197, 198, 199, 212, 221.

Afonso X, rei de Castela e León: passim.

Afonso III, rei de Portugal: 141, 150.

Afonso Fernández: 141.

Alfonso Pérez de la Cámara: 212.

André Fernández [de Castro], pertegueiro de Santiago: 12.

Ares González, fillo de Gonzalo Pérez de Borraxeiros: 185, 205. 


\section{B}

Berenguela, infanta de Castela e León: 88, 89, 93.

Berenguela Afonso: 182.

D

Diego Eanes: 52.

Domingo Eanes, alcalde sobrel fecho de la Cruziada: 100.

E

Elvira López: 63.

Enrique, infante de Castela e León: 76.

Enrique III, rei de Castela e León: 116.

Estefanía: 101, 220.

Estevo Fernández, adiantado e meiriño maior de Galicia: 162, 174, 175, 208, 209, 222.

Estevo Rodríguez, veciño de Ribadavia: 183.

\section{$\mathbf{F}$}

Fernando, mestre, cóengo de Santiago de Compostela: 93.

Fernando Afonso, cóengo de Lugo, vigairo do deádego: 192bis.

Fernando Afonso, cóengo de Santiago de Compostela: 93.

Fernando de la Cerda, infante de Castela e León: 168, 169, 183bis, 185, 205.

Fernando Eanes Batisela: 99.

Fernando II, rei de León e Galicia: 5, 17, 27, 28, 28, 31, 32, 33, 40, 41, 45, 71, 80, 81, 82, 116, 142, 143, 149, 157, 219.

Fernando III, rei de Castela e León: 2, 6, 7, 8, 9,12, 14, 22, 23, 25, 26, 28, 34, 47, 48, 49, $50,51,52,53,54,55,57,58,59,61,62,63,65,66,69,80,81,82,84,85$, 90, 92, 95, 97, 98, 106, 107, 108, 119, 123, 124, 130, 131, 142, 147, 153, 156, 159, 164, 165, 167, 176, 183bis, 195, 198, 199, 207, 211, 212, 221.

Fernando IV, rei de Castela e León: 212.

Fernando Pérez, fillo de Rodrigo Rodríguez de Sarria: 169.

Fernando Rodríguez de Castro: 11.

\section{G}

García, bispo de Silves: 129.

García Fernández, mestre de Alcántara: 117bis.

García Rodríguez de Neira: 59.

García Xil, meiriño maior de León: 115.

Gonzalo Eanes de Nóvoa: 117bis.

Gonzalo Eanes de Nóvoa: 12.

Gonzalo Fernández de Sanxurxo: 127. 
Gonzalo Morán, meiriño maior de León: 42.

Gonzalo Pérez de Borraxeiros, pai de Ares González: 185, 205.

Gonzalo Yáñez, porteiro de Afonso X: 88.

Gutierre Pérez, home de Afonso X: 220, 222.

Gutierre Suárez: 141.

L

Lope Díaz de Rojas, meiriño maior de Galicia: 163.

Lope Díaz: 205.

Loureno Suárez Gallinato: 123B.

Luis, herdeiro do reino de Francia: 88, 89, 93.

M

María Pérez, muller de Paio Arias: 70.

Marique Xil: 181.

Martín, bispo de León: 129.

Martiño Chapela: 123.

Martiño López, alcalde real: 136.

Martiño, bispo de Mondoñedo: 126.

Mateo, xuíz de Lugo: 96.

Men Rodríguez de Pontedeume: 2.

Miguel, bispo de Lugo: 8.

Moor Afonso: 127, 185, 205.

Moyr, almoxarife de Afonso X, sogro de Abraham aben Xuxén: 206.

Munio Fernández de Rodeiro, meiriño maior de Galicia: 12, 195.

$\mathbf{N}$

Nuno, bispo de Mondoñedo: 127bis.

Nuno Pérez, xuíz da terra de Pruzos: 2.

\section{o}

Osorio Díaz: 171.

\section{$\mathbf{P}$}

Paio Arias, marido de María Pérez: 70.

Paio Gómez Chariño: 223.

Pedro Cordeiro, alcalde de Afonso X: 131, 136, 139, 140.

Pedro Fernández: 122.

Pedro Fernández de Pontevedra, pescudador no bispado de Astorga: 42.

Pedro Martínez, porteiro de Afonso X: 206. 
Pedro Muñiz, mestre da Orde de Santiago: 209.

Pedro Nunes de Santiago, pescudador no bispado de Astorga: 42.

Pedro Pardo: 127.

Pedro Pérez de Lama de Dozón: 5.

Pedro Rodríguez, alcalde de Afonso X: 131, 136, 139, 140.

Pedro Rodríguez de Sarria, pai de Fernando Pérez: 169.

Ponce de Vale: 17, 105.

\section{$\mathbf{R}$}

Raimundo de Borgoña, conde de Galicia: 72.

Rodrigo Arias: 183.

Rodrigo García, meiriño maior de Galicia: 114, 115, 118, 127.

Rodrigo Gómez de Galicia: 91, 114, 127.

Rodrigo Rodríguez de Sarria, pai de Fernando Pérez: 169.

\section{S}

Sancho IV, rei de Castela e León: 2, 5, 116.

-infante: 180, 183, 193, 194, 196, 197, 198, 207, 208, 223.

Sancho Sánchez, escudeiro, enviado do rei de Aragón: 182.

Simón Ruiz de los Cameros: 204.

$\mathbf{T}$

Tareixa Xil: 144.

\section{$\mathbf{U}$}

Urbano IV, papa: 129.

Urraca Afonso, tía de Afonso X: 204.

V

Vasco López: 5.

$\mathbf{X}$

Xoán I, rei de Castela e León: 116.

Xoán II, rei de Castela e León: 116.

Xoán Afonso, arcediago [de Trastámara] compostelán: 129.

Xoán Arias, arcebispo de Santiago de Compostela: 14, 16, 75, 90, 93.

Xoán Fernández, meiriño maior de Galicia: 203, 205.

Xoán Fernández, porteiro de Afonso X: 182.

Xoán Gato: 145, 193, 194, 196.

Xoán Hurtado de Mendoza, meiriño maior de Galicia: 163. 


\section{REFERENCIAS BIBLIOGRÁFICAS}

- Álvarez Castrillón, José Antonio (2007): La comarca de los Oscos en la Edad Media. Poblamiento, economía y poder, Oviedo, Consejería de Cultura y Turismo/KRK Ediciones.

- Ayala Martínez, Carlos de (ed.) (1995): Libro de Privilegios de la Orden de San Juan de Jerusalén en Castilla y León (Siglos XII-XV), Madrid, Instituto Complutense de la Orden de Malta.

- Ballesteros Beretta, Antonio (1918), Alfonso X, emperador electo de Alemania, Madrid, Juan Pérez Torres.

- Ballesteros Beretta, Antonio (1984), Alfonso X el Sabio, Barcelona, El Albir.

- Barral Ribadulla, Dolores (1998): La Coruña en los siglos XiII al XV. Historia y configuración urbana de una villa de realengo en la Galicia medieval, A Coruña, Fundación Pedro Barrié de la Maza.

- $\mathrm{BCPMHAO} \mathrm{=} \mathrm{Boletín} \mathrm{de} \mathrm{la} \mathrm{Comisión} \mathrm{Provincial} \mathrm{de} \mathrm{Monumentos} \mathrm{Históricos} \mathrm{y} \mathrm{Artísti-}$ cos de Orense, 3 (1906-1909): «Documentos históricos»: 208 e 332.

- Buján RodríGuez, María de las Mercedes (1996): Catálogo archivístico del Monasterio de Benedictinas de San Payo de Antealtares, Santiago de Compostela, Santiago de Compostela, Consorcio de Santiago.

- CAl PARdo, Enrique (1984): El monasterio de San Salvador de Pedroso en tierras de Trasancos. Colección Documental, A Coruña, Deputación Provincial.

- Cal PARdo, Enrique (1985): «El monasterio de “Dueñas” de Santa Comba de Órrea», Estudios Mindonienses, 1, 13-81.

- Cal Pardo, Enrique (1990): Catálogo de los documentos medievales, escritos en pergamino, del Archivo de la Catedral de Mondoñedo (871-1492), Lugo, Deputación Provincial.

- CAl PARdo, Enrique (1991): «De Viveiro en la Edad Media», Estudios Mindonienses, 7, 11-226.

- Cal Pardo, Enrique (1999): Colección diplomática do Arquivo da Catedral de Mondoñedo, Santiago de Compostela, Consello da Cultura Galega.

- CAMBÓN SuÁREZ, Segundo (1957): El monasterio de Santa María de Melón (siglos XII y XIII), Santiago de Compostela, Universidade. Tese de doutoramento inédita.

- CaÑIzares del Rey, Ventura (2002): Colección Diplomática (569-1463). [Edición de Manuel Rodríguez Sánchez e Óscar González Murado]. Lugo, Diócesis de Lugo.

- CAÑIzARes del Rey, Ventura (2015): Colección Diplomática III (1183-1315). [Transcripción, edición e índices de Manuel Rodríguez Sánchez, Óscar González Murado e María Luisa Doval García]. Lugo, Diócesis de Lugo. 
- Cavero Domínguez, Gregoria/Encarnación Martín López (2000): Colección documental de la catedral de Astorga. II. (1126-1299), León, Caja España de Inversiones/ Archivo Histórico Diocesano de León.

- CDH-RAG = Colección de Documentos Históricos. Tomo I (1915), A Coruña, Boletín de la Real Academia Gallega.

- CRespo Pozo, José Santiago (1964-1966): «El Priorato de Santa María la Real de Junquera de Ambía», en Estudios (1964): 287-307 e 443-466, (1965): 242-262 e 441-472, (1966): 97-108.

- Díaz Martín, Luis Vicente (1997-1999): Colección documental de Pedro I de Castilla (1350-1369), Salamanca, Junta de Castilla y León, Consejería de Educación y Cultura.

- DACO = Documentos del Archivo de la Catedral de Orense (1917), Ourense, Comisión Provincial de Monumentos Históricos y Artísticos.

- Dono Lopez, Pedro (2010): Colección de documentos en pergamiño do mosteiro de Santa Comba de Naves. Introdución, edición e índices, Santiago de Compostela, Facultade de Filoloxía, Departamento de Filoloxía Galega. Tese de doutoramento inédita.

- Duro Peña, Emilio (1972): «Catálogo de documentos reales del Archivo de la Catedral de Orense (844-1520)», Miscelánea de Textos Medievales, 1, 9-146.

- Duro PeÑa, Emilio (1977): El monasterio de San Esteban de Ribas de Sil, Ourense, Deputación Provincial.

- FERNÁNDEZ RodRíguez, Manuel (2004): Toronium. Aproximación a la historia de una tierra medieval, Santiago de Compostela, Instituto de Estudos Galegos Padre Sarmiento.

- FERnÁNDEZ SuÁREZ, Elisa (1974): «El monasterio de Santa Cristina de Ribas de Sil», Boletín Auriense, 4, 7-66.

- FernándeZ de Viana y Vieites, José Ignacio (2009): Colección Diplomática do mosteiro de San Pedro de Vilanova de Dozón, Santiago de Compostela, Consello da Cultura Galega.

- Fernández de Viana y Vieites, José Ignacio/María Teresa GonZález Balasch (2002): «Pergamiños soltos do mosteiro de Caaveiro», Cátedra. Revista de Estudios Eumeses, 9, 337-447.

- Fernández-Villamil Alegre, Enrique (1942): «Privilegios reales del Museo de Pontevedra», Museo de Pontevedra, 1, 31-56, 79-106, 132-174.

- FlóREz, Henrique (1764): España Sagrada. Tomo XVIII. De las Iglesias Britoniense y Dumiense, incluidas en la actual de Mondoñedo, Madrid, Oficina de Antonio Marín.

- Gaibrois de Ballesteros, Mercedes (1922-1928): Sancho IV de Castilla, Madrid, Revista de Archivos, Bibliotecas y Museos. 3 tomos. 
- García-Fernández, Miguel/Diana Pelaz Flores/Ricardo Pichel (2020): «Galicia e El-Rei ou como reinar desde a distancia: comunicación política arredor de dous novos privilexios rodados de Xoán II», Madrygal. Revista de Estudios Gallegos, 23, 139-180.

- García Oro, José (1991): «La ciudad de Lugo y la Iglesia en la Baja Edad Media», Lucensia, 3, 47.

- García TAto, Isidro (2004): Las encomiendas gallegas de la Orden militar de San Juan de Jerusalén. Estudio y edición documental. Tomo I. Época medieval, Santiago de Compostela, Instituto de Estudos Galegos Padre Sarmiento.

- GonzálEz, Tomás (1830): Colección de privilegios, franquezas, exenciones y fueros concedidos a varios pueblos y corporaciones de la Corona de Castilla, copiados de orden de S. M. de los registros del Real Archivo de Simancas. Tomo V, Madrid, Imprenta Real.

- González Balasch, María Teresa (2004): El Tumbo B de la Catedral de Santiago, Santiago de Compostela, Cabildo de la S.A.M.I. de Santiago de Compostela/Seminario de Estudos Galegos.

- GonzÁlez Garcés, Miguel (2008): Historia de La Coruña. Edad Media, A Coruña, Fundación Caixa Galicia.

- González GonZÁLEZ, Julio (1943): Regesta de Fernando II, Madrid, CSIC-Instituto Jerónimo Zurita.

- GonZÁlez GonZÁLEZ, Julio (1944): Alfonso IX, Madrid, CSIC-Instituto Jerónimo Zurita.

- GonzÁLEZ GonzÁLEZ, Julio (1951): Repartimiento de Sevilla, Madrid, CSIC-Escuela de Estudios Medievales.

- GonZÁlEz GonzÁLEZ, Julio (1980): Reinado y diplomas de Fernando III, Córdoba , Caja de Ahorros y Monte de Piedad.

- GonZÁLEz JimÉnEZ, Manuel (ed.) (1991): Diplomatario andaluz de Alfonso X, Sevilla, El Monte. Caja de Huelva y Sevilla.

- GonZÁlez JiménEZ, Manuel/María Antonia CARMOnA RuIz (2012): Documentación e Itinerario de Alfonso X el Sabio, Sevilla, Universidad.

- GonZÁlEz VÁzQuEZ, Marta (1996): El arzobispo de Santiago: una instancia de poder en la Edad Media (1150-1400), Sada, Seminario de Estudos Galegos/Ediciós do Castro.

- Grassotti, Hilda (1981): Estudios medievales españoles, Madrid, Fundación Universitaria Española.

- HERNÁNDEZ, Francisco J. (1994): Las rentas del rey: Sociedad y fisco en el reino castellano del siglo XIII, Madrid, Centro de Estudios Ramón Areces.

- HeRnándeZ, Francisco J. (2021): Los hombres del rey y la transición de Alfonso X el Sabio a Sancho IV (1276-1286), Salamanca, Universidad. 2 vols. 
- Herrera, María Teresa/María Nieves SÁnchez/María Estela GonZÁlez De Fauve/ María Purificación ZABIa (1999): Textos y Concordancias de Documentos castellanos de Alfonso X, Madison, Hispanic Seminary of Medieval Studies. Ed. en CD-ROM.

- HerRero Jiménez, Mauricio (2004): «Documentos de la Colección de Pergaminos del Archivo de la Real Chancillería de Valladolid», en El Reino de León en la Edad Media, 11, León, Caja España de Inversiones/Archivo Histórico Diocesano de León: 9-240.

- KleINE, Marina (2015): La cancillería de Alfonso X. Actores y prácticas en la producción documental, Sevilla, Universidad de Sevilla - Cátedra Alfonso X el Sabio.

- LEIRÓs FeRnÁNDEZ, Eladio (1951): Catálogo de los pergaminos monacales del Archivo de la S.I. Catedral de Orense, Santiago de Compostela, El Eco Franciscano.

- López FerReIro, Antonio (1895): Fueros municipales de Santiago y su tierra. Ed. facsimilar (1975), Madrid, Castilla.

- López Ferreiro, Antonio (1901): Colección Diplomática de Galicia Histórica, Santiago de Compostela, Tipografía Galaica.

- LóPEZ Ferreiro, Antonio (1902): Historia de la Santa A.M. Iglesia de Santiago de Compostela. Tomo V, Santiago de Compostela, Seminario Conciliar Central.

- López SANGiL, José Luis (2002): «Relación de la documentación del monasterio de Santa María de Monfero», Estudios Mindonienses, 18, 279-740.

- LoRenzo, Ramón (2016): Colección documental do mosteiro de Montederramo, Santiago de Compostela, Consello da Cultura Galega.

- Lucas Álvarez, Manuel (1958): «La colección diplomática del monasterio de San Lorenzo de Carboeiro», Compostellanum, 3, 221-308 e 547-638.

- LuCAS ÁlvareZ, Manuel (1975): «El monasterio de San Julián de Moraime en Galicia», en Homenaje a Don Agustín Millares Carlo, tomo 2, 605-643, Las Palmas de Gran Canaria, Caja Insular de Ahorros de Gran Canaria.

- LuCAs Álvarez, Manuel (1998): El Tumbo A de la Catedral de Santiago. Estudio y Edición, Santiago de Compostela, Cabildo de la S.A.M.I. Catedral de Santiago de Compostela/Seminario de Estudos Galegos.

- LuCAS ÁlVAREZ, Manuel (1999): El archivo del monasterio de San Martiño de Fóra o Pinario de Santiago de Compostela, Sada, 2 tomos, Seminario de Estudos Galegos/ Ediciós do Castro.

- Lucas Álvarez, Manuel (2001): San Paio de Antealtares, Soandres y Toques: tres monasterios medievales gallegos, Sada, Seminario de Estudos Galegos/Ediciós do Castro.

- Lucas Álvarez, Manuel (2003): El monasterio de San Martiño Pinario de Santiago de Compostela en la Edad Media, Sada, Seminario de Estudos Galegos/Ediciós do Castro. 
- Lucas Álvarez, Manuel/Pedro Pablo Lucas Domínguez (1996): El monasterio de San Clodio do Ribeiro en la Edad Media: estudio y documentos, Sada, Seminario de Estudos Galegos/Ediciós do Castro.

- Maciñeira Pardo de Lama, Federico (1892): Crónicas de Ortigueira, A Coruña.

- Mansilla Reoyo, Demetrio (1958): «La documentación española del Archivo del Castel S. Angelo (395-1498)», Anthologica Annua, 5, 385-448.

- Martínez Martínez, Martín (1997): Cartulario de Santa María de Carracedo. 992-1550. Volumen I, Ponferrada, Instituto de Estudios Bercianos.

- Mayán Fernández, Francisco (1994): Historia de Mondoñedo. Desde sus orígenes hasta 1833, en que dejó de ser capital de provincia, Lugo, Deputación Provincial.

- Méndez Pérez, José/Pablo S. Otero Piñeyro Maseda/Miguel Romaní Martínez (2016): El monasterio de San Salvador de Chantada (siglos XI-XVI). Historia y documentos, Santiago de Compostela, Instituto de Estudos Galegos Padre Sarmiento.

- MeruÉndano, Leopoldo (1908): «Los documentos antiguos del archivo del Ayuntamiento de Ribadavia», Boletín de la Comisión Provincial de Monumentos Históricos y Artísticos de Orense, 3:60, 193-202.

- Meruéndano, Leopoldo (1909): «El fuero municipal de Ribadavia», Boletín de la Comisión Provincial de Monumentos Históricos y Artísticos de Orense, 3:69, 373-385.

- Miguel Vigil, Ciriaco (1889): Colección histórico-diplomática del Ayuntamiento de Oviedo, Oviedo, Imprenta de Pardo, Gusano y Comp. $\underline{\text { a Editores. }}$

- Miramontes Castro, María (1996): «Catálogo da documentación medieval do Museo de Pontevedra», Museo de Pontevedra, 50, 109-432.

- Novo Cazón, José-Luis (1986): El priorato santiaguista de Vilar de Donas en la Edad Media (1194-1500), A Coruña, Fundación Pedro Barrié de la Maza.

- Palacios Martín, Bonifacio (dir.) (2000): Colección diplomática medieval de la Orden de Alcántara (1157?-1494). Tomo I: De los orígenes a 1454, Madrid, Fundación San Benito de Alcántara/Editorial Complutense.

- Pardo Rodríguez, María Luisa (2009): La cancillería de don Fernando de la Cerda, infante de Castilla y León (1255-1275), León, Universidad.

- Pérez-Bustamante, Rogelio (1976): El gobierno y la administración territorial de Castilla (1230-1474), Madrid, Universidad Autónoma. 2 vols.

- Pérez Rodríguez, Francisco Javier (2004): Os documentos do Tumbo de Toxos Outos, Santiago de Compostela, Consello da Cultura Galega.

- Pichel GotérRez, Ricardo (2009): Fundación e primeiros séculos do mosteiro bieito de Santo Estevo de Chouzán (sécs. IX-XIII), Noia, Toxosoutos. 
- Portela Silva, María José/José García Oro (1997): La Iglesia y la ciudad de Lugo en la Baja Edad Media. Los señoríos. Las instituciones. Los hombres, Santiago de Compostela, Instituto de Estudos Galegos Padre Sarmiento.

- Rey CAíña, José Ángel (1985): Colección diplomática de Ferreira de Pallares, Granada, Universidad. Tese de doutoramento inédita.

- RISCO, Manuel (1798): España Sagrada. Tomo XLI. De la santa Iglesia de Lugo: continuación de su historia desde el siglo XII hasta fines del XVIII, Madrid, Viuda e Hijo de Marín.

- Rodríguez CARBia, Eloy/José Carlos Beiró PiñeIro (2003): Cartas de privilexio e franqueza da monarquía á vila de Padrón (Séculos XII ao XVII), Sada, Ediciós do Castro.

- Rodríguez Fernández, Carlos (1990): La colección diplomática de San Vicente del Pino, Granada, Universidad.

- Rodríguez MuÑIz, Víctor (2010): O mosteiro de Santa Cristina de Ribas de Sil na Idade Media, Ourense, Boletín Auriense.

- Romaní Martínez, Miguel (1989): Colección diplomática do mosteiro cisterciense de Santa María de Oseira (Ourense), 1025-1310, Santiago de Compostela, Departamento de Historia I.

- Ruiz Asencio, José Manuel (1993): Colección documental del Archivo de la Catedral de León, VIII (1230-1269), León, Centro de Estudios e Investigación «San Isidoro»/ Caja España de Inversiones/Archivo Histórico Diocesano.

- Ruiz de la PeÑa Solar, Juan Ignacio (2007): «Desarrollo urbano y reacción señorial: monasterios 'versus' concejos en el noroeste peninsular (siglos XII-XIII)», en El monacato en los reinos de León y Castilla (siglos VII-XIII). X Congreso de Estudios Medievales, 2005, Ávila, Fundación Sánchez/Albornoz, 327-360.

- SÁNCHEZ BeLDA, Luis (1953): Documentos reales de la Edad Media referentes a Galicia. Catálogo de los conservados en la sección de Clero del Archivo Histórico Nacional, Madrid, Dirección General de Archivos y Bibliotecas.

- Torres Fontes, Juan (1977): «La Orden de Santa María de España», Miscelánea Medieval Murciana, 3, 73-118.

- VAquero Díaz, María Beatriz (2004): Colección diplomática do mosteiro de San Salvador de Celanova (ss. XIII-XV), Vigo, Concello de Celanova/Universidade de Vigo.

- Vaquero Díaz, María Beatriz/Francisco Javier Pérez Rodríguez (2010): Colección documental del Archivo de la Catedral de Ourense, II (1230-1300), León, Centro de Estudios e Investigación «San Isidoro»/Caja España de Inversiones/Archivo Histórico Diocesano. 


\title{
La piel del leopardo: Galicia y el ordenamiento territorial alfonsí
}

\author{
Francisco J. Hernández \\ Carleton University, Ottawa (Canadá)
}

DOI: 10.17075/gtax.2021.003 
* Simon Doubleday me convenció para que escribiera este trabajo y luego ha contribuido a mejorarlo con observaciones muy pertinentes. He podido superar en parte las limitaciones bibliográficas del confinamiento en Ottawa gracias a los materiales que Pablo Ordás, Miguel Calleja Puerta y José Antonio Álvarez Castrillón me han enviado generosamente desde Galicia y Asturias. Mi hermano Mario, también desde Galicia, ha leído, releído y comentado detalladamente este trabajo con perspicacia, erudición y paciencia extraordinarias. Francisco Javier Pérez Rodríguez ha dialogado conmigo desde Ourense, guiándome con sabiduría y generosidad por la geografía y la historia de Galicia, ha identificado gran parte de los topónimos problemáticos citados en los libros de cuentas y ha hecho posible la realización del mapa aquí publicado, junto con otros que ha sido necesario dejar para mejor ocasión. A todos ellos, mi más profundo agradecimiento. Naturalmente, soy responsable único y exclusivo de cualquier error que haya podido deslizarse en lo que sigue. 
A mi hermano Mario

La Galicia que Alfonso X hereda como uno de sus reinos principales en 1252 estaba marcada, como la piel de un leopardo, con las manchas de los señoríos laicos y eclesiásticos, y con los claros de las tierras de hombres sujetos directamente al rey, agrupados en concejos. Mucho más tarde, a fines del siglo XVIII, las manchas se habían extendido hasta oscurecer la mayor parte de esa piel. El señorío secular afectaba por entonces al 48\% de la población y al 54\% de la tierra; el episcopal al 25\% sobre un 20\% del territorio; y el monástico al 13\% en ambas categorías, lo que dejaba poco más del 10\% bajo el dominio directo de la Corona². Esas medidas globales desvirtúan una distribución desigual: el realengo se concentraba en el noroeste (corregimientos de Viveiro, Betanzos y A Coruña), quedaba eclipsado en el centro (Lugo y Santiago) y reaparecía débilmente en Tui y Ourense ${ }^{2}$. Dentro de la monarquía hispánica de la Edad Moderna, Galicia era la «tierra señorial por excelencia»³, pero esta situación, que se prolongó hasta principios del siglo XIX, no había estado predeterminada.

La Galicia del siglo xIII no presagiaba necesariamente ese futuro. Aunque no podemos cuantificarla con instrumentos como los creados en el XVIII por el Marqués de la Ensenada, la publicación reciente de una serie de estudios y ediciones de fuentes documentales permite entrever una configuración distinta de la que terminó por imponerse al final de la Edad Media.

En la Galicia medieval había dos regímenes básicos de dominio territorial: la tierra llana (a terra chá, en gallego), con villas aforadas, sin más señor que el rey (realengos, sujetos a los fueros y tributos de la Corona, fraccionada en mandationes, prestimonios, tenencias, etc.), y la tierra privilegiada, con señoríos eclesiásticos (cotos) o laicos, cuyos pobladores estaban básicamente sujetos a la tierra que trabajaban y debían ofrecer por ella tributos y prestaciones diversas a sus señores ${ }^{4}$. El contraste entre ambas categorías, y el forcejeo a favor de una u otra, subyace en el diálogo judicial entre Alfonso X y el obispo de Ourense en 1259. El obispo exigía que los habitantes de la ciudad le dieran «seruicios e derechos [que] se acostumbraron a dar a los sennores de Gallizia en las sos tierras, e en los sos cotos, segund la costumbre de la tierra»; Alfonso $\mathrm{X}$ reconoció esos derechos, pero empezó a socavarlos sustrayendo de la jurisdicción

1 Roel 1989: 119-120; Saavedra 1990: 109.

2 Saavedra 1990: 112, con un análisis detallado.

3 López Díaz 1991: 561-62.

4 El contraste entre tierra llana y villas aforadas ya fue señalado por López Ferreiro, en 1895: 153-154. 
episcopal a los orensanos cuando tuvieran pleitos entre sí y ordenando «que ninguno dellos no peche ninguna cosa sino cuemo lo usan en las otras uillas de Gallizia aforadas, que más acerca e más uezinas son de Orens» ${ }^{5}$.

Entre las villas aforadas, sometidas directamente a la Corona, no estaba ninguna de las cinco ciudades episcopales: Santiago, Tui, Ourense, Lugo, Mondoñedo. Tampoco los señoríos laicos tenían gran importancia. Las familias aristocráticas del XII, que habían dominado el país como condes al servicio de los reyes de León, no lograron consolidarse como verdaderos linajes al no contar con un patrimonio territorial suficiente ni estable, como ejemplifica el caso paradigmático de los Traba ${ }^{6}$. Frente a los caseríos de los concellos de realengo y los pazos de la nobleza rural se erguían las moles catedralicias de los eclesiásticos, cuyas capitales y cotos estaban sometidos al señorío de sus prelados, empezando con el arzobispo compostelano, señor de la inmensa Tierra de Santiago ${ }^{7}$. Relativamente alejados de las ciudades estaban los cotos señoriales de los 185 cenobios, 33 de ellos femeninos, que se extendían por todo el antiguo reino, un mundo monástico cuya amplitud y complejidad podemos contemplar ahora gracias al espléndido estudio de Francisco Javier Pérez Rodríguez ${ }^{8}$. Aunque sin llegar a niveles tibetanos, la Galicia de mediados del siglo XIII podría ser descrita como una tierra de clérigos y monjes. No obstante, frente al listado anterior, cabe citar los 175 centros principales de recaudación tributaria (con 43 puntos menores dentro del condado de Trastámara) que la Corona mantenía en Galicia en la década de $1290^{9}$. Aunque no se trate de instituciones estrictamente comparables, las magnitudes en juego sugieren un cierto equilibrio entre los territorios sometidos a la Corona y a la Iglesia en el reino de Galicia.

Así era ya ese reino en 1230, cuando Fernando III lo recogió a la muerte de su padre, Alfonso IX, último rey independiente de León; y así continuó durante la primera década del reinado alfonsí (1252-1284). Luego vino el declive de las instituciones eclesiásticas que empieza a finales de la década de 1260 y parece resultado de presiones internas (vacío arzobispal de Santiago entre 1266 y $1286^{10}$, usurpaciones generalizadas en los cotos monásticos ${ }^{11}$ ) y externas (exacciones fiscales de Alfonso X, guerra civil de 1282-1284, minoría caótica de Fernando IV desde 1295²), las cuales se

5 1259, febrero, 5. Toledo. Ed. B. Vaquero Díaz y F. J. Pérez Rodríguez, 2, 2010: 284-289, n.o 471.

6 Pallares y Portela, que proporcionan un esquema de la descendencia del «fundador», Pedro Froilaz (1993: 832). Barton (1997) ofrece un árbol genealógico más completo (p. 306) y una serie, en orden alfabético, de biografías esquemáticas de los sucesores del mismo P. Froilaz (Fernando Pérez, Gonzalo Fernández y Gómez González), con las tenencias que ocuparon (Appendix 1).

7 Pallares Méndez, Pérez Rodríguez, González Vázquez, Vaquero Díaz 1992.

8 2, 2019. Listado en pp. XIV-XXVI.

$9 R R, 2,260-303$.

10 López Ferreiro 1902: 228-257; HH: 4.4.6.

11 Ver más adelante, nota 143.

12 Sobre los desastres que siguieron a la muerte de Sancho IV en Galicia, ver los dramáticos testimonios recogidos por Lorenzo Rodríguez, notario de Búbal y Castela (Lu.) en 1302-04-29 (ed. Dono López 2010, n. 82). También López Ferreiro (1902: 268-269). 
manifiestan dramáticamente en el desplome de la población monacal en las tres décadas finales del siglo ${ }^{13}$.

Esa curva descendente se cruza con otra de signo contrario, empujada por el ímpetu regalista de Alfonso X (1252-1284) y Sancho IV (1284-1295), monarcas que favorecen a los concejos frente a los señores, crean o refuerzan las pueblas de realengo, y reclaman el poder judicial supremo frente a la nobleza privilegiada y los eclesiásticos ultramontanos.

\section{ABADENGOS: EXCEPCIONALIDAD GALAICA}

Los tres puntos anteriores han sido cuando menos esbozados por otros historiadores, pero la existencia de documentos poco estudiados y la aparición de otros inasequibles hasta ahora permiten contemplar más de cerca lo que parece haber sido una vigorosa política territorial alfonsí destinada a contener o reducir los señoríos eclesiásticos y seculares ${ }^{14}$. Entre otras valiosas fuentes, publicadas en los últimos años dentro y fuera de Galicia, contamos con los libros de cuentas de la cancillería real, que yo mismo he sacado a la luz y han sido poco explotados en este contexto. Los registros de Alfonso X fueron mayormente destruidos a su muerte en 1284, pero sus libros de contabilidad sobrevivieron y sirvieron de modelo para mantener su sistema tributario durante el reinado siguiente de Sancho IV (1284-1295) ${ }^{15}$. A través de ellos es posible vislumbrar la visión que el «centro» —es decir, la Corte, dondequiera que estuviera, que siempre fue lejos con Alfonso X, en Burgos, Toledo, Sevilla, etc.- tenía sobre la organización territorial y política de Galicia, y las medidas adoptadas en consecuencia.

Como instrumentos de contabilidad, creados para anotar y vigilar la actividad económica de la Corona ${ }^{16}$, estos libros tienen un carácter estrictamente utilitario. Básicamente, conservan tres tipos de cuentas: 1) padrones, que recogen los centros de tributación, con sus ingresos, y ofrecen una geografía hacendística de los reinos $^{17}$, excluido el de Murcia, que tenía contabilidad aparte; 2) libros de ingresos y gastos diarios de la Cancillería organizados cronológicamente ${ }^{18}$; y 3) nóminas de Cor-

13 Pérez Rodríguez, 1, 2019: 256-258.

14 Asunto ya esbozado por Pérez Rodríguez 2015: 446-453.

15 Libros conservados desde fines del siglo XiII en la catedral de Toledo, aunque algunos de ellos fueron llevados a Madrid en el siglo XIX y se custodian en el Archivo Histórico Nacional. Bibliografía esencial en $H H$ (2021) con lista de «Libros y cuadernos de la cancillería castellana» publicados hasta ahora, a los que hay que añadir los otros ocho editados en en el mismo libro, identificados como R1, R2, R3, R4, R5, R6, R7 y R8.

16 Uso ‘Corona' en el sentido metafórico de ‘reino', tal como hoy se entiende, aunque su terminología no empezó a extenderse en el de Castilla y León hasta la década de 1320 (Hernández 2018: 398-402). La Academia la describe de este modo: «CoRONA por cierta especie de figura synecdoche, que toma el signo por el significado, se usa freqüentemente para significar el Réino o la Monarchia: como La Corona de España, la Corona de Fráncia. Latín. Regnum», 1729: https://webfrl.rae.es/DA.html.

17 Publicados en $R R, 1993$.

18 Publicados por Gaibrois 1922-1928 y López Dapena 1984. 
$t^{19}$, ordenadas según el rango de las personas: miembros de la familia real, fuerzas armadas, oficiales del rey, y proveedores de bienes y servicios. Su carácter esencialmente económico, desprovisto de juicios de valor, así como el hecho de ser productos directos de la cancillería real, otorgan a estos libros un inapreciable valor histórico. Esa indudable condición no les priva de errores, que no deben de ser descartados como tales, sino tenidos en cuenta como un aspecto más del funcionamiento de la administración «central» castellanoleonesa.

Los padrones más completos con que contamos pertenecen a los años de 1290 y 1292. Galicia aparece en ellos como parte de un reino de León que, a efectos de la recolección de tributos ordinarios (I), estaba subdividido en cuatro regiones, ordenadas topográficamente desde el sur por la cancillería: [1] Extremadura leonesa, con 17 lugares situados en las diócesis de Badajoz, Cáceres, Coria, Ciudad Rodrigo y Salamanca, [2] Tierra de León, con 80 lugares en Zamora y León, [3] Asturias, con 128, y [4] Galicia, con 175 centros principales, a los que se suman 43 puntos menores dentro del condado de Trastámara, como ya he adelantado. Estos padrones solo incluyen los lugares que tributaban regularmente a la Corona, y omiten los dominios eclesiásticos y laicos, cuyos señores recibían las gabelas vasalláticas de sus habitantes. En el caso de Galicia, eso supone que las cinco capitales eclesiásticas, Santiago, Tui, Ourense, Lugo y Mondoñedo, sometidas al señorío de los obispos y cabildos correspondientes, quedan excluidas de esos padrones.

Los padrones de tributos ordinarios (I) servían para calcular los ingresos y gastos de todo el reino, y pueden ser considerados precedentes de los actuales presupuestos generales del Estado. A su lado, los libros de cuentas de 1290 y 1292 contienen otros siete padrones menores, con una extensión geográfica reducida en función de su temática: tercias (II), salinas (III), morerías (IV), heredamientos (V), fonsadera de Asturias (VI), servicio de los eclesiásticos (VII) y tributos de los judíos (VIII). Galicia solo aparece en dos de esos listados: el que enumera los heredamientos dados por el rey, que se limita a ocho personas $(\mathrm{V})^{20}$, y el que prescribe el servicio extraordinario que debían pagar los eclesiásticos en 1290 (VII), el cual consideraremos enseguida.

No causa sorpresa que Galicia carezca de centros de tributación para las minorías islámica y judía, ya que ambas tenían una presencia muy escasa en la región ${ }^{21}$. Tampoco sorprende su ausencia en la breve sección sobre salinas, dada la exigüidad de la producción local ${ }^{22}$, aunque el propio libro de 1290 registra el tributo sobre la sal pagado en Viveiro ${ }^{23}$. Lo que realmente es chocante es que Galicia no figure en la sección sobre las tercias eclesiásticas (II), recogidas sistemáticamente en los de-

19 Publicados en $H H$.

$20 R R, 1: 330-331$.

21 Sobre los judíos gallegos ver Antonio Rubio 2007 y 2012; sobre los musulmanes y conversos, González Paz 2004. No tienen en cuenta la información negativa de $R R$.

22 Ferreira Priegue 1988: 157.

23 Viveiro tributaba por ella, pero como parte de los derechos debidos al rey $(R R, 1: 260)$. 
más reinos, contra viento episcopal y marea papal, durante los reinados de Alfonso X y Sancho IV. No obstante, esa situación parece congruente con la exención de tributos ordinarios disfrutada por las capitales eclesiásticas. Eso no quiere decir que sus habitantes estuviesen libres de tributos: los ordinarios iban al obispo y los extraordinarios al rey. A su vez, estos fueron pedidos con tanta o mayor frecuencia que los ordinarios, disfrazados con el inocuo nombre de servicios, a partir de 1269.

Los eclesiásticos gallegos no estaban libres de esa plaga. También ellos tuvieron que arrimar el hombro. Sirva como ejemplo el servicio cobrado en 1290 para enjugar los gastos de la guerra con Aragón en el verano de $1289^{24}$ :

\begin{tabular}{|l|l|l|l|}
\hline $\begin{array}{l}\text { Servicio exigido a las diócesis del reino de León } \\
\text { (según el orden de la cancillería) }\end{array}$ & mrs & \\
\hline Zamora: obispo + cabildo & 10000 & \\
\hline Salamanca: obispo + cabildo & 10000 & \\
\hline Ciudad Rodrigo: obispo + cabildo & 3000 & \\
\hline Coria: obispo (3000) + cabildo (1000) & 4000 & & \\
\hline Badajoz: obispo, eximido de pago 25 & 0 & $\rightarrow 37000$ & \\
\hline León, sede vacante: solo deán y cabildo & 10000 & \\
\hline Mondoñedo: obispo + cabildo & 10000 & \\
\hline Lugo: obispo + cabildo & 6000 & \\
\hline Ourense: obispo + cabildo & 12000 & \\
\hline Tui, sede vacante: solo el cabildo & 6000 & $\rightarrow 54000$ & \\
\hline Santiago: arzobispo + cabildo & 20000 & $\rightarrow 8000$ & \\
\hline Oviedo: sede vacante: solo deán y cabildo & 8000 & $\rightarrow 8000$ & \\
\hline Astorga: sede vacante: solo deán y cabildo & 8000 & $\mathbf{1 0 7 0 0 0}$ \\
\hline [suma de las catedrales: & & & \\
\hline
\end{tabular}

Las aportaciones exigidas a las catedrales oscilan dentro de los márgenes fijados para los tributos ordinarios de ciudades enteras. Limitándonos a las del reino de León por las mismas fechas, vemos que Badajoz tributaba 9200 mrs; Cáceres, 4500; Coria, 2000; Ciudad Rodrigo, 14 040; Salamanca, 31 072; Zamora, 24 400; León, 12 900; Astorga, 9600; y Oviedo, 5100²6.

Del total requerido a las trece sedes catedralicias del reino de León, las cinco de Galicia contribuyen con algo más de la mitad (50,46\%). No obstante, el

$24 R R, 1: 334-336$. Sobre la guerra contra Alfonso III de Aragón y Alfonso de la Cerda, pretendido rey de Castilla, ver Gaibrois 1922: 229-235.

25 La exención seguramente se deba a la devastadora guerra civil desatada en Badajoz entre bejaranos y portugaleses, cruelmente reprimida por Sancho IV en 1289.

26 Tablas en $R R, 1$ : CI-CV. 
cálculo no refleja del todo las posibilidades de cada una de ellas. Aparte del agujero provocado por la exención de Badajoz, están las aportaciones anómalas de las sedes vacantes, cuyo cabildo catedralicio es el único contribuyente. Este, a su vez, solía tener una asignación similar a la de Coria, donde los canónigos tributan la cuarta parte del total, al tener ingresos en esa proporción respecto al obispo - proporción que no se cumplía, por excepción, en Santiago ni en Tui, cuyos cabildos eran más ricos que el prelado ${ }^{27}$ - . Así, resulta que las cuatro sedes vacantes aportan aproximadamente la cuarta parte de lo que cabría esperar si tuviesen obispo. No obstante, esa reducción de la aportación eclesiástica no afectaba a los ingresos globales de la Corona, ya que esta tenía el control directo de las mesas, o rentas, episcopales mientras las sedes permanecían vacantes.

En cuanto a la lista de abades (benedictinos y cistercienses), priores (agustinos) y cenobios, que debían contribuir al servicio de 1290, vemos que, de los 57 incluidos en la lista para todo el antiguo reino leonés, veintiséis estaban dentro de Galicia y, aunque lo eran todos los que están, no están todos los que había: faltan todos los de la diócesis de Ourense, donde se contaban, por lo menos, otros dieciséis, algunos tan importantes como los monasterios benedictinos de Celanova y Santo Estevo de Ribas de Sil, y los cistercienses de Oseira, Xunqueira de Espadanedo y Montederramo $^{28}$. La lista elaborada por la cancillería no solo presenta esa clamorosa omisión; también comete otro error de bulto al colocar dentro de la diócesis de Mondoñedo a once monasterios que estaban en la de Santiago.

$/[$ f. $49 \mathrm{v} / \mathrm{a}]$

\begin{tabular}{|c|c|}
\hline \multicolumn{2}{|l|}{ [Galicia] } \\
\hline Abades y monasterios del obispado de Mondoñedo ${ }^{29}$ & mrs \\
\hline $\begin{array}{l}\text { El abad e el conuento del monesterio de Monfero }{ }^{30} \cdot \mathrm{ii} \cdot \mathrm{mill} \text { mrs. [Cister / diócesis } \\
\text { de Santiago] }\end{array}$ & 2000 \\
\hline $\begin{array}{l}\text { El abad e el conuento de Villanueua de Lorençana }{ }^{31} \text {.iiii-mill mrs. [OSB / } d \text {. de } \\
\text { Mondoñedo] }\end{array}$ & 4000 \\
\hline El prior e el conuento de Caaueyro ${ }^{32}$.ii.mill mrs. [agustinos ${ }^{33} /$ d. de Santiago] & 2000 \\
\hline
\end{tabular}

27 Y lo siguieron siendo hasta el siglo XVIII (Eiras Roel 1989: 127).

28 Estos y los anteriores se encuentran entre los 83 monasterios gallegos, 18 de ellos femeninos, citados en el testamento de 1199 otorgado por Urraca Fernández de Traba, e identificados por Pérez Rodríguez (1, 2019: 299-304). El testamento, de 1199, julio 30, fue publicado por López Ferreiro en 1901.

29 Se indica la orden a que estaban afiliados en 1290 y la diócesis a la que pertenecía cada uno. Francisco J. Pérez Rodríguez me ha ayudado a resolver la mayoría de las identificaciones problemáticas. Para la identificación completa de cada cenobio, ver su obra de 2019.

30 Santa María de Monfero.

31 San Salvador de Lourenzá.

32 San Xoán de Caaveiro.

33 Canónigos regulares de San Agustín. 


\begin{tabular}{|c|c|c|}
\hline El prior de Sant Johan de Coua ${ }^{34}$ mill.mrs. [agustinos / d. de Santiago] & 1000 & \\
\hline El abad de Sant Andrés ${ }^{35}$.ii.mill mrs. [OSB / d. de Santiago] & 2000 & \\
\hline El abad de Çys ${ }^{36}$.ii.mill mrs. [OSB / d. de Santiago] & 2000 & \\
\hline El abad de Bergondo ${ }^{37} \cdot d \cdot$ mrs. $[O S B / d$. de Santiago $]$ & 500 & \\
\hline El abad de Siauia ${ }^{38} \cdot d \cdot \operatorname{mrs} .[O S B / d$. de Santiago] & 500 & \\
\hline El abad de Meyramia ${ }^{39}$ mill mrs. [OSB / d. de Santiago] & 1000 & \\
\hline El abad de Sant Yusto de Tojos Outos mill.d. mrs. [OSB / d. de Santiago] & 1500 & \\
\hline El abad de Sant Yoane de Poyo ${ }^{40}$ mill.d. mrs. [OSB / d. de Santiago] & 1500 & \\
\hline El abad de Armenteyr $a^{41}$ mill.d. mrs. [Cister / d. de Santiago] & 1500 & \\
\hline Summa xix.mill.[d.] & & 19500 \\
\hline \multicolumn{3}{|l|}{ Abades e priores e conuentos del obispado de Tui } \\
\hline El abad e el conuento de Melon ${ }^{42}$.iii-mill mrs. [Cister / d. de Tui] & 3000 & \\
\hline El abad d'Oya ${ }^{43}$.ii-mill mrs. [Cister / d. de Tui] & 2000 & \\
\hline El abad de Barrantes ${ }^{44} \cdot d \cdot$ mrs. [OSB / d. de Tui] & 500 & \\
\hline El prior de Pedroso ${ }^{45} \cdot d \cdot$ mrs. [agustinos / d. de Mondoñedo] & 500 & \\
\hline Summa $\quad$ vi·mill. & & 6000 \\
\hline \multicolumn{3}{|l|}{ Abades e conuentos del obispado de Lugo } \\
\hline El abad e el conuento de Penil${ }^{46} \cdot d \cdot$ mrs. $[O S B /$ d. de Lugo $]$ & 500 & \\
\hline El abad de Mont Fort ${ }^{47}$ mill mrs. [OSB / d. de Lugo] & 1000 & \\
\hline El abad de Sant Moes ${ }^{48}$.ii.mill mrs [OSB / d. de Lugo] & 2000 & \\
\hline El abad de Chantada ${ }^{49} \cdot d \cdot \operatorname{mrs}$. [OSB / d. de Lugo] & 500 & \\
\hline El abad de Castro de Rey $\cdot d \cdot$ mrs. [Cister / d. de Lugo] & 500 & \\
\hline [f. 49v/b] El abad de Leyrado ${ }^{50}$ mill mrs. [Ferreira de Pallares, OSB / d. de Lugo] & 1000 & \\
\hline
\end{tabular}

34 San Xoán da Cova.

35 San Pedro de Soandres, diócesis de Santiago.

36 San Salvador de Cis, monasterio benedictino situado en Oza dos Ríos (Co.).

37 San Salvador de Bergondo.

38 San Mamede de Seavia.

39 San Xulián [=Julián] de Moraime.

40 San Xoán de Poio, Pontevedra, fue benedictino; hoy es convento mercedario.

41 Santa María de Armenteira.

42 Santa María de Melón.

43 Santa María de Oia.

44 San Salvador de Barrantes.

45 San Salvador de Pedroso. F. J. Pérez me comenta: «no está en el obispado de Tui jsino en el de Mondoñedo!».

46 F. J. Pérez, sugiere que se trata de San Vicente de Pombeiro [Cluny]; a pesar de la diferencia de nombre. El hecho de «que vaya antes de Monforte, del que está cerca, lo hace... probable».

47 San Vicente de Monforte.

48 San Xulián de Samos.

49 San Salvador de Chantada.

50 A mi nota de «no localizado», contesta F. J. Pérez: «No me extraña, porque no hay ningún monasterio de Leirado, ni en la diócesis de Lugo ni en otra; estando regido por un abad y con esa cantidad, lo normal, por exclusión, es que se trate de Santa María de Ferreira de Pallares [OSB], que es el que queda con posibilidades para satisfacer eso, pues los demás ya están todos: Meira, Penamaior, Samos, Castro de Rei, Chantada, Pombeiro y Carboeiro». 


\begin{tabular}{|l|l|l|}
\hline El abad de Sant Lorenço de Caruoeiro ${ }^{51}$ mill mrs. [OSB / d. de Lugo] & 1000 & \\
\hline El abad de Sant Antolin ${ }^{52}$ d’Amatos mill mrs. [OSB / d. de Lugo] & 1000 & \\
\hline El abad de Meyra ${ }^{53}$ mill.d· mrs. [Cister / d. de Lugo] & 1500 & \\
\hline El abad de Peña Mayor ${ }^{54}$ mill mrs. [Cister / d. de Lugo] & 1000 & \\
\hline Summa ·x.mill & & $\mathbf{1 0 0 0 0}$ \\
\hline [suma de los monasterios] & & $\mathbf{3 5 5 0 0}$ \\
\hline
\end{tabular}

La omisión de los monasterios aurienses sería advertida, cuando menos, por los oficiales de la Corona residentes en la zona, como «Guillem Pérez, escriuano del rrey, rreçebedor das contas e das pesquisas por el rrey en Gallizia», hombre que había participado en la redada de 1285 para identificar y penalizar a los usureros cristianos y que, a principios de 1286, había realizado una pesquisa para fichar a los pecheros gallegos que habían evitado tributar haciéndose pasar por caballeros ${ }^{55}$. En todo caso, el desaguisado ya se había remediado cuatro años después, cuando Sancho IV volvió a pedir un extraordinario sacrificio económico para sufragar la conquista de Tarifa ${ }^{56}$. Los libros de cuentas revelan que la cancillería tenía ahora datos más precisos sobre la estructura eclesiástica de Galicia y la identidad de sus centros más prósperos, aunque todavía coloca dos monasterios lucenses dentro de la diócesis de Santiago:

\section{Tributos extraordinarios pedidos a la Iglesia}

\begin{tabular}{|l|l|l|}
\hline Diócesis de Santiago & $1294^{57}$ & $1290^{58}$ \\
\hline arzobispo $(30000)+$ cabildo $(50000)$ & $80000^{59}$ & 20000 \\
\hline S. a María de Sar [agustino] & 1000 & - \\
\hline S. Paio de Antealtares [OSB] & 3000 & - \\
\hline S. Pedro ${ }^{60}$ de Fóra $[O S B]$ & 2000 & - \\
\hline
\end{tabular}

51 San Lourenzo de Carboeiro.

52 Santo Antoniño de Toques.

53 Santa María de Meira.

54 Santa María de Penamaior.

55 AHN, Clero, c. 502/14. Carta de 1286-01-06, A Coruña, con copia de la orden de Sancho IV (1285-06-10, Toledo). Ed. Gaibrois, 3, 1922-1928: n.o 83 (omite el texto que precede a la carta real); López Sangil 2020: n. 540. Guillem Pérez está entre los escribanos del rey en la Nómina de 1285, con una soldada anual de $200 \mathrm{mrs}(H H, \mathrm{R} 3: 22.16)$ y aparece entre «los que cogieron o pesquirieron fecho de las osuras [sic] de Gallizia [en 1285]: auienlo de recabdar Pero Ferrandez de Çella $\tau$ Guillen Perez, escriuanos del Rey» (HH, R1: 449).

56 Contexto en Gaibrois 1919-1920.

57 1294-03-03, Valladolid. Tributo solicitado para sufragar el sitio de Tarifa. Ed. López Dapena 1984: $345-346$

58 1290-01-31, Toledo. Servicio impuesto para pagar por la guerra con Aragón en 1289. Ed. $R R$, 1: 334-336. La petición de 1290 tiene una distribución caótica: coloca la mayor parte de los monasterios de Santiago en la diócesis de Mondoñedo.

59 La asignación del cabildo, mucho más alta que la del arzobispo, es totalmente anómala.

60 López Dapena: «Martín». 


\begin{tabular}{|c|c|c|}
\hline S. Xusto de Toxos Outos [OSB] & 2000 & 1500 \\
\hline S. a María de Sobrado [Cister] & 4000 & - \\
\hline - -S. ${ }^{a}$ María de Meira [Cister] $\rightarrow$ diócesis de Lugo & 1000 & 1500 \\
\hline S. a María de Monfero [Cister] & 1000 & 2000 \\
\hline San Xoán de Poio $[O S B]$ & 1000 & 1500 \\
\hline S. a María de Armenteira [Cister] & 1000 & 1500 \\
\hline - -S. Xulián de Samos $[O S B] \rightarrow$ diócesis de Lugo & 500 & 2000 \\
\hline S. Xoán de Caaveiro [agustino] & 1000 & 2000 \\
\hline S. Salvador de Cins $[O S B]$ & 2000 & 2000 \\
\hline \multirow[t]{2}{*}{ S. a María de Aciveiro ${ }^{61}[O S B]$} & 2000 & - \\
\hline & 101500 & 34000 \\
\hline \multicolumn{3}{|l|}{ Diócesis de Ourense } \\
\hline obispo + cabildo & 25000 & 12000 \\
\hline $\begin{array}{l}\text { S. Salvador de Celanova + prioratos de S. Pedro de Rocas y S. }{ }^{\text {a }} \text { Co- } \\
\text { loma }[O S B]\end{array}$ & 4000 & - \\
\hline Santo Estevo de Ribas de Sil [OSB] & 1000 & - \\
\hline S. ${ }^{\text {a }}$ María de Montederramo ${ }^{62}[$ [ister $]$ & 1000 & - \\
\hline S. Clodio ${ }^{63}$ do Ribeiro $[O S B]$ & 1000 & - \\
\hline S. a María de Oseira [Cister] & 4000 & - \\
\hline S. a María de Xunqueira de Espadanedo [Cister] & 1000 & - \\
\hline \multirow[t]{2}{*}{ S. a Cristina de Ribas de Sil $[O S B]$} & 500 & - \\
\hline & 37500 & 12000 \\
\hline \multicolumn{3}{|l|}{ Diócesis de Lugo } \\
\hline vicarios del obispo electo + cabildo, etc. & 15000 & 6000 \\
\hline S. ${ }^{\text {a }}$ María do Cebreiro ${ }^{64}[O S B]$ & 1000 & - \\
\hline S. Vicente de Monforte $[O S B]$ & 1000 & 1000 \\
\hline S. Xulián de Samos $[O S B]$ & 2000 & 2000 \\
\hline \multirow[t]{2}{*}{ S. María de Meira [Cister] } & 500 & 1500 \\
\hline & 19500 & 10500 \\
\hline \multicolumn{3}{|l|}{ Diócesis de Mondoñedo } \\
\hline obispo + cabildo & 25000 & 10000 \\
\hline S. Salvador de Pedroso [agustino] & 500 & 500 \\
\hline \multirow[t]{2}{*}{ S. Salvador de Lourenzá $[O S B]$} & 2000 & 4000 \\
\hline & 27500 & 14500 \\
\hline
\end{tabular}

61 López Dapena: «Açeveiro».

62 López Dapena: «Mont de Riaño».

63 López Dapena: «Cloxo».

64 López Dapena: «Corneyro». 


\begin{tabular}{|l|l|l|}
\hline Diócesis de Tui & $1294^{65}$ & \\
\hline Cabildo & - & 6000 \\
\hline S.․ María de Melón [Cister] & - & 3000 \\
\hline S.․ María de Oia [Cister] & - & 2000 \\
\hline San Salvador de Barrantes [OSB] & - & 500 \\
\hline & - & $\mathbf{1 1 5 0 0}$ \\
\hline [total de las cinco diócesis] & $\mathbf{1 8 6 0 0 0 +}$ & $\mathbf{8 2 5 0 0}$ \\
\hline
\end{tabular}

Al comparar las contribuciones ya anotadas del servicio de 1290 con las exigidas en 1294 puede verse cómo estas duplican con creces las anteriores, y eso sin tener en cuenta la aportación de Tui, que no figura en esta tabla porque todavía se estaba negociando cuando ya se habían fijado las demás. La cantidad exigida al arzobispo de Santiago, fray Rodrigo González, O.P. (1286-130466), era tan abrumadora que este se negó a pagarla. Para tapar ese agujero, el rey recurrió al concejo de la Coruña, puebla realenga, y al de Pontevedra, señorío del arzobispo ${ }^{67}$, al que pidió $5000 \mathrm{mrs}$, y ordenó a Fernando Ruiz de Castro, pertiguero, o justicia, puesto por el rey en el señorío arzobispal de Santiago, que facilitara la compensación del concejo por medio de embargos «en las rrentas, e en los pechos, e derechos, e en todas las otras cossas que el arçobispo ý á, e en las eglesias dende» ${ }^{68}$. La animosidad desplegada contra el señor arzobispo no necesita comentarios.

\section{REALENGOS: LA TIERRA LLANA, O TERRA CHÁ}

Se llamaba «tierras» y también «condados» a las unidades políticas y administrativas básicas que formaban el reino de Galicia. Las más relevantes en el siglo XII eran las de Trastámara, Montenegro, Monterroso, Sarria, Lemos, Toroño y Limia $^{69}$. Estas y otras comarcas menores eran entregadas por los reyes de León como «tenencias» a hombres prominentes conocidos como «condes». El título indicaba la «tenencia» temporal de esos lugares y su consecuente eminencia aristocrática, pero no significaba lo que más tarde entendía Salazar de Mendoza y sancionó la Academia, que «los títulos de Condes se dieron perpetuos para los sucesores, con tierras y juris-

65 1294-03-15, Valladolid. Ed. López Dapena 1984: 352-354. Dos cartas al deán de Tui y a los abades de Oya y Melón sin indicar la cantidad, que parece quedar pendiente de negociación.

66 López Ferreiro 1902: 254-277.

67 Por donación de Fernando II: 1180, diciembre 15, Salamanca; ed. González Balasch 2004, n.o 24.

68 1294-09-2, Palenzuela. Ed. López Dapena 1984: 357-358.

69 Jular 1990: 74-80. 
dicción, a que llaman Condados $»^{70}$. Ni los condados eran hereditarios, ni había linajes asociados a ellos en la Galicia de los siglos XII y XIII: el título condal, relacionado o no con un lugar específico, confería «una representación del rey», el cual podía otorgarla o cancelarla, como Pallares y Portela han demostrado usando el caso de los Traba. Entre otros argumentos recuerdan cómo Gómez González de Traba, conocido como «conde de Trastámara» (fl. 1164-1209), perdió ese y otros dominios cuando fue desterrado por el rey Alfonso IX hacia 1200, aunque recuperó la tenencia de Trastámara cuando volvió a su lado en $1204^{71}$. Lo que el rey daba, el rey lo podía quitar y volverlo a otorgar $^{72}$. En las Cortes de León de 1208, Alfonso IX reafirmaba esa autoridad al proclamar el derecho del fisco a incautarse de los bienes y tenencias del señor que fuera desterrado por el rey ${ }^{73}$. La situación no era diferente en el reino de Castilla, donde una familia tan prominente como los Lara tenía un dominio patrimonial muy reducido - hasta que Alfonso X entregó la tenencia de Sevilla y otras tierras a Nuño González ${ }^{74}$ Janna Bianchini ha observado que la resistencia de Alfonso IX de León a la patrimonialización de las tenencias y su capacidad para darlas y quitarlas revelan un poder y una capacidad de acción frente a la nobleza que ya hubiera querido para sí Felipe Augusto de Francia (1165-1223) ${ }^{75}$. En el reino de León, como también en el de Castilla, los reyes eran quienes otorgaban, o retiraban, las tenencias. Queda por ver qué era lo que esperaban de sus tenentes como contrapartida.

\section{RODRIGO GÓMEZ DE TRABA: SERVIR LOS DINEROS}

La política territorial de Alfonso IX en Galicia fue continuada y reforzada por su hijo, Fernando III, y por su nieto, Alfonso X. En el caso de los Traba, los reyes castellanos que sucedieron al rey leonés adoptaron al hijo del conde Gómez González, del mismo modo que este se adaptó a un reino que triplicaba en extensión al que le había visto nacer. Rodrigo Gómez (fl. 1201-1260) ${ }^{76}$ se casó con Mayor Alfonso, hija de Alfonso Téllez de Meneses, matrimonio que no tuvo descendencia, pero que

70 Citado por el Diccionario de Autoridades, 1726-1739, s.v. ‘condado’. Sobre el carácter no hereditario del título condal en Castilla, antes de 1250, ver Doubleday 2001: 13.

71 López Ferreiro 1902, ap. 6; Pallares y Portela 1993: 833, 836; Calleja 2000: 290, nota 24.

72 Cf. Doubleday 2001: 15. Sobre la tenencia de Sevilla, ver más abajo, nota 83.

73 Cortes, 1,1861 : 48, §4.

74 Sobre la inestabilidad del patrimonio nobiliario antes de la aparición del sistema de mayorazgo en el siglo XIV, ver Pallares y Portela Silva (1993: 832) y Doubleday (2001: 15-16). Vuelvo sobre lo mismo al final de este trabajo.

75 2013: 38. Sobre el uso estratégico de las tenencias por Alfonso IX en la década de 1120, ver eadem, 2012: 190-192.

76 Figura conocida gracias al extraordinario estudio que don José Villa-Amil y Castro publicó sobre él en 1879-1880, reeditado en 1971. Ver también el trabajo de Miguel Calleja Puerta 2000. 
le conectó con la poderosa familia castellana de los Meneses ${ }^{77}$ : su sobrina, también llamada Mayor, sería la madre de la reina María de Molina ${ }^{78}$. Don Rodrigo también representó un papel importante en las grandes conquistas andaluzas de Fernando III, pero siempre se mantuvo apegado a su tierra natal. López Ferreiro dice de él que fue «el principal señor de Galicia en su tiempo, [y] tenía en su casa la servidumbre de un Príncipe» ${ }^{79}$.

Mas lo que ahora es oportuno resaltar es su servicio a Fernando III en las guerras de Andalucía, donde participó en las conquistas de Córdoba (1236), Jaén (1246) y Sevilla $(1248)^{80}$. Su principal tenencia en esta época era la gran tierra galaica de Trastamar, nombre que Alfonso X adoptó para bautizar a la alquería de Alcalá de Guadaíra que le entregó en 1253 como premio por su intervención en el asedio a Sevilla ${ }^{81}$. Esa era la contrapartida, el quid pro quo, que los reyes de León y Castilla esperaban de sus tenentes: que fuesen a la guerra con el ejército real llevando una hueste de tantas lanzas como les permitieran las rentas de sus tenencias. Durante el mismo sitio de Córdoba de 1236, varios nobles llegaron al real con una hueste inferior a la debida, y Fernando III les ordenó volver a casa para que regresaran «con los caballeros (milites) con que estaban obligados a servir al rey» ${ }^{82}$. Alfonso X recuerda la misma obligación a los nobles que le abandonan durante la rebelión de 1272. A su hermano, el infante Felipe, le reprocha no haber ido en su «serujçio en la guerra de los moros», cuando debía «seruir los dineros que d’él [del rey] tomastes, et la tierra que d’él tenedes» ${ }^{83}$. Lo mismo dice a Lope Díaz de Haro $^{84}$ y a Ferrán Ruiz de Castro ${ }^{85}$, mientras a Nuño González de Lara le recuerda cómo le dio Sevilla, «que es la más honrrada tenençia de todos

77 Así lo indica ya Pedro Afonso, conde de Barcelos, miembro de la misma familia: «Dom Rui Gomez foi casado com dona Moor Afonso, filha de dom Afonso Telez, o que pobrou Alboquerque, e de dona Elvira Rodríguez Giroa [Girón], e nom houve semel» (1, 1980: 177 §13B2). La documentación coetánea confirma esta relación: estando en León, en 1247 (abril 19), «Rodrigo Gómez, con mia muyer dona Maor Alfonso», reconoce y aprueba, en lo que le corresponda, la carta de «don Alfonso Télez, padre de dona Maor Alfonso», con la que este entregaba la villa de Acebedo (NE de León, próximo a la frontera con Asturias), al hospital de San Nicolás del Camino (AHN, Clero, carp. 1738, n. 3. Ed. Castán Lanaspa 1984: 159). Agradezco a Miguel Calleja que me llamara la atención sobre este documento.

78 Ver cuadro genealógico de los Téllez de Meneses en Reglero 1993: 114.

79 1902: 371. Apoya su afirmación con la prosa que precede a la cantiga 114 del Cancionero de Colocci-Brancuti: «Esta cantiga fez Pero Velho de Taveiroos e Paai Soarez, seu irmão, a duas donzelas mui fremosas e filhas d'algo assaz, que andavam em cas Dona Maior [Alfonso de Meneses], molher de Dom Rodrigo Gomes de Trastamar. E diz que se semelhava[m] ũa a outra tanto que adur poderia homem estremar ũa da outra; e seendo ambas um dia folgando per ũa sesta em um pomar, entrou Pero Velho de sospeita [e], falando com elas, chegou o porteiro e levantou-o end'a grandes empuxadas, e trouve-o mui mal». Cito la versión publicada en Cantigas Medievais Galego-Portuguesas 2021: 113.

80 Villa-Amil 1971: 277-278; J. González, 1, 1980: 172; Calleja 2000: 289.

81 Lugar llamado «Çerraja, a que [el rey] puso nombre Trestamar». J. González, 2, 1951: 21.

82 «[...] quidam tamen ex eis de mandato regis redierant pro militibus habendis, cum quibus regi seruire tenebantur». Juan de Soria, ed. Charlo Brea 1977: 117, §74.

83 Ed. González Jiménez 1998: 98.

84 Cuando le ordena que se una al príncipe heredero, el infante Fernando de la Cerda, y «le siruades con la tierra e dineros que uso d'él tomastes» [como soldada]. Ibid: 105.

85 Le acusa de traicionarle, «teniendo vos tierra et dineros del rey, con que le auedes de seruir», Ibid., 106. 
los regnos, con muy grandes retenençias», las cuales le permitieron tener «trezientos caualleros por vasallos, de los mejores infançones que auía en Castilla, et en León, et en Galizia» ${ }^{86}$. Conviene subrayar esa obligación que contraía el tenente, ya que servir los dineros y la tierra de la tenencia, acudiendo a la guerra, al lado del rey, con una hueste proporcional a la misma tenencia, era un aspecto fundamental de la relación entre el monarca y la nobleza, algo que parece haber pasado desapercibido hasta ahora ${ }^{87}$, a pesar de los testimonios de 1236 y 1272, que los libros de cuentas de Sancho IV confirman y cuantifican retrospectivamente ${ }^{88}$.

El rango social y económico de los nobles, que les permitía tener huestes con que servir al rey, les convertía en los personajes más importantes de la Corte real, al lado de los obispos. La eminencia de ambos grupos, armas y letras, bellatores et oratores, era reconocida y proclamada en los diplomas solemnes de los reyes, cuyas disposiciones aparecían sancionadas con las «firmas» de unos y otros, colocadas en columnas que flanqueaban el signo del rey. La cancillería, órgano portavoz del monarca, era la que decidía la prelación implícita en esas columnas, un orden que, a su vez, dependía del favor del rey, igualmente manifiesto en las tenencias o tierras asignadas a sus grandes vasallos.

Rodrigo Gómez, hijo del conde Gómez González, «confirma» desde el primer momento en los diplomas de Fernando III posteriores a la incorporación de León a Castilla (otoño de 1230). En enero de 1231 es el segundo de los vasallos leone$\operatorname{ses}^{89}$, pero dos meses después ya ocupa el primer lugar, posición que mantiene hasta el fin del reinado en mayo de $1252^{90}$. Esa preeminencia que la cancillería fernandina le concede, por encima de todos los ricohombres del reino de León, y no solo de Galicia, encuentra su eco en las anotaciones cronológicas de los documentos locales. Claro que los notarios gallegos no aluden a la prelación cortesana, sino a las tenencias que la justifican: en abril de 1235 se dice que Roy Gómez es tenente de Trastamar, Monterroso, Montenegro, et alias terras ${ }^{11}$. En marzo de 1236 aparece como «domno Roderico Gomez, tenente Trastamar, Montem Rosum, Montem Nigrum, Prucios, Nendos et alias terras $»^{92}$. Dos contratos de agosto de 1246 y otro de 1248 vuelven a mencionar su tenencia de «Trastamar, Monterroso y Montenegro»" ${ }^{93}$, y un acuerdo de 1249, alcanzado en Monfero, dieciocho kilómetros al este de Betanzos, alude a la reciente conquista

86 Ibid., 101. Sobre la autenticidad de estas cartas, ver Hernández 2015.

87 Barton se preguntaba (1997: 155): «was it simply the selfish prospect of self-advancement or a sense of loyalty to their lords that impelled nobles to take up arms?».

88 En Apéndice 2 se citan los caballeros que debían aportar varios infanzones. Listados completos en $H H$ : R3 y R4. Ver también la Nómina de Andalucía en $R R, 1:$ 414-419.

89 J. González 1980-86, n.o 297.

90 1231, marzo 10, Alba de Tormes. Ibid, n.o 311.

91 López Sangil 2020: n.․․ 258.

92 Ibid.: n.. 265 .

93 Ibid.: n. 0 328, 329 y 348. 
de Sevilla y a las mismas tenencias de nuestro hombre ${ }^{94}$. En otros diplomas, los notarios se ahorran la enumeración de sus tierras y le describen simplemente como «obtinente principatu in Gallecia» ${ }^{95}$, alusiones a un «principado» que sugieren su posición como primer vasallo del rey en Galicia (y en León) ${ }^{96}$, y alternan con otras que vuelven a especificar sus tenencias.

Muerto Fernando III en mayo de 1252, el magnate gallego sigue «confirmando» los privilegios rodados del nuevo rey, Alfonso X, pero ha dejado en ellos el primer puesto a Rodrigo y Martín Alfonso. Estos hijos naturales, o de ganancia, del prolífico Alfonso IX de León ${ }^{97}$, se mantienen como confirmantes leoneses hasta 1268 y 1272 respectivamente, aunque habían perdido también su primacía en 1255, como veremos enseguida ${ }^{98}$. Rodrigo Gómez, que morirá antes que ellos, sigue siendo considerado «príncipe» de Galicia por los notarios de su tierra ${ }^{99}$, pero, cuando un documento de julio de 1255 cita sus tenencias, solo incluye las de Monterroso y Pallares, y omite la de Trastámara ${ }^{100}$, tan íntimamente ligada antes al magnate como sugiere el uso de su nombre para bautizar la alquería del repartimiento sevillano. Tal vez no es coincidencia que ahora, en diciembre de 1256, don Rodrigo se deshaga de su Trastamar sevillana, vendiéndosela a la Orden de Calatrava ${ }^{101}$. Posiblemente para compensarle por la pérdida de la gran tenencia gallega, el rey le asignó rentas en otros lugares, como los tres mil maravedís de la martiniega de Toro que reconoce haber recibido en septiembre de $1255^{102}$. Entre 1255 y 1257, los notarios gallegos dejan de citar sus tenencias

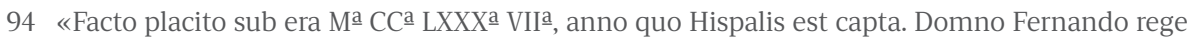
regnante in multis, dompno Roderico Gomez tenente Montem Rosum, Montem Nigrum et Transtamar» (ibid.: n.․ 355).

95 1240, marzo l: Rodríguez González y Rey Caíña 1992: n.ํㅜ 134. Sobre la terminología prínceps/ principatus, ver Doubleday 2001: 13-14.

96 1248, abril 24: «Tenente principatu Gallecie domino Roderico Gomecii»; 1253, dic. 25: «Obtinente principatu Gallecie domno R. Gómez»; «Tenente principatu Gallecie domno Roderico Gomez» (Álvarez Castrillón 2013: 92-93, 97-99 y 99-100); 1255, julio 21: «Príncipe de Galiza don Rodrigo Gómez» (Souto Cabo 2003: n.o 48); 1258, agosto 2: «Accipientem principatum Gallecie domno Ruderico Gomiz» (Rodríguez González y Rey Caíña 1992: n.ํㅜ 165).

97 Tuvo ocho hijos legítimos y diez bastardos (Vajay 1989: 369).

98 Rodrigo fue adelantado de la Frontera y confirma los rodados hasta noviembre de 1268 (DAAX, n. 354). Martín fue caballero de la Orden de Santiago, confirma después de su hermano hasta enero de 1272 (DAAX, n.o 391) y murió antes del 17 de abril, cuando su viuda afora una tierra próxima a Betanzos. Un privilegio de Alfonso X del año siguiente indica que D. Martín había sido enterrado en el monasterio de Sancti Spíritus de Salamanca, que él y su esposa habían fundado: 1273, mayo 27, Ávila; ed. Echániz Sans 1993, n.은 24 y 25.

99 En diciembre de 1253 el abad de Lourenzá afora una heredad, que es fechada «tenente principatu Gallecie domno Roderico Gomez», y del mismo modo es citado el siguiente 22 de febrero (ed. Álvarez Castrillón 2013: 97-99 y 99-100). En julio de 1255, otro documento de Lourenzá menciona al «principe de Galiza dom Rodrigo Gómez»; ed. Souto Cabo 2003, n.으 48.

100 En febrero de 1260 es mencionado como «ricome en Trastamara», pero no como tenente (ibid.: n. 122). La pérdida de la tenencia de Trastámara por R. Gómez necesita un apoyo documental inaccesible para mí en marzo de 2021, adhuc sub pandemia.

101 Venta de 1255, dic. 26: ed. J. González, 2, 1951: 326-327. Permiso del rey para consumar la venta de 1256 , enero 10, Vitoria, ed. $D A A X$, n.으 170.

102 Ed. Martín Martín 1982, n.ํㅡㄴ 152 (edición defectuosa); Souto Cabo 2003: n.․ 51. No es coincidencia que el mismo 20 de septiembre Alfonso X fundara la puebla de Ortiguiera dándole el fuero de Benavente. Cf. Ruiz de la Peña 1977: 35-40. 
y se refieren a él simplemente como ricohombre ${ }^{103}$ o como prestamero ${ }^{104}$. Y es precisamente asociado a una cuadrilla de caballeros prestameros como aparece en la última aventura que conocemos de su vida, cuando, junto con ellos, invade violentamente el coto monacal de Monfero en 1258 y provoca un pleito que termina en noviembre de 1261 con la condena de los invasores, una sanción de la que se libra por haber fallecido un año antes ${ }^{105}$.

Rodrigo Gómez debió de morir hacia el mes de febrero de 1260: un mes antes aún «confirma» los privilegios de Alfonso X, pero un mes después deja de aparecer en ellos ${ }^{106}$. En su última presencia como confirmante le precedían los dos hijos de ganancia de Alfonso IX, quienes tampoco ocupaban ahora el primer lugar. Un mozo con sangre real estaba por delante de todos ellos desde agosto de $1255^{107}$ : Alfonso Fernández el Niño ${ }^{108}$, hijo ilegítimo de Alfonso X, probablemente nacido unos catorce años antes que el infante Fernando de la Cerda ${ }^{109}$, el «primogénito» habido con la reina Violante en octubre de este mismo 1255.

\section{ALFONSO FERNÁNDEZ EL NIÑO, TENENTE DE TRASTÁMARA}

Cuando, en agosto de 1255, Alfonso X le coloca por delante de todos sus vasallos leoneses, incluidos los de Galicia, Alfonso Fernández habría alcanzado ya su mayoría de edad -lo que permite fijar su nacimiento en $1241^{110}$ - . Su posición como primer vasallo leonés era tanto una distinción honorífica como la consecuencia de ser

103 1255, mayo 2, Monfero: «Ricome donno Roderico Gomez»; 1256, diciembre, 6: «Ricus home domno Roderico Gomescii» (López Sangil 2020: n.o 368 y 369); 1257, diciembre 25: «Ricome dom Roderico Gomez» (Souto Cabo: 2003: n.․72).

104 1257, julio 25: «Prestamario in Gallecia Roderico Gomecii» (López Sangil 2020: n.o 371). Los prestameros de Galicia merecen un estudio aparte. Véase, de momento, lo que decía Cristina Jular en 1999.

105 Las actas cubren el período de 1258-1261 y están escritas en gallego, con citas de documentos reales en castellano. El pleito enfrenta al abad cisterciense de Monfero con un grupo de caballeros encabezado por «don Roy Gómez», acusados de invadir los territorios (cotos) del señorío monástico. Se conservan dos ejemplares coetáneos del mismo texto, con variantes de interés lingüístico: ARG, Pergs., 117/1 (ed. Souto Cabo 2003: n.o 151 [omite los textos en castellano] y López Sangil 2020: n. 391 ); ARG, Pergs., 117/2 (ed. Martínez Salazar 1913: 31-43).

$106 D A A X$, n.o 237 y 239. No obstante, un documento de 15 de junio 1260 todavía cita como referente a «don Rodrigo Gómez ricome en Galizia»: Álvarez Castrillón, Oscos, 2011: n.o 130.

107 1255, agosto 16, Valladolid (ed. Pino Rebolledo 1988: no 7). No está todavía en el rodado del anterior 9 de julio (DAAX, n.․158).

108 Así es llamado en la Crónica de Alfonso X compilada hacia 1344, pero en la documentación de la época que he podido consultar es simplemente conocido como «Alfonso Fernández, fijo del rey».

109 Nacido en Valladolid el 23 de octubre de 1255, según certificado de su mayoría, dado catorce años después (1269, julio 13), por los obispos de León, Martín Fernández (que le había bautizado), y de Osma, don Agustín: ed. Berger, 4, 1902: 372: no 5559.

110 Salazar Acha (1990) fue quien clarificó que su madre fue Elvira Rodríguez, hija de Rodrigo Fernández de Villada, mujer que merece un estudio detallado. 
un verdadero rico-hombre, con rentas y tenencias superiores a las adjudicadas a otros grandes vasallos, como sus tíos leoneses, Rodrigo y Martín Alfonso, o el gran Rodrigo Gómez de Traba, colocados a su zaga en los privilegios rodados.

La desaparición de los libros de la cancillería alfonsí obliga a rastrear esas rentas y tenencias en las anotaciones cronológicas de los notarios locales. Antes de ver lo que dicen en Galicia, conviene visitar otras regiones. En la antigua Tierra de León, el archivo de Carrizo, monasterio leonés favorecido por Elvira Rodríguez, la madre del Niño, conserva documentación particular de interés. En 1258 era «tenente de Valdorna, de mano del rey, don Alfonso, infante de Molina» ${ }^{111}$, el veterano hermano de Fernando III, tío de Alfonso X ${ }^{112}$. Pero, un año después, la tenencia había pasado al joven Alfonso. A lo largo de la década de 1259-69, la misma documentación identifica como tenente de Valduerna (y de Laguna de Negrillos) a «don Alfonso Fernández». Una vez es descrito como «infante» ${ }^{113}$, pero ese es un error que no vuelve a repetirse, y sigue siendo identificado como lo que es, «fiyo del rey don Alfonso» ${ }^{114}$. En la misma década, también figura como tenente de Mayorga de Campos ${ }^{115}$. Tanto en el caso de Valduerna y Laguna, como en el de esta importante villa vallisoletana, la referencia añade los nombres de los merinos locales que actuaban como lugartenientes de don Alfonso, confundido a veces con su homónimo, el hermano de Fernando III, que tendría unos cuarenta años más que él. La confusión debería haberse disipado una vez muerto el viejo infante en enero de 1272, pero seguramente ha perdurado porque su título de señor de Molina pasó a su hija, Blanca de Molina, y de ella, a su marido ${ }^{116}$, el mismo Alfonso Fernández el Niño que, en julio de 1274, es identificado como «Don Alfonso, fiio del rey don Alfonso, señor de Molina» ${ }^{117}$, o, también, como «tenente de

111 Casado Lobato 1983: n.. 326, 327 y 328.

112 Casado Lobato 1983: n.. 326, 327 y 328. El infante era señor de Molina por su casamiento con Mafalda, hija de Gonzalo Pérez de Molina. Muerto este, el infante Alfonso empieza a titularse señor de Molina y Mesa en 1243/46. Cf. Estepa 2006: 71-73 y 81-83.

113 «El infante don Alfonsso Fernández, tenente [el] honor de Palacios [de Valduerna]» (Casado Lobato 1983: n.ㅇ 342).

114 1259-10: «Alfonsso Fernández, tenente Valdornia; de sua mano Vidal Sánchez» (ibid: n.o 345); 1259-12: «Tenente Valdorna Alfonso Fernández $\tau$ so merino Fernán Rodríguez» (ibid.: n.o 348); 1261-09: «Tenyente Valdornia don Alfonso Fernández, suo merino don Salamón» (ibid.: n.o 384); 1262-03: «Don Alfonso Fernández, fiyo del rey don Alfonso, señor de Laguna [de Negrillos]» (ibid.: n.o 390); 1262-05: «Tenente Valdorna don Alfonso Fernández, merino Salamón» (ibid.: n.. 393); 1263-04: «Tenente Valdorna Alfonso Fernández, merino Domingo Ferrero» (ibid:: n.o 398); 1264-04: «Tenente Valdornia don Alfonso Fernández, sou merino Domingo Ferreyro» (ibid.: n.ㅇ 404); 1267-02: «Tenente Valduerna don Alfonso Fernández, sous merinos Domingo Ferero $\tau$ don Salamon $\tau$ Johan Pérez teniendo el cellero» (ibid.: n.․4 418); 1268-03: «Tenente Palacius de Valdorna don Alfonso» (ibid.: n.o 423); 1269-08: «Tenente Laguna [de Negrillos] Alfonso Fernández» (ibid.: no 433).

115 1261, mayo: «Tenyente de Mayorga don Alfonso Fernández, fiyo del rey don Alfonso» (ibid:: noㅡ 382). 1265, septiembre 28: compraventa de casas en León, «tenyente Mayorga don Alfonso Fernández, fiyo del rey don Alfonso, so merino, Martín García, fiyo dde García Faybez» (Fernández Catón 1978: 421-422, n.․2).

116 Se desconoce la fecha del matrimonio, pero debió celebrarse antes de febrero de 1267, porque un contrato de esa fecha, en el que participa Gonzalo Morán, hermano uterino del Niño, tiene como testigo a «Johan Pérez, omne [de] don Alfonso $\tau$ de dona Branca» (ed. Casado Lobato 1983: n.o 418).

117 Ibid.: n.․ 451. 
Mayorga, don Alfonso Fernández, señor de Molina e de Mesa» en marzo de $1275^{118}$. Como tenente de Valduerna y Laguna de Negrillos sigue figurando hasta $1276{ }^{119}$, pero en 1278 es llamado «señor de Laguna» ${ }^{120}$, y, después de su muerte, ocurrida en 1281, su viuda también es descrita como «señor [sic] de Valduerna», lo que significa que el matrimonio había recibido el señorío hereditario de esos lugares, administrados antes como tenencia ${ }^{121}$, noticia que, como excepción, sirve para corroborar que las tenencias eran concesiones temporales y no donaciones perpetuas, como ya se ha indicado.

Alfonso Fernández recibió otra tenencia más sustanciosa en Asturias. Así lo proclama un contrato de compraventa fechado en diciembre de 1257, siendo «don Pedro obispo en Ouiedo; don Alfonso, fillo del rre, teniente Ouiedo de mano del rre, Alfonso Nicolás ${ }^{122}$ teniente la villa de sua mano; hye don Gonzaluo Morán ${ }^{123}$, merino maor del rre en todas Asturias ${ }^{124}$. Para entregar Oviedo al Niño, Alfonso X tuvo que quitársela a Gonzalo Ramírez, hijo de Ramiro Frólaz, ricohombre asturiano, que había confirmado los privilegios de Fernando III desde abril de 1250, como segundo vasallo leonés, detrás de Rodrigo Gómez, y que siguió en los alfonsíes, cada vez más relegado, hasta septiembre de 1258; aunque todavía disfrutaba de la tenencia ovetense en junio de $1255^{125}$.

El Niño debió de ocuparla poco después, pero, de momento, solo podemos documentarla a partir de 1257. Su tenencia ovetense es mencionada sin cesar durante veintitrés años más, hasta $1278^{126}$, cuando el panorama político del reino cam-

118 Ibid:: n.우 458 .

119 Ibid.: n.ㅇ 469, 473.

120 Ibid.: n. 989 y 497.

121 Como señorío, ambos lugares estaban exentos de tributar a la Corona, como se indica en el libro de cuentas de 1290, donde se justifica la falta de tributo porque «tiénelos por heredamiento doña Branca de Molina» (RR, 1: 209, §41). En su testamento de junio de 1293, doña Blanca deja una manda para «Pasqual Pérez, mio escribano de Palacio de Valduerna» y concede a «Gonzalo Pérez, mio escanciano, la escribanía de Laguna de Negriellos por toda su vida». Ed. Gaibrois, 3, 1922-1928: n. 470.

122 Sobre este personaje, ver Ruiz de la Peña Solar 1975.

123 Casado con Elvira Rodríguez, la antigua amiga de Alfonso X y madre de Alfonso Fernández.

124 Tuero Morís 1994: n.o 25.

125 J. González, 1, 1980: 169; 3, 1986, n.ํ 788; DAAX, n.으 212. En 1253 recibe un donadío menor en Bululés, término de Tejada, Sevilla (J. González, 2, 1951: 39 y 240). En abril de 1255 seguía en Sevilla, donde ejecuta una manda testamentaria de Bernalt d'Orellac [ $i=A u r i l l a c ?]$ a favor de la catedral. Ed. Ballesteros 1913, n.o 70. Aparece como tenente de Oviedo en octubre de 1251, en diciembre de 1252, enero de 1253 y junio de 1255, y, en cada caso, se indica quién está «recibiente los derechos de la villa» en su lugar, mientras el Niño sigue en Sevilla. Ed. Tuero Morís 1994: n.o 12, 13, 14, 18.

126 1257, diciembre (Tuero Morís 1994: n.o 25); 1258, febrero 25 (ibid.: n.o 26); 1258, julio 3 (ibid.: n. 28); 1258, octubre 17 (Fernández Conde 1978: n.o 106); 1259, enero (Tuero Morís 1994: n.o 31); 1258, julio 3 (ibid.: n. 28); 1259, agosto 19 (Fernández Conde 1978: n.o 109); 1259, diciembre 24 (Tuero Morís 1994: n.o 34); 1260, enero 23 (ibid.: n.o 35); 1260, abril 26 (ibid.: n. 37); 1261, abril 26 (ibid.: n.o 38); 1262, junio 22 (ibid.: n. 40); 1263, agosto 8 (ibid.: n.o 43); 1263, agosto 25 (ibid.: n.o 44); 1264, febrero 13 (Fernández Conde 1978: n. 115); 1264, abril 23 (Tuero Morís 1994: n.o 46); 1264, junio 6 (ibid.: n.․ 47); 1264, julio 29 (ibid.: n.o 49); 1264, septiembre 20 (ibid.: n. 이); 1265, agosto 20 (Fernández Conde 1978: n. 117); 1266, diciembre 9 (Tuero Morís 1994: n.o 51); 1267, febrero 23 (ibid.: n.o 52); 1267, abril 23 (ibid.: n.o 53); 1267, agosto 20 (ibid.: n.o 54); 1267, dic. 1 (Fernández Conde 1978: n.o 122); 1268, enero 23 (Tuero Morís 1994: n.o 56); 1272, diciembre 14 (ibid.: n.ㅇ 63); 1273, septiembre 23 (ibid.: n. 5); 1274, febrero 19 (Fernández Conde 1978: n. 133); 1274, agosto 1 (Tuero Morís 1994: n.․67); 1276, agosto 22 (ibid.: n.ํ71); 1278, junio 30 (Fernández Conde 1978: n.ํ139). 
bia radicalmente con el reconocimiento del infante Sancho como corregente y la creación de una corte sometida al infante, paralela a la del rey y sostenida con los recursos de las tierras situadas al norte del Sistema Central ${ }^{127}$. Las noticias que los notarios ovetenses aportan durante los veintitrés años precedentes son especialmente expresivas. Baste, de momento, con una de ellas. Como todos los documentos ya citados, el acta de compraventa dada en octubre de 1258 nombra a las autoridades eclesiásticas y laicas, pero aporta detalles que suelen omitirse sobre la administración de la tenencia: «Don Pedro obispo en Ouiedo. Don Alfonso, fillo del rey, teniente Ouiedo de mano del re; don Bartolomé Périz recibiente los derechos de la villa de parte de don Girallo Stévaniz, que la tien arrendada de don Velasco Lópiz, que ganó los derechos de la villa de don Alfonso, fillo del rey» ${ }^{128}$. Es decir, el Niño tenía un encargado (Bartolomé Périz en este caso, aunque Pedro Périz aparece más veces con esa función y es identificado como «merino» del hijo del rey ${ }^{129}$ ) de recibir sus derechos, tributos cuya recaudación había conseguido por subasta Velasco López, quien, a su vez, había subarrendado la recogida física del impuesto a un tercer hombre, Geraldo Estébanez. Vista desde otro ángulo, la acción del tenente con mayor repercusión local era la recepción de las rentas regias que tenía asignadas a su favor, las cuales eran entregadas a un «merino» menor, o sayón ${ }^{130}$, que estaba al servicio exclusivo del tenente y disponía de potestades coercitivas para conseguirlas.

También en Galicia consiguió el Niño tenencias importantes, aunque llegó a ellas más tarde que a las de Valduerna y Oviedo. Ya hemos visto cómo don Rodrigo Gómez, el anterior príncipe de Galicia, había fallecido en 1260, después de haber visto disminuidas sus tenencias. Ignoramos lo que Alfonso X hizo con ellas durante el lustro siguiente; pero, el menos desde 1265, los notarios gallegos indican que el Niño había «obtenido el principado de Galicia» ${ }^{131}$ o se refieren a él como tenente de Trastámara ${ }^{132}$ y Montenegro ${ }^{133}$. Su preeminencia en todo el antiguo reino queda subrayada en 1266: «Reynaua el rey don Affonso in León et in Castella, don Afonso,

$127 \quad H$ H, 1, cap. 3.3.3.

128 Ed. Fernández Conde 1978: n.o 106.

129 1268, enero 23. Ed Tuero Morís 1994: n.o 56.

130 El Diccionario de Autoridades alega esta cita: «Merino, o sayón, que huviere de entregar a alguno de deudo que otro le deba, o de otra cosa que tenga de lo suyo, no tome más para sí de la valía del diezmo» (Nueva Recopilación, lib. 3, tit. 4, ley 3). Y s.v. sayón: «En los fueros que dio a la ciudad de León el rey don Alonso el quinto, el año de mil y veinte, [...], está nombrado el Maiorino de el Rey como Juez mayor, y el sayón, como su executor y ministro» (P. Salazar y Mendoza, Origen de las dignidades seglares de Castilla y León..., Toledo, 1618, lib. I, cap. 18, f. 21r).

131 «Obtinente primcipatum Gallecie domno Alfonso» en contratos del 3 de enero (Rodríguez González y Rey Caíña 1992: n.o 99) y del 30 de diciembre de 1265 (Álvarez Castrillón 2013: 105).

132 1265, enero 28: Documento redactado «en tenpo de rey don Affonso, rricome en Trastamar seu fillo, don Affonso [...] Eu Pedro Pérez, dito de Jenrroço, notario jurado dado del rey en terra de Pruçus, [...] escriuí esta carta [...]». Ed. López Sangil 2020: n.o 399.

133 1265, abril 4: «Obtinente in Monte Nigro et in Trastamar domno Alfonso». Ed. Rodríguez González y Rey Caíña 1992: n. 162. 
seu fillo, tenendo Galliza» ${ }^{134}$. De modo parecido sigue siendo citado hasta septiembre de $1274^{135}$, en las vísperas de la fatídica «ida al imperio», que retuvo a Alfonso X en Provenza hasta finales de 1275. Fue en el verano de ese año cuando tuvo lugar la devastadora incursión de los benimerines en Andalucía, la muerte del heredero y de otras figuras relevantes del reino, mientras Sevilla resistía bajo el mando del don Alfonso Fernández ${ }^{136}$.

De hecho, el «príncipe de Galicia» había pasado buena parte de su vida en Sevilla. En la década de 1260 se había mantenido junto a su padre y trabajado en la cancillería ${ }^{137}$. El rey había depositado en él toda su confianza y le retuvo frecuentemente a su lado. Cuando escribe la famosa carta a su hijo Fernando, en medio de la terrible sublevación nobiliaria de 1272, Alfonso X termina pidiéndole que «quando leyéredes esta carta, sea ý Alfonso Fernández, mio fijo, si fuere convusco, e don Jufré [de Loaysa], e Diego de Corral, e non otro» ${ }^{138}$. El absentismo del Niño no le impidió compartir la agresiva política de su padre hacia los señoríos eclesiásticos de Galicia. Las sentencias de Alfonso X dictadas sobre los pleitos que enfrentaban al obispo de Ourense en $1259^{139} \mathrm{y}$ al arzobispo compostelano en $1261^{140}$, contra sus respectivos concejos, habían sido superficialmente favorables a los obispos, pero habían sido un golpe bajo contra los señoríos eclesiásticos, pues habían reconocido el derecho a existir de los concejos como asambleas independientes del señor, derecho enfáticamente negado por el obispo auriense, y, sobre todo, habían reafirmado la posición del rey como juez supremo en todos los litigios que no fueran estrictamente eclesiásticos.

Las relaciones entre Alfonso X con los jerarcas gallegos empeoraron después del fallecimiento del arzobispo Juan Arias en abril de 1266. Con el pretexto de proteger los bienes de la mesa arzobispal hasta la elección de un nuevo prelado ${ }^{141}$, el rey se apropió de todos ellos y dispuso de sus rentas, dentro y fuera de la Tierra de Santiago, durante el subsiguiente interregno, que se prolongó durante más de siete años, hasta 1273, cuando, el 26 de diciembre, estando en Orvieto, Gregorio X proclamó arzobispo a Gonzalo Gómez, maestrescuela de Santiago. (La intervención alfonsí en poco se diferenciaba de las actuaciones de los prestameros gallegos, caballeros de alta y baja condición, que imponían a la fuerza su «encomienda» sobre los bienes y vasa-

134 1266, junio 8 (ibid.: n.o 132). La misma frase se repite, con variantes menores, en carta sin día,

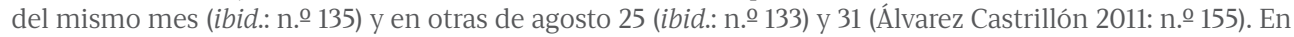
noviembre 24 reaparece «obtinente principiatum Gallecie domno Alfonsius» (Rodríguez González y Rey Caíña 1992: n. 64).

135 1267-01-02: AHN, [mº de Lourenzá], clero, c. 1107/19; 1267-07-28 (Fernández de Viana 2009: n.o 60); 1268-09-06 (Álvarez Castrillón, Oscos, 2011: n.o 166); 1269-01-02 (López Sangil 2020: n.o 412); 1269-05-26 (Souto Cabo 2003: n.․ 253); 1274-09-22 (López Sangil 2020: n.․4 432).

$136 H$ H, cap. 2.4.2, 2.5.2.

137 Kleine 2012, n.․ 34 del catálogo.

138 Ed. Rodgers 1991-1992: 79.

139 1259, febrero, 5. Toledo. Ed. Vaquero Díaz y Pérez Rodríguez, 2, 2010: n. o 471.

140 1261, febrero 21, Sevilla. Ed. López Ferreiro 1895: 248-261; Craddock 1998: 221-274. 3.4.8. y 5.1.3.

141 Sobre la teoría y práctica alfonsí del ius spolii aplicado a las sedes vacantes, ver $H H$, cap. 3.4.7, 
llos de monasterios y obispados para usarlos a su antojo, práctica que el papa Urbano IV imputó al difunto Rodrigo Gómez en $1263^{142}$, que los abades de once monasterios gallegos denunciaron en $1268^{143}$ y que se seguía practicando en 1315 , cuando, en el caos de la minoría de Alfonso XI, su tío, el infante Felipe, se apoderó de la ciudad y coto episcopal de Lugo y expulsó al obispo, el cual, a su vez, intentó recuperarlos dándoselos en «encomienda» a don Alfonso, hijo del Infante don Juan) $)^{144}$.

El rey no aceptó de buena gana al arzobispo impuesto desde Orvieto por el papa y empezó a hostigarle tan pronto como volvió de Beaucaire, donde el mismo Gregorio X le había humillado negándole rotundamente la corona imperial. Esa fue la hora del concejo de Santiago, cuando los burgueses se confabularon con el rey para desmantelar el señorío arzobispal compostelano. Así lo declara, dos años después, un memorándum papal de 1279. Alfonso X - dice su versión castellana- había intervenido en «la discordia que fue entr'él [el arzobispo] e los omnes de la çiudat de Santiago, a sugestión de los quales el rey fizo fazer dannos sin cuento, non tan solament al arçobispo e a la eglesia, mas a los que [se] tienen con ellos e los ayudan» ${ }^{145}$. Eso no fue todo. A mediados de 1277, quizá por las mismas fechas en que mandaba matar a su hermano Fadrique y a Simón Ruiz de los Cameros, Alfonso X envió un ejército contra Santiago bajo el mando de «un hijo suyo». No pudo ser don Sancho, empeñado por entonces en la ocupación de Vizcaya ${ }^{146}$, sino el más maduro y experimentado Alfonso Fernández, que invadió la ciudad, se apropió de los bienes del arzobispo, revocó sus privilegios y derogó su señorío ${ }^{147}$. Por su parte, don Gonzalo Gómez huyó a Italia y se refugió en la curia papal, donde malvivió hasta su muerte, acaecida hacia fines de $1280^{148}$.

142 1263, marzo 28, Orvieto. El papa condena y prohíbe esa práctica «que commenda vulgariter nuncupatur». Ed. Cal Pardo 2005: 447-448, n.으 B3.

143 1268, abril 26, Jerez. Alfonso X responde a los abades de Oseira, Melón, Sobrado, Meira, Montederramo, Armenteira, Oia, Monfero, Fiães, Penamaior y Xunqueira de Espadanedo, y ordena al adelantado mayor de Galicia que, entre otras cosas, no permita a «los meyrinos, e a los mayordomos, e a los caualleros, que lles quebranten sos grangias nen les metan ý mogieres, nen coman en ellas carne, nen les tomen los derechos de los cotos [...], nin conssintades a los caualleros prestameros que [...] les tomen las comendas por fuerça». AHN, Clero, c. 1803/3 [Oya]. Reg.: Sánchez Belda 1953: 340-341 (n.o 783). En el XIv la práctica de extorsionar a iglesias y monasterios imponiéndoles una protección mafiosa se había convertido en un problema sistémico. En las Cortes de 1326, Alfonso XI la prohíbe en Castilla (Cortes, 1, 1861: 392, §6), pero la permite en Galicia, aunque la restringe a los «comendadores de linaje» (Cal Pardo 2005: 200). El rey intentó terminar con el problema en 1348 (Cortes, 1, 1861: 590, §225), pero el problema seguía en pie bajo Juan I (Cortes, 2, 1863 : 458 §8).

144 1315, agosto, 15. Ed. Martín Fuertes 1995, n.을 2872.

145 Ed. Linehan 1980: 142; nueva edición en $H H$, Apéndice.

146 HH, cap. 2.6.

147 Ed. Baronius-Raynaldi 1880: 427. López Ferreiro ya notó la importancia de esta carta, pero solo consideró como posibles líderes del ejército alfonsí a los hijos legítimos del rey (1902: 243). A mediados de 1277, Sancho tenía 19 años, Pedro 17, Juan 15 y Jaime 11. En cambio, Alfonso, el Niño, tendría unos 34 y era un guerrero curtido.

148 Sobre sus apuros económicos, ver $H H$, 1: 5.1.1. Murió durante el período de sede vacante que separa los pontificados de Nicolás III y Martín IV (1280-08-22-1281-02-22), tal como dice Martín IV al reservarse la provisión de la iglesia de Santiago, por haber acaecido la muerte del arzobispo en la curia (apud Sedem Apostolicam... vacantem): Viterbo 1281-02-28, ed. Domínguez Sánchez 2010: n.o․ 1. 
En lugar del infeliz arzobispo, Alfonso X colocó, como administrador de la diócesis, al boyante Pay Dacana (o Pelayo Pérez de Cana), trovador, cortesano próximo al rey ${ }^{149}$, y abad de Valladolid, después de haber sido arcediano de Astorga ${ }^{150}$. La administración de Compostela por Pay Dacana, compartida teóricamente con el arcediano Martín Fernández, como representante del cabildo ${ }^{151}$, secundados ambos por oficiales laicos, es uno de los detalles omitidos en la versión latina del memorial de 1279, que se limitará a acusar al rey Alfonso de agraviar al arzobispo y a la iglesia de Santiago, maltratando de muchas maneras a sus vasallos, sus tierras y sus puertos, forzando las iglesias y dañando a la servidumbre arzobispal ${ }^{152}$. La versión castellana del texto recoge la mismas acusaciones y añade que el rey había «embargado e ocupado todo el arçobispado, o por sí o por otro, e á dos annos que fizo de las rendas a su uoluntad» $»^{153}$-dato que sirve para fijar en 1277 la expedición punitiva contra el señorío arzobispal de Santiago realizada por el Niño, tenente de Trastámara-.

Un año después, el notario público del rey en Pontedeume redactaba una carta de donación a favor del monasterio de Monfero, «en tempo de rrey nosso dom Affonso, en Castella e en Leon; rricome de Trastamar don Affonso, fillo del rrey [...], arçobispo de Santiago don Gonzalo Gómez» ${ }^{154}$. Pero, en mayo de 1278, ni el tenente de Trastámara estaba en Trastámara, ni el arzobispo de Santiago en Santiago. Como ya se ha señalado, el acceso del infante Sancho a la regencia conjunta de los reinos en ese año cambió la dinámica política del reino y esa es posiblemente la razón por la que desde este momento perdemos la pista de don Alfonso Fernández en Galicia. Antes de abandonarla, conviene indagar sobre lo que la tenencia significó para él, para Trastámara y para las otras tierras que su padre, el rey, le había asignado.

El documento más revelador para ese fin es la sentencia que Alfonso X había dado en Valladolid, el 30 de abril de 1274, para dirimir el pleito entre el concejo de Avilés y el tenente de Oviedo, Alfonso Fernández ${ }^{155}$. El Niño había recurrido a su padre porque Avilés se negaba a pagar portazgo por las mercancías que sus gentes transportaban a la capital, gabela que «dauan los otros todos de la tierra» y le correspondía como uno de los derechos de su tenencia. Avilés alegó que no lo habían pagado desde que Alfonso IX les eximiera de hacerlo y, aunque el escrito de su privilegio «ar-

149 Identificado como administrador de la diócesis en acta capitular de 11 sept. 1281 (cit. López Ferreiro, Historia, t. 5, 1902: 244; agradezco a José C. Santos Paz, de la Universidade da Coruña, el texto de la edición que prepara de las actas [carta particular de 2015, dic. 8]). La confianza que Alfonso X había depositado en él desde hacía tiempo queda reflejada en su participación en la conjura con el vizconde de Narbona entre diciembre de 1276 y febrero de 1277: Hernández y Linehan 2004: 161-165.

150 Identidad revelada por las cartas de 1280, mayo 22, Aix-en-Provence, y 1280, ago. 15, Sevilla; ed. Daumet 1913: 167-69 y 170-172, doc. XII y XIV. Sobre su carrera posterior, ver HH, cap. 5.4, 7.2, 10.8 y 9, y 11.2.

151 Ver Apéndice 2, n.․ㅡ 23.

152 «Item gravat archiepiscopum et ecclesiam Compostellanam in portibus et vassallis multipliciter et multa dampna et violentias fecit inferri ecclesiis et personis ecclesiasticis sibi subjectis», $H H, 2$ : Apéndice 3.1, §3.4.

153 Ibid.

154 1278, mayo 2. Ed. López Sangil 2020: n. 462.

155 Ed. Sanz Fuentes et alii 2011: n.ํㅜ 14. 
diera quando se les quemara la villa», su uso ininterrumpido bastaba para probarlo. El rey aceptó al final ese argumento y les eximió de «portage enna villa de Ouiedo, qu'él [don Alfonso Fernández] tenía de mí por tierra». Ahora bien, la expresión usada por Alfonso X indica que lo que su hijo tenía en Oviedo no era, ni más, ni menos, que los dineros recaudados en la ciudad como tributos de la Corona, y que eso era una parte del conjunto de ingresos que recibía anualmente como soldada -algo que queda especialmente claro en los centenares de casos recogidos en las nóminas de 1285 y $1293^{156}$ - Eso era lo que significaba tener una ciudad, una villa, u otros recursos del rey, «por tierra». Por ejemplo, en 1285, la cancillería de Sancho IV asigna al infante don Juan 500 mrs «que touiese cad'año, por tierra [...], en Villalán», y daba a Martín Pérez de Portocarrero 1000 mrs que «son puestos por tierra en la juderia de Villa Real» ${ }^{157}$. También se decía «tener en tierra», o «tener en tierra cierta», y todo venía a significar lo mismo ${ }^{158}$.

Las tenencias del siglo XII, que habían conllevado obligaciones feudales diversas para la población de las tierras afectadas, se habían transformado durante la segunda mitad del XIII en concesiones de rentas de la Corona, dadas a los integrantes de la nobleza alta y baja (ricohombres, infanzones y mesnaderos) a cambio de su servicio en las fuerzas armadas ${ }^{159}$. Al menos esa era la situación en Castilla. En Galicia, siempre excepcional, los tenentes, o sus representantes, parecen haber seguido exigiendo prestaciones o gabelas, por encima del tributo usual, en las poblaciones realengas.

Sancho IV intentó terminar con esa práctica en el verano de 1286, cuando realizó una larga gira por Galicia: ya había llegado a Ourense en la segunda mitad de julio y no salió del reino hasta fines de septiembre ${ }^{160}$. Estando en Santiago, atendió a «las muchas querelas que me fezieron por toda la tierra de Gallizia por do yo andé, e me enbiaron fazer de los otros logares que non fuy», lo que había sucedido por la novedad de su presencia: «depués que el rrey dom Fernando, mio auuelo, veniere a Santiago a enterrar su padre, el rrey don Alfonso [IX], mio bisauuelo, que auía mas de ·L· años que non entrara en Gallizia otro rrey, si non yo agora». Las quejas que oyó acusaban a «los prelados, e los rricosomnes, e los abbades, e los caualleros, e los terreros, e los coteros» de haber aprovechado esa ausencia de medio siglo para exigir derechos señoriales injustos, que ahora invalidaba, como era el de la mañería, que privaba de herencia a los parientes del hombre que moría sin hijos legítimos ${ }^{161}$, o las multas por

156 Especialmente en R3, R4 y R7. Ed. HH, 2, Apéndices.

$157 H H$, 2, R1: 184 y R3: 9.13. Más ejemplos en esa documentación, con casos muy abundantes de «en tierra» $\mathrm{y}$ «en tierra cierta». El significado de «tierra cierta» fue expuesto por vez primera en $R R, 1$ : XXXIV-XLIII, XLIX-LI, LXXXI-LXXXII.

158 Entre los muchos ejemplos que se hallan en las cartas originales del rey integradas en la Crónica de Alfonso $X$, baste citar la dirigida a su hermano, el infante Felipe, donde le recuerda cómo le dio «todas las terçias del arçobispado de Toledo, et de los obispados de Áuila, e de Segouia, e otros dineros de sus rentas, que vos dio que touiésedes d'él en tierra». Ed. González Jiménez 1998: 97.

$159 H H, 2$, especialmente R3 y R4.

160 Gaibrois, 3, 1922-1928: documentos 124 a 132. Cf. Pérez Rodríguez 2015: 442-443.

161 García González 1951-1952: 224-299. 
«muertes achacadas», que penalizaban al dueño de objetos inanimados o de animales que causaban muertes fortuitas («si el carro ferie alguno et murie, tomauan el carro et los bues») $)^{162}$.

La transformación de los condados en tenencias y de las tenencias en depósitos bancarios controlados por la Corona fue seguida por otras medidas que disolvieron tanto la cohesión de los antiguos condados como las pretensiones de los descendientes de los antiguos condes, impulsando de ese modo la autoridad de la monarquía y su capacidad de acción en Galicia ${ }^{163}$. Ese proceso queda especialmente claro en el emblemático caso del antiguo condado de Trastámara.

\section{TRASTÁMARA, ENGRANDECIDA Y FRAGMENTADA}

La muerte sin sucesión legítima en 1260 de Rodrigo Gómez, último descendiente directo del comes Rudericus de Traua, que confirma los privilegios dados por Alfonso VII a la iglesia de Santiago en $1127^{164}$, seguramente facilitó la ocupación definitiva del condado por los oficiales de Alfonso X y la concesión de sus rentas, recogidas por administradores locales, a su hijo Alfonso Fernández, primer ricohombre de León. Por el momento desconocemos si su viuda, Blanca de Molina, o Isabel, hija de ambos, siguieron recibiendo al menos una parte de los derechos o las tierras de Trastámara, como había sucedido con las tenencias leonesas de Valduerna y Laguna de Negrillos ${ }^{165}$.

Lo que nos importa es que el siguiente ricohombre con tierras en Galicia fue Juan Alfonso de Alburquerque ${ }^{166}$, miembro de la extensa familia de los Meneses a la que habían pertenecido Mayor Alfonso, mujer de Rodrigo Gómez, Blanca de Molina, viuda de Alfonso Fernández, y la propia reina, luego llamada María de Molina. Juan Alfonso de Alburquerque figura entre los ricohombres que confirman los primeros privilegios rodados de Sancho IV en julio de $1284^{167}$ y sigue apareciendo en ellos hasta noviembre de $1292^{168}$. En el invierno 1294, después de haberse aliado al infante don Juan, en deservicio del rey, cayó en desgracia. Fue luego apresado en Galicia por Pay Gómez Chariño y solo se salvó de ser ejecutado porque «era su pariente de la reyna, [...] e punó en lo guardar de muerte, [...]. E ella sacolo de la prisión [...] e fuese para el

162 1286, septiembre 9, Santiago de Compostela. Ed. López Ferreiro 1895: 374-376.

163 Un proceso ya apuntado por Pérez Rodríguez 2015: 449-452.

164 López Ferreiro 1901, 4: apéndices 13 y 14, cit. Pallares y Portela 1993: 830.

165 Ver anterior nota 114.

166 Uso la forma moderna del topónimo pacense, pero, cuando cito textos medievales, mantengo la versión arcaica de 'Albuquerque', que sobrevive en la ciudad así llamada en Nuevo México.

167 Desde el primero conocido, de 1284, julio 28, donde ocupa el 70 lugar. $H H$, 2, Itinerario.

168 Kurtz 2013: 229. 
rey de Portogal» ${ }^{169}$. Antes de salir del reino y establecerse con gran éxito en el vecino, Juan Alfonso había sido adelantado mayor de Galicia entre 1289 y 1291 y tenido tierras en el condado de Trastámara. Pero no había sido el único, ni el condado era ya lo que había sido bajo Alfonso IX de León.

La primitiva tierra de Trastamar, que se extendía entre el río Tambre y las Rías Altas, se habían ampliado hacia el este y el sureste para incluir muchas otras tierras consideradas autónomas previamente. Las de Montenegro, Monterroso, Pallares, Ulloa y Sarria, así como otros lugares menores, habían sido agrupadas en una Tierra Llana, que fue, a su vez, integrada en el Condado de Trastamar (ver el mapa al final de este trabajo). Así lo refleja el libro de cuentas de 1290, que muy probablemente recoge censos de Alfonso X, y así lo confirman varias asignaciones registradas en las nóminas de 1285 y 1293.

El censo de 1290 manifiesta la consumación de una doble maniobra geopolítica de gran calado: la ampliación administrativa del distrito, por un lado, y la fragmentación de sus rentas, por otro. La región aparece ahora notablemente ampliada respecto a su situación antes de 1230, cuando era una más de las grandes terras, o condados. En 1290 su contorno se ha modificado para absorber varias de esas terras, y el conjunto se ha subdividido en tres grandes distritos fiscales: 1) puertos del norte cuyo tributo principal grava la pesca de la ballena (ballenación); 2) pueblas del condado de Trastámara; y 3) lugares de la Tierra Llana, territorio que cubre la actual comarca de la Terra Chá pero se extiende más allá de sus límites modernos, donde ha dejado un nombre que no responde al paisaje, sino a la antigua condición de sus hombres.

Así fue cómo las rentas de esta engrandecida Trastámara no fueron entregadas a un solo tenente en 1290, sino que fueron distribuidas entre veintidós vasallos del rey, a los que se sumó una mujer excepcional, de origen portugués: María Fernández Coronel, ama de la reina María de Molina ${ }^{170}$. Entre los tres ricohombres que ostentan el mayor rango, destaca Juan Alfonso de Alburquerque ${ }^{171}$, que tiene 9000 de los 24000 mrs de la guerra proyectados en las ballenerías, y varias rentas más en las pueblas y en las villas de la Tierra Llana, asignaciones que, con ligeras variantes, se vuelven a registrar en la Nómina de $1293^{172}$, donde se confirma que todas ellas proceden de un «condado de Trastamar» que se ha extendido sobre otras tierras.

Otra porción de las rentas del condado corresponde a once infanzones de Galicia, segundo rango horizontal de la nobleza militarizada, que se agrupa-

169 Crónica de Fernando IV, 2017: 9. Contexto en Kurtz, ver nota anterior.

170 Cf. $H H, 1$, cap. 15.2.2.

171 Ver Apéndice 2, n.․․ 15 .

$172 H H, 2, \mathrm{R} 7: 1.2 .2 .5$. 
ba verticalmente por regiones ${ }^{173}$. En este grupo hay que destacar el caso de Gonzalo Osórez (n.․14), que, en 1290, tiene asignaciones en Monterroso, Pallares y Orcellón, rentas que vuelve e recibir en la Nómina de 1293, donde se indica lo que tiene «en Monte Roso, que es en el condado de Trastamar», aludiendo, una vez más, a la ampliación de Trastámara a costa de las tierras vecinas.

Un segmento más de las mismas rentas pasa a tres mesnaderos, situados en el tercer rango dentro de las fuerzas armadas y exentos de aportar compañones cuando iban a la guerra. Hay cinco hombres más que reciben rentas de Trastámara y pueden haber sido mesnaderos, o, tal vez, oficiales del rey. En todo caso, se confirma lo que ya estaba claro durante la tenencia de Alfonso Fernández el Niño: el condado ha dejado de ser una circunscripción gobernada por un conde como delegado del rey. Esa mediación, junto con los poderes señoriales que acarreaba, ha desaparecido en la segunda mitad del siglo xIII; los antiguos condados, o terras, han sido fragmentados y convertidos en realengos plenos, controlados por adelantados y merinos, encargados de mantener el orden y vigilar la recaudación anual de tributos, convertidos, a su vez, en las soldadas que sostienen la máquina militar de la monarquía alfonsí174.

Los señoríos creados en esos mismos lugares vendrían luego. Un intento temprano es el de Vasco Fernández de Rodeiro (n. 23). Tal vez descendiente de Pay Muñiz de Rodeiro, primer pertiguero conocido de Santiago ${ }^{175}$, don Vasco fue admitido como vasallo del infante Sancho durante la dramática deposición vallisoletana de Alfonso X en 1282, cuando fue premiado con «la tierra de Canba por heredamiento» ${ }^{176}$. Encuadrado en la hueste gallega de Sancho IV como infanzón, recibió una generosa soldada, tan sustancial como para obligarle a mantener una compaña de diez compañones, o caballeros, aunque solo se presentó con tres cuando fue llamado para acudir a la liberación de Jerez en el verano de 1285 - y fue multado por ello- - No obstante sigue apareciendo en las nóminas de la Corte hasta 1292, cuando debió de apostar por una de las facciones de la corte que chocaron con el rey, tal vez la del infante don Juan, donde también estaba Juan Alfonso de Alburquerque, y fue desterrado por Sancho IV. Perdemos su

173 La Nómina del reino de León de $1285(H H, \mathrm{R} 3)$ no tiene listado de ricohombres, pero registra 79 infanzones de Galicia, 17 de León, 6 de Asturias, 30 de Portugal y 2 leoneses «que moran en el Andalucía». Por debajo de ellos están los mesnaderos: 202 de Galicia, 118 de León, 17 de Asturias, 62 de Portugal y 35 leoneses de Andalucía. A ellos se añaden los «mesnaderos que fueron del rey don Alfonso»: 64 de Galicia, 16 de León, 1 de Asturias y 47 de Portugal. La participación mayoritaria de Galicia en el ejército se mantiene en la Nómina general de 1293 (HH, R7), donde, por debajo de 18 ricohombres (8 de Castilla, 6 de León y 4 de Andalucía), hay 78 infanzones (16 de Castilla, 7 de León, 10 de Asturias, 35 de Galicia y 10 de Portugal) y 73 mesnaderos (18 de Castilla, 20 de Toledo, 12 de León, 3 de Asturias, 17 de Galicia y 3 de Portugal). Evidentemente, se trata de cifras que merecen un estudio aparte.

174 Jular 1990: 165-167; Pérez Rodríguez 2015: 444.

175 En datación de una donación al monasterio de Oseira de 1210, «regnante Rege domno Alfonso in Legione, in Gallecia, et in Asturiis; perticario sancti Iacobi domno Pelagio Muniz de Rodeyro; episcopo Lucense domno Roderico». Ed. Romaní, 1, 1989: n.o 13. González Vázquez 1996: 207.

176 1282, mayo 13, Valladolid, en confirmación de Fernando IV, Paredes de Nava, 7 enero 1297. AHD Compostela, Privilegios reales, leg. 5, n.으 19 (privilegio rodado en mal estado). 
pista desde ese momento, pero no la de su grupo familiar ${ }^{177}$, que sigue en Camba y se instala en el lugar como linaje, con su señorío, durante el siglo XIV, dejando una marca indeleble en la toponimia de la zona, atenidos al actual concello de Rodeiro.

El desarrollo de linajes señoriales comienza tímidamente a fines del XIII y estalla en la segunda mitad del XIV, cuando el conde de Trastámara y señor de Lemos y Sarria, convertido en rey Enrique II de Castilla después de matar a su hermano en 1369, compró la lealtad a su monarquía sembrando con señoríos una tierra abonada con el sistema del mayorazgo. La creación de linajes asociados a tierras inalienables e indivisibles fue un fenómeno que afectó a todo el reino, desde Estaca de Bares hasta Gibraltar, pero alcanzó una virulencia especial en Galicia, donde las familias de la nobleza media, los Sotomayor, Andrade, Osorio, Moscoso, Suevos, Ulloa, Monterrey, etc. establecieron, ahora sí, esos linajes que triunfan a fines del siglo Xv. El porqué de esa nueva excepcionalidad galaica merece un estudio aparte ${ }^{178}$. Baste constatar aquí que fue entonces, en la segunda mitad del xiv, cuando el realengo de Galicia fue despedazado y convertido en señoríos, traicionando la política territorial que Alfonso X y Sancho IV habían llevado a cabo, precisamente, en el mismo condado de Trastámara desde donde, un siglo después, partió un ímpetu contrario.

177 González Vázquez 1996: 207; Rodríguez López 1999: 146-152.

178 Eiras Roel (1989: 123 ) ya señaló que «nobleza e hidalguía aprovecharon la crisis bajomedieval para anexionarse propiedades y rentas de los monasterios, y quizá también la jurisdicción sobre algunos de sus vasallos». 


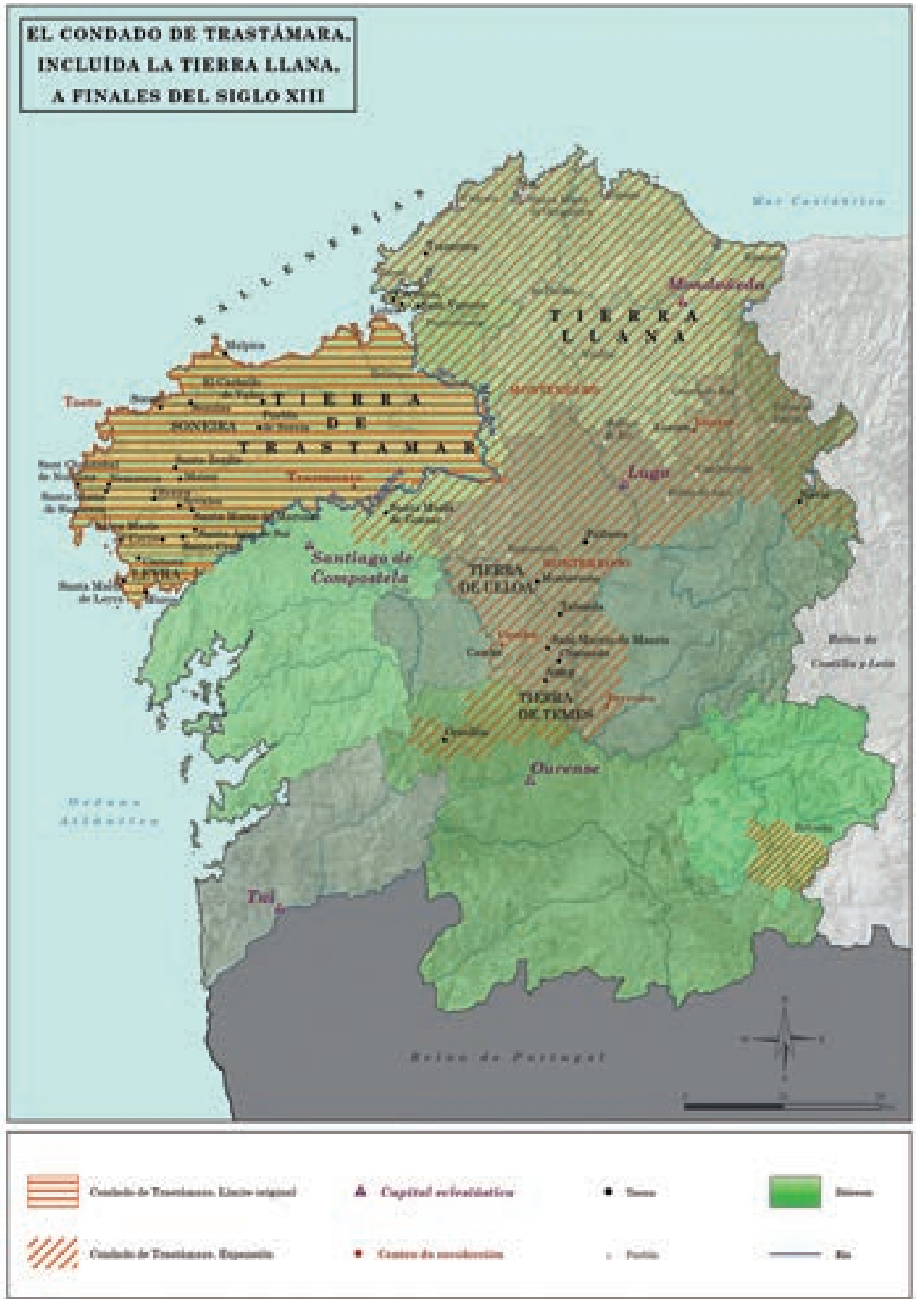

El mapa solo pretende indicar los lugares de realengo que la cancillería real consideraba dentro del Condado de Trastámara y la extensión aproximada de las zonas donde estaban enclavados, todo ello en el contexto de las divisiones diocesanas. De los 175 centros realengos principales de Galicia incluidos en el censo de 1290, solo se recogen aquí los 17 de Trastámara, junto con los 43 lugares del condado. Para representar la compleja subdivisión jurisdiccional de toda Galicia en zonas de realengo y cotos señoriales, eclesiásticos y laicos, habría que definir todos esos cotos, así como la extensión territorial de los concejos realengos. El resultado gráfico seguramente se aproximaría a la imagen moteada de una piel de leopardo, tal como se propone al principio de este trabajo. Cartografía de Víctor Bauzas, de Santiago de Compostela. 


\section{APÉNDICE 1}

El Condado de Trastámara en 1290:

lugares y personas que reciben sus tributos como soldada ${ }^{179}$.

[1] Centros principales de Trastámara (17 lugares, n.ำ130-146) dentro de la lista general del reino de Galicia (175 lugares, n.․․ 129-204) ${ }^{180}$.

[130] Viveiro*- «condado [de Trastamar]» $»^{181}$.

[131] Montenegro, Tierra de— «condado [de Trastamar]».

[132] Villalba* — «condado [de Trastamar]».

[133] Castroverde* — «condado [de Trastamar]».

[134] Adai, Puebla de* (o de Adae, en tierra de Sarria, Lu.).

[135] Castro de Rey* — «condado [de Trastamar]».

[136] Monterroso, Tierra de- «condado [de Trastamar] $»^{182}$.

[137] Santa Marta de Ortigueira*.

[138] Trastamar- «condado [de Trastamar]».

[139] Camba* (actual concello de Rodeiro, Po.).

[140] Cedeira*.

[141] Navia, Castiel de* y Luazes (Navia de Suarna y Val de Luaces, en el actual concello de Pol [Lu.]).

[142] Muro, Puerto de* — «condado [de Trastamar]» (Muros, Co.).

[143] Malpica (+puerto)* — «condado [de Trastamar]» (Malpica de Bergantiños, Co.).

[144] Sereia*- «condado [de Trastamar]» (Cereixo, Co.) ${ }^{183}$.

[145] Tosto, ballenación de- «condado [de Trastamar]» (en Camariñas, Co.).

[146] Ferreira— «condado [de Trastamar]» (Ferreira de Pantón, Lu.).

179 El padrón con que contamos del condado de Trastámara se halla en el libro de cuentas de 1290 $(R R, 1: 298-300)$ y falta en el de 1292. Las cantidades asignadas en este listado están expresadas en «moneda nueva» (mn) y no están multiplicadas por seis para calcular su valor en «moneda de la guerra», que es la que predomina en los otros libros de la cancillería de Sancho IV. En el listado siguiente, la primera cantidad de mrs es la asignada al personaje, la segunda representa el total acumulado en cada unidad tributaria, por ejemplo, «50 mn/100 a Gonçalo Ossorez en Pallares» indica que G.O. recibe $50 \mathrm{mrs}$ de los 100 asignados al lugar de Pallares. T= Condado de Trastamar en 1290: RR, 1: 298-303. 1: $260-297$.

180 El número inicial indica su posición en la lista de lugares del reino de León publicados en $R R$,

181 He marcado con un asterisco (*) los centros también incluidos en la lista siguiente.

182 Monterroso abarcaba la comarca de A Ulloa, actuales municipios de Antas de Ulla, Palas de Rei y Monterroso (Lu.).

183 Probablemente A Ponte do Porto (Camariñas, Co.) o Cereixo, en la vecina parroquia de Santiago de Cereixo (Vimianzo, Co.) (FJPR). 
[2] Condado de Trastámara, listado particular ${ }^{184}$.

\section{Ballenerías}

Tributos asignados, sin indicar los puertos, a:

don Juan Alfonso de Alburquerque (1500 mrs),

Pay Varela (1750) y Pero Varela $(323,33)$,

Ferrán Páez de Betanzos $(166,66)$ y

Ruy Páez, hijo de Pay Gómez [Chariño] (250).

\section{Pueblas}

[1] Betanzos: 350 mrs a Diego Gómez e hijo Ferrán Díaz.

[2] Las Puentes de Ume: 600 mrs Ferrán Pérez de Andrade y a Pero Rodríguez, h. de Ruy Sordo (As Pontes de García Rodríguez).

[3] La Puentedeume: 150 mrs a Ferrán Pérez de Betanzos.

[4] Ferrol: 120 mrs a Ferrán Pérez d’Andra (lugar llamado Ferrol de Rey en 1292-05-08).

[5] Cedeira*: 212,50 mrs a Ferrán Díaz, h. de Diego Gómez.

[6] Santa Marta de Ortigueira*: 690,50 mrs a Diego Gómez.

[7] Viveiro*: 300 mrs a Ferrán Díaz, h. de Diego Gómez y a Arias Pérez Agudo.

[8] Ribadeo: 275 mrs a Diag Anaya y a Alfonso López Sayavedra.

[9] Burón: 100 mrs a Diag Anaya (A Proba de Burón, Lu.).

[10] Castroverde*: 250 mrs a Diego López Farria y Pero Ferrández d’Aguiar (37 km al SW de Burón, Lu.).

[11] Adele [=Adai*]: 225 mrs, sin asignar (Aday o Adae, ver n.․ 134 en p. 182).

[12] Castro de Rey*: 200 mrs a Alfonso López Saya Vedra (Lu.).

[13] Otero de Rey: 950 mrs a Juan Alfonso de Albuquerque (=Outeiro de Rei, Lu.).

[14] Villalba*: 580 mrs a Juan Alfonso de Albuquerque y Martín Mariño (Vilalba, Lu.).

[15] La Repostaría: 200 mrs a Garci Gómez, h. de Vasco Gómez Troco (actuales San Xusto y San Cibrao da Repostería, en Palas de Rei, Lu.).

[16] Robreda: 100 mrs a Garci Gómez, h. de Vasco Gómez Troco (=Robledo de Domiz, o de Valdeorras, Ou. $)^{185}$.

185 Diploma de Carta de 1255: «Don Rodrigo Suárez meyrino maior de toda Galiza, Lourenzo Moniz, de sua mano, meirino en Roureda en Valdeores». Ed. Souto Cabo 2003: n.은. 


\section{Tierra llana}

[17] Tierra de Ulloa, con Palas de Rei, San Jurge, Legunde, Calendas de Monterroso: 240 mrs a Pero Sánchez, h. de Sancho Pérez de Ulloa (lugares de San Xurxo, Ligonde y Caldelas, Lu. $)^{186}$.

[18] Camba*: 50 mrs a Vasco Ferrández de Rodeiro (Camba, Santa Eulalia de [arciprestazgo de Camba y Dozón], diócesis de Lugo; Rodeiro, Po.).

[19] La quarta de Monterroso: 50 mrs a Vasco Ferrández de Rodeyro (Monterroso, Lu.). [20] Pallares: 100 mrs a Vasco Ferrández de Rodeyro y Gonzalo Osórez (=Ferreira de Pallares, Lu.).

[21] Monterroso: 240 mrs a Gonzalo Osórez.

[22] Orzellón: 50 mrs a Gonzalo Osórez (=Orcellón-Carballido?, Ou.).

[23] Taboada: 110 mrs a Ferrán Ybáñez de Leyra (concello de Taboada, Lu.).

[24] Asma: 120 mrs a Ferrán Ybáñez de Leyra (13 km al sur de Taboada) ${ }^{187}$.

[25] Chantada, cellero de: 150 mrs a Ferrán Ybáñez de Leyra (Pobra de Chantada, Lu.).

[26] Sant Martin de Maaris: 10 mrs a Ferrán Díaz, h. de Diego Gómez (San Martiño de Mariz, Chantada, Lu.).

[27] Luazes: 200 mrs a don Esteban Ferrández [de Castro], en acostamiento (Val de Luaces en el actual concello de Pol, Lu. $)^{188}$.

[28] Trasancos ${ }^{189}: 175$ mrs a don Juan Alfonso de Alburquerque (Trasancos corresponde al antiguo arciprestazgo del mismo nombre en la diócesis de Mondoñedo: incluye a Santa Cecilia de Trasancos, parroquia de Ferrol, y, más al norte, San Mateo de Trasancos).

[29] Tierra de Muño Ferrández Nogueirol: 50 mrs (no identificado) ${ }^{190}$.

[30] Tierra de Martín Ferrández: : 150 mrs (no identificado).

[31] Tierra de Juan González de Saz: 220 mrs (no identificado; más miembros de la familia Saz en n.․ 43).

[32] Tierra de Ferrán Varela: 100 mrs (no identificado).

[33] Malpica*: 130 mrs sin asignar (ver arriba).

[34] Navia*: 150 mrs a don Esteban Ferrández, en acostamiento (ver arriba).

186 La tierra de Ulloa ocuparía las dos márgenes del río Ulla, incluyendo parroquias de los actuales concellos de Antas de Ulla y Monterroso (Lu). Entre Palas de Rei, que es villa, y su término y la Ulloa estaría la Repostería. Santiago de Ligonde es feligresía del concello de Monterroso; San Xurxo debe tratarse de San Xurxo de Terra Chá (Antas de Ulla, Lu.), en la que se encuentran los lugares de San Xurxo y de Caldelas, que sería este Calendas de Monterroso (FJPR).

187 Alfonso IX fundó la villa de Chantada en la tierra de Asma; desde entonces se suele alternar Chantada y Asma para designar lo mismo, aunque parece que 'puebla' se asociaba solo con Chantada, nunca con Asma. El monasterio de San Salvador de Asma también llamado, a veces, de Chantada. La tierra de Asma ocuparía tanto el actual concello de Chantada como la mayor parte del de Carballedo (Lu), algunas de cuyas parroquias formaban parte de la tierra de Temes. Cf. González Balasch, «Relaciones», 1987 (FJPR).

188 Donde Alfonso X funda la Pobra de Valonga; comprendería al menos parte de ese concello actual (FJPR).

189 Transcrito erróneamente en RR como «Trasantos».

190 Los Noguerol tenían propiedades en las tierras de Temes y Vilamarín, en los límites de las actuales prov. de Lugo y Ourense, en el término de los actuales concellos de A Peroxa y Vilamarín (Ou) (FJPR). 
[35] Lubre, Cervatos, Sant Vizente, encomiendas de: 32,66 mrs a Ferrán Pérez d’Andrade (Lubre, Cervás y San Vicenzo de Elviña, Co.) ${ }^{191}$.

[36] El Carballo de Valar: 100 mrs a Ferrán Ybáñez de Leyra (lugar no identificado).

[37] Tierra de Temes: 50 mrs a don Ferrán Pérez Ponz en acostamiento ${ }^{192}$.

[38] [Leira, A Coruña] feligresias de Santa María de Leyra, de Santa María de Coyro, de Santa Agia de Sor, de Santa María de Maronas y de Santa Cruz ${ }^{193}: 115$ mrs a Ferrán Díaz, h. de Diego Gómez.

[39] Feligresias de Santa María de Gonzar, de Santa María de Sagueros, de Sant Christobal de Nomlina [?] y de Santa María de Brigueyros: 25 mrs a Ferrán Rodríguez, h. de Ruy Vasquez de Santa Eugea. (Solo identificamos Gonzar, Lu.).

[40] feligresias de Sezulas e de Soesto ${ }^{194}: 50$ mrs a doña María Ferrández Coronel, ama de la reyna (Santo Estevo de Cesullas, Cabana de Bergantiños, Co., y Santo Estevo de Soesto, Laxe, Co.).

[41] Muro[s]", puebla, con su alfoz, la puebla de Sereia con su alfoz, Maino y Brandanos [Brandaos?], «salvo lo que tiene ahí, por tierra, Juan González de Saz; más Barcalla y Nemancos, como lo tenié [sic] Ruy Páez»: 300 mrs a Pero Páez Maimón y a Pay Maimón ${ }^{195}$.

[42] Olveira, Brandemir [=Brandomil], Arvales, Sant Cofinade, con la tercia de Cornota [no identificados] e de Santa Zezilia: 220 mrs a don Juan Alfonso d'Albuquerque ${ }^{196}$. [43] En Soneira' ${ }^{197}$, e en la tierra que tiene Juan de Saz, h. de Ruy Ferrández de Saz, e Ferrán Bezerra, salvo lo que tiene Juan González de Saz: 375 mrs a Ferrán Díaz, h. de Diego González de Roa. (Soneira era arciprestazgo del arcedianato de Trastámara, también tierra, que comprendería, en todo o en parte, los actuales concellos de Cabana de Bergantiños, Coristanco, Zas, Vimianzo, Laxe, parte también de Camariñas).

191 Son las actuales feligresías que componen el concello de Ares (Co.): Santa Baia de Lubre (hoy San Xosé de Ares), San Pedro de Cervás y San Vicente de Caamouco (FJPR).

192 Tierra al sur del Búbal, básicamente en el actual concello de A Peroxa (Ou.) pero también en Carballedo (Lu.), donde está la parroquia que conserva el nombre; probablemente también incluyese, en todo o en parte, el concello de Vilamarín (Ou.) (FJPR).

193 Santa María de Coiro y Santa Mariña das Maroñas en el concello de Mazaricos (Co.); Santa Agia de Sor tiene que ser Santa Baia de Chacín, porque está entre las dos anteriores; Santa Cruz sería Santa Cruz de Campolongo (Negreira, Co.), limítrofe con Chacín y próxima ás Mariñas. A Santa María de Leira hay que identificarla con Santa María de Lira, en el concello de Carnota (Co.) (FJPR).

194 San Esteban de Soesto en arcip. Soneira, arc. Trastámara, dióc. Santiago; y San Juan de Soesto en arciprestazgo de Seaya, en el mismo arcedianato (Censo, 1829: 322).

195 La tierra de Barcala es el actual concello de Negreira (Co.), y Nemancos, el arciprestazgo más occidental del arcedianato de Trastámara, que comprendería, al menos y más o menos, los actuales concellos de Muxía, Fisterra, Cee, Corcubión y Dumbría (Co.). Maino y Brandanos deben de estar por los concellos de Camariñas, Vimianzo, Muxía o Dumbría; como mucho Santa Comba y Mazaricos (FJPR).

196 San Martiño de Olveira (Dumbría, Co.), San Pedro de Brandomil (Zas, Co.); San Mamede de Alborés (Mazaricos, Co.), y la tercia de Carnota sería la de una de las iglesias de San Mamede o Santa Comba de Carnota (Carnota, Co.). Santa Zezilia debe de ser Santa Sía de Roma (Zas) y Arvales por Alborés tiene lógica del gallego al castellano.

197 Terra de Soneira, A Coruña. Era cabeza de un arciprestazgo del arcedianato de Trastámara. Transcrito erróneamente en $R R$ como «Soueira». Ver mapa de Martínez Lema 2010: 19. 


\title{
APÉNDICE 2
}

Tenentes del Condado de Trastámara en 1290.

\begin{abstract}
Abreviaturas
FJPR: anotación de F. J. Pérez Rodríguez.

mn: moneda nueva, las otras cantidades son maravedís «de la guerra», moneda usual de cuenta.

R\#: registro publicado en $H H, 2$, 2021, Apéndices.

T\#: Lugar de Trastámara en 1290, con el número asignado en $R R$, 1: 298-300.

TL\#: Lugar de la Tierra Llana de Trastámara en 1290, con el número de $R R$, 1: 300-303.
\end{abstract}

1. Alfonso López Saavedra (o Sayavedra), infanzón de Galicia en 1285, con 1500 mrs, debe aportar 5 compañones (R3: 1.23); le faltan 3 en la hueste de Jerez de 1285 y pierde 600 mrs (R4: 1.2.11). En 1290 tiene 200 mn/200 en Ribadeo y 75 mn/275 en Castro de Rei (T8 y T12, p. 299): total de 275 mrs mn. En 1293, aparece degradado al rango de mesnadero de Galicia, pero retiene lo anterior $(275 \mathrm{mn} \times 6=1650)$ y recibe 1350 mrs más en la judería de Burgos y 1000 en la de Miranda de Ebro (cantidad que antes tenía en Sepúlveda), lo que supone un total de 4000 mrs en 1293 (R7: 3.5.6, donde, por error, se le asigna un total de 6000).

2. Arias Pérez Agudo, infanzón de Galicia en 1293 (R7: 2.4.21). En 1290 tiene 220 mn/300 en Viveiro $(220 \mathrm{mn} \times 6=1320)(\mathrm{T7}, \mathrm{p} .299)$. En 1293, como infanzón, tiene $4200 \mathrm{mrs}$ «en dineros», sin más detalles.

3. Diago Anaya, infanzón de Galicia en 1293 (R7: 2.4.20). En 1290 tiene 200 mn/275 en Ribadeo y 100 mn/100 en Burón (T8 y T9, p. 299). En 1293, como infanzón, además de lo anterior $(300 \mathrm{mn} \times 6=1800)$, recibe $10 \mathrm{mrs} m n(=60)$ en la iglesia de Sant Christóbal de Suarna (tierra de Navia, como Navia de Suarna) y 1000 más en «los diezmos de los puertos», con un total de 2860 mrs (R7: 2.4.20).

4. Diego Gómez de Galicia (o de Roa), infanzón de Galicia y portero mayor (en 1285: R3: 1.1); portero mayor del reino de León en 1287 (RR, 1: 338); merino mayor en Galicia en 1288: En 1290 tiene 307,50 mn/350 en Betanzos y 690,50 mn/690,50 en Santa Marta d'Ortiguera (T1 y T6, p. 298 y 299) (307,5 + 690,5 = $998 \mathrm{mn} \times 6=5988)$. En 1293 pasa a su hijo, Ferrán Díaz, infanzón de Galicia, (R7: 2.4.3, q.v.). Ver n.o 7.

5. Diego López de Sarria, mesnadero de Galicia en 1285 (R3: 3.146), cuando tiene 600 mrs (está repetido en R3: 3.181 y borrado de la lista de mesnaderos de Portugal en R3: 10.32). En 1290 tiene 150 mn/250 mn (= 900) en Castroverde (T10, p. 299). En 1293 tiene 2000 mrs «en dineros» y sigue como mesnadero de Galicia (R7: 3.5.10).

6. Esteuan Fernández [de Castro], don, ricohombre del reino de León. Había sido pertiguero de Santiago (1276-07-14: DAAX, n.. 429) y merino mayor de Galicia bajo 
Alfonso X (1278-09-27: AM Segovia, c.3/7 - 1281-07-25: DAAX, n. 482). Es luego adelantado en Galicia del infante Sancho (1282-05-12, RR 1, 1993: 469) y pertiguero de Santiago en 1285 (R1: 197, 284). En ese año le descuentan 3400 mrs por los 22 caballeros que no aportó a la hueste de Jerez (R4: 4.3.1). En 1290 tiene en acostamiento de 100 mn/100 (=600 mrs) en Navia (de Suarna, Lu.) y 200 mn (=1200 mrs) en [Val de] Luaces (Pol, Lu.) (TL27 y TL34, p. 301). Murió en el mismo 1290. Cf. HH, 1, cap. 8.9.

7. Ferrán Díaz, fijo de Diego Gómez de Roa, infanzón de Galicia en 1293 (R7: 2.4.3). En 1290 tiene 55 mn/300 en Viveiro (T7, p. 299), 32,50 mn/350 en Betanzos (T1, p. 298), 375 mn/375 en Soneira (TL43, p. 303), 10 mn/10 en San Martín de Maaris (San Martiño de Mariz, Chantada) (TL26, p. 301); 115 mn/150 en las feligresías de Santa María de Leyra, Santa María de Coyro, Santa Agia de Sor, Santa María de Maronas y Santa Cruz ${ }^{198}$ (TL38, p. 302); 212,50 mn/212,50 en Cedeira (T5, p. 298). En 1293, como infanzón, tiene 2250 mrs en Cedeira, 3555 en Ortigueira, 690 en las feligresías anteriores, 2100 en Betanzos y 410 en otros lugares, con un total de 10480 mrs (R7: 2.4.3).

8. Ferrán Páez de Betanzos: En 1290 tiene 166,66 mn/4000 en las ballenerías de Trastámara (RR: p. 298, con patronímico erróneo de Pérez); 150 mn/150 en Pontedeume (T3, p. 298). En 1293 todo ha pasado a Alfonso Suárez, hijo de Alfonso Suárez de Deza, y se indica que «las Puentes de Vme (...) son en este condado (de Trastamar)» (R7: 2.4.33).

9. Ferrán Pérez de Andrade, infanzón de Galicia en 1293 (R7: 2.4.24). En 1290 tiene 120 mn/120 en Ferrol (T4, p. 298); 213,33 mn/600 en Pontedeume (T2, p. 298); 32,66 mn/32,66 en las encomiendas de Lubre, Çeruaes, Sant Viçente ${ }^{199}$ (TL35, p. 301). Recibe la misma asignación en 1293, más 1004 mrs «en los diezmos de los puertos», con un total de 3200 mrs (R7: 2.4.24).

10. Ferrant Pérez Ponz, ricohombre del reino de León, amo del heredero de Sancho IV, futuro Fernando IV. En 1285 sufre un descuento de 6000 mrs por los 30 caballeros que no aportó a la hueste de Jerez (R4: 1.1.1.4). (Ver $H H, 1$, cap. 2.6, 11.2 y 4, etc.). En 1290 tiene, aparte de muchos otros beneficios, $50 \mathrm{mn} / 50$ en acostamiento, en Tierra de Temes ${ }^{200}$ (TL37, p. 302).

11. Ferrán Rodríguez, fijo de Ruy Vasquez de Santa Eugea o Santa Ougeya: (R3: 3.165-69), hermano de Vasco Rodríguez, mesnadero de Galicia (R3: 129). En 1290 tiene 25 mn/25 en Gonzar (Santa María de Gonçar) y en otras feligresías identi-

198 Santa María de Coiro y Santa Mariña das Maroñas están en el concello de Mazaricos, Co.; Santa Agia de Sor debe ser Santa Baia de Chacín, porque está entre las dos anteriores; Santa Cruz es Santa Cruz de Campolongo (Negreira, Co.), limítrofe con Chacín y próxima a Mariñas. Santa María de Leira debe ser Santa María de Lira, en el concello de Carnota, Co. (FJPR).

199 Actuales feligresías que componen el concello de Ares, Co.: Santa Baia de Lubre (hoy San Xosé de Ares), San Pedro de Cervás y San Vicente de Caamouco (FJPR).

200 En los actuales concellos de A Peroxa y Vilamarín, Ou., en los límites de las actuales provincias de Lugo y Ourense (FJPR). 
ficadas: Santa María de Sagueros, Sant Christoual de Nomlina(?), Santa María de Brigueyros (TL39, p. 302).

12. Ferrant Yuáñez de Leyra, infanzón de Galicia en 1285 (= Ferrán Eanes en R3: 1.33), con 600 mrs. Pierde 400 por la mengua de Jerez de 1285 (R4: 1.6.27). En 1290 tiene 100 mn/100 en Caruallo de Valar (TL36, p. 302); 110 mn/110 en Taboada, Lu. (TL23, p. 300); 120 mn/120 en Asma (Chantada) (TL24, p. 301) y 150 mn/150 en el cellero de Chantada (TL25, p. 301).

13. Garçi Gómez, fijo de Vasco Gómez Troco, infanzón de Galicia en 1293 (R7: 2.4.1.8). En 1290 tiene 200 mn/200 en La Repostería (San Cibrao da Repostería, Palas de Rei, Lu.) (T15, p. 300) y 100 mn/100 en Roureda (Robledo de Domiz) (T16, p. 300). En 1293 tiene 2000 mrs en dineros.

14. Gonçalo Ossórez, infanzón de Galicia en 1293 (R7: 2.4.8). En 1290 tiene 240 mn/240 en Monterroso, Lu. (TL21, p. 300); 50 mn/100 en Pallares (TL20, p. 300); 50 mn/50 en Orzellón (TL22, p. 300). En 1293 tiene 1290 mrs «en Monte Roso, que es en el condado de Trastamar», junto con 300 en Camba (concello de Rodeiro, Po.), 600 en Pallares (Ferreira de Pallares. Lu.) y 300 en Orzellón (concello de Boborás), lugares que están «en este condado [de Trastamar]» (R7: 2.4.8).

15. Johan Alfonso d'Albuquerque, don, ricohombre de León en 1285, cuando sufre un descuento de 1800 mrs por no haber aportado 9 caballeros a la hueste de Jerez (R4: 1.1.10). Fue adelantado mayor de Galicia en 1289-06-09-1291-06-22 ${ }^{201}$. En 1290 tiene 9000 mrs (1500 mn/4000) en las ballenerías (RR: p. 298); 175 mn/175 en Trasancos ${ }^{202}$ (TL28, p. 301); 220 mn/220 en Olueyra, Brandemir, Aruales, Sant Cofinade, con la terçia de Cornota e de Santa Çeçilia ${ }^{203}$ (TL42, p. 302); 289 mn/580 en Villalba (T14, p. 299); 950 mn/950 en Oter de Rey (T13, p. 299). En 1293 tiene 9000 mrs en «la ballenaçión del condado de Trastamar», 1680 en Vilalba, 5700 en Oter de Rey, 1500 en Trasancos y 1320 en los lugares ya citados de Olueyra, Brandemir, Aruales, Sant Cofinade, con la terçia de Cornota e de Santa Çeçilia (R7: 1.2.2.5).

16. María Fernández Coronel, ama de la reina María de Molina. En 1290 tiene 50 mn/50 en las feligresías de Sezulas (Santo Estevo de Cesullas, feligresía del concello de Cabana de Bergantiños, Co.) y de Soesto (Santo Estevo de Soesto, feligresía del concello de Laxe, Co.) (TL40, p. 302).

17. Pay Varela, infanzón de Galicia en 1293 (R7: 2.4.1). En 1290 tiene 1750 mn/4000 en las ballenerías de T (RR: p. 298). En 1293 tiene 1500 mrs «en tierra de Sayán, que es en este condado (de Trastamar)» (R7: 2.4.1). (+Pero Varela, hijo de Pay Varela: 323,33 mn/4000 mrs en las ballenerías de T [RR: p. 298]).

201 Kurtz 2013: 227.

202 Actuales concellos de Valdoviño, Ferrol, Narón, Neda y San Sadurniño (Co.) (FJPR).

203 San Martiño de Olveira (Dumbría, Co.), San Pedro de Brandomil (Zas, Co.), San Mamede de Alborés < Arbales (Mazaricos, Co.), Santa Comba de Carnota (Carnota, Co.) y Santa Sía de Roma (Zas, Co.) < Santa Zezilia (FJPR). 
18. Pero Fernández d’Aguiar. En 1290 tiene 100 mn/250 en Castroverde, Lu. (T10, p. 299).

19. Pero Páez Maimón: En 1290 tiene 150 mn/300 en la puebla de Muro, puebla de Sereia (Cereixo) ${ }^{204}$, Mayno y Brandanos (TL41, p. 302).

20. Pero Rodríguez, mesnadero de Galicia en 1293 (R7: 3.5.2), hijo de Ruy Sordo infanzón de Galicia (R3: 1.42). En 1290 tiene 250 mn/600 en Pontedeume (T2, p. 298) y en 1293 tiene 1500 mrs de nuevo en Pontedueme, «que es en el condado [de Trastamar]», más 500 mrs «en los diezmos de los puertos» (R7: 3.5.2).

21. Pero Sánchez, fijo de Sancho Pérez de Ulloa, mesnadero de Galicia en 1285 (R3: 3.122), cuando tiene 400 mrs de soldada. En 1290 tiene 240 mn/240 en Tierra de Ulloa, con Palas de Rey, San Jurge (San Xurxo de Terra Chá, Antas de Ulla, Lu.), Legunde (Santiago de Ligonde, feligresía del concello de Monterroso) y Calendas de Monterroso (TL17, p. 300).

22. Ruy Páez, fijo de Pay Gómez [Chariño, infanzón de Galicia]. En 1290 tenía 250 mn/4000 mrs en las ballenerías de Trastamar (RR: p. 298). En 1293 controlaba el «portadgo de Lama de Godino, que es en Sanabria» y debía transferir 1000 mrs de los fondos de ese portazgo a Ferrán García de Sanabria, infanzón de Tierra de León (R7: 1.2.23).

23. Vasco Fernández de Rodeiro, inscrito como vasallo del infante Sancho en 1282 (mayo 2, Valladolid), cuando recibe «la tierra de Camba por heredamiento» $(H H$, cap. 8.9). En 1285, siendo infanzón de Galicia, «tiene en tierra cierta, en la tierra que dizen Camba, que es del condado [de Trastamar]», 50 mrs. Tiene, además, «el çellero de Vema [Bama], que es del arçobispo (...), e, sobresto, anle a conplir los arrendadores del arçobispado a mil mrs, a $\cdot v \cdot s s$. Estos tiene con la seña de Santiago, de más de los tres mill mrs que tiene en el rrey». Debía servir con 10 compañones (R3: 1.3). También en 1285 es el primero de los 35 infanzones de Galicia multado «por razón que minguara con vna quantía de [siete] conpañones, con los que auía de seruir [en Jerez], $\tau$ non siruió» (R2: 111 y R4: 1.2.1). Su hermano parece haber sido Martín Fernández, arcediano de Cornado en la iglesia de Santiago ${ }^{205}$, con quien recaudó «las sacadas de tierra de Sanctiago destos dos seruiçios que prometieron al rrey en Burgos», cantidades que no había entregado en octubre de 1285, cuando el lugarteniente del pertiguero de Santiago recibió la orden de «que les tomen todo quanto les fallaren, tan bien mueble commo rayz, e que los [sic] entregasen a don Marcos $\tau$ a Gonçalo Arias, que los an de dar a don Esteuan [Fernández de Castro, pertiguero mayor]» (R2: 108). En febrero de 1282 se vio obligado a entregar lo que tenía asignado en el cellero arzobispal de Bama (R3: 1.3). En 1290 tiene ingresos en Trastámara:

204 Probablemente A Ponte do Porto (Camariñas, Co.) o Cereixo, en la vecina parroquia de Santiago de Cereixo (Vimianzo, Co.) (FJPR).

205 Durante la sede vacante de Santiago, fue el administrador de la diócesis propuesto por el cabildo, mientras Pai Dacana (alias «Pelayo Pérez») fue el designado por el rey (López Ferreiro, 5, 1902: 245; HH, 1: cap. 3.4.8). Está documentado como arcediano de Cornado entre 1283 y 1286 (González Vázquez 1996: 207). 
50 mn/50 en Camba (como en 1285) (T18, p. 300); 50 mn/50 en la quarta de Monterroso (T19, p. 300) y 50 mn/100 en Pallares (Ferreira de Pallares, Lu.) (TL20, p. 300). En 1291 tiene asignados $717 \mathrm{mn} / 69520 \mathrm{mrs}$ en la judería de Valladolid, como vasallo del infante Fernando, el cual se los quita para dárselos a don Alfonso de Molina (RR, 1: 142). En 1292 pierde los 300 mrs de las rentas de Camba, que «[s] on puestos al infante don Fernando para Gonçalo Osores, su vasallo, los que y solía tener Vasco Ferrández de Rodeyro [...] por heredamiento, [a quien] echó el rey de la tierra» $(R R, 1: 267)$.

\section{Tenentes de Trastámara en 1290}

\section{Ricohombres:}

Esteuan Fernández [de Castro] [6]

Ferrant Pérez Ponz, ricohombre del reino de León [10]

Johan Alfonso d'Albuquerque, don, ricohombre de León [15]

\section{Infanzones:}

Alfonso López Saavedra [1]

Arias Pérez Agudo [2]

Diago Anaya [3]

Diego Gómez de Galicia (o de Roa) [4]

Ferrán Díaz, fijo de Diego Gómez de Roa [7]

Ferrán Pérez de Andrade [9]

Ferrant Yuáñez de Leyra [12]

Garçi Gómez, fijo de Vasco Gómez Troco [13]

Gonçalo Ossórez [14]

Pay Varela [17]

Vasco Fernández de Rodeiro [23]

\section{Mesnaderos:}

Diego López de Sarria [5]

Pero Rodríguez, fijo de Ruy Sordo [20]

Pero Sánchez, fijo de Sancho Pérez de Ulloa [21]

\section{Ama de la reina:}

María Fernández Coronel [16] 


\section{Sin rango explícito:}

Ferrán Páez de Betanzos [8]

Ferrán Rodríguez, fijo de Ruy Vasquez de Santa Eugea [11]

Pero Fernández d’Aguiar [18]

Pero Páez Maimón [19]

Ruy Páez, fijo de Pay Gómez Chariño [22] 


\section{REFERENCIAS BIBLIOGRÁFICAS}

\section{Abreviaturas}

- DAAX = GonZÁLEz JimÉNEZ, Manuel (ed.) (1991): Diplomatario andaluz de Alfonso X, Sevilla, El Monte.

- HH = HERNÁNDEZ, Francisco J. (2021): Los hombres del rey y la transición de Alfonso X el Sabio a Sancho IV (1276-1286), 2 vols., Salamanca, Universidad.

- MHE = Memorial Histórico Español.

- $R R=$ HERnÁNDEZ, Francisco J. (1993): Las rentas del rey, 2 vols., Madrid, Fundación Ramón Areces.

\section{Artículos y libros citados}

- Álvarez Castrillón, José Antonio (2013): «Cartas de fuero y licencias ad populandum del monasterio de Lorenzana. Contribución al corpus de los fueros rurales de Galicia», Cuadernos de Estudios Gallegos, 60:126, 85-123.

- Álvarez Castrillón, José Antonio (2011): Colección diplomática del monasterio de Santa María de Villanueva de Oscos (1139-1300), Oviedo, Real Instituto de Estudios Asturianos.

- Antonio Rubio, María Gloria de (2007): «Judíos en Galicia: visión panorámica y nue-

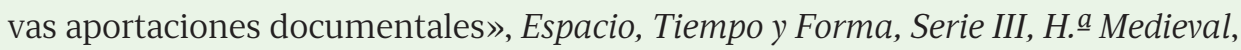
20, 289-314.

- Antonio Rubio, María Gloria de (2012): «Judíos y juderías en la Galicia medieval», Minius. Revista do Departamento de Historia, Arte e Xeografía, 20, 7-28.

- Ballesteros Beretta, Antonio (1913): Sevilla en el siglo XIII, Sevilla, Duque de T'Serclaes Tilly.

- Baronius, CAESAR/O. RAInALDI/A. TheIner (1870): Annales ecclesiastici. Tomus XXII (1251-1285), Parisiis-Bruxellis, Barri-Ducis, Ludovicus Guérin.

- Barton, Simon (1997): The aristocracy in twelfth-century León and Castile, Cambridge/New York, Cambridge University Press.

- Berger, Elie (ed.) (1902): Layettes du Trésor de Chartes, 4 (1262-1270), Paris, Plon.

- Bianchini, Janna (2013): «The Distribution of Tenancies in León, c. 1200-1250: Charter Evidence for a History of Power», Journal of Medieval Iberian Studies, 5:1, 33-46.

- Bianchini, Janna (2012): The Queen's Hand: Power and Authority in the Reign of Berenguela of Castile, Philadelphia, University of Pennsylvania Press.

- Calleja Puerta, Miguel (2000): «De me domno Roderico Gomecii, totis vassallis meis: un mandato señorial de principios del siglo XIII», en El legado cultural de la 
Iglesia Mindoniense: Ferrol, 16, 17, 18 de setembro, 1999. I Congreso do Patrimonio da Diócesis de Mondoñedo, A Coruña, Universidade, 285-298.

- Cantigas Medievais Galego-Portuguesas, 2021: https://cantigas.fcsh.unl.pt/cantiga.asp?cdcant=113 [última consulta: enero 2021].

- Casado Lobato, M. o Concepción (1983): Colección diplomática del Monasterio de Carrizo, 2 vols., León, Centro de Estudios e Investigación «San Isidoro».

- Castán Lanaspa, Guillermo (1984): «San Nicolás del Real Camino, un hospital de leprosos castellano-leonés en la Edad Media», Publicaciones de la Institución Tello Téllez de Meneses, 51, 107-221.

- CORTES de los antiguos reinos de León y Castilla, ver Real ACADEMia de la Historia.

- Craddock, Jerry R. (1998): «El texto del Espéculo», Initium. Revista Catalana d’Istòria del Dret, 3, 221-274.

- CRÓNICA de Alfonso X (1998): ed. M. GonZÁlez JimÉneZ, Murcia, Real Academia Alfonso X el Sabio.

- CRÓNICA de Fernando IV (2017): ed. Carmen Benítez Guerrero, El Puerto de Santa María, Universidad de Sevilla.

- DAumet, Georges (1913): Mémoire sur les relations de la France et de la Castille de 1255 à 1320, Paris, Fontemoing.

- Diccionario de Autoridades, ver Real Academia Española.

- Domínguez SánCHEZ, Santiago (2010): Documentos de Martín IV (1281-1285) referentes a España, León, Universidad.

- Dono López, Pedro (2010): Colección de documentos en pergamiño do Mosteiro de Santa Comba de Naves. Introdución, edición e índices, Santiago de Compostela, Universidade. Tesis doctoral inédita.

- Doubleday, Simon R. (2001): The Lara Family, Crown and Nobility in Medieval Spain, Cambridge, Mass., Harvard University Press.

- ECHÁNIZ SANS, María (1993): El monasterio femenino de Sancti Spíritus de Salamanca. Colección diplomática (1268-1400), Salamanca, Universidad.

- EIRAS Roel, Antonio (1989): «El señorío gallego en cifras. Nómina y ranking de los señores jurisdiccionales», Cuadernos de Estudios Gallegos, 103, 113-135.

- Fernández Catón, José María (1978): Catálogo del Archivo Histórico Diocesano de León, León, Centro de Estudios e Investigación «San Isidoro».

- Fernández Conde, F. J./Isabel Torrente Fernández/Guadalupe de la Noval MenÉndez (1978): El monasterio de S. Pelayo de Oviedo. Historia y fuentes, t. 1. Colección diplomática (996-1325), Oviedo, Monasterio de San Pelayo. 
- FeRnández de Viana y Vieites, José Ignacio (2009): Colección diplomática do mosteiro de San Pedro de Vilanova de Dozón, Santiago de Compostela, Consello da Cultura Galega.

- FerReira PRIEGUe, Elisa (2002): «El poblamiento urbano en la Galicia medieval», en J. A. Solórzano Telechea/B. Arízaga Bolomburu (eds.): El fenómeno urbano medieval entre el Cantábrico y el Duero. Revisión historiográfica y nuevas propuestas de estudio, Santander, Asociación de Jóvenes Historiadores de Cantabria, 367-420.

- FerReira PRIEGUe, Elisa (1988): Galicia en el comercio marítimo medieval, [A Coruña], Fundación Pedro Barrié de la Maza.

- Gaibrois, Mercedes (1919-1920): «Tarifa, y la política de Sancho IV de Castilla», Boletín de la Real Academia de la Historia, [1] 74 (1919): 418-436; [2] 74 (1919): 521-529; [3] 75 (1919): 349-355; [4] 76 (1920): 53-77; [5] 76 (1920): 123-160; [6] 76 (1920): 420-448; [7] 77 (1920): $192-215$.

- GaibroIs, Mercedes (1922-1928): Historia del reinado de Sancho IV de Castilla, 3 vols., Madrid, Real Academia de la Historia.

- García GonzÁlez, J. (1951-1952): «La mañería», Anuario de Historia del Derecho Español, XXI-XXII, 224-299.

- González Balasch, María Teresa (2004): Tumbo B de la Catedral de Santiago, Sada (A Coruña), Ediciós do Castro.

- GonZÁlez GonZález, Julio (1980, 1983, 1986): Reinado y diplomas de Fernando III, 3 vols., Córdoba, Monte de Piedad.

- GonZÁLEZ GonZÁLEZ, Julio (1951): Repartimiento de Sevilla, 2 vols, Madrid, CSIC.

- GonzálEz GonzÁLEZ, Julio (1944): Alfonso IX, Madrid, CSIC.

- GonZález PAZ, Carlos Andrés (2004): «Sarracenos, moros, mudéjares y moriscos en la Galicia medieval», Cuadernos de Estudios Gallegos, 51:117, 281-312.

- GonZÁlez VázQuez, Marta (1996): El arzobispo de Santiago: una instancia de poder en la Edad Media (1150-1400), A Coruña, Seminario de Estudos Galegos.

- HeRnÁndeZ, Francisco J. (2018): «Historiografía y propaganda: Juan Manuel, Alfonso XI de Castilla, Afonso IV de Portugal», en F. J. Hernández/Rocío Sánchez Ameijeriras/Emma Falque (eds.), Medieval Studies in Honour of Peter Linehan, Firenze, SISMEL-Galuzzo, 373-448.

- HeRnándeZ, Francisco J. (2015): «La reina Violante de Aragón, Jofré de Loaysa y la Crónica de Alfonso X. Un gran fragmento cronístico del siglo XIII reutilizado en el XIV», Journal of Medieval Iberian Studies, 7:1, 87-111.

- Hernández, Francisco J./Peter Linehan (2004): The Mozarabic Cardinal, Firenze, SISMEL-Galuzzo. 
- [JuAn DE SORIa] (1997): Chronica latina regum Castelle. Ed. Luis Charlo Brea, en Chronica hispana saeculi XIII, Turnhout, Brepols, 33-118.

- Jular Pérez-Alfaro, Cristina (1999): «Los bienes prestados: estrategias feudales de consolidación señorial», Historia Agraria. Revista de Agricultura e Historia Rural, 17, 73-98.

- Jular Pérez-Alfaro, Cristina (1990): Los adelantados y merinos mayores de León (siglos XIII-XV), León, Universidad.

- KLeINE, Marina (2012): La cancillería real castellana durante el reinado de Alfonso X (1252-1284): una aproximación prosopográfica (tesis doctoral), Sevilla, Universidad. Tesis publicada posteriormente como La cancillería real de Alfonso X. Actores y prácticas en la producción documental, El Puerto de Santa María, Universidad de Sevilla/Cátedra Alfonso X el Sabio, 2015.

- KuRTZ, William S. (2013): «Juan Alfonso de Alburquerque: noble del reinado de Sancho IV de Castilla y León», Revista Portuguesa de História, 44, 215-236.

- Linehan, Peter (1980 y 1983): «The Spanish Church Revisited: The Episcopal Gravamina of 1279», en B. Tierney/Peter Linehan (eds.), Authority and Power. Studies on Medieval Law and Government Presented to Walter Ullmann on his Seventieth Birthday, Cambridge, CUP, 127-147; reimpr. Spanish Church and Society, IX.

- López Dapena, Asunción (1984): Cuentas y gastos (1292-1294) del rey don Sancho IV el Bravo (1284-1295), Córdoba, Monte de Piedad y Caja de Ahorros de Córdoba.

- LóPEZ DíAZ, María (1991): «Alteraciones en el mapa jurisdiccional gallego durante la edad moderna: las desmembraciones eclesiásticas del siglo XVI», Estudios Mindonienses, 7, 559-588.

- López Ferreiro, Antonio (1901): «XX. Año 1199. Testamento de Doña Urraca Fernández, hija del Conde D. Fernando Pérez de Traba, viuda de D. Juan Arias», Galicia Histórica, 1:20, 84-89.

- López Ferreiro, Antonio (1895): Fueros municipales de Santiago y de su Tierra, Santiago de Compostela, Seminario Conciliar.

- LóPEz Ferreiro, Antonio (1901 y 1902): Historia de la Santa A.M. Iglesia de Santiago de Compostela, tomos 4 y 5, Santiago de Compostela, Seminario Conciliar.

- López SANGiL, José Luis (2020): «El monasterio cisterciense de Santa María de Monfero en su documentación (1088-1300)», Nalgures, 16, 11-680.

- Martín MarTín, José Luis (1989): Documentación medieval de la iglesia catedral de Coria, Salamanca, Universidad.

- Martín Martín, José Luis (1982): Documentos zamoranos. I, Documentos del Archivo Catedralicio de Zamora: Primera parte (1128-1261), Salamanca, Universidad.

- Martínez Salazar, Andrés (1911): Documentos gallegos de los siglos XIII al XVI, A Coruña, Imprenta de la Casa de Misericordia. 
- Pallares MÉNDEZ, María del Carmen (1979): El Monasterio de Sobrado: un ejemplo del protagonismo monástico en la Galicia Medieval, A Coruña, Diputación Provincial.

- Pallares Méndez, María del Carmen/Francisco Javier Pérez Rodríguez/Marta GonZález VázQuez/María Beatriz VAQueRo Díaz (1992): «La Tierra de Santiago, espacio de poder (siglos XII y XIII)», Sémata. Ciencias Sociais e Humanidades, 4, 133-174.

- Pallares MÉndeZ, María del Carmen/Ermelindo Portela Silva (1993): «Aristocracia y sistema de parentesco en la Galicia de los siglos centrales de la Edad Media el grupo de los Traba», Hispania. Revista Española de Historia, 53:185, 823-840.

- Pallares MÉndez, María del Carmen (1978): «Los cotos como marco de los derechos feudales en Galicia durante la Edad Media (1100-1500)», Liceo Franciscano, 31:2, 201-225.

- Pedro Afonso, conde de Barcelos (1980): Livro de linhagens do conde don Pedro, ed. José Mattoso, Portugaliæ Monumenta Historica, Nova Série II, 2 vols., Lisboa, Academia das Ciências.

- Pérez Rodríguez, Francisco Javier (2019): Los monasterios del reino de Galicia entre 1075 y 1540: de la reforma gregoriana a la observante (Anejos de Cuadernos de Estudios Gallegos, XLVII), 2 vols., Santiago de Compostela, Instituto de Estudos Galegos Padre Sarmiento, CSIC, Xunta de Galicia.

- PÉrez Rodríguez, Francisco Javier (2015): «The Kingdom of Galicia and the Monarchy of Castile-León in the Twelfth and Thirteenth Centuries», en James D'Emilio (ed.), Culture and Society in Medieval Galicia: A Cultural Crossroads at the Edge of Europe, Leiden, Brill, 429-462.

- Pino Rebolledo, Fernando (1988): Catálogo de los pergaminos de la Edad Media (1191-1393), Valladolid, Archivo Municipal.

- Real Academia Española (1726-1739): Diccionario de Autoridades: https://webfrl. rae.es/DA.html [última consulta: enero 2021].

- Real ACAdemia DE la Historia $(1861,1863)$ : Cortes de los antiguos reinos de León y de Castilla, tomos I y II, Madrid, Real Academia de la Historia.

- Reglero de la Fuente, Carlos M. (1993): Los señoríos de los Montes Torozos. De la repoblación al Becerro de las Behetrías (siglos X-XIV), Valladolid, Universidad.

- RodGers, Paula Kelley (1991-1992): «Alfonso X writes to his son: Reflections on the Crónica de Alfonso $X$ (together with a commentary on and critical text of the unique Alfonsine letter that it preserves)», Exemplaria Hispanica, 1, 58-79.

- Rodríguez GonzáLEZ, Ángel/José Ángel Rey CAíña (1992): «Tumbo de Lorenzana», Estudios Mindonienses, 8, 11-324.

- RodríGuez LóPEZ, Ana (1999): «Estrategias monásticas y relación con los grupos dominantes locales. La influencia del Monasterio de Oseira en el medio social en el siglo XIII», en Reyna Pastor/Esther Pascua Echegaray/Ana Rodríguez López/ Pablo 
Sánchez León, Transacciones sin mercado: Instituciones, propiedad y redes sociales en la Galicia monástica, 1200-1300, Madrid, CSIC, 139-192.

- Romaní Martínez, Miguel (1989): A colección diplomática do mosteiro cisterciense de Santa María de Oseira (Ourense), 1025-1399, Santiago de Compostela, Universidade.

- Ruiz de la PeÑa Solar, Juan Ignacio (1977): «Poblamientos y cartas pueblas de Alfonso X y Sancho IV en Galicia», en Antonio Ubieto Arteta (ed.), Homenaje a D. José María Lacarra de Miguel en su jubilación del profesorado, Zaragoza, Anubar, 5 vols.; 1977-1981; III, 1977, 27-60.

- Ruiz DE La PeÑa Solar, Juan Ignacio (2004): «Las ciudades de señorío eclesiástico y los conflictos por el control del gobierno local (1252-1350», en José Ignacio de la Iglesia Duarte (coord.), Conflictos sociales, políticos e intelectuales en la España de los siglos XIV y XV. XIV Semana de Estudios Medievales, Nájera, del 4 al 8 de agosto de 2003, Logroño, Instituto de Estudios Riojanos, 113-146.

- Ruiz de la PeÑa Solar, Juan Ignacio (1975): «Alfonso Nicolás, burgués de Oviedo y alcalde del rey», Asturiensia Medievalia, 2, 113-176.

- SAAVEDRA, Pegerto (1990): «Contribución al estudio del régimen señorial gallego», Anuario de Historia del Derecho Español, 60, 103-184.

- Salazar y Acha, Jaime de (1990): «Precisiones y nuevos datos sobre el entorno familiar de Alfonso X el Sabio, fundador de Ciudad Real», Cuadernos de Estudios Manchegos, 20, 211-231.

- SÁNCHEZ BELDA, Luis (1953): Documentos reales de la Edad Media referentes a Galicia. Catálogo de los conservados en la sección de Clero del Archivo Histórico Nacional, Madrid, Dirección General de Archivos y Bibliotecas.

- Sanz Fuentes, M.a Josefa/José A. Álvarez Castrillón/Miguel Calleja Puerta (2011): Colección diplomática del Concejo de Avilés en la Edad Media (1155-1498), Avilés, Universidad de Oviedo.

- Souto CaBo, José Antonio (2003): Documentos galego-portugueses dos séculos XII e XIII (Revista Galega de Filoloxía, Monografías, 5), A Coruña, Universidade.

- Torres Fontes, Juan (2008): Documentos de Alfonso X el Sabio, Murcia, Academia Alfonso X el Sabio.

- Tuero Morís, Montserrat (1994): Documentación de la Catedral d’Uviéu. (Sieglu XIII), Oviedo, Academia de la Llingua Asturiana.

- VAJAY, Szabolcs de (1989): «From Alfonso VII to Alfonso X, the first two centuries of the Burgundian dynasty in Castile and León - a prosopographical catalogue in social genealogy, 1100-1300», en Studies in Genealogy and Family History in tribute to Charles Evans on the occasion of his eightieth birthday, Salt Lake City, Association for the Promotion of Scholarship in Genealogy, 366-417. 
- VAquero Díaz, M. a Beatriz/Francisco J. Pérez RodríGuez (2010): Colección documental del archivo de la Catedral de Ourense. Vol. I (888-1230), Vol. II (1231-1300). León, Centro de Estudios e Investigación «San Isidoro»/Caja España de Inversiones/ Archivo Histórico Diocesano.

- Villa-Amil y CASTRo, José ((1971): «Rodrigo Gómez. Cuadro histórico de las costumbres de la nobleza gallega en el siglo XIII», Grial, 9:33, 273-302. [1ª ed.: en Revista de la Universidad de Madrid, 5 [1875] (3): 301-10; 5 [1875] (6): 584-94; y 6 [1876] (4): 391-415]. 


\title{
Pontevedra, a cidade que floreceu na Baixa Idade Media: adentrándonos na dieta medieval a través dos restos humanos
}

\author{
Olalla López-Costas* \\ EcoPast (GI-1553), Área de Arqueología, Dpto. de Historia, \\ Universidade de Santiago de Compostela
}

DOI: 10.17075/gtax.2021.004 
* A autora deste traballo está financiada polo proxecto «Pollutio», Plan Nacional Retos JIN 2019 (PID2019-111683RJ-I00), Ministerio de Ciencia e Innovación, e pola Beca Leonardo a Investigadores y Creadores Culturales 2020 da Fundación BBVA, «Las epidemias del hambre». 


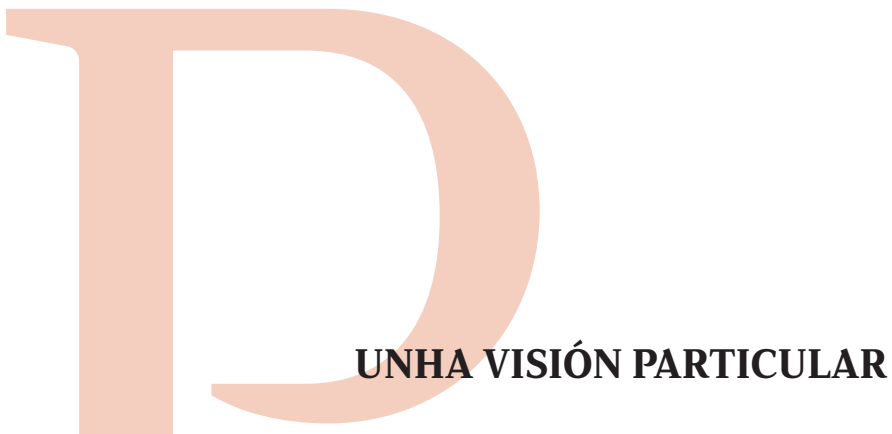

Parece ser que segundo a consciencia popular nada sucedía en Galicia nos tempos de Afonso X. Pénsase que mentres en Castela se loitaba, se repoboaba e medraban as cidades, Galicia permanecía imperturbable co dominio da nobreza e a Igrexa, con pouco máis que dicir. Nada máis lonxe da realidade, o século XIII foi determinante en moitas áreas de Galicia e viu entre outras cousas florecer as urbes gremiais. Entre elas destaca o crecemento dunha vila mariñeira nas Rías Baixas que tivo nese século quizais o máis grande esplendor económico da súa historia: Pontevedra. Este progreso sucedeu grazas en parte á acción dos reis Fernando II e Afonso X, que promoveron que se alzase este lugar como un centro de comercio de recursos mariños de primeira orde, así como a xestión do señorío compostelán e do concello. Para iso adentrareime na historia desta vila a través dos seus habitantes e a dieta que mantiñan, xa que na Pontevedra medieval os reis, o peixe e a dieta formaban un todo.

Tratarei nos próximos parágrafos de condensar a información que temos desta cidade mariñeira por excelencia de Galicia, pero a través dunha visión moi particular. Pontevedra tivo ata agora uns cronistas excelentes como José Armas Castro (1992) ou Juan Juega Puig (2012), entre moitos outros homes e algunha muller dos que irei citando traballos. A súa historia baséase na información documental que se preservou da Pontevedra medieval e constitúe un corpus magnífico para facernos unha idea do carácter, da economía e da evolución da cidade. Neste caso, eu collo o relevo comparando a historiografía cos datos obtidos a través dun rexistro moi particular, os restos óseos humanos. Debo confesar neste punto que o libro que Armas Castro publicou en 1992 foi desde o principio unha guía nas miñas investigacións e resulta eminentemente sorprendente a coincidencia dos datos obtidos a partir da información documental cos analizados no rexistro arqueolóxico. Constitúe Pontevedra, polo tanto, un exemplo paradigmático de como arqueoloxía e historiografía camiñan polo mesmo sendeiro, moitas veces sen tocarse, pero de seguro obtendo resultados complementarios. A miña «historia da Pontevedra medieval» está sustentada na propia xente que a fixo florecer, nos seus corpos e no testemuño que constitúen os seus esqueletos.

Nas escavacións de mediados da década dos 2000 nas que participei como especialista en osteoarqueoloxía (2007-2010) atopáronse restos humanos ben conservados en tres das necrópoles do centro de Pontevedra: Santa María a Maior 
ou dos Pescadores, San Bartolomeu O Vello e San Domingos. Empréganse eses restos neste traballo, xunto coa descrición das súas áreas funerarias para facer unha reconstrución do día a día da vila durante os séculos XIII ao XV a través dun exemplo, que é a reconstrución da súa dieta. Analízase tamén o papel que tiveron os reis, entre eles Afonso X e Fernando II, no aflorar desta vila galega.

\section{OS ESTUDOS EN RESTOS HUMANOS}

O traballo con restos humanos, normalmente esqueletos, de contextos arqueolóxicos é unha disciplina que desde hai máis de século e medio vén reconstruíndo o día a día das persoas que viviron hai centros e miles de anos (para España, ver Campillo 1993, Márquez-Grant et alii 2011). Recibe múltiples nomes que van de osteoarqueoloxía, antropoloxía física, antropoloxía biolóxica, osteoloxía ou bioarqueoloxía no mundo anglosaxón. Ao contrario do que popularmente se cre, un esqueleto «fala» moito máis da vida da persoa que da súa morte (Campillo 1993). Isto débese a que a súa forma e a composición están máis condicionadas polo transcurso da vida do individuo, sendo a morte algo momentáneo, case ínfimo, no relato dese ser. Xa que logo, o esqueleto dunha persoa informa sobre a súa saúde e o seu benestar, os cambios na dieta e mobilidade, algúns trazos da súa actividade e o seu perfil biolóxico incluíndo o sexo, a idade e as características físicas. Se contamos cun número representativo de individuos dunha poboación, poderemos ademais empregar esta información para reconstruír o perfil demográfico e as características «máis físicas» da sociedade (Larsen 2002). Este último salto, intentando entender as poboacións humanas no canto dos individuos, supuxo unha revolución na maneira de traballar con esqueletos humanos de contextos arqueolóxicos e permitiunos abrir fiestras directas á vida no pasado (Wood et alii 1992). Unha sociedade é moito máis que un conxunto de individuos, polo que só se pode comprender cando se consideran os aspectos supra-individuais, esta maneira de traballar coñécese como o uso dunha perspectiva poboacional.

A finais do século pasado, tras a revolución que supuxo comezar a considerar a perspectiva poboacional, os avances técnicos no estudo de esqueletos fixeron que a investigación tornase nunha hiper-especialización que permitiu adentrarnos nos detalles máis concretos das técnicas e da súa aplicación. Os equipos de traballo vencellábanse a unha técnica ou tipo de estudos concreto realizando análises centradas na antropoloxía física ou na osteoloxía con pouca conexión con outras disciplinas como a historia ou a arqueoloxía. Foron aparecendo cada vez máis os traballos multidisciplinares que combinan especialistas de varias ramas para acadar obxectivos comúns. Non obstante, nos últimos dez anos e cara ao futuro, os avances semellan adentrarse na interdisciplinariedade ou transdisciplinariedade, acadando unha cone- 
xión máis real entre os varios saberes para coñecer mellor o obxecto ou o período que intentamos entender. É dicir, xa non somos varios especialistas contando os resultados e buscando nexos, senón que os estudos nacen xa empregando aproximacións de varias fontes e a historia e arqueoloxía son consideradas no deseño desde o principio. Esta transdiciplinariedade permite acadar metas máis complexas, como pode ser a visión holística da alimentación na vila de Pontevedra.

Hoxe en día existen moitas maneiras de estudar os «mortos» para reconstruír a vida: desde as máis clásicas como poden ser as medidas (antropometría) ou as características morfolóxicas (estudos macroscópicos de enfermidades) ata as máis modernas baseadas na composición química (isótopos estables) ou molecular (espectroscopia ou ADN). Todas experimentaron un avance considerable nos últimos anos grazas ao abaratamento e á mellora das técnicas analíticas (tales como as xenómicas ou as análises en espectrómetros de masas) e aos avances informáticos que permiten traballar con datos múltiples e complexos. Existen, polo tanto, moitos tipos de análises, mais dentro das particularidades da maneira de vivir que quedan reflectidas nos restos óseos, a saúde, o crecemento e a alimentación son, probablemente, as máis importantes.

Un tipo de traballo no que se vén avanzando moito nos últimos anos é o dos estudos bioxeoquímicos, entre eles as análises de isótopos estables para reconstruír a dieta e a mobilidade. As diversas partes do esqueleto fálannos de momentos da vida diferentes, ao renovarse continuamente no caso dos ósos podemos reconstruír os últimos anos de vida, mentres que é posible achegarse á infancia analizando os dentes, xa que estes se forman no crecemento e permanecen case inalterables. Os estudos de isótopos estables para a paleodieta son posibles mediante a extracción dunha molécula moi resistente e abundante que se preserva no esqueleto, o coláxeno, e a posterior medición dos seus aspectos isotópicos calculando a proporción que hai de carbono-13 e $12\left(\delta^{3} \mathrm{C}\right)$ e de nitróxeno-15 e $14\left(\delta^{15} \mathrm{~N}\right)$. Como son estables, estes non varían co paso do tempo (como sucede co carbono-14, ${ }^{14} \mathrm{C}$ ). Como moitos alimentos teñen uns valores característicos, os aspectos dos humanos van depender da proporción destes alimentos nas diversas comidas. Así, o sinal característico do esqueleto dunha persoa vai estar determinado polo tipo e proporción de alimentos consumidos.

No referente a España, aínda que os estudos de esqueletos humanos e de paleopatoloxía (estudo das enfermidades ou patoloxías antigas) comezaron un pouco máis tarde que noutras áreas de Europa, como Francia, o avance foi constante e con bo paso. Destacan a produción de varias teses centradas en reconstruír a vida de áreas xeográficas concretas; por exemplo, para Galicia. a feita polo doutor José Carro Otero (1971) ou a miña propia varios anos despois (López-Costas 2012); mentres que na última década están vendo a luz traballos doutorais máis centrados na resposta de hipóteses concretas que alcanzan un maior impacto internacional, tales como a dieta ou a contaminación por mercurio (ex. López-Costas/Müldner 2019, Álvarez-Fer- 
nández et alii 2020). En Galicia somos uns cantos especialistas os que dedicamos a vida profesional ao estudo desta disciplina. Moitos investigadores, e cada vez máis investigadoras, traballamos analizando as necrópoles galegas tratando de reconstruír a vida diaria no pasado. Somos todos herdeiros de Miguel Fusté Ara, o que probablemente foi o primeiro antropólogo físico en realizar os seus estudos nesta esquina da Península. Fíxoo na coñecida necrópole da Lanzada e baixo o paraugas do Museo de Pontevedra (Blanco Freijeiro et alii 1961). Quizais o Padre Sarmiento, coas súas descricións deste xacemento, xa puxera a primeira pedra (Sarmiento 1950). O certo é que na actualidade, a pesar da mala conservación dos restos esqueléticos, Galicia é unha das áreas de España mellor estudadas, destacando, entre outros, pola cantidade de análises de isótopos estables para reconstruír a dieta. De seguro, no futuro próximo as antropólogas, bioarqueólogas, osteólogas ou calquera dos moitos sinónimos que ten a nosa profesión seguirán producindo información sobre os modos de vida no pasado. Coma neste caso que expoño a continuación, axudándonos a recompoñer de que maneira unhas decisións rexias cambiaron o devir de toda unha vila e dunha rexión.

\section{PONTEVEDRA E OS PRIVILEXIOS REAIS}

O burgo ou vila de Pontevedra non precisa presentación na xeografía galega. Capital de provincia, está situada ao fondo dunha das rías máis produtivas de Galicia, desde onde leva séculos vertebrando o devir da zona central das Rías Baixas e por extensión do sur de Galicia. Aínda que a orixe urbana de Pontevedra non está totalmente clara, parece que o comercio marítimo e o mar son de especial importancia (Méndez Martínez 1988). A ponte vella da cidade e a súa situación estratéxica no camiño de peregrinación cara a Santiago de Compostela son a outra razón de peso para acadar a protección real (Armas Castro 1992). No ano 1180 a cidade foi doada á Igrexa compostelá por Fernando II, o mesmo rei que no ano 1169 lle concede o foro real que impulsa o seu crecemento (López Ferreiro 1895: 162). Os privilexios a partir deste momento non paran de sucederse; entre outros, a redución da pena por naufraxio aos barcos desta cidade en todo o reino de León por Fernando II (Armas Castro 1992: 53).

Sucedeu que no ano 1229 o rei Afonso IX lle concedeu á vila de Pontevedra o privilexio sobre a seca, o transporte e a venda de peixe, así como o feito de ser o único porto de carga e descarga desde Baiona ata o norte (Méndez Martínez 1988). Outorgoulle expresamente a facultade de secar as pescadas e vendelas por mar e terra dentro e fóra do reino de León. O seu fillo Fernando III, no ano 1238, confirma estes dereitos e concédelle, xunto co porto de Noia, a exclusividade de fabricar saín de sardiña. Estas concesións son confirmadas posteriormente por Afonso X e Fernando IV. De feito, o foro de Fernando II puido chegar a nós grazas á carta de confirmación dos 
privilexios feita por Afonso X en 1264, que inclúe unha copia literal e que se conserva no Museo de Pontevedra (Fernández Villamil 1942, Armas Castro 1992).

A partir de 1250 a vila toma un goberno en forma de concello («grupo de homes bos») similar ao doutras vilas baixo a autoridade do arcebispo de Compostela, cunhas liberdades que lle van permitir adaptarse ao crecemento imparable da actividade no século XIII e XIV (López Ferreiro 1895). A cidade dedícase principalmente á preparación e exportación de pescada, congro e sardiña; moitas veces nos baixos das casas, mentres que outras capturas, como chocos e abadexos, estaban exentos de impostos para a xente de Pontevedra (Armas Castro 1992). O protectorado da mitra compostelá xunto cunha maior autoxestión dos recursos polo concello e a importancia dos gremios van facer que a cidade acade unha estrutura comercial óptima nestes séculos e medre de maneira vertixinosa. Curiosamente, as mesmas características xunto coa perda dos privilexios reais en favor doutros portos son, segundo Juega Puig (2012), as causas do ocaso de Pontevedra durante o século XVI e sobre todo no XVII. Este autor reflexiona sobre a imposibilidade súa de adaptarse ao dinamismo mercantil marcado polos portos sen ataduras feudais do norte de Europa, por exemplo en cousas tan sinxelas como mover o calendario pola presenza dos cardumes de sardiñas.

\section{OS BARRIOS, AS IGREXAS E OS CEMITERIOS DA VILA}

O núcleo inicial de poboación de Pontevedra xurdiu no burgo e ao redor da igrexa de Santa María, posteriormente chamada «Santa María a Maior» ou «a dos Pescadores». Distínguense no século XII dúas áreas, a vila amurallada e o arrabalde da Moureira. Este último sitúase na liña entre o río Lérez e o litoral e incluía as casas dos pescadores cunha conformación moi semellante entre elas (Méndez Martínez 1988), tendo estas un baixo destinado a taller de afumado de peixes ou á fabricación de saín. Na chamada «vila», as casas eran máis señoriais e mellor construídas (Méndez Martínez 1988) e desde o século XIII estaban rodeadas por unha muralla de pedra, da que se atoparon abundantes vestixios arqueolóxicos. Neste século, o aumento de poboación dentro da muralla fai que se cree unha nova freguesía, San Bartolomeu -posteriormente, «San Bartolomeu o Vello»-, e o Burgo pequeno fóra dela. Ao saír pola porta sur está o campo de San Domingos (hoxe, a Praza de España), onde se situaba o convento homónimo. A muralla vai definir os espazos, pero tamén as clases sociais. De maneira xeral, os habitantes máis pobres sitúanse nos arrabaldes exmuros, sobre todo na Moureira, mentres que no interior da vila vivían as familias aristocráticas e as pertencentes aos diversos gremios (Armas Castro 1992: 241).

Os privilexios reais fan que floreza a pesca de baixura e aumente a demografía. Empezan a chegar emigrantes doutras áreas de Galicia e a asentarse co- 
merciantes e artesáns. O aumento demográfico vai continuar de maneira imparable ata chegar ao máximo no século XV (Armas Castro 1992). Outro dato da intensidade comercial é que Pontevedra conta desde mediados do século xiII cun mercado semanal e unha feira anual en setembro na área baleira ao redor de San Bartolomeu. De feito, próximos ou rodeando as igrexas de Santa María, San Bartolomeu e San Domingos aparecen espazos sen casas adicados a cemiterio, onde se fan actividades como as xuntanzas veciñais ou gremiais, ademais do citado mercado (Armas Castro 1992: 95).

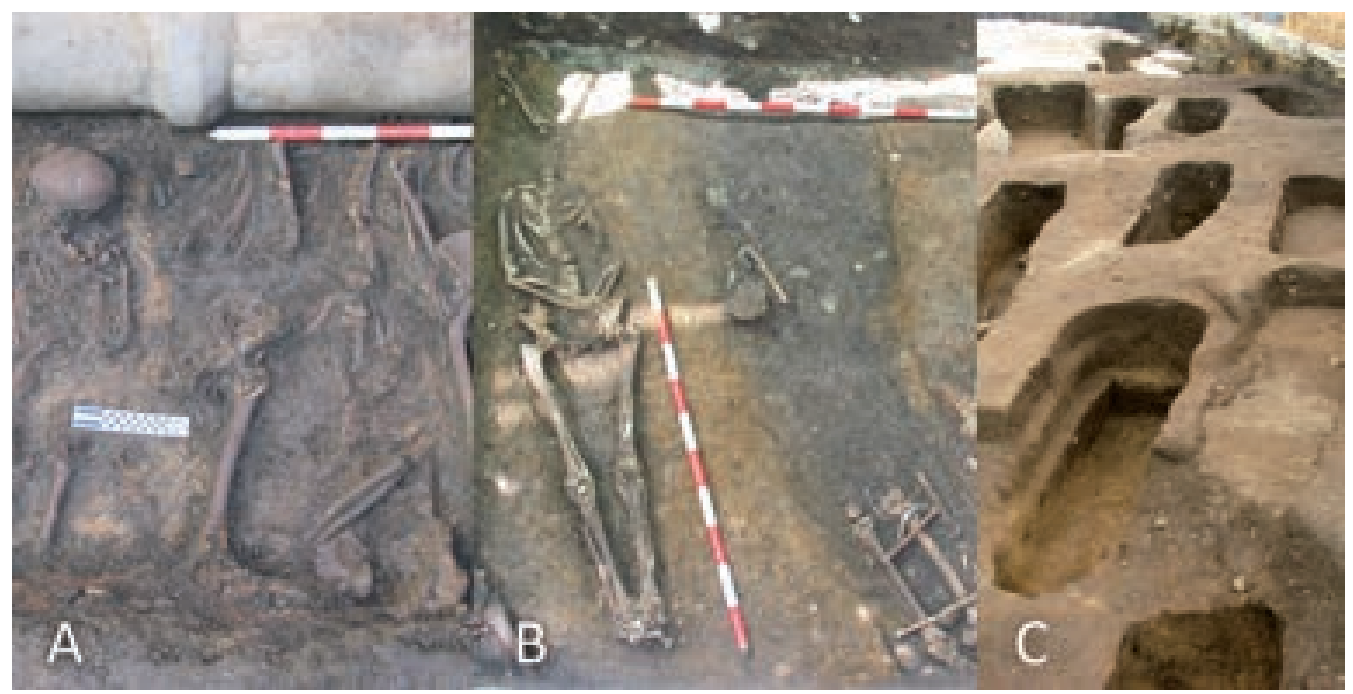

Fig. 1. Escavacións arqueolóxicas de inhumacións nas necrópoles de Santa María (A), San Bartolomeu (B) e San Domingos (C), onde se observa o diferente uso do espazo e a distribución dos enterramentos e restos humanos.

Dos varios cemiterios de Pontevedra, tres foron escavados nos últimos vinte anos e contan con estudos osteoarqueolóxicos dos esqueletos. Deses tres, dous pertencen ao interior das murallas da vila e outro ao exterior. As necrópoles escavadas abranguen enterramentos datados maioritariamente entre os séculos XIII e XV, e chegan, no caso de Santa María, ata o século XviI nos seus enterramentos cotiáns. Os cemiterios de Santa María e San Bartolomeu foron escavados de maneira conxunta durante varias intervencións, as máis prolongadas no tempo corresponden aos anos 2007 e 2008 (Constela Doce 2007, Chao Álvarez 2008), mentres que o de San Domingos foi intervido nos anos 2008 e 2009 (Constela Doce 2008). A historiografía indica que a nobreza e a burguesía máis acomodada prefiren os espazos conventuais para 
facerse enterrar ou no interior dos templos da cidade, mentres que a clase media e a baixa se fan inhumar no camposanto que rodea as igrexas (Armas Castro 1992: 266). As tumbas do interior da muralla están vencelladas ás fraternidades que tiveron un elevado carácter relixioso desde os ordenamentos de Afonso X en 1252, que prohibe os procesos organizativos (ordenamentos de burgos onde se vetaban as coalicións e ligas, e só se permitían cando tiñan un motivo caritativo ou funerario). As fraternidades ofrécenlles ás familias o pagamento do funeral e do enterro, polo que terminan por xestionar os camposantos (Armas Castro 1992: 168-170). Polo tanto, e como explicarei deseguido, baseándonos nos documentos, os esqueletos do cemiterio que rodean a Santa María e San Bartolomeu relacionaríanse coa clase media e con actividades de pesca e artesanía, respectivamente; mentres que en San Domingos poderiamos agardar persoas dunha clase social lixeiramente máis elevada.

A de Santa María é unha igrexa que pertence ao gremio dos mareantes ou todas as profesións relacionadas co mar, desde pescadores ata patróns. A igrexa actual foi levantada a cargo dese gremio no ano 1559 sobre unha anterior románica (Filgueira Valverde 1991). Nas escavacións de 2007 e 2008 atopáronse os alicerces dela, que cortaban varias tumbas, polo que sabemos que o cemiterio conservado é anterior. Os enterramentos rodean completamente a igrexa e as áreas de escavación situáronse na zona oeste onde se fixeron varias sondaxes: unha gran sondaxe na entrada norte (S.8) e, sobre todo, na fachada que dá cara ao leste (Constela Doce 2007, Chao Álvarez 2008). A Sondaxe 8 era extremadamente profunda e nos primeiros metros de terra descubriuse unha fosa común datada no século XVII-XVIII, onde se atoparon 22 esqueletos enterrados en dúas camadas de terra nunha mesma fosa (López-Costas 2012). O resto da sondaxe proporcionou restos óseos sen conexión anatómica presumiblemente atribuíbles a finais da Idade Media ou primeiros da Moderna, polo que se trataba de remocións de terra (debido á fragmentación e falta de individualización non se incluíron nos estudos antropolóxicos poboacionais). Na zona do leste e nas partes das fachadas do norte e do sur que lindan con esta, descubríronse numerosos enterramentos e deposicións secundarias que falan dun aproveitamento do terreo intenso. Ao contrario que no mundo islámico, os cemiterios cristiáns de clase social media-baixa destacan por un uso do espazo intenso con enterramentos duns por riba doutros, cortando fosas anteriores e situando os ósos ao lado do novo corpo (fig. 1). Todos os enterramentos escavados en Santa María estaban orientados en sentido oeste-leste, seguindo a liña marcada pola ábsida da igrexa. Ningún dos individuos tiña enxoval, salvo algúns alfinetes que poderían relacionarse cos sudarios de enterramento. Nenos, mulleres e homes compartían espazo sen diferenza de sexo ou idade. Nestas áreas, e excluíndo os enterramentos da fosa común, púidose recuperar un total de 60 individuos cunha conservación suficiente para estimar o sexo e a idade de cada un deles (López-Costas 2008, López-Costas 2012), os outros restos óseos presentaban un estado de conservación moi deficiente ou tratábase de grandes osarios que non permitían a individualización. 
Entre mediados e finais do século XIII, o templo de Santa María queda pequeno e xa non pode acoller os habitantes dunha vila en continua expansión. Os gremios dos artesáns acollen cada vez a máis familias e deciden fundar un novo templo ao que asociarse e onde facerse enterrar. Trátase de San Bartolomeu («o Vello»), que acolle principalmente os gremios de carpinteiros, toneleiros, pedreiros e ferreiros. As escavacións de 2007 e 2008 descubriron dúas áreas de enterramento separadas por un muro. Ao norte da igrexa vese unha área menos coidada que suxire unhas inhumacións de persoas con menores recursos; a preservación dos esqueletos aquí é moi deficiente, polo que non podemos saber moito máis das súas características. Preto da entrada principal ao leste escavouse no ano 2007 a chamada «sondaxe 16», que se caracterizaba de novo por esqueletos sen enxoval e dispostos en sentido oeste-leste e que reutilizan o espazo, pero de maneira menos intensa que en Santa María (fig. 1). Nenos, mozos, maiores, homes e mulleres comparten espazo cunha distribución que suxire unidades familiares (aínda que sen probas empíricas). Neste xacemento recuperouse un total de 20 esqueletos, ben conservados e individualizados e numerosos pertencentes a área norte-leste, cunha conservación moi deficiente (López-Costas 2008, López-Costas 2012). A igrexa de Santo Bartolomeu foi derruída e no mesmo soar e con case a mesma planta atópase hoxe o Teatro Principal.

Finalmente, ás aforas da muralla situábase o convento de San Domingos. As ruínas do convento son visibles e o cemiterio está baixo a Praza de España. Nos anos 2008 e 2009, as obras dun aparcadoiro subterráneo fixeron que se escavase esta necrópole (Constela Doce 2008). Apareceron entón unha serie de fosas de inhumación perfectamente organizadas en liñas cabeza-pés, con sentido norleste-suroeste. A adscrición cronolóxica sitúase posiblemente no baixomedieval, aínda que é complicada debido á falta de enxoval e á mala preservación que non permite a datación por ${ }^{14} \mathrm{C}$. Un dos esqueletos foi atopado cun rosario nas mans, namentres que o o resto se atopou sen enxoval. Neste caso, os corpos non eran depositados directamente sobre a terra cun sudario coma nos anteriores, senón que son visibles os negativos das caixas e recuperáronse varios cravos (fig. 1). O tamaño reducido dalgunhas das fosas suxire enterramentos secundarios. A preservación dos esqueletos neste caso era moi mala, e non se puido facer máis que unha aproximación preliminar onde se identificaron 19 individuos dos 35 enterramentos (Franco Montesdeoca 2017).

Unha vez presentadas as necrópoles e os esqueletos, procedo a explicar os resultados dos estudos de reconstrución da paleodieta que foron posibles nos esqueletos das necrópoles de Santa María e San Bartolomeu, mentres que en San Domingos a mala conservación non permitiu a obtención de coláxeno ben preservado ata o momento. 


\section{ALIMENTACIÓN NA PONTEVEDRA MEDIEVAL A TRAVÉS DOS ISÓTOPOS ESTABLES}

O estudo dos resultados de reconstrución da paleodieta das necrópoles de Pontevedra foi publicado de maneira máis sucinta (López-Costas/Müldner 2019) como parte dun número especial sobre estudos de dieta na Península Ibérica e illas (López-Costas/Alexander 2019). Farei aquí un resumo dos principais resultados, mentres que os aspectos técnicos poden ser consultados na publicación (López-Costas/Müldner 2019). Dentro dos esqueletos conservados das dúas necrópoles, tomouse unha mostra de 63 adultos maiores de 9 anos para facer unha reconstrución da dieta. Ademais, eliximos 26 mostras de animais para coñecer os valores locais e aproximarnos á xestión do gando. Extraeuse coláxeno nunha mostra de óso, a maioría das veces pequenos fragmentos de costela no caso dos humanos, despois de desmineralizala, xelatinizala e liofilizala. Medíronse nun espectrómetro de masas os ratios de carbono-13 e nitróxeno-15 (os dous isótopos estables menos abundantes) con respecto á cantidade dos máis abundantes carbono-12 e nitróxeno-14. Os resultados preséntanse con respecto a un estándar coa notación $\delta^{13} \mathrm{C}$ para o carbono e $\delta^{15} \mathrm{~N}$ para o nitróxeno. Os valores de $\delta^{13} \mathrm{C}$ son sempre negativos ao ser o estándar usado un fósil cunha cantidade moi alta de ${ }^{13} \mathrm{C}$. O $\delta^{13} \mathrm{C}$ varía coa dieta rica en recursos mariños ou coas chamadas plantas $\mathrm{C}_{4}$, tales coma o millo miúdo ou o sorgo (ambos producindo valores altos ata $-10 \%$ ) ou recursos terrestres (valores baixos ata $-23 \%$ ). No caso do $\delta^{15} \mathrm{~N}$, os valores son positivos e varían entre a dieta baseada en vexetais (valores baixos arredor de 4 ou 8\%) e aumenta co consumo de produtos animais como a carne ou os lácteos (ata 15 ou 17\%o). Os números son orientadores e varían coas condicións ecolóxicas de cada zona, por iso é preciso analizar a fauna doméstica. Por outro lado, e co fin de evitar estar analizando moléculas contaminadas que sufrisen grandes cambios cos procesos postmortem, como a putrefacción do corpo ou as alteracións químicas relacionadas co ambiente de enterramento, faise un control estrito das mostras de coláxeno extraídas, desbotando aquelas que non cumpran cos parámetros de composición elemental típicos desta molécula. Unha selección de mostras de coláxeno foron analizadas con espectroscopia de infravermello e con pirólise GC-MS para detectar estas contaminacións e alteracións, e en ambos os dous casos se obtiveron bos resultados (Kaal et alii 2016, Martínez Cortizas/López-Costas 2020).

As mostras procesadas de gando son restos óseos de animais con marcas de ter sido consumidos (marcas de corte). Pertencen aos depósitos arqueolóxicos das dúas necrópoles de Santa María e San Bartolomé, xunto con mostras das escavacións na Praza de España preto da necrópole de San Domingos e das escavacións arqueolóxicas da Ponte do Burgo e da Ampliación do Museo de Pontevedra. Todas elas foron atopadas en estratos de contexto medieval, aínda que non é posible identificar con certeza o século. Analizáronse ósos de nove bois ou vacas (xénero Bos), catro ca- 
prinos (ovellas, cabras) e dous porcos (fig. 2). Todos os restos pertences a adultos salvo un caprino (cordeiro-cabrito) e un leitón. Estes dous teñen un sinal isotópico máis alto en $\delta^{15} \mathrm{~N}(12,2 \%$ e 9,6\% respectivamente), resultado da lactación dos primeiros meses de vida (o leite materno é un produto animal e, polo tanto, enriquecido en ${ }^{15} \mathrm{~N}$ ). $\mathrm{O}$ resto dos valores do gando doméstico herbívoro (Bos e caprinos) analizado é o esperable cun valor medio de $\delta^{13} \mathrm{C}$ de $-21,0 \pm 0,4 \%$ o $(\mathrm{n}=11)$ que vai desde $-21,9 \%$ ata $-20,5 \%$, e para un medio de $5,1 \pm 1,0 \%$, coas mostras entre $3,7 \%$ o e $7,3 \%$ o para $\delta^{15} \mathrm{~N}$. Isto interprétase como un gando probablemente local e homoxéneo no manexo que inclúe plantas das chamadas $\mathrm{C}_{3}$, que son a maioría dos pastos galegos. Excluímos o emprego de millo miúdo como forraxe ou o pastoreo en áreas moi próximas ao mar ou en marismas. $\mathrm{Na}$ tradición galega aparecen as papas de millo miúdo como alimento de animais preñados ou pequenos, sobre todo vacas e becerros (Moreno-Larrazabal et alii 2015); este feito non pode ser demostrado cos nosos resultados. Aínda ben, ha de terse en conta que a alimentación durante períodos curtos de tempo non é probable que teña un reflexo na variación do sinal isotópico dos ósos.

As vacas, bois ou becerros son moi homoxéneos (fig. 2) e polo seu tamaño é posible que proveñan de fóra da vila, dos pastos próximos. Os pastos, hortas e viñas que rodeaban Pontevedra estaban protexidos polo concello e destinados ao abastecemento da vila, tal e como se pode ver nas Ordenanzas de 1496 (Armas Castro 1992: 175), polo que é probable que o gando viñese dunha área de 20-30 km. Pode que existisen pequenas diferenzas no manexo da cabras ou ovellas con respecto ás vacas, xa que as primeiras teñen os valores de $\delta^{15} \mathrm{~N}$ lixeiramente máis altos, sobre todo unha delas (fig. 2). Neste caso, as ovellas ou cabras precisan menos espazo para criárense, polo que poden provir de áreas familiares ou mesmo dos pequenos terreos arredor de Pontevedra. Un pasto moi fertilizado, por exemplo con bostas, ou manter os animais en cercados pequenos poden explicar o enriquecemento en ${ }^{15} \mathrm{~N}$; mentres que a introdución de carne bovina dependía das dúas carnizarías documentadas en período medieval, xa que, como nos indica a documentación, os prezos conservados son principalmente deste tipo de carne, e estas tiñan arrendadas terras preto da vila para proverse (Armas Castro 1992: 176). O único porco adulto analizado ten uns valores que entran dentro da media dos herbívoros (-20,4\%o e 6,6\%o; fig. 2), o que se traduce en que tiña unha alimentación eminentemente herbívora, sen acceso a refugallos cárnicos das cociñas, como é de esperar nun animal destas características nun período onde a carne e o leite escaseaban.

O noso estudo conta cun bo número de mostras de peixes da ría, algúns deles cun tamaño moi elevado, como é o caso das pescadas, que posuían grandes mandíbulas. Analízanse restos de tres pescadas, dous bonitos e, posiblemente, un sanmartiño e un pargo. Ademais, incluíuse unha vértebra de golfiño con marcas de corte, que confirman o seu procesamento para o consumo. Neste caso, o estudo 
isotópico informa dos valores dos recursos mariños locais no caso do $\delta^{13} \mathrm{C}$ cun medio de $-12,1 \pm 0,6 \%$ o $(n=9)$, mentres que o $\delta^{15} \mathrm{~N}$, cunha media de $12,7 \pm 1,9$, informa do nivel de carnivoría dos ditos animais, tendo en conta que a cadea alimentaria no medio mariño é sempre máis longa que a terrestre. Teñen un tamaño e nivel de carnivoría especialmente elevado as pescadas (fig. 2), o que é destacable, xa que esta especie forma parte das empregadas para a exportación. Polo tanto, vese que a fauna mariña procesada é probablemente local, da ría ou de rías próximas, e inclúe individuos de gran tamaño.

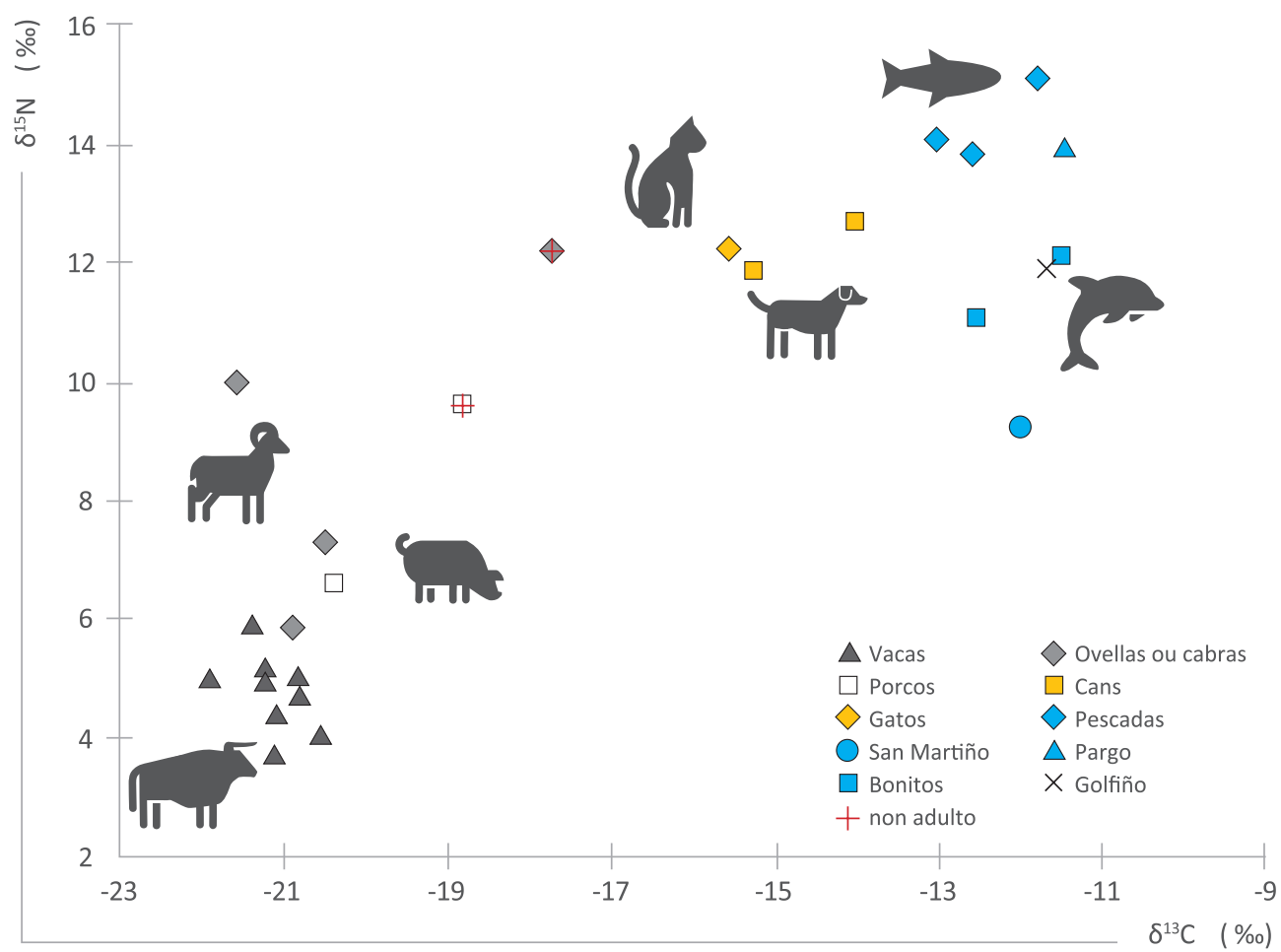

Fig. 2. Gráfico cos valores de isótopos estables da fauna analizada en Pontevedra.

Os animais domésticos, como cans $(\mathrm{n}=2)$ e gatos $(\mathrm{n}=1)$ atopados en contextos medievais dos xacementos da Praza de España e a Ponte do Burgo, teñen uns valores moderadamente altos en $\delta^{13} \mathrm{C}$ e $\delta^{15} \mathrm{~N}(-14,9 \pm 0,8 \%$ e $12,3 \pm 0,4 \%$, respectivamente) (fig. 2). Isto é interpretado como que ambos os dous tipos eran alimentados cunha boa cantidade de peixe ou outros recursos mariños, que probablemente eran os refugallos das casas, sen diferenzas claras entre cans e gatos. $\mathrm{O}$ alto consumo de peixe nestes animais, cunha dieta tan asociada á das persoas xa que conviven moitas 
veces nas casas, é un bo indicativo de ata que punto os recursos do mar eran de continuo consumo. No entanto, o feito de que os porcos non mostren valores compatibles con consumo do mar pode relacionarse con que viñan de granxas fóra de Pontevedra ou que tiñan vexetais dabondo nas hortas familiares para evitar empregar os restos de peixe como base da súa alimentación.

Con respecto ás mostras de humanos analizadas, xuntas caracterízanse por unha $\delta^{13} \mathrm{C}$ elevada, $-16,3 \pm 1,8 \%$, con respecto a outras mostras da Península Ibérica, pero similares ás medias atopadas na costa galega como as da Lanzada $\left(-16,0 \pm 1,5 \%\right.$ ) (López-Costas/Müldner 2016). Estes datos, xunto co $\delta^{15} \mathrm{~N}$ tamén relativamente alto $12,6 \pm 1,2 \%$, interprétanse como un forte consumo de recursos mariños e de plantas $\mathrm{C}_{4}$ (fig. 3). Os textos indican que a planta $\mathrm{C}_{4}$ de cultivo nas áreas que rodean a cidade é principalmente millo miúdo (Armas Castro 1992), que se corresponde con dúas especies, máis probablemente o Panicum miliaceum L. e menos abundante o paínzo ou Setaria italica L. Diferenzas no consumo de millo miúdo (caracterizado por elevado $\delta^{13} \mathrm{C}$ e baixo $\delta^{15} \mathrm{~N}$ ), marisco ou peixe pequeno (caracterizado por elevados $\delta^{13} \mathrm{C}$ e algo máis elevado $\delta^{15} \mathrm{~N}$ ) e peixe ou cefalópodos de tamaño grande (caracterizado por elevados $\delta^{13} \mathrm{C}$ e $\delta^{15} \mathrm{~N}$ ) poderían explicar a variabilidade nas mostras, así como a propia fisioloxía das persoas. Non obstante, esta xente tamén consumía plantas das chamadas $\mathrm{C}_{3}$, onde se incluirían a maioría dos cereais, verzas e legumes de cultivo tradicional en Galicia, mais non é probable que os produtos de orixe animal terrestre tales como lácteos, ovos ou carne abundasen na dieta dos pontevedreses do período medieval enterrados nos camposantos ao redor das dúas igrexas. Este feito último concorda coa información obtida dos documentos, onde se le o baixo número de carnizarías da vila (dúas; Armas Castro 1992: 176). Dos nosos datos podemos deducir, ademais, que os produtos animais derivados do gando doméstico eran máis ben escasos, que non constituían un grupo fundamental na mesa dos pontevedreses. Este tipo de alimentación cunha forte achega de produtos do mar e millos miúdos tan particular parece ser característico da costa galega e das Rías Baixas e diferénciase doutras áreas de Europa, onde, aínda que os recursos mariños chegaron a ser importantes, non constitúen, xunto co millo, un binomio tan forte na alimentación, nin sequera nas áreas costeiras ou nas illas.

Outro dos aspectos que destaca no estudo dos humanos son as diferenzas entre as mostras procedentes de Santa María e as de San Bartolomeu (fig. 3). No tocante a San Bartolomeu, analizáronse un total de 16 mostras probablemente pertencentes ao período (XIII-XV d. C.), cunha media de $-16,9 \pm 1,0 \%$ para $\delta^{13} \mathrm{C}$ (máximo, mínimo de $-15,2 \%$ e e $-18,7 \%$ o) e de $11,7 \pm 1,0 \%$ o $\left(12,9 \%\right.$ e 9,9\%o) para o $\delta^{15} \mathrm{~N}$. En Santa María temos 38 individuos asimilables ao período medieval ou, como moito, inicios da Idade Moderna (XIII-XV d. C.), cuns valores de $\delta^{13} \mathrm{C}$ de $-16,6 \pm 0,8 \%$ (cun máximo de $-14,6 \%$ e un mínimo de $-18,5 \%$ ) e $\delta^{15} \mathrm{~N}$ de $12,9 \pm 1,1 \%$ (desde $15,1 \%$ a a $9,6 \%$ ). Ademais inclúense no estudo 9 individuos atopados na primeira fase de enterramentos que pro- 
bablemente pertencen ao Período Moderno (séculos XVI-XVII d. C.), con valores (media de $-13,8 \pm 3,6 \%$ e $12,9 \pm 1,3 \%$ o) que se distribúen en dous grupos, como se observa na figura 3, cunha distribución moi ampla, sobre todo no caso de $\delta^{13} \mathrm{C}$, cun máximo que alcanza os 10,0\% e un mínimo de -20,3\%o (fig. 3).

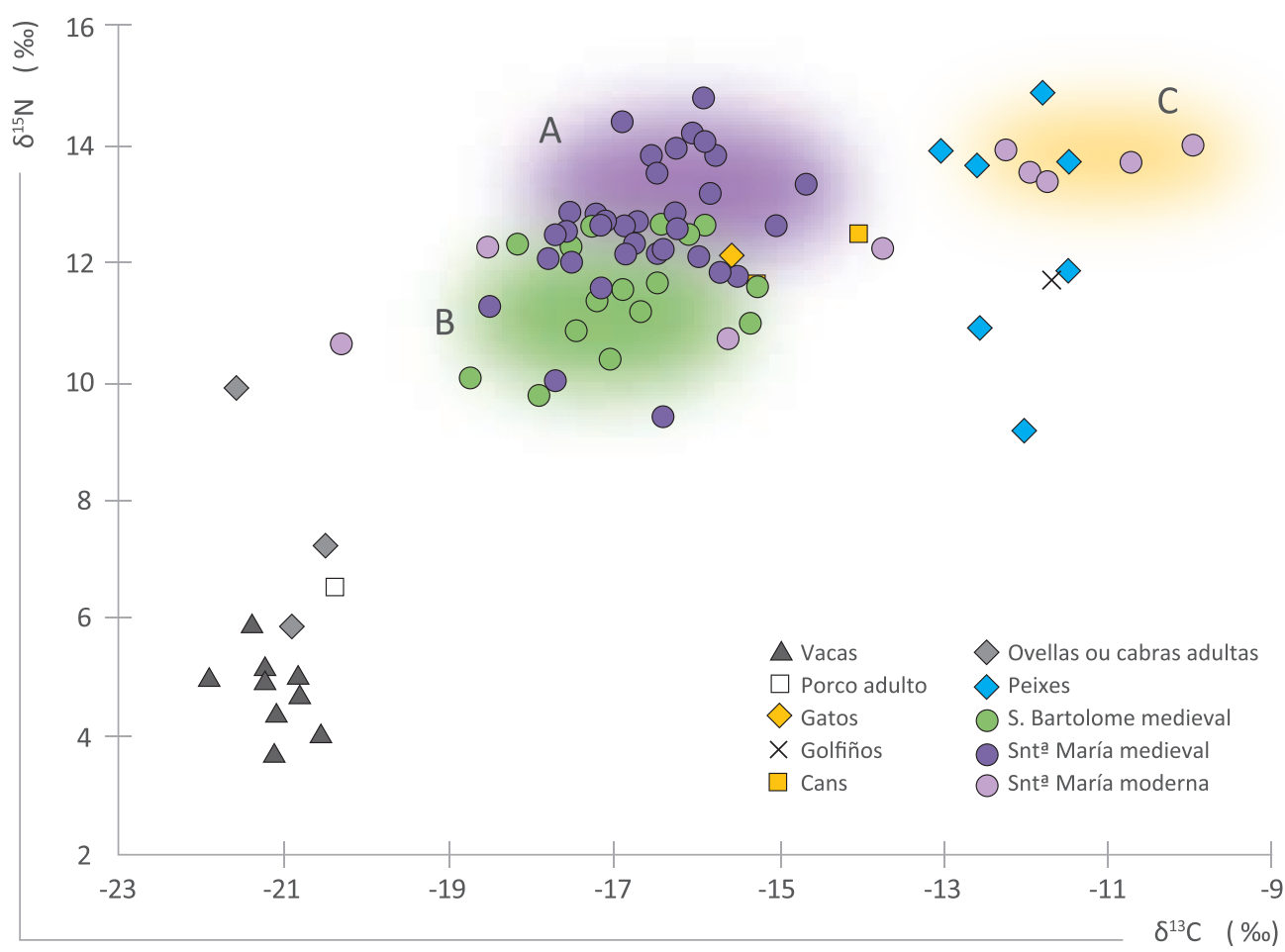

Fig. 3. Gráfico cos valores de isótopos estables das mostras de humanos analizados en Pontevedra. Os números remarcan a diferenza en $\delta^{15} \mathrm{~N}$ entre as fases medievais de Santa María (A) e San Bartolomeu (B), e os valores elevados en $\delta^{13} \mathrm{C}$ que caracterizan o forte consumo de millo das Américas nalgún individuo das fases finais de Santa María (C).

Para o período baixomedieval (séculos XIII ao XV), as diferenzas entre mostras son estatisticamente significativas en $\delta^{15} \mathrm{~N}$ pero non no $\delta^{13} \mathrm{C}$. Este dato sorprendeunos ao principio xa que, como os fregueses de Santa María pertencían ás familias vencelladas co mar, agardabamos que estes tivesen un maior consumo de produtos mariños. Na figura 3 obsérvase esa tendencia a que estas mostras teñan uns valores lixeiramente máis elevados en ${ }^{13} \mathrm{C}$, pero, como se indica, non son significativas por que hai un nivel de solapamento alto. A alta dependencia da cidade dos alimentos mariños fixo moi probablemente que todos os seus habitantes (polo menos as familias gremiais) tivesen un acceso directo a eles e constituísen a base do seu consumo. 
Destacamos a este nivel que non se observaron diferenzas cando se compararon mostras procedentes de esqueletos de ambos os dous sexos (o sexo do esqueleto pode tomarse, con algunhas precaucións, como indicativo do xénero) e as diversas idades. Neste último caso, temos en conta que a persoa máis nova incluída no estudo tiña de 9 a 12 anos de idade estimada, estando a maioría dos oito non-adultos entre os 16 e os 20 anos. Isto fíxose para evitar no posible o sinal do período de lactación (o leite materno eleva o $\delta^{15} \mathrm{~N}$ ) e na actualidade estamos facendo novos estudos para determinar a idade de desteta e aproximarnos máis á dieta na infancia. Polo tanto, podemos afirmar que homes e mulleres, así como desde a mocidade ata a vellez (3 individuos superaban os 60 anos de idade biolóxica estimada), consumían sen diferenza os mesmos produtos. Aínda que esta técnica non é capaz de detectar diferenzas na cantidade, pódese asumir que as familias compartían mesa e acceso aos recursos. Nunha pesca dominada pola baixura, os homes virían con probabilidade comer ás súas casas, o que explicaría a falta de diferenzas por sexo e idade.

Pero, a estas alturas, como podemos explicar que as diferenzas entre os períodos medievais das dúas igrexas sexan, principalmente, no $\delta^{15} \mathrm{~N}$ ? A resposta que nos parece máis probable ten que ver co tipo de peixe ao que se tiña acceso. Na Pontevedra dos séculos do XIII ao XV d. C., non todos os produtos mariños servían para o comercio. Existen unhas especies que son secadas ou afumadas para a súa preservación: a pescada, o congro e o polbo, así como a sardiña, que normalmente se conservaba en salgadura (Armas Castro 1992: 146). A documentación indica que estes procesados se importaban a diversas áreas de Europa, incluída a Valencia islámica e cristiá (Ferreira Priegue 1987). Trátase de dous procesos diferentes que conducen ao incremento do ${ }^{15} \mathrm{~N}$ nos comensais. No caso da pescada e congro, elixíanse os individuos de máis tamaño entre estes animais, de por si grandes depredadores, polo que o seu nivel de carnivoría elevado fai pensar que terían un $\delta^{15} \mathrm{~N}$ alto (tal e como se observa nas mostras de pescada analizadas). As sardiñas, polo tamaño, non terían estas características pero o sal fai que os corpos acumulen máis ${ }^{15} \mathrm{~N}$, tal e como se observa nas áreas con abundantes salinas ou lagos salgados, como determinamos nun estudo que fixemos en Écija (Sevilla) (Inskip et alii 2019). Polo tanto, o consumo de peixe preservado en salga produciría o mesmo efecto. A nosa hipótese é que as familias da freguesía de Santa María tiñan acceso a estes produtos destinados á exportación e ricos en ${ }^{15} \mathrm{~N}$ xa que se encargaban de pescalos e procesalos nos baixos das casas, mentres que as familias dos gremios de artesáns de San Bartolomeu terían acceso ao peixe e mariscos non destinados á exportación, sendo estes caracterizados polo mesmo sinal $\delta^{13} \mathrm{C}$ pero cun $\delta^{15} \mathrm{~N}$ máis baixo.

Finalmente, obsérvase que no último momento de enterramentos en Santa María (séculos XVI-XVII), a dieta diversifícase moitísimo (fig. 3), incluíndo algúns individuos moi enriquecidos en ${ }^{13} \mathrm{C}$. Ao final do século XV introdúcense novas artes de pesca, tales como a pesca do cerco, que permite atrapar os cardumes de sardiñas case enteiros. A sobreexplotación da ría causou a falta de sardiñas documentada nos 
anos 1525, 1550, 1575 e 1595 (Filgueira Valverde 1991, Juega Puig 2012). Xusto nese momento, a produción de cereais baixou, entre outras razóns polo empeoramento das condicións climáticas na recrudescencia da Pequena Idade do Xeo (Martínez Cortizas et alii 1999). Ademais, a cidade de Pontevedra vai perder a súa predominancia na costa sur galega, pola existencia de regulacións moi pechadas, que foran útiles nos séculos anteriores (Pereira Fernández 1997, Juega Puig 2012). Outros portos do sur de Galicia, como os de Vigo ou Noia, ocuparán o lugar da vila pontevedresa e dos seus habitantes na política e economía galega, que sufrirán as consecuencias deste ocaso en forma de diversos períodos de fame no século XVI e, sobre todo, no XVII. Os impostos excesivos e a rixidez das institucións fixeron que esta vila levase peor os períodos de carestía, polo que a maioría do peixe é destinado a pagar as taxas (Pereira Fernández 1997), que antes eran pagadas en forma de viño (Pereira Fernández 1997, Juega Puig 2012). O concello arrenda barcos con cereais para alimentar a poboación nos peores momentos e prodúcese a entrada dun cereal de alto rendemento que fai paliar esta fame: o millo das Américas. O millo americano é cultivado nos campos arredor de Pontevedra pero tamén traído desde Asturias por barco desde polo menos o ano 1612 (Juega Puig 2012) -chámase, neste caso, o «pan do mar». Este cereal caracterízase por ter un moi elevado $\delta^{13} \mathrm{C}$, o que se transmitiría aos tecidos humanos, tal e como se observa nos valores extremadamente altos atopados nos enterramentos da fase moderna de Santa María (fig. 3, área C).

\section{A VIDA NA PONTEVEDRA MEDIEVAL}

Nestas liñas tratei de expoñer como a cidade de Pontevedra se converteu no século XIII nun núcleo político e mercantil de primeira orde. Os privilexios reais, ratificados entre outros polo rei Afonso X, permitíronlle dominar o comercio de produtos mariños na Península e en boa parte de Europa. Os barcos pontevedreses do século XIII entraron nos principais portos estranxeiros, incluídos Holanda e Inglaterra (Armas Castro 1992). Estas actividades da pesca e os seus derivados, como o proceso de salga ou de afumado do peixe, foron exercidas principalmente polos habitantes da vila (Juega Puig 2012), e así parece que lles quedou marcado nos ósos.

A evolución de Pontevedra, estimulada polos privilexios e exencións reais e pola riqueza da súa ría (Armas Castro 1992: 59), fixo que medrasen os seus barrios paralelos ao crecemento da igrexa de Santa María a Maior, e á orixe e expansión da freguesía de San Bartolomeu. Os gremios e o concello van determinar a vida na vila limitando as importacións e asegurando a subministración equitativa dos bens básicos (Armas Castro 1992). Esta equidade obsérvase na reconstrución da alimentación a través dos esqueletos (López-Costas/Müldner 2019). Os cemiterios de Pontevedra e 
os seus esqueletos son un fiel reflexo dos seus fregueses, especialmente do seu poder económico no caso dos tipos de enterramento e as diferenzas na distribución do espazo entre San Domingos, San Bartolomeu e Santa María. Aínda que semellantes na súa evolución, as dúas últimas necrópoles mostran variacións na alimentación. Estas parecen estar vencelladas ás actividades das familias e ao maior acceso a produtos destinados á exportación, como pescadas de gran tamaño, congros e polbos, ou sardiñas salgadas ou saín, por parte dos habitantes dos barrios asociados a Santa María. Os artesáns de San Bartolomeu e as súas familias terían acceso a un peixe de menor tamaño e de consumo fresco.

Finalmente, reflexionamos sobre a especificidade da dieta na costa galega, que parece ter mantido un padrón dominado polos recursos do mar, peixes e mariscos, e o consumo de vexetais, incluíndo unha boa cantidade de millo miúdo. Ao contrario doutras áreas como Asturias, os millos destínanse aquí preferentemente para consumo humano, e non para o gando. A riqueza das rías galegas ten na cidade de Pontevedra e na súa evolución no século XIII un exemplo moi ilustrativo. Así mesmo, a decadencia dos séculos XVI e XVII serve como mostra da fraxilidade destes ecosistemas e da importancia de optar por políticas flexibles adaptadas á preservación da nosa terra e das súas xentes.

\section{AGRADECEMENTOS}

Os meus agradecementos á delegación de Patrimonio Histórico da Xunta de Galicia por apoiar os estudos nestes xacementos, así como ao Museo de Pontevedra polo apoio ao traballo con restos humanos en Pontevedra e noutras necrópoles da provincia. O estudo isotópico foi feito coa colaboración de Gundula Müldner, da Universidade de Reading. Grazas a Juan Carlos Castro, Xavier Chao e Xurxo Constela, así como aos demais integrantes das empresas de arqueoloxía Anta de Moura, Tomos e Citania polo traballo ben feito no campo e a axuda prestada nestes anos. Grazas a Pedro López Barja polos seus comentarios a unha versión previa do manuscrito. O meu agradecemento a Simon R. Doubleday pola invitación a participar neste libro e as súas suxestións ao texto, e a José Armas Castro por ter escrito o seu. 


\section{REFERENCIAS BIBLIOGRÁFICAS}

- Álvarez-Fernández, Noemí/Antonio Martínez Cortizas/Olalla López-Costas (2020): «Atmospheric mercury pollution deciphered through archaeological bones», Journal of archaeological science, 119, 105-159.

- ARMas Castro, José (1992): Pontevedra en los siglos XIII a XV, configuración y desarrollo de una villa marinera en la Galicia Medieval, Pontevedra, Fundación Pedro Barrié de la Maza Conde de Fenosa.

- Blanco Freijeiro, Antonio/Miguel Fusté Ara/Alfredo García Alén (1961): «La necrópolis galaico-romana de La Lanzada (Noalla, Pontevedra), I», Cuadernos de Estudios Gallegos, 16, 141-158.

- Campillo, Domingo (1993): Paleopatología. Los primeros vestigios de la Enfermedad. Parte primera, Barcelona, Fundación Uriach, 1838.

- CARro Otero, José (1971): Anatomía antropológica antigua del Pueblo Gallego: Siglos I al VII d.C. Tese de doutoramento. Universidade de Santiago de Compostela.

- CONSTEla Doce, Jorge Juan (2007): «Actuación arqueolóxica no marco da rexeneración do arrabalde de Santa María, zona intramuros, Pontevedra. Informe valorativo (CD 102A 2007/196-0)». Orixinal depositado na Consellería de Cultura e Deporte. Dirección Xeral de Patrimonio. Xunta de Galicia.

- Constela Doce, Xurxo (2008): «Informe valorativo da Escavación en área do ámbito do aparcamento subterráneo proxectado na Praza de España da cidade de Pontevedra. Citania Arqueoloxía S.L.». Orixinal depositado na Consellería de Cultura e Deporte. Dirección Xeral de Patrimonio. Xunta de Galicia.

- Chao Álvarez, Francisco Javier (2008): «Actuación arqueolóxica no marco da rexeneración do arrabalde de Santa María, zona intramuros, Pontevedra. Escavación arqueolóxica das gabias de instalación nos sectores 1 e 3. 1B e 3A, B, C. Informe valorativo (CD 102A 2007/698-0)». Orixinal depositado na Consellería de Cultura e Deporte. Dirección Xeral de Patrimonio. Xunta de Galicia.

- Fernández Villamil, Enrique (1942): «Privilegios reales del Museo de Pontevedra», El Museo de Pontevedra, 132-174.

- Ferreira Priegue, Elisa María (1987): Galicia en el comercio marítimo medieval, A Coruña, Fundación Pedro Barrié de la Maza. (Colección Documentos históricos).

- Filgueira Valverde, José (1991): La basílica de Santa María de Pontevedra, A Coruña, Fundación Pedro Barrié de la Maza, Conde de Fenosa.

- Franco Montesdeoca, Álvaro (2017): «Trabajo Fin de Máster: Estudio de la necrópolis de Santo Domingo en Pontevedra». Universidade de Santiago de Compostela.

- Inskip, SARAH/Gina CARROLL/Andrea WATERs-Rist/Olalla López-Costas (2019): «Diet and food strategies in a southern al-Andalusian urban environment during 
Caliphal period, Écija, Sevilla», Archaeological and Anthropological Sciences, 11, 3857-3874.

- JuEga Puig, Juan (2012): «El comercio marítimo en Galicia 1525-1640», Obradoiro de Historia Moderna, 21, 105-130.

- KaAL, Joeri/Olalla LóPEZ-Costas/Antonio MarTínez CortizAs (2016): «Diagenetic effects on pyrolysis fingerprints of extracted collagen in archaeological human bones from NW Spain, as determined by pyrolysis-GC-MS», Journal of archaeological science, 65, 1-10.

- LARSEN, Clark Spencer (2002): «Bioarchaeology: The Lives and Lifestyles of Past People». Journal of Archaeological Research, 10, 119-166.

- LóPEZ-Costas, Olalla (2008): «Resumen anual ano 2008 do proxecto “Antropoloxía dos restos óseos humanos de Galicia [...]”. Unpublished work». Orixinal depositado na Consellería de Cultura e Deporte. Dirección Xeral de Patrimonio. Xunta de Galicia.

- López-Costas, Olalla (2012): Antropología de los restos óseos humanos de Galicia: estudio de la población romano y medieval gallega. Tese de doutoramento. Universidad de Granada.

- LóPEz-Costas, Olalla/Michelle ALEXANder (2019): «Paleodiet in the Iberian Peninsula: exploring the connections between diet, culture, disease and environment using isotopic and osteoarchaeological evidence», Archaeological and Anthropological Sciences, 11, 3653-3664.

- LÓPEZ-Costas, Olalla/Gundula MüLDNER (2016): «Fringes of the empire: Diet and cultural change at the Roman to post-Roman transition in NW Iberia», American Journal of Physical Anthropology, 161, 141-154.

- López-Costas, Olalla/Gundula MüLDNER (2019): «Boom and bust at a medieval fishing port: dietary preferences of fishers and artisan families from Pontevedra (Galicia, NW Spain) during the Late Medieval and Early Modern Period», Archaeological and Anthropological Sciences, 11, 3717-3731.

- López Ferreiro, Antonio (1895): Fueros municipales de Santiago y de su tierra, Santiago de Compostela, Seminario Central.

- MÁrquez-Grant, Nicholas/Carme Rissech/Olalla LóPEZ-Costas/Inmaculada Alemán/Luis CARO DobÓN (2011): «Spain/España», en N. MÁrQueZ-GRANT/ L. FIBIGER (coords.), The Routledge Handbook of Archaeological Human Remains and Legislation: an international guide to laws and practice in the excavation, study and treatment of archaeological human remains, London, Routledge, Taylor and Francis Group, 423-438. 
- MARTínez Cortizas, Antonio/Olalla LóPEz-COSTAS (2020): «Linking structural and compositional changes in archaeological human bone collagen: an FTIR-ATR approach», Scientific Reports, 10, 17888.

- Martínez Cortizas, Antonio/Xavier Pontevedra-Pombal/Eduardo García-RodEjA/Juan C. NOvOA-MUÑOZ/William SHOTYK (1999): «Mercury in a Spanish peat bog: Archive of climate change and atmospheric metal deposition», Science, 284, 939-942.

- MÉndez MarTínez, Gonzalo (1988): «La morfología urbana de Pontevedra hasta 1900», en R. Villares (coord.), La ciudad y el mundo urbano en la historia de Galicia, Tórculo, 253-268.

- Moreno-LaRrazabal, Aitor/Andrés Teira-Brión/Itsaso SoPElana-Salcedo/Amaia ARRANZ-OTAEGUI/Lydia ZAPATA (2015): «Ethnobotany of millet cultivation in the north of the Iberian Peninsula», Vegetation History and Archaeobotany, 24, 541-554.

- Pereira Fernández, Xosé Manuel (1997): «Pontevedra en el siglo Xvi. Contribución al estudio de la historia urbana de Galicia», Obradoiro de Historia Moderna, 6, 239-262.

- Sarmiento, Fray Martín (1950): Viaje a Galicia, Ms. de la Abadía de Silos 1754-1755, Santiago de Compostela, Instituto Padre Sarmiento de Estudos Galegos.

- Wood, James W./George R. Milner/Henry C. HARPENDing/Kenneth M. WeISS/Mark N. COHEN/Leslie E. EISENBERG/Dale L. HutChINSON/Rimantas JANKAUSKAS/Gintautas ČESNYS/M. Anne KaTZENBERG/John R. LUKACS/JANET W. MCGRATH/Eric ABELLA RotH/ Douglas H. UbeLAKER/Richard G. WILKINSON (1992): «The Osteological Paradox: Problems of Inferring Prehistoric Health from Skeletal Samples (and Comments and Reply)», Current Anthropology, 33, 343-370. 



\title{
Facerse presentes. As mulleres da familia real castelá e o reino de Galicia na culminación plenomedieval $^{*}$
}

\author{
Diana Pelaz Flores" \\ Universidade de Santiago de Compostela
}

DOI: $10.17075 /$ gtax.2021.005 
* Este traballo levouse a cabo no marco do proxecto «Espacios femeninos cortesanos: Ámbitos curiales, relaciones territoriales y prácticas políticas en los reinos de la Península Ibérica ca. 1252-1504», con referencia PGC2018-099205-A-C22, concedido polo MICINN e cofinanciado pola Axencia Estatal de Investigación e o Fondo Europeo de Desenvolvemento Rexional (FEDER). Gustaríame agradecer a Miguel García-Fernández a lectura deste texto e a corrección da tradución á lingua galega, así como aos editores deste volume os seus acertados comentarios para mellorar a versión final do texto.

** https://orcid.org/0000-0002-5499-4739. Membro do Grupo de Investigación de Referencia Competitiva «Síncrisis. Estudios en Formas Culturais», da Universidade de Santiago de Compostela. 


\section{INTRODUCIÓN}

A vinculación da raíña Violante de Aragón e o mosteiro de Santa Clara de Allariz é un feito sobradamente coñecido. A raíña, defensora da espiritualidade clarisa e da renovación impulsada polas ordes mendicantes, decidiu fundar un mosteiro no municipio ourensán no ano 1286 e reforzar a súa devoción cara á Orde de Santa Clara (Katz 2015, Vaquero Díaz 2021). A promoción de obras relixiosas era unha das funcións máis intimamente vinculadas ao oficio das raíñas medievais e das mulleres da familia rexia no seu conxunto, como defensoras dos ideais espirituais do

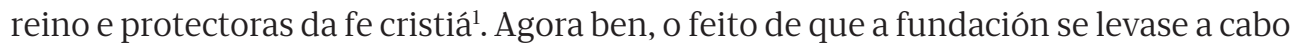
dentro do territorio que comprendía o reino de Galicia non debe ser pasado por alto. O enclave elixido pola raíña non se atopaba próximo a ningunha das súas propiedades señoriais e tampouco era un lugar de paso frecuente, cando menos no marco da itinerancia cortesá ${ }^{2}$. En consecuencia, facíanse presentes dous suxeitos que non sempre se viron reivindicados pola historiografía recente, nin entre eles, nin respecto ao marco do poder político que constituía a corte: os membros femininos da liñaxe rexia, raíñas e infantas, e o reino de Galicia.

A corte castelá, ao igual que as súas homólogas peninsulares e mais europeas, caracterizábase polo seu semi-nomadismo, isto é, polo seu desprazamento ao longo dos territorios do reino por razóns moi diversas, que ían desde os conflitos políticos ou militares á representación da autoridade rexia, xa que era fundamental que o rei fose coñecido polos seus gobernados (Cortes de los antiguos reinos 1883: vol. I, 410, Carrasco Manchado 2008). A pesar da necesidade da monarquía de darse a coñecer ante os seus súbditos, os percorridos descritos polo rei, a raíña ou os infantes e infantas non conseguían abarcar a totalidade do territorio que aseñoraban, nin tam-

1 Pick 2017: 104-168.

2 Aínda que non se conservaron nin carta de arras nin documentos relativos ao dote de dona Violante, Ma Jesús Fuente, seguindo a Enrique Flórez, sinala que a raíña dispuxo, dentro do territorio castelán, de Valladolid, San Esteban de Gormaz, Astudillo, Ayllón, Curiel e Béjar, ademais de Hervás, Plasencia, Hontoria e Olmillos, e das prazas murcianas de Alguazas e Alcantarilla (Fuente Pérez 2016: 143-144 e 150). Acerca dos condicionantes á hora de elixir a vila de Allariz para promover nela o mosteiro, véxase o capítulo de Vaquero Díaz neste volume. 
pouco visitaban coa mesma frecuencia todos os lugares polos que se movían 3 . O reino de Galicia é un bo exemplo desa menor presenza da monarquía ${ }^{4}$ ou, cando menos, doutras formas da Coroa de facerse presente, sobre todo a partir da unión dos reinos de León e Castela no 12305. Destas estratexias de representación, xestión e goberno do reino tamén participan raíñas e infantas, a través de fórmulas, igualmente, diversas. Para iso fixarémonos na relación que mantiveron con aquelas prazas que, dentro do seu ámbito señorial, se inscribían na realidade galega, así como nas estratexias de promoción espiritual que emprenderon ao longo do século XIII. Todo iso sen deixar de lado o testemuño de ferramentas de tipo retórico que evidenciaban a capacidade das mulleres da parentela rexia para colaborar na imaxe e autoridade que a monarquía trataba de irradiar ao conxunto territorial que administraba.

\section{NON HAI MONARQUÍA SEN RAIIÑA. DO SEU PESO POLÍTICO AO PROCESO DE DEFINICIÓN AFONSINO}

Afirmaba o Rei Sabio nas Partidas que o rei debía amar á súa muller «porque él et ella por casamiento segund nuestra ley son como una cosa» (Las Partidas 1807: Partida II, Título VI, Lei II, 42). Esta é unha das sentenzas que contribuíron a poñer de manifesto, desde o ámbito legal, unha realidade que se viña observando ao longo do período medieval. Fronte a outras figuras femininas da realeza, Afonso X salientou a da raíña en tanto que consorte e, en consecuencia, reforzou o peso do matrimonio como base do seu poder e fonte a través da cal recibía a graza divina que lle confería a súa autoridade rexia. O código legal afonsino non falaba doutros membros da parentela rexia, salvo a súa descendencia directa, isto é, os infantes e infantas, sobre os que se mencionaba brevemente como debían ser educados (Las Partidas 1807: Partida II, Título VII, Leis II-XIII, 44-54). Pola contra, non se insistiría, en cambio, no papel das irmás do rei, pezas chave dentro da política dos reinos de León e Castela entre os séculos XI e XII, do mesmo xeito que apenas se aludía á condición da

3 Non se trata dunha circunstancia que caracterice á monarquía castelá fronte a outras das súas homólogas, senón que pode apreciarse noutras, como a de Portugal, cuxa espacialidade se orienta arredor de Lisboa, Santarém, Évora ou Coimbra, como as principais prazas do reino sobre as que facer gravitar a corte (Costa Gomes 1995).

4 Esta afirmación garda relación coa itinerancia rexia, diferente doutras formas de representación da autoridade rexia ou da autoridade doutras figuras dentro da familia real, como os fillos do rei, particularmente visible no caso dos infantes Fernando e Sancho durante o reinado de Afonso X. A súa relación con Galicia é visible desde esferas diversas, que van desde a relación coas vilas de reguengo ao padroado relixioso, do que pode servir como exemplo a capela dedicada á Virxe no Mosteiro de San Salvador de Oña, a instancias de Sancho IV despois do seu ascenso ao trono (Senra Gabriel y Galán 2002).

5 Aínda que posteriormente á unión dos reinos o marco territorial galego puidese ser aproveitado para reivindicar a autoridade rexia, como aconteceu no caso dos infantes Fernando de la Cerda ou do seu irmán, o posterior rei Sancho IV (Olivera Serrano 2001). 
raíña madre, cuxa influencia e peso específico a través da posibilidade do exercicio da rexencia si se contemplaban.

Aínda que, como sinalou Theresa Earenfight (2014: 123-131), as mulleres vían relegados os seus dereitos ao trono a favor dos varóns da liñaxe no proceso de definición experimentado pola monarquía ao longo do século XII, desempeñaron un papel nada desprezable na dirección dos reinos. Princesas e infantas convertéronse en instrumentos chave da acción política e diplomática, pola súa función como raíñas estranxeiras capaces de exercer unha importante influencia tamén a nivel cultural, ademais de converterse en transmisoras de lexitimidade, mediadoras naturais e transformadoras do espazo cortesán no que se insiren. A procura dun herdeiro varón e as prohibicións impostas polo dereito canónico respecto da afinidade de parentesco activaron notablemente as estratexias matrimoniais no continente europeo e a creación de novos vínculos a nivel diplomático cos reinos veciños, en ocasións moi distantes xeograficamente falando (Rodríguez López 2014: 23-29). Unha tendencia que precisamente se verá alterada co matrimonio entre Afonso X e Violante de Aragón, tras o que se consolidaron, aínda que por razóns moi diversas, as unións matrimoniais intrapeninsulares tras malograrse a chegada ao trono do seu primoxénito, o infante Fernando da Cerda, casado con Branca de Francia.

Grazas á obra de Afonso X tamén se daba cobertura legal á relevancia acadada polas mulleres que precederon á súa muller, a raíña Violante de Aragón, e a aquelas que a seguirían despois, como estreitas colaboradoras na gobernanza do reino, artífices de acordos e mais alianzas con outras monarquías, administradoras do territorio, símbolo solemne da maxestade rexia en cerimonias ou entradas triunfais, ademais de gardiás da memoria dinástica e a devoción cristiá (Earenfight 2005). Coincidía o recoñecemento historiográfico da súa intelixencia e sagacidade políticas coa súa presenza en actos cruciais do goberno dos reinos, o que pon de manifesto a confianza depositada nelas por parte dos seus pais, maridos ou irmáns (Beceiro Pita 2009: 540-541). Por sinalar só algúns dos exemplos máis representativos, habería que lembrar a rápida actuación da raíña Berenguela ao achandar o camiño ao trono do reino de León para Fernando III exhibindo tanto a súa hexemonía sobre as principais prazas do reino -máis aínda, naquelas que lle correspondían como señora, como era o caso da cidade de Toro-, como no marco historiográfico (Shadis 2009: 73-96, Pelaz Flores 2020: 26-28). Tamén o faría Violante de Aragón negociando a paz en Córdoba coa insurrecta nobreza liderada por Nuño González de Lara non só en nome do rei (Doubleday 2015: 142-148), senón reinterpretando de forma autónoma as súas palabras para conseguir poñer fin ao conflito da forma máis rápida e eficaz posible e, aínda máis, «[andando] en lugar del rey por la tierra», de acordo coa expresión empregada anos despois por Sancho IV para referirse á actuación política e xudicial da súa nai no reino de León, establecendo un 
claro paralelismo coa figura xurídica da «lugartenencia», como xa puxo de manifesto Francisco Hernández (2015: 94-99) .

As mulleres da parentela rexia en xeral, e as raíñas consortes en particular, contaron co recoñecemento da súa autoridade e a súa capacidade de actuación en prol dos intereses familiares e, en definitiva, da monarquía. A súa posición dentro da liñaxe familiar concedíalles a oportunidade de desenvolver a súa axencia política de acordo cun carácter relacional que se conectaba non só cos seus propios intereses persoais, senón tamén cos do seu marido e fillos, aos que se podería engadir os da súa liñaxe paterna; aínda que, por outra banda, non se debería perder de vista a súa capacidade para influír e mediar, fomentando que as súas aspiracións se convertesen tamén nas dos membros masculinos do tecido familiar (Fuente Pérez 2016: 138-140). Un comportamento que garda estreita relación co condicionamento que o xenro imprimiu ás diferentes posicións que varóns e mulleres podían desempeñar no seo da familia real, sen o cal non se pode comprender nin a súa forma de actuar nin de relacionarse, incluso cando se inverten os roles para exercer a titularidade do reino, como demostra o caso da raíña Berenguela e a súa vontade de entregar o trono ao seu fillo, o ata entón infante Fernando (Pelaz Flores 2017: 309-312) .

Falar do concepto de rexinalidade ou de poder rexio feminino no século XIII supón falar, máis aló da participación política das soberanas, de cambio e de adaptación; da súa vontade por involucrarse na andadura monárquica e do recoñecemento externo brindado ás súas accións, tanto cando eran comisionadas para iso como cando actuaron pola súa propia convicción, demostrando en ambos os dous casos un coñecemento amplo e preciso do funcionamento político e da relevancia da súa posición rexia. Tamén sería aproveitada a súa imaxe, desde o punto de vista retórico e simbólico, ademais de redobrar os esforzos destinados a diseminar a inxerencia da parella rexia para consolidar a imaxe e a percepción da monarquía, tanto no plano laico como eclesiástico. De todo iso tentarei ocuparme nos seguintes apartados.

6 Trátase dunha referencia verdadeiramente interesante, que establece unha conexión evidente coa expresión empregada polas raíñas aragonesas que ocuparon a «lugartenencia», como sinala Lledó Ruiz no seu estudo sobre a terceira muller de Pedro IV de Aragón e primeira raíña lugartenente, Leonor de Sicilia (Ruiz Domingo 2017). A raíña indicou que a súa responsabilidade gobernativa emanaba do rei, «del qual tenim loch», isto é, que se encontraba a exercer o poder no seu lugar, do mesmo modo que sentenciaba Sancho IV a propósito da función da súa nai no ano 1264. Se ben nos reinos de León e Castela a «lugartenencia» non chegou a institucionalizarse, como xa expuxen noutra ocasión (Pelaz Flores 2017: 253-255), en parte debido á presenza do rei no territorio que enseñorou, coa excepción da partida de Afonso X a Francia para entrevistarse co papa a propósito do fecho del Imperio, esta alusión documental non pode pasarse por alto en ningún caso, dado o valor semántico que posúe.

7 Co fin de comprender mellor as razóns que levaron a dona Berenguela a optar por ceder o goberno ao seu fillo e, en consecuencia, evitar calquera posible inxerencia por parte do que fora o seu marido, o rei Afonso IX de León, con relación á complexidade que supuxo a actitude do rei en canto que consorte do reino, pode consultarse a obra editada por Beem e Taylor (2014). 


\section{INSTRUMENTOS DO PODER REXIO NO REINO DE GALICIA E A SÚA RELACIÓN COAS MULLERES DA FAMILIA REAL}

As visitas cortesás marcan, como xa foi sinalado, non só unha particular relación entre a familia real e o territorio, senón tamén unha forma de percibila, máis concretamente por quen se dispón a observala desde o noso momento actual. Con todo, existen outro tipo de indicios acerca da presenza da monarquía que deben terse en conta, posto que permiten coñecer algunhas das chaves da comunicación política entre a Coroa e o reino ${ }^{8}$. Non só a través daqueles signos mediante os que a institución se facía presente por si mesma, como a moeda, senón tamén a través daqueles elementos que recoñecen a autoridade rexia e, sobre todo, que ofrecen unha imaxe concreta da Coroa e das persoas que a integran. Neste sentido, a intricada rede tecida desde a corte pola raíña e os infantes cara aos seus oficiais marca o inicio da conectividade destes cun territorio moito máis amplo que o percorrido xunto á propia corte ${ }^{9}$. Porén, centrareime na simboloxía contida nos documentos chancelerescos de maior solemnidade mediante os cales as diferentes pezas da monarquía eran representadas ante as institucións galegas, máis aló da súa propia presenza física.

No caso do reino de Galicia, consérvanse algúns privilexios confirmatorios cuxa expedición se solicitou á chancelaría rexia para asegurar o desfrute de exencións, doazóns de lugares que se realizaran con anterioridade ou a consecución de recursos que asegurasen o mantemento, por exemplo, das institucións monásticas $^{10}$. Ademais do acto de comunicación que se desprende a propósito, é relevante tamén sinalar que adoitaba producirse previa comparecencia na corte, en boa parte das ocasións aproveitando un momento de solemnidade para a Coroa, como a chegada ao trono dun novo soberano ou a reunión dos axentes de poder e representantes do reino que propiciaba a celebración de Cortes. Por exemplo, así se testemuña no caso da ratificación de todos os privilexios dos que gozara o mosteiro cisterciense de Santa María de Monfero, outorgada por Afonso XI de acordo coa petición que se lle

8 Habería que considerar tamén a necesidade de incorporar aos representantes do reino de Galicia nos sucesos relevantes para a monarquía, como as vodas dos membros da parentela rexia, por exemplo a notificación enviada por Afonso X ao concello de Ourense acerca do compromiso matrimonial da súa primoxénita, a infanta Berenguela (véxase o documento número 88 do diplomatario contido neste volume). A transmisión da mensaxe estimularía a proximidade desde a distancia, ademais de mostrar a importancia de atraer aos representantes dos diferentes territorios, nun proceso de comuñón con eles fomentado desde a monarquía. Véxase o documento número 93 do mesmo diplomatario, en relación co agradecemento do rei cara á Igrexa de Santiago e os concellos de Santiago, Pontevedra e da terra de Santiago pola homenaxe prestada á infanta dona Berenguela ante o seu compromiso co primoxénito do rei de Francia.

9 Esta forma de «facerse presentes» podía supoñer un apoio ao fortalecemento da autoridade rexia no territorio pero tamén podía converterse, chegado o momento, nun foco de resistencia cara ao seu poder, ao estar baseada nas relacións de dependencia e lealdade coas diferentes figuras da parentela rexia. Concretamente, no reinado de Afonso X compróbase o interese no territorio galego tanto dos seus fillos máis vellos, o infante don Fernando de la Cerda e o infante don Sancho, como tamén da raíña Violante de Aragón, pero tamén na importancia á hora de conceder as tenencias galegas, en mans de personaxes de prestixio e próximos o sangue rexio, encargados de velar pola estabilidade do reino en nome do rei. Baste sinalar o caso de Afonso Fernández o Neno, fillo ilexítimo de Afonso X, tenente de Trastámara, coñecido como «príncipe de Galicia». Véxase nesta obra o capítulo de Francisco J. Hernández.

10 Precisamente pode consultarse neste volume o diplomatario confeccionado por Francisco Javier Pérez Rodríguez. 
elevara nas cortes que tiveran lugar en Burgos, en 1315 (AHN, Clero, Carp. 505, n.․ 13 e 16. 1315, agosto, 30. Burgos $)^{11}$. O monarca continuaba así co ronsel trazado polos seus proxenitores, de protección e benfeitoría cara ao tecido monástico galego ${ }^{12}$.

O desprazamento ata a corte permitía evidenciar as condicións de vida destes centros, así como crear lazos que estimulasen as relacións para coa monarquía, tamén no relacionado coa nobreza, a Igrexa ou, en menor medida, os representantes urbanos con capacidade para falar en nome dos intereses galegos. Esta dinámica, que afunde as súas raíces en reinados anteriores, iríase afianzar a medida que transcorría a Idade Media, aínda que a representación do panorama urbano galego non acadase o mesmo peso que o das dezaoito cidades con voto en Cortes $^{13}$. Deixando á marxe estas cuestións que desprazarían o noso foco de análise cara a un moi distinto, a comparecencia ante o rei ou a súa chancelaría solicitando a expedición dun novo diploma rexio é verdadeiramente relevante, en particular pola fórmula elixida para confeccionar moitos dos documentos orixinais conservados: a do privilexio rodado.

Lonxe de consideralo un mero soporte para conter unha acción legal determinada, a aparencia do documento pon de manifesto a importancia da sanción que lle brindan os actores cuxos nomes quedan rexistrados. Todos eles, incluídos os que actúan como confirmadores, eran considerados parte substancial da oficialización do contido do diploma, sen importar que estivesen presentes no momento da súa expedición (Arias Guillén 2021: 163). É, entón, cando se debe prestar atención á incorporación xunto ao rei doutras persoas da súa contorna familiar que tamén participan da acción contida no documento. Trátase dunha demostración do seu peso no seo do corpo político da monarquía, entendido como unha institución complexa, que supera os límites do corpo físico do monarca, por un lado, pero no que tamén se dá información acerca das circunstancias familiares que rodean ao soberano e o seu reinado, por outro.

Sen esquecer a importancia doutras fórmulas destinadas á exaltación da memoria que irán sucumbir co paso do tempo (Rodríguez López 2011: 297-301), a utilización da imaxe rexia, asociada aos outros membros da liñaxe, constitúe un elemento de grande alcance neste tipo de diplomas. En ocasións só de forma previa á listaxe de confirmadores, subliñando o seu peso na acción legal, noutras -máis habituais a medida que avanza o século XIII cara á Baixa Idade Media- tamén na intitulación documental, ao nome do rei únense o da súa muller e, cando menos, o do herdeiro. Mentres as dúas pezas da parella rexia son indisolubles, o terceiro elemento pode dar cabida non só ao herdeiro, senón tamén a outros dos seus irmáns -varóns, nesta altura do período, tendo en conta a ampla descendencia que procrearon tanto

11 Cortes de los antiguos reinos, vol. 1, cap. XL, cortes de Burgos, 293-299.

12 No diplomatario elaborado por Francisco Javier Pérez Rodríguez pode atoparse unha mirada máis precisa acerca da política confirmatoria desenvolvida polo monarca, en particular no tocante ao tecido monástico galego.

13 A cidade de Zamora pasou a encargarse de representar a voz das cidades galegas, o que evidencia a falta de peso específico á hora de poder transmitir as súas peticións de forma directa, a través dos seus propios procuradores (Carretero Zamora 2008, 99). 
Fernando III e Beatriz de Suabia como Afonso X e Violante de Aragón-, cando menos nos documentos que se conservaron en relación con Galicia ${ }^{14}$.

En tanto que creador e mantedor da memoria en si mesmo, o privilexio rodado, diseminado ao longo e ancho do reino a partir da petición do interesado, contribuía ao recoñecemento dos seus soberanos como depositarios da autoridade rexia. A raíña desempeñaba un papel de chanzo entre o presente e o futuro dinástico, pero tamén lograba incorporar o principio feminino á representación da monarquía, de acordo coa complexidade corporal citada con anterioridade (Pelaz Flores 2018). Os nomes de dona Beatriz e dona Violante serviron para transmitir ese significado sobre o soporte escriturario, ademais de ofrecerlle un espazo específico xunto ao rei, reforzando o seu recoñecemento e relevancia, tanto política como simbólica, ante o reino. Neste sentido, a falta de referencia a dona Xoana de Ponthieu (ca. 1216-1279/r. 1237-1252) (Sánchez de la Mora 2007), segunda muller de Fernando III, non obedece a unha alteración no procedemento chanceleresco, senón que garda relación co momento de expedición documental: a produción de novos diplomas estaba intimamente relacionada coa chegada ao trono dun novo monarca, polo que as datas de expedición informan acerca do momento de comparecencia ante a corte e coinciden co momento de maior ebulición da produción documental.

Non resulta casual, polo tanto, que os privilexios expedidos a favor dos mosteiros de San Salvador de Chantada ${ }^{15}$, San Salvador de Celanova ${ }^{16}$ e a igrexa e mosteiro de Santiago Apóstolo no Burgo de Ribadeo ${ }^{17}$ se levasen a cabo nos dous primeiros anos do goberno de Fernando III, despois de ser recoñecido como soberano do reino de León de acordo co contido da Concordia de Benavente (11 de decembro de 1230), na que a raíña Berenguela desempeñou un papel chave, en particular despois do seu encontro coa raíña Teresa de Portugal nas vistas de Valencia de Don Juan $\left(\right.$ Martin 2007) ${ }^{18}$.

A expedición deste tipo de privilexios non se reservou, en todo caso, ao momento da chegada ao trono dun novo gobernante, como se aprecia polas da-

14 As infantas tamén participaron do proceso de representación da monarquía e dos seus usos retóricos, como se observa a través das diversas fórmulas diplomáticas empregadas nos privilexios rodados a propósito. Por exemplo, na confirmación realizada polo rei Afonso X da metade da igrexa de Santa María de Couso de Vilariño, de acordo coa doazón feita polo rei Afonso IX, o diploma contén a seguinte fórmula: «el rey Don Alfonso, regnant en uno con la reyna donna Yolant, mi mugier e con mis fijas, la inffante donna Berenguela e la inffante donna Beatriz». A ausencia dun herdeiro varón no momento da redacción do diploma xustifica a inclusión das infantas (AHN, Clero Regular-Secular, carp. 1447, n. 11. 1255, xaneiro, 19. Burgos).

15 Confirmáronselle ao mosteiro todos os seus privilexios, mercés e exencións, así como os seus coutos e herdades. AHN, Clero, Carp. 1067, docs. 7 e 11. 1231, outubro, 27. Valladolid.

16 Nesta ocasión, tratouse da doazón do lugar de Moxios, en territorio de Baronceli, tal como no seu día fixera o rei Afonso IX de León, en Pantón, o 12 de abril de 1215. AHN, Sigil-Sello, C. 11, n. 4. 1232, abril, 13. Ourense (data da confirmación polo rei Afonso X: 1255, marzo, 29. Sahagún). Noutro documento, datado tres días máis tarde, facíase doazón da illa de Santo Estevo e a concesión do privilexio de couto a favor do mosteiro de Coruxo. AHN, Sigil-Sello, C. 7, n.o 6. 1232, abril, 15. Ourense.

17 Tratábase da concesión da cuarta parte do froito das viñas. AHN, Estado, Atado 3167, Exp. 4 (n.은 19). 1232, novembro, 11.

18 Do total de doce castelos que se designaron como garantía do acordo entre Fernando III e as infantas, sete eran galegos: Lobancana, Cabreira, Candrei, Allariz, Santa Cruz, San Xoán de Pena Corneira e Milmanda. Os fideles destes: Rodrigo Gómez, Fernando Yáñez, Paio Arias, Xoán Pérez, Arias Fernández de Meira, Pedro Mañón, Pedro Mariño, Rodrigo Páez de Candrei e os seus fillos, os fillos de Melendo Blázquez, Rodrigo Suárez, Martín Gil de Asturias, Sebastián Gutiérrez, Ordoño Álvarez, Fernando Álvarez e Paio Pérez (Rodríguez 1994: 176). 
tas que poden rastrearse ao respecto durante os reinados de Fernando III, Afonso X, Sancho IV, Fernando IV ou, incluso, Afonso XI ${ }^{19}$. A súa demanda e posterior conservación reforzaron a relación coas institucións monásticas galegas, aínda que tamén habería que ter en conta a expedición a favor doutros poderes do reino, tanto no que respecta á nobreza como ao tecido urbano (Arizaleta 2010). Fronte a monarcas como Afonso IX, que se fixo presente de maneira intensa no territorio galego a través das visitas que realizou a diferentes poboacións galegas (Rodríguez Ennes 2016) ou elixindo ser enterrado na catedral de Santiago de Compostela, outros soberanos insistiron en sancionar os privilexios outorgados polos seus antecesores, acompañados da alusión á familia real e a un nutrido grupo de confirmadores (Arias Guillén 2018). Porén, habería que ter en conta as novas concesións de mercés e privilexios polos reis plenomedievais, entre os cales á chancelaría do rei Afonso X reflicte unha fluída interacción co territorio galego, tanto no relativo ás institucións locais como ás relixiosas ou asistenciais ${ }^{20}$.

O privilexio rodado trasladaba a idea da monarquía como a unión dos individuos que a representaban no momento concreto da expedición documental, insistindo na unidade matrimonial e aquel/es chamado/s seguir o seu ronsel no futuro. A raíña víase reforzada, como enlace entre pai e fillo/s pero tamén por si mesma, como figura política autónoma e independente, que podía outorgar mercés e privilexios e desenvolver un labor representativo a través da súa persoa. Coma o rei, a idea da condición rexia existía no imaxinario colectivo de forma arquetípica, provista dos signos do seu poder e dos elementos que caracterizaron a súa voz e actitude. O tombo do mosteiro cisterciense de Toxos Outos (A Coruña) é unha boa mostra diso. Nel contense a representación dun total de once figuras rexias, das cales catro están dedicadas a raíñas: Tareixa de Portugal, Urraca de León, Berenguela de Castela e Violante de Aragón. Composto por orde do abade don Sancho en 1289, enmarca o seu papel político e os signos de poder que se lles asocian (a coroa, a súa figura entronizada en actitude dialogante cara aos varóns que as acompañan), ademais de revelar a importancia desas personaxes na evolución do mosteiro (Nogales Rincón 2006: 103$-105)^{21}$. Coas súas representacións deixábase constancia do significado concedido ás súas funcións, nun proceso de asimilación que se estimulaba a partir da recepción de mercés e privilexios, reforzaba a súa presenza en Galicia e informaba da adhesión á monarquía, tamén a través dos seus membros femininos.

19 En consecuencia poden rastrearse as sucesivas confirmacións de privilexios desenvolvidas por estes monarcas en beneficio dos mosteiros de San Salvador de Chantada (AHN, Clero Regular-Secular, carp. 1067, n. 10. 1259, setembro, 26. Toledo), Santa María de Monfero (AHN, Clero Regular-Secular, carp. 501, n.음 2. 1258, abril, 21. Valladolid; AHN, Clero Regular-Secular, carp. 505, n. 12. Valladolid. 1306, xullo, 26. Carrión de los Condes), Santa María de Melón (AHN, Clero Regular-Secular, carp. 1447, n. 6. 1255, xaneiro, 12. Burgos) ou Santa María de Oia (AHN, Clero Regular-Secular, carp. 1825, n.ำ 7. 1329, xuño, 17. Madrid), por citar só algúns exemplos.

20 Para ter unha visión máis axustada da intensa política do rei Afonso X, pode consultarse o diplomatario incorporado nesta obra, confeccionado polo profesor Francisco Javier Pérez Rodríguez.

21 Concretamente, a actitude coa que aparece representada Violante de Aragón permitiulle a Mạ Jesús Fuente sinalar o paralelismo que existe coa representación da raíña Blanca de Castela xunto ao seu fillo, Luis IX, de acordo cunha actitude humilde aínda que demostrando a súa capacidade de consello e ensino, tamén debido ás influencias francesas na miniatura do cartulario coruñés (Fuente 2017: 69). 


\section{SEÑORAS E BENFEITORAS NO REINO DE GALICIA}

Aínda que escasos á luz da documentación conservada, os contactos mantidos por parte das raíñas co reino de Galicia resultan de grande interese polos interrogantes que permiten formular a propósito. Tendo en conta que o territorio galego non forma parte dos percorridos máis habituais da monarquía, podería supoñerse que existe un maior estrañamento por parte da familia real. Que xustifica entón o auspicio e, máis aínda, a creación de casas monásticas no seu marco territorial? Constitúe un indicador das outras variables que se deben ter en conta á hora de comprender o funcionamento da relación entre a monarquía e o reino, con independencia do papel que desempeña a itinerancia cortesá? Ou, precisamente, é un elemento distintivo con respecto a outros territorios igualmente estraños aos seus percorridos? Atopar resposta a todas estas preguntas non é, nin moito menos, un propósito sinxelo.

Fronte a outros territorios igualmente minoritarios nas rutas dos desprazamentos rexios, o reino de Galicia contaba cunha serie de particularidades que non eran estrañas á monarquía. A presenza da tumba do Apóstolo Santiago xunto coa relevancia da sé compostelá constitúen dous activos de grande importancia, así retórica como simbólica, que se percibe, por exemplo, no outorgamento do oficio de capelán maior do rei a aquel que ocupase a dirección da diocese, que se estende ao longo da Baixa Idade Media ${ }^{22}$. O peso da Igrexa galega á vista da expedición de privilexios rodados confirmatorios faise tamén evidente, indicando o recoñecemento concedido ás dioceses de Lugo, Mondoñedo, Ourense ou Santiago, como parte interesada na exhibición da súa autoridade a teor do contido da acción documental ${ }^{23}$.

Aínda que escasos, os testemuños documentais que sitúan ás raíñas e infantas na xestión do territorio e institucións galegas son representativos do empeño por involucralas na defensa dos intereses da monarquía fronte á nobreza, o que tamén podía resultar un estímulo á hora de outorgar mercés ás institucións monásticas. Este sería o caso do privilexio concedido pola raíña Berenguela ao cenobio coruñés de Santa María de Sobrado, no que comezou sinalando que «yo, donna Berengela, por la graçia de Dios, reina de León y Galizia, juntamente con mis hijos don Fernando y don Alonso, de mi propia y libre voluntad ago carta de donación, concesión, confirmación y firmaça a Dios y al monesterio de Sobrado y a vos, frai Enrrique,

22 Salazar y Acha xa sinalou que moitos dos arcebispos de Santiago recibiron o oficio de capelán maior do rei, que exerceron de forma efectiva mentres se encontraron na corte. Se ben no século xiII xa se facía patente o costume de designar un prelado para asumir o oficio de capelán, desde o cal continuar o seu ascenso dentro da carreira eclesiástica, a entrega do cargo dentro do servizo rexio non tardou en consolidarse e asociarse ao titular da diocese compostelá (Salazar y Acha 2000: 223-224).

23 O exame da listaxe de confirmadores dentro dos privilexios rodados é sumamente interesante por ofrecer unha imaxe dos personaxes de maior prestixio político do conxunto do reino, tanto a nivel laico como eclesiástico, ofrecendo ademais a posibilidade de observar as variacións que poden introducirse ao respecto en función dos intereses territoriais contidos en cada documento de forma particular (García-Fernández/Pelaz Flores/Pichel Gotérrez 2020: 164-165). 
abad», así como ao convento das monxas cistercienses a el adscrito, da herdade que lle pertencía en Villanueva de Cea, situada entre Mayorga e Valderas (AHNO, Osuna, CP. 46, D. 18. 1215, abril, 14. Sahagún).

Trátase dun documento interesante por varios motivos, xa que nel non hai referencia ningunha a Castela, aínda que a raíña era rexente do reino no nome do seu irmán, o rei Henrique I, o que demostra o seu interese por resaltar o vínculo que a unía a León e Galicia ${ }^{24}$, reino do que ademais foi recoñecida como tenente por Afonso IX de acordo co seu contrato de arras (Bianchini 2012: 56-59). A concesión da tenencia a favor de dona Berenguela reforzou o vínculo coa monarquía a través da raíña fronte ao seu anterior titular, o conde Gómez González de Traba, sinalando unha práctica que se convertería en frecuente á hora de adxudicar os enclaves que formaron parte do señorío rexio, seleccionado lugares fronteirizos ou sensibles aos intereses nobiliarios, cuxa posesión se vía así reforzada desde a Coroa ${ }^{25}$. Se ben é certo que dona Berenguela non acudiu a Galicia co seu fillo, o rei Fernando III, unha vez que se fixo co reino de León, para asegurar a posesión do territorio galego, a súa actuación cara ao mosteiro de Sobrado pode conectarse con outras accións de benfeitoría desenvolvidas polo propio rei, nas que se alude de forma expresa ao consentimento proporcionado pola raíña nai, facendo máis complexa a fórmula intitulatoria do privilexio rodado e mostrando, en consecuencia, a particularidade da súa autoridade real durante o reinado de Fernando III, de acordo co sistema de cogobernanza identificado por Miriam Shadis (2009: 10-20) ${ }^{26}$.

As infantas veríanse, igualmente, involucradas nesta mesma práctica. A entrega de fortalezas ou prazas fronteirizas seríalles confiada en lugares tan destacados como a fronteira con Portugal ou nos confíns do reino de Galicia, como indican as posesións entregadas ás infantas Dulce e Sancha de León (Rodríguez López 1994: 178-180, Bianchini 2012: 191-192). Con iso insístese de novo na responsabilidade que se lles outorga na defensa de lugares con gran valor estratéxico desde o punto de vista da defensa e a autoridade sobre o territorio galego. Esta tarefa defensiva desenvolveríase no seu nome, dada a súa xuventude, o que pon ao descuberto a capacidade representativa que se concede ás infantas á hora de multiplicar a imaxe da monarquía, aproveitando para iso a todos os integrantes da familia real. Non obstan-

24 Dona Berenguela empregou con frecuencia esa mesma intitulación, non só en documentos relacionados con Galicia, senón tamén na concesión doutros privilexios outorgados, entre outros, ao mosteiro de Eslonza (Shadis 2009: 64-86).

25 As posesións galegas de dona Berenguela redondeábanse coa concesión dos castelos de San Paio de Lodo, Aguiar da Moá, Alba de Bunel, Candrei e Aguilar de Pedrayo (Rodríguez López 1994: 159).

26 A variación respecto á fórmula habitual resulta de grande elocuencia, como se aprecia no comezo dun privilexio outorgado a favor do mosteiro de Santa María de Oia polo que se lle ratificou a posesión das herdades, igrexas, doazóns, liberdades e privilexios concedidos previamente polos reis Afonso VII, Fernando II e Afonso IX de León: «Ego Ferrandus, Dei gratia rex Castillem e Toletum, Legionem e Galliziem, una cum vxore mea Beatrice Regina e cum filiis meis Alfonso, Frederico, Ferrando e (En)rico, ex assensu e beneplacito Regine domine Berengarie, genetricis mee» (AHN, Clero Regular-Secular, carp. 1789, no 9. 1231, febreiro, 28. Salvatierra de Tormes). 
te, tamén poderían asumir un papel máis activo na súa etapa adulta, como sinala a identificación da infanta dona Dulce como tenente da fortaleza de Santa Cruz, tarefa asumida nos anos finais da súa vida, cando menos entre 1239 e 1245, xunto coa infanta dona Sancha. A esta última tamén se lle encomendaría nas mesmas datas (1237-1245) a tenencia de Valdeorras, dentro dunha estratexia de administración e defensa por parte das mulleres da liñaxe común no territorio galego (García-Fernández, no prelo) ${ }^{27}$.

Tan importante como a entrega de fortalezas foi a daquelas prazas que representaban intereses económicos de gran valor para a Coroa, como ocorre no caso da entrega da Coruña para as infantas Dulce e Sancha, un dos principais portos de reguengo da costa galega, instituído en 1208 polo seu pai, o rei Afonso IX (Barral Rivadulla 1998: 30-31). O núcleo reguengo tivo que afianzarse fronte á rivalidade do veciño Burgo de Faro, que se resistía a despoboarse en prol da expansión da praza fortificada (Ferreira Priegue 1988: 81), facendo necesaria a petición das infantas ante o rei Fernando III en 1235 para instar ao comendador a dar cumprimento ao mandato rexio e á súa autoridade como señoras da Coruña (Barral Rivadulla 1998: 29). A súa vinculación coa vila mariñeira facilitaría que, ou ben baixo o seu señorío, ou ben como recoñecemento cara ao seu labor como señoras por parte dos monarcas sucesivos, se concedesen prebendas como o monopolio do comercio e depósito do sal en toda Galicia (González López 1992: 217) ${ }^{28}$, ademais de continuar os lazos que se levaron a cabo con outros poderes tan destacados no reino de Galicia como a Igrexa de Santiago, á que confirmaron a tenencia de 300 marabedís nas rendas da Coruña, como no seu día fixera o seu pai (González Garcés 1987: 169).

Precisamente a doazón realizada por Afonso IX a favor das infantas en 1217 contemplaba, así mesmo, a tenencia doutras vilas e territorios galegos, como os de Traba, Allariz, Milmanda e Ribadavia ${ }^{29}$, mediante as que se aseguraría o mantemento do seu estado a través do cobro das súas rendas, ao mesmo tempo que se garantiu o seu mantemento dentro do reguengo ao reintegrarse na Coroa tras o seu matrimonio ou o seu falecemento; contribuíase, por outra banda, ao afianzamento da autoridade da monarquía fronte á posible inxerencia externa do abadengo e do señorío laico (González Garcés 1987: 168, Sánchez Chouza 2005: 156).

A unión entre ambos os reinos de León e Castela baixo o goberno de Fernando III non serviu para perpetuar a concesión de municipios que, dentro do espazo galego, fosen administrados polas consortes, nin tampouco polas infantas. En parte debido ao desprazamento da espacialidade rexia cara ao sur-leste da súa área xeográfica e tamén en relación coa súa vontade de expandirse cara ao sur da

27 Quero mostrar o meu máis sincero agradecemento ao autor, por permitirme consultalo aínda antes da súa publicación.

28 Documento datado en Vitoria, o 2 de decembro de 1255. Pode consultarse o número 87 do diplomatario de Pérez Rodríguez, no presente volume.

29 Uniríanse a estas posesións a tenencia de Valdeorras, en mans da infanta dona Dulce, ao menos, en 1237, como acredita González Garcés (1987: 185). 
Península. Con todo, habería que ter en conta a concesión entre as arras das raíñas castelás de municipios que salpicaron a ruta trazada polo Camiño Francés rumbo a Santiago de Compostela, como Nájera, Belorado, Castrojeriz, Burgos, Astudillo ou Carrión de los Condes; unha tendencia que conecta os señoríos entregados ás raíñas Leonor Plantagenet, Berenguela de Castela, Beatriz de Suabia e, posteriormente, Violante de Aragón (Cerda Costabal 2016: 73-77, Rodríguez López 2013: 170-182, Fuente Pérez 2016: 143-144).

As mulleres de Fernando III, as raíñas Beatriz de Suabia e Xoana de Ponthieu, non tiveron ocasión de visitar o reino de Galicia ou, cando menos, os testemuños documentais e historiográficos non deixaron constancia diso. Como xa se indicou, o caso de Violante de Aragón é diferente. Aínda que tampouco resulta sinxelo situar a súa presenza en Galicia, o seu padroado relixioso expón unha relación moi estreita co reino. O seu testamento, estudado por Melissa Katz, é boa mostra diso, ao querer promover os conventos das Ordes de Santo Domingo e San Francisco radicados no soar galego, decidindo entregar a cada un deles 3000 marabedís (Katz 2013: 56 e 64, nota 44). A súa vontade veríase redondeada pola fundación do convento de Santa Clara de Allariz, concibido como espazo destinado a aloxar os seus restos mortais tras o estrañamento cara ao seu marido ${ }^{30}$. Como parte do reguengo, non se trataba dun núcleo descoñecido para a familia real, pois foi visitado en varias ocasións por Afonso IX de León e posteriormente por Sancho IV, ademais de ser o primeiro lugar en recoñecelo como rei en Galicia (Katz 2015: 815-816) ${ }^{31}$.

Por último, habería que ter en conta a creación de redes entre os cortesáns e o persoal do séquito real e o territorio galego como outro marco de representación e de conectividade entre Galicia e a contorna da monarquía. Xa fosen de cargos capaces de situarse dentro do tecido cortesán ou das doazóns que emprenderan pola súa parte, ábrese un novo escenario de actuación e análise coa raíña como canal de transmisión. Algúns deles, como os capeláns García Blandes e Afonso Domínguez de León, serviron á raíña Violante de Aragón polo menos na última etapa da súa vida,

30 O maltreito estado económico da soberana, dadas as malas relacións co seu esposo na última parte do seu reinado, redundou en que a fundación do convento clariso e a concesión de mercés que facilitasen o afianzamento da comunidade fosen realizadas a instancias de Sancho IV, sinalando, en calquera caso, que estas accións se levaban a cabo a pedimento da raíña Violante. Conforme esas mercés, entregouse ao convento o privilexio de facer un novo poboamento que deixase exento do pago de moeda foreira a traballadores e poboadores (AHN, Clero Regular-Secular, carp. 1429, n. 8. 1293, xullo, 12. Burgos), que puidesen dispoñer das súas herdades con liberdade (AHN, Clero Regular-Secular, carp. 1429, n. 4. 1291 , marzo, 22. Palencia), así como o privilexio de couto para esas mesmas herdades (AHN, Clero Regular-Secular, carp. 1429, n. 9. 1293, xullo, 12. Burgos).

31 Sancho IV tamén estimulou as relacións da familia real con Galicia, a partir da concesión de diversas propiedades señoriais ao seu fillo, o infante Felipe de Castela, quen desempeñou ademais a dignidade de pertegueiro maior de Santiago. Tanto el coma a súa esposa, Margarita de la Cerda, encargáronse da administración deses señoríos, como indica a venda realizada por esta última á morte do seu esposo da terra de Parga e o castelo de Guitiriz, xa a comezos do século XIV. A súa vinculación con Galicia sería redondeada da man do enterramento que brindarían a unha das súas fillas na catedral de Ourense, de acordo coa identificación do sepulcro realizada por Eduardo Pardo de Guevara (2017: 441-442). 
cando o proxecto devocionario de Allariz estaba en vías de alcanzarse, e como tales, serían recoñecidos e gratificados no testamento da raíña polo seu labor de asistencia espiritual (Katz 2013: 56). Non obstante, habería que valorar a incorporación doutros membros do servizo real que, vinculados ao reino de Galicia, tamén conseguiron articularse no ámbito cortesán xunto á consorte. Neste sentido, non pode deixar de mencionarse a doazón efectuada por María Fernández Coronel, ama da raíña María de Molina e da súa filla, a infanta Isabel de Castela, aínda que supere o propósito cronolóxico do presente traballo ${ }^{32}$. No seu caso, entregou ao cabido da catedral de Lugo as propiedades que tiña no couto de Santo Eusebio da Peroxa, situado en Ourense (AHN, Clero Regular-Secular, Carp. 1506, n.ํㅜ 18. 1308, marzo, 9).

A expansión da lírica galego-portuguesa no espazo cortesán de Fernando III e, sobre todo, do seu fillo, Afonso X, foi crucial á hora de estimular a atracción de trobadores e poetas do ámbito noroccidental da Península Ibérica e favorecer a riqueza cultural, que posteriormente animaría outras cortes próximas, como a de Dinís I de Portugal a seguir o seu exemplo. Neste sentido, podería citarse o caso de Estêvão da Guarda, do que algúns autores suxiren que puido acompañar á raíña Isabel de Aragón no seu séquito e iniciar unha fulgurante carreira ao servizo de Dinís I (Homen 1987, Del Río Riande 2009: 48, nota 24), formulación que, aínda plausible, de acordo co papel feminino na dinamización cultural e literaria, suscita controversia ao contrastar con outros traballos que lle outorgan unha orixe netamente portuguesa (Pagani 1971).

$\mathrm{O}$ interese rexio por estimular un ambiente cultural refinado e acorde aos gustos do momento xa se comezara a sentir con forza da man de Leonor Plantagenet, quen favoreceu a chegada dun nutrido grupo de trobadores e xograres desde Gascuña e Provenza, ronsel que seguiron os sucesivos monarcas, avivando a produción lírica mediante a adaptación da temática e estrutura das composicións transpirenaicas (Cerda Costabal/Martínez Llorente 2019: 76-79). Raíñas e incluso infantas serían obxecto dalgúns dos versos elaborados por Garcia Burgalês ou Pero da Ponte, autor dun pranto dedicado á raíña Beatriz de Suabia despois do seu falecemento (Corral Díaz 2017), ademais do xa citado Estevan da Guarda (Corral Díaz 1996: 259-261). Nun momento determinado tamén podían converterse no obxecto da pluma destes trobadores, como Johan Zorro ou Gonçal 'Eanes do Vinhal, que dedicaron algunhas das súas cantigas á posible relación sentimental mantida pola raíña Xoana de Ponthieu cun dos fillos do seu marido, o infante Henrique. A forza da historia tratada nas súas composicións facilitou que estas chegasen a converterse en cancións populares, pero, sobre todo, revela o seu potencial para coñecer o clima vivido na corte, xa se tratase de visións mordaces ou dramáticas, desde a deformación dos feitos nos que participou a raíña -neste caso, representando o papel da amada- ou desde a veracida-

32 María Fernández Coronel foi a única muller nomeada, xunto cunha vintena de vasalos do rei no ano 1290, tenente de parte das rendas do señorío Trastámara, afincadas nas freguesías de Santo Estevo de Cesullas e de Santo Estevo de Soesto. Véxase o estudo neste volume realizado por Francisco Hernández. 
de (Víñez Sánchez 1994: 1165-1166). Versos en que destaca a raíña Beatriz de Suabia, xa fose como esposa ou como nai do rei, pero nos que se lexitima, sobre todo, o papel das raíñas como referencia feminina ante o reino, isto é, como exemplo para o resto das mulleres, a través da alusión mariana, que tamén se converte nunha característica da devoción rexia (Souto Cabo 2016).

\section{CONCLUSIÓNS}

Aínda que desapercibido en moitas ocasións, o papel das mulleres da familia real non pode desligarse da actuación dos seus homólogos masculinos, tampouco con relación ao máis noroccidental dos reinos peninsulares. O reino de Galicia, que desempeñara un papel de gran relevancia na monarquía leonesa altomedieval, continuaría a formar unha parte fundamental do espazo rexio tras a reunión de León e Castela baixo o mandato de Fernando III e de vital importancia para a estabilidade do conxunto territorial durante o reinado de Afonso X. Pola súa parte, as mulleres da familia real foron experimentando unha delimitación máis clara das súas funcións, sobresaíndo de forma máis contundente a consorte rexia, aínda que sen esquecer o papel que a maternidade lle confería tanto como apoio do goberno do seu fillo como, chegado o caso, baixo a institución da rexencia. O diálogo establecido cos diferentes ámbitos de poder tamén fixeron de Galicia, nun momento dado, un escenario adecuado ou necesario para os seus intereses. Ocorreu baixo a tenencia de Berenguela de Castela, baixo o señorío de diferentes prazas por parte das infantas dona Dulce e dona Sancha de León, como tamén ocorrería tempo despois coa fundación de Santa Clara de Allariz por parte de Violante de Aragón ou, xa no século XIV, da man do pulso mantido entre María de Molina e o arcebispo compostelán Berenguel de Landoira. A falta de centralidade non era, pois, un pretexto para desprezar o marco territorial galego, senón para manter o seu control desde a monarquía mediante os seus diferentes representantes ou, chegado o caso, encontrar un lugar de refuxio que, ao mesmo tempo, fose estratéxico.

Neste sentido, hai que ter en conta que a raíña podía desempeñar dous papeis, non necesariamente coincidentes: por unha banda, mostrarse como símbolo retórico da unidade da familia real e, en consecuencia, recurso da estabilidade e o bo goberno do reino, e, por outra banda, desenvolver a súa actividade individual, na que se xuntaban a súa autoridade institucional e os seus intereses persoais. É entón cando se aprecia a súa participación nas loitas de poder e a súa conexión con outros axentes políticos, tanto masculinos como femininos, e coas institucións relixiosas, que lles permiten forxar unha imaxe de piedade que transcende os límites da súa vivencia persoal. En definitiva, cando se manifestan algúns dos vínculos que formarían parte do seu marco relacional, sobre o que se sustentaba a súa capacidade de actuación e a súa inxerencia política. 


\section{REFERENCIAS BIBLIOGRÁFICAS}

- ARIAS Guillén, Fernando (2019): «Algun fecho señalado que sea a honra del rey: royal privileges and the construction of royal memory in Castile (c. 1158-1350)», Journal of Medieval Iberian Studies, 11:1, 40-58.

- ARIAS GUILLÉN, Fernando (2021): The triumph of an accursed lineage. Kingship in Castile from Alfonso X to Alfonso XI (1252-1350), Londres/Nova York, Routledge.

- ARIzaleta, Amaia (2010): Les clercs au palais. Chancellerie et écriture du pouvoir royal (Castille, 1157-1230), París, e-Spania ebooks.

- Beceiro Pita, Isabel (2009): «La parentela regia femenina en los relatos cronísticos alfonsíes y bajomedievales», en Maa Isabel del Val Valdivieso/Pascual Martínez Sopena (dirs.), Castilla y el mundo feudal. Homenaje al profesor Julio Valdeón, Valladolid, Junta de Castilla y León/Universidad de Valladolid, vol. II, 531-546.

- Barral Rivadulla, Dolores (1998): La Coruña en los siglos XIII al XV. Historia y configuración urbana de una villa de realengo en la Galicia medieval, A Coruña, Fundación Pedro Barrié de la Maza/CSIC. Instituto de Estudos Galegos Padre Sarmiento.

- BEEM, Charles/Miles TAYLOR (eds.) (2014): The male behind the Queen: Male consorts in History, Nova York, Palgrave Macmillan.

- Bianchini, Janna (2012): The Queen's Hand. Power and Authority in the Reign of Berenguela of Castile, Philadelphia, University of Pennsylvania Press.

- Carretero Zamora, Juan Manuel (2008): La averiguación de la Corona de Castilla, 1525-1540: los buenos vecinos pecheros y el dinero del Reino en época del emperador carlos V, Valladolid, Junta de Castilla y León, vol. 1.

- Cerda Costabal, José Manuel (2016): «Matrimonio y patrimonio. Las arras de Leonor Plantagenet, reina consorte de Castilla», Anuario de Estudios Medievales, 46:1, 63-96.

- Cerda Costabal, José Manuel/Félix Martínez Llorente (2019): «Un documento inédito y desconocido de la cancillería de la reina Leonor Plantagenet», En la España Medieval, 42, 59-91.

- Corral Díaz, Esther (1996): As mulleres nas cantigas medievais, Santiago de Compostela, Seminario de Estudos Galegos.

- Corral Díaz, Esther (2017): «A morte en feminino na lírica galego-portuguesa: o pranto por Beatriz de Suabia», Revista de Literatura Medieval, XXIX, 91-106.

- CORTES de los antiguos reinos de León y Castilla (1883), Madrid, Real Academia de la Historia, 1.

- Costa Gomes, Rita (1995): A corte dos reis de Portugal no final da Idade Média, Lisboa, DIFEL. 
- Doubleday, Simon R. (2015): The Wise King. A Christian Prince, Muslim Spain, and the Birth of the Renaissance, Nova York, Basic Books.

- EARenfight, Theresa (2005): «Partners in Politics», en Theresa Earenfight (ed.), Queenship in Political Power in Medieval and Early Modern Spain, Burlington, Asghate, XIII-XXVIII.

- EARENFight, Theresa (2014): Queenship in Medieval Europe, Nova York, Palgrave Macmillan.

- Ferreira Priegue, Elisa (1988): Galicia en el comercio marítimo medieval, A Coruña, Fundación Pedro Barrié de la Maza.

- Fuente PÉREz, Ma Jesús (2016): «Tres Violantes: las mujeres de una familia en el poder a lo largo del siglo XIII», Anuario de Estudios Medievales, 46:1, 137-165.

- Fuente PÉrez, Ma Jesús (2017): Violante de Aragón. Reina de Castilla, Madrid, Dykinson.

- GARCía-FERnÁNDEZ, Miguel (no prelo): «Nin santas, nin pecadoras; ou todo e máis. Da condición feminina ás voces e actuacións das mulleres na documentación medieval galega», Madrygal. Revista de Estudios Gallegos.

- García-Fernández, Miguel/Diana Pelaz Flores/Ricardo Pichel Gotérrez (2020): «Galicia e El-Rei ou como reinar desde a distancia: comunicación política arredor de dous novos privilexios rodados de Xoán II», Madrygal. Revista de Estudios Gallegos, 23, 139-180.

- GonZález Garcés, Miguel (1987): Historia de La Coruña: Edad Media, A Coruña, Caixa Galicia.

- González LóPEz, Emilio (1992): Historia de la ciudad de La Coruña: la Edad Antigua y la Media, A Coruña, Deputación Provincial.

- HeRnÁNDEZ, Francisco J. (2015): «La reina Violante de Aragón, Jofré de Loaysa y la Crónica de Alfonso X. Un gran fragmento cronístico del siglo XIII reutilizado en el XIV», Journal of Medieval Iberian Studies, 7:1, 87-111.

- HeRnándEZ, Francisco J. (2021): «La piel del leopardo: Galicia y el ordenamiento territorial alfonsí», en José Miguel Andrade Cernadas/Simon R. Doubleday (eds.), Galicia no tempo de Afonso X, Santiago de Compostela, Consello da Cultura Galega, 153-198, neste mesmo volume.

- Homen, Armando Luís de Carvalho (1987): «Um aragonés na corte portuguesa: Estêvão da Guarda (1299-1325)», en Actas das II Jornadas Luso-Espanholas de História Medieval, Porto, Centro da História da Universidade de Porto, vol. I, 195-200.

- KaTZ, Melissa R (2013): «The final testament of Violante de Aragón (c. 1236-1300/01): Agency and (dis)empowerment of a dowager queen», en Elena Woodacre (ed.), 
Queenship in the Mediterranean. Negotiating the Role of the Queen in the Medieval and Early Modern Eras, Nova York, Palgrave Macmillan, 51-71.

- Katz, Melissa R. (2015): «A Convent for La Sabia. Violante of Aragón and the Clarisas», en James D’Emilio (ed.), Culture and Society in medieval Galicia. A Cultural Crossroads at the edge of Europe, Leiden/Boston, Brill, 812-836.

- LAS PARTIDAS del rey don Alfonso X (1807), Madrid, Real Academia de la Historia, II.

- Martin, Georges (2007): «Negociación y diplomacia en la vida de Berenguela de Castilla (1214-1246). Cuestionamiento genérico», e-Spania, 4.

- Nogales Rincón, David (2006): «Las series iconográficas de la realeza castellano-leonesa (siglos XII-XV)», En la España Medieval, 29, 81-111.

- Pagani, Walter (1971): «Il Canzoniere di Estevan da Guarda», Studi Mediolatini e Volgari, XIX, 53-179.

- Olivera Serrano, César (2001): «Fortalezas y villas del rey: Notas sobre la frontera galaico-portuguesa en tierras orensanas a fines del siglo XIII», Cuadernos de Estudios Gallegos, XLVIII:114, 99-113.

- PARdo DE Guevara y VAldÉs, Eduardo (ed.) (2017): Mujeres con poder en la Galicia medieval (siglos XIII-XV). Estudios, biografías y documentos, Santiago de Compostela, CSIC. Instituto de Estudos Galegos Padre Sarmiento.

- Pelaz Flores, Diana (2017): Reinas consortes. Las reinas de Castilla en la Edad Media (siglos XI al XV), Madrid, Sílex.

- Pelaz Flores, Diana (2018): «Reynante(s) en vno. Fundamentación teórica del poder de la pareja regia en la Corona de Castilla durante la Baja Edad Media», Anuario de Estudios Medievales, 48:2, 845-869.

- Pelaz Flores, Diana (2020): «Casa, convento y palacio. La mujer en la sociedad de los siglos XI al XIII», en Féminas. El protagonismo de la mujer en los siglos del románico, Aguilar de Campoo, Fundación Santa María la Real, 15-39.

- PÉrez Rodríguez, Francisco Javier (2021): «Diplomatario galego de Afonso X», en José Miguel Andrade Cernadas/Simon R. Doubleday (eds.), Galicia no tempo de Afonso X, Santiago de Compostela, Consello da Cultura Galega, 43-152, neste mesmo volume.

- PICK, Lucy K. (2017): Her Father's Daughter: Gender, Power, and Religion in the Early Spanish Kingdoms, Nova York, Cornell University Press.

- Río RiAnde, Ma Gimena del (2009): «Trovadores de la corte dionisiana: poética nobiliaria y cancionero regio», en Olivia Rodríguez-González/Laura Mariño Sánchez (coords.), Novas achegas ao estudio da cultura galega: enfoques literarios e socio-históricos, A Coruña, Universidade, 41-55. 
- RodríGuez ENNES, Luis (2016): «Cinco privilegios monásticos confirmados por Alfonso IX de León y Galicia en tierras de Laxe (A Coruña) el 25 y 26 de julio de 1228», Revista de Estudios Histórico-Jurídicos, XXXVIII, 179-200.

- RodRíguez LóPEz, Ana (1994): La consolidación territorial de la monarquía feudal castellana. Expansión y fronteras durante el reinado de Fernando III, Madrid, Consejo Superior de Investigaciones Científicas.

- Rodríguez LóPEZ, Ana (2011): «La preciosa transmisión. Memoria y curia regia en Castilla en la primera mitad del siglo XIII», en Pascual Martínez Sopena/Ana Rodríguez López (eds.), La construcción medieval de la memoria regia, Valencia, Universitat de València, 293-322.

- RodRíGUEZ LóPEZ, Ana (2013): «Stratégies matrimoniales, stratégies patrimoniales: autor du pouvoir des femmes au royaume de León-Castille (XII ${ }^{e}$-XIII ${ }^{e}$ siècles)», en Martin Aurell (ed.), Les stratégies matrimoniales (IXe-XIII ${ }^{e}$ siècles), Turnhout, Brepols, 169-191.

- RodRíGUez LóPEZ, Ana (2014): La estirpe de Leonor de Aquitania. Mujeres y poder en los siglos XII y XIII, Barcelona, Crítica.

- Ruiz Domingo, Lledó (2017): «Del qual tenim loch. Leonor de Sicilia y el origen de la lugartenencia femenina en la Corona de Aragón», Medievalismo, 27, 303-326.

- Salazar y Acha, Jaime (2000): La casa del rey de Castilla y León en la Edad Media, Madrid, Centro de Estudios Políticos y Constitucionales.

- SÁnchez Chouza, José Manuel (2005): A Coruña en la Baja Edad Media, A Coruña, Ediciós do Castro/CSIC. Instituto de Estudos Galegos Padre Sarmiento.

- SÁNCHEZ DE Mora, Antonio (2007): «Doña Juana de Ponthieu, reina de Castilla y señora de Marchena», en Juan Luis Carriazo Rubio/Ramón Ramos Alfonso (eds.), Actas de las XI Jornadas sobre Historia de Marchena: La mujer en la Historia de Marchena, Marchena: del 4 al 7 de octubre de 2005, Marchena, Ayuntamiento de Marchena, 11-24.

- SenRa Gabriel y Galán, José Luis (2002): «Ben per está aos reis d'amaren Santa María: La capilla de Nuestra Señora en el Monasterio de San Salvador de Oña: una iniciativa de Sancho IV el Bravo (1285) en el marco de un panteón funerario», en Maㅡ Dolores Barral Rivadulla/José Manuel Bernardi López Vázquez (eds.), Estudios sobre patrimonio artístico: homenaje del Departamento de Historia del Arte y de la Facultad de Geografía e Historia de la Universidad de Santiago de Compostela a la Prof. Dra. Ma del Socorro Ortega Romero, Santiago de Compostela, Xunta de Galicia, 141-164.

- SHADIS, Miriam (2009): Berenguela of Castile (1180-1246) and Political Women in the High Middle Ages, Nova York, Palgrave Macmillan. 
- Souto CaBo, José Antonio (2016): «En cas da Ifante: figuras femininas no patrocínnio da lírica galego-portuguesa (I)», en Esther Corral Díaz/Elvira Fidalgo Francisco/ Pilar Lorenzo Gradín (eds.), Cantares de amigos: estudos en homenaxe a Mercedes Brea, Santiago de Compostela, Universidade, 857-870.

- VAQUeRo DíAz, Ma Beatriz (2021): «Santa Clara de Allariz, historia dunha fundación real (ss. XIII-XV)», en José Miguel Andrade Cernadas/Simon R. Doubleday (eds.), Galicia no tempo de Afonso X, Santiago de Compostela, Consello da Cultura Galega, 275-297, neste mesmo volume.

- VÍÑEZ SÁNCHEZ, Antonia (1994): «Súplica y réplica: el infante don Enrique en la lírica gallego-portuguesa», en Ma Isabel Toro Pascua (ed.), Actas del III Congreso de la Asociación Hispánica de Literatura Medieval (Salamanca, 3 al 6 de octubre de 1989), Salamanca, Universidad de Salamanca, tomo II, 1161-1170. 



\title{
Cara e cruz: conflito político, territorio e padroado rexio en Galicia durante o reinado de Afonso $X$ e Violante de Aragón*
}

\author{
Rosa M. Rodríguez Porto \\ Universidade de Santiago de Compostela
}

DOI: $10.17075 /$ gtax.2021.006 
* Parte das ideas presentadas neste traballo foron formuladas orixinalmente en Historia e culto das raínas santas da Casa de Hungría nos reinos occidentais da Península (Ss. XIII e XIV). Memoria inédita da Bolsa de Investigación da Deputación da Coruña (2011). Agradézolle a Ricardo Pichel a súa xenerosa axuda, comentarios e suxestións. 


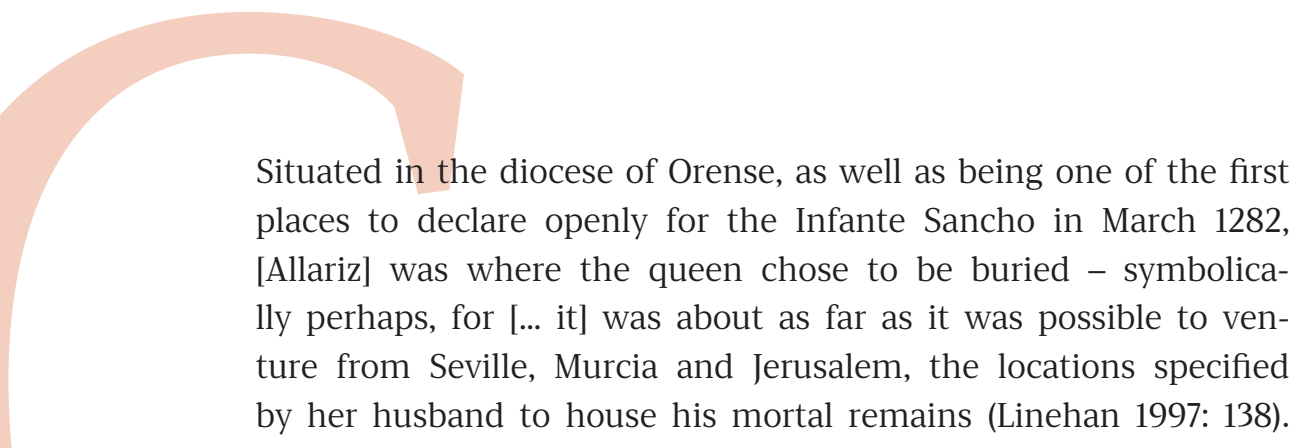

Coa súa ironía habitual, Peter Linehan referíase así á decisión da raíña Violante de ser soterrada no convento de Santa Clara de Allariz, que ela mesma fundara no ano en que o infante Sancho se rebelou contra seu pai, facendo voar os vimbios que mantiñan unida a familia real e o propio reino dende a morte do herdeiro Fernando de la Cerda. Como ben sinalaba o historiador británico, rei e raíña non podían terse afastado máis na altura da súa morte, facendo patente na súa distancia no só a ruptura conxugal mais tamén a diferenza entre as súas posturas ante un presente incerto. Porén, as diverxentes actitudes de Afonso e Violante cara a Galicia poderían revelar ademais unha concepción distinta do papel que este territorio habería de xogar no taboleiro político ibérico a finais do século XIII, máis importante do que o seu suposto carácter periférico permitiría adiviñar. Neste senso, un exame pausado do rexistro documental e do intricado relato histórico destas décadas convulsas permitirá recoñecer trazas destas visións irreconciliables xa con anterioridade, contextualizar mellor a fundación allaricense, así como outros xestos de favor que a raíña mostrou cara ao antigo reino galego, ademais dos intentos da nobreza e da Igrexa locais por suscitar o apoio da soberana fronte á indiferenza -se non aberta hostilidade- do Rei Sabio.

\section{AFONSO X E O CABIDO COMPOSTELÁN: CRÓNICA VISUAL DUN DESACORDO}

Unha das imaxes máis coñecidas do Rei Sabio é a que se encontra no Tombo A compostelán (Arquivo da Catedral de Santiago, CF 34, fol. 71r; Fig. 1), reproducida en infinidade de ocasións en toda clase de obras e materiais relativos ao seu reinado. Aparece alí efixiado a cabalo e armado coa lanza, unha representación que ten a súa inspiración -de igual modo que as dos reis de León, Fernando II (fol. 44v) e Afonso IX (fol. 62v)- na sixilografía, como sinalou Rocío Sánchez Ameijeiras (2008: 213). De facto, é moi probable que o modelo inmediato desta ilustración fose o selo pendente 


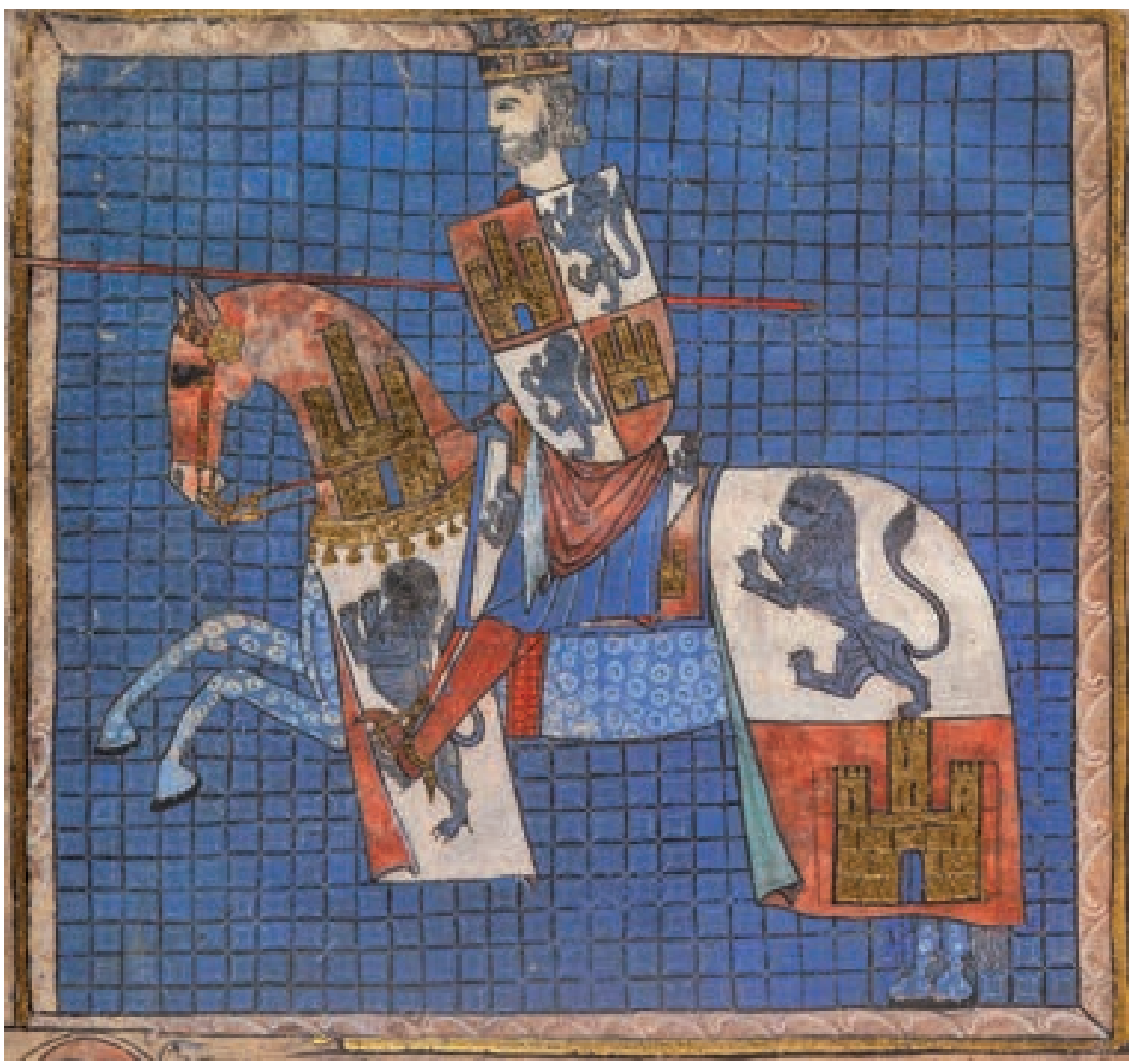

Fig. 1: Afonso X. Tumbo A (Arquivo da Catedral de Santiago de Compostela, CF 34, fol. 71r).

do documento orixinal copiado xusto a continuación da imaxe, o único correspondente a Afonso X en todo o códice. Trátase dun privilexio polo cal o Rei Sabio outorga ao arcebispo Xoán Arias († 1266) e aos seus sucesores a vila e alfoz de Xallas, datado o 4 de novembro de 1255 en Burgos ${ }^{1}$. A pesar das obvias limitacións do miniaturista, o uso de ouro e a multiplicación dos cuarteis de Castela e León no escudo e na montura confiren certa solemnidade á imaxe. Aínda así, as efixies do rei e de seu pai Fernando III non poden compararse coas que ornaban os folios precedentes desta colección documental, testemuñando que os tempos de gloria de Compostela xa pasaran, tras a unificación dos reinos e o subseguinte desprazamento da basílica xacobea como centro cerimonial e panteón rexio. Non obstante, é probable que o ambicioso prelado compostelán pensase que non todo estaba perdido e que pagaba a pena actualizar a

1 Véxase o doc. 75 do diplomatario recompilado por Francisco Javier Pérez neste volume. 
galería rexia do Tombo A coa incorporación do Rei Sabio e seu pai, co fin de suscitar no novo soberano o desexo de emular aos seus predecesores.

Aínda que é preciso encadrar esta intervención en datas moi próximas á da emisión do documento orixinal, quizais contra 1256, xa antes -na altura de 1238, momento do seu ascenso á dignidade arcebispal- Xoán Arias decidira engadir ao códice toda unha serie de confirmacións e concesións de Fernando III á sé (fols. 67r-69v). Este feito dá unha idea do carácter inaugural e programático da empresa, acorde coa súa vontade de devolver á catedral compostelá a preeminencia de época xelmiriana. A esta iniciativa seguirían outras, que mostran as inquedanzas e recursos do que Linehan (1971: 265) consideraba «one of the greatest ecclesiastical pirates of thirteenth-century Spain»: a construción dun gran pazo arcebispal -mal chamado «de Xelmírez»- e un claustro que servirá de modelo ás outras catedrais galegas, incluíndo a fundación dunha Capela dos Arcebispos destinada ao enterramento dos prelados de Santiago, así como o frustrado proxecto de renovación da cabeceira catedralicia consonte o novo gusto gótico, seguindo o exemplo da sé leonesa². Que a primeira ampliación do Tombo A só fose decorada con iniciais iluminadas mentres que para a segunda se decidise engadir dúas ilustracións, ocupando cada unha máis de medio folio, deixa ver que o arcebispo tiña postas grandes esperanzas no novo monarca. A este respecto, o coidado en acomodar as efixies de Fernando III e Afonso X ás dos reis precedentes -o primeiro sedente como no caso das imagines de época xelmiriana, o segundo a cabalo coma Fernando II e Afonso IX- tería contribuído a xerar unha percepción de continuidade institucional e de favor rexio ininterrompido dende a inventio dos restos do Apóstolo Santiago. Chama a atención, neste senso, que se substituíse a espada presente nos selos contemporáneos afonsinos por unha lanza que resultaría anacrónica naquela altura, pero que asimilaba figurativamente o Rei Sabio cos reis de León que tanto enxalzaran a sé compostelá. Igualmente significativo é que o documento recolla unha doazón ao arcebispo e aos seus sucesores, especificando que a concesión é «por muchos servicios buenos e grandes que [Juan Arias] me fizo, [...] e porque fallé siempre en él lealtat e uerdat» (Lucas Álvarez 1998: 316-319, doc. 165).

Se a idea de representar o monarca como cabaleiro ben podería deberse ao desexo de afagar un rei que dificilmente podía competir coas fazañas reconquistadoras de seu pai, e a selección do documento tiña a clara intención de recalcar a proximidade entre rei e arcebispo, ningunha das dúas estratexias deu froito á hora de espertar o favor do rei. O propio manuscrito fai visible este fracaso, xa que non se engadirían máis mercés rexias a esta colección. O Tombo A péchase simbolicamente, como lembra Sánchez Ameijeiras (2008: 214), coa copia do signo rodado que iluminaría o privilexio orixinal aquí trasladado (fol. 71r), involuntario recoñecemento de que o Rei Sabio sempre sería unha figura ausente, cuxa vontade só

2 Sobre o proxecto de cabeceira gótica, véxase Puente Míguez (1999). Carrero Santamaría (2014) ten cuestionado ou relativizado o rol de Xoán Arias nalgunhas destas empresas, excepto no relativo ao claustro. 
se faría sentir en Compostela a través da produción da súa chancelaría. O desenlace desta historia é ben coñecido. Os desacordos entre Xoán Arias e o rei por mor da súa arbitraxe no preito que enfrontaba o cabido cos burgueses de Santiago deixaron paso ao enfrontamento aberto (Linehan 1971: 265). O monarca quixo sacar partido da situación de caos xerada tras a morte do prelado interferindo na elección do seu sucesor, o que non foi aceptado polos cóengos composteláns. Nin tan sequera a designación papal de Gonzalo Gómez (1273-1289) puido reconducir o conflito, máis ben todo o contrario, dado vez que o novo arcebispo foi expulsado polo rei, quen privou ademais aos prelados composteláns do dominio sobre a cidade 3 .

Como aventura Joseph F. O’Callaghan (1998: 190-191, 216-217), é posible que un eco desta disputa se perciba nas Cantigas de Santa María, nas que Afonso se intitula «Rei de Castela e de Santiago de Compostela» (c. 367), nunha rima que podería ser non tan arbitraria como parece. É precisamente no terreo das imaxes onde a política anti-compostelá do Rei Sabio se fai explícita, aínda que non é doado determinar se esta estratexia trataba de reconducir o fervor popular cara aos santuarios marianos baixo a protección especial do soberano, polo menos na realidade virtual do manuscrito ${ }^{4}$. Algúns deles, como os de Santa María del Puerto ou a Arrixaca de Murcia, estaban en conexión directa coa política rexia de consolidación e repoboación da fronteira, e outro tanto pode dicirse da elección da advocación de Santa María de España para a súa nova orde militar, destinada á expansión marítima do outro lado do Estreito de Xibraltar (Torres Fontes 1976). No entanto, por forza, habería tamén razóns máis persoais. Da predilección do rei pola Virxe de Villalcázar de Sirga -«logar muy maravilloso» (c. 253)- é mostra a dedicación de catorce cantigas, varias das cales escenifican esta rivalidade coa sede xacobea presentando ao apóstolo baixo unha luz negativa. Foi John E. Keller (1987) quen puxo de relevo este fenómeno, sobre o que teñen insistido outros autores ${ }^{5}$. En todos os exemplos destacados, os protagonistas son peregrinos a Compostela de paso polo santuario palentino, onde son testemuñas dos moi superiores poderes de intercesión da Virxe. É o caso da cantiga 218 -que non chegou a ilustrarse-, na que se narra como un romeiro alemán busca en balde a axuda de Santiago para curar a súa parálise ata que, despois de varias penalidades, é abandonado á porta da igrexa de Villasirga. O contraste non pode ser máis extremo: mentres que o protagonista non só non recuperara a súa mobilidade perante o altar de Santiago senón que perdera a vista tamén, agora, pola contra, a Virxe liberarao de todos os seus males. Por se esta comparación non fose elocuente dabondo, na cantiga 278 (Florencia, BNC, Banco Rari 20, fol. 96r; Fig. 2) o rei trobador exhorta

3 Para unha revisión en profundidade do conflito entre monarca e cabido, resultado da política afonsina de contención dos dominios eclesiásticos, remito ao artigo de Francisco J. Hernández neste mesmo volume.

4 Fronte á temperá protección aos peregrinos que testemuña o doc. 20 do diplomatario galego e a mención de Santiago -«que es nuestro sennor e nuestro defensor e nuestro padre»- no seu testamento (cf. González Jiménez 1991: 549).

5 Véxanse tamén Procter (1951: 29) e Fernández Fernández (2008). 


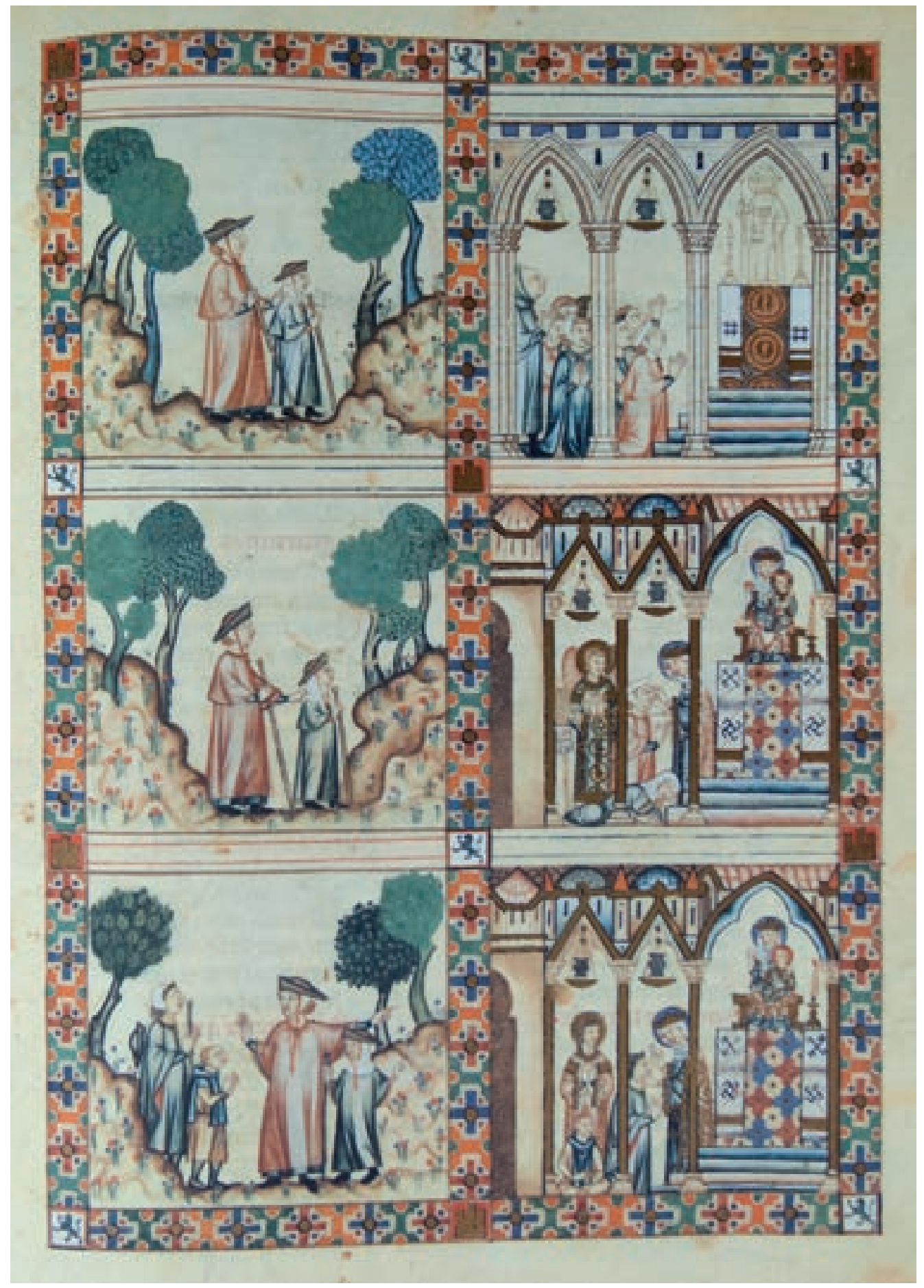

Fig. 2: Afonso X, Cantigas de Santa María. Cantiga 278 (Florencia, Biblioteca Nazionale Centrale, Banco Rari 20, fol. 96r). 
os seus lectores -na voz da súa protagonista- a non visitar a basílica xacobea, xa que só no santuario palentino as súas oracións serán escoitadas: «[...] un ome cego achou / que a Santiago ya; mais ella ll' aconssellou / que fosse por Villa-sirga / se quisesse lum’ aver» (Mettmann 1986: III, 51). Este diálogo aparece representado nas dúas viñetas inferiores da ilustración correspondente, nas que a peregrina -agora recuperada a vista, a diferenza das viñetas superiores- fai acenos a outro romeiro cego que se dirixe a Compostela acompañado do seu guía.

O seu xesto leva a nosa mirada cara á viñeta contigua, onde asistimos á milagrosa curación do peregrino, cuxos ollos volven ter luz pola intervención da Virxe, á vez estatua sobre o altar do santuario e imaxe presente corporalmente. As cores vivas e a duplicación da imaxe mariana parecen expresión do seu poder sobrenatural, ante o cal a estatua monocroma do apóstolo, representado na mesma posición dúas escenas máis arriba, palidece literal e metaforicamente (Fernández Fernández 2008: 89). Máis extraordinario aínda é que se lle atribúa un coñecido milagre xacobeo á Nai de Deus. É o caso da cantiga 175 (Escorial, T.I.1, fols. 231v-232r), na que toda mención á intervención sobrenatural do apóstolo en favor dun mozo inxustamente aforcado en Toulouse cando ía en peregrinación a Santiago é obviada, aparecendo a Virxe como autora do milagre. Elaboración máis temperá desta historia remonta ao Liber Sancti Iacobi e da súa difusión europea é testemuño a súa recompilación no Speculum Historiale de Vicent de Beauvais e, pouco máis tarde, na Lenda Áurea de Jacopo da Varazze, obra case contemporánea do marial rexio (Keller 1987: 72-73). De acordo co relato afonsino, que segue no substancial a tradición xacobea, sería a Virxe a que mantería milagrosamente con vida o romeiro mentres penduraba da forca durante meses, tempo empregado polo seu pai en chegar a Compostela -peregrinación infrutuosa unha vez máis- e volta a Toulouse para recuperar o seu cadáver. Estes exemplos entran en contradición coa visión máis conciliadora presentada por Anthony Cárdenas (2009: 26), para quen as políticas piadosas de Afonso X serían «all inclusive». Porén, á hora de avaliar a relevancia desta polémica en imaxes é preciso abordar o problema creado pola limitadísima recepción do gran marial rexio na vida do Rei Sabio fóra do máis estrito círculo cortesán (cf. Ferreira 2016). Se no caso do Tombo A, o presunto destinatario nunca chegou a ver a súa rexia efixie, é pouco probable que a mensaxe anti-xacobea das Cantigas chegase aos ouvidos do arcebispo don Gonzalo -exiliado na curia- ou á propia Compostela. Dalgún modo, o seu foi un diálogo frustrado e, en último termo, imposible. Neste senso, e dende a perspectiva das artes visuais, a inexistencia de máis obras vencelladas ao monarca en territorio galego ou cunha conexión galega de entre as súas empresas culturais é o máis claro sinal de que o seu mundo e intereses estaban noutro lugar..., certamente en Sevilla, Murcia e Xerusalén, pero tamén as terras do Imperio e o alén do Estreito. 


\section{LIBROS E DOCUMENTOS PARA UNHA RAÍNAA: DOUS TOMBOS COMPOSTELÁNS A CONTRALUZ DA POLÍTICA CASTELÁ-LEONESA}

Fronte a un rei que nunca chegou a visitar a basílica xacobea, pequenos indicios aquí e alá permiten argumentar que Violante ben puido terse desprazado a Santiago ou, polo menos, ser percibida polos seus coetáneos como unha figura máis achegada á Igrexa compostelá, xeográfica e politicamente. Xa no seu estudo do Tombo A, Rocío Sánchez suxería que o fracaso desta empresa puido supor a confección doutro códice de luxo en datas próximas, o chamado Tombo Colorado, do que só se conserva unha copia tardía (Sevilla, Biblioteca Capitular, ms. 82-1-13), dada a coñecer no seu día por José María Fernández Catón (1990). A xulgar por este testemuño, a nova obra debeu de ofrecer unha versión da vella colección documental actualizada aos novos modos e repertorios formais da época, mais con dúas modificacións significativas. Por unha parte, os materiais orixinarios serían reorganizados comezando agora a partir dos documentos relativos a Raimundo de Borgoña e á raíña Urraca (1109-1126), á infanta Urraca e á súa irmá Elvira. Esta escolla revelaría que quen estivese ao cargo «comprendía todavía la estructura de la doble genealogía que gobernaba la ordenación de la primera parte del Tumbo A», unha dupla xenealoxía institucional -doazóns rexias e do Infantado- que confluían precisamente na raíña Urraca, infanta e logo raíña de León e Castela (Sánchez Ameijeiras 2009a: 67). Por outro lado -e este detalle é máis relevante aínda para o que aquí se trata-, todas as infantas e raíñas serían representadas con coroas no Tombo Colorado, a diferenza do que sucedía no seu referente, onde só Urraca merecía este tratamento. Máis que un problema de comprensión das realidades do Infantado, daquela xa desaparecido, este ascenso das mulleres rexias en termos simbólicos podería deberse, en opinión de Sánchez Ameijeiras (2008: 216), ao desexo de «invocar unos ojos femeninos como posibles espectadores privilegiados del nuevo códice: los de la entonces reina de Castilla Violante de Aragón».

Pouco se sabe acerca do padroádego exercido pola raíña Violante, para alén da fundación clarisa de Allariz e do seu apoio á Orde Franciscana, aínda que varios aspectos poderían apuntalar esta suxestiva hipótese. En primeiro lugar, parece moi probable que ela fose a comitente do Officiumet Vita S. Elisabeth Landgraviae Thuringiae (Paris, Bibliothèque nationale de France, N.A.L. 868), como argumentei noutro lugar ${ }^{6}$. Ora ben, a esta obra haxiográfica dedicada a honrar a memoria de Santa Isabel de Hungría, medio irmá da súa nai, e destinada probablemente á capela baixo a advocación da santa na catedral de Sevilla, poderían engadirse outros manuscritos. Dispersos no rexistro documental destas décadas atopamos dous textos que permi-

6 Remito a Rodríguez Porto (2012: II, 7-39). Cf. Avril (1983: 82, n.o 94, ils. XLVIII, CVIII e F); Joneitis/ Blume (2007) e Joneitis (2008). 
ten afirmar a familiaridade da raíña co mundo dos libros, á parte das grandes obras auspiciadas polo seu home. O primeiro deles é unha carta datada en 1272 e destinada ao freire Diego de Rois, na que se lle reclama en nome do seu irmán Sancho, arcebispo de Toledo, a devolución dos libros que pertenceran a don Lope, bispo de Sigüenza. Ao ver que o franciscano rexeitaba a entrega dicindo que as obras eran en realidade un depósito da raíña Mencía († 1270), viúva de Sancho II de Portugal, Violante responderíalle con retranca: «fray Diego, bien sabedes que tales libros como aquellos non serien de la Reyna» (Rubio García 1985: 550). A soberana tiña claro, xa que logo, cales eran os libros que conviñan a unha raíña e cales non formarían parte da súa biblioteca; neste caso, libros de natureza teolóxica e xurídica. Con todo, iso non significa que Violante non soubese manexarse no complexo mundo da lexislación castelá e leonesa. Proba diso é que, segundo se le nun rexistro dos libros pertencentes no seu día ao Marqués de Montealegre (1677), a raíña tería entregado aos veciños de Talavera unha copia ilustrada do Fuero Juzgo con «Retratos de todos los reyes Godos de España» (Rodríguez Moniño 1950: 457).

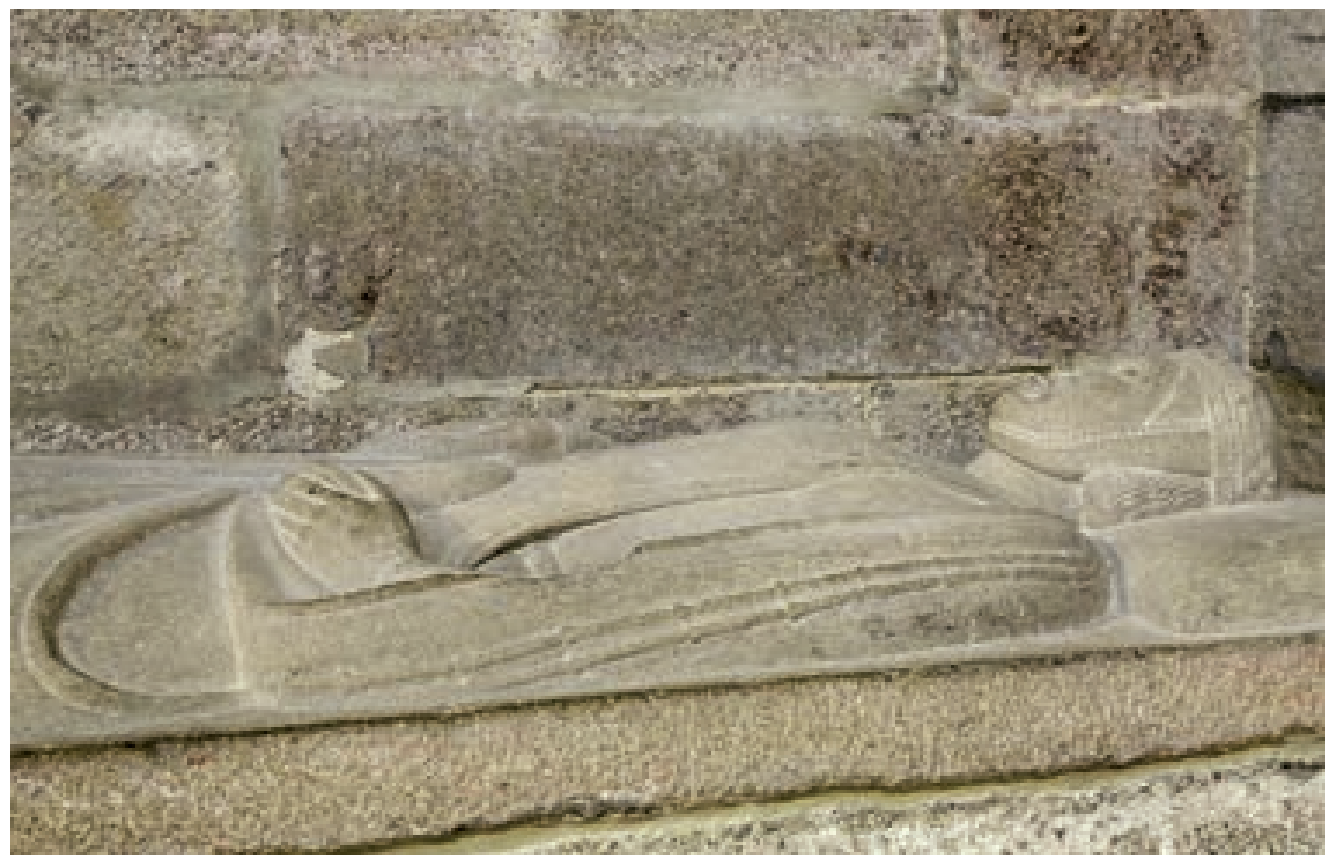

Fig. 3: Tumba da raíña Berenguela de Aragón (†1147). Catedral de Santiago de Compostela. 
Sánchez Ameijeiras sitúa a copia e ilustración do novo cartulario entre 1253, data da derradeira concesión copiada a partir do modelo, e 1263, ano do último documento copiado. Tamén contra a década de 1260 debeu de procederse á renovación do panteón rexio compostelán, coa labra dunha efixie xacente (Fig. 3) para a raíña Berenguela († 1149), muller de Afonso VII e filla de Ramón Berenguer III. A innegable oportunidade desta iniciativa, ao coincidir coa chegada ao trono castelán dunha segunda raíña do veciño Aragón, parece apuntar na mesma dirección. Tanto esforzo por parte de Xoán Arias e do cabido compostelán, nos mesmos anos en que o Rei Sabio non acababa de poñerse do lado da Igrexa de Santiago no seu preito cos burgueses da cidade, invita a pensar que, efectivamente, se estaba a procurar o amparo de Violante. Esta posibilidade encaixaría coa información fornecida por certos cronistas franciscanos do século XviII, que atribúen a fundación do convento de Santa Clara de Santiago polas mesmas datas á mesma soberana. Se ben esta afirmación foi desmentida de modo categórico por José García Oro (1988: 121-123), podería conter algo de verdade. Aínda que a fragmentaria documentación conservada non permite confirmar que a raíña visitase Compostela, o certo é que Violante viaxou polo reino de León entre o outono de 1264 e o inverno de 1265, ao ser nomeada polo seu home lugartenente deste territorio, precisamente para arbitrar certos conflitos locais nos que colidían -como en Compostela- a xurisdición municipal, eclesiástica e rexia ${ }^{7}$ Tamén en 1264, a raíña despregaba toda a súa capacidade mediadora na resolución doutro conflito legal, atendendo ás queixas presentadas polos concellos de Estremadura a propósito da aplicación do Fuero Real afonsino no lugar do tradicional Fuero Juzgo. E, de modo aínda máis visible, contribuía a afogar a revolta dos mudéxares en Murcia ao conseguir que seu pai Jaume I e Afonso X resolvesen as súas diferenzas, garantindo o indispensable apoio aragonés que o seu home precisaba (Fuente Pérez 2017: 135-136; González Jiménez 2004: 158-161, 176-181). A estratexia compostelá de procurar a axuda da raíña non ía desencamiñada e contaba con alentadores precedentes.

Pola contra, a concesión en 1294 do vello código visigodo aos habitantes da súa vila de Talavera, á que me referín antes, sitúanos nun contexto político diametralmente oposto, unha vez desencadeado o preito sucesorio, un ambiente en que se encadraría tamén a confección doutro códice compostelán que podería ter como destinataria implícita a Violante. Trátase do Tombo de Toxos Outos (Madrid, Archivo Histórico Nacional, códices L. 1002-B), copiado e ilustrado cara a 1289 a instancias do abade Sancho Eanes ${ }^{8}$. Como é sabido, o mosteiro de San Xusto de Toxos Outos dependía da Igrexa de Santiago dende a súa fundación como eremitorio polos nobres Froila Afonso e Pedro Muñiz, autorizada polo arcebispo Xelmírez. A influencia do modelo catedralicio é patente na decisión de incluír imaxes dos reis e raíñas

7 Debo esta información á xenerosidade de Francisco J. Hernández, cuxo futuro traballo sobre Violante botará luz, sen dúbidas, sobre os aspectos da biografía da raíña que permanecen aínda na escuridade.

8 Unha nota moderna escrita no volto do primeiro folio de garda antigo indica: «Scribere fecit domnus Sancius, abbas Sancti Iusti, era M CCC XXVII, quinto kalendas maarci» (Pérez Rodríguez 2004: 19). 


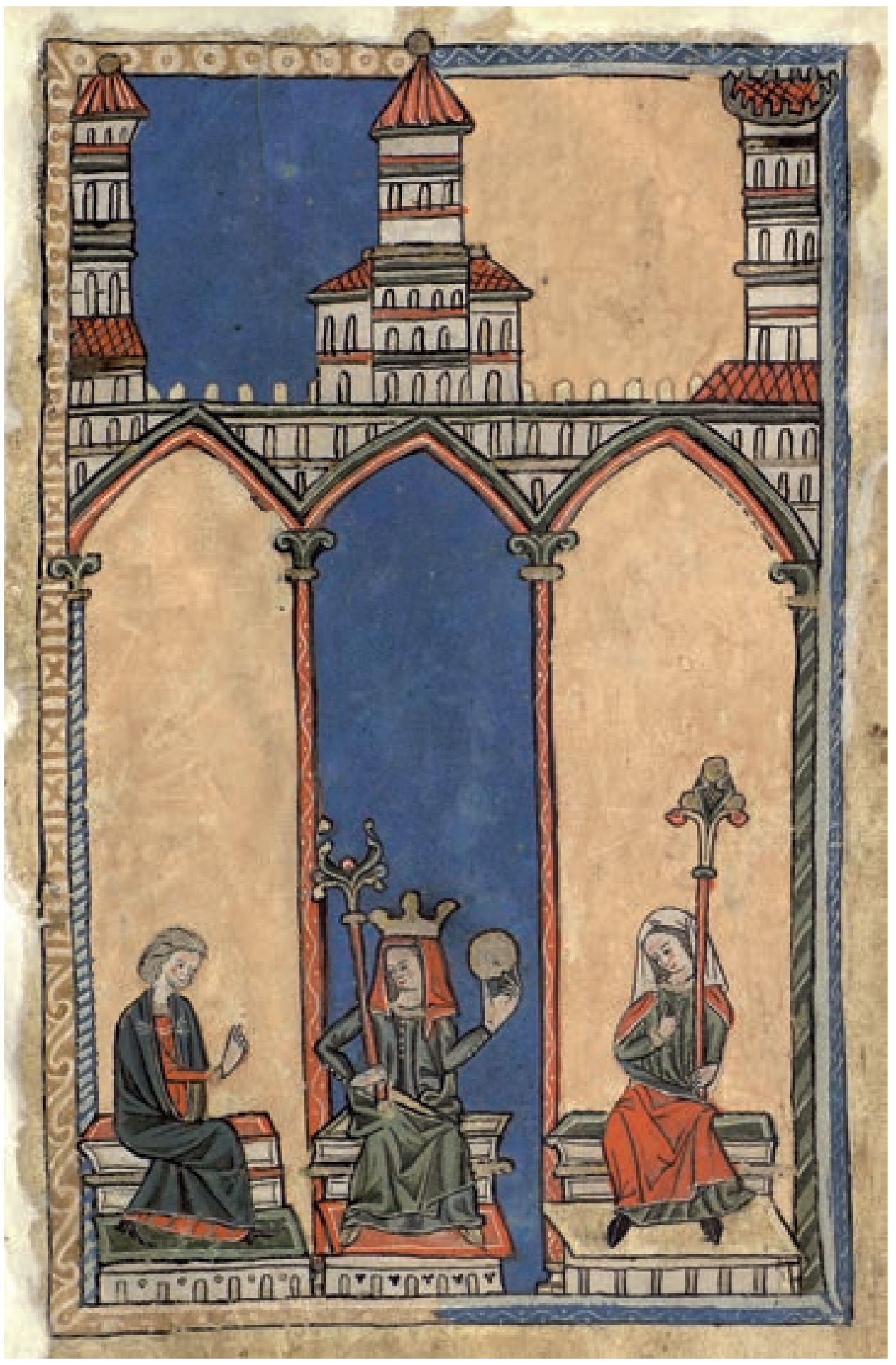

Fig. 4: Dona Teresa de Portugal, acompañada da súa filla Urraca Enríquez e o home desta, Vermudo Pérez de Traba. Tumbo de Toxos Outos (Madrid, Archivo Histórico Nacional, códices L. 1002-B, fol. 6v). 


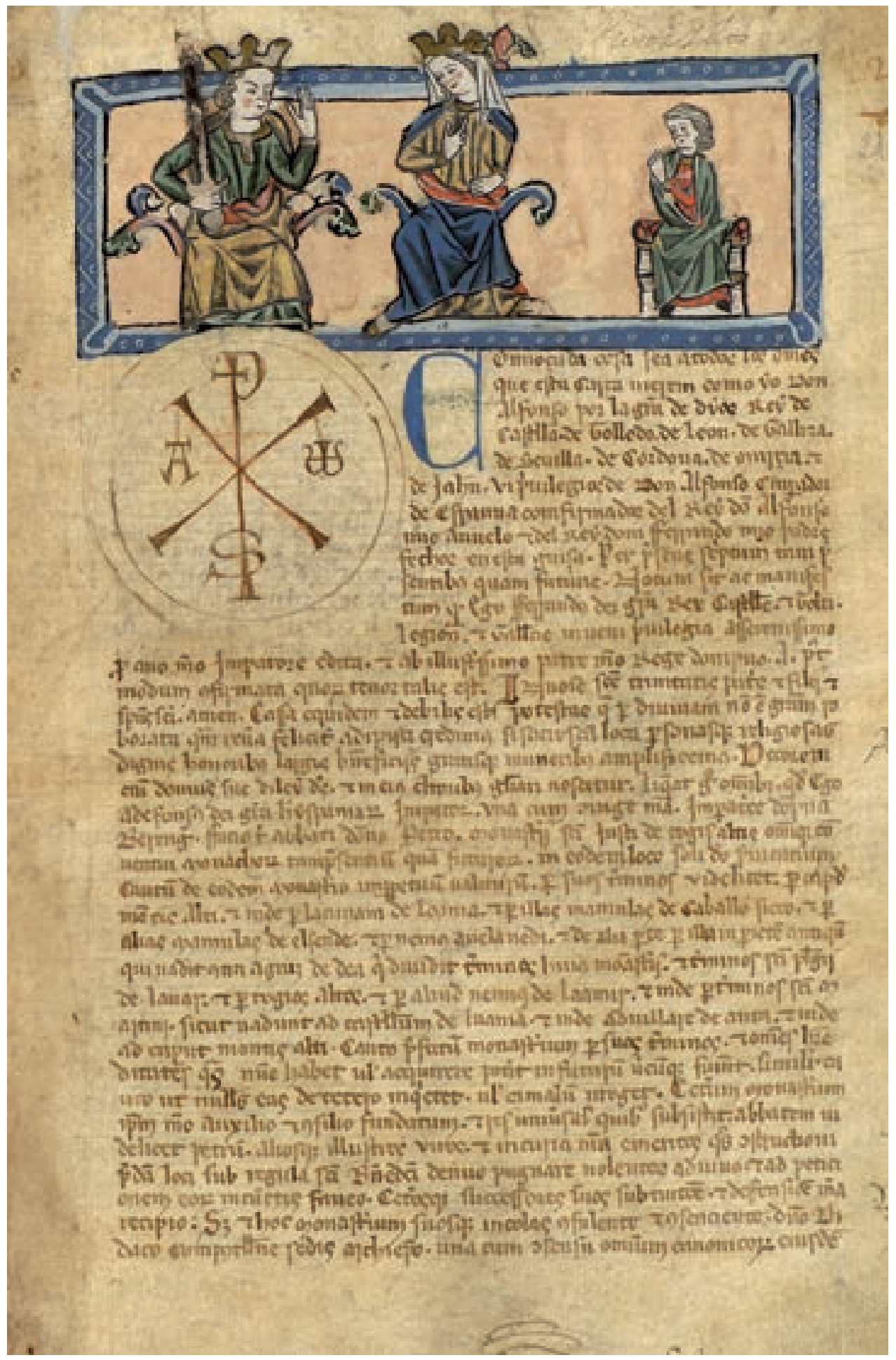

Fig. 5: Afonso X, Violante de Aragón e Fernando da Cerda. Tumbo de Toxos Outos (Madrid, Archivo Histórico Nacional, códices L. 1002-B, fol. 21r). 
mencionados na documentación nel compilada. Ao igual que no Tombo A e o Tombo Colorado, as raíñas ocupan nesta obra un lugar privilexiado, xa que aparecen en catro das sete ilustracións que se inclúen no manuscrito. Así, dona Teresa, futura raíña de Portugal, é efixiada acompañada da súa filla Urraca Enríquez e do home dela, Vemudo Pérez de Traba (fol. 6v; Fig. 4), Urraca de Portugal figura xunto a Fernando II (fol. 9v), e o mesmo Berenguela de Castela xunto a Afonso IX (fol. 26r). A propia Violante comparece acompañando Afonso X e o seu fillo Fernando de la Cerda (fol. 21r; Fig. 5), representado como o neno que era no momento en que se emitiu o documento. Esta disposición traduce visualmente as fórmulas de outorgamento dos documentos copiados a continuación, das que só transcribirei aquí a correspondente á miniatura en que aparecen os nosos protagonistas: «Et yo, sobredicho rey don Alfonso, regnante en uno cun la reyna donna Yolant, mi mugier, te cum myo fijo don Fernando en Castella et en Toledo, en Leon, en Galliza, en Seuilla, en Cordoua, en Murcia, en Jahen, en Baeza, en Badalloz et en el Algarue, otorgo este priuilegio et confirmolo». Emporiso, a rareza da representación de rei e raíña xuntos -os paralelos son contados- podería ser indicativa, quizais, de que o rol feminino ía máis aló da simple confirmación da vontade dos seus esposos, ou que así o percibían os que deseñaron as ilustracións do Tombo de Toxos Outos 9 .

Neste senso, convén lembrar que se trata dun ciclo pictórico selectivo, pois coa excepción da primeira miniatura dedicada aos fundadores do cenobio e ao arcebispo Xelmírez (fol. 1r), só se ilustran documentos reais, que constitúen unha minoría en comparación coas doazóns e concesións realizadas pola nobreza local. É máis, nin sequera foron efixiados todos os monarcas que aparecen no tombo como protectores do mosteiro, constatándose a paradoxal ausencia de Afonso VII, talvez o soberano máis estreitamente vencellado a Toxos Outos. En cambio, represéntase a dona Teresa (Fig. 4) en tanto que sogra de Vermudo Pérez de Traba, que é quen outorga o documento. Como xa advertira Ghislaine Fournés (2008: §19), a condesa ocupa o lugar central da composición e aparece coroada, portando cetro e orbe, se ben non era raíña de Portugal naquela altura. O Conde de Traba, pola contra, queda desprazado cara á esquerda, desprovisto de calquera insignia de poder. Non é esta a única instancia en que as raíñas mostran un status similar ou mesmo superior ao dos seus consortes e familiares. Dáse a circunstancia, por exemplo, de que o trono en que se asenta a raíña Urraca é máis grande e máis alto que o do seu home Fernando II, un detalle que non puido ser froito do azar. Outro tanto sucede coa efixie da raíña dona Berenguela, quen, ao dispor o seu trono sobre un estrado, consegue impor a súa presenza sobre a do seu esposo Afonso IX.

9 Só dous exemplos, coetáneos, veñen á mente: a representación de Sancha de Castilla xunto a Afonso II de Aragón no Liber Feudorum Maior (Barcelona, ACA, Cancillería, Registros, n.o 1, fol. 93r; 1192) e a de Leonor de Inglaterra con Afonso VIII no Tumbo Menor de Castilla facendo doazón da vila de Uclés á Orde de Santiago (Madrid, AHN, cód. 1046-B, fol. 15r). 
A ilustración correspondente a Afonso X e Violante (Fig. 5) sería aínda máis sutil na súa redefinición do papel da raíña en relación co rei. El porta unha espada, ela un cetro, emblemas ambos das súas respectivas xurisdicións, é dicir, do poder para facer e facer cumprir a lei. Ao seu carón, represéntase o herdeiro, no que se fundirían as súas liñaxes (Prado Vilar 2009: 220, n. 67). Violante comparece, xa que logo, en calidade de raíña, esposa e nai, e o seu propio xesto, chamando a atención sobre a súa persoa, parece destinado a lembrarlles tanto ao seu home coma ao espectador o seu papel na xestación do herdeiro e a perpetuación da dinastía castelá-leonesa.

Se no Tombo Colorado crin ver a pegada da presenza de Violante en León contra 1264, a data máis tardía do Tombo de Toxos Outos déixanos en terreo máis sólido, posto que para entón a súa actividade -potencial ou real- en Galicia vén referendada polo rexistro documental. En 1289 o convento de Santa Clara de Allariz era xa, como veremos, unha realidade institucional, polo menos no papel, xa que se procedera á compra dos terreos onde se levantaría a súa fábrica, e Sancho IV aprobara a súa xurisdición (García Barriuso 1990: 18-19). No ano de 1286, cando se concedían estas mercés a Allariz, o rei estaba en Galicia, pero resulta moi pouco probable que a produción do cartulario noiés se concibise para preservar a memoria desta visita e estimular o favor do Bravo. O prominente lugar acordado ás soberanas e, en particular, o xesto desafiante de Violante non encaixan ben con este escenario, tampouco que ningún dos documentos copiados corresponda ao seu reinado. De facto, non se lle escaparía á audiencia do cartulario a anacrónica representación de Fernando de la Cerda, case quince anos despois do seu pasamento e cando seu irmán xa reinaba, contravindo o estipulado por Afonso X no seu testamento. Non podo evitar pensar que esta imaxe encerra máis dunha clave para entender a tortuosa relación entre Violante e Sancho, e os efectos deste drama familiar non só no destino do convento allaricense senón tamén do reino de Galicia ata que Afonso XI, bisneto de Afonso X e Violante, se fixese co poder.

\section{O CONVENTO DE SANTA CLARA DE ALLARIZ E O SEU TESOURO: PADROADO, MEMORIA E PREITO DINÁSTICO}

O 18 de xullo de 1292 o cardeal Matteo d'Aquasparta comunicoulles aos franciscanos da provincia de Santiago e ao gardián e lector da Orde en Ourense que se outorgara licenza á «excelentísima dona Violante, raíña de Castela e León» para a fundación do convento de Santa Clara de Allariz. A propósito deste documento, razoaba con meridiana claridade Mercedes Durany que a dita licenza tivo que ser solicitada con anterioridade a esta data. Polo tanto, a esta petición non sería alleo o 
feito de que o 21 de abril dese mesmo ano se reuniran as Cortes de Valladolid, nas que se depuxo a Afonso X e se outorgou a rexencia ao infante Sancho, «con el apoyo de los señores eclesiásticos gallegos y la nobleza del reino» (Durany Castrillo 2009: 138; véxanse tamén Linehan 1997: 137-138 e Katz 2015: 814-816). Así a todo, non mencionaba esta autora que nesta altura a vila de Valladolid estaba aínda nas mans de Violante e que o seu apoio sería decisivo nesta primeira fase da revolta. Por se quedase algunha dúbida sobre os sentimentos da soberana, a Crónica de Afonso X (González Jiménez 1998: 223) confirma a sospeita: «Et plaziél mucho por esta boz que tomara [Sancho] contr el rey don Alfonso, su marido». Non fora sempre así, e a propia historia da fundación allaricense daría motivos a nai e fillo para futuros enfrontamentos.

Fíxose referencia antes á compra dos terreos onde se erixiría o convento e á concesión do privilexio de couto a Santa Clara por parte de Sancho IV en 1286, a petición de súa nai. No entanto, é preciso lembrar que na mesma visita a Galicia na que se emitiron eses documentos, o novo rei designou tamén aos prelados das sés de Compostela e Ourense, respectivamente o dominico Rodrigo González (1286-1304) e o temible Pero Eanes de Novoa (1286-1308), que acabaría por se converter no peor inimigo dos franciscanos na provincia. ¿Descoñecía Sancho que puxera un lobo a termar do rabaño materno? Con independencia da resposta que deamos a esta cuestión, o certo é que o apoio que lle prestaba o prelado ourensán debía de ser demasiado importante como para perdelo, aínda que este último se negase a consagrar a fundación da súa nai e non autorizase a inhumación na igrexa do convento ${ }^{10}$. Non sería ata 1294 cando se celebrou a consagración do templo, se ben oficiada polo bispo dominico de Silves (Portugal), Domingos Soares ${ }^{11}$. E se, por unha banda, Sancho non aforraría xestos de favor cara ao convento das clarisas, o futuro da fundación quedaría seriamente comprometido en 1288 pola decisión de retirarlle á súa nai o control sobre as máis ricas vilas que formaban parte do seu dote -Valladolid, Plasencia, Ayllón, Astudillo, Curiel, San Esteban de Gormaz e Béjar- para entregalas á súa muller María de Molina (Kinkade 1992-1993: 14). Neste senso, e aínda que a historiografía previa veña dicindo o contrario, acerta Melissa R. Katz (2013: 56-57) ao sinalar a relativa pobreza das mandas de Violante no seu testamento de 1292, no que ordena ser enterrada «en esse monesteyro de allariz que yo ffago dela orden de santa clara en derecho del altar de sancta maria dentro del coro de las duenas $\gg^{12}$.

Esta circunstancia podería explicar o durísimo ton en que está redactado este documento, onde a raíña lle esixe ao seu fillo «por la bendiçion de su padre

10 Nótese que, en 1303, os freires de Ourense aínda estaban acollidos en Allariz (García Oro 1988: 141).

11 Madrid, AHN, Clero Secular-Regular, carp. 1429, n.․ 10. Publicado por López (1927: 29-30) e García Barriuso (1990: 35-36). Este documento está dixitalizado en PARES: http://pares.mcu.es/ParesBusquedas20/catalogo/description/5861428 [última consulta: abril 2021].

12 Madrid, AHN, Clero Secular-Regular, carp. 1429, n.o 5. Publicado por Castro (1722: I, 324-327), López (1927: 15-18) e García Barriuso (1990: 25-28). Presento aquí a miña transcrición do documento. Tamén está dixitalizado en PARES: http://pares.mcu.es/ParesBusquedas20/catalogo/description/4896826 [última consulta: abril 2021]. 
et de su madre» que non lle retire o dominio dos lugares que aínda estaban no seu poder ata que as súas disposicións sexan cumpridas, e mesmo que «por la bendiçion de dios et de sancta maria premera mjente et dessi por la de su padre et su madre» non embargue nin desapodere os seus executores testamentarios. De facelo, Violante ameaza: «demandegelo dios et sancta maria su madre enel cuerpo et enel alma et en todas las cossas que del fueren et lo quela mj alma lazrare por ello demandegelo dios en la suya et nunca gelo perdone». As súas palabras non parecen expresión dunha fonda relación materno-filial, nin sequera dunha interesada alianza nai-fillo, como recentemente argumentou María del Mar Graña Cid (2019: 75) ${ }^{13}$.

Talvez a ambigüidade da representación de Violante e Fernando de la Cerda no Tombo de Toxos Outos (Fig. 5) respondese non só ao afastamento entre Sancho IV e súa nai, senón tamén á crecente desafección de moitos dos nobres e eclesiásticos galegos que apoiaran o infante en 1282 e que, naquela altura, comezaban a mostrar a súa preferencia polo infante Xoán (Gaibrois 1922-1928: I, 156). Que as cousas non melloraron coa morte de Sancho en 1295 pode comprobarse lendo outro documento, datado a finais de setembro dese ano en Medina de Rioseco -é dicir, dous meses despois das Cortes de Valladolid polas que se recoñeceron aos diversos titores que se repartirían o poder durante a minoría de Fernando IV-, no que Violante reitera a súa vontade de entregar todos os seus bens ao convento de Allariz, os que tiña nesa altura e os que tería no momento da súa morte. De novo, a linguaxe da raíña é ameazante, dirixindo agora a súa maldición non só contra o novo rei mais tamén contra calquera -«fijos nin nietos nin heredero que yo aya»- que fose quen de oporse aos seus designios ${ }^{14}$. Por iso sorprende a lectura que del fai Katz (2013: 59), que ve nestas palabras «an attempt at reconciliation or, at least a stoic truce, between the two widowed queens». Tal afirmación contradise coa estampa que presenta a Crónica de Fernando IV, dos primeiros meses de 1296, cando María de Molina tivo que facer fronte á conxura do infante Xoán e de Afonso de la Cerda coa intención de dividir entre eles o reino castelán-leonés, así como á declaración conxunta de guerra por parte dos reis de Portugal, Aragón, Francia e Granada en apoio das pretensións do infante de la Cerda (Gaibrois 1936: 102-112). O papel de Violante nesta ofensiva non foi menor, aparecendo visiblemente ao lado do infante Xoán, proclamado rei de León, Galicia e Sevilla en abril dese ano, co apoio de boa parte da nobreza galega e dos seus prelados, entre eles o bispo de Ourense (Linehan 1997: 141-142). É neste contexto no que a vella raíña, que nunca perdera a esperanza de recuperar as súas antigas posesións -se ben

13 Como sinala María Jesús Fuente (2017: 159), «Violante desconfiaba de su hijo, y Sancho desconfiaba de su madre, tenía buenas razones para hacerlo».

14 «Et qual quier que contra ello fuere aya la yra de dios e la mi maldiçion que nunqua pueda seer saluo por cosa que diga nin que faga» (transcrición miña). Ourense, Arquivo Histórico Provincial de Ourense (AHPOu), Allariz, carp. 6, n.ํㅡㄹ. Nin Atanasio López nin Patrocinio García Barriuso transcriben este documento, aínda que alude a el Olga Gallego (1986: 45). Agora pode consultarse en GALICIANA: http:// arquivo.galiciana.gal/arpadweb/es.ga.32054.ahpou/es/catalogo_imagenes/grupo.do?path=1855 [última consulta: abril 2021]. 
non semellaba confiar en ningún dos seus novos aliados-, tratou pola forza de entrar en Valladolid. Ao ver que se lle negaba o paso, «fue muy sannuda e amenazolos de muerte» (Benítez Guerrero 2017: 27).

Non é este lugar para matinar se Violante tiña unha «inveterate tendency to conspiracy» ou se os seus innegables dotes políticos poderían tela convertido nunha outra Berenguela se as circunstancias lle fosen máis favorables ${ }^{15}$. Porén, en calquera caso, os recentes intentos de rehabilitar a súa figura non deberían apagar os trazos incómodos da personaxe que retratan os documentos e testemuños contemporáneos -algúns, como vimos, mesmo autógrafos-, e que nos falan dunha muller astuta, fascinante e remisa a abandonar a posición de poder e privilexio que, non sen motivo, cría que lle pertencía. Baixo a luz da evidencia aquí presentada, coido que Santa Clara de Allariz foi moito máis que un simple «spiritual and emotional refuge» (Katz 2015: 819) para Violante en tanto que fundación que aspiraba a ser o novo panteón rexio dun territorio que, durante estes anos, a piques estivo de desligarse da coroa castelá baixo o infante Xoán ${ }^{16}$. Para ponderar o seu valor en termos xeopolíticos, convén engadir, ademais, a proximidade do convento á fronteira portuguesa e a súa favorable localización a carón da Vía da Prata, un dos eixes principais de articulación peninsular (Graña Cid 2019: 74). Este vínculo teríase reforzado polo feito de que a provincia franciscana de Santiago -cuxo provincial Frei García Blandes († 1332) aparece como fiduciario no testamento da raíña, da que era confesor, e sería enterrado en Allariz- exercería a súa xurisdición sobre terras portuguesas ata 1415. Por se todo isto non fose suficiente, dende 1282, unha princesa aragonesa -a súa sobriña Isabel- reinaba no país veciño. As dúas coincidiran brevemente durante a estadía de Violante na corte de seu irmán Pere III, como se lembra na vita da rainha santa, escrita pola súa sucesora Isabel de Cardona ${ }^{17}$. Aínda que non é posible afirmar a relevancia deste feito na elección de Allariz para a fundación rexia, pola contra a influencia determinante do convento allaricense na futura creación de Santa Clara de Coimbra por Isabel de Portugal en 1314 está fóra de toda dúbida ${ }^{18}$.

A comparación coa súa sobriña, aparentemente tan afastada da súa belicosa tía, revela afinidades insospeitadas que, pola súa vez, lle outorgan outros matices á actividade de patrocinio de Violante. A máis destacada destas coincidencias é que as dúas preferiron enterrarse nas súas respectivas fun-

15 A cita é de Linehan (1997: 138). Sobre o proxecto de rexencia con Fernando de la Cerda, tal e como pode adiviñarse na chamada Crónica del alboroço, véxase Hernández (2015).

16 Cf. tamén Fuente Pérez (2017: 184) sobre o valor político da fundación; e Graña Cid (2019: 75) sobre o xeito no que a raíña foi quen de poñer a Orde Franciscana ao seu servizo.

17 « [D]izia esta Rainha Dona Isabel, que se acordaua que em leuando Exrey Don Iames para Poblete, hu elle escollera sa sepultura, que vira ir em pos el dous Reys seus filhos, \& tres Rainhas; as quais eraõ a madre desta Dona Isabel, \& et a Rainha Dona Violãnte, que foi mulher delRey Dom Affonso filho delRey Dom Fernand, que filhou Seuilla aos Mouros, \& a outra Rainha era mulher del Rey Dom Iames, a que ficaua o Reyno de Maorgas» (Brandão 1980: VI, 496b-497a). Este traslado acontecería en 1278.

18 Este aspecto xa fora tratado en Rodríguez Porto (2011: 43-68). Véxanse García Oro (1990: 116-117) e agora Graña Cid (2019: 74-75), quen insisten na relación destes dous conventos coas clarisas de Zamora. 
dacións clarisas, lonxe dos lugares escollidos polos seus maridos ${ }^{19}$. Non menos importante é que tanto Violante como Isabel fixeran da súa relixiosidade franciscana unha sorte de devoción dinástica. Este aspecto pode percibirse especialmente ao cotexar o testamento da primeira cunha carta escrita pola segunda:

donna Yolant por la gracia de dios rreyna de Castiella et de Leon, en mjo sano entendimiento qual mele dios dios [sic], et en mj cunplida memoria et en mj salut con mj buena voluntad et con grant deuoçion, por mucho bien et mucha merçet que me dios ffizo et sennalada mjente por muchos et muchas de mjo linage que ffizo acabar su vida et su ffazienda en grant omillat et con sancta religion. Otorgo et prometo de tomar la orden de Sancta Clara enel monesterio de allariz que yo ffago et quando melo dios guisare a mj onrra et aquella del monesterio, a loor de dios e de Sancta Maria ssu madre et de Sancta Clara, et de acabar enella mj vida ${ }^{20}$.

nós Dona Isabel mulher em outro tempo do muito alto, \& muy nobre Rey, \& Senhor D. Diniz [...]: avendo feusa em nosso Senhor Jesu Christo, \& na Virgem Santa Maria sá Madre, \& na Corte Celestial, \& avendo devoçom na Ordem de Santa Clara, como sempre aquelles, \& aquellas onde nos vehemos, aviamos posto em nossa vontade, que se acontecesse que nós moressemos antes que o dito Rey D. Diniz nosso marido lidimo, que aviamos devoçom de morrer no avito de Santa Clara (Ribeiro de Vasconcelos 1894: 10)

Non queda moi claro se a raíña de Castela facía alusión a santa Isabel de Hungría, medio irmá de súa nai, ou á súa propia irmá, a infanta Sancha, finada en Terra Santa con sona de santa, de acordo co que relata don Juan Manuel no seu Libro de las armas (Jaspert 1997). No caso de Isabel de Portugal, podería estar evocando a memoria da súa nai, Constanza de Sicilia, gran protectora dos franciscanos, así como a da súa avoa Violante de Hungría e, por suposto, a da propia Violante de Aragón. Neste senso, débese insistir na especial vinculación entre a Casa Real de Aragón e a Orde Franciscana, moito máis marcada que no caso da familia real castelá, o que facería das clarisas a opción natural tanto para a raíña Violante como para a súa sobriña en Portugal, rompendo coa secular preferencia polos cistercienses en ambos os dous reinos (Katz 2013: 55) ${ }^{21}$. Proba desta consciente asimilación entre a súa orixe aragonesa e a protección das clarisas é que as dúas uniran, dun xeito ou doutro, a exaltación

19 D. Dinís se fixera enterrar no mosteiro cisterciense de Odivelas.

20 Coma na nota 12.

21 Sobre o padroádego da Orde Franciscana en Aragón e Castela, remito a García Oro (1990), Webster (1993), Gutiérrez Baños (2017: 283-296), Cendón/Fraga (2017: 341-345) e Graña Cid (2019). 
de santa Clara de Asís como fundadora da orde feminina coa de Isabel de Hungría, membro da súa propia beata stirps, reivindicada orgullosamente por Violante no seu testamento ${ }^{22}$. Así, a bula Licetis, datada o 13 de febreiro de 1291, concedía indulxencias a quen visitase Santa Clara de Allariz polo Nadal e polas festas da Anunciación, Purificación e Asunción, ademais dos días dedicados a san Francisco, santa Clara, santo Antón e santa Isabel de Hungría ${ }^{23}$. Isabel, pola súa parte, non deixará de referirse a Santa Clara de Coimbra no seu segundo testamento, escrito en 1327, como «meu mosteiro de Sancta Clara e Sancta Izabel» (Sousa 1793: I, 117 e 119, n.ํ16), e incluirá unha imaxe da santa turinxia no seu nomeado sepulcro pétreo ${ }^{24}$.

Sen facermos máis fincapé na comparación entre as dúas raíñas, que daría moito xogo noutro lugar, non quixera deixar de insistir noutro punto común entre elas, a súa predilección por imaxes da Virxe e o Neno, da que son exemplo tanto a Virxe abrideira allaricense (Fig. 6) como a luxosa imaxe en prata sobredourada que hoxe se conserva no Museu Machado de Castro (inv. 6034), ambas son doazóns ás súas fundacións respectivas ${ }^{25}$. Así a todo, se no caso da raíña portuguesa son varias as obras de ourivaría e xoias que poden atribuírse ao seu patrocinio, entre as pezas conservadas en Santa Clara de Allariz só cómpre relacionar a mencionada Virxe en marfil á iniciativa de Violante, pois é a única cuxa cronoloxía encaixa no arco temporal da súa vida, como tratarei de argumentar a continuación. Obra mestra da eboraria medieval e das máis icónicas da arte medieval hispana, certamente digna dunha raíña, moito se ten escrito sobre esta peza, tanto para determinar o seu lugar de produción coma para explicar a súa orixinal tipoloxía, para a que se poden citar moi poucos paralelos, en boa medida por recibir a censura do Concilio de Trento ${ }^{26}$. De especial interese para este traballo é a hipótese presentada por Rocío Sánchez Ameijeiras (2009b: 364-365), para quen este tipo de imaxes, que se abren para a contemplación dos Gozos de María tallados no seu interior, poderían ser concibidas en resposta ás sofisticadas miniaturas despregadas nos «Códices das Historias» das Cantigas de Santa María, así como nas reflexións poetolóxicas e cuestións de retórica visual xeradas polo proceso de ilustración do marial rexio.

En realidade, nin sequera é posible determinar que pezas da capela privada de Violante serían entregadas ao convento, ou mesmo se as súas derradeiras vontades serían respectadas, xa que no seu testamento non se detalla o contido da súa doazón e non coñecemos inventarios medievais nos que se consigne a orixe do

22 En xeral, sobre a noción de beata stirps, véxanse Vauchez (1977), Hoch (1992) e Klaniczay (2002).

23 Segundo Jacobo de Castro (1722, I, 328), a bula Licet is estaba custodiada no arquivo do convento. Porén, non se conserva traza dela. Atanasio López publicáraa en 1927 a partir do Bullarium Franciscanum (IV, p. 218). Véxase García Barriuso (1990: 24).

24 Sobre o túmulo, véxase Pato de Macedo (1999).

25 Sobre esta última, véxase Domenge/Molina (2009).

26 Remito aos traballos de Sánchez Ameijeiras (2009b: 364) e Katz (2012) para unha avaliación da historiografía precedente. Todos os autores que se ocuparon dela dataron esta obra no último terzo, máis precisamente no último cuarto do século XIII. 


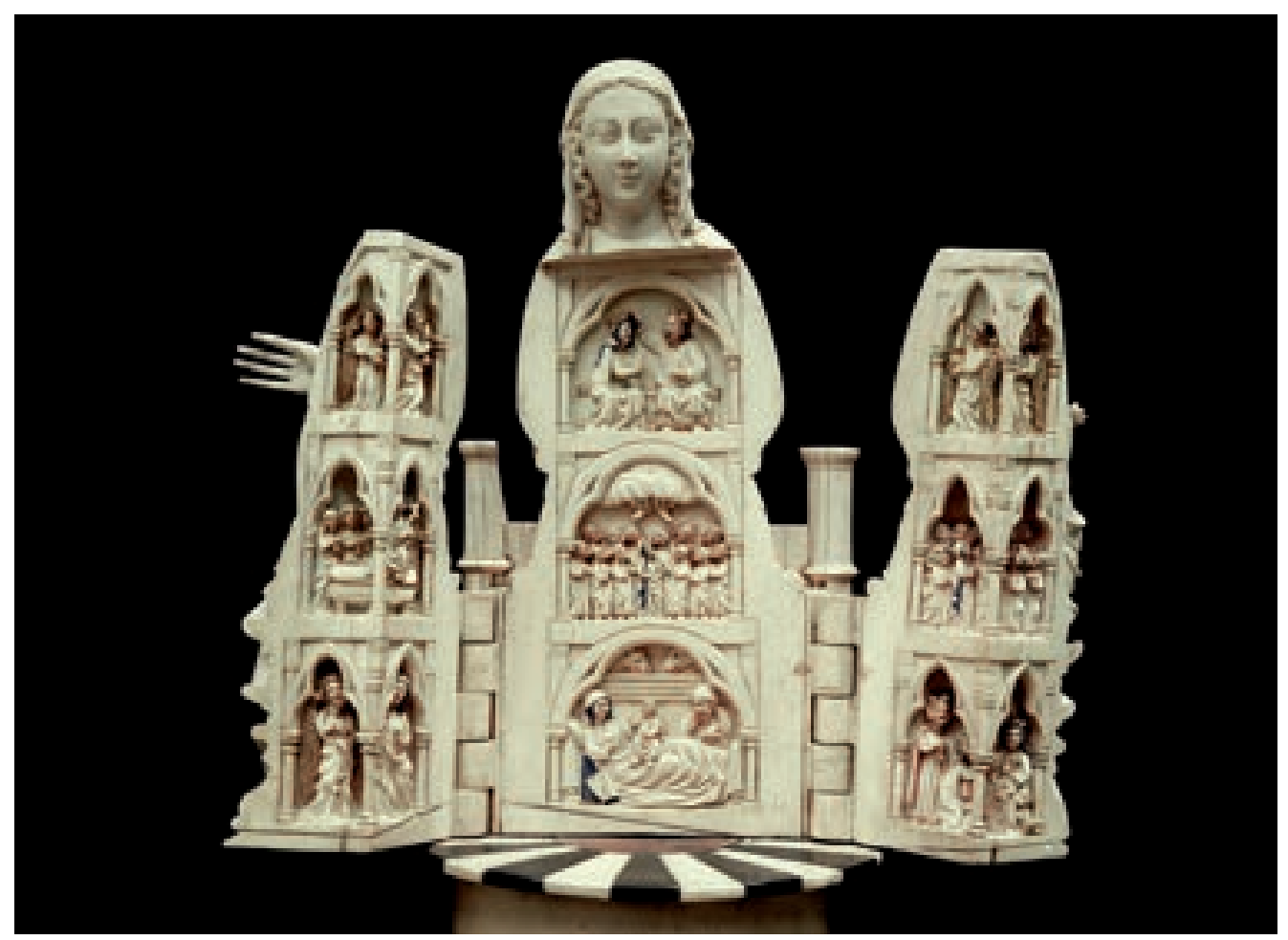

Fig. 6: Virxe abrideira (Real Monasterio de Santa Clara de Allariz).

legado que hoxe conservamos. Maiores problemas presenta aínda a azarosa historia posterior do tesouro allaricense, xa que a fábrica medieval foi arrasada polo lume en 1758, momento en que deberon de perderse tamén algúns dos preciosos obxectos que alí se conservaban dende a Idade Media. Entre as obras superviventes, as intervencións tardías e non sempre afortunadas contribuíron tamén a desfigurar o conxunto, así como a desorientar os escasos investigadores que ocuparon del $^{27}$. Pero, vaimos amodo, separando o gran da palla e tratando de presentar esta maraña de forma intelixible. No seu testamento, Violante indica que 4000 marabedís terán que ser entregados ás monxas para adquirir os libros que precisaren, e que elas serán as destinatarias de «mio lecho [et] toda mj ropa», además de «toda mj capiella assi que les yo di commo lo que yo tengo». Destes asertos pódese deducir que antes de 1292, e cando o convento aínda estaba en construción, a raíña xa fixera entrega dalgún obxecto da súa capela. Considero que a Virxe abrideira estaría entre elas, a xulgar por un pequeno detalle, ata o de agora inadvertido na documentación xerada polo preito entre a co-

27 Ese é o caso da cruz de cristal de roca, da que se falará despois, cuxas alteracións -nalgún momento indeterminado tras a Guerra Civil- poden documentarse comparando as publicacións de José Villa-amil y Castro (1899) e Marvin Chauncey Ross (1933) cos informes das últimas restauracións. As ditas alteracións inclúen a remontaxe da peza e, o que é peor, a substitución de parte das miniaturas medievais baixo cristal que a decoraban por outras imaxes de resaibo barroco. 
munidade clarisa e o bispo Eanes de Novoa. Nunha acta notarial escrita con motivo do dito preito, hoxe conservada grazas a un traslado feito contra 1647, faise alusión ao primeiro selo do convento, e ao da propia abadesa, Sancha Eanes, que aparecen descritos nos seus pormenores. Por este texto podemos saber que o selo de Santa Clara era «de forma longa e tinna en si imagen de Sancta Maria, seente en cadeira con seu fillo no braço e unha semellança de flor de lis en su mao, et as letras do seelo eran estas: Sigillum dominarum de Sancta Clara de conbentu de Allaris ${ }^{28}$. As coincidencias coa talla en marfil son evidentes, e non podo evitar pensar que este obxecto, sen dúbida o máis extraordinario de cantos gardasen as monxas e claro expoñente da condición rexia do convento, se convertería dende o primeiro momento nunha especie de imaxe corporativa para a comunidade. Se esta hipótese non é errada, o deseño do selo permitiría mesmo reconstruír o aspecto orixinal da obra, xa que a Virxe efectivamente parece soster un obxecto na súa man dereita, hoxe perdido, que ben podería ser unha flor de lis.

Se o exposto ata aquí non pasa de ser conxectural, a partir deste punto toda certeza desaparece. A infatigable Sancha Eanes reaparece noutro importante documento que, de novo, dá unha idea da precariedade da fundación rexia nestas primeiras décadas. Trátase doutro protocolo notarial, no que se procede á apertura e lectura pública do testamento de Violante en presenza do rei Fernando IV, o 22 de xaneiro de 1302, é dicir, tan só un día antes das nupcias do soberano con Constanza de Portugal $^{29}$. Para tal fin, a abadesa desprazaríase a Benavente, onde estaba a corte antes de partir para Valladolid, lugar onde se celebraría o enlace. Se Violante morrera, como parece máis probable, contra 1300 preto de Roncesvales, non pode dicirse dos seus descendentes inmediatos que se desen moita présa en cumprir coas súas derradeiras vontades $^{30}$. De facto, aínda que nesta altura se documentan algunhas mercés rexias e pode que a igrexa estivese xa rematada ao ano seguinte, cómpre pór en dúbida que as mandas testamentarias da raíña se fixesen efectivas, polo menos inmediatamente e de modo consistente ${ }^{31}$. Se, ademais, como aventura Mercedes Durany (2009: 141), Sancha Eanes finou pouco despois, é de supor que o convento ficaría nesa altura privado da súa máis enérxica defensora. Por este motivo, é necesario acoller con cautela as referencias ao padroado da raíña que achamos en fontes posteriores. Deixando á marxe as breves noticias que achega Ambrosio de Morales (1765: 158-159) -quen refire a existencia de «Reliquias menudas que dejó la Reyna en Cruces y Portapaces de pla-

28 A carta está datada o 2 de marzo de 1294. Foi publicada por López (1927: 34-35) e García Barriuso (1990: 34-35), e coméntaa García Oro (1988: 140). Consérvase en Madrid, AHN, Clero Secular-Regular, carp. 4900, n.․ㅡ 1 .

29 Aínda que a listaxe de testemuñas está incompleta, aparece encabezada por Juan Núñez de Lara e os seus partidarios. A raíña María de Molina, distanciada do seu fillo, non é mencionada no documento.

30 Así foi determinado por Enrique Flórez (1790: 369), a partir dunha breve noticia no Cronicón de Cardeña. As referencias a contrario por Gerónimo de Quiroga ou Jacobo de Castro carecen de fundamento, a pesar do que argumente Katz (2015: 826-830).

31 As concesións e mercés de Fernando IV detállanse en García Barriuso (1990: 41-45). 
ta», ademais de presentar unha lenda piadosa sobre a orixe da Virxe abrideira-, todos os investigadores que se ocuparon do tesouro allaricense parecen conceder fiabilidade a un inventario, datable en 1570, do que se conserva un traslado de 1647 entre a documentación que custodia o Archivo Histórico Nacional. Foi publicado parcialmente por Jacobo de Castro (1722: I, 327-328) na primeira parte do seu Arbol chronologico de la Santa Provincia de Santiago e tamén o transcribiron despois José Villaamil y Castro (1899: 133-134), Patrocinio García Barriuso (1990: 79-81) e outros autores ${ }^{32}$. En lugar de remitir a estas publicacións, coido que paga a pena presentalo aquí de novo para analizalo en detalle. Neste texto, no decurso dunha breve exposición sobre as persoas enterradas no convento, indícase que:

Tiene esta Sancta y Real casa muchas cosas que la Reyna Doña Violante traxo a ella. Tiene vna ymagen de Nuestra Señora de bulto de finissimo marfill que es vna de las mas devotas y preciossisimas que ay enel mundo; tiene vna puerta paz de plata mui bien guarneçida con su beril en medio delle está vn lignum crucis y en todo el demas hueco muchedumbre de diversas reliquias; y otra portapaz desta echura tambien de plata sobre dorada, que tiene de la faxa conque fue ceñido Christo nuestro redemptor y una estilla dela cuna y de la piedra del sepulcro de Nuestra Señora; Yten mas vn Sanctiago de plata de bulto con un escudo con su beril, y dentro otro pedaço del Lignum Crucis; Ytem mas vna cruz de plata hueca bien guarneçida que tiene vn dedo del bien aventurado San Bartholome; Yten mas otras dos cruçes de plata huecas como estan llenas de reliquias de diversos santos y santas quela reyna trajo a esta casa [...].

Yten estan aqui hornamentos que de su capilla dio a esta Sancta y Real casa frontales, capas, Casullas, palia, doseles.

Tiene mas que dio la reyna Doña Violante, otras ymagines de bulto de Nuestra Señora de marfil.

Yten mas tiene la cassa que dio la reyna Doña Violante tres cruçes de christal hermossisimas.

Como pode comprobarse, trátase dunha listaxe na que parecen incluírse obxectos de todo tipo e moi probablemente diferente cronoloxía, resultado de

32 Este inventario forma parte tamén do documento AHN, Clero Secular-Regular, carp. 4900, n.응 1. Segue a unha copia do testamento da raíña e ao protocolo notarial documentando a petición ao bispo de Silves, antes mencionado. Describe os seus contidos García Barriuso (1990: 103-106). Inclúo aquí a miña transcrición. 


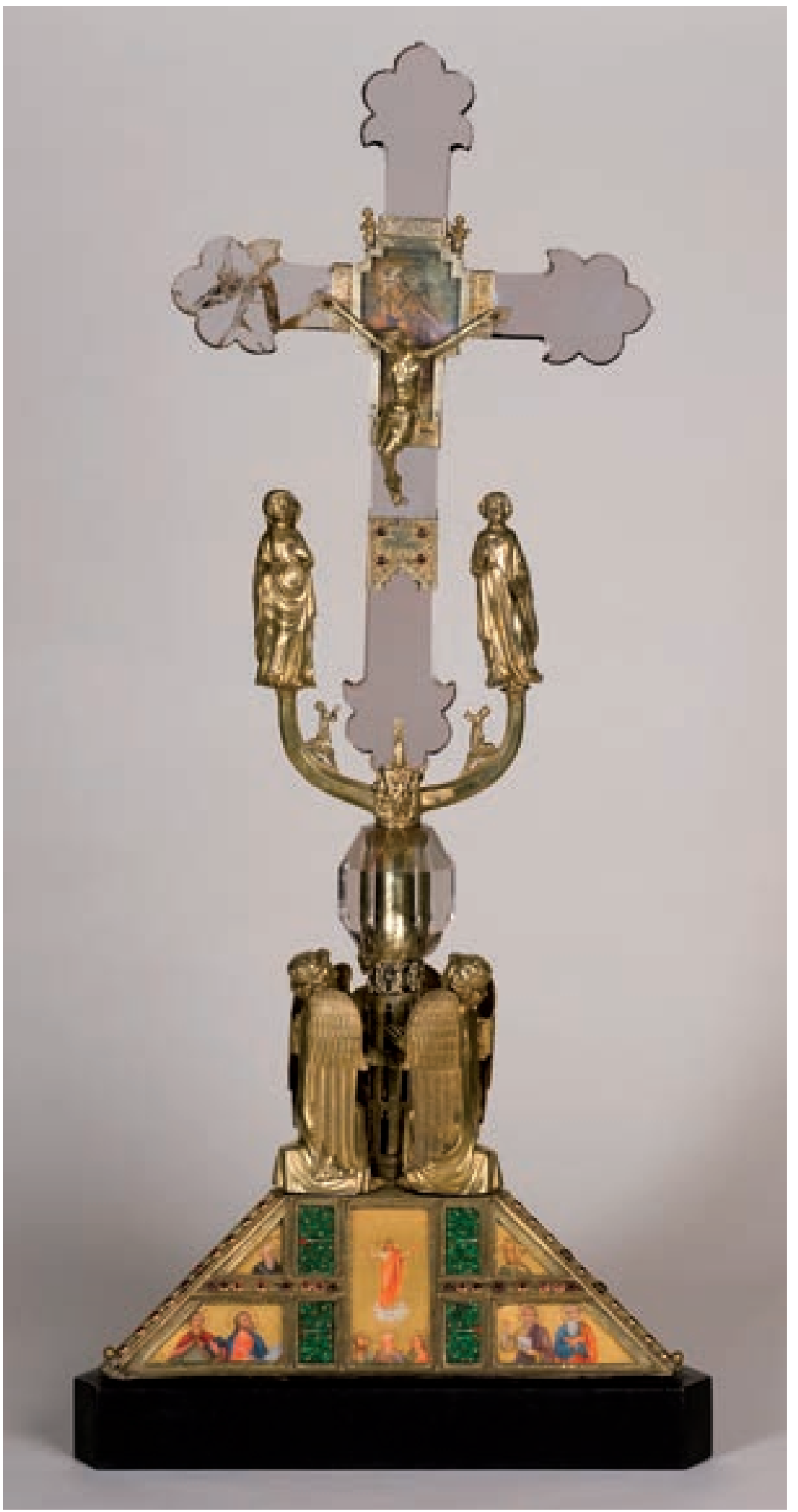

Fig. 7: Cruz de cristal de rocha do infante Felipe e Margarita de la Cerda (Real Monasterio de Santa Clara de Allariz). 
diversas doazóns ao longo do tempo. Ese sería o caso dunha imaxe de Santiago que, pola descrición, podería ser do século XIV ou mesmo posterior. A inmensa maioría deles non se conservan e é de imaxinar que desapareceron no lume de mediados do século XVIII (cf. González García 1990: 243-256). Tampouco parece que esta sección do documento, redactada por Francisco Hoyero [Siero?], vigairo do convento, mereza particular credibilidade, a xulgar pola alusión que se fai ao principio ao rei Jaume I, quen supostamente tería comezado a «edificar esta Sancta y Real casa en la hera de mill y tresçientos y veinte y quatro».

Con todo, tradicionalmente se quixo ver na cruz de cristal de roca conservada na institución (Fig. 7) unha das tres «hermossisimas» pezas incluídas neste inventario e, en consecuencia, parte da doazón fundacional de Violante, a pesar de que a análise estilística da obra leva a unha datación incompatible con esta posibilidade. Tanto a forma flordelisada da cruz, realizada en cristal veneciano, como as miniaturas baixo cristal, tamén de procedencia veneciana, non son anteriores á morte de Violante $^{33}$. Outro tanto pode dicirse dos esmaltes parisienses de plique ensamblados na base da cruz, e das imaxes de prata da Virxe, san Xoán, anxos e apóstolos que a decoran, de factura local e que remiten a obras aviñonensas datables na terceira década do século $\mathrm{XIV}^{34}$. Dado que dedicarei un estudo monográfico a esta peza extraordinaria, na que se probará que foi realizada para o infante Felipe (1292-1327) e a súa muller Margarita de la Cerda (1293-1328?), non me demorarei sobre esta cuestión aquí35. Outro tanto pode dicirse do fragmento ilustrado das Vidas y pasiones de los apóstoles de Bernardo de Brihuega, recentemente achado entre a documentación procedente de Allariz no AHPOu (Fragmentos, carp. 3, n. 4/5) ${ }^{36}$. Tan só quería alertar sobre os erros aos que nos pode conducir a falta de documentación fiable e o -comprensibledesexo de facer máis tanxible a lembranza dunha soberana poderosa que, abofé, tivo que verse rodeada de libros luxosos e ornamentos preciosos ${ }^{37}$.

Lamentablemente, debemos contentarnos cos testemuños albiscados e o balance agridoce que nos deixan. É de supor que a época de esplendor de Santa Clara de Allariz que conmemoraban os cronistas do século XVI fose máis ben a que resultou do padroádego do infante Felipe e Margarita de la Cerda, derradeiro

33 Así o argumentaron, respectivamente, Hahnloser/Brugger-Koch (1985: 124-125, n. 135) e Spiandore (2014: 80-81 e 457-462).

34 Poden compararse cos recollidos en Gaborit-Chopin (1998: 206-217). Véxase tamén Taburet-Delhaye (1995: 13).

35 «La cruz de cristal de Allariz: Un manifiesto político transparente» (en preparación).

36 Dá noticia deste documento Ricardo Pichel en https://textorblog.wordpress.com/2019/04/08/ la-tradicion-vernacula-de-la-obra-de-bernardo-de-brihuega-noticia-de-un-nuevo-hallazgo/ [última consulta: abril 2021]. Véxase agora tamén un primeiro estudo destes fragmentos en Pichel (2021).

37 Por razóns de estilo tamén convén datar con posterioridade á morte da raíña (ca. 1330) o díptico-relicario de Santa Úrsula de Las Huelgas, que recentemente lle foi atribuído por Gómez-Chacón (2020). É moi probable que esta peza chegase ao mosteiro cisterciense tras a desamortización procedente dunha fundación dominica, San Pablo ou Caleruega. En calquera caso, non parece crible pensar, como fai Fuente Pérez (2017: 193), que o papel político desempeñado por Violante lle impedise dedicarse a actividades culturais. 
episodio dese preito sucesorio ao que tantas veces se aludiu neste traballo e ao que a fortuna do convento e novo panteón dinástico estaba indivisiblemente ligada. Para cando Afonso XI acabase con toda oposición interna, o tempo dunha gran fundación rexia xa pasara. A este respecto, resulta irónico e talvez premonitorio que a propia Violante non chegase a enterrarse en Allariz, como era o seu desexo. Mais iso non diminúe o interese e ambición dos seus designios para este territorio, que podería ter desempeñado un papel aínda máis importante no contexto peninsular se os plans da raíña se fixesen realidade. É certo que a visión afonsina acabaría por imporse nas centurias seguintes -na práctica, coa consolidación do eixe vertebrador norte-sur do reino e, de modo máis sutil, coa asimilación da súa concepción imperial pan-ibérica- pero coido que corresponde a Violante o xerme dese «ensayo de Infantazgo [masculino]» que García Oro (1988: 136) quixo ver no protagonismo dos infantes Juan e Felipe ao longo destas décadas. É precisamente a vella institución do Infantado a que vencella os exemplos analizados nestas páxinas, dende os tombos composteláns á fundación allaricense. Quizais sexa casualidade que Allariz se sitúe no triángulo imaxinario conformado por Xunqueira de Ambía, Porqueira e Celanova, terras que tradicionalmente pertenceran ás infantas de León ${ }^{38}$. O que non é coincidencia é que se poida recoñecer en Allariz a pegada de dous modelos rexios, o mosteiro cisterciense de Las Huelgas de Burgos e o priorado de Sigena, que, pola súa banda, trataran de adaptar a institución do Infantado aos novos tempos (Walker 2005). A descendencia de Allariz, pola súa vez, habería que procurala nos reinos veciños, en Santa Clara de Coimbra e Santa Clara de Pedralbes, onde dúas raíñas da Casa de Aragón continuarían o padrón da súa antecesora Violante. Serían estes os últimos elos dunha cadea de metamorfoses e estratexias a través das cales as mulleres das dinastías castelá-leonesa, aragonesa e portuguesa tratarían de crear refuxios onde retirarse e honrar a memoria dos seus, ou ben ámbitos de poder a través dos que continuar marcando os destinos dos seus reinos.

38 Estes territorios aparecen consignados no testamento da infanta Elvira (1099). Véxanse Martin (2008: §38) e Henriet (2008: §1-2). 


\section{REFERENCIAS BIBLIOGRÁFICAS}

- AvriL, François et alii (1983): Manuscrits enluminés de la Peninsule Ibérique, Paris, Bibliothèque Nationale de France.

- Benítez Guerrero, Carmen (2017): Crónica de Fernando IV. Estudio y edición de un texto post alfonsí, El Puerto de Santa María, Cátedra Alfonso X el Sabio/Universidad de Sevilla.

- BRANDÃo, Francisco (1980 [1672]): Monarquía Lusitana, Lisboa, Imprensa Nacional-Casa da Moeda.

- Cárdenas, Anthony (2009): «Alfonso X, Saint James, and the Virgin», Latin American Institute - Research Paper Series, 50, 3-37.

- Carrero Santamaría, Eduardo (2014): «Obispos y obras en Santiago de Compostela entre los siglos XII y XIII. La definición del espacio litúrgico en la catedral», en María Dolores Teijeira et alii (eds.), La creación artística en los reinos de Castilla y León (1050-1500), Madrid, Sílex, 173-201.

- CASTRO, Jacobo de (1722): Arbol Chronologico de la Provincia de Santiago, Salamanca, Francisco García Onorato y San Miguel.

- Cendón Fernández, Marta/Dolores Fraga SAmpedro (2017): «De la monarquía a la burguesía. Empresas artísticas en los conventos femeninos de la Galicia medieval», en Gemma-Teresa Colesanti et alii (eds.), Clarisas y dominicas. Modelos de implantación, filiación, promoción y devoción en la Península Ibérica, Cerdeña, Nápoles y Sicilia, Florencia, Firenze University Press, 339-383.

- Domenge, Joan/Anna Molina (2009): «Les “nobles i riquesofrenes” d'Isabel de Portugal. Orfebreries de la reina santa», en Princeses de terres llunyanas. Catalunya i Hongria a l'edatmitjana, Barcelona, Museu d'Historia de Catalunya/Magyar Nemzeti Múzeum, 307-323.

- Durany CASTRILLo, Mercedes (2009): «El monasterio de Santa Clara e Allariz», en Raquel Casal et alii (eds.), Galicia monástica. Estudios en homenaje a la profesora María José Portela Silva, Santiago de Compostela, Universidade, 131-152.

- Fernández Catón, José María (1990): El llamado Tumbo Colorado y otros códices de la Iglesia Compostelana: ensayo de reconstrucción, León, Centro de Estudios e Investigación «San Isidoro»/Archivo Histórico Diocesano.

- FERNÁNDEZ FERNÁNDEZ, Laura (2008): «Imagen e intención. La representación de Santiago Apóstol en los manuscritos de las Cantigas de Santa María», Anales de Historia del Arte, 18, 73-94.

- Ferreira, Pedro Manuel (2016): «The Medieval Fate of the Cantigas de Santa Maria», Journal of the American Musicological Society, 69:2, 295-353. 
- FlóREz, Enrique (1790): Memorial de las Reynas Catholicas. Historia genealógica de la casa real de Castilla y de León, Madrid, Viuda de Marín.

- Fournès, Ghislaine (2008): «Iconologie des infantes (Tumbo A et Tumbo B de la cathédrale de Saint-Jacques de Compostelle et Tumbo de Touxos Outos)», e-Spania, 5 (http://e-spania.revues.org/12033) [última consulta: abril 2021].

- Fuente Pérez, María Jesús (2017): Violante de Aragón. Reina de Castilla, Madrid, Dyckinson.

- Gaborit-Chopin, Danielle (coord.) (1998): L'art au temps des Rois Maudits: Philippe le Bel et ses fils, Paris, Reunion des Musées Nationaux.

- GaIBroIs, Mercedes (1922-1928): Historia del reinado Sancho IV de Castilla, Madrid, Tipografía de la «Revista de Archivos, Bibliotecas y Museos», 3 vols.

- Gaibrois, Mercedes (1936): María de Molina, tres veces reina, Madrid, Espasa-Calpe.

- Gallego, Olga (1986): «Dominio y bienes de Santa Clara», Boletín Auriense. Anexo: Santa Clara de Allariz, 70: Centenario da fundación, 43-61.

- García Barriuso, Patrocinio (1990): «Documentación sobre la fundación, privilegios y derechos históricos del monasterio de Santa Clara de Allariz», Liceo Franciscano, 127-129, 11-107.

- García Oro, José (1988): San Francisco de Asís en la España medieval, Santiago de Compostela, CSIC/Liceo Franciscano.

- García Oro, José (1990): «La primitiva instalación de las Clarisas en Galicia», Liceo Franciscano, 127-129, 109-145.

- Gómez-Chacón, Diana Lucía (2020): «Recuerdos de Hungría: la reina Violante de Aragón, Helena de Veszprém y el díptico-relicario de Santa Úrsula del monasterio de Las Huelgas de Burgos», De Arte, 19, 7-23.

- GonZÁLez García, Miguel Ángel (1990): «El arte en el monasterio de Santa Clara de Allariz», Liceo Franciscano, 127-129, 229-256.

- GonZÁlez JimÉneZ, Manuel (1991): Diplomatario andaluz de Alfonso X, Sevilla, Fundación El Monte.

- GonZÁlez JimÉnez, Manuel (ed.) (1998): Crónica de Alfonso X, Murcia, Real Academia de Alfonso X el Sabio.

- GonZÁlez JimÉneZ, Manuel (2004): Alfonso X el Sabio, Barcelona, Ariel.

- Graña CID, María del Mar (209): «The Mendicant Policies of the Queens of Castile in the Thirteenth Century. The Implantation of the Convents», en Nikolas Jaspert/ Imke Just (eds.), Queens, Princesses and Mendicants: Close Relations in a European Perspective, Zürich, LIT Verlag, 65-83.

- GutiérRez BAÑos, Fernando (2017): «La promoción artística en los conventos de Clarisas durante la Baja Edad Media: los coros de los conventos de Santa Clara de 
Salamanca y de Toro», en Mujeres en silencio: El monacato femenino en la España medieval, Aguilar de Campoo, Fundación Santa María la Real, 283-330.

- Hahnloser, Hans R./Susanne BrugGer-Koch (1985): Corpus der Hartsteinschliffe des 12.-15. Jahrhunderts, Berlin, Deutscher Verlag für Kunstwissenschaft.

- HenRiet, Patrick (2008): «Infantes, Infantaticum. Remarques introductives», e-Spania, 5 (http://e-spania.revues.org/12593) [última consulta abril 2021].

- Hoch, Adrian S. (1992): «Beata Stirps, Royal Patronage and the Identification of the Sainted Rulers in the St. Elizabeth Chapel at Assisi», Art History, XV:3, 279-295.

- JASPERT, Nikolas (1997): «Heresy and Holiness in a Mediterranean Dynasty: the House of Barcelona in the Thirteenth and Fourteenth Centuries», en D. I. Agius/ R. I. Netton (eds.), Across the Mediterranean Frontiers: trade, politcs and religion, 650-1450, Turnhout, Brepols, 105-135.

- JonEITIS, Diana (2008): «Ein früher Elisabethzyklus von Hof Alfons X. von Kastilien», Carl Justi Vereinigung, 20, 4-20.

- Joneitis, Diana/Dieter Blume (2007): «Eine Elisabeth-Handschrift vom König Alfons'X. von Kastilien», en Dieter Blume/Matthias Werner (eds.), Elisabeth von Thüringen, eine europäische Heilige. 3. Thüringer Landesausstellung. Aufsätze, Wartburg, Petersberg, 325-339.

- Katz, Melissa R. (2012): «The Non-gendered Appeal of Virge Ouvrant Sculpture: Audience, Patronage, and Purpose in Medieval Iberia», en Therese Martin (ed.), Reassessing the Roles of Women as «Makers> of Medieval Art and Architecture, Leiden, Brill, 37-91.

- Katz, Melissa R. (2013): «The Final Testament of Violante de Aragón (c. 1236-1300/01): Agency and (Dis)Empowerment of a Dowager Queen», en Elena Woodacre (ed.), Queenship in the Mediterranean: Negotiating the Role of the Queen in the Medieval and Early Modern Eras, London, Palgrave Macmillan, 51-71.

- Katz, Melissa R. (2015): «A Convent for La Sabia: Violante de Aragón and the Clarisas of Allariz» en James D'Emilio (ed.), Culture and Society in Medieval Galicia: A Cultural Crossroads at the Edge of Europe, Leiden, Brill, 812-836.

- Keller, John E. (1957): Collectánea Hispánica: Folklore and Brief Narrative Studies, Newark, Juan de la Cuesta, 61-68 («King Alfonso’s Virgin of Villa-Sirga: Rival of St. James of Compostela») e 69-76 («More on the Rivalry of St. James and Santa Maria»).

- KinKADE, Richard P. (1992-1993): «Violante of Aragon (1236/7-1300?): An Historical Overview», Exemplaria Hispanica, 2, 1-37.

- Klaniczay, Gabor (2002): Holy Rulers and Blessed Princesses. Dynastic Cults in Medieval Central Europe, Cambridge, Cambridge University Press. 
- Linehan, Peter (1971): The Spanish Church and the Papacy in the Thirteenth Century, Cambridge, Cambridge University Press.

- Linehan, Peter (1997): The Ladies of Zamora, University Park PA, Pennsylvania State University Press.

- LóPEZ, Atanasio (1927): «Apuntes históricos sobre el convento de Santa Clara de Allariz (siglos XIII y XIV)», Boletín de la Comisión Provincial de Monumentos Históricos y Artísticos de Orense, VIII:172, 8-18; 173, 25-32; 174, 49-53.

- Lucas Álvarez, Manuel (1998): La documentación del Tumbo A de la Catedral de Santiago de Compostela: estudio y edición, Santiago de Compostela, Cabildo de la S.A.M.I. Catedral de Santiago de Compostela/Seminario de Estudios Galegos.

- Martin, Georges (2008): «Le testament d'Elvire», e-Spania, 5 (http://e-spania. revues.org/12303) [última consulta: abril 2021].

- Mettmann, Walter (ed.) (1986): Alfonso X, Cantigas de Santa María, Madrid, Castalia, 3 vols.

- Morales, Ambrosio de (1765): Viage a los Reynos de León, y Galicia, y Principado de Asturias, Madrid, Antonio Marín.

- O'Callaghan, Joseph F. (1998): Alfonso X and the Cantigas: A Poetic Biography, Leiden, Brill.

- Pato DE MACEDo, Francisco (1999): «O túmulo gótico de Santa Clara, en José Ignacio Calvo Ruata (ed.), Imagen de la Reina Santa: Isabel, infanta de Aragón y Reina de Portugal, Zaragoza, Institución Fernando el Católico, 93-114.

- Pérez Rodríguez, Francisco Javier (2004): Os documentos do Tombo de Toxos Outos, Santiago de Compostela, Consello da Cultura Galega.

- PicheL, Ricardo (2019): «La tradición vernácula de la obra de Bernardo de Brihuega: noticia de un nuevo hallazgo», TextoR (https://textorblog.wordpress. com/2019/04/08/la-tradicion-vernacula-de-la-obra-de-bernardo-de-brihuega-noticia-de-un-nuevo-hallazgo/) [última consulta: abril 2021].

- Pichel, Ricardo (2021): «Las Vidas y pasiones de los apóstoles de Bernardo de Brihuega a la luz de un nuevo testimonio castellano», en Belén Almeida Cabrejas/ Fernando Larraz Elorriaga/Marina Serrano Marín (eds.), Babel a través del espejo. Libro homenaje a Joaquín Rubio Tovar, Alcalá de Henares, Universidad, 55-67.

- Prado Vilar, Francisco (2009): «Lacrimae rerum: San Isidoro de León y la memoria del Padre», Goya, 328, 195-221.

- Procter, Evelyn S. (1951): Alfonso X of Castile: Patron of Liteature and Learning, Oxford, Clarendon Press.

- Puente Míguez, José Miguel (1999): «La frustrada catedral gótica de Santiago de Compostela ¿eslabón perdido en las relaciones artísticas entre Francia y España 
en el siglo XIII?», en Christian Freigang (ed.), Gotische Architektur in Spanien, Frankfurt, Iberoamericana - Vervuert, 41-58.

- Ribeiro de Vasconcelos, Antonio G. (1894): Evolução do culto de Santa Isabel de Aragão, esposa do rei lavrador Dom Dinís de Portugal, a Rainha santa, Coimbra, s.e.

- Rodríguez Moniño, Antonio (1950): «La colección de manuscritos del Marqués de Montealegre (1677)», Boletín de la Real Academia de la Historia, CXXVI, 427-492.

- Rodríguez Porto, Rosa M. (2011): Historia e culto das raíñas santas da Casa de Hungría nos reinos occidentais da Península (ss. XIII e XIV). Memoria inédita da Bolsa de Investigación da Deputación da Coruña.

- Rodríguez Porto, Rosa M. (2012): Thesaurum: La 'Crónica Troyana de Alfonso XI' (Escorial, h.I.6) y los libros iluminados de la monarquía castellana (1284-1369). Tese de doutoramento inédita. Santiago de Compostela, Universidade.

- Ross, Marvin Chauncey (1933): «O esmalte cloisonné da crús de Allariz», Nós, 112, 58-60.

- Rubio GarCía, Luis (1985): «En torno a la biblioteca de Alfonso X el Sabio», en Fernando Carmona/Francisco Javier Flores Arroyuelo (eds.), La lengua y la literatura en tiempos de Alfonso X. Actas del Congreso Internacional, Murcia, 5-10 marzo, 1984, Murcia, Universidad, 531-552.

- SÁnCHEZ AMEIJEIRAS, Rocío (2008): «Sobre las modalidades y funciones de las imágenes en el Tumbo A», en Tumbo A. Índice de los privilegios reales, que contiene este libro intitulado de la letra A: original conservado en la Biblioteca de la Catedral de Santiago, Santiago de Compostela, Archivo Biblioteca de la Catedral de Santiago/ Madrid, Editorial Testimonio, 143-216.

- SÁnchez AmeijeIRAS, Rocío (2009a): «Dando forma al tiempo: estrategias visuales y cartularios ilustrados», Studium Medievale, 2, 61-84.

- SÁnCHEZ AmEIJEIRAS, Rocío (2009b): «'Como a Virgen santa paresceu, paresçia’: Las empresas marianas alfonsíes y la teoría neoplatónica de la imagen sagrada”, en Isidro Bango Torviso (ed.), Alfonso X el Sabio, Murcia, Editora Regional de Murcia, 357-365.

- Sousa, António Caetano de (1793): Provas da Historia Genealogica da Casa Real Portugueza, Lisboa Occidental, Officina SYLVIANA da Academia Real.

- SPIANDORE, Silvia (2014): Preziose trasparenze: La miniatura veneziana sotto cristallo di rocca (secoli XIII-XIV). Tese de doutoramento inédita. Padua, Università di Padova.

- TABURET-DeLHAYE, Elisabeth (1995): «L'orfèvrerie au poinçon d'Avignon au XIV siècle», Revue de l'art, 108, 11-22.

- TORRes Fontes, Juan (1976): «La Orden de Santa María de España», Miscelánea Medieval Murciana, 3, 73-118. 
- VAUCHEZ, André (1977): Beata stirps: sainteté et lignage en Occident au XIII et XIV siècles», en Georges Duby/Jacques le Goff (eds.), Famille et parenté dans l'Occident medieval, Rome, École Française de Rome, 397-407.

- Villa-amil y CASTRo, José (1899): «Cruz de cristal conservada en Allariz», Boletín de la Comisión Provincial de Monumentos Históricos y Artísticos de Orense, I:8, 129-136.

- WALKER, Rose (2005): «Leonor of England, Plantagenet Queen of King Alfonso VIII of Castile, and her foundation of the Cistercian abbey of Las Huelgas. In imitation of Fontevraud?», Journal of Medieval History, 31, 346-368.

- WEBSTER, James (1993): Els Menorets: the Franciscans in the realms of Aragón from St. Francis to the Black Death, Toronto, Pontifical Institute. 


\title{
Santa Clara de Allariz, historia dunha fundación real (ss. XIII-XV)
}

\author{
Ma Batriz Vaquero Díaz \\ Universidade de Vigo
}

DOI: 10.17075/gtax.2021.007 



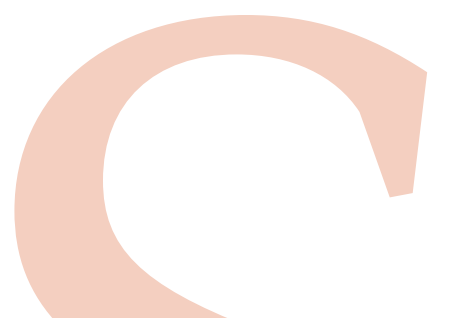

O presente traballo pretende facer un breve retrato do mosteiro de Santa Clara de Allariz ao longo da Idade Media, baseado nunha colección documental que inclúe 376 documentos, dos que dous pertencen ao século XII, noventa ao XIII, cento catro ao XIV e cento oitenta ao xv; documentación custodiada na súa maior parte nos arquivos Histórico Provincial de Ourense e Histórico Nacional e, en moito menor medida, nos do propio mosteiro de Santa Clara, da Catedral de Ourense e do reino de Galicia ${ }^{1}$ O número e a tipoloxía dos documentos conservados revelan a importancia da perda documental que sufriu o convento, que deixa moi pouca información sobre a organización interna da congregación e a vida en comunidade, e orienta forzosamente o estudo cara aos vínculos institucionais co Papado e a Coroa a través dos privilexios pontificios e reais, ao rol que os lazos familiares e devocionais da nobreza xogaron na formación do patrimonio monástico a través de testamentos e doazóns, aos conflitos pola salvagarda dese patrimonio a través dos preitos nos que o convento litigou con señores, oficiais reais e concellos, e, por último, á adquisición e explotación das terras de cultivo a través de contratos de compravenda e aforamento.

O estudo preséntase dividido en catro apartados adicados o primeiro ao estudo da fundación, o segundo ao dominio monástico, o terceiro ás rendas reais e actividades gandeiras e agrícolas, e o cuarto á composición social, organización interna e vida da comunidade.

\section{A FUNDACIÓN}

A primeira noticia do mosteiro de Santa Clara de Allariz data do ano 1282, cando Mateo, cardeal de Santa María in Porticu, sabedor de que a raíña Violante de Aragón decidira fundar un mosteiro de monxas clarisas en Allariz, ordena aos responsables dos Frades Menores da provincia de Santiago e ao custodio, gardián e lec-

1 A edición da colección documental de Santa Clara de Allariz nace do entusiasmo de Mercedes Durany polo estudo da historia de Allariz e nela participamos a propia Mercedes, Francisco Javier Pérez Rodríguez, Mํa Ascensión Enjo Babío, Ma José Losada Meléndez, Amalia López Martínez, Víctor Rodríguez Muñiz e eu mesma, integrantes do grupo de investigación de Historia Medieval da Universidade de Vigo, que me permitiron utilizar o seu traballo antes da súa publicación na colección Gallaecia Monumenta Historica do Consello da Cultura Galega. 
tor do convento franciscano de Ourense, que vixíen e contribúan á súa constitución². Catro anos máis tarde, en 1286, Macías Nunes, procurador da abadesa e monxas de Santa Clara de Zamora, de onde procederán a primeira abadesa e monxas do convento allaricense, aparece en Allariz mercando herdades no Pombal para construír sobre elas o novo mosteiro e ese mesmo ano o rei Sancho IV, a petición da súa nai Violante de Aragón, ordena que se faga o convento de clarisas na vila e acouta o lugar en que será construído. Haberá que esperar a 1288, para que apareza na documentación a primeira abadesa, Sancha Eanes, e aínda máis, ata 1294, para que o bispo de Silves, frei Domingo, poña a primeira pedra da igrexa e a consagre xunto co cemiterio 3 .

En 1292, dous anos antes da consagración, dona Violante outorga un testamento no que promete tomar a orde de Santa Clara no mosteiro de Allariz e acabar a súa vida nel, elixe o coro das monxas na igrexa de Santa María como lugar de enterramento e revoga dúas promesas anteriores nas que sinalaba como lugares de enterramento o mosteiro no que fora soterrada a súa nai Violante de Hungría e o convento de Zamora do que ela mesma fora benfeitora. Como fundadora dota xenerosamente á congregación con 200000 marabedís dos da guerra: 100000 para a obra do mosteiro e 100000 para bens destinados ao mantemento das monxas. Deixa tamén 4000 marabedís para libros e a súa capela, outros 6000 para mercar bens cos que se manteña un capelán que cante misa diaria por ela e os seus familiares, e para o seu enterramento 10000 marabedís, o seu leito e toda a súa roupa ${ }^{4}$.

As motivacións do proceder de dona Violante parecen responder tanto a causas de tipo persoal como político. Dende o punto de vista persoal, a súa actuación en Allariz pon de manifesto o seu interese por ir máis aló do papel de benfeitora para converterse en fundadora dun convento, condición que, sen menoscabo da súa devoción, lle permitiría concentrar nel os seus ingresos e obter unha residencia ocasional na que refuxiarse, xa viúva, lonxe da problemática situación familiar que provocou o enfrontamento dos infantes De la Cerda co futuro rei Sancho IV (Katz 2015: 813 e 826). Todo parece indicar que dende o punto de vista económico a fundación cumpriu as súas expectativas pero non sucedeu o mesmo co proxecto de vida en comunidade posto que non existe ningunha proba de que a raíña vivise nin fose soterrada en Allariz, situación que ela mesma predixo no seu testamento cando afirma que o outorgaba por se «non pudiese tomar la orden asi como sobredicho es» ${ }^{5}$.

2 AHN, Clero, Santa Clara de Allariz, 1429/1.

3 AHPOu, Santa Clara de Allariz, C. 6/13 e C. 6/14; AHN, Clero, Santa Clara de Allariz, 1430/8; AHPOu, Santa Clara de Allariz, Lib. 66/54v; AHN, Clero, Santa Clara de Allariz, 1429/10. Durany pon en dúbida a procedencia zamorana da abadesa Sancha Eanes argumentando unha posible filiación con Gonzalo Eanes de Zarracós (Durany 2009: 136).

4 AHN, Clero, Santa Clara de Allariz, 1429/5. Doazóns confirmadas por dona Violante en 1295, nun documento que inclúe tanto o outorgado no primeiro documento como todo canto puidese doar en diante (AHPOu, Santa Clara de Allariz, C. 6/25).

5 AHN, Clero, Santa Clara de Allariz, 1429/5. García Oro afirma taxativamente que a raíña nin viviu nin foi enterrada en Allariz (García Oro 1999: 144) e tampouco Katz pode demostrar que o seu corpo fose trasladado a Galicia dende Roncesvalles, lugar onde faleceu (Katz 2015: 827-829). 
Segundo García Oro, Violante de Aragón foi a precursora do padroádego real das ordes mendicantes que, entre o último cuarto do século XIII e a primeira metade do XIV, sería utilizado pola Coroa para converter Santa Clara de Allariz na clave de bóveda dun proxecto concibido para «equipar no lonxano reino galego unha cidade rexia» consolidada coa fundación do mosteiro e convertida no centro dun infantado en Galicia; proxecto que, de ter existido, non chegou nunca a plasmarse na realidade (García Oro 1999: 116 e 132-133). Máis realista parece a tese proposta por Pérez Rodríguez, segundo a cal foron a relevancia da condición de vila de reguengo de Allariz e o contrapeso que supuña a fundación fronte ao señorío episcopal de Ourense as razóns da escolla da vila como localización das clarisas (Pérez 2018: 102).

Pese ao decidido apoio real e pontificio á fundación de Santa Clara, a súa consagración resultou accidentada ao verse afectada polo conflito xurdido nos últimos anos do século XIII entre Pedro Eanes de Nóvoa, bispo de Ourense, e os franciscanos da cidade (Pérez 2018: 109-110). A negativa do bispo de Ourense de consagrar a igrexa e o cemiterio motivou que o bispo de Silves, frei Domingo, acudise a Allariz en 1294 para poñer a primeira pedra da igrexa e consagrala xunto co cemiterio, despois de que a abadesa Sancha Eanes llo pedise argumentando que «porque assi, como vós sauedes, a eigleia non se pode fazer como deue si algun bispo y non poer a primeira pedra e non consagrar o çimiterio» ${ }^{6}$.

Fronte aos problemas eclesiásticos que dificultaron o inicio da vida canónica de Santa Clara, o mosteiro foi apoiado sen fisuras por Violante de Aragón, o seu fillo Sancho IV e os monarcas que o sucederon, co outorgamento de abundantes concesións e confirmacións de privilexios (García Oro 1999: 140-143 e Nieto 1990: 122).

A fundación real e a elección que en 1327 o infante don Filipe e a súa muller dona Margarida fixeron da igrexa conventual como lugar de sepultura outorgaron a Santa Clara un prestixio que converteu ao mosteiro no lugar de enterramento de destacados personaxes da nobreza ourensá baixomedieval. Enterramentos acompañados coa fundación de capelas, nas que se oficiarán misas cantadas polas almas dos oferentes, e que serán financiados con espléndidas mandas testamentarias ${ }^{7}$.

De todo o patrimonio arquitectónico e escultórico que deberon xerar os enterramentos (sepulturas, covas, monumentos) e capelas nas que se cantarían misas pola alma do defunto, non quedan na actualidade máis probas materiais que algúns arcos góticos reciclados como peches de vans posteriores ou utilizados para sepulcros na coxía norte do claustro baixo, polo que a única información coa que contamos é a que proporcionan os testamentos e doazóns nos que se ordena a súa cons-

6 AHN, Clero, Santa Clara de Allariz, C. 4900, 1-1-1/7rv e De los Ríos 1973: 931-932.

7 A libertade de sepultura para quen queira ser enterrado no mosteiro de Santa Clara foi concedida por Nicolás IV en 1291 (Domínguez 2009: 441, n. 478). Para o documento de Afonso XI, AHN, Clero, Santa Clara de Allariz, 1430/3. 
trución e mantemento ou os documentos de época moderna nos que se describe o estado das edificacións ${ }^{8}$.

Paradigmático é o caso de Rodrigo Páez de Biedma, copeiro maior do infante don Pedro, que no seu testamento redactado en 1342 pide que o «enterrem dentro, eno moesteyro de Santa Clara d'Allariz, aos pẽes da sepultura en que jaz o inffante don Fillipe; et se acaesçer de tiraren o corpo do inffante dom Fillipe dalli onde agora iaz, mando que en aquelle lugar en que o a el trasladaren que y me deyten, á par da sepultura do dito inffante, en hũa sepultura que seia mays bayxa que a de dom Fillipe»?.

Paradigmático pero non único posto que entre 1302 e 1402 se conservan outros catro testamentos nos que os outorgantes, Gonzalo Eanes de Zarracós e a súa viúva María Vázquez, Tareixa Pérez Feixoo e dona Aldonza, aia da raíña de Castela, mandan que os enterren no mosteiro e fundan senllas capelas ${ }^{10}$.

\section{O DOMINIO}

A formación do dominio de Santa Clara comezou coa concesión, feita por Sancho IV entre 1286 e 1293, de cinco privilexios nos que define, outorga e acouta o espazo no que se construirá o mosteiro; autoriza ás monxas para que poidan dispoñer dos seus bens e entregar ao mosteiro, se así o desexan, o obtido coa súa venda, establecendo como única limitación que este alcance un patrimonio de 40000 marabedís da guerra; e asenta os privilexios e exencións de que gozará o couto"11.

Definido como «aquel lugar do ellas an de fazer el monesterio, por aquellos terminos que Iohan Rodriguez, nuestro alcallde, gelo amojone por nuestro mandado», o couto debeu resultar un espazo moi limitado; de feito, o 12 de xullo de 1293 o rei aumenta a súa extensión autorizando que se faga unha poboación xunto aos edificios conventuais para que nela se establezan «los menestrales de qualesquier menesteres que seam para las obras del monesterio, et sus omes e sus apaniaguados». Os poboadores, presentes e futuros, serán vasalos do convento e recibirán o seu foral, quedando así mesmo exentos de todo tributo rexio salvo o de moeda foreira. E, por último, concede nese mesmo ano dous novos documentos: no primeiro exime ao

8 García González 1990: 232. García Barriuso publica o informe escrito en 1613 polo deán Gerónimo Chirinaga sobre o convento no que afirma que no coro só se permite a sepultura dos corpos reais (dona Violante, o infante don Filipe e dona Margarida) mentres que no corpo da igrexa, ao carón da pía de auga bendita, están soterrados Xoán Rodríguez de Biedma e frei García Blanes (García Barriuso 1990: 84-85)

9 AHN, Clero, Santa Clara de Allariz, 1429/20.

10 AHPOu, Santa Clara de Allariz, C. 6/29. ACO, Monacais, 1765. AHPOu, Santa Clara de Allariz, C. 6/44. AHPOu, Santa Clara de Allariz, 9788, C. 51/1r-2v. Existe un cuarto testamento destas características expedido en 1299 pero a súa deterioración non permite ler o nome da testadora (Arquivo do convento de Santa Clara de Allariz, n.․ㅜ 18).

11 AHN, Clero, Santa Clara de Allariz, C. 1430/8. AHN, Clero, Santa Clara de Allariz, C. 1429/4 e 8. 
convento de permitir a entrada dos oficiais reais para tomar prendas ou facer xustiza, e no segundo estende a exención do pago de todo tributo rexio salvo moeda foreira aos lugares e herdades do mosteiro e aos homes que vivan neles ${ }^{12}$.

Tan importante como o apoio de Sancho IV e dos reis que confirmaron os seus privilexios foi a concesión de dúas bulas: a outorgada por Gregorio XI en 1375 acollendo baixo protección apostólica ao convento de Santa Clara de Allariz e aos seus bens, e a Laudabilis sacra religio de Bonifacio VIII, de 1296, que exime aos conventos da Orde de Santa Clara do pago de todo imposto laico ou eclesiástico, exención que na década dos setenta do s. XIV confirma o bispo auriense don Martiño ao outorgar ás monxas que non sexan obrigadas a pagar nas súas posesión presentes ou futuras o décimo nin outros impostos eclesiásticos nin «quaesquer tallas e colleitas, nen a pagar portagen nen dereyturas nen outras exações et posturas a quaesquer reys e prinçipes ou outras pesõas seglares» ${ }^{13}$.

Na documentación medieval de Santa Clara unicamente en tres ocasións aparecen incumprimentos sobre a exención de peitas ás persoas que vivisen nas casas do convento e traballasen as súas herdades que obrigaron ao mosteiro a reclamar ante os xuíces de Allariz para que se respectase o mandato de Sancho IV. Na primeira, segundo consta nunha sentenza de 1378, foi o concello da vila o que a incumpriu cando «lles lleuauan e querian lleuar los dichos pechos e trebutos cada que en la dicha villa de Allariz eran demandados», razón pola cal a abadesa afirmaba que non podía «auer pobladores ningunos pera las casas del dicho monesterio, nin otrosi lauradores pera las herdades que al dicho monesterio pertenesçian». O xuíz sentencia a favor do convento pese a que o concello de Allariz argumentaba que a súa conduta era debida a que algúns veciños da vila ían residir nas casas do mosteiro, malia non ser caseiros del nin labrar as súas herdades, para non pagar as peitas e tributos co concello ${ }^{14}$. Nas outras dúas reclamacións, realizadas polo mosteiro en 1420 e 1427, o convento denuncia ante os xuíces de Allariz que os cobradores do portádego da vila non gardan os privilexios e exencións de que gozan o convento e os seus dependentes. Reclamacións nas que os xuíces volven dar a razón ao mosteiro, e ordenan aos portageyros da vila que cesen no cobro do portádego e devolvan as cantidades confiscadas como garantía do pago aos familiares e caseyros do mosteiro ${ }^{15}$.

Sobre o concello do couto apenas existen mencións nos séculos medievais, quizais porque as súas pequenas dimensións e a importancia da vila e concello de Allariz anulou ou reduciu drasticamente a súa actividade de forma semellante á que Olga Gallego describe para o ano 1560, cando se produce a súa desmembración (Gallego 1986b: 142). A documentación medieval menciona unicamente tres xuíces:

12 AHN, Clero, Santa Clara de Allariz, C. 1429/8. AHN, Clero, Santa Clara de Allariz, C. 1430/8.

13 Ed. A. López 1915: 46-47. J. H. Sbaralea (1768): 401. Tradución da confirmación da bula de Bonifacio VIII en AHN, Clero, Santa Clara de Allariz, C. 1430/10.

14 AHN, Clero, Santa Clara de Allariz, C. 1430/5.

15 AHPOu, Santa Clara de Allariz, Lib. 47/157r e 156r. 
Xoán Fernández, veciño e morador do couto, aparece en 1473 como mordomo e procurador do mosteiro e xuíz do couto de Santa Clara; Vasco de Nanín, morador en Nanín, vasalo e caseiro do mosteiro, aparece como xuíz do couto en 1487, e Pedro Alfaiate figura en 1496 como morador no couto e xuíz, procurador e mordomo da abadesa de Santa Clara dona María Méndez de Zarracós ${ }^{16}$.

No documento de desmembración do couto outorgado por Filipe II cítanse cinco granxas «anexas ao couto» habitadas por vasalos do mosteiro e situadas en Roiriz, A Torre, Lamas, Nanín e Figueiredo (Gallego 1986b: 139-141 e Sánchez/Enjo 2011-2012: 774 e 778). Posiblemente a extensión do foral do couto a «todos os otros sus lugares, poblados e por poblar, que agora an o averan d'aqui adelante en todos nuestros regnos» e a prohibición da entrada nel aos adiantados, meiriños e oficiais reais, que outorgaría de facto a eses lugares o dereito de poñer neles xuíces e nomear os seus propios oficiais, fosen a causa do nacemento das granxas en núcleos territoriais situados nas inmediacións de Allariz, nas que se concentraba un número relevante de propiedades monásticas habitadas por vasalos do mosteiro ${ }^{17}$.

A única mención conxunta destes cinco lugares na documentación medieval de Santa Clara prodúcese no ano 1489 nunha sentenza de Sancho García del Espinar, alcalde maior do reino de Galicia, contra o concello de Allariz por non respectar as exencións concedidas aos vasalos do couto do convento por Sancho IV e confirmadas polos seus sucesores. Nela os únicos vasalos e caseiros do mosteiro prendados por non participar nun pedido de Xoán Pimentel, señor de Allariz, aos que se prohibe levar o seu gando a pastar nos prados do concello, reciben os nomes de Vasco de Nanin, Rodrigo de la Torre, Alonso de Laja, Gonçalo de Ruyriz e Pero de Figueiredo. Antropónimos que coinciden cos nomes das granxas anexas, salvo no caso de Laja, posible erro do notario que expide o documento. A única información sobre a incorporación a Santa Clara deses lugares é a que aparece nunha doazón de dona Aldonza Nunes en 1289 e nun foro outorgado polo marchante Pedro Gómez en 1485 que revela que, a finais da Idade Media, Santa Clara seguía posuíndo unicamente unha parte das herdades do lugar de Nanín ${ }^{18}$.

Ademais do couto do propio mosteiro nas aforas da vila de Allariz, Santa Clara posúe tamén os coutos de Mourazos, Loureses, Nocelo da Pena e Mañoi ${ }^{19}$.

O couto de Loureses foi doado a Santa Clara no testamento de Xoán Rodríguez de Biedma no ano 1400 «con todas las rendas que eu y ey, e labranças de pan, e seruiçios, e senorio, e outras casquer coussas que me a min y perteesçe de aber en qualquier manera» e cinco anos despois a súa víuva Tareixa López de Orozco, reco-

16 AHPOu, Santa Clara de Allariz, Lib. 10/101r. AHPOu, Santa Clara de Allariz, Lib. 5/24rv. AHPOu, Santa Clara de Allariz, Lib. 14/232r-234r.

17 AHN, Clero, Santa Clara de Allariz, C. 1430, n.ํ 8. Ed. A. López (1927): 27. P. García Barriuso (2002): 31 .

18 AHPOu, Santa Clara de Allariz, Lib. 47/405r. AHPOu, Santa Clara de Allariz, Lib. 6/8r.

19 O couto de Mourazos está situado no actual concello de Verín, Loureses no dos Blancos, Nocelo da Pena en Sarreaus. 
ñece ao mosteiro o dereito á posesión do couto e desembarga as súas rendas e bens. E en 1482 o conde de Monterrei, Sancho de Ulloa, doa ao mosteiro para que recen pola alma da súa muller, Tareixa de Estúniga, unha vaca que o concello de Loureses lle daba anualmente ${ }^{20}$.

O couto de Nocelo da Pena foi tamén entregado ás monxas por Xoán Rodríguez de Biedma no seu testamento, co mesmo tipo de bens e por idénticas razóns piadosas ás alegadas para a doazón de Loureses. A seguinte información sobre o couto procede da pescuda e apeo que realiza en 1496 o seu xuíz Pedro de Pazos ${ }^{21}$.

Pola súa parte, a incorporación do couto de Mourazos ao patrimonio de Santa Clara realizouse mediante o outorgamento de dúas doazóns. Na primeira, Xoán Rodríguez de Biedma e Tareixa López de Orozco outorgan, en 1394, os bens que tiñan na aldea de Mourazos para que o mosteiro faga nela unha granxa, e na segunda, en 1482, Sancho de Ulloa entrega ao mosteiro os tres casais que posúe no lugar, o que converte a Mourazos en couto redondo ${ }^{22}$.

E, por último, o mosteiro de Santa Clara posúe o couto de Mañoi, lugar situado na contorna do río Arnoia, que non é posible localizar na actualidade. Sabemos da súa existencia por un documento do ano 1376 no que Clara Afonso, monxa Santa Clara, afora, entre outros moitos casares e herdades, o seu couto de Mañoi e sinala ao mosteiro como a súa voz a perpetuidade despois da súa morte ${ }^{23}$.

En boa lóxica os catro coutos que posúen as clarisas debían ter un concello, por reducido que fose; porén para os séculos medievais só existen dúas mencións. Na primeira, de 1482, aparece en Loureses un conçejo que, xunto cos omes buenos de Loreses, son responsables da entrega anual dunha vaca o día de Todos os Santos ao conde de Monterrei, renda que este doará ao mosteiro de Santa Clara. En Mourazos haberá que esperar ao ano 1491 para ter a primeira noticia do seu concello, con motivo da usurpación da xurisdición do couto que pretendeu facer Francisco de Estúniga ${ }^{24}$.

Fóra dos coutos, a documentación sitúa as terras de cultivo do convento nos arredores do actual termo municipal de Allariz, situados nos concellos de Rairiz de Veiga, A Bola, Cartelle, A Merca, Taboadela e Paderne de Allariz. Esa disposición parece responder á existencia das granxas da Torre, Nanín, Roiriz e Figueiredo, que concentrarían a maior parte das herdades nas inmediacións da vila.

A maioría desas propiedades adícanse ao cultivo do cereal, e as poucas mencións referidas ao cultivo da vide sitúan as viñas preto de Allariz, nas parroquias de Pazos de San Clodio e Proente e no lugar de Santa Locaia, que conta ademais

20 AHPOu, Santa Clara de Allariz, Ca. 9781/15, 7v-9r. AHPOu, Santa Clara de Allariz, Ca. 9781/15, 7r-9v. AHPOu, Santa Clara de Allariz, Lib. 31/8-9.

21 AHPOu, Santa Clara de Allariz, Ca. 9781/15, 7v-9r. AHPOu, Santa Clara de Allariz, Lib. 14, 232r-234r.

22 AHN, Clero, Santa Clara de Allariz, C. 1430/6 e AHPOu, Santa Clara de Allariz, Lib. 31/8-9.

23 AHPOu, Santa Clara de Allariz, C. 6/46.

24 AHPOu, Santa Clara de Allariz, Lib. 31/8-9 e 17rv. 
cun lagar. Menos numerosas aínda son as viñas situadas nas inmediacións da vila de Monterrei e nas parroquias de Pazos e Tamaguelos, no actual concello de Verín.

\section{RENDAS REAIS, GANDARÍA E AGRICULTURA}

Fundamentais na composición do patrimonio monástico foron as rendas reais outorgadas ao mosteiro de Santa Clara. Concedeunas Afonso XI que en 1329, obedecendo o desexo dos xa defuntos infante don Filipe e dona Margarida, doa ao convento de Santa Clara de Allariz, «para el mantenimiento de su monasterio», catro mil marabedís anuais situados, dous mil deles, nas rendas e dereitos reais en Castrelo de Miño, e os outros dous mil sobre os dereitos reais en Viana e no Bolo, e sinala como responsables directos do cobro os recadadores das rendas (pechos) e dereitos nos ditos lugares, con independencia do tipo de contrato - en renta, o en fialdat, o en otra manera qualquier - que os capacite para exercer ese labor ${ }^{25}$.

Nas décadas que seguiron á concesión foron constantes os incumprimentos na entrega das rendas e as consecuentes protestas e demandas que o mosteiro de Santa Clara se viu forzado a realizar. Na primeira delas, sobre as rendas de Viana e do Bolo, de 1336, o mosteiro denuncia ante Afonso XI a Pedro Fernández de Castro e os tenentes dos castelos de Viana e O Bolo porque lles embargan os 2000 marabedís anuais que el mesmo lles concedera en 1329. O rei afirma estar obrigado a adicar esa renda á intendencia dos castelos e compensa ao mosteiro outorgándolle 2000 marabedís nos décimos do porto de Bayona de Miñor, ao tempo que confirma os outros 2000 situados sobre as rendas e dereitos de Castrelo de Miño, e engade 2000 máis concedidos como un xuro de herdade que debe pagar anualmente a cámara real ${ }^{26}$.

O segundo grupo de demandas xira arredor dos 2000 marabedís situados sobre as rendas e dereitos de Castrelo de Miño e foron presentadas entre 1417 e 1433 ante os xuíces do couto de Castrelo de Miño, do rei en Ribadavia, de don Diego de Estúniga, e do mordomo deste último, Xoán Soutelo, e nas sentenzas de todas elas aparecen os recadadores das rendas como responsables dos impagos ${ }^{27}$. Será en 1432, cando as demandas do mosteiro chegan aos correxedores do rei en Galicia, que se comece a sinalar ao concello e habitantes do couto de Castrelo de Miño como culpables do incumprimento, e os sentencien a cumprir coas obrigas para co mosteiro de Santa Clara e ao pago das custas do xuízo. O mesmo sucede coa sentenza do ano

25 AHN, Clero, Santa Clara de Allariz, C. 1430/3.

26 AHN, Clero, Santa Clara de Allariz, C. 1430/3.

27 Para a comunicación da sentenza: AHPOu, Santa Clara de Allariz, Lib. 47/166r. Para a carta executoria da sentenza: AHPOu, Santa Clara de Allariz, Lib. 47/157r-159v; AHPOu, Santa Clara de Allariz, Lib. 47/165; AHN, Clero, Santa Clara de Allariz, Lib. 47/162; AHN, Clero, Santa Clara de Allariz, C. 1430/3. AHN, Clero, Santa Clara de Allariz, Lib. 47/163; 160r; 215v-217r. Para a doazón da renda do celeiro en Vilanova dos Infantes: AHN, Sigiliografía, Ca. 57/1. AHPOu, Santa Clara de Allariz, Lib. 47/215r-218v. 
1481, ditada polo gobernador do reino de Galicia, Fernando de Acuña, aínda que neste caso o documento evidencia a submisión do concello aos seus señores, os condes de Monterrei e Ribadavia, que reparten a medias o couto, cando «dize que la mytad que cabe a pagar a lo del conde de Monterrey se le paga, e que lo que cabe a pagar al conde de Ribadauia non gelo queria pagar» ${ }^{28}$.

En 1482 un acordo co concello da vila de Baiona revela que tamén a recadación dos 2000 marabedís dos décimos dos portos de Galicia que se realizaba en Baiona causou problemas ao mosteiro de Santa Clara, aínda que de menor envergadura e máis puntuais, segundo o que sabemos pola documentación conservada ${ }^{29}$.

Unha das actividades que se revela como importante durante a Idade Media para o mosteiro é a gandaría. Na documentación de Santa Clara aparecen nos séculos medievais porcos e porcallas formando parte das dereituras entregadas nos foros e con moita menos frecuencia vacas e bois, estes últimos formando parte de xugadas entregadas ao mosteiro en mandas ou doazóns que se utilizan para labrar as terras ${ }^{30}$.

A presenza do gando ovino entre os bens doados ao convento de Santa Clara de Allariz aparece por primeira vez no testamento de Violante de Aragón, cando cita entre os bens incluídos nas compras que fixo para o mosteiro «oueyas e vacas e otros ganados qualesquier» ${ }^{31}$. A cita, pouco relevante ao ser unha relación xenérica que pretende cubrir todas as posibles posesións, verase apoiada polo privilexio outorgado en 1302 por Fernando IV, no que concede ao mosteiro e aos seus pastores a exención total de impostos sobre 1500 cabezas de ovellas e carneiros, permite que os rabaños se movan e pasten libremente e que os pastores poidan cubrir as súas necesidades de leña e cortiza para o calzado nos seus montes. Concesión confirmada por Afonso XI en dúas ocasións: na primeira, de 1319, a petición do convento e coa intercesión do infante don Filipe, o rei aumenta o número de cabezas de gando exentas de impostos ata 2000, e na segunda, de 1326, confirmará ese segundo documento ${ }^{32}$.

É de supoñer que coas exencións concedidas pola Coroa ao mosteiro de Santa Clara de Allariz, este gozou dunha situación privilexiada na cría de gando ovino e na comercialización da la. Porén só aparece unha mención fóra da documentación real, referida ás cen ovellas no couto de Mourazos que Xoán Rodríguez de Biedma doa ao mosteiro do ano 1394, e, segundo Olga Gallego, non existe ningún dato

28 AHPOu, Santa Clara de Allariz, Lib. 47/165 e 162.

29 AHPOu, Santa Clara de Allariz, Libro 47/375.

30 «Hun jugo de boys, dessos meus que y andan, e duas vacas» no testamento de Fernando Eanes de Ourense, alcalde do rei en Monterrei, de 1310 (ACOu, Escrituras 2/41); «hun par de boys» no testamento de Pedro Eanes do Portelo en 1402 (AHPOu, Santa Clara de Allariz, C. 6/51); unha vaca que o concello de Loureses entrega cada ano a Sancho de Ulloa e que este dona a Santa Clara en 1482 (AHPOu, Santa Clara de Allariz, Lib. 31/8-9.); e o gando de Santa Clara ao que o concello de Allariz non permite pastar nos seus prados (AHPOu, Santa Clara de Allariz, Lib. 47/405r).

31 AHPOu, Santa Clara de Allariz, C. 6/25.

32 AHN, Clero, Santa Clara de Allariz, C. 1429/17. 


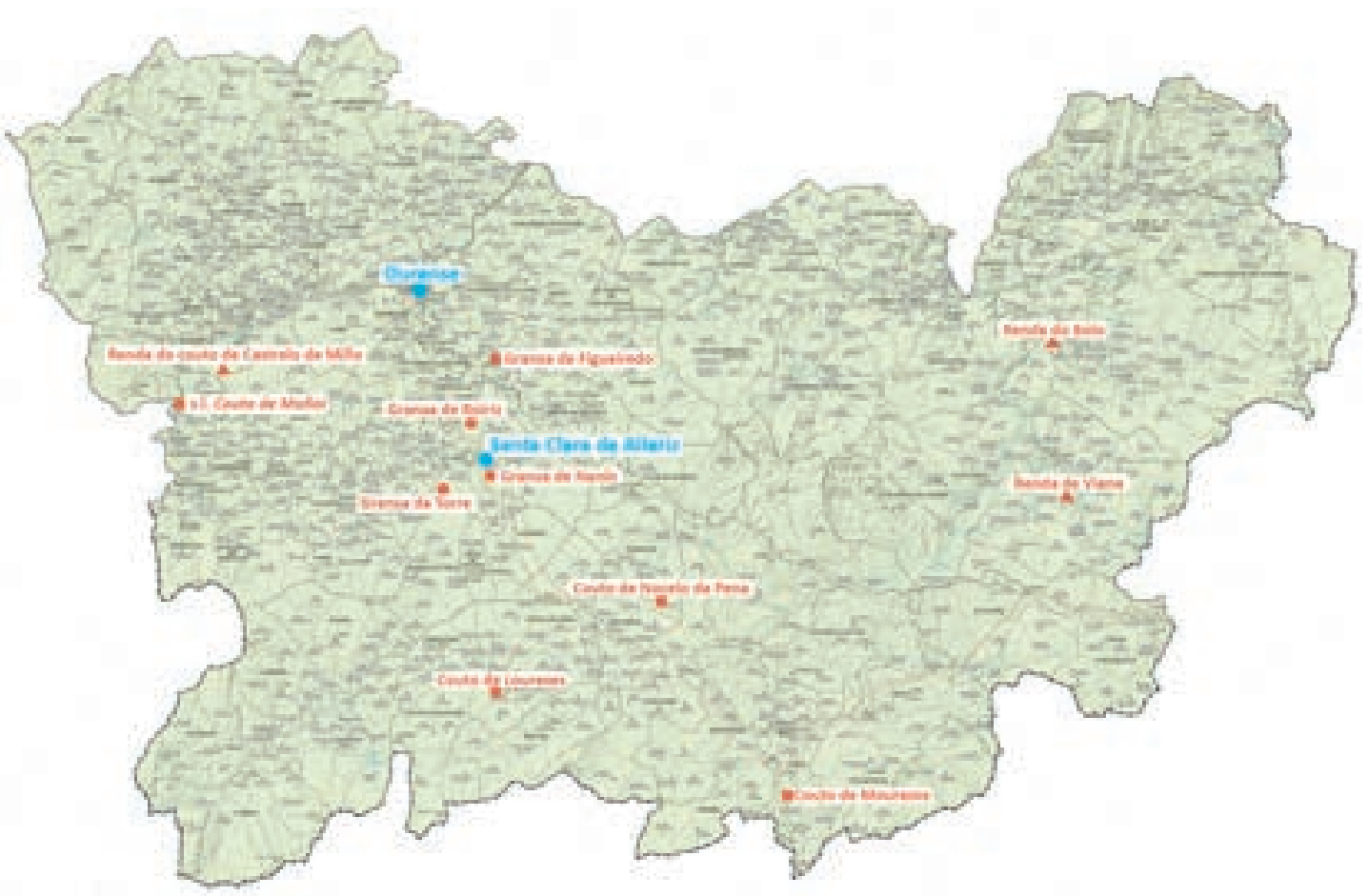

Mapa de coutos, granxas e rendas de Santa Clara de Allariz [Elaboración propia sobre o Mapa de parroquias de Galicia 1:200.000 (2009)].

concreto sobre a cría de gando ovino nin a comercialización da la na Idade Moderna (Rodríguez 1993: 225 e Gallego 1986a: 52-53)33.

Tampouco consta na documentación medieval que o mosteiro de Santa Clara tivese o dereito de presentación de ningunha igrexa, nin sequera sobre Santa María da Pinza, igrexa da diocese de Astorga e situada no actual concello de Viana do Bolo, que si aparece vinculada a el na Idade Moderna (Gallego 1986a: 56 e García Barriuso 1990: 86).

\section{A COMUNIDADE}

Durante a Idade Media, a comunidade do mosteiro de Santa Clara de Allariz estivo organizada xerarquicamente cunha abadesa á fronte da institución, as vigairas, auxiliares ou suplentes en caso de necesidade da abadesa na administración económica, e o convento integrado polas monxas. 
Entre os anos 1288 e 1500 documéntanse trece abadesas á fronte mosteiro. A primeira, Sancha Eanes, que lidera a construción e establecemento da casa no período da fundación entre os últimos anos do século xiII e principios do século XIV; sete no século XIV: Toda Díaz, Urraca Martiz ${ }^{34}$, María Fernández, Constanza López, Eusebia, Leonor e Leonor González, que exercerá o cargo tamén nos primeiros anos do século seguinte; e seis ao longo do século xv: Margarida Gómez, Moor de Limia, Moor de Silván, Leonor Álvarez de Robreda, Sancha Salgada e María Méndez de Zarracós, documentada ata o ano 1507 (vide Táboa 1).

\begin{tabular}{|c|c|c|}
\hline Datas & Nome & Outros cargos e filiación \\
\hline 1288-1309 & Sancha Eanes & \\
\hline $1312-1331$ & Toda Díaz & $\begin{array}{l}\text { Monxa de Santa Clara (1293) } \\
\text { Filla de Pedro Eanes Feixoo e dona Elvira } \\
\text { Irmá de Tareixa Pérez }\end{array}$ \\
\hline 1334 & Urraca Martiz & \\
\hline $1345-1347$ & María Fernández & $\begin{array}{l}\text { Monxa (1310) } \\
\text { Filla de don Fernando Eanes de Ourense: } 109\end{array}$ \\
\hline $1350-1364$ & $\begin{array}{l}\text { Constanza López } \\
\text { Vigaira Berenguela López (1361-1363) }\end{array}$ & \\
\hline 1364 & Eusebia [...] & Filla de Rodrigo González \\
\hline 1376-1379 & Leonor & \\
\hline $1394-1413$ & Leonor González & \\
\hline $1420-1444$ & Margarida Gómez & $\begin{array}{l}\text { Monxa (1404-1408) } \\
\text { Filla de Xoán González de Camba e Sancha } \\
\text { Nunes sobriña de Xoana e Sancha Nunes }\end{array}$ \\
\hline 1446 & Moor de Limia & Curmá de don Xoán de Estúniga \\
\hline 1450 & Moor de Silván & \\
\hline $1454-1480$ & $\begin{array}{l}\text { Leonor Álvarez de Robreda } \\
\text { Vigaira Beatriz Afonso (1454) }\end{array}$ & $\begin{array}{l}\text { Monxa (1429) } \\
\text { Abadesa vella (1481-1482) }\end{array}$ \\
\hline $1480-1493$ & Sancha Salgada & Monxa (1462-1480) \\
\hline $1495-1507$ & $\begin{array}{l}\text { María Méndez de Zarracós } \\
\text { Vigaira Tareixa García (1500) }\end{array}$ & Monxa (1462-1480) \\
\hline
\end{tabular}

Táboa 1. Abadesas e vigairas de Santa Clara de Allariz (séculos XIII-XV).

Entre as funcións das abadesas estaba o coidado espiritual e material das relixiosas, a administración dos bens do mosteiro e a elección dos cargos que debían auxilialas nesas tarefas (Rodríguez 1993: 99-101). Non obstante, debido á irregular conservación dos fondos documentais de Santa Clara, apenas temos noticias sobre as

34 Sen localizar, incluída por Rodríguez Núñez na listaxe de abadesas de Santa Clara (Rodríguez 1993: 297). 
funcións de «nai espiritual» que debían cumprir as abadesas que, segundo os documentos conservados, adicaron os seus esforzos á fundación e á organización da vida comunitaria nos primeiros anos do mosteiro, para centrarse a partir dese momento na adquisición, explotación e defensa das propiedades, na administración dos coutos e terras que integran o dominio monástico e no cobro das cantidades situadas sobre rendas concedidas por Afonso XI e confirmadas polos seus sucesores.

Foi Sancha Eanes, primeira abadesa de Santa Clara por vontade da fundadora Violante de Aragón e nomeada por ela testamenteira en 1302, quen sacou adiante o proxecto. Como testamenteira velou polo cumprimento das últimas vontades da raíña para co mosteiro e como abadesa desempeñou un papel relevante no conflito co bispo de Ourense na consagración da igrexa e o cemiterio en 1294. A súa actuación tamén foi básica na adquisión do patrimonio monástico mediante a compra de propiedades nos arredores do mosteiro e nos actuais concellos de Allariz, Paderne de Allariz, Xunqueira de Ambía e Rairiz de Veiga ${ }^{35}$.

Superado con éxito o momento da fundación, a adquisición do patrimonio produciuse na maior parte dos casos a través de doazóns e mandas testamentarias nas que participaron en maior ou menor medida todas as abadesas.

A explotación das terras de labor realízase no mosteiro de Santa Clara mediante o outorgamento, confirmación, cambios nos bens e licenzas dos omnipresentes contratos forais, que supoñen unha elevada porcentaxe da documentación conservada. As concesións concéntranse sobre todo no século xv e unicamente María Fernández, Mor de Limia e Mor de Silván non outorgan ningún foro, posiblemente pola pouca documentación que dos períodos en que foron abadesas chegou ata a actualidade.

A defensa das propiedades, dereitos xurisdicionais e rendas do mosteiro centrou tamén boa parte da actividade despregada polas abadesas de Santa Clara. Na salvagarda dos bens inmobles tanto urbanos como rurais destacan as actuacións de tres abadesas: Margarida Gómez no século xiv e Sancha Salgada e María Méndez de Zarracós no XV. A primeira consegue que dona Leonor González, para evitar «pleitos e custas, danos e a escomoyon», entregue ao convento os bens que herdara do seu home, o escudeiro Men Rodríguez de Vilaseco, e o pago de dous mil marabedís «por pena e postura» en $1424^{36}$. Tamén co obxectivo de evitar preitos, a abadesa Sancha Salgada chega a un acordo en 1483 co escudeiro Xoán de Robreda para que renuncie ao casal que fora da monxa Leonor Fernández a cambio de percibir mentres viva oitenta marabedís da renda do casal, quedando os catro restantes para Santa Clara como recoñecemento de señorío ${ }^{37}$. Cando o acordo non é posible, óptase por interpoñer unha denuncia ante o xuíz ordinario de Allariz, como sucede na construción sen

35 AHN, Clero, Santa Clara de Allariz, 1429/5; 4900/1-1-1, f. 7r-v; e 1429/6.

36 AHPOu, Santa Clara de Allariz, Lib. 30/414r-415r.

37 AHPOu, Santa Clara de Allariz, Lib. 90/178. 
permiso dunha casa nunha propiedade do mosteiro, na Fontaíña ${ }^{38}$. O último instrumento utilizado para preservar as propiedades do mosteiro foron as pescudas e apeos que en 1496 ordenou María Méndez de Zarracós no couto de Nocelo da Pena e no lugar de Pazos ${ }^{39}$.

A defensa dos dereitos xurisdicionais do mosteiro ocupou boa parte das denuncias presentadas polas abadesas. En 1378 dona Leonor reclama as exencións de taxas no seu couto vulneradas polos oficiais do concello de Allariz e, en 1490, Sancha Salgada presenta unha queixa pola usurpación da xurisdición dese mesmo couto ${ }^{40}$.

No referido ás rendas reais, as primeiras reclamacións efectuadas por unha abadesa, da que non coñecemos o nome, prodúcense en 1336 polos impagos das rendas situadas en Viana e no Bolo, ás que seguirán as protestas sobre as do couto de Castrelo de Miño en 1417, que continuou Margarida Gómez, ao tempo que reclamaba tamén os pagos situados no celeiro de Vilanova dos Infantes en 1424. Nos últimos anos do século XV, en 1482, será Sancha Salgada a abadesa que proteste polo impago dos décimos dos portos en Baiona ${ }^{41}$.

Con frecuencia a importancia dalgúns asuntos levou ás abadesas a saír da clausura e acudir alí onde os xuíces escoiten as súas alegacións e resolvan os seus problemas (Rodríguez 1993: 100). Segundo a documentación, a primeira foi Mor de Limia, que en 1446 acode á aldea de Mourazos para recibir como vasalos aos moradores do couto. En 1450 Mor de Silván recibe en Ourense os bens que a monxa Esteveíña Nunes deixou ao convento. E, por último, Sancha Salgada, despois dunha primeira experiencia fóra do convento en 1474 cando aínda era monxa, volverá saír ata «las puertas de Vydal Ferrero, que son en la freguesya de Santo Esteboo» en 1490 para denunciar ante Nuno Soutelo, xuíz de Allariz, a Xoán Fernández por estar a facer, sen dereito nin permiso, casa nun pardiñeiro na rúa da Fontaíña, que era propiedade do convento, e tres anos despois, en 1493, desprazouse ata a aldea de Vilardevós para ordenar aos seus oficiais que non consintan a Francisco de Estúñiga nin a ningunha outra persoa perturbar a posesión do couto de Mourazos ao mosteiro de Santa Clara ${ }^{42}$.

O segundo lugar na xerarquía da comunidade monástica de Santa Clara ocúpano as vigairas, que actúan en representación da congregación en actos xurídicos realizados no mosteiro ou fóra del, auxiliando á abadesa ou substituíndoa

38 AHPOu, Santa Clara de Allariz, Lib. 4/553r.

39 Para Nocelo da Pena vide AHPOu, Santa Clara de Allariz, Lib. 14/232r-234r. Para Pazos, AHPOu, Santa Clara de Allariz, Lib. 42/4r-6r.

40 AHN, Clero, Santa Clara de Allariz, 1430/5. AHPOu, Santa Clara de Allariz, Lib. 29/42-43 e Lib. $31 / 17 \mathrm{rv}$

41 AHN, Clero, Santa Clara de Allariz, 1430/3. AHPOu, Santa Clara de Allariz, Lib. 47/163 e Lib. 47/160r; 216v-217r e 375.

42 AHPOu, Santa Clara de Allariz, Lib. 29/42-43. AHPOu, Santa Clara de Allariz, C. 6/62. AHPOu, Santa Clara de Allariz, Lib. 4/553r e Lib. 31/18. 
cando non está presente ${ }^{43}$. Entre 1288 e 1500 a documentación recolle tres vigairas: Berenguela López, vigaira de Constanza López entre 1361-1363; Beatriz Afonso, que aparece como vigaira de Leonor Álvarez de Robreda en 1454, e Tareixa García, que exerce baixo o mandato de María Méndez de Zarracós en 150044.

Tanto Beatriz Afonso como Tareixa García aparecen xunto á abadesa do convento no outorgamento dos dous foros nos que figuran, a primeira en 1454, primeiro ano como abadesa de Leonor Álvarez de Robreda, e a segunda en 1500, coa abadesa María Méndez de Zarracós. Coa cautela que impón que só haxa unha mención para cada unha, podemos supoñer que actuaban como auxiliares das abadesas na administración económica ${ }^{45}$.

Distinto é o caso de Berenguela López, que aparece por primeira vez como vigaira substituíndo á abadesa Constanza López nos últimos anos da súa vida, no outorgamento de dous documentos de carácter económico: outorgando unha licenza para aforar en 1361 á monxa dona Tereixa Téllez e aforando parte dun casal en Biduedo con licenza do convento en $1446^{46}$.

Calcular o número de monxas que profesaron no convento ao longo do período medieval é complicado porque depende directamente da cantidade de documentos conservados, que aumentan exponencialmente ao longo do século XV, e dos cambios na redacción da intitulación, na que nos dous primeiros séculos de vida do mosteiro se utilizan normalmente fórmulas xenéricas como «conuento do dito mosteiro», «ao conuento e frayras do dito mosteiro» ou «as frayras e monjas do dito mosteiro», que non identifican a ningunha monxa en particular ${ }^{47}$.

Será a partir do segundo cuarto do xv cando comecen a aparecer as primeiras mencións nas que se identifican polo seu nome unha parte das monxas que asisten ao cabido, como sucede nun foro de 1429 no que aparecen «Beatriz Afonso, e Moor Ferrandez, e Eynes Gomez, e Eynes Gonçalues, e Eynes de Ramoyn, e Tereyja Affonso, e Costança Gomez, e Lyonor de Reboreda, monjas do dito mosteiro, nós todas, e outra grande parte das donas e monjas do dito noso moesteiro que estamos juntadas dentro, ena igleia de Santa Maria a Grande, per canpãa tangida, segundo que avemos de vso e de custume de nos ajuntar pera o tal negoçio» ${ }^{48}$.

Sendo conscientes de que nin sequera no mellor dos casos podemos saber exactamente cantas monxas formaban parte da comunidade, en Allariz conta-

43 Na documentación de Santa Clara non aparece a figura da procuradora interna da comunidade (ou celareira), cuxa función, segundo o estudo de Rodríguez Núñez sobre as mendicantes femininas en Galicia, era encargarse da «percepción de rendas e pagos no mosteiro, o que implicaría o mantemento da contabilidade do mesmo» (Rodríguez 1993: 106).

44 AHPOu, Santa Clara de Allariz, Lib. 19/422. AHPOu, Santa Clara de Allariz, C. 6/45. AHPOU, Casa de Vilanova de Arroxo, Ca. 23942/01. AHPOu, Santa Clara de Allariz, Lib. 16/463r-464v.

45 AHPOU, Casa de Vilanova de Arroxo, Ca. 23942/01. AHPOu, Santa Clara de Allariz, Lib. $16 / 463 r-464 v$.

46 AHPOu, Santa Clara de Allariz, Lib. 19/422 e C. 6/45.

47 AHPOu, Santa Clara de Allariz, C. 6/50 e 52.

48 AHPOu, Santa Clara de Allariz, C. 6, n.․57. 
bilízanse un total de cincuenta e dúas monxas ao longo do período medieval, divididas cronoloxicamente da seguinte maneira: dúas entre 1288 e 1300, once durante o século XIV, vinte na primeira metade do S. XV e trinta e nove entre 1454 e 1500 . A finais da Idade Media, no ano 1499 catorce monxas asisten ás reunións capitulares, cifra que Rodríguez Núñez, no seu estudo sobre as mendicantes galegas, considera alta posto que o seu ingreso estaría posiblemente limitado pola capacidade económica do convento (Rodríguez 1993: 114).

Respecto á composición social, os estudos das comunidades de clarisas na Coroa de Castela e en Galicia destacan a súa aristocratización ao ser escollidas con frecuencia para a educación e forma de vida das mulleres pertencentes á nobreza, condición que se intensifica nas que desempeñan cargos directivos nos mosteiros ${ }^{49}$. O indicio que permite identificar ás nobres de forma máis segura é a utilización de dona ou don antepostos ao seu nome ou ao dalgún familiar directo; seguindo ese criterio e exceptuando as abadesas incluídas na táboa 1, en Allariz aparecen no século XIV seis nobres: Tareixa Rodríguez e Inés e María Rodríguez, viúva e fillas respectivamente de Rodrigo Méndez de Ambía; Inés Rodríguez, filla de Rodrigo Fernández de Limia e neta de Fernando Eanes Churrichao; Berenguela López, filla de Sancho López de Robreda e dona Aldonza Martiz, e Tareixa Téllez, filla de Rodrigo González Tello e dona Xoana.

No século seguinte, en 1439 destaca, pola riqueza dos ben achegados Constanza González de Laza, sobriña de Tareixa Eanes do Carballo, e en 1402 aparece a única monxa que procede a ciencia certa dunha familia burguesa, Esteviña Nunes, filla de Pedro Eanes do Portelo ${ }^{50}$. Coñecemos tamén o caso de María Rodríguez, que é nomeada por primeira vez como asistente ao cabido do 13 de abril de 1496 como criada da monxa Aldonza González e reaparece ao día seguinte convertida en monxa, conversión que podería facernos pensar nunha relación de parentesco ou familiaridade entre ambas ${ }^{51}$.

Se a información sobre as monxas provenientes de familias nobres ou burguesas é escasa, a referida ao resto da congregación tampouco é abundante. A esa escaseza hai que engadir a dificultade de interpretar o valor dos dous termos que con maior frecuencia se utilizan para denominar as integrantes da congregación: monxas e freiras. Durante o século XIV nas intitulacións destácase a abadesa do «convento do mosteiro», termo xenérico para referirse á comunidade monástica, pero dende principios do xv comeza a diferenciarse sistematicamente entre «o conuento e frayras do dito mosteiro $»^{52}$ ou entre «frayras e monjas do dito mosteiro» $»^{53}$, expresións

49 García Oro sustenta esa tese para o conxunto dos mosteiros de clarisas hispanos (García Oro 2006: 138) e Rodríguez Núñez destaca para Santa Clara de Allariz o peso das monxas nobres fronte á única burguesa, Esteviña Núnez, que aparece na documentación do mosteiro nos anos 1402-1433 (Rodríguez 1993 : 47-48). Vide tamén AHPOu, Santa Clara de Allariz, Lib. 66/51v; C. 6/51 e 62.

50 AHPOu, Santa Clara de Allariz, Lib. 24/1r-3r e C. 6/51.

51 AHPOu, Santa Clara de Allariz, Lib. 16/436v-437v e 460rv.

52 AHPOu, Santa Clara de Allariz, C. 6/52.

53 AHPOu, Santa Clara de Allariz, C. 6/55. 
que parecen diferenciar o convento formado polas monxas profesas, das freiras, leigas que terían a función de atender asuntos da comunidade fóra do mosteiro. Porén, a partir de 1437 utilizaranse expresións como «donas e convento do dito mosteyro», «donas e monjas do dito noso moesteiro» ou «todas frairas donas do dito mosteiro» ${ }^{54}$, nas que a hipotética diferenciación desaparece ou cambia de significado (Rodríguez 1993: 109).

Só cinco monxas, as frayras Tareixa Rodríguez, Dominga Estévez e Aldonza Estévez e as monjas Sancha Salgada e Constanza Pérez, actúan en representación do mosteiro durante a Idade Media.

As tres primeiras aparecen en dúas ocasións, na primeira dise que as «frayras do dito mosteiro de Santa Clara» Tareixa Rodríguez e Aldonza Estévez compareceron no claustro da igrexa de Santiago de Allariz xunto cun procurador do convento, Xoán de Santa Clara, para denunciar que os cobradores de diversos tributos na vila de Allariz non gardan os privilexios e exencións do convento e dos seus dependentes ${ }^{55}$. Na segunda, a súa tarefa foi denunciar o impago dos dous mil marabedís anuais que o convento tiña situados nas rendas do couto de Castrelo de Miño. Para iso preséntanse ante os xuíces reais en Ribadavia cun poder da abadesa Margarida Gómez e un escrito de «requerimento e de fronta» no que solicitan que se obrigue a pagar aos arrendadores das rendas sen que se esixa ningunha prenda aos couteiros ou a quen labre as herdades do couto ${ }^{56}$.

No caso das monxas Sancha Salgada e Constanza Pérez, as saídas do convento teñen como obxectivo a xestión de propiedades aforadas. Sancha Salgada actúa cun poder da abadesa e monxas de Santa Clara para aforar no seu nome herdades na aldea de Mourazos $^{57}$. Pola súa parte, Constanza Pérez toma posesión en tres ocasións, entre o 16 de agosto e o 4 de setembro de 1487, dunha viña que finalmente presenta ante Vasco de Nanín, xuíz do couto de Santa Clara, para obter a completa posesión da viña ${ }^{58}$.

Entre os casos descritos aparecen algunhas diferenzas significativas que poderían estar relacionadas coa existencia dos dous grupos de monxas que describe Rodríguez Núñez no seu estudo sobre as mendicantes galegas: o das monxas pertencentes ao «grupo reitor do convento», no que estarían Sancha Salgada e Constanza Pérez, ambas as dúas capitulares, identificacadas como monja e resolvendo problemas relacionados coa xestión de bens aforados; e o das monxas externas, profesas adicadas á xestión de asuntos externos que non se axustan á definición de «serviciais ou conversas», con frecuencia iletradas, ao que poderían pertencer Tareixa Rodríguez, Dominga Estévez e Aldonza Estévez, denominadas freyras, e que partici-

54 AHPOu, Santa Clara de Allariz, C. 6/58 e 57. AHPOu, Santa Clara de Allariz, Lib. 18/497-498.

55 AHPOu, Santa Clara de Allariz, Lib. 47/157r.

56 AHPOu, Santa Clara de Allariz, Lib. 47/160r.

57 AHPOu, Santa Clara de Allariz, Lib. 73/113v-115r.

58 AHPOu, Santa Clara de Allariz, Lib. 5/24r e 24r-v. 
pan na resolución de problemas vinculados coa exención de tributos na vila de Allariz ou coas malas prácticas dos recadadores de rendas reais no couto de Mourazos.

Para Rodríguez Núñez existe unha clara diferenza na extracción social entre os dous grupos pero indica que, máis aló das funcións que cumpren no mosteiro, non existían diferenzas á hora da toma de decisións na comunidade. No caso de Allariz, a falta de documentación non permite comprobar cal foi a participación das tres freiras mencionadas nos asuntos da comunidade (Rodríguez 1993: 111-112).

Sabemos moi pouco da vida cotiá das monxas de Allariz porque os procesos de produción e conservación das fontes documentais do mosteiro preservaron sobre todo documentos relacionados coa administración dos seus bens e as transaccións económicas que dela se derivaron. O único documento que describe un dote é a confirmación que o conde Sancho de Ulloa fai en 1487 da doazón a Santa Clara que o seu mordomo, Afonso de Entrala, fixo das xeiras entregadas polos veciños de Mourazos ao casteleiro de Oímbra «con vna su hija que metiera frayra» ${ }^{59}$.

A documentación si conserva, en cambio, a memoria da protección outorgada ás monxas polo rei Sancho IV, que en 1286 outorga, no mesmo privilexio en que acouta o lugar sobre o que se está a construír o mosteiro, un permiso ás clarisas de Allariz para herdar e dispoñer do seu patrimonio persoal. Protexidas polas concesións de reis e papas, as clarisas puideron conservar, adquirir e administrar os bens que herdaban baixo certas condicións, proceder que quedou rexistrado nas transaccións económicas que realizaron elas mesmas durante a súa vida no mosteiro.

Para administrar os bens que conservan despois da súa entrada en clausura as monxas necesitan o permiso da abadesa e das monxas que integran o convento. Para evidenciar o acordo do mosteiro, os documentos que rexistran as disposicións ou transaccións realizadas utilizan fórmulas que insisten na concesión da licenza e na presenza física de quen autoriza o acto xurídico. Así, no aforamento outorgado por Beatriz e Violante Afonso en 1413 indícase que se fixo «con liçençia et outorgamento de dona Leonor Gonçalues, abadesa do dito moesteiro, que está presente e outorgante a esta carta e ao que se en ela contén» ${ }^{60}$.

Nalgúns casos abadesa e convento van máis aló da simple autorización ou permiso, como sucede en 1350 cando a monxa Berenguela López de Robreda arrenda por dous anos os seus bens en terras de Viana, O Bolo e Trives, indicando que o fai non só por outorgamento e licenza da abadesa Constanza López e do convento, senón tamén polo seu mandado, ou en 1376 cando Clara Afonso, recibida «liçençia e outoridade e con outorgamento de dona Lionor, abadesa do dito mosteiro, e do conuento do dito mosteiro», afora os bens que posúe arredor do río Arnoia por ela e polo mosteiro, e sinala, como receptores das rendas xeradas, a si mesma mentres viva e ao mosteiro despois da súa morte. Proceder menos incisivo pero probablemente máis

59 AHPOu, Santa Clara de Allariz, Lib. 31/13.

60 AHPOu, Marqués de Leis, C. 24/2. 
frecuente é o de incluír ao mosteiro na cláusula de retracto na que se indica que, se os foreiros quixesen vender, debía ser frontada a monxa que afora ou o mosteiro ${ }^{61}$.

As compravendas conservadas na documentación de Santa Clara, todas elas realizadas co previo consentimento da abadesa e convento, son un bo expoñente da capacidade das monxas allaricenses para dispoñer das súas propiedades. Así, en 1408 Margarida Gómez, futura abadesa de Santa Clara, merca a Aldonza Estévez, monxa de Santa Clara de Ribadeo, todo o que esta recibiu como herdo dos seus pais no bispado de Ourense por 300 marabedís, e encarga do pago a frei Fernando de Lugo $^{62}$. E, en 1482, Ines de Ramuín afirma que a abadesa e o convento lle outorgaron a licenza para vender todo o que herdou dos seus pais a don García Díaz de Cadórniga por vinte mil marabedís, «acatando mis enfermedades e grandes dolençias que en mi cuerpo tengo, e pera los remedios dellas» ${ }^{63}$.

A venda dunha herdade en Mazaira que no ano 1331 fixeron ao mosteiro de Montederramo as irmás e monxas Inés e María Rodríguez semella ser o último chanzo na superación do enfrontamento entre a súa familia e o mosteiro cisterciense. Enfrontamento do que nos informan tres documentos outorgados por dona Tareixa Rodríguez, nai de Inés e María e tamén monxa en Santa Clara. No primeiro dos cales, datado ca. 1303, doa a Santa María de Montederramo lugares en Santa Mariña de Asadur polos grandes danos que o seu irmán fixera ao mosteiro; no segundo, de 1319, fai unha nova doazón ao mosteiro «por emenda das malfeytorias e das roubas» que lle fixera o seu fillo Xil Nunes neses mesmos lugares; e, por último, en 1329, confirma a renuncia que ela e o seu marido fixeran sobre herdades en Costa de Asadur, renuncia que, polo que parece, nunca cumprira ${ }^{64}$. Os documentos de 1303 e 1319 foron outorgados ante notario no mosteiro de Santa Clara sen que conste a licenza da abadesa e do convento, comportamento sen ningún precedente coñecido entre as integrantes do convento e difícil de explicar a pesar da condición social da outorgante.

Exemplo da presión que o mosteiro chegou a exercer sobre as mulleres que se acollían á súa hospitalidade foi o acontecido con dona María López de Lemos, que no testamento que redactou en 1313 revoga a doazón que fixera a Santa Clara argumentando que a doazón non era «perfeyta nem acabada» e que a fixo estando presa no mosteiro contra a súa vontade, sen poder saír e levada ao mosteiro mediante engano; que a abadesa e donas lle foron «moyto engratas» e que non tiñan aínda a posesión nin o dereito dos bens previamente doados, razóns suficientes para unha revogación ao non ter ela ingresado no mosteiro, ás que engade que «o dereyto

61 AHPOu, Santa Clara de Allariz, Lib. 30/408v-409v. AHPOu, Santa Clara de Allariz, C. 6/46. AHPOu, Santa Clara de Allariz, Lib. 15/6.

62 «...os quaes ditos trezentos marabedis da dita moneda me por ela deu e pagou frey Fernando de S[...] de Lugo en dineiros feitos e en panores de prata, que os montou a meu prazer e os eu reçeby en façe do notario e testemoias desta carta», Arquivo do convento de Santa Clara de Allariz, n.․․ 17.

63 AHPOu, Santa Clara de Allariz, Protocolos, 3322.

64 ACO, Monacais, Montederramo, n.으 2193, 1767, 2001 e 2160. 
manda que, se home ou moller de orden algũa cousa der a aquel moesteyro hu está en orden et se despoys del seýr, que leue todo aquelo que lle deu», deixando no aire a dúbida sobre un posible ingreso no convento do que despois se arrepentiu ${ }^{65}$.

Que en 1380 as Cortes de Soria establezan que os mosteiros fosen considerados como herdeiros directos dos bens obtidos en calquera maneira polas monxas, sen necesidade de testamentos específicos, podería explicar que non se conservase na documentación de Santa Clara ningún testamento outorgado por monxas ou freiras (Rodríguez 1993: 175). Posiblemente tamén facilitou á institución reclamar os seus dereitos sobre o herdo das monxas, tal e como sucedeu coa entrega ao mosteiro que fixo Nuno González, párroco de Santiago de Allariz, dos bens da monxa defunta Esteveíña Nunes, filla de Pedro Eanes do Portelo, por entender que retelos era unha práctica abusiva contra a institución, herdeira da monxa nos bens usurpados ${ }^{66}$.

Fóra do convento pero traballando para el aparecen os mordomos, oficiais que participaban na administración do patrimonio e na recadación de rendas, desenvolvendo o seu traballo en lugares nos que as monxas posuían dereitos xurisdicionais ${ }^{67}$. A eles súmanse os procuradores, que se ocupan das reclamacións, demandas e preitos en defensa das propiedades, dos dereitos xurisdicionais e do pago de rendas que conforman o patrimonio monástico, labores que os obrigan a presentarse ante os xuíces ou realizar desprazamentos que poden ocupar varias xornadas para facer pescudas e apeos de bens. Documéntanse ao longo da Idade Media dezanove procuradores de Santa Clara, algúns dos cales exerceron simultaneamente o cargo de mordomo. Cítanse tamén entre os traballadores dependentes do mosteiro dous criados, dous acemeleiros da abadesa e catro carpinteiros, sen que saibamos deles nada máis que os seus nomes e oficios.

En conclusión, o mosteiro de Santa Clara de Allariz, fundado pola raíña Violante de Aragón na vila real de Allariz, agasallado polos seus sucesores no trono con substanciosas cantidades de diñeiro situadas sobre rendas reais e elixido pola nobreza da contorna como casa das súas fillas e retiro das matriarcas viúvas, revélase como un importante centro de poder feminino en terras do bispado de Ourense. Lamentablemente unha documentación moi deturpada polos problemas de conservación dificulta seguir ás clarisas de Allariz na súa vida dentro do mosteiro, da que unicamente se conservan algúns flashes nos que aparece unha nai compartindo vida coas súas fillas tamén monxas, o cabido autorizando a venda dos bens doutra monxa para adquirir os remedios que alivien a súa enfermidade ou abadesas e freiras saíndo da clausura para defender os intereses da comunidade.

65 Lorenzo 2020: 955-963, doc. 774.

66 AHPOu, Santa Clara de Allariz, C. 6/62.

67 Segundo Olga Gallego, os mordomos completaban esas dúas funcións coa comercialización do que a comunidade non consumía, actividade que non quedou plasmada na documentación medieval do mosteiro (Gallego 1886a: 58). 


\section{REFERENCIAS BIBLIOGRÁFICAS}

- Domínguez SáncheZ, Santiago (2009): Documentos de Nicolás IV (1288-1292) referentes a España, León, Universidad.

- DuRany Castrillo, Mercedes (2009): «El convento de Santa Clara de Allariz (1282-1312)», en Raquel Casal/José Miguel Andrade/Roberto J. López (eds.), Galicia monástica. Estudos en lembranza da profesora María José Portela Silva, Santiago de Compostela, Universidade, 131-151.

- Gallego Domínguez, Olga (1986a): «Dominio y bienes de Santa Clara», en Santa Clara de Allariz. Séptimo Centenario de la Fundación. Boletín Auriense, Anexo 5, Ourense, 43-62.

- Gallego Domínguez, Olga (1986b): «El coto de Santa Clara de Allariz», en Santa Clara de Allariz. Séptimo Centenario de la Fundación. Boletín Auriense, Anexo 5, Ourense, 139-143.

- García BarRiuso, Patrocinio (1990): «Documentación sobre la fundación, privilegios y derechos históricos del Monasterio de Santa Clara de Allariz», en J. P. Paz (coord.): Santa Clara de Allariz: historia y vida de un monasterio, Ourense, Servizo de Publicacións da Deputación de Ourense, 11-107.

- García GonzáLEZ, Miguel Ángel (1990): «El arte en el monasterio de Santa Clara de Allariz», en J. P. Paz (coord.): Santa Clara de Allariz: historia y vida de un monasterio, Ourense, Servizo de Publicacións da Deputación de Ourense, 229-256.

- García Oro, José (1999): «La primitiva instalación de las clarisas en Galicia», en J. P. Paz (coord.): Santa Clara de Allariz: historia y vida de un monasterio, Ourense, Servizo de Publicacións da Deputación de Ourense, 109-145.

- GARCía ORo, José (2006): Los franciscanos en España: historia de un itinerario religioso, Santiago de Compostela, El Eco Franciscano.

- Garcimartín Muñoz, N./Sergio Santos Otero (2011-2012): «Documentación del archivo del Convento de Santa Clara de Allariz», Boletín Auriense, 41-42, 517-546.

- GonzÁLEZ Borrajo, Maa del Pilar (1986): «Evolución histórica del Monasteiro de Santa Clara de Allariz», en Santa Clara de Allariz. Séptimo Centenario de la Fundación. Boletín Auriense, Anexo 5, Ourense, 87-93.

- Katz, Melisa R. (2015): «A Convent for La Sabia. Violante of Aragón and the Clarisas of Allariz», en J. D'Emilio (ed.), Culture and society in medieval Galicia: a cultural crossroads at the edge of Europe, Leiden, Brill, 812-836.

- Limia Gardón, Francisco Xosé (1990): «El Convento de Santa Clara de Allariz entre los siglos XV al XVIII», en J. P. Paz (coord.): Santa Clara de Allariz: historia y vida de un monasterio, Ourense, Servizo de Publicacións da Deputación de Ourense, 147-199. 
- López, Atanasio (1915): La Provincia de España de los Frailes Menores. Apuntes histórico-críticos sobre los orígenes de la Orden Franciscana en España, Santiago, El Eco Franciscano.

- LóPEZ, Atanasio (1927): «Apuntes históricos sobre el convento de Santa Clara de Allariz (Siglos XIII y XIV», BCMO, VIII:172, 173, 174, 8-18, 25-32, 49-53.

- LoRENZO, Ramón (2020): Colección documental do mosteiro de Montederramo, Santiago de Compostela, Consello da Cultura Galega.

- Mapa de parroquias de Galicia 1:200.000 (2009): A parroquia en Galicia. Apéndice estatístico e cartográfico, Xunta de Galicia, SITGA.

- Nieto Soria, José Manuel (1990): «Franciscanos y franciscanismo en la política y en la corte de la Castilla Trastámara (136-1475)», Anuario de Estudios Medievales, 20, 109-131.

- PÉREZ Rodríguez, Francisco Javier (2018) «Los mendicantes en el reino de Galicia: instalación, problemas y adaptación (siglos XIII-XIV)», en David Chao Castro/ Isabel González/Fernando López Alsina (coords.), Franciscanos en la Edad Media. Memoria, cultura y promoción artística, Edizioni dell'Orso, 97-113.

- Reglero de la Fuente, Carlos Manuel (2021): Monasterios y monacato en la España medieval, Madrid, Marcial Pons.

- Ríos, A. de los (1973): Historia social, política y religiosa de los judíos en España y Portugal, Madrid, Aguilar.

- RodríGuez MuÑIz, Clara Cristela (1993): Los conventos femeninos en Galicia. El papel de la mujer en la sociedad medieval, Lugo, Deputación Provincial.

- SÁncheZ Ferro, Pablo/Ma Ascensión Enjo BABío (2011): «Achega ao estudo da "desmembración” do couto do Convento de Santa Clara de Allariz», Boletín Auriense, 41-42, 765-788.

- SBARALEA, Giovanni (1768): Bullarium franciscanum, Roma, Sacrae Congregationis de Propaganda Fide. 

Sabean quantos este liuro virem... A recepción galega do legado historiográfico e haxiográfico do Rei Sabio na primeira metade do século XIV

\author{
Ricardo Pichel \\ Universidad de Alcalá \\ Instituto da Lingua Galega (Universidade de Santiago de Compostela)
}

DOI: $10.17075 /$ gtax.2021.008 
*A realización deste traballo enmárcase nos proxectos de investigación «PTGM. Patrimonio textual na Galicia medieval: prosa documental e literaria» do Instituto da Lingua Galega (Universidade de Santiago de Compostela) e «HERES. Patrimonio textual ibérico y novohispano. Recuperación y memoria» da Universidad de Alcalá (CM, 2018-T1/HUM-10230), en colaboración con «LEHIAL. El legado historiográfico de Alfonso X (1270-1350): teoría histórica, tradiciones literarias y textos inéditos» (MCIU PGC2018-097250-B-IO0, Universidad de Salamanca) e «MELE. Da memória escrita à leitura do espaço: Pedro de Barcelos e a identidade cultural do Norte de Portugal» (FCT POCI-01-0145-FEDER-032673, Universidade do Porto). Agradezo as valiosas indicacións de Mariano de la Campa Gutiérrez, Miguel García-Fernández, Ramón Mariño Paz, Clara Pascual-Argente, Rosa María Rodríguez Porto, Harvey L. Sharrer, José António Souto Cabo e Xavier Varela Barreiro, que permitiron mellorar significativamente este traballo. A cita que encabeza o título procede da Crónica troiana patrocinada por Fernán Pérez de Andrade en 1373 (BNE ms. 10233, f. 100r; BITAGAP manid 1068). As siglas empregadas no artigo son as seguintes: $\mathrm{ACOu}=$ Arquivo da Catedral de Ourense, $\mathrm{AHN}=$ Archivo Histórico Nacional (Madrid), AHPOu = Arquivo Histórico Provincial de Ourense, ANTT = Arquivo Nacional da Torre do Tombo (Lisboa), ARAG = Arquivo da Real Academia Galega (A Coruña), ARG = Arquivo do Reino de Galicia (A Coruña), BAV = Biblioteca Apostolica Vaticana (Città del Vaticano, Roma), BCB = Biblioteca da Casa de Bragança (Vila Viçosa), BDH = Biblioteca Digital Hispánica, BGHUsal = Biblioteca General Histórica de la Universidad de Salamanca, BL = British Library (Londres), BMP = Biblioteca de Menéndez Pelayo (Santander), $\mathrm{BnF}=$ Bibliothèque nationale de France (París), BNE = Biblioteca Nacional de España (Madrid), BNP = Biblioteca Nacional de Portugal (Lisboa), BPE = Biblioteca Pública de Évora, GE = General Estoria, HSA = Hispanic Society of America (NY); RBME = Real Biblioteca del Monasterio de El Escorial. 


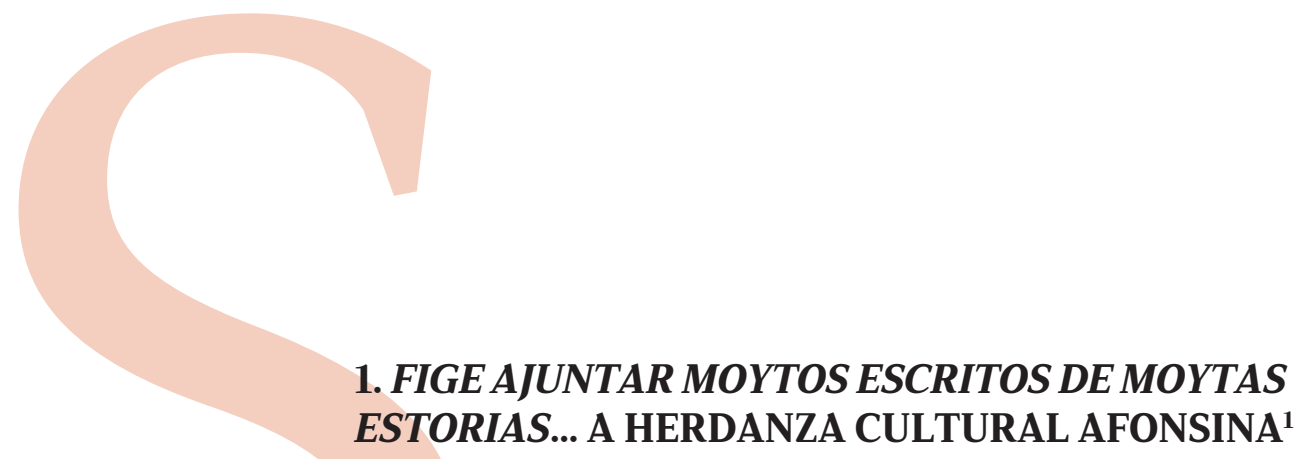

Como é ben sabido, Afonso X concibiu e despregou de maneira colo$\mathrm{sal}^{2}$ diferentes iniciativas culturais ao longo das case catro décadas nas cales se forxou a súa traxectoria política e intelectual, primeiro como infante e despois como rei, en campos tan diversos como a historia, a ciencia, o dereito, a poesía, a música ou a cultura visual $^{3}$. Á marxe da súa obra lírica - relixiosa e profana-, para a que se serviu da tradición lingüística e literaria galego-portuguesa, boa parte da produción derivada dos restantes saberes cultivados foi coñecida e, dun modo ou doutro, asimilada máis alá da corte rexia castelá, dentro e fóra dos lindes da Coroa, en particular nos diferentes espazos culturais activos no Occidente peninsular desde finais do século XIII. No que respecta ao estudo dos «feytos antigoos», as fondas implicacións ideolóxico-políticas e o vasto e diverso cúmulo de coñecementos compilados nelas caracterizan as dúas iniciativas cronísticas do Rei Sabio. Conectando coa omnipresente tradición isidoriana, orientounas, por un lado, cara ao pasado hispánico, é dicir, o relato da historia das comunidades e territorios supeditados ao seu dominio ou influencia (a Estoria de España); e, por outro, cara ao pasado universal, isto é, a crónica, moito máis ambiciosa, de todos os feitos acontecidos no mundo desde a súa creación (a General Estoria). Poucas décadas após a súa concepción, ambas as empresas historiográficas viaxaron e circularon a través de diferentes iniciativas de copia, tradución e refundición tanto no reino portugués como por terras galegas. O mesmo aconteceu co portentoso tesouro haxiográfico —os cinco libros das Vitae sanctorum - compilado por un dos seus máis estreitos colaboradores, Bernardo de Brihuega, concibido, en gran medida, para a súa integración na General Estoria. Por último, para alén doutros ámbitos do saber ${ }^{4}$, a pro-

1 A cita que encabeza esta epígrafe procede da Geral Estoria galega (RBME ms. O.I.1, f. 1v). Un panorama xeral sobre os textos historiográficos galegos de procedencia afonsina pode lerse en Lorenzo (2000: 367-390; 2002: 94-107), Rodríguez (2003), López Martínez-Morás (2007: 458-464) ou Corral Díaz/Pichel et alii (2020: 67-99).

2 En referencia á acertada expresión empregada por Joseph T. Snow (2020:14-15) no seu prólogo á monografía colectiva Alfonso el Sabio: cronista y protagonista de su tiempo (Fidalgo ed. 2020: 11-24).

3 Véxanse, entre outras, as aproximacións de Procter (2002), Márquez Villanueva (2004), Bautista (2014c) ou Doubleday (2015) para un repaso sobre a transcendencia da produción afonsina en termos de renacemento e renovación cultural.

4 A literatura científica de procedencia afonsina tamén tivo o seu eco en terras occidentais, como demostra a tradución parcial xudeo-portuguesa do Libro complido en los judizios de las estrellas feita en 1411 
dución lexislativa afonsina foi outra das esferas de coñecemento de maior impacto en termos de asimilación social e cultural, como demostran os numerosos vestixios -máis de medio centenar- da tradución das Sete Partidas tanto en Galicia como en Portugal, así como doutros regulamentos normativos coetáneos impulsados desde a corte rexia, como as Flores de Dereito, texto elaborado polo xurista italiano Giacomo Giunta no segundo cuartel do trescentos, ou o xa afonsino Foro Real 5 .

\section{A RECEPCIÓN DA HISTORIA UNIVERSAL DO REI SABIO}

A General Estoria é unha das principais mostras culturais do intricado proxecto sociopolítico e universo intelectual do Rei Sabio, concibida como unha historia universal desde a orixe da humanidade até o século XIII, cando foi proxectada e compilada a partir de ca. 1265-70. A pesar da existencia na época doutras crónicas universais (por exemplo, o Pantheon de Godofredo de Viterbo), o singular proxecto afonsino destacou por moitas razóns: por un lado, a reivindicación do uso do vernáculo fronte ao latín, a lingua de poder e de cultura imperante até ese momento; por outro, o alcance enciclopédico e a diversidade dos contidos recollidos e incorporados á obra, así como a súa complexidade estrutural, a riqueza e variedade das fontes empregadas ou o refinamento estilístico. O intenso labor de investigación, tradución, compilatio e ordinatio do taller historiográfico promovido por Afonso X cristalizou nunha rigorosa organización dos contidos por idades, reinados e pobos, ben como na exexese das fontes a través de comentarios, glosas e digresións propiciadas polo propio equipo de sabios colaboradores que traballaban so o mecenado do monarca. Do punto de vista cronolóxico, os contidos escolmados organizábanse consonte unha armazón temporal baseada nas seis idades estabelecidas por Agostiño de Hipona de acordo cos feitos do Antigo e do Novo Testamento; porén, non hai unha correspondencia biunívoca entre idade bíblica e sección da obra, debido á diferente extensión

en Torres Vedras (Lisboa) a partir da versión castelá promovida por Afonso X (BETA texid 1018; BITAGAP texid 1224). O manuscrito alxamiado, identificado por Gerold Hilty (1982), consérvase hoxe na Bodleian Library de Oxford (Laud Or. 310; BITAGAP manid 1486); véxase unha recapitulación en Fernández Fernández (2013: 130-131).

5 Por limitacións de espazo, non poderemos abordar aquí o referido á recepción da produción xurídica afonsina na Galicia baixomedieval, para o que remitimos a un recente estado da arte en Corral Díaz/ Pichel et alii 2020: 135-211 e, en particular, para a recepción e difusión das Sete Partidas, en Pichel 2021a (cf. Domingues 2021 para o ámbito portugués). No ámbito galego conservamos, máis alá dalgunhas referencias indirectas a exemplares hoxe perdidos, unha ducia de testemuños fragmentarios de case todas as Partidas —salvo da segunda- (BITAGAP texid 14545), ademais dalgúns fragmentos das Flores de Dereito (BITAGAP texid 9842), do Foro Real (BITAGAP texid 9841 e manid 4094) e, xa na época de Afonso XI, do Ordenamento de Alcalá (BITAGAP texid 9428). Véxase un panorama xeral actualizado sobre a tradución entre linguas vernáculas na Galicia medieval en Pichel (2021c); véxase tamén Rodríguez (1999), Noia Campos (2004) e Ferreira (2012). 
dos relatos incluídos en cada parte. Deste modo, a pauta estrutural que vertebrou a progresión cronolóxica de cada unha das seccións da General Estoria veu dada polos Canones chronici de Eusebio de Cesarea e Xerome, o que permitiu, ademais, compatibilizar e complementar o relato sagrado coa máis diversa materia profana.

Das seis partes proxectadas no obradoiro afonsino completáronse, aínda que en diferente grao de compilación, as catro primeiras ${ }^{6}$, ficando a quinta avanzada mais non finalizada e a sexta parte nun estadio redaccional moi incipiente ${ }^{7}$. Da primeira e da cuarta parte, conservamos dous manuscritos elaborados na corte rexia, ademais dunha trintena de copias posteriores elaboradas entre os séculos XIV e XVI ${ }^{8}$.

\subsection{A General Estoria no Occidente peninsular. A versión galega de GE1}

No reino portugués, a General Estoria sería moi probabelmente coñecida xa no reinado de D. Dinis (1279-1325) e a súa influencia comeza a ser manifesta desde o segundo cuartel do trescentos até ben entrado o século XVI. É o que acontece coa Crónica de 1344, na cal certas referencias a Hércules como fundador da monarquía hispánica e a reinterpretación dalgunhas pasaxes do libro da Xénese evidencian o coñecemento por parte do Conde de Barcelos da historia universal afonsina ${ }^{9}$. Pola mesma época testemúñase a lectura comentada do códice eborense $R$ da General Estoria, no cal se rexistran numerosas correccións e glosas ao Salterio afonsino da responsabilidade dun avezado lector portugués ${ }^{10}$. Porén, o período de máis intensa recepción da obra en Portugal é o século XV, en particular no seo da corte dos Avis, para a que se coñecen diferentes indicios indirectos da súa circulación e difusión por parte de monarcas, infantes e cronistas, para alén dun conxunto de vestixios fragmentarios que dan conta

6 O magno proxecto afonsino continuaba en andamento por volta de 1280, cando o copista Martín Pérez de Maqueda finaliza a versión rexia da cuarta parte da General Estoria. Porén, o falecemento do monarca en 1284 paralizou definitivamente a continuación dos traballos de harmonización e conciliación dos materiais previstos para as últimas dúas partes da obra.

7 Máis alá da sexta parte, só coñecida a través dun borrador (Sánchez-Prieto Borja/Almeida 2009) e dalgúns outros testemuños moi fragmentarios (BETA manid 6064), aínda continuamos sen coñecer o contido de certas seccións de GE3 e, sobre todo, de GE5. Conservamos dous manuscritos afonsinos da primeira (BNE ms. 816; BETA manid 1055) e da cuarta parte (BAV ms. Urb. Lat. 539; BETA manid 1077), ademais dunha trintena de copias elaboradas entre os séculos XIV e XVI (BETA texid 1008).

8 Para a tradición textual e manuscrita da General Estoria (BETA texid 1008) véxanse, entre outros, os traballos de Gómez Redondo (1998: 703-704, 2007: 4011-4019), Fernández-Ordóñez (1992, 2002a), Sánchez-Prieto Borja (2009b: I, xliii-lxxv; 2021), Almeida (2013, 2018) e Bautista (2020b). O texto crítico integral pódese ler na edición coordinada por Sánchez-Prieto Borja (2009a; cf. 2016).

9 Véxase ao respecto os recentes traballos de Miranda (2015) e Ferreira (2015: 65-68; 2019: 197-216).

10 Trátase do ms. CXXV/2-3 da Biblioteca Pública de Évora (BETA manid 1062) que, xunto co ms. RBME I.I.2 (BETA manid 1076), conforma a coñecida como Estoria de la Biblia, elaborada por volta de 1330-40 no círculo cortesán da raíña dona María de Portugal (Rodríguez Porto 2012a: II, 339-453). O manuscrito eborense preserva as seccións bíblicas da segunda e terceira partes da General Estoria, así como o Eclesiástico de GE4. Para os comentarios, redixidos nunha variedade lingüística fortemente interferida polo castelán, presentes neste códice, véxase Leite (2017a). 
dun proxecto de tradución portuguesa do texto afonsino ${ }^{11}$. Finalmente, no século XVI, o Auto de la Sebila Casandra revela, de novo, o coñecemento da General Estoria, neste caso por parte de Gil Vicente, ao inspirarse no relato da singular profecía de Casandra integrado na crónica universal do Rei Sabio (Leite 2009, 2017b).

Polo que respecta ao ámbito territorial e cultural galego, desde mediados do trescentos e durante o terceiro cuartel desta centuria, asistimos á tradución e copia de, como mínimo, unha parte significativa do volume textual transmitido nos dous primeiros libros da General Estoria. O códice escurialense O.I.1 (BITAGAP manid 1089; Fig. 1), coñecido coa sigla $F$, é unha tradución parcial da primeira parte (GE1) da compilación afonsina ${ }^{12}$. É o principal testemuño occidental da obra, pois consérvase (case) íntegro e representa o vestixio material máis antigo coñecido (mediados do século XIV). Como é sabido, GE1 abrangue os cinco libros do Pentateuco -isto é, os relatos bíblicos correspondentes ás dúas primeiras idades e ao comezo da terceira: da Creación ao Diluvio e de aí ao reinado de Abraham até a morte de Moisés-e, para alén dos materiais bíblicos, nel foron obxecto de combinación fontes moi diversas de contido laico, como Isidoro de Sevilla, Plinio, Lucano, Ovidio ou os mitógrafos medievais (Sánchez-Prieto Borja 2009b: I, lxxc-xcii; 2021). O tal códice escurialense (F) transmite no seu estado actual máis da metade da Xénese, nomeadamente os seis primeiros libros e a metade do sétimo, na altura do relato da loita de Xacob co anxo (cap. 22). A coidada factura do manuscrito, que o individualiza fronte aos restantes testemuños da tradición galego-portuguesa, reflíctese especialmente na decoración e disposición das iniciais capitulares ${ }^{13}$ (Fig. 1).

11 Coñécense seis fragmentos da primeira e da segunda parte da tradución portuguesa da Geral Estoria datados entre os séculos XV e XVI (BITAGAP texid 1244). Cinco deles consérvanse no Arquivo Nacional da Torre do Tombo - Caixa 13, maço 10, n. 30 (BITAGAP manid 5893); Caixa 21, n. 29 (BITAGAP manid 1495); Caixa 21, n. 30 (BITAGAP manid 1502); Caixa 21, n. 31 (BITAGAP manid 1501); Caixa 21, n. 32 (BITAGAP manid 1500)_ e un máis no Arquivo Distrital de Castelo Branco (CNCVL / 01 / Livro 014 / Maço 02; BITAGAP manid 3746). Véxase un estado da arte sobre a recepción portuguesa da General Estoria no XV en Leite (2017b), e, en particular, para a corte dos Avis, en Leite (2012: 241-269).

12 O texto foi editado por Martínez-López (1963) -inútil sen a exhaustiva revisión e corrección realizada por Lorenzo/Couceiro Pérez (1999a e 1999b) - e parcialmente por Sousa (1964: 2-62); e tamén está accesíbel no CGPA. Hoxe contamos tamén cunha nova transcrición paleográfica deste testemuño e da súa retradución (cf. infra), elaborada no marco dos proxectos PTGM e HERES, accesíbel no EGPA-lit (Escritorio Galego-Portugués Antigo. Textos Literarios).

13 Un primeiro intento de descrición codicolóxica deste manuscrito en Campos Souto (1997). Máis alá da alternancia cromática (en tinta azul e vermella) e a diversa ornamentación afiligranada, é moi salientábel a xerarquización das capitais de acordo coa presenza de determinadas fronteiras textuais ou estruturais —como o cambio de idade ou de libro-, para as que se reservan iniciais de grandes dimensións (9-10 unidades de pautado), a diferenza das seccións capitulares menores, para as que se empregan capitais de entre 2 e 6 unidades de pautado (dependendo se é inicio de rúbrica ou de texto). Esta disposición das iniciais capitais, así como o propio acabado da ornamentación, parecen remitir a un modelo decorativo moi próximo ao códice considerado rexio da GE1 (BNE ms. 816), o cal resulta de sumo interese para imaxinarmos a materialidade dunha versión, como se lembrará, aínda non depurada do punto ideolóxico —como é o caso do antígrafo de F- O testemuño K da segunda parte da General Estoria (BNE ms. 10237; BETA manid 1067), de cronoloxía similar (ca. 1340), representa un caso equivalente, do punto de vista textual (Almeida 2009: I, lxxix-lxxx) e material, ao do códice galego, o que merecería un estudo conxunto, tendo en conta, ademais, que, para alén de $K$, conservamos outro testemuño desa versión preliminar da GE2 nos materiais afonsinos incorporados na Historia troyana de Pedro I (cf. infra). 


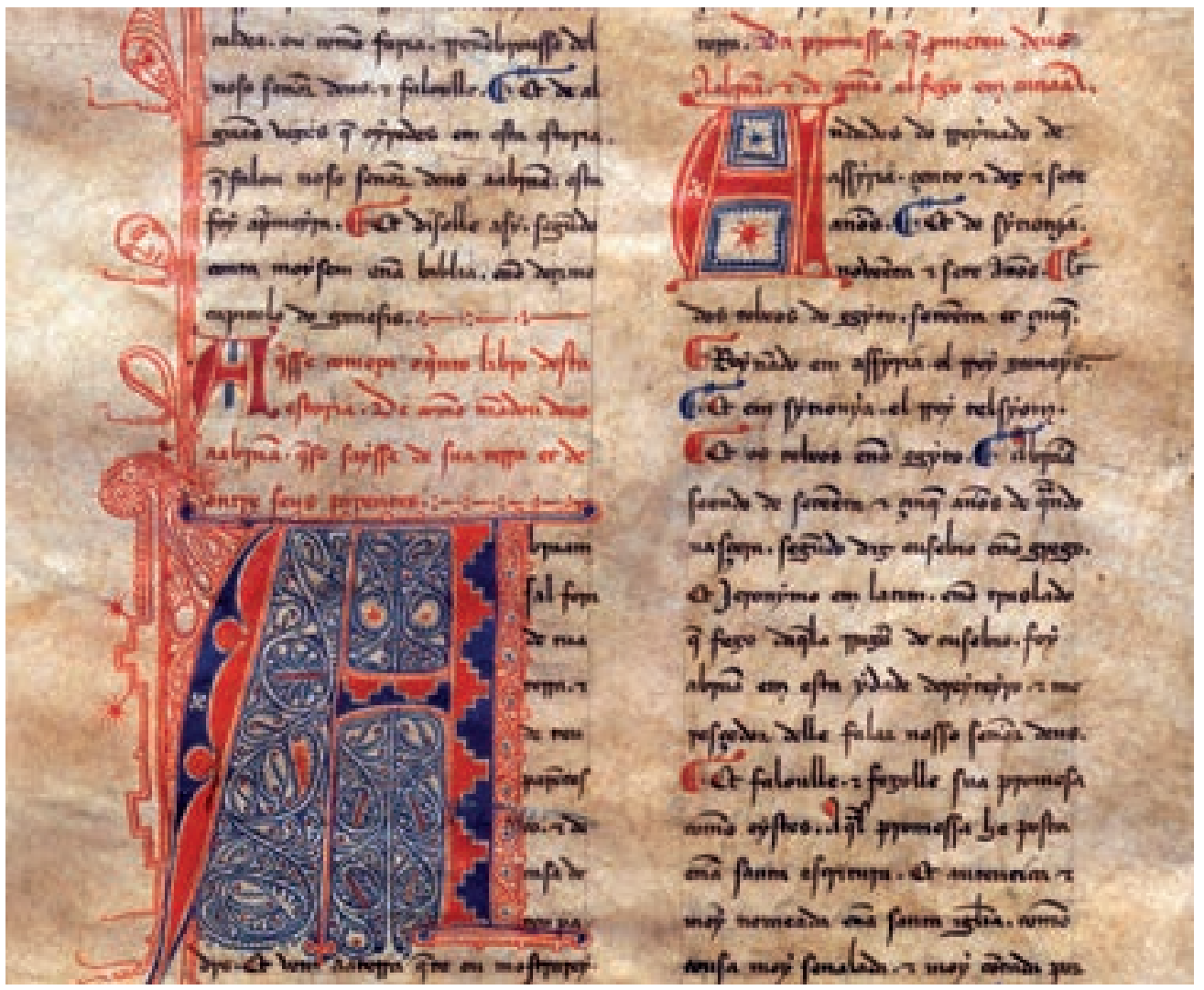

Fig. 1. Geral Estoria galega, inicio do quinto libro da Xénese e do seu primeiro capítulo. (๔ Real Biblioteca del Monasterio de El Escorial, ms. O.I.1, f. 86v).

O antígrafo de $F$, con todo, non é o exemplar hoxe conservado na BNE (ms. 816), pois a nivel textual a tradución galega remite a un testemuño previo, unha versión preliminar á sancionada polo monarca — da que hoxe non temos constancia directa- que non reflectía certas emendas presentes en $A$ mais que, polo contrario, presentaba certas pasaxes ausentes nos restantes testemuños da tradición e que acabarían sendo corrixidas ou censuradas na posta a limpo do texto. Inicialmente interpretáronse esta secuencias como interpolacións dunha familia textual específica allea á inaugurada por $A$ (García Solalinde 1930: li-lxvii); porén, a natureza controvertíbel - probabelmente considerada indecorosa ou impúdica- dalgunhas das innovacións presentes en $F$ levou a crítica a reinterpretalas como segmentos xenuínos reflexo dunha etapa redaccional previa á fixación do texto definitivo trasladado ao códice rexio (o arquetipo $O_{1}$ ), momento en que se executaría un proceso de omisión ou reformulación propositado nunha derradeira fase de depuración ideolóxica ${ }^{14}$. Un

14 É un aspecto que aínda precisa dun estudo pormenorizado, mais xa foi apuntado por diversos autores desde os traballos de Diego Catalán (Catalán 1978: 268-269; 1992: 23, 39; 1997: 51; Martínez 1998: 
dos exemplos máis nítidos desta purga discursiva é a substitución da referencia máis ou menos explícita ao sexo masculino («cortoulle aquelo con que o engendrara, pero nom se nom os dous compañoos de baixo, que som a hũa maneira feitos») por unha expresión bastante máis lacónica e pudorosa («quel cortó una parte del cuerpo») para aludir ás circunstancias do nacemento de Venus:

E enna volta das armas, segundo dizem tódoslos autores, ferío Júpiter a Saturno, seu padre, éntrelas pernas e cortoulle aquelo con que o engendrara, pero nom se nom os dous compañoos de baixo, que som a hũa maneira feitos. E dizem que caerom enno mar e levantarom hũa espuma. E chamarom a aquela espuma frodos. E tam grande materia eram eles e tam grande espuma era aquela que eles levantarom da ferida que derom enna agoa, que se criou e se fezo ende a deesa de apostura e de amor a que os gentiis chamarom Venus. E doutra guisa chamarom a aquela espuma frodos que naceo de Saturno, deesa Frodisa. E Frodisa e Venus hũa cousa som. (RBME ms. O.I.1, f. $127 \mathrm{va}^{15}$ )

E en la buelta de las armas, segund dizen todos los autores, firió Júpiter a Saturno yendo empós él tal colpe quel cortó una parte del cuerpo, e diz que cayó en la mar, e levantóse una materia ende. E aquella materia llamáronla frodos. E tan grand era aquella materia que de la ferida que dio en el agua que se crió e se fizo ende la deesa del apostura e de los amores a que los gentiles llamaron Venus. E d'otra guisa d'aquella espuma frodos que nació de Saturno llamaron a esta deesa Frodissa. Onde Frodissa e Venus una cosa son. (SánchezPrieto Borja 2009b: I, 304-305)

Esta mesma configuración discursiva, máis arcaica, tamén se encontra noutro manuscrito escurialense da GE1. Trátase do testemuño $E$, unha retradución castelá elaborada na primeira metade do século xv, que transmite o mesmo contido

179-183; Fernández-Ordóñez 2002b: 51; Sánchez-Prieto Borja 2002: 75; 2009: I, xc-xci). Véxanse outros casos de censura ou modificación ideolóxica noutras partes da General Estoria, como na quinta (Almeida/Trujillo 2009a: I, xc-c; 2009b) ou na segunda (Almeida 2009: I, lxxix-lxxx; Pichel 2016: 101-123; cf. infra). O termo antígrafo fai referencia ao modelo ou antecedente directo usado para executar a copia dun texto.

15 Edición propia (cf. Martínez López 1963: 248). A retradución do testemuño E (cf. infra) transmite o mesmo texto: «e en la buelta de las armas, segund dizen todos los atores, firió Júpiter a Saturno, su padre, entre las piernas e cortóle aquello con que le engendrara, pero non si non los dos compañones de baxo, que son a una manera fechos. E dizen que cayeron en el mar e levantaron una espuma. E llamaron aquella espuma frodos. E de tan grand materia eran ellos e tan grand espuma era aquella que ellos levantaron de la ferida que dieron en el agua, que se crio e fizose ende la deesa de apostura e de amor a que los gentiles llamaron Venus. E de otra guisa llamaron aquella espuma frodos que nació de Saturno, deesa Frodisa. E Frodisa e Venus una cosa son» (RBME ms. Y.III.12, f. 132va). 
proxectado para $F$ e presenta diversos occidentalismos imputábeis ao seu máis que probábel modelo textual galego ${ }^{16}$. A dependencia de $E$ con respecto a $F$ parece, por tanto, segura, aínda que descoñecemos cal foi o contexto de produción ou a motivación que levou a realizar ese esforzo de (re)tradución existindo, naquela altura, outros moitos testemuños en castelán ${ }^{17}$. Polo que respecta á praxe tradutora de $F$ fronte ao seu modelo —do cal, como vimos, non se conserva o seu antígrafo-, parece caracterizarse por unha tendencia lingüística máis literal e analítica, a diferenza do que acontece cun dos fragmentos portugueses de GE1, máis afastado, sintético e menos literal con respecto ao modelo afonsino ${ }^{18}$.

\subsection{0 contexto de produción e o testemuño indirecto da Historia troiana}

Non sabemos cal foi a motivación ou o alcance da tradución e confección deste coidado exemplar $(F)$. Descoñecemos se o que se pretendía era dispor dun ou máis volumes de natureza bíblica que transmitise(n) todo ou parte do Antigo Testamento, ou se se trataba dunha serie libraria coa tradución íntegra ou parcial de GE1, mais da cal só conservamos unha parte do primeiro libro ${ }^{19}$. En calquera caso, o acto de escritura parece que se interrompeu voluntariamente no último folio conservado do códice ${ }^{20}$. De acordo co que presupomos sobre o seu contexto de produción, non é descartábel que a confección do manuscrito se interrompese tras o abandono da iniciativa do seu probábel patrocinador e supervisor, Nuno Freire de Andrade II,

16 Sobre a configuración lingüística do ms. E (RBME ms. Y.III.12; BETA manid 1061), véxase Martínez López (1963: xviii-xix, 301-325), Rodríguez (1999: 1293), Fernández-Ordóñez (2002b: 46, 51), Sánchez-Prieto Borja (2009b: I, cxxii).

17 Neste sentido, chámanos moito a atención o feito de non ser este o único caso de retradución relacionado coa prosa medieval galega, pois aconteceu exactamente igual e na mesma época, como se verá (cf. infra n. 50), cunha das versións galegas da Estoria de España (ms. Ae) e tamén cun dos testemuños da Crónica de 1404 (ms. E). Non temos datos acerca das razóns que puideron motivar a confección destas versións, se se empregaron para consumo interno, ou se foron concibidas para préstamo ou presente e, por tanto, para proxección fóra do espazo territorial e cultural galego.

18 Trátase do ms. ANTT Fragmentos, Caixa 13, maço 10, n. 30 (BITAGAP manid 5893). O confronto con $F$ foi realizado por Leite (2017a); cf. Martínez López (1963: 301-325), Sousa (1964), Peres Rodrigues (1999) e Alonso Parada (2015).

19 Concordamos coa valoración que fai ao respecto Sánchez-Prieto Borja (2016: 40 e n. 40), pois, en efecto, o acto de copia desde o comezo de GE1 non significa necesariamente que se levase a cabo a copia completa da General Estoria —así o imaxinaba García Solalinde (1930: xxxv) para o códice galego-, nin tan sequera é proba —engadimos nós- de que a intención fose copiar ou traducir toda a primeira parte da obra, pois, máis alá da inxente inversión en recursos humanos e económicos para logralo, podería existir calquera outra motivación ou restrición - temática ou tipolóxica-, como se ve, por exemplo, na selección da materia bíblica operada na coñecida como Estoria de la Biblia (cf. supra n. 11).

20 O escribán finaliza a copia do capítulo 22 do sétimo libro na sétima e última liña da segunda columna do recto do folio (153r) e a seguir deixa en branco o resto da columa e o verso do mesmo folio (que, en todo caso, ficou sinalizado co pautado da caixa de escritura). Actualmente o último caderno do manuscrito está desorganizado, pois o que debería ser o último folio (o 153) encóntrase en penúltimo lugar (por detrás do f. 152). 
no contexto do seu paso a Portugal a mediados do trescentos (non posterior a 1355) ${ }^{21}$. Este destacado membro da influente casa e corte señorial dos Andrade, irmán máis vello do trastamarista Fernán Pérez o $B o^{22}$, emigrara definitivamente para Portugal ao servizo dos reis Pedro $\mathrm{I}^{23}$ e Fernando I, ostentando no reino veciño, entre outros cargos, o de Chanceler-mor e o de Mestre da Orde de Cristo ${ }^{24}$.

Non é casualidade que o mecenado do outro testemuño galego da Geral Estoria se atribúa, de novo, a esta mesma figura, pois comparte con $F$ un ambiente de produción moi similar en termos cronolóxicos e xeográficos, mais con notábeis diferenzas no que respecta ao contexto sociocultural e político en que se emprendeu esta segunda iniciativa de recepción da obra afonsina. Trátase, no entanto, dun testemuño indirecto, froito da integración dun conxunto de interpolacións no fío narrativo da Historia troyana, compilación de materia clásica patrocinada ca. 1365-69 por Pedro I de Castela. Como consecuencia da inestabilidade política da época - a guerra civil que o enfrontou con Henrique de Trastámara-, o proxecto de compilación textual e recreación pictórica da obra ficou paralizado e o manuscrito rexio sufriu unha deterioración importante. Porén, poucos anos despois (ca. 1369-73), o malogrado códice de Pedro I recalaría no seo do círculo petrista andradino e acabaría por ser restaurado e completado nas súas lagoas materiais e textuais baixo a supervisión de Nuno Freire de Andrade II, actividade da cal xurdirá a coñecida como Historia troiana bilingüe ${ }^{25}$.

A amplificatio de orixe afonsina incorporada á Historia troyana supuxo profundar no relato bélico de tradición francesa ${ }^{26} \mathrm{Co}$ auxilio doutras fontes que permitían completar o contexto fundacional previo e os antecedentes da guerra, así como o

21 A esta circunstancia parecen apuntar algunhas notas marxinais coetáneas no códice da Geral Estoria (ff. 131-132) onde se recolle o nome de «Nuno Freyre» asociado a varias fórmulas de beizón e boaventura consignadas posibelmente polo propio escribán (cf. BITAGAP bioid 4048). O referente dos referidos apuntamentos tense asociado unhas veces ao copista e/ou tradutor do manuscrito e outras ao seu promotor, ao tempo que se conxecturou a identificación do tal personaxe coa figura homónima de Nuno Freire de Andrade I, cabaleiro de Afonso XI e tío do que hoxe en día se considera o comitente probábel do manuscrito (Martínez López 1963: x-xi; González López 1980; Lorenzo 1993: 292; Noia 1995: 34; Campos Souto 1997: 125; Mariño Paz 1998: 154; Noia 2004: 732; cf. Pichel 2014: 108-114, 2021b; Mariño Paz 2018: 111; Corral Díaz/Pichel et alii 2020: 70).

22 Como é sabido, Fernán Pérez de Andrade encargou en 1373 a tradución da Crónica troiana galega (BNE ms. 10233; BITAGAP manid 1068), baseada nun exemplar próximo á Crónica troyana patrocinada polo rei Afonso XI (RBME ms. H.j.6; BETA manid 1561) e finalizada a finais de 1350 (o texto foi editado por Lorenzo 1985; unha recapitulación recente sobre este texto en Corral Díaz/Pichel et alii 2020: 31-38).

23 Aparece xa documentado no tratado de Canaveses como un dos vasalos do infante D. Pedro encargados de observar e cumprir a avinza - asinada o 5 de agosto de 1355- celebrada co seu pai, o rei Afonso IV, pola cal se puña fin á guerra civil a conta do asasinato de dona Inés de Castro.

24 Véxase un aproximación á traxectoria político-cultural de Nuno Freire de Andrade II en Pichel (2012a: 120-124; 2014: 108-114).

25 Para a tradición e transmisión textual e iconográfica da Historia troyana (BETA texid 1143) e da Historia troiana bilingüe (BITAGAP texid 5936), así como a intencionalidade e o contexto de produción e mecenado de ambos os proxectos, véxase Rodríguez Porto (2012a: II, 719-788; 2012b), Pichel (2013: I, 63-174; 2016, 2017); unha recapitulación recente en Corral Díaz/Pichel et alii (2020: 39-46).

26 O fío narrativo principal da Historia troyana de Pedro I procede da prosificación ibérica do Roman de Troie (composto por Benoît de Sainte-Maure ca. 1155-65), a través da Crónica troyana de Afonso XI (D’Ambruoso 2012; Pichel 2016; unha recapitulación recente en Pascual-Argente 2020). 
relato ulterior tras a definitiva destrución de Troia ${ }^{27}$. Todos estes contidos consérvanse principalmente na sección galega do manuscrito bilingüe custodiado na Biblioteca de Menéndez Pelayo de Santander ${ }^{28}$ (ff. 1-21, 29-36, 44-49) e aparecen compilados nas tres primeiras partes da General Estoria. Porén, a versión que ofrece a Historia troyana non procede directamente da compilación universal afonsina, senón que foi escolmada a partir dalgúns materiais afonsinos previos, como o perdido Libro de Troya -tradución historiada con base na Histoire ancienne jusqu’à César- ou a Estoria de las Bretañas -tradución indirecta da Historia regum Britanniae -29 . A natureza redaccional destas fontes - preliminar con respecto á súa adaptación na crónica afonsina- acostuma favorecer a emerxencia de pasaxes discursivas non censuradas como consecuencia do refinamento ideolóxico ao cal se sometían as versións definitivas dos textos unha vez sancionadas polo rei. Precisamente, igual que acontecía coa tradución de GE1, neste outro testemuño achamos novas e valiosas evidencias desa purga discursiva, como o episodio do cruento fratricidio dun infante da casa real - Apsirto, asasinado a mans da súa irmá, Medea, ambos fillos do rei cólquide Eetes-, no contexto da dramática fuxida de Xasón e de Medea tras a conquista do vélaro de ouro ${ }^{30}$.

\section{A PROXECCIÓN DA CRÓNICA PARTICULAR (POST)AFONSINA}

Se ben non é comparábel en extensión coa magnitude da historia universal, certo é que a composición da Estoria de España ficou máis próxima da súa finalización, dado que, polo que sabemos, os colaboradores do Rei Sabio lograron compilar o relato até finais do século XII, por volta da morte de Fernando $\mathrm{II}^{31}$. A pri-

27 Entre outros episodios seleccionados e incorporados á Historia troyana, destacan a fundación do primeiro emprazamento troiano por Dárdano, a primeira destrución de Troia en tempos de Laomedonte, o relato da argonáutica (a viaxe de Frixo e Hele, a conquista do vélaro de ouro etc.), as historias entrecruzadas de Xasón, Medea e Hipsípila, a infancia de Paris e os amores con Enone, o xuízo da mazá ou o feitizo de Aquiles. Polo que respecta aos nostoi (o retorno dos heroes gregos aos seus fogares tras a guerra), engádese o relato do exilio de Eneas en Cartago e no Lacio, así como o simbólico resarcimento dos seus descendentes, entre eles Bruto, fundadores vindeiros de Roma e Britania. As cinco interpolacións afonsinas integradas na Historia troyana foron estudadas en detalle en Pichel (2016: 56-100 e 2018).

28 BMP ms. 558 (BITAGAP manid 1558; BETA manid 1562). A última interpolación (a historia de Bruto) consérvase, parcialmente, nos últimos folios do ms. BNE 10146 (BETA manid 1399), o outro testemuño coñecido da Historia troyana. O texto das interpolacións pode lerse en Parker (1975) —sempre que se consulten á par as revisións de Lorenzo (1982)— e Pichel (2013: II; 2018: 96-100); e tamén está accesíbel no CGPA.

29 Rodríguez Porto (2012a: II, 750-783; 2012b); Pichel (2016: 101-151; 2018).

30 Esta e outras pasaxes similares foron estudadas en Pichel (2012b: § 16-20; 2016: 115-118). Como xa se indicou anteriormente (cf. supra n. 13), o ms. BNE 10237, unha copia parcial dunha versión preliminar de GE2, presenta a mesma configuración discursiva que o testemuño galego.

31 Para un panorama xeral da composición, transmisión e tradición textual da Estoria de España (BETA texid 10664), así como das súas versións e derivacións cronísticas, véxanse, entre outros moitos, Gómez Redondo (1998: 645-686), Fernández-Ordóñez (2000a, 2000b, 2002b), Hijano Villegas (2014, 2020a) ou Bautista (2020b). 
meira redacción da obra -a Versión primitiva - foi elaborada entre 1270 e 1274, mais ficou inconclusa e o relato suspendido, dependendo da crítica, nalgún punto do longo intervalo que separa os reinados de Fernando I e Afonso VIII; unha interrupción talvez motivada pola necesidade de concentrar os esforzos do taller na composición da General Estoria ${ }^{32}$. Posteriormente, o retorno á crónica particular nos últimos anos do seu reinado (1282-1284) materializouse na concepción dunha segunda redacción -a Versión crítica - na cal o relato avanza, polo menos, até o último cuartel do século XII, incluíndo seccións de grande relevancia narrativa como os reinados de Fernando I, Sancho II ou Afonso VI, e execútase unha importante refundición do texto primitivo, tanto do punto de vista formal -como se verifica en certos retoques cronolóxicos, nunha marcada tendencia á abreviación ou na dislocación de capítulos e bloques narrativos completos- como ideolóxico, neste último caso, cunha notábel tendencia promonárquica ${ }^{33}$. Unha terceira redacción da crónica particular, a Versión amplificada ou sanchina, foi composta por volta de 1289 baixo a supervisión de Sancho IV ${ }^{34}$, baseada nunha reformulación retórica e ideolóxica da Versión primitiva, como se lembrará máis adiante.

A Estoria de España tivo unha enorme difusión, dentro e fóra da Coroa, superando o medio centenar de copias, para alén de múltiplas refundicións, extractos, epítomes e ampliacións cronísticas ao longo de todo o medievo. A extraordinaria diversificación do texto, a miúdo subvertido ideoloxicamente, derivou no desenvolvemento dun novo subxénero literario —o das crónicas xerais- así como a proliferación de diferentes reelaboracións, desde a Crónica de Castilla (ca. 1300) até a Crónica de España editada en 1521 por Florián de Ocampo, pasando por outros textos debedores do material historiográfico afonsino, como a Crónica de veinte reyes ou a Crónica abreviada de don Juan Manuel (ca. 1320-1325). Precisamente, dous dos primeiros exemplos de reescritura do texto afonsino, a Versión amplificada de Sancho IV

32 Esta primeira redacción (BETA texid 1005) consérvase no códice afonsino $E_{1}$ (RBME ms. Y.I.2; BETA manid 1006) e nos dous primeiros cadernos do ms. $E_{2}$ (RBME ms. X.I.4; BETA manid 1007) compilado en tempos de Afonso XI (ca. 1340), chegando até a metade do reinado de Afonso II, nos inicios do séc. IX. Para a discutida cronoloxía da confección deste códice rexio e o seu contexto de produción, véxase Rodríguez Porto (2012c); cf. Fernández Fernández (2021). O texto principal da Versión primitiva pódese ler na edición de Menéndez Pidal (1955) e na edición dixital coordinada por Ward (2016), onde tamén se pode consultar a transcrición paleográfica dos principais testemuños desta versión.

33 Sobre a radicalización ideolóxica do modelo afonsino na segunda redacción da Estoria de España véxase Fernández-Ordóñez (2000b: 49-61). O único testemuño íntegro da Versión crítica (BETA texid 4477), o ms. Ss (Fundación Caja Duero ms. 40; BETA manid 3273), identificado nos anos 80, permitiu confirmar as conxecturas de Ramón Menéndez Pidal sobre a natureza do texto como representante dunha versión aínda afonsina datada nos últimos anos do seu reinado. Doutra parte, a Crónica de 1404, no tramo dos reis astur-galaico-leoneses até Ramiro I, conforma outra das fontes máis valiosas para coñecer o texto da Versión crítica (cf. infra n. 39 e 50). A edición, aínda parcial, da Versión crítica en Fernández-Ordóñez (1993) e Campa Gutiérrez (2009); véxase tamén Ward (2016) para a transcrición do importante testemuño Ss.

34 A Versión amplificada (BETA texid 10664) consérvase en varios tramos do mencionado códice rexio $E_{2}$ (RBME ms. X.I.4; cf. infra), mais só para a historia entre Ramiro I e Fernando III. Para o relato anterior, só se conserva o testemuño indirecto da anteriormente coñecida como Versión enmendada después de 1274 e da Crónica carolingia (ou Crónica fragmentaria) para o tramo dos primeiros reis asturianos (Bautista 2003, 2006). O texto da Versión amplificada en Menéndez Pidal (1955). 
(1289) e a Crónica de Castilla (ca. 1300), ademais da Crónica particular de San Fernando (ca. 1295-1312), son os que con máis rapidez e intensidade se asimilaron no espazo cultural occidental, como demostran as diferentes versións, de orixe galega e portuguesa, que circularon desde as primeiras décadas do trescentos até os inicios do XV, quer como copias e traducións -íntegras ou parciais- autónomas, quer como corpus historiográfico esencial para a (re)elaboración ou copia de certas compilacións e refundicións de diferente calado e motivación, como é o caso da Crónica de 1344 -e a súa Refundição ca. 1400-, da coñecida como Crónica geral galega ou da Crónica de 1404.

\subsection{A recepción da Versión amplificada sanchina}

Así pois, desde os inicios do trescentos até as primeiras décadas do século XV arribaron ás terras galego-portuguesas diversos materiais historiográficos (post)afonsinos, entre eles, a Estoria de España, a popular Crónica de Castilla ${ }^{35}$ ou a Crónica particular de San Fernando ${ }^{36}$. Diferentes iniciativas de copia, tradución e compilación de todos estes materiais circularon primeiramente no seo dalgúns ambientes nobiliarios afincados no antigo marco transfronteirizo da diocese de Tui, mais tamén noutros núcleos señoriais, neste caso eclesiásticos, vinculados ás sés (arce)bispais

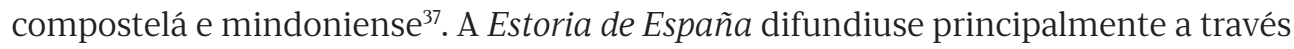
da Versión amplificada sanchina e da refundición da Crónica de Castilla, mais tamén houbo un percorrido significativo da segunda redacción afonsina (a Versión crítica). Aínda que parece razoábel conxecturar a circulación —e talvez a tradución- do texto íntegro da Estoria de España, o certo é que todos os testemuños dos que hoxe temos noticia, mesmo de modo indirecto, só transmiten o relato dos reis astur-galaico-leoneses desde Ramiro I a Vermudo III de acordo coa Versión amplificada, ou ben -no caso da Crónica de 1404- a historia gótica e do reino asturleonés até Ramiro I con base na Versión crítica ${ }^{38}$. Canto ao relato dos monarcas casteláns desde Fernando I até a definitiva unión dos reinos en 1230, a fonte preferida e amplamente difundida foi a refundición da Crónica de Castela.

É ben significativo que o material historiográfico de preferencia importado e consumido polos diferentes núcleos occidentais de poder fose, preci-

35 Para a Crónica de Castilla (BETA texid 1129) remitimos aos traballos de Gómez Redondo (1999: 1230-1231), Campa Gutiérrez (2010) e Hijano Villegas (2012, 2014, 2020a). A edición do texto en Rochwert-Zuili (2010).

36 Para a Crónica particular de San Fernando (BETA texid 9790), véxanse principalmente Gómez Redondo (1999: 1238-1248), Fernández Gallardo (2009, 2010) e Hijano Villegas (2018, 2020b). O texto pode lerse na edición da Primera Crónica General de Menéndez Pidal (1955) e na recente edición dixital de Duxfield (2018), onde tamén se pode consultar a transcrición paleográfica dos principais testemuños da obra.

37 Talvez tamén a sé tudense, como se discutirá máis abaixo a raíz da proposta de Monteagudo (2019a). Canto á sé mindoniense, a súa vinculación coa produción historiográfica galega conxectúrase para a compilación da Crónica de 1404 (cf. infra n. 50).

38 Para esta sección da Crónica de 1404, na cal se emprega como fonte principal a Versión crítica da Estoria de España, véxase Pérez Pascual (1990: I, 111-121), Catalán (1997: 103-106, 116-124, 206-240) e Bautista (2014b). 
samente, o que menos pegada afonsina transmitía. Son coñecidas as innovacións ideolóxicas que, a través de múltiplas glosas e amplificacións retóricas, reconfiguran a primitiva redacción afonsina da Estoria de España, agora subvertida ao servizo das urxencias sociopolíticas de Sancho IV tan só cinco anos despois da súa chegada ao trono, entre outras cuestións, o abandono da reivindicación neogoticista da monarquía castelá-leonesa ou a preferencia por unha praxe política baseada no pacto estamental $^{39}$. A pegada da deriva ideolóxica inaugurada pola Versión amplificada alcanzou o discurso doutras obras inmediatamente posteriores, como a Crónica de Castilla e a Crónica particular de San Fernando. As elites señoriais -leigas e eclesiásticas- que durante as décadas iniciais do trescentos actuaron como detentores deste corpus historiográfico non debían ser alleas ao nesgo ideolóxico das versións que, non por acaso, recibiran ou encargaran copiar e traducir, nun período de particular crispación diplomática entre o debilitado e disputado poder rexio, a Igrexa e a alta nobreza levantadiza $^{40}$. Un delicado contexto político herdado desde o conflito dinástico de 1282-1284 e agudizado tras o falecemento de Sancho IV (1295) na etapa de minoridade de Fernando IV (até 1301) debido, entre outras razóns, ás dificultades para lexitimar o matrimonio do seu pai con María de Molina e ao levantamento do seu tío, o infante Juan, quen reclamaba tamén o trono. Doutra parte, o clima de desafección entre os nobres galegos fronte á Coroa, representado en diferentes actuacións de rebeldía -en particular, no caso de Fernando Ruíz de Castro (cf. infra)-, así como o descontento da curia compostelá, poderían estar na base da sutil capitalización político-cultural dun discurso historiográfico, de clara orientación castelanista e señorializante, facilmente reinterpretábel como proclive aos intereses comúns fronte ao poder rexio.

39 Entre outros aspectos, o novo discurso sanchino da Versión amplificada non compartía a reivindicación neogoticista da monarquía castelá-leonesa - pola cal se facía entroncar a secuencia de monarcas astur-galaico-leoneses, da cal o propio Afonso é herdeiro directo, coa liñaxe dos godos-, en prol dunha visión castelanista favorábel aos lazos de natureza co territorio fronte á vinculación dinástica ou pertenza xenealóxica no que respecta aos dereitos ao imperium territorial, de tal modo que os artífices da reconquista terían sido os «naturaes da terra» (isto é, os españois), e non os reis godos e os seus herdeiros. Outra innovación fundamental - e necesaria na altura - do discurso sanchino avogaba pola promoción dun modelo de relacións políticas baseado no pacto cos estamentos, de tal modo que non se oculta o enaltecemento de nobres e prelados fronte á figura do rei. Véxase ao respecto Fernández-Ordóñez (2000b: 61-65) e Bautista (2003, 2006).

40 Na nosa opinión e sen ánimo de tratar por extenso aquí esta cuestión, o servilismo identificábel na elaboración das versións galegas - a diferenza do que, conforme a Crónica de 1344, ocorre na tradición portuguesa- da Estoria de España e da Crónica de Castela fronte aos seus modelos casteláns (Lorenzo 1999; 2002: 98-99) talvez non sexa tan casual como parece, froito dunha tradución mecánica e case literal, e acaso responda, no contexto político descrito, a unha estratexia consciente de asunción silenciosa -máis alá da inclusión de certas actualizacións localistas- do nesgo ideolóxico do texto que se estaba a trasladar, tanto no caso da versión sanchina da Estoria como no da súa principal derivación cronística. 


\subsection{0 ms. BNE 8817 e a primeira compilación historiográfica}

O códice 8817 da Biblioteca Nacional de España preserva o compendio historiográfico tradicionalmente coñecido como Crónica geral galega ${ }^{41}$, unha compilación organizada en dous volumes que, como mínimo, a partir do século XVII xa conformaban unha unidade codicolóxica ${ }^{42}$. O proceso de ensamblaxe deste facticio (ms. A; Fig. 3) ten a súa xénese en tempos de Fernando IV (ca. 1300-1312), momento en que debeu circular un ou máis exemplares da Crónica de Castilla nalgunhas das principais cortes señoriais instaladas no norte e no sur da diocese de Tui -isto é, as terras de Toroño e do Minho-, en especial os Lima-Batisela e os Riba de Vizela. Nestas coordenadas xurdirá nos inicios do trescentos o interese por copiar e traducir o relato dos monarcas casteláns —-desde Fernando I a Fernando III- transmitido pola crónica postafonsina, que, máis alá da súa circulación autónoma (a Crónica de Castela), acabaría sendo aproveitada como base estrutural para a Crónica de 1344 e como núcleo primixenio da referida Crónica geral galega. Neste último caso, o relato transmitido pola Crónica de Castela (A2 $b^{43}$; Fig. 2) completouse na altura, ademais, cun breve apéndice alusivo aos últimos anos do reinado de Fernando III e aos subseguintes até Sancho IV (sección A2d).

Porén, este primeiro núcleo narrativo (A2), localizado na segunda metade do códice BNE 8817 (ff. 91-229), foi completado pouco tempo despois, dentro do segundo cuartel do século XIV (ca. 1330-40 ${ }^{44}$ ), con diferentes (para)textos e fontes

41 O texto foi editado por Lorenzo (1975-77) e é accesíbel desde o CGPA; para a sección do Liber regum tamén contamos coa edición de Catalán/Andrés (1870: 338-343). Sobre a orixe e composición do ms. BNE 8817 (BITAGAP manid 1066; cf. BITAGAP texid 1245) véxase Lorenzo (1975-77: I, xxxvii-xlvi) e Catalán (1992: 193-195); unha recapitulación en López Martínez-Morás (2007: 458-460), Lorenzo (2002: 97-99) e Corral Díaz/Pichel et alii (2020: 77-90). Existe copia parcial moderna deste facticio na Academia das Ciências de Lisboa (Série Azul, ms. 1651; BITAGAP manid 1740). O termo facticio fai referencia a un códice creado a partir doutros manuscritos que nun momento dado se encadernaron formando unha unidade codicolóxica.

42 Véxase ao respecto Menéndez Pidal (1918: 150), Catalán (1959: 16-17; 1962: 316), Lorenzo (1975-77: I, xxvii-xxviii; 2002: 97). Entre finais do XV e comezos do XVI, o códice facticio formaba parte da biblioteca do VI condestábel de Castela, Juan Fernández de Velasco e Guzmán († 1613), conde de Haro e V duque de Frías (Fernández Pomar 1967: 107, no 68), antes de ingresar a mediados do XVIII na Real Biblioteca de Madrid. Nesta mesma institución permanecería temporalmente o ms. A' (cf. infra n. 49), tras o seu paso polo salmantino Colegio Mayor de Cuenca, a cuxo fondo bibliográfico se incorporara procedente da biblioteca do diplomático e humanista Lorenzo Ramírez de Prado († 1658) (Lilao Franca/Castrillo González 1997-2002: II, 855-856).

43 Usamos a terminoloxía estabelecida por Miranda (2009a, 2010a, 2012) para facer referencia ás distintas seccións do ms. BNE 8817 (ms. A): $A 1$ (ff. 1-88; BITAGAP cnum 1841), A2a (ff. 89-91; BITAGAP cnum 1840), A2b (ff. 92-229; BITAGAP cnum 1934), A2c (ff. 230-265; BITAGAP cnum 1935) e A2d (ff. 229 e 265; BITAGAP cnum 1934).

44 No que respecta á sección A1 do facticio, a análise lingüística do texto (Álvarez/Xove 1998; Monteagudo 2019b: 370-377; cf. Morais-Barbosa 1958, 1960) encaixa coa datación proposta polo editor da obra (Lorenzo 1975-77), quen propón unha cronoloxía contemporánea á confección de A2 (ca. 1300-12). Porén, os elementos que apuntan a este arco limitado aos primeiros anos do trescentos (cf. Souto Cabo 1993: 541, n. 31), máis alá de que poderían igualmente operar, aínda que de modo máis esporádico, nas décadas inmediatamente posteriores, ben poderían adscribirse tamén ao antígrafo, xa traducido, do cal se copiaría $A 1$ (isto é, o prototipo ${ }^{*} \alpha_{1}$ conxecturado por Catalán; cf. infra n. 63). Por outra parte, tanto o trazado da letra —un pouco máis cursiva do que en A2-, como o contexto codicolóxico do antecedente castelán do cal procede -o ms. rexio $E_{2}$ (orig) emendado (cf. infra n. 45)- e, como se verá, o contexto político-cultural onde parece encaixar a súa elaboración, convidan a situar a copia de $A 1$ ca. 1330-40 (Rodríguez Porto 2012: II, 58, 785; Pichel 2017b: 118-119), unha datación similar á proposta por Catalán na súa Silva textual (1997: 293), entre a segunda e 


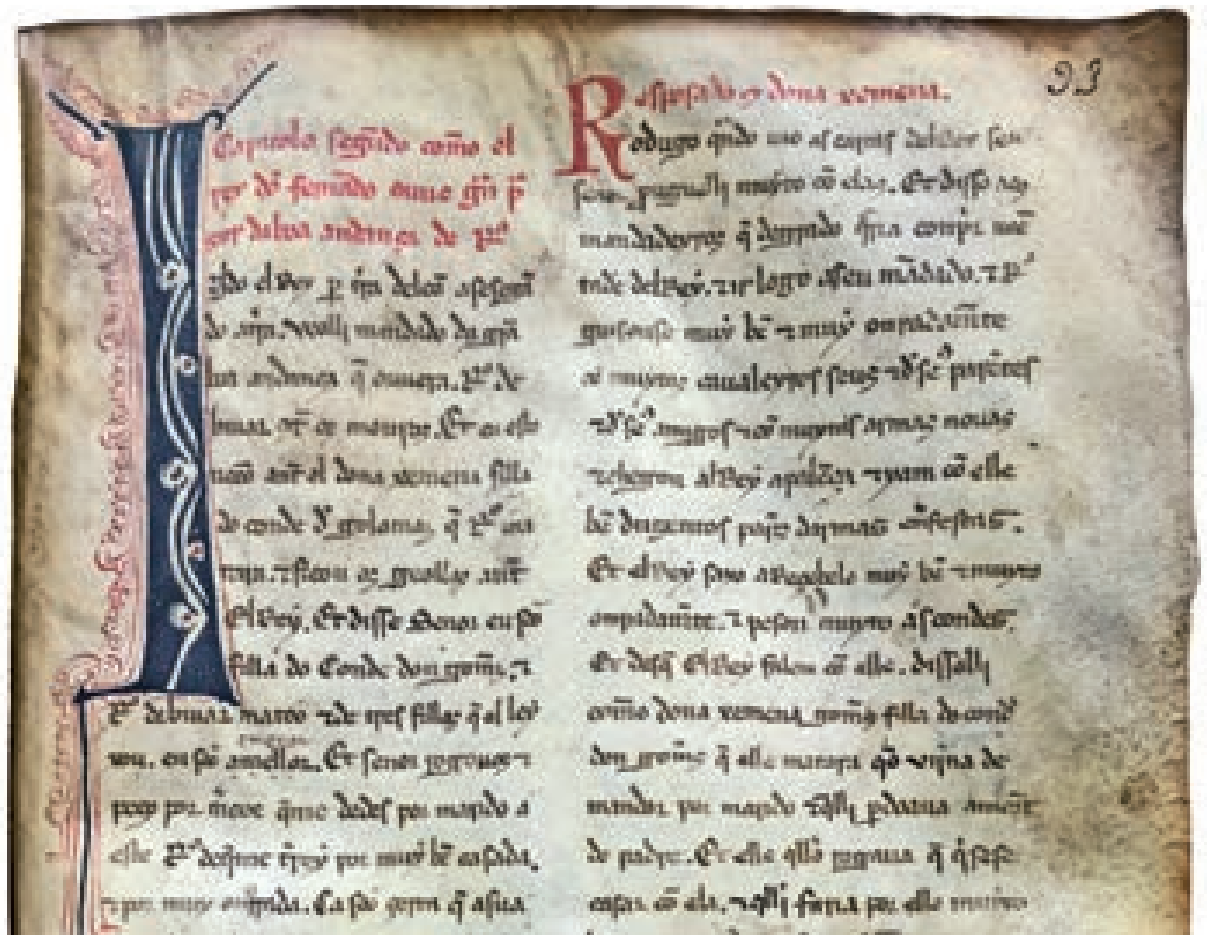

Fig. 2. Crónica de Castela integrada como sección $A 2 b$ da Crónica geral galega. (ㄷ) Biblioteca Nacional de España, ms. 8817, f. 93r).

que ampliaban, por un lado, o relato neogótico precedente, e por outro, as noticias dos reinados tras Fernando III até Fernando IV. No primeiro caso, incorpórase a historia dos reis galaico-leoneses desde Ramiro I até Vermudo III a partir dunha tradución parcial (sección A1) da versión sanchina da Estoria de España (a Versión amplificada) ${ }^{45}$.

a terceira década do século XIV. Canto ao modus operandi tradutivo de $A 1$ fronte ao seu modelo castelán, véxase Bello Rivas (1995, 1998, 1999).

45 Como se sabe, as versións galego-portuguesas da Versión amplificada sanchina —-tanto a representada pola sección $A 1$ do ms. BNE 8817 e as súas copias ca. 1390-1430, como a utilizada polo Conde Barcelos na súa Crónica de 1344 e despois na Refundição de ca. 1400- teñen a súa orixe no testemuño rexio $E_{2}$ (RBME ms. X.I.4; BETA cnum 12425; Fig. 3), mais non no seu estado actual, senón antes de que, por volta de 1340 e baixo a supervisión de Afonso XI, se ensamblase o códice rexio de Sancho IV (1289) ao material afonsino preexistente (os dous últimos cadernos de $E_{1}$ ) e se completase con outros segmentos narrativos (Catalán 1962: 32-87; 1997: 485-486; Fernández-Ordóñez 2000a: 234-238, 243-244; 2002b: 56-63). O modelo exportado ao Occidente peninsular sería, por tanto, a versión orixinal non intervida en tempos de Afonso $\mathrm{XI}-E_{2}$ (orig), de acordo coa nomenclatura estabelecida por Catalán-, despois desmembrada nas seccións $E_{2} c$ (ff. 23-79 e 82-198) e $E_{2} d$ (ff. 257-320) do ms. RBME X.I.4. De igual modo que a súa descendencia galego-portuguesa, esta versión rexia da crónica sanchina iniciaba o relato no reinado de Ramiro I, pois para a materia anterior xa se proxectara empalmar coa redacción primitiva transmitida polo códice afonsino $E_{l}$, que chegaba até o final de Afonso II (esta circunstancia non foi tomada en consideración por Monteagudo 1995 , para quen a ausencia da materia anterior a Ramiro I na tradución galega da Estoria de España sería deliberada e estaría relacionada co antagonismo das dúas visións historiográficas en confronto, a compostelá e a castelá, sobre a reivindicación xacobea; cf. Lorenzo 2013). A utilización de $E_{2}$ (orig) como modelo das versións occidentais é indubidábel, ademais, tendo en conta que todas elas reflicten a incorporación das emendas e adicións apuntadas por un ou máis correctores coetáneos nas seccións sanchinas do códice escurialense —isto é, a instancia textual E (orig)-corr - (Catalán 1962: 54-55 e 318-322; 1997: 288-292; cf. Lorenzo 1975-77: I, 
Por outro lado, prolóngase o relato sobre Fernando III após o falecemento de Afonso IX (sección A2c), a partir da narración da Crónica particular de San Fernando ${ }^{46}$, tras o cal se reescribe a citada sección A2d coas noticias actualizadoras dos reinados sucesivos até os tempos de Fernando IV ${ }^{47}$. Por último, complétase o inicio da Crónica de Castela (A2b), a modo de prólogo (sección A2a), co relato esquemático, baseado no Liber regum ${ }^{48}$, da historia gótica e do asentamento da monarquía castelá ${ }^{49}$.

xxxix-xli). É interesante apuntar, ademais, que o ms. Xx (BNE ms. 7583; BETA manid 1024; Bautista 2006) e o perdido ms. *Gran (Catalán 1997: 293-294) presentan esta mesma orixe textual.

46 É factíbel que a tradución da Crónica particular de San Fernando (BITAGAP texid 9418; BETA texid 9790) poida estar relacionada cos materiais que completaban a versión sanchina da Estoria de España ensamblados no facticio rexio $E_{2}$, en particular a sección $E_{2} f$ (ff. 321-359; BETA cnum 13272).

47 Esta sección (A2d), orixinariamente copiada no f. 229rb-229vb, foi apagada para poder continuar a seguir o relato de Fernando III a partir da Crónica particular de San Fernando. Porén, o compilador decidiu non prescindir igualmente dese apéndice actualizador sobre os últimos anos do reinado de Fernando III até Fernando IV e copiouna tras A2c, no f. 265. Sobre a reescrita da sección A2d véxase Lorenzo (1975-77: I, xlii) e Miranda (2012).

48 En particular, na versión toledana elaborada por volta de 1219 con base na versión orixinal navarra rematada ca. 1205. Sobre a difusión do Liber regum (BETA texid 1145) no Occidente peninsular, primeiramente no Livro de Linhagens de don Pedro Barcelos, véxase Cintra (1950), Catalán (1995: 533) e os traballos de Bautista (2010, 2013, 2020a).

49 Os materiais transmitidos polo facticio BNE 8817 foron reaproveitados entre finais do XIV e primeiras décadas do XV. Da tradución da Versión amplificada sanchina fixéronse varias copias, mais só unha delas se conserva de maneira autónoma: trátase do ms. A' (BGHUsal ms. 2497; BITAGAP manid 1496; BETA manid 1923), elaborado ca. 1390-1420 con base nun testemuño perdido intermedio (" $A x$ ) entre $A$ e $A$ ', e do cal se fixo unha retradución castelá (ms. Ae; BNE ms 643; BETA manid 1022) a finais do século xv (Lorenzo 1975-77: I, xlvii-lvii; Catalán 1995: 529-532, 1997: 239-240). As demais copias da Estoria de España e da Crónica de Castela -así como tamén dos paratextos incorporados a A2b - consérvanse na anónima Crónica de 1404 (BITAGAP texid 1309; BETA texid 1138), unha compilación xeral con vontade universalista na cal se ensaia un relato do mundo desde a súa creación até o reinado de Henrique III (1390-1406) e da cal se conservan dous testemuños galegos, $V$-ca. 1430 (HSA ms. B2278; BITAGAP manid 1509; BETA manid 3267) - e $S$-ca. 1400-10 (BMP ms. 62; BITAGAP manid 1561)-, ademais dunha retradución castelá da primeira metade do século XV (RBME ms. X.I.8; BETA manid 1293). Desde os estudos de Catalán, o contexto de produción da Crónica de 1404 vincúlase, con acerto, á diocese mindoniense (Catalán 1992: 185-196; 1997: 236-240; Bautista 2010: § 35-38), talvez na órbita señorial dos Enríquez de Castro (Pichel 2017b: 138-139; 2018; Mariño Paz 2018: 112). Véxase unha recapitulación recente e bibliografía sobre a composición e orixe textual, o contexto de produción e a discusión sobre a tradición manuscrita en Corral Díaz/Pichel et alii (2020: 9199) e Pichel (2021d), aínda que continúan sendo fundamentais os traballos de Pérez Pascual (1990, 1991a, 1991b, 1993, 2002, 1994). O texto da Crónica de 1404 foi editado por Pérez Pascual (1990: II, 4-342), salvo nos bloques narrativos transmitidos polo ms. BNE 8817 (Lorenzo 1975-77), e tamén por Catalán / Andrés (1970: 239-286) no que respecta á sección do Liber regum. Canto ás copias tardías da Estoria de España, o texto de $A$ ' só era coñecido até agora a través do aparato crítico de variantes da edición de Lorenzo (1975-77) e -neste caso tamén para Ae- das citacións incluidas nos traballos de Catalán (1992: 335, 1997: 484). Actualmente continúa en curso a transcrición paleográfica de todos estes testemuños ( $\left(A^{\prime}, A e, V, S\right.$ e $E$ ), no marco dos proxectos PTGM e HERES, que será accesíbel no portal EGPA-lit. 


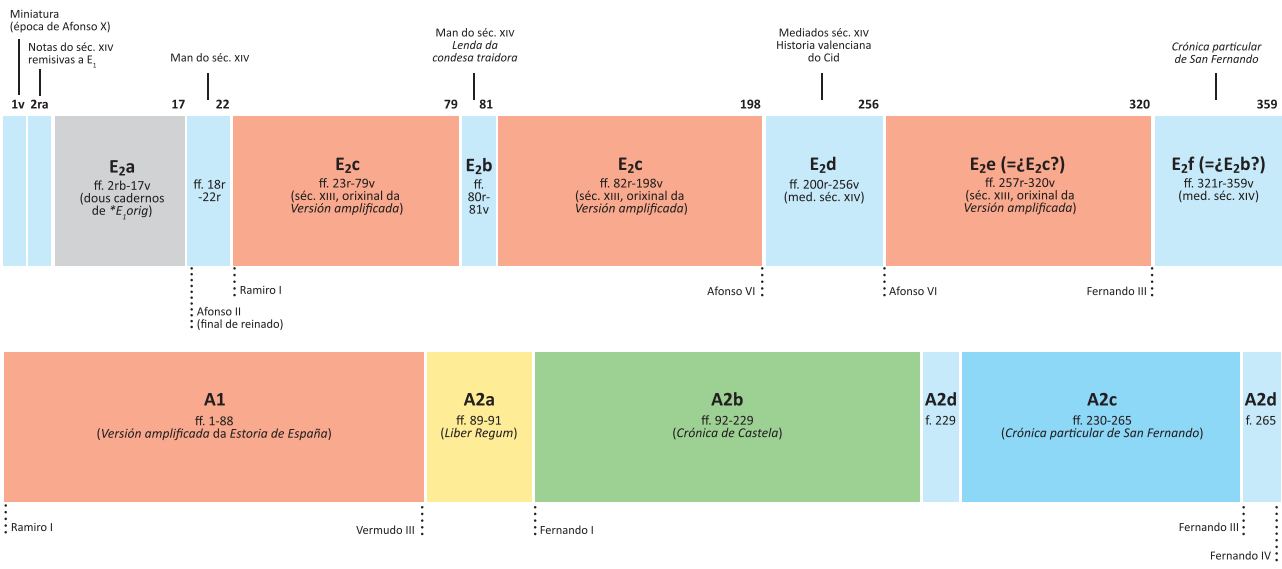

Fig. 3. Composición e contidos dos mss. RBME X.I.4 [E2] (arriba ${ }^{50}$ ) e BNE 8817 [A] (abaixo).

\subsection{Ideoloxía e mecenado. 0 patrocinio transfronteirizo}

Como xa se adiantou, toda esta actividade cronística emprendida desde comezos do século XIV poderá asociarse a diferentes iniciativas político-culturais nas cales, en boa medida, estarían envolvidos algúns membros da corte señorial dos Lima-Batisela - coñecidos polo alcume dos Pancente $0^{51}$-, principais herdeiros do capital liñaxístico e cultural dos poderosos Traba ${ }^{52}$. Falamos, en particular, do magnate Fernán Fernández de Lima II³ (fl. 1261-1312) e do seu primoxénito Joán Fernández

50 O diagrama superior é unha adaptación do esquema elaborado para o proxecto de «Estoria de Espanna Digital» dirixido por Aengus Ward (https://blog.bham.ac.uk/estoriadigital/sobre-esta-edicion/).

51 Un alcume probabelmente vinculado á súa procedencia xeográfica orixinaria no Baixo Miño (oriúndos, talvez, do actual Pancenteo, no concello do Rosal), ben coñecido na altura, como revelan os nobiliarios portugueses ou as crónicas castelás, como a Crónica de Alfonso XI (cf. infra n. 59).

52 Con eles emparentan desde a segunda metade do século XII. O primeiro Batisela, Fernando Airas (fl. 1147-1196), era un dos fillos de Airas Calvo, avó do trobador Osoiro Eanes (Souto Cabo 2012: 81-123), de onde parte a xeración dos Lima. O casamento de Teresa Bermúdez (1153-1219, filla de Bermudo Pérez e Urraca Henriques, irmá de Afonso Henriques) e de Urraca Fernández (1165-1199) - sobriña e filla, respectivamente, de Fernando Pérez de Traba - con dous irmáns da estirpe dos Lima, Fernando Airas (Batisela) e Joan Airas (Nóvoa), fillos de Airas Calvo, dá unha idea clara do prestixio acadado por esta familia, tradicionalmente considerada como un ramo menor dos Traba (cf. Pardo de Guevara y Valdés 2001: 68, n. 11; 2012: 366, n. 11). Para o vínculo familiar e sociopolítico dos primeiros Batisela cos Traba e con Afonso IX, así como a súa estreita afinidade con algúns dos primeiros trobadores galegos (como Osoiro Eanes, Joan Lopez de Ulhoa, Fernan Paez de Tamallancos, Pedro Paez Bazaco ou Joan Soarez Somesso) remitimos aos traballos de García Álvarez (1966), Monteagudo (2008: 137-138, 321-332), Pardo de Guevara y Valdés (2011), Sottomayor-Pizarro (2011, 2015), Souto Cabo (2012: 79-161, 234-235, 245-249) e Ferreira (2019: 195-197, 341, 511-513, 524-530).

53 Descendente de Fernán Eanes de Lima I, fillo de Joán Fernández de Lima I e da súa primeira muller, Berengária Afonso de Baião, e neto do primeiro Batisela Fernando Arias. A presenza de Fernán Fernández de Lima II en Portugal rexístrase desde 1261, como testemuña da demarcación do couto de Portel. A súa dilixente xestión como tenente das terras de Toroño e Lima documéntase a cabalo das dúas centurias. A partir de 1278 sitúase en Castela, xunto ao seu irmán Joán Fernández, como ricome de Afonso X, condición que conservou durante o reinado de Sancho IV - para quen traspasaría a súa lealdade unha vez falecido o Rei Sabio- e até o final do de Fernando IV (1312), altura en que se terá retirado da vida pública e, probabel- 
de Lima III ${ }^{54}$ (fl. 1288-1316) —este último probábel comitente da copia galega do Livro de Tristam ${ }^{55}$ - , que poderían ter propiciado nun primeiro momento a circulación, copia e/ou tradución do primitivo conxunto historiográfico constituído principalmente pola Crónica de Castela $(A 2 b)$. A significativa relación destes dous últimos elos dos «Lima antigos» coas cortes rexias castelá e portuguesa ${ }^{56}$, así como os vínculos familiares e culturais, máis alá dos Traba, con algunhas das liñaxes galego-portuguesas máis prestixiosas na altura — como os Soverosa, os Aboim-Portel, os Castro ou os Riba de Vizela $^{57}$ (cf. infra) - poderían ter coadxuvado na adquisición e difusión, a varios niveis, dos materiais historiográficos necesarios para emprender as diferentes empresas cronísticas que hoxe coñecemos.

Ora ben, na xustaposición desta narrativa cos outros (para)textos -así como na propia copia e tradución deses materiais- que acabarían dando lugar ao relato extenso da denominada Crónica geral galega, así como nas diferentes iniciativas de copia e/ou tradución hoxe representadas polo ms. BNE 8817, deberon estar involucrados outros espazos e axentes culturais, aínda que igualmente vinculados, polo menos en parte, á mesma corte señorial limense. En efecto, tanto a incorporación da Estoria de España (A1) como o breve texto introdutorio (A2a) que actúa como gonzo entre a relato dos reis astur-galaico-leoneses e a historia dos monarcas casteláns parecen representar unha iniciativa vinculada á sé compostelá baixo o auspicio

mente, falecería, pois xa non é referido na corte de Afonso XI (Sottomayor-Pizarro 2011: 66; Ferreira 2019: 567).

54 Joán Fernández de Lima III é fillo nado do primeiro matrimonio con Sancha Vásquez de Soverosa. Destas primeiras nupcias naceu tamén Rui Fernández de Lima III, continuador da liñaxe e representante inaugural do novo ramo dos Lima desenvolvido na segunda metade do século XIV, cuxa derivación acabará sendo exclusivamente portuguesa a partir de finais desta centuria (cf. infra n. 67). Do segundo matrimonio de Fernán Fernández con Maria Fernandes de Gondiães, surxiu unha descendencia de orientación principalmente eclesiástica, na cal salienta Joán Fernández de Lima IV, arcebispo de Compostela entre 1330 e 1338 (cf. infra), ademais de Álvaro Fernández de Lima (cóengo de Santiago) e Gil Fernández de Lima II (Ferreira 2019: 594-595).

55 Para a vinculación de Joán Fernández de Lima coa tradución do Livro de Tristam véxase Pichel/ Varela Barreiro (2017: 182-190), Mariño Paz (2018: 109) e Corral Díaz/Pichel et alii (2020: 48-51).

56 Así o demostran as subscricións, en calidade de ricomes, na documentación do último terzo do século XIII e comezos do XIV: Fernán Fernández subscribe diplomas desde 1278 na corte afonsina, ao paso que o seu primoxénito actúa como confirmante da corte de D. Dinis até finais do século XIII (1288-1300), e desde comezos do trescentos subscribe en terras galegas como ricome de Fernando IV até 1310.

57 A vinculación cos Soverosa e cos Riba de Vizela é manifesta, unha vez que Sancha Vásquez, primeira muller de Fernán Fernández de Lima II, é filla do trobador Vaasco Gil de Soverosa e de Fruilhe Fernandes de Riba de Vizela. O primoxénito de Sancha e Fernán, Joán Fernández de Lima III, sería sepultado no mosteiro bieito de Santa Maria de Pombeiro de Riba de Vizela (concello de Felgueiras), do cal sería o seu padroeiro, ao lado da arca tumular do primeiro conde de Barcelos, fillo de Teresa Martins de Soverosa e neto de Martim Gil de Soverosa (medio irmán do citado trobador) e mais de Inés Fernández de Castro (sobre o vínculo entre os Castro e os Riba de Vizela, cf. infra). Canto á liñaxe dos Aboim-Portel, o citado Joán Fernández casa con Maria Eanes, filla do trobador e reputado valido de Afonso III, João Peres de Aboim (fl. 1215-1285). Un repaso destas conexións familiares asociadas á produción literaria transfronteiriza nas primeiras décadas do trescentos, así como as referencias bibliográficas correspondentes —ás cales cómpre engadir, polo menos, os ensaios de Calderón Medina (2018), Ferreira (2019) e García-Fernández (2021) - pode lerse en Pichel/Varela Barreiro (2017: 197-200). 
de Joán Fernández de Lima IV ${ }^{58}$ (Fig. $4^{59}$ ), arcebispo de Santiago entre 1331 e 1338, moi probabelmente coa intención, entre outras querenzas, de lle conferir maior visibilida-

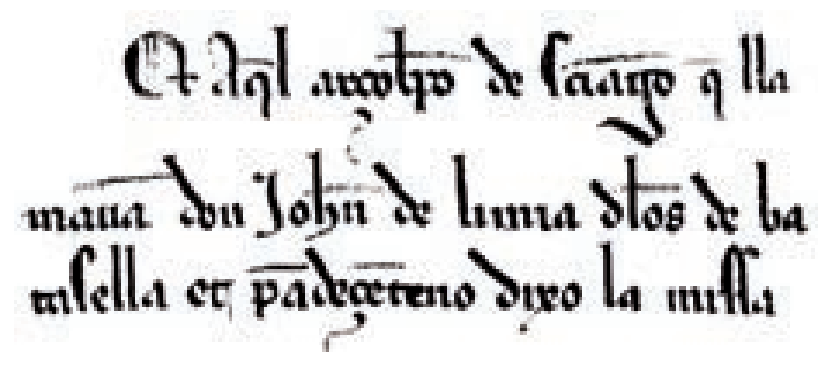

Fig. 4. Fragmento da Crónica de Alfonso XI onde se menciona o arcebispo compostelán. (๔ Real Biblioteca del Monasterio de El Escorial, ms. Y.II.10, ff. 90v-91r).

58 Seguindo Sottomayor-Pizarro (2011, 2015) e Ferreira (2019: 595), é fillo de Fernán Fernández de Lima II coa súa segunda muller Maria Fernandes de Gondiães, dos que tamén nacería outro cóengo compostelán, Álvaro Fernández de Lima, como xa foi indicado. Sobre o arcebispo Lima e o seu contexto familiar, os traballos de Pardo de Guevara y Valdés (2001: 67-70; 2012: 366-369) deben actualizarse cos de Sottomayor-Pizarro (2011: 69-70; 2015: 33-35); véxase tamén Linehan (1993: 578-579, 592, 601). A significativa familiaridade coa que se menciona o alcume e a procedencia liñaxística da familia na inconclusa versión orixinal da Crónica de Alfonso XI, impulsada polo propio Afonso XI e talvez proxectada polo seu chanceler Fernán Sánchez de Valladolid («Et aquel arçobispo de Santiago que llamavan don Joán de Limia de los Batasella et Pandecenteno»; cf. infra Fig. 4 e n. 60), dá unha idea da proximidade deste núcleo señorial ao poder rexio e ao seu universo cronístico e aparato propagandístico desde finais do reinado de Fernando IV e durante o de Afonso XI (1312-1350). Neste sentido, non é descartábel que a chegada e circulación da Estoria de España sanchina, entre outros materiais, por terras galegas poida estar relacionada co protagonismo do arcebispo limense no contexto da coroación en Burgos de Afonso XI (1331), na que el é oficiante.

59 Reprodúcese a versión vulgata da Crónica de Alfonso XI — baseada na inconclusa versión que Fernán Sánchez de Valladolid deixaría interrompida en 1344- preservada no manuscrito rexio trasladado en 1376 por encargo de Henrique II a cargo do seu xustiza maior Juan Núñez de Villazán. Nel pode lerse, no capítulo dedicado á coroación do rei no mosteiro das Huelgas en Burgos (1331), a secuencia da celebración da misa oficiada polo arcebispo compostelán: «Et era alli el arçobispo de santiago don iohan de limia. et el obispo de burgos et el obispo de palençia et el obispo de calahorra et el obispo demendonedo et el obispo de Jahen. Et aquel arçobispo de sanctiago que lla| ${ }^{911}$ mauan don Johan de limia delos batasella et pandeçenteno dixo la missa. et offiçiaron la missa las monjas del monesterio» (transcrición paleográfica a partir do ms. RBME Y.II.10, f. 90vb ${ }_{25-29}-91 \mathrm{ra}_{1-4}$; cf. Cerdá y Rico 1787: 188). Na reelaboración posterior do texto feita pouco despois -a denominada Gran Crónica de Alfonso XI- non se inclúe a alusión da procedencia liñaxística (Batisela) nin do alcume da familia (Pancenteo): «Y era alli el arçobispo de Santiago que llamauan don Joan de Limia e dixo la misa» (cf. Catalán 1977: I, 509).

60 Tanto no caso do relato da Estoria de España sanchina como no prólogo baseado no Liber regum que antecede a Crónica de Castela, selecciónanse e acrecéntanse mencións explícitas ao privilexio do Voto de Santiago a través, entre outros asuntos, do relato da concesión do referido imposto por parte de Ramiro I tras a intercesión do Apóstolo na batalla de Clavijo. A asociación do arcebispo Joán Fernández de Lima IV na conformación do ms. BNE 8817 xa fora formulada por Rodríguez Porto (2012a: II, 58, 785) e revisada por Pichel/Varela Barreiro (2017: 199, n. 101) e Pichel (2017b: 118-119). 
A conexión compostelá xa fora posta de relevo por Bautista (2010: § 35-37), seguindo Catalán, no que respecta aos materiais historiográficos necesarios para a elaboración dos diferentes conxuntos cronísticos hoxe coñecidos. Nese sentido, tamén se ten explorado a implicación doutros representantes do alto clero galego na tradución e compilación destes materiais, como o arcebispo compostelán Rodrigo de Padrón (1307-1316) ou o bispo de Tui Joán Fernández de Soutomaior I (1286-1323), posíbeis co-patrocinadores, de acordo con Monteagudo (1995, 2019a: 947-948), da Crónica geral galega. Pola nosa parte, non concordamos coa hipótese dun padroádego exclusivamente eclesiástico para todo o conxunto cronístico coñecido a través do ms BNE 8817, pois, polo menos, a difusión inaugural do núcleo primixenio representado pola Crónica de Castela $(A 2 b)$-ou acaso unha primeira tradución da Estoria de España antecedente de $A 1$ (cf. infra n. 63)- parece responder máis ben a intereses nobiliarios por parte dun medio señorial laico con estreitas conexións, no só coa corte rexia, mais tamén cos grandes núcleos de poder señorial na área transfronteiriza, caso da influente liñaxe dos Aboim-Portel, os Castro ou os fidalgos de Riba de Vizela (cf. infra). De acordo con isto, e tomando en consideración outros indicios ${ }^{61}$, os dous últimos representantes dos Batisela tradicionais -Fernán Fernández Lima II e o seu fillo Joán Fernández Lima III ${ }^{62}$ - parecen reunir as mellores condicións en termos de patrocinio político-cultural desa primeira empresa historiográfica galega hoxe testemuñada no facticio madrileño.

Ora ben, cómpre non esquecer que este códice non debía representar na altura a única iniciativa galega de asimilación dos materiais cronísticos importados; lembremos, neste sentido, a necesaria circulación dos prototipos ${ }^{*} \alpha_{1}$ e ${ }^{*} \alpha_{2}$-antecedentes de $A 1^{63}$ e $A 2$, respectivamente- e que estarían tamén na base da primeira

61 Para alén dos vínculos políticos, culturais e familiares descritos, outras razóns de orde lingüística e referidas á historia externa do códice BNE 8817 parecen reforzar a hipótese da implicación dos Lima nas diferentes iniciativas historiográficas en foco. Por un lado, os trazos dialectais da tradución apuntan cara á área meridional tudense (Álvarez/Xove 1998; cf. Lorenzo 1975-77: I, xxviii-xxxvi; II, xliii-xlvi; Monteagudo 2019b: 370-377). Doutra parte, a presenza do que parece ser unha nota de posesión no f. 89r da sección $A 2 a-0$ que correspondería á cuberta inicial do volume A2- sitúa o códice da Crónica de Castela amplificada a finais do século XIV entre os bens patrimoniais de Fernán Eanes de Lima II, señor das terras de Lima e Soutomaior, e da súa muller dona Joana Vásquez das Seixas, casal encomendeiro documentado desde o último terzo do século XIV (Pichel 2017b: 120-123). Recoñecemos, con todo, que estes dous indicios poderían apuntar tamén, como veremos a seguir, á (co)participación do bispo de Tui Joán Fernández de Soutomaior I.

62 Monteagudo (2019a: 950-951) tamén incide na importancia na corte dionisina tanto de Joán Fernández de Lima III como de Martim Gil de Riba de Vizela II, mais sen chegar a asocialos co mecenado cronístico en cuestión.

63 Polo menos no que respecta á Estoria de España, máis alá dos testemuños correspondentes á tradición galega coñecida $\left(A, A^{\prime},{ }^{*} A x, A e\right.$ e as copias integradas na Crónica de 1404 ; cf. infra), debeu de existir, como mínimo, un outro estrato textual, máis próximo ao modelo castelán do cal se traduce $-E_{2} c-$ e no cal se reproduce o mesmo esquema figurativo, representado polo ms. BMP 62 (BITAGAP manid 1561), tradicionalmente coñecido como o testemuño máis antigo da Crónica de 1404 (S) e no cal se proxectaron miniaturas ao comezo de cada reinado (véxase en Pichel 2021d unha primeira aproximación ao estudo textual e codicolóxico do ms. S, feito en colaboración con Rosa María Rodríguez Porto). 
redacción da Crónica de $1344^{64}$. Porén, non é factíbel, cos datos que hoxe manexamos, distinguir cal(es) destas iniciativas inaugurais foron promovidas polos «Lima Antigos» mencionados, e cal(es) outra(s) puideron emprender, de ser o caso, outras instancias señoriais. Neste sentido, a proposta defendida por Monteagudo non deixa de ser suxestiva, en particular, polo que respecta ao perfil e influencia político-cultural deses dous persoeiros (Rodrigo de Padrón e Joán Fernández de Soutomaior I), moi ben relacionados, tamén, coas cortes rexias de Fernando IV e D. Dinis ${ }^{65}$. No entanto, o que resulta máis significativo, ao noso entender, é a estreita relación dos descendentes do bispo tudense con Fernán Eanes de Lima II -o último representante do ramo galego dos Lima ${ }^{66}$-, quen, como xa vimos (n. 60), posuíu, xunto coa súa primeira muller, Joana Vásquez das Seixas, un dos volumes (A2) do facticio BNE 8817. Fernán Eanes, señor de Fornelos e Soutomaior, herdaría dous importantes núcleos patrimoniais ao longo das décadas 70 e 80 do século XIV. Por un lado, á morte do seu pai (posterior a 1380), accedería á posesión de todo o patrimonio familiar dos Lima ${ }^{67}$. Por outro, foi designado herdeiro en 1371 polo seu tío materno Joán Fernández de Soutomaior II, tamén bispo de Tui (1351-1385), polo cal recibe unha parte importante dos bens desta

64 Véxase ao respecto Cintra (1951: I, cccxvii-cccxxx), Catalán/Andrés (1970: xliv-xlix), Catalán (1995: 526-529), Lorenzo (2002: 99). Con todo, téñase en conta que, de acordo con Ferreira (2005: 51-59, 757-759; 2010; 2012: § 16-30; 2019), os modelos empregados por don Pedro Afonso non terían por que estar mediatizados pola tradición galega e, por tanto, poderían proceder directamente da corte rexia castelá.

65 Para o compostelán Rodrigo de Padrón véxase López Ferreiro (1902: V, 278-346) e a recapitulación de Monteagudo (1995: 45-50). Para o Soutomaior, é especialmente interesante a información proporcionada por Sottomayor-Pizarro (2012: 146-147, 226); véxase tamén Vila (2010: 41-52, 246-249).

66 As conexións familiares entre os Lima e os Soutomaior remóntanse, polo menos, á xeración de Joán Fernández de Lima I (primoxénito de Fernando Arias Batisela e avó de Fernán Fernández de Lima II), cuxo irmán menor Gil Fernández de Lima casa con Elvira Pais de Soutomaior. Para o percurso vital de Fernán Eanes de Lima II en terras galegas, os datos fornecidos por Pardo de Guevara y Valdés $(2011,2012)$ e Sottomayor-Pizarro $(2011,2015)$ deben completarse con información relativa ao seu primeiro matrimonio e á actividade encomendeira deste casal (véxanse as referencias precisas en Pichel 2017b: 122, n. 11 e 123-134). As circunstancias adversas para a promoción social e económica - en gran medida agravadas polas intervencións de Henrique III contra o casal polos danos e prexuízos ocasionados en diferentes lugares e coutos dos mosteiros lugueses de San Salvador de Chantada e Santo Estevo de Chouzán-, unidas ao conflito avivado entre Castela e Portugal nos últimos anos do século XIV, deberon propiciar a definiva migración de Fernán Eanes cara ao reino portugués, onde se instala en terras alto-minhotas e casa en segundas nupcias con Teresa Gomes da Silva. Alí toma partido polo monarca luso e participa en 1398 na conquista de Tui e no cerco de Salvaterra, servizos polos cales João I lle concede unha serie de importantes doazóns, entre elas a torre de Giela e a terra de Valdevez con todas as súas xurisdicións; unhas cesións que, ao fin e ao cabo, viñan compensar a perda de todos os bens acumulados na familia que lle foran confiscados en Galicia por Henrique III, agraviado pola súa lealdade ao rei portugués. Precisamente, no contexto desta incautación debeu xestionarse o traspaso forzado, por parte da Coroa, dos bens patrimoniais dos Lima-Seixas para outras mans dentro da Casa de Lemos. Véxase ao respecto unha recapitulación en Pichel (2017b: 134-139).

67 Joán Fernández de Lima III, primoxénito de Fernán Fernández, morrera sen descendencia, polo cal os seus bens pasarían como herdanza ao seu irmán Rui Fernández, casado con Maria Afonso Churruchao, conectando, así, a liñaxe tradicional dos Lima (Batisela) cos novos descendentes (os «Lima Modernos»), activos na segunda metade do trescentos. Unha boa parte dos bens de Rui Fernández acabarían chegando finalmente ao seu neto, Fernán Eanes, herdados a través do seu pai, Álvaro Fernández de Lima I —casado con Inés Fernández de Soutomaior e segundoxénito de Rui Fernández-. Este último fora o destacado petrista responsábel da reaproximación da familia a Portugal no marco do tenso conflito propiciado pola guerra civil entre Pedro I e o futuro Herique II e a loita polos dereitos da Coroa tras o rexicidio e a instauración da nova dinastía trastámara (Sottomayor-Pizarro 2015: 32-33, 35-36, 40-41). 
influente casa señorial ${ }^{68}$. Así pois, en calquera dos dous casos, sería factíbel presupor a incorporación ao patrimonio dos Lima-Seixas das vellas crónicas recreadas a comezos de século.

Polo que respecta ao reino portugués, a difusión de todos estes materiais non debeu ser allea á promoción doutras empresas cronísticas e liñaxísticas, mais tamén romancescas, xurídicas ou científicas, impulsadas desde a corte rexia de D. Dinis ${ }^{69}$ e por algúns dos núcleos señoriais máis influentes durante as primeiras décadas do trescentos e xa desde finais do século XIII, prolongando o labor cultural impulsado na corte de Afonso III. No ámbito historiográfico, máis alá da probábel lectura e tradución da General Estoria na súa corte (cf. supra § 2.1), D. Dinis promovería a tradución integral do Livro de Rasis, comisionada por Pero Eanes de Aboim, segundo señor de Portel —e cuñado de Joán Fernández de Lima III- entre os anos 1287 e 1315, e na cal xa participaría o seu pai, João Peres de Aboim, a partir de $1263^{70}$. Poucos anos máis tarde, o Livro velho de linhagens $^{71}$ sería promovido, na súa primeira redacción, por Gil Martins, antigo mordomo maior de Afonso III e avó do segundo Conde de Barcelos, Martim Gil de Riba de Vizela II (cf. infra). Pola súa parte, a corte dionisina manifestou tamén o seu interese, no campo da literatura ficcional, polo ciclo artúrico $^{72}$, reflectido na tradución do Livro de Merlim (ca. 1300-10) e tamén, con bastante probabilidade, na difusión da materia tristaniana, hoxe só coñecida a través do fragmento galego do Livro de Tristam (ca. 1300-40). Polo que respecta á prosa xurídica, a circulación e asimilación das Partidas en Portugal testemúñase desde finais do século

68 A importante doazón, realizada en Milmanda en xaneiro de 1371, consistía principalmente nunha serie de señoríos coas súas fortalezas (como as de Soutomaior, Fornelos e Crecente), que representaban en gran medida o núcleo primitivo daquela antiga e destacada estirpe galega. Dous días antes desta doazón, o Soutomaior outorgara testamento en favor de Fernán Eanes como herdeiro, ficando como executores testamentarios o seu pai Álvaro Rodríguez, o seu tío Joán de Castro (bispo de Tui) e a irmá do testador. Para o alcance da doazón e as insólitas circunstancias que motivaron a transmisión dos bens do Soutomaior ao seu sobriño Fernán Eanes, véxase Sottomayor-Pizarro (2015: 40-42).

69 Catalán mesmo non descartaba a posibilidade de que fose o propio D. Dinis quen encargase a versión galego-portuguesa da Crónica de Castela (Catalán/Andrés 1970: xlix). Un panorama xeral da produción cultural de D. Dinis en Osório (1993) ou Pizarro (2012: 319-223), entre outros. Deixamos fóra deste rápido balance —centrado nas obras en prosa - a produción e mecenado de D. Dinis no ámbito da lírica trobadoresca (unha discusión recente sobre o seu contributo á «Compilación xeral» representado no Livro das Cantigas do Conde de Barcelos en Monteagudo 2019a; cf. infra n. 107).

70 En relación co mecenado e as fases de tradución do perdido Livro de Rasis ou Crónica do Mouro Rasis (BITAGAP texid 7245), do cal só se conserva a súa tradución castelá (Catalán/Andrés 1970), véxase Rei (2010) e Ferreira (2012: §12). Lembremos, ademais, que no seo deste scriptorium familiar tamén se elaboraría o importante cartulario coñecido como Livro dos bens de D. João de Portel (BITAGAP texid 5975; Azevedo 1906-10).

71 Sobre a xénese e mecenado do Livro velho de linhagens (BITAGAP texid 1171), cuxa datación oscila entre a proposta máis recuada (ca. 1270) e a penúltima década do XIII (ca. 1286-90) de acordo coas dúas fases de redacción da obra, véxase Piel/Mattoso (1980), Mattoso (1999), Miranda (2010b, 2012) e Ferreira (2012: § 13).

72 Véxase Ailenii (2019) para un panorama actualizado da recepción occidental do romance arturiano a través dos primeiros testemuños coñecidos da tradución galego-portuguesa. Véxanse tamén os traballos de Lorenzo Gradín / Souto Cabo et alii (2001), Pichel/Varela Barreiro (2017) e Lorenzo Gradín/Pedro (2017) para o Livro de Merlim (BITAGAP texid 1398) e o Livro de Tristam (BITAGAP texid 1483). 
XIII e durante a primeira década do trescentos na órbita curialesca dionisina ${ }^{73}$. Canto á tradución do texto, os primeiros vestixios coñecidos datan de mediados do $\mathrm{XIV}^{74}$; porén, existen indicios documentais e lingüísticos que permiten situar as primeiras iniciativas de tradución no primeiro cuartel da centuria e, probabelmente, por iniciativa de D. Dinis ${ }^{75}$. Para alén das Partidas, tamén se traduciron nesta época o Fuero Real e as Flores de Derecho, coincidindo, en parte, cos primeiros anos do seu reinado, se ben non hai evidencias directas de que se tratase dunha iniciativa impulsada polo monarca $^{76}$. Por último, no ámbito científico, D. Dinis encargou en 1318 ao seu físico, o Mestre Giraldo, o coñecido Livro de Alveitaria, unha compilación de hipiatría baseada na Mulomedicina do dominico Teodorico Borgognoni e no De medicina equorum do mariscal calabrés Giordano Ruffo ${ }^{77}$.

Atendendo a este contexto tan proclive á asimilación e tradución de produtos culturais foráneos, propiciado polo neto, tamén trobador, do Rei Sabio, a Crónica de Castilla podería ter circulado tamén desde moi cedo na corte nobiliaria dos Riba de Vizela, en particular, na do xa mencionado II conde de Barcelos, Martim Gil de Riba de Vizela II (fl. 1260-1312), reputado fidalgo ao servizo da corte dionisina ${ }^{78}$ e, de acordo con Miranda (2009a, 2010a, 2012), talvez promotor da tradución dalgunha das versións da Crónica de Castela que circularían na altura en medios galegos e portugueses ${ }^{79}$. Para alén da súa prestixiosa ascendencia acumulada por vía paterna —os

73 Así o demostra o emprego do texto en diferentes decisións lexislativas outorgadas polo monarca entre 1295 e 1309 (Domingues 2021: 105).

74 Trátase dos códices da Terceira Partida (ANTT, Leis e Ordenações, Núcleo Antigo 3; BITAGAP manid 1436), copiado en 1341, e, en época coetánea, o da Primeira Partida (BNP Alc. 463; BITAGAP manid 1132). Véxase Domingues (2021: 107-110) para a fecunda tradición manuscrita destes dous textos (BITAGAP texid 1132 e 1134).

75 Canto á Terceira Partida, Ferreira (1984: 116) considera un dos fragmentos conservados en Braga anterior a 1341 (Domingues 2021: 114). Polo que respecta á Primeira Partida, é bastante probábel que o seu antígrafo, importado desde a corte dionisina nas primeiras décadas do XIV, fose un modelo galego-portugués xa traducido en medios galegos (Ferreira 1980: xlix-lxii; cf. infra n. 168).

76 Os únicos testemuños portugueses coñecidos do Fuero Real (BITAGAP texid 1207) e das Flores de Derecho (BITAGAP texid 1100) foron copiados conxuntamente ca. 1273-1284 (BITAGAP cnum 1754 e 1755) - a partir dunha tradución orixinal elaborada por volta de 1267- nun códice facticio de finais do século XIII (ANTT FC/001/398; BITAGAP manid 1145) que contén textos legais relativos ao concello da Guarda (Ferreira 1987: 38-42, 1993; Ferreira 2012: § 14-15). Para a tradución galega destes dous códigos legais, elaborada a cabalo dos séculos XIII e XIV, véxase infra n. 109.

77 Sobre o texto e o único testemuño conservado, catrocentista, do Livro de Alveitaria (BITAGAP texid 1099, manid 1044) véxanse os traballos de Rio Riande (2010) e Pérez Barcala (2019, 2020). Para a tradución galega do De medicina equorum, véxase infra n. 107.

78 Na corte de D. Dinis, Martim Gil desempeñou o cargo de alférez maior do reino durante dezasete anos, ademais de mordomo maior do infante herdeiro e terceiro Conde de Barcelos. Porén, a partir de 1312 viuse forzado ao exilio acusado polo rei de ser vasalo do monarca castelán. Véxase Sottomayor-Pizarro (1999: I, 552-555) para unha breve biografía deste magnate.

79 As motivacións aducidas por Miranda (2012) —e discutidas recentemente por Monteagudo (2019a: 948-949) - polas cales se identifica o II Conde de Barcelos como probábel promotor da versión da Crónica de Castela que hoxe coñecemos e dos seus paratextos parecen encaixar mellor se as aplicamos non ao ms. BNE 8817 (seccións $A 2 c, A 2 b$ e $A 2 d$ ), mais a algún outro testemuño do texto que tivese circulado naquela altura na corte dos Riba de Vizela, quer chegado directamente desde a corte castelá, quer froito dunha versión xa traduzida en medios galegos e relacionada co testemuño A2 integrado no ms. BNE 8817 (cf. supra n. 64). Paga a pena lembrar aquí a opaca referencia a unha perdida «coroniqua de Galliza» mencionada polo 
Maia e os Sousa-, os fortes vínculos, por vía materna, de Martim Gil II cos Castro, dos que se torna directo representante da súa poderosa liñaxe en contexto portugués ${ }^{80}$, así como o interese dos Riba de Vizela pola memoria liñaxística reflectida, como xa se indicou, na composición do Livro velho de linhagens, poderían ter motivado a circulación - como vía de entrada ou de saída- de materiais historiográficos procedentes da corte castelá (a Estoria de España, a Crónica de Castela ou a redacción toledana do Liber regum). Con certeza, a eventual implicación dos fidalgos de Riba de Vizela na recepción e difusión da Crónica de Castela fai preludiar o enorme interese historiográfico que suscitarán este texto e mais a Estoria de España no círculo nobiliario do III conde de Barcelos, don Pedro Afonso, quen os empregará como fonte estrutural principal na súa Crónica de $1344^{81}$. Décadas despois, como xa foi dito, estes e outros materiais volverán reaparecer na Crónica de 1404 e na Refundição de comezos do xv da crónica do conde don Pedro ${ }^{82}$.

En definitiva, de acordo co exposto nalgunha ocasión ${ }^{83}$, a estreita relación do núcleo señorial dos Lima-Batisela coas cortes rexias veciñas, mais tamén os seus vínculos familiares e culturais con algunhas das liñaxes máis prestixiosas da altura, tanto galegas (os Castro, os Soutomaior), como portuguesas (os Riba de Vizela, os Aboim-Portel), convida a pensarmos en termos de copatrocinio transfronteirizo no que respecta á circulación e difusión destes textos ao longo das primeiras décadas do trescentos. Non hai dúbida, porén, de que nesta trama de conexións político-culturais e familiares xogou tamén un papel decisivo a apropiación por parte da curia eclesiástica compostelá —e talvez tamén tudense- dun discurso con gran potencial propagandístico no que respecta ás reivindicacións do alto clero galego, en particular as de motivación xacobea. Na conxunción de todos estes factores poderá entenderse o xurdimento e difusión aquén e alén Miño de todos estes materiais cronísticos hoxe

bacharel Cristóvão Rodrigues Acenheiro nas súas Chronicas dos Senhores Reis de Portugal (1535), como posíbel texto asociado aos materiais preexistentes ou derivados dos modelos textuais empregados tanto polo Conde de Barcelos como polos círculos señoriais que o precederon nesta querenza historiográfica (Catalán/ Andrés 1970: xxxiv-xliv; Lorenzo 2002: 103; Miranda 2009b; Moreira 2012, 2013).

80 Martim Gil de Riba de Vizela era fillo de Milia Andrés de Castro, neto de André Fernández de Castro e sobriño-neto de Estevo Fernández de Castro, cuxo belicoso fillo, Fernando Ruíz de Castro morrería no cerco de Monforte en 1304 a mans do infante Felipe, irmán de Fernando IV (Pardo de Guevara y Valdés 2000: I, 127). Como lembra Miranda (2012: 133-134), coa morte de Fernando Ruíz, a liñaxe dos Castro fica debilitada, pois o seu único representante por vía masculina, Pedro Fernández de Castro, o seu fillo, era aínda unha crianza. Precisamente, nese difícil contexto, o conde Martim Gil asume a protección do seu primo instituíndoo como o seu único herdeiro. Sobre a posíbel implicación dos Lemos —en especial a nai de Pedro Fernández de Castro, dona Violante Sánchez, filla ilexítima de Sancho IV—, na circulación de textos desde a corte rexia castelá, véxase o adiantado nas conclusións deste traballo (n. 116).

81 Como é sabido, a redacción orixinal da Crónica de 1344 (BITAGAP texid 9644) só se coñecía, até hai pouco, a través dunha tradución parcial castelá. Véxase agora Bautista/Moreira (2021) para unha recente análise sobre a tradición textual da Crónica de 1344 á luz da descuberta de dous testemuños portugueses da primeira redacción.

82 Sobre a segunda redacción da Crónica de 1344 (BITAGAP texid 1221), véxase Cintra (1951: I, xxix-xxx, lxiv-lxxv) e Catalán (1995: 526-529; 1997: 165-181). Unha actualización a respecto da súa tradición manuscrita e castelá en Moreira / Askins (2015).

83 Pichel/Varela Barreiro (2017: 187-90), Pichel (2017b: 118-119), Corral Díaz/Pichel et alii (2020: 82-83). 
coñecidos a través de compilacións coetáneas ou tardías, quer as copias galegas que integran o facticio 8817 da BNE, quer os escasos testemuños que conservamos da primeira redacción da Crónica de 1344 e da Crónica de 1404.

\section{E DESQUE EU ANDEY OS MAIS ANTIGOS MOESTEYROS E MAIS COMPRIDOS DE LIUROS... O TESOURO HAXIOGRÁFICO DE BERNARDO BRIHUEGA $^{84}$}

Con certeza, un dos colaboradores máis estreitos do taller historiográfico afonsino foi o cóengo da igrexa de Sevilla, natural da vila homónima alcarreña, Bernardo de Brihuega, «clericus et alumnus» — como el mesmo declara- do Rei Sabio. Desde os comezos da década dos setenta traballou intensamente baixo o seu patrocinio con vistas á compilación dun vasto tesouro haxiográfico coñecido como as Vitae Sanctorum, conformado por cinco libros sobre a Historia da Salvación a partir do Novo Testamento: a vida de Xesús e de Santa María (libro I), as vidas e paixóns dos apóstolos (libro II), as paixóns dos mártires (libro III), as vidas dos confesores (libro IV) e a vida das santas virxes (libro V). As sucesivas batidas «per todoslos moesteyros de seu reyno ${ }^{85} \gg$ na procura dos materiais haxiográficos necesarios para construír este extenso corpus deron como resultado unha primeira versión en latín (ca. 1270-75 ${ }^{86}$ ), da cal conservamos algúns testemuños tardíos —compilados no século $\mathrm{XV}$ - e moi fragmentarios ${ }^{87}$. Pouco tempo despois, durante os anos seguintes (ca.

84 A cita que encabeza esta epígrafe procede do Livro dos mártires (BCB Livro ํo 36, f. 145r).

85 Na versión portuguesa do Livro dos mártires, impreso en 1513 por João Pedro Bonhomini de Cremona (BCB Livro no 36, f. 145r), podemos coñecer con bastante detalle o proceso de selección e compilación das fontes supervisado con grande esmero polo Rei Sabio: «E por ende nom se deve maravilhar nenhũu se eu, Bernaldo de Briuega, clerigo do mui nobre meu senhor, El Rei Dom Afonso, havendo mandamento dele de traladar as vidas dos Martires e dos outros Santos, faço ende muitos livros, e maiormente havend'os de achegar per seu mandado, per muitos logares departidos, e nom os achando as sazões certas que os mester havia, e demais havendo-as, per prema dele, a traladar o mais compridamente que as achar podía. Ca a razom que eu prometí de partir este Terceiro Livro em duas partes, tinha que se tinha meu senhor El Rei assaz por pagado das paixões que eu em aquelas duas partes posera. Mas ele, veendo que minguavam i muitos dos que ele sabia, e que havia i algũas que nom eram bem compridas mandou-mas ir buscar e emmendar, per todolos moesteiros de seus reinos, segundo que vos hei muitas vezes contado. E, des que eu andei os mais antigos moesteiros e mais compridos de livros, teendo que nom acharia em nenhũns deles outros mais do que em eles achara, fiz ende a terceira [parte] que de suso havedes ouvida, mas depois me mandou ele que andasse pelos outros todos, e achei as paixões destes martires que estam aqui escritos, de que me conveo fazer aquesta quarta parte» (apud Cepeda 1982: xxxviii-xxxix; cf. Sonsino/Cruz/Sobral 2018).

86 A estimación cronolóxica, tanto da versión latina como da romance (cf. infra), foi proposta por Bautista 2017.

87 BGHUsal mss. 2538 a 2541; RBME ms. f.I.1. Desta primeira redacción latina só coñecemos o texto dos últimos tres libros (parcialmente no caso da terceira e quinta parte) e un pequeno fragmento do segundo (Díaz y Díaz 1962, 1996: 37-41; Martins 1972: 105-109; Pérez-Embid Wamba 2002: 255-302; Martín-Iglesias 2016a). Véxase agora o estudo exhaustivo dos testemuños salmantinos elaborado por Martín-Iglesias (2020). 
1275-84) e de modo paralelo á composición da General Estoria, o propio Bernardo continuaría este labor de ampliación e conciliación das diversas fontes reunidas, mais a partir dunha redacción máis refinada, cunha maior coherencia discursiva e xa traducida para lingua vernácula. Con toda probabilidade, a finalidade principal desta segunda versión, xa romanceada, sería a súa incardinación na crónica universal afonsina, en particular, no que respecta á materia correspondente á Sexta Parte (Bautista 2015). Porén, o propio corpus haxiográfico tamén tería circulado de maneira autónoma xa desde o inicio -máis adiante coñecido como Genesi alfonsi ${ }^{88}$-, do mesmo modo que acontecería con outras producións (re)creadas no taller historiográfico e xurídico afonsino con independencia da súa conformación ou integración como parte dun proxecto editorial máis amplo, como no caso das Sete Partidas, a Estoria de España ou a propia General Estoria ${ }^{89}$.

Desta segunda redacción romance coñécense diferentes versións castelás e portuguesas, mais só de maneira parcial e correspondentes aos tres primeiros libros, de tal modo que a narración relativa aos confesores e ás virxes só nos é coñecida a través dos exemplares latinos antes mencionados. A difusión da obra de Brihuega en romance é moi temperá e a súa lectura parece estar asociada, tanto no reino portugués como na Coroa de Castela, ao interese que debeu suscitar nalgúns ambientes cortesáns a posibilidade de acceder a todo este vasto corpus que, dalgún modo, difería ou complementaba a rica tradición haxiográfica consolidada durante a segunda metade do século XIII, como no caso da Legenda aurea de Jacopo da Varazze (ca. 1260), as Vitae sanctorum de Rodrigo de Cerrato (rematadas ca. 1275) ou as Legende sanctorum de Juan Gil de Zamora (iniciadas por volta de 1279-89). O carácter autónomo e cariz doxolóxico das vitae compendiadas nestes lendarios contrastaba co método narrativo - de natureza cronística e clara influencia afonsina- despregado na

88 Esta denominación menciónase en dúas versións quiñentistas da obra de Bernardo de Brihuega: por un lado, na impresión vallisoletana de 1502 - hoxe perdida- dos cinco libros de Brihuega da cal dá noticia Frederick J. Norton $(1973,1978)$; por outro, no prólogo da versión portuguesa publicada en 1505 polo impresor Valentim Fernandes - a instancias da raíña dona Leonor de Lencastre- do libro II, as Vidas e paixões dos apóstolos (Cepeda 1982-89: I, xxiv-xxvi; Bautista 2015: 261-264).

89 Coñécense varios exemplos (in)directos desta dupla conformación textual no taller afonsino, quer aínda como rascuño ou corpus preliminar, quer xa como produto acabado ou nunha fase redaccional e figurativa ulterior, entre outros: o Libro del fuero de las leyes (ca. 1265), que transmite nun manuscrito de coidada factura — cunha vintena de pequenas miniaturas e varias iniciais historiadas- (BL Add. 20787; BETA manid 1112) a primeira redacción do que despois constituiría a Primera Partida (Rodríguez-Velasco 2010: 107-111; Rodríguez Porto 2012a: II, 765); ou o romanceamento do Chronicon Mundi de Lucas de Tui —o Tudense alfonsí (Jerez 2020)—, coñecido a través do testemuño H -BNE ms. 9268; BETA manid 3290- da Versión crítica e da Crónica de 1404 na cal se emprega como fonte da historia imperial (Bautista 2014b). Canto á General Estoria, anteriormente xa mencionamos algúns textos autónomos e coexistentes coa crónica universal (cf. supra § 2.2): o perdido Libro de Troya - conxecturado a partir do testemuño da Historia troyana de Pedro I-, que transmitía unha tradución historiada con base na Histoire ancienne jusqu’à César e que só coñecemos compilado, como «estoria unada» - a coñecida como a Estoria de Troya - na segunda e terceira partes da General Estoria (Rodríguez Porto 2012a: II, 750-783, 2012b; Pichel 2016: 124-130); a Estoria de las Bretañas baseada nun compendio da Historia regum Britanniae — probabelmente un manuscrito francés da Primera versión variante da vulgata galfridiana (Pichel 2018)—, da cal se conserva un testemuño moi parcial e tardío no exemplar facticio que transmite a Historia troyana polimétrica (BNE ms. 10146). 
Historia da Salvación concibida por Bernardo, na cal a contextualización cronolóxica e política dos santos referidos e dos seus feitos - por exemplo, a adscrición da passio dun determinado apóstolo ou mártir ao emperador romano correspondente- era un aspecto crucial, así como a interconexión dos diferentes relatos e dos axentes implicados neles ${ }^{90}$.

\section{4 .1. A difusión da obra de Brihuega en Portugal e na Coroa de Castela}

No ámbito portugués, aínda que os testemuños conservados son tardíos, sábese que as primeiras traducións da obra remontarían en última instancia á fecunda actividade literaria emprendida durante o reinado de $\mathrm{D}$. Dinis desde finais do século XIII e durante o primeiro cuartel do trescentos. O estudo da tradición textual e manuscrita inaugurado por Mário Martins desde mediados do século pasado (1959, $1969,1972)$ e continuado, entre outros, por Isabel Vilares Cepeda $(1975,1982-89,1993)$, ten demostrado, por un lado, a existencia de versións integrais hoxe perdidas dos libros II e III, como pouco, desde finais do século XIV e durante a primeira metade do XV, cuxa promoción se poderá vincular a diferentes impulsos culturais baixo os reinados de João I e D. Duarte. Por outra parte, o exame dos estratos lingüísticos ${ }^{91}$ rastrexábeis nos testemuños hoxe conservados das Vidas e paixões dos apóstolos e do Livro dos mártires ${ }^{92}$ confirma a dupla hipótese de que todos eles remiten en último termo á produción cultural dionisina e de que as primeiras traducións portuguesas non se realizarían directamente desde a versión latina do Briocano, mais a través dun modelo xa romanceado. Sobre esta última cuestión volveremos brevemente máis adiante.

Polo que respecta á Coroa de Castela, os testemuños máis antigos datan de finais do século XIII ou comezos do XIV (ca. 1290-1320) e, de acordo coa súa materialidade e cos datos coñecidos da súa procedencia, parecen representar tamén unha iniciativa asociada ao ambiente cortesán. Polos escasos testemuños que nos chegaron, sempre moi fragmentarios, sabemos que nesa altura, a cabalo das dúas centurias, se emprendeu unha das primeiras empresas de difusión das Vitae de Bernardo, a pouca distancia da súa primeira versión traducida, coa copia e ilumina-

90 Cepeda (1982-89: I, xxvii-xxxvii). Unha recente recapitulación ao respecto en Sobral (2021).

91 Véxase, en particular, a recente análise de Sobral e Cardeira (2018) sobre o Livro dos mártires, en que se confirma o estado da cuestión formulado anteriormente por Martins (1972: 105-129) e Cepeda (1982-89: I, xxiii; 1993).

92 Do libro II (BITAGAP texid 1044), editado por Cepeda (1982-89), consérvase un coidado códice alcobacense copiado en 1442-1443 (BNP ms. ALC. 280; BITAGAP manid 1121) e un impreso publicado en 1505 por Valentim Fernandes a instancias da raíña dona Leonor de Lencastre (BCB Livro no 23 ; BITAGAP manid 1032; cf. copid 1110), para alén dun fragmento da segunda metade do XIV ao cal nos referiremos máis adiante (BNP ms. 5, no 28; BITAGAP manid 1504; Cepeda 1975). Do libro III (BITAGAP textid 1032), cuxa transcrición é accesíbel no Corpus de Textos Antigos (Sonsino/Cruz/Sobral 2018), consérvase só a segunda metade da obra nun único postincunábel impreso en 1513 baixo o auspicio do rei Manuel I (BCB Livro no 0 36; BITAGAP manid 1028; cf. copid 1103, 1104, 1164 e 1846), para alén dun fragmento do século XV (ANTT, Fragmentos c. 20, no 10; BITAGAP manid 1750) dado a coñecer por Cepeda (1993). 
ción —en varios manuscritos de aparato-, se non de toda a obra, si polo menos do segundo e terceiro libro ${ }^{93}$. A materia - apostólica e martirial-compilada nestes dous volumes foi obxecto de copia e refundición durante o trescentos, tal como demostra a compilación haxiográfica de finais do século XIV ou comezos do XV conservada na Biblioteca Nacional de España ${ }^{94}$. Polo que respecta á materia cristolóxica do primeiro libro de Brihuega -ausente, como xa indicou, na tradición latina e portuguesa coñecida-, consérvanse algúns testemuños fragmentarios ${ }^{95}$ fundamentais para deducir, polo menos de modo parcial, o alcance dos contidos compilados na sexta parte da General Estoria, na cal se integraría boa parte da materia recollida no primeiro volume das Vitae sanctorum (Bautista 2015, 2017).

\subsection{Galicia nos primordios da difusión do magno corpus haxiográfico de Bernardo de Brihuega}

Voltando aos inicios da recepción da obra do Briocano, hai indicios suficientes da súa circulación —e talvez copia ou tradución- en terras galegas poucas décadas despois da súa composición en romance na corte afonsina ${ }^{96}$. Os referidos fragmentos das Vidas y pasiones de los apóstoles identificados no Arquivo Histórico Provincial de Ourense (Fig. 5), hoxe desencadernados e restaurados, foran reutilizados no seu momento como cubertas dun libro de apeo dos bens do mosteiro de Santa

93 BETA texid 11193, 4634, 4635, 4636. Os fragmentos identificados recentemente no Arquivo Histórico Provincial de Ourense (Fragmentos, carp. 3, no 4/5; BETA manid 4222) pertencen a un coidado códice -proxectado para incluír miniaturas- do libro II de Brihuega e transmiten varios capítulos das vitae dos apóstolos Tomé, Marcos e André (Pichel/Sánchez Ferro 2019; 2021b: 60-64). Coñécese, ademais, outro fragmento coetáneo e relacionado co anterior — co que talvez conformaba unha mesma iniciativa libraria en varios volumes-, neste caso iluminado e pertencente ao libro III (o Libro de los mártires), que actualmente é obxecto de estudo e edición no marco da «Red del Libro Medieval Hispánico» (RED2018-102330-T).

94 Os estudos de Bautista (2014a, 2015, 2017) descartaron a tradicional consideración deste manuscrito (BNE ms. 10252; BETA manid 2819) como unha peculiar versión da Legenda aurea e permitiron identificar as Vitae sanctorum de Brihuega como a súa fonte haxiográfica principal. De acordo con este autor, o dito testemuño remontaría a unha primeira redacción romanceada do texto de Bernardo (polo menos da segunda e terceira partes), máis arcaica do que a versión que ofrecen as traducións portuguesas (cf. Pichel 2021b: 62-63). No seu estado actual transmite unha colección case completa de 12 pezas relativas ás vidas dos apóstolos e evanxelistas (libro II), máis un grupo de 18 textos dedicados ás paixóns de diferentes mártires (libro III), para alén doutros materiais compilados como a Summa de ecclesiasticis officiis de Jean Beleth, a propia Legenda aurea ou a colección haxiográfica coñecida como Virtutes apostolarum (Bautista 2014a). Sobre este manuscrito, e en particular no que respecta á tradición miraculística xacobea representada polos Miraglos de Santiago (BETA texid 4634, cnum 9104), véxase a edición e estudo de Connolly (1990) e os traballos de Fidalgo/Brea (2004: 194-209) e Fidalgo (2005).

95 Un deles, copiado a mediados do século XIV, consérvase na Biblioteca Francisco de Zabálburu (ms. 11-144; BETA manid 4056) e transmite, de acordo con Bautista (2017: § 10-12), a parte inicial do libro I (BETA texid 11194). Un segundo testemuño é copia, tamén incompleta, da segunda metade do XVI —a partir, de acordo co escribán, dun modelo textual «antiquísimo»— e interrompe a narración no relato da Última Cea, compartillando trazos estilísticos co testemuño da Zabálburu e preservando novas seccións descoñecidas até agora (Bautista 2017: § 18-21).

96 Como vimos anteriormente, a obra de Brihuega non foi unha excepción, pois a chegada a terras galegas doutros produtos historiográficos asociados coa corte foi tamén moi temperá, como demostra a copia e tradución da Crónica de Castela e da versión sanchina da Estoria de España nos primeiros decenios do trescentos (cf. §3.2). 
Clara de Allariz. A presumíbel localización do códice do cal proceden estes fragmentos no convento allaricense -fundado, como é ben sabido, en 1282 por dona Violante de Aragón-fornécenos algúns indicios canto á xénese e ao posíbel itinerario desta versión ilustrada da obra de Brihuega ${ }^{97}$. De acordo con Rodríguez Porto, parece factíbel que este códice fose concibido baixo o padroado do infante Felipe (1292-1327) - fillo de Sancho IV e de dona María de Molina- e a súa muller dona Margarita de la Cerda (1293 - ca. 1328) - neta de Afonso X, con quen casa en 1315-, ambos os dous protectores do mosteiro ourensán naquela altura ${ }^{98}$. A querenza pola materia haxiográfica no ambiente cortesán é coñecida e demostra o interese pola lectura - textual e visual— dunha obra como as Vitae sanctorum de Brihuega desde finais do século XIII: desde a tradición haxiográfica franciscana, de natureza isabelina, representada polo Officium et vita S. Elisabeth landgraviae Thuringiae, cuxo mecenado ca. 1270-1284 foi atribuído á raíña dona Violante ${ }^{99}$, até a compilación de vidas de santos, romances haxiográficos e outras lecturas de orde piadosa - como o Cuento de una santa emperatrís, o Otas de Roma ou as vitae de María Exipcíaca e de María Madalena, entre outras-que transmite o ms. RBME h.i.13, copia tardía dun códice do primeiro cuartel do XIV que puido pertencer á raíña dona María de Molina ${ }^{100}$.

As posibilidades de estudo da recepción galega da obra de Brihuega -neste caso o libro II- non parecen esgotarse aquí, con todo. Do mesmo xeito que acontece co corpus historiográfico (post)afonsino, de ningún modo resulta desatinado preguntarse polo alcance ou proxección da materia haxiográfica de Brihuega en termos de copia ou mesmo tradución, nin tampouco acerca dunha posíbel circulación destes materiais cara ao reino portugués. Para dar resposta, aínda que sexa moi rudimentaria, a esta formulación, convén repararmos no contexto sociocultural en que se inscribe o testemuño ourensán das Vidas y pasiones de los apóstoles, tanto no relativo á actividade literaria operativa nesas coordenadas espazo-temporais, como no que respecta ás redes de poder que puideron propiciar unha tradición textual alternativa tomando como punto de partida o códice allaricense. No primeiro caso, xa foron referidas as diferentes iniciativas de (re)creación historiográfica asociadas á liñaxe dos Lima desde os inicios do trescentos (§ 3.3). Precisamente, quen lidera a comunidade clarisa receptora do códice de Brihuega posúe vínculos con este núcleo señorial, para alén da súa proximidade ao poder rexio. En efecto, dona Sancha Eanes, primeira aba-

97 Polo menos no que concirne ao libro II e talvez tamén ao III de acordo co indicado canto á relación entre ambos os testemuños recentemente identificados (cf. supra n. 94).

98 Véxase o traballo de Rodríguez Porto publicado neste mesmo volume, no cal se adianta esta hipótese e se pon en relación co patrocinio doutras pezas artísticas como a coñecida cruz de cristal de rocha conservada no convento alaricano.

99 Un estudo completo, incluído o seu contexto de produción, do Officium et Vita (BnF ms. NAL 868) en Rodríguez Porto (2012a: II, 7-39).

100 Sobre a composición e mecenado desta colección haxiográfica (BETA manid 1303), editada por Moore (2008) e Zubillaga (2008), véxanse as consideracións de Gómez Redondo (1999: 1341-1370; cf. 2007: 3913, 3918, 3925; 2009: 54-56) e unha recapitulación recente en Zubillaga (2021: 288-291). 


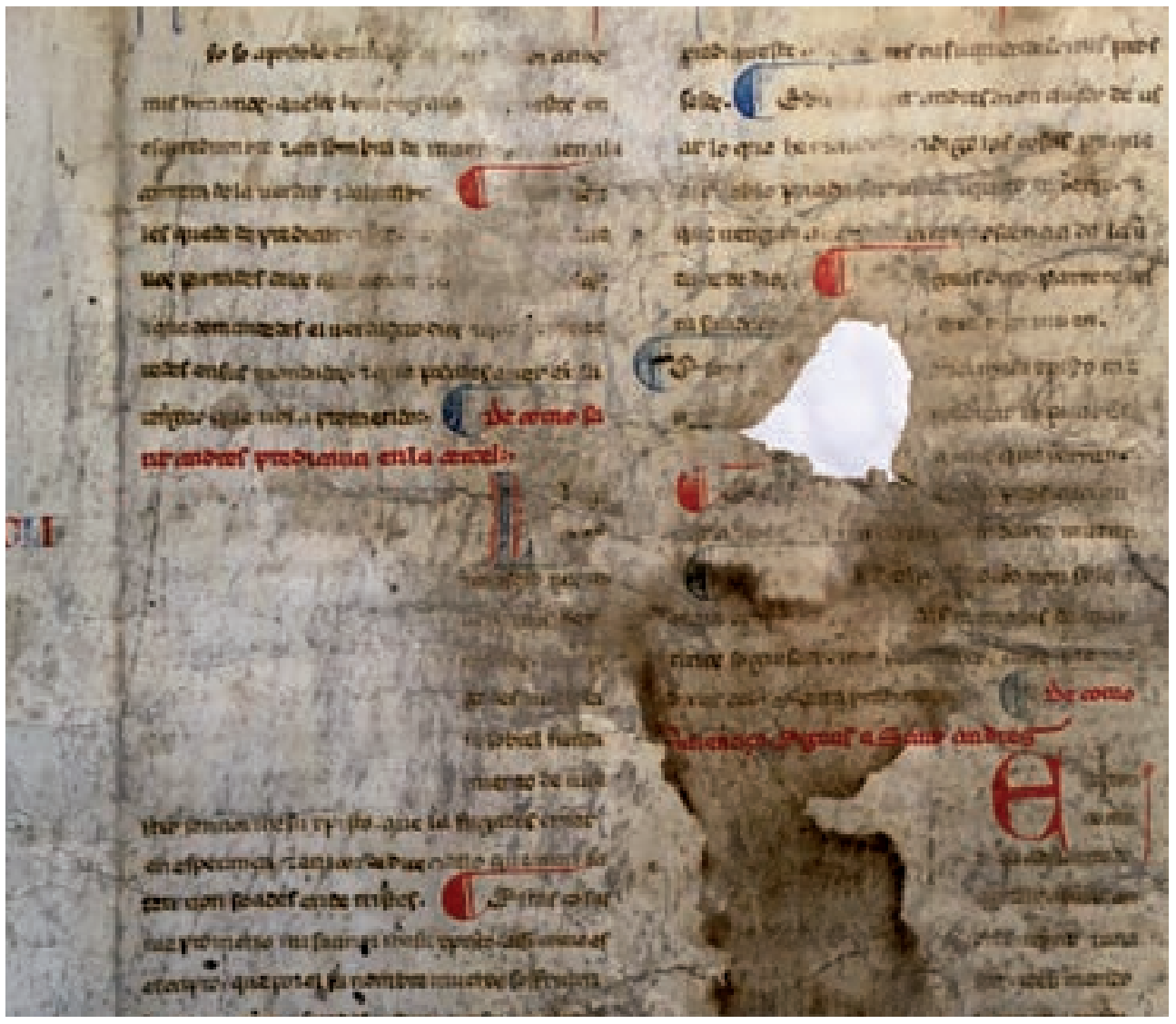

Fig. 5. Vidas y pasiones de los apóstoles (๔ Arquivo Histórico Provincial de Ourense, Fragmentos, carp. 3, n.. 4-5, f. 1v).

desa de Santa Clara de Allariz, está emparentada cos cabaleiros de Zarracós ${ }^{101}$ (conc. A Merca) - unha das herdanzas adquiridas pola comunidade-, entre os que se encontra o seu irmán Gonzalo Eanes, vasalo de Fernán Fernández de Lima II ${ }^{102}$, como vimos, un dos posíbeis implicados na copia ou tradución da Crónica de Castela (ca. 1300-12).

A sospeita dunha posíbel circulación do texto entre estas dúas influentes liñaxes (os Eanes de Allariz e os «Lima Maiores») e a súa proxección cara ao reino veciño non esvaece cando analizamos a tradición manuscrita portuguesa máis temperá das Vidas e paixões dos apóstolos. Como xa adiantamos, para alén do códice

101 Dona Sancha era probabelmente filla de Joán Pérez, tamén miles de Zarracós, cabaleiro ao servizo de Afonso X, aínda que parece que se aliñou a favor do infante don Sancho tras a sublevación nobiliaria de 1272 (Durany Castrillo 2009: 135; García-Fernández 2017: 126; cf. García Oro 1990: 125-136). Canto á filiación de dona Sancha co seu irmán, véxase, por exemplo, o testamento da súa cuñada, María Vásquez, muller de Gonzalo Eanes (Ferro Couselo 1996: I, 62-66, doc. 42).

102 De acordo coa homenaxe ordenada na carta de perdón e pacto que Fernán Fernández Lima outorga en Ourense o 25 de agosto de 1300 (ACOu, Escrituras 21, n.ํ 103 e Escrituras 12, n.ํ16; Vaquero Díaz/ Pérez Rodríguez 2010: II, 573-575, doc. 718). 
alcobacense encargado polo abade Estevão de Aguiar e copiado por frei Bernardo de Alcobaça e frei Nicolau Vieira en 1443-1444 (Cepeda 1982-89: I, liv-lvi), consérvase un fragmento de mediados ou do terceiro cuartel do século XIV ${ }^{103}$ (Fig. 6) pertencente a un coidado códice que parece constituír o modelo textual común tanto da referida copia alcobacense como do postincunábel impreso por Valentim Fernandes (Cepeda 1975; 1982-89: I, lxxvii-lxxix). En contraste co resto da tradición manuscrita portuguesa (libros II e III), a configuración codicolóxica deste testemuño é moi similar á do volume ourensán, en particular, no que respecta aos elementos decorativos, epigráficos e de ordenación interna do texto (capitais con decoración afiligranada, en alternancia cromática vermello-azul e con disposición xerarquizada $\left.{ }^{104}\right)$. Porén, o aspecto máis rechamante é a planificación e disposición dos espazos reservados para as miniaturas que encabezan cada capítulo, do mesmo modo que acontece no testemuño do $\mathrm{AHPOu}^{105}$.

103 Cepeda (1975: 299) data o fragmento (BNP ms. 5, n. 28) nos finais do século XIV ou comezos do XV, mais a letra e as solucións gráfico-lingüísticas do texto suxiren unha datación un pouco máis recuada. Trátase dun fragmento pertencente a un códice extenso (a folla conservada corresponde ao f. 156 e ao capítulo «CLVI»), que debeu pertencer á rica biblioteca de D. Francisco de Melo Manuel (Cabrinha), adquirida pola Biblioteca Nacional de Lisboa en 1852. O fragmento transmite o relato da vida de santo André correspondente aos capítulos 176-179 do libro II de Brihuega, de acordo coa versión portuguesa editada por Cepeda (1982-89: II, 198-200). Curiosamente, trátase do contexto inmediatamente previo ao contido conservado nos fragmentos ourensáns (do capítulo 179 en diante; Pichel 2021b: 61).

104 Con todo, hai certos elementos que non se reproducen no códice portugués, polo xeral, máis humilde que o alaricano, aínda que presenta algunhas innovacións. As capitais son de pequenas dimensións, aínda que reproducen, polo menos, dous niveis de xerarquía: abranguen dúas unidades de pautado no comezo de capítulo e unha cando inician rúbrica (e talvez reservaban unha capital de maior tamaño para o comezo de cada vida ou paixón apostólica). No caso do fragmento ourensán, as dimensión son similares (2-3 unidades de pautado), mais non se dá, polo menos no sorporte que se conservou, a diferenza xerárquica de tamaño (as rúbricas comezan cunha inicial maiúscula regular). Por outra parte, o códice allaricense presenta caldeiróns (alternando vermello e azul), ausentes no fragmento da BNP. Por último, canto aos elementos epigráficos, a capitulación do fragmento da BNP aparece na marxe superior, mentres que no do AHPOu se consigna na marxe vertical (á altura da rúbrica de cada capítulo) e a marxe de cabeza resérvase para a identificación —numérica e textual—das vitae correspondentes (Pichel 2021b: 61).

105 Que saibamos, esta cuestión non foi considerada até agora para o fragmento da BNP (cf. Cepeda 1975; 1982-89: I, lxxvii-lxxix), mais é de capital interese para reconstruír o modelo textual e iconográfico que puido estar detrás deste códice portugués. Neste sentido, parece evidente que, en última instancia, o modelo introducido en Portugal sería con toda probabilidade unha versión ilustrada da obra de Brihuega similar ás que hoxe coñecemos (o exemplar do AHPOu e o testemuño iluminado do Libro de los mártires ao cal xa nos referimos antes). 


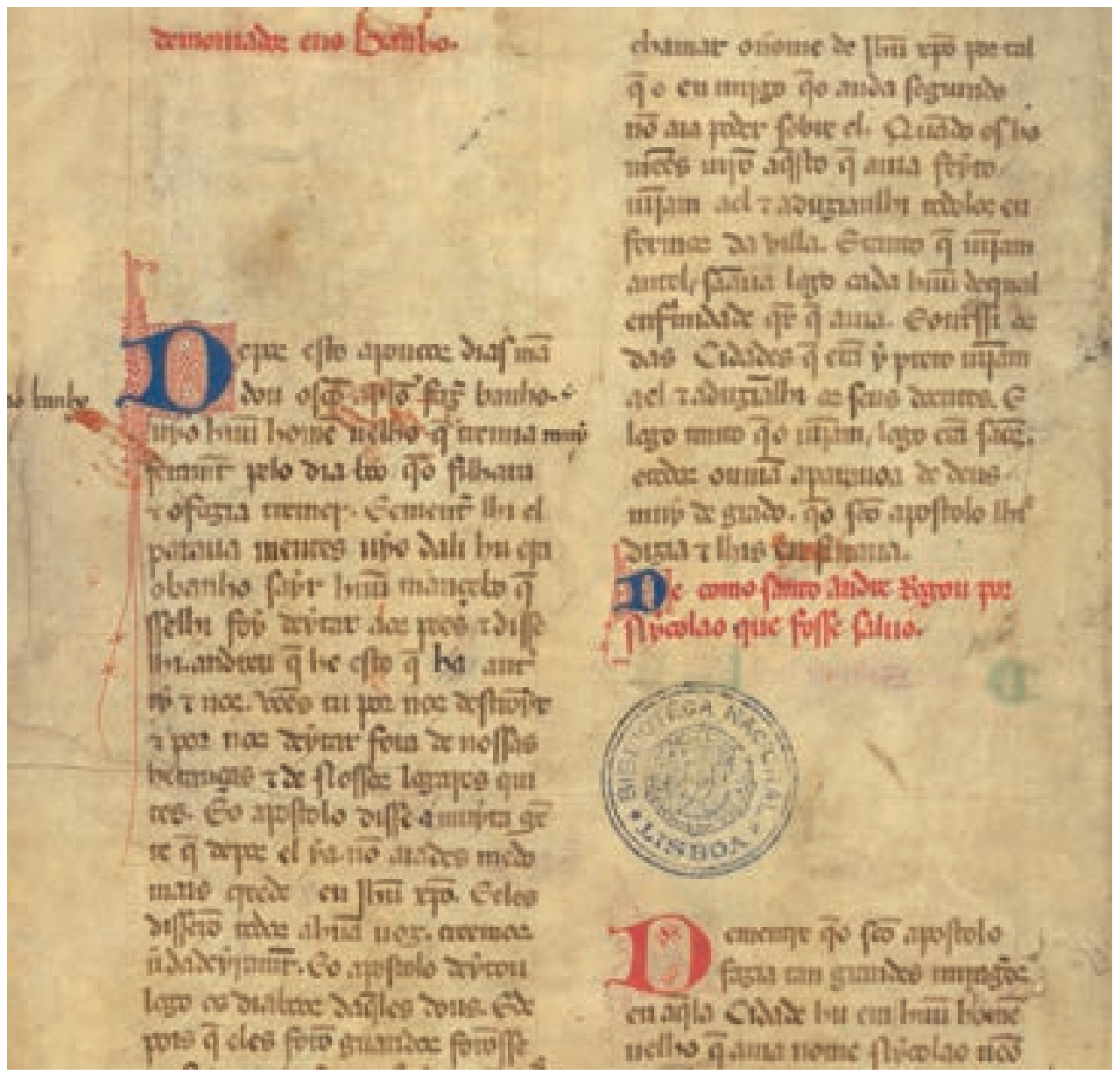

Fig. 6. Vidas e paixões dos apóstolos (ㄷ Biblioteca Nacional de Portugal, ms. 5, no 28, f. 1v).

Á vista das consideracións expostas até aquí e como xa apuntamos noutro traballo (Pichel/Sánchez Ferro 2019), non podemos descartar a posibilidade de que entre as versións portuguesas do libro II de Brihuega - en particular o testemuño de mediados do séc. XIV- e o modelo castelán ilustrado que hoxe coñecemos mediase un exemplar confeccionado en medios culturais galegos a partir do testemuño allaricense, quer unha copia, quer xa unha tradución, que posteriormente se difundise no núcleo cortesán de D. Dinis e/ou en determinados núcleos señoriais ao longo das primeiras décadas do trescentos. Neste sentido, para alén do intercambio cultural operativo nesta época na área transfronteiriza tudense (cf. infra $\S 5$, n. 107, no que respecta, en particular, á transferencia no ámbito franciscano, non sería en absoluto estraña a circulación de textos de carácter relixioso - neste caso de materia haxiográfica- entre os territorios de Galicia, Castela e Portugal, como acontece, por exemplo, 
coa transmisión da Crónica dos ministros gerais da Ordem dos Fraires Menores na segunda metade do século $\mathrm{XV}^{106}$.

\section{CABO}

\section{A circulación de textos de procedencia afonsina na Galicia medieval} foi intensa e temperá, especialmente nas terras transfronteirizas que conformaban a antiga diocese de Tui. Un espazo tradicionalmente caracterizado polas continuas transferencias culturais aquén e alén Miño entre diferentes cortes señoriais con estreitos vínculos familiares e moi ben posicionadas canto á súa relación co poder rexio ${ }^{107}$. Desde

106 A recepción e tradución no Occidente peninsular da Chronica XXIV Generalium Ordinis Fratrum Minorum, atribuída ao monxe franciscano Arnaud de Sarrant, debeu cristalizar no terceiro cuartel do século XV, primeiro en ambiente cultural galego e posteriormente en Portugal. O único testemuño conservado desta tradición é un manuscrito portugués (BNP, Coleção Manuscritos Reservados, IL. 94; BITAGAP manid 1043) confeccionado en 1470 no convento de Santo António de Vila Franca de Xira baixo a supervisión do freire galego Antonio da Ribeira, naquela altura vicario do referido oratorio ribatexano. O modelo textual empregado para esta copia foi unha primeira tradución galego-portuguesa, hoxe perdida -e baseada, por súa vez, nunha tradución castelá de mediados do Xv- elaborada por volta de 1465 probabelmente por un clérigo galego vinculado ao convento de San Francisco da Coruña (Souto Cabo 2016; Mariño Paz 2018: 114; Corral Díaz/Pichel et alii 2020: 109-115; cf. Capdevila Arrizabalaga/Soriano Robles 2020).

107 En efecto, hai suficientes evidencias e indicios da transferencia cultural entre Galicia e Portugal neste espazo transfronteirizo durante toda a época medieval. Centrándonos no período que nos ocupa aquí (finais do séc. XIII - comezos do XIV), e á marxe da tradición historiográfica e haxiográfica analisada neste traballo, lembremos, por un lado, a produción lírica dionisina reflectida no conxectural Livro de Trovas do rei (BITAGAP texid 9608), no cal se compilarían tamén materiais trobadorescos de orixe galega (estado da arte recente en Monteagudo 2019a). Polo que respecta á prosa romancesca, a copia galega do Livro de Tristam remontaría en última instancia a unha primeira tradución galego-portuguesa, elaborada no último terzo do século XIII —-talvez ca. 1270-80-, na cal poderían estar involucrados algúns membros da corte señorial dos Aboim-Portel (síntese en Pichel / Varela Barreiro 2017). Canto á literatura xurídica, o códice portugués da Primeira Partida (BITAGAP manid 1132), de mediados do xIV, non representaría unha tradución directa desde o castelán, mais unha versión realizada por un copista de orixe galega ou sobre un modelo xa traducido en medios galegos (Ferreira 1980: xlix-lxii; Mariño 1998: 153). O tal antecedente podería estar emparentado con algún dos testemuños galegos datados con anterioridade á copia portuguesa, isto é, os mss. ARAG, Col. Pergameos, P. Caixa 3-8 (BITAGAP manid 1470) e ARG, Col. fragmentos de códices e impresos, CI-3 (BITAGAP manid 1471), elaborados entre finais do século XIII e o primeiro cuartel do XIV (Ferreira 1980: lvi, n. 68; Corral Díaz/Pichel 2020 et alii: 151; Pichel 2021a: 131 e n. 19). Non hai dúbida, en todo caso, de que no espazo tudense debeu haber continuidade ao longo dos séculos XIV e XV no que respecta á circulación dos textos xurídicos afonsinos máis alá das Partidas, como demostra a utilización por parte dun notario da zona, Vasco Lourenzo de Tui, dun exemplar misceláneo do Fuero Real (BNE ms. 710; BETA manid 1054) no cal se incorporan numerosas glosas marxinais e intervencións correctivas no texto principal (BITAGAP manid 4094); véxase unha recapitulación ao respecto en Corral Díaz/Pichel et alii (2020: 141, 197-198) e Pichel (2021d: 129-130). Por último, polo que respecta ao ámbito científico-técnico, para alén da tradución dionisina elaborada en 1318 polo Mestre Giraldo (cf. supra n. 77), a obra de Giordano Ruffo foi tamén traducida en terras meridionais galegas nalgún momento do século XIV, tal como se desprende do estudo crítico do Tratado de Alveitaría (BITAGAP texid 1099, manid 1974; Pérez Barcala 2013), copia galega de comezos do Xv realizada -a partir dunha tradución trecentista perdida - por Álvaro Eanes da Seira, notario baionés ao servizo de Joán Fernández de Soutomaior III, bispo de Tui entre 1408 e 1423. Precisamente, este último dato, como xa foi apuntado nalgunha ocasión (Corral Díaz/Pichel et alii 2020: 218), permitiría relacionar a influente liñaxe dos Soutomaior coa lectura e mecenado de textos de carácter técnico ou didáctico, en especial os de natureza veterinaria. Este posíbel interese pola hipiatría -moi afín, polo demais, a outras inclinacións cabaleirescas 
finais do século XIII e até mediados do XIV —con maior intensidade nas tres primeiras décadas do trescentos- inaugúrase en Galicia o proceso de asimilación da literatura historiográfica e xurídica de orixe (post)afonsina, coa copia e tradución, por un lado, da General Estoria, da Estoria de España e das súas derivacións cronísticas máis populares (a Crónica de Castilla e a Crónica particular de San Fernando), e por outro, de boa parte do corpus lexislativo das Partidas ${ }^{108}$, así como doutros textos xurídicos como o Fuero Real ou as Flores de Derecho ${ }^{109}$. Trátase dun período coincidente coa fecunda expansión cultural impulsada, desde Portugal, por D. Dinis no período final do seu reinado (1290-1325) e polo III Conde de Barcelos no segundo cuartel do XIV, e, desde a Coroa de Castela, a través das diferentes empresas historiográficas e literarias promovidas desde o ambiente rexio de Sancho IV, Violante de Aragón, Fernando IV, María de Molina e Afonso XI, para alén doutras iniciativas de carácter nobiliario como a produción asociada a D. Juan Manuel.

Polo que respecta á historiografía, a clamorosa ausencia de indicios da circulación nesta altura das versións afonsinas da Estoria de España (a primitiva e a crítica ${ }^{110}$ ) contrasta coa rápida asunción dos modelos cronísticos subvertidos tras a reformulación sanchina da Versión amplificada, nun contexto particularmente proclive, por parte das elites nobiliarias e eclesiásticas galegas, a rendibilizar un discurso, de signo pro-castelanista e señorializante, máis acomodaticio e acorde coas súas obrigas e necesidades de afianzamento político-ideolóxico. Nestas coordenadas e durante as primeiras décadas do século XIV, deberon canalizarse diferentes iniciativas señoriais fraguadas no espazo transfronteirizo das terras de Toroño e do Minho, e tamén baixo a influencia da sé arcebispal de Santiago, orientadas á importación e difusión dos principais produtos cronísticos da altura. Entre elas, as influentes cortes dos LimaBatisela e dos Riba de Vizela deberon impulsar, de maneira autónoma ou colaborativa, a copia e/ou tradución duns prototipos - casteláns ou galego-portugueses- que xa circulaban a comezos do trescentos. Ben é certo que nesta actividade puideron estar implicados, en diferente grao, outros axentes culturais relacionados, como os

como a caza, unha práctica cinexética ben recoñecíbel nesta liñaxe (Vila 2010: 223-233)-, unido á vinculación do bispo Joán Fernández de Soutomaior I (1286-1323) coa corte dionisina (cf. supra §3.3 e n. 66), convida a imaxinar posíbeis canais de circulación deste tipo de textos entre Galicia e Portugal, en particular no que respecta á tradución trecentista perdida do Tratado ou mesmo algún exemplar da súa fonte latina.

108 Conforme os vestixios materiais conservados, a Primeira (BITAGAP texid 1214) e a Terceira Partida (BITAGAP texid 1215) son as que primeiramente se traducen, entre finais do século XIII e primeiras décadas do XIV, coincidindo, tamén, coa datación conxectural dos primeiros testemuños portugueses hoxe coñecidos a través de copias de mediados do trescentos (cf. supra n. 74 e 75). Tras esta primeira etapa, a partir do segundo cuartel do trescentos e durante a segunda metade do XIV e comezos do XV conservamos vestixios galegos da tradución das restantes Partidas, salvo da Segunda, da cal non se conserva ningún exemplar (máis detalles sobre as diferentes campañas galegas de tradución das Partidas en Pichel 2021a: 121-126).

109 Canto a estes dous códigos legais (BITAGAP texid 9841 e texid 9842), consérvanse dous fragmentos de orixe berciana copiados — probabelmente nun mesmo volume facticio, como no caso portugués (cf. supra n. 76) - entre finais do século XIII e o primeiro cuartel do XIV (BITAGAP manid 1450 e 1494). véxase Corral Díaz/Pichel et alii (2020: 195-206) para un estado da arte.

110 A Versión crítica, como xa vimos, só se incorpora ao labor historiográfico galego a comezos do século XV, como fonte estrutural da Crónica de 1404 (cf. supra n. 38). 
Aboim-Portel, os Castro ou os Soutomaior, mais o que si parece factíbel é a mediación da sé compostelá na última fase compositiva reflectida no ms. BNE 8817.

Se a antiga diocese de Tui representou a comezos do trescentos un espazo converxente de (re)apropiación ideolóxica dos materiais cronísticos derivados da Estoria de España sanchina ${ }^{111}$, na área noroccidental coruñesa canalizouse o interese pola historiografía universal e a materia antiga a través da corte nobiliaria dos «Andrade Maiores» ${ }^{112}$. Así se deduce do probábel mecenado a mediados do XIV da tradución da primeira parte da General Estoria - polo menos da materia bíblica extraída do libro da Xénese- por parte de Nuno Freire de Andrade II, primoxénito do cabaleiro Rui Fernández de Andrade e de dona Inés González de Soutomaior, así como da restitución material e tradución parcial, algúns anos máis tarde (ca. 1369-73), da Historia troyana de Pedro I, na cal se interpolan diversas narrativas seleccionadas da materia troiana compilada por Afonso X na segunda parte da General Estoria.

Enmarcada nestes circuítos señoriais de entrada e saída, a produción literaria galega da primeira metade do século XIV e, en xeral, de toda a Baixa Idade Media, representa un gonzo ineludíbel para explicar a xénese ou a prolongación de certas tradicións textuais e manuscritas cultivadas no ámbito portugués e castelán ${ }^{113}$. Neste sentido, o valor do ms. BNE 8817 é un punto de apoio para o estudo da difusión occidental da cronística (post)afonsina, en particular no que respecta á Crónica de 1344 do Conde de Barcelos e ás súas fontes, baseada nos prototipos que deron lugar ao códice facticio galego e que, cando menos en parte, proceden do manuscrito rexio $E_{2}$ nunha fase compositiva anterior á ensamblaxe do códice facticio en tempos de Afonso XI. Se no caso dos testemuños galegos da Estoria de España e da Crónica de Castela a filiación coa tradición textual portuguesa é evidente -tamén no que respecta á segunda redacción da Crónica de Barcelos con respecto á Crónica de 1404-, no ámbito haxiográfico, aínda que con moitas máis reservas, ben podería acontecer algo semellante coa versión ilustrada das Vidas y pasiones de los santos de Bernardo de Brihuega levada ao convento de Santa Clara de Allariz, acaso copiada ou mesmo traducida en medios galegos antes da súa chegada ao reino portugués como parte do intenso programa cultural impulsado por D. Dinis.

111 Como xa se indicou, a diocese de Mondoñedo terá un particular protagonismo no labor historiográfico retomado entre finais do século XIV e primeiras décadas do XV (cf. supra n. 49).

112 Esta designación permite individualizar o ramo dos descendentes dos Freire de Andrade surxidos nas primeiras décadas do XIV, acompañando a debilitada liña xenealóxica do século anterior, protagonizada por Fernán Pérez de Andrade I e Pedro Fernández de Andrade (véxase unha recapitulación e bibliografía en Pichel 2014: 100-102).

113 Nun dos seus traballos máis valorados, Lorenzo (2002) insistía na «interconexión» da prosa galega coa tradición literaria e historiográfica veciña. Un aspecto fundamental, como ben salientaba López Martínez-Morás (2007), á hora de ponderar as moitas luces da literatura medieval galega máis alá do patrimonio lírico trobadoresco. Nesa mesma liña de investigación ou divulgación perseveran outros traballos recentes en prol da reavaliación e valorización do inesgotábel legado da prosa medieval galegoportuguesa forxada na Galicia baixomedieval (Pena 2013: 247-287; Souto Cabo 2016; Corral Díaz/Pichel et alii 2020: cf. 251-256). 
A prolongación da actividade historiográfica galega durante o catrocentos, máis alá das iniciativas de copia e compilación encamiñadas á elaboración da anónima Crónica de 1404, reflectiuse no interese -interno ou foráneo- por consultar e difundir en castelán algúns dos textos galegos producidos nesa época, tal como demostran as tres iniciativas de retradución entre mediados e finais do século xv das versións galegas da Geral Estoria (GE1), da Versión amplificada e da propia Crónica de 1404.

Doutra parte, é interesante tamén reparar no estadio ou natureza redaccional dos modelos textuais importados e traducidos en medios galegos e/ou portugueses, non só porque permite, ás veces, reconstruír camadas compositivas hoxe imperceptíbeis na instancia textual na cal se preserva un determinado texto -polo xeral, copias non coetáneas-, mais tamén porque nos fornece unha valiosa información contextual no que respecta á procedencia ou localización deses manuscritos e ao perfil ou grao de proximidade dos individuos que podían acceder a eles. Nos casos analizados neste traballo, os modelos utilizados para a tradución da Versión amplificada $(A 1)$ e da primeira parte da Geral Estoria $(F)$ representan, en efecto, manuscritos procedentes do escritorio rexio, nun estadio textual ou codicolóxico definitivo ou moi próximo a el: por un lado, $A 1$ deriva de $E_{2}$, ou dunha copia del, na súa redacción aínda autónoma e coa integración das notas correctivas coetáneas $\left(E_{2}\right.$ (orig)-corr); por outro, $F$ procede dunha versión preliminar ao códice rexio, cunha redacción aínda sen depurar en termos de refinamento estilístico e censura (o arquetipo $O_{1}^{114}$ ).

En calquera caso, o acceso a este corpus —ben sexa por préstamo ou obsequio, ben por encargo de copia ou tradución- non debía ser o máis habitual, pois despois de todo tratábase de materiais exclusivos do scriptorium rexio, de moi restrinxida circulación, vinculados a unha etapa compositiva preliminar ou definitiva e, por tanto, menos proclives a unha difusión ulterior máis alá do seu uso interno ${ }^{115}$.

Neste sentido, parece factíbel conxecturar, como vía de entrada dos textos (post)afonsinos contemplados neste traballo - talvez tamén no caso dalgúns textos xurídicos como as Partidas-, certos membros da parentela rexia de Sancho IV moi vinculados con Galicia e coas súas principais elites nobiliarias: máis alá da súa

114 O mesmo acontece, como se viu, na materia troiana afonsina interpolada na Historia troyana de Pedro I (e tamén presente, na súa maior parte traducida, na versión bilingüe comisionada polos Andrade), neste caso procedente de materiais non depurados alleos á redacción definitiva que hoxe coñecemos para a segunda parte da General Estoria.

115 Sobre a necesaria e probada existencia de rascuños e cadernos de traballo ou compilatorios no taller historiográfico afonsino, véxanse, entre outros, Menéndez Pidal (1951), Catalán (1976, 1997), Fernández-Ordóñez (1992, 2000c), Almeida (2009: I, lxxix-lxxx, xcii-xciv), Sánchez-Prieto Borja/Almeida (2009: I, 727-728), Bautista (2014b), Pichel (2016: 130-152; 2018) ou Jerez Cabrero (2020). O exemplares $A 1$ e $F$ referidos aquí non son os únicos exemplos coñecidos na produción literaria galega de copia ou tradución de versións preliminares ou definitivas. Acontece algo semellante na tradución da Versión crítica da Estoria de España compilada na Crónica de 1404 (Bautista 2014b), así como nas traducións andradinas da Crónica troyana de Afonso XI —realizada a partir do antígrafo do códice rexio RBME H.j.6 (BETA manid 1561) — e da Historia troyana de Pedro I - baseada no propio exemplar rexio que se estaba a restaurar, unha versión que nunca se chegaría a pasar a limpo- (véxase unha síntese sobre estas dúas traducións troianas en Corral Díaz/Pichel et alii 2020: 31-46; cf. supra § 2.2). 
nai (Violante de Aragón) e esposa (María de Molina), é particularmente interesante a posíbel implicación de dous dos seus fillos: por un lado, o infante don Felipe e a súa muller dona Margarita de la Cerda, xa mencionados; por outro, dona Violante Sánchez (ca. 1281-1330), muller de Fernando Ruíz de Castro e, por tanto, principal herdeira na altura do señorío de Lemos ${ }^{116}$.

Este e outros indicios apoian a idea de que os axentes culturais implicados na recepción e asimilación destes textos debían posuír un vínculo de proximidade á corte rexia abondo estreito como para acceder e reaproveitar este tipo de materiais. Oportunidade, en definitiva, e vontade de proxectar e refractar, na lingua propia, os «feytos antigoos» das «moytas estorias» das santas e sabedoras xentes daquel pasado remoto e incerto presente.

116 En relación a dona Violante Sánchez, filla ilexítima de Sancho IV e María de Meneses, véxase Garcia (2008) e García-Fernández (2021: 54, n. 34). Estas e outras cuestións relacionadas cos axentes e circuítos culturais involucrados na circulación de textos na Galicia baixomedieval son abordados nunha investigación en curso realizada en colaboración con Miguel García-Fernández e Rosa María Rodríguez Porto. 


\section{REFERENCIAS BIBLIOGRÁFICAS}

- AILENII, Simona (2019): A tradução galego-portuguesa do romance arturiano. Os primeiros testemunhos, Porto, Estratagias Criativas.

- Almeida, Belén (2009): General Estoria. Segunda Parte, Madrid, Fundación José Antonio de Castro, Biblioteca Castro, 2 vols.

- Almeida, Belén (2013): «General Estoria. Breve panorama crítico», Revista de El Colegio de San Luis, 3:6, 166-181 (https://dialnet.unirioja.es/descarga/articulo/4988745.pdf) [última consulta: 15/07/2021].

- ALMEIDA, Belén (2018): «La materialidad de la historiografía alfonsí: desde el cuaderno de trabajo al códice regio (y más allá)», Bibliographica, 1:1 (https://bibliographica. iib.unam.mx/revista/index.php/RB/article/view/6) [última consulta: 15/07/2021].

- Almeida, Belén/Elena Trujillo (2009a): General Estoria. Quinta Parte, Madrid, Fundación José Antonio de Castro, Biblioteca Castro, 2 vols.

- Almeida, Belén/Elena TrujiLlo (2009b): «Censura y modificación ideológica en la Quinta Parte de la General Estoria de Alfonso X el Sabio», Diálogo de la Lengua, 1, 1-14.

- Alonso PARADa, Raquel (2015): «La traducción gallega de la General Estoria: mudanzas en el dominio de la morfología verbal», en Elisa Borsari (coord.), En lengua vulgar castellana traducido. Ensayos sobre la actividad traductora durante la Edad Media, San Millán de la Cogolla, Cilengua, 3-22.

- Álvarez, Rosario/Xosé Xove (1998): «Lingua e variación dialectal na Crónica Xeral Galega», en Dieter Kremer (ed.), Homenaxe a Ramón Lorenzo, Vigo, Galaxia, vol. 1, 29-58.

- Azevedo, Pedro A. (1906-1910): Livro dos bens de D. João de Portel, Lisboa, Arquivo Histórico Português.

- Bautista, Francisco (2003): «Hacia una nueva "versión” de la Estoria de España: texto y forma de la Versión de Sancho IV», Incipit, 23, 1-59.

- Bautista, Francisco (2006): La Estoria de España en época de Sancho IV: sobre los reyes de Asturias, Londres, Queen Mary, University of London, Department of Hispanic Studies (Papers of the Medieval Hispanic Research Seminar 50).

- Bautista, Francisco (2010): «Original, versiones e influencia del Liber regum: estudio textual y propuesta de stemma», e-Spania, 9 (https://doi.org/10.4000/e-spania.19884) [última consulta: 15/07/2021].

- Bautista, Francisco (2013): «Genealogías de la materia de Bretaña: del Liber regum navarro a Pedro de Barcelos (c. 1200-1350)», e-Spania, 16 (https://doi. org/10.4000/e-spania.22632) [última consulta: 15/07/2021]. 
- Bautista, Francisco (2014a): «Bernardo de Brihuega y la colección hagiográfica del ms. BNE 10252», Zeitschrift für romanische Philologie, 130, 71-104 (https://doi. org/10.1515/zrp-2014-0004) [última consulta: 15/07/2021].

- Bautista, Francisco (2014b): «Para la tradición textual de la Estoria de España de Alfonso X», Romance Philology, 68, 137-210 (https://doi.org/10.1484/ J.RPH.5.107635) [última consulta: 15/07/2021].

- BAUTiSTA, Francisco (2014c): «El renacimiento alfonsí: renovatio y saber en la producción cultural de Alfonso X (1252-1284)», en La cultura en la Europa del siglo XIII: emisión, intermediación, audiencia, Navarra, Gobierno de Navarra, 85-96.

- Bautista, Francisco (2015): «El final de la General Estoria», Revista de Filología Española, 95, 251-278.

- Bautista, Francisco (2017): «Sobre la tradición textual de la segunda parte de la General Estoria», Bulletin of Spanish Studies, 94:7, 1093-1108 (https://doi.org/10.10 80/14753820.2017.1316943) [última consulta: 15/07/2021].

- BaUtista, Francisco (2020a): «De nuevo sobre el Libro de las generaciones y linajes de los reyes (o Liber regum): recuperación de la versión toledana de hacia 1219», e-Spania, 37 (https://doi.org/10.4000/e-spania.37546) [última consulta: 15/07/2021].

- Bautista, Francisco (2020b): «Alfonso X y la historia», en Elvira Fidalgo (ed.), Alfonso X el Sabio: cronista y protagonista de su tiempo, San Millán de la Cogolla, Cilengua, 65-87.

- Bautista, Francisco/Filipe Alves Moreira (2021): «Para a tradição textual da Crónica de 1344: dois manuscritos da versão original», Zeitschrift für romanische Philologie, 137:1, 183-216.

- Bello Rivas, María Xesús (1995): A traducción galega da Crónica General. Entre dependencia e innovación. Tese de licenciatura inédita. Santiago de Compostela, Universidade.

- Bello Rivas, María Xesús (1998): «O texto galego da Crónica General e o seu traductor», en Dieter Kremer (ed.), Homenaxe a Ramón Lorenzo, Vigo, Galaxia, 59-69

- Bello Rivas, María Xesús (1999): «La Crónica General de España y su traducción gallega», en Aurelio González et alii (coords.), Discursos y representaciones en la Edad Media. Actas de las VI Jornadas Medievales, México, UNAM, El Colegio de México, 153-168.

- BETA = Faulhaber, Charles B. (dir.) (1997-): Bibliografía Española de Textos Antiguos, Berkeley, University of California, The Bancroft Library (https://bancroft.berkeley. edu/philobiblon/beta_ga.html) [última consulta: 15/07/2021].

- BITAGAP = Askins, Arthur L-F. (dir.) (1997-): Bibliografia de Textos Antigos Galegos e Portugueses, Berkeley, University of California, The Bancroft Library (https://bancroft.berkeley.edu/philobiblon/bitagap_ga.html) [última consulta: 15/07/2021]. 
- CALDERón Madina, Inés (2018): Los Soverosa. Una parentela nobiliaria entre tres reinos. Poder y parentesco en la Edad Media hispana (siglos XI-XIII), Valladolid, Universidad.

- CAmpa GutiÉrrez, Mariano de la (2009): La Estoria de España de Alfonso X. Estudio y edición de la Versión crítica desde Fruela II hasta la muerte de Fernando II, Málaga, Analecta Malacitana.

- CAmpa Gutiérrez, Mariano de la (2010): «La Crónica de Castilla como representante de la Estoria de España de Alfonso X: estudio y edición», en José Manuel Fradejas Rueda/Déborah Dietrick Smithbauer/Demetrio Martín Sanz/Ma Jesús Díez Garretas (eds.), Actas del XIII Congreso Internacional Asociación Hispánica de Literatura Medieval (Valladolid, 15 a 19 de septiembre de 2009). In memoriam Alan Deyermond, Valladolid, Universidad/Ayuntamiento, vol. 1, 489-505.

- CAmpos Souto, María Begoña (1997): «Bases para una edición de la versión gallega de la General Estoria: estudio codicológico del manuscrito O.I.1 del Monasterio de San Lorenzo del Escorial», en Andrew M. Beresford (coord.), 'Quien hubiese tal ventura'. Medieval Hispanic Studies in Honour of Alan Deyermond, London, Queen Mary and Westfield College, 119-126.

- Capdevila Arrizabalaga, Irene/Lourdes Soriano Robles (2020): «La versió catalana medieval de la Crònica dels XXIV Generals», Arxiu de Textos Catalans Antics, 32, 461-500 (http://revistes.iec.cat/index.php/ATCA/article/viewFile/148493/146174) [última consulta: 15/07/2021].

- Catalán, Diego (1959): «La Crónica Geral de Espanha del Conde Don Pedro de Barcelos (1344) y los orígenes de la Historiografía Portuguesa», Ibérida, 2, 11-101.

- Catalán, Diego (1962): De Alfonso X al Conde de Barcelos. Cuatro estudios sobre el nacimiento de la historiografía romance en Castilla y Portugal, Madrid, Gredos/ Seminario Menéndez Pidal.

- CATALÁn, Diego (1976): «El taller historiográfico alfonsí. Métodos y problemas en el trabajo compilatorio», Romania, 84, 354-375.

- Catalán, Diego (1977): Gran Crónica de Alfonso XI, Madrid, Gredos/Universidad Complutense de Madrid, Seminario Menéndez Pidal, 2 vols.

- Catalán, Diego (1978): «Los modos de producción y “reproducción” del texto literario y la noción de apertura», en Manuel Gutiérrez Esteve/Jesús Antonio Cid Martínez/Antonio Carreira (coords.), Homenaje a Julio Caro Baroja, Madrid, Centro de Investigaciones Sociológicas, 245-270.

- Catalán, Diego (1992): La Estoria de España de Alfonso X. Creación y evolución, Madrid, Seminario Menéndez Pidal/Universidad Autónoma de Madrid.

- Catalán, Diego (1995): «La expansión al Occidente de la Península Ibérica del modelo historiográfico de la Estoria de España. Nuevas precisiones», en Cilene 
da Cunha Pereira/Paulo Roberto Dias Pereira (coords.), Miscelânea de estudos lingüísticos, filológicos e literários in Memoriam Celso Cunha, Rio de Janeiro, Nova Fronteira, 521-532.

- Catalán, Diego (1997): De la silva textual al taller historiográfico alfonsí. Códices, crónicas, versiones y cuadernos de trabajo, Madrid, Fundación Ramón Menéndez Pidal/Universidad Autónoma de Madrid.

- Catalán, Diego/Soledad de Andrés (1970): Edición crítica del texto español de la Crónica de 1344 que ordenó el Conde de Barcelos don Pedro Alfonso, Madrid, Gredos/ Seminario Menéndez Pidal.

- CePEDA, Isabel Vilares (1975): «Um fragmento inédito das Vidas e Paixões dos Apóstolos», Boletim de Filologia, 24, 295-304.

- CEPEDA, Isabel Vilares (ed.) (1982-89): Vidas e Paixões dos Apóstolos, Lisboa, Instituto Nacional de Investigação Científica/Centro de Linguística da Universidade de Lisboa, 2 vols.

- CEPEDA, Isabel Vilares (1993): «Os Quarenta mártires de Sebaste. Un testemunho manuscrito do século XV em português», Theologica, 28:2, 507-514.

- Cerdá Y Rico, Francisco (1787): Cronica de D. Alfonso el Onceno de este nombre de los reyes que reynaron en Castilla y en Leon, segunda edicion conforme a un antiguo ms. de la Real Biblioteca del Escorial, y otro de la Mayansiana: e ilustrada con apendices y varios documentos. Parte I, Madrid, Imprenta de D. Antonio de Sancha.

- CGPA = Varela Barreiro, Xavier (dir.) (2015-): Corpus Galego-Portugués Antigo, Santiago de Compostela, Universidade de Santiago de Compostela, Instituto da Lingua Galega (http://ilg.usc.gal/cgpa/) [última consulta: 15/07/2021].

- CinTRA, Luís Filipe Lindley (1950): «Uma tradução galego-portuguesa desconhecida do Liber Regum», Bulletin Hispanique, 52, 27-40.

- CinTra, Luís Filipe Lindley (1951): Crónica geral de Espanha de 1344. Edição crítica do texto português, Lisboa, Academia Portuguesa da História, vol. 1 [reedición en 1983-90, Lisboa, Imprensa Nacional, Casa da Moeda, 4 vols.].

- Connolly, Jane E. (1990): Los miraglos de Santiago. Biblioteca Nacional de Madrid, MS 10252, Salamanca, Universidad.

- CoRral Díaz, Esther / Ricardo Pichel (coords.)/Marina Aurora GaRZón FernándeZ/ Tania VÁzquez García/Miguel García-FernándeZ (2020): Guía para o estudo da prosa galega medieval, Santiago de Compostela, Xunta de Galicia, Centro Ramón Piñeiro para a Investigación en Humanidades (Col. Argamed 3) (http://www.cirp. gal/w3/publicacions/pub-0511.html) [última consulta: 15/07/2021].

- D’Ambruoso, Claudia (2012): Edición crítica y estudio de la Crónica Troyana promovida por Alfonso XI. Tese de doutoramento inédita. Santiago de Compostela, Universidade. 
- DíAZ y DíAZ, Manuel (1962): «La obra de Bernardo de Brihuega, colaborador de Alfonso X», en Strenae. Estudios de filología e historia dedicados al Profesor Manuel García Blanco (Acta Salmanticensia, Serie de Filosofia y Letras, 13), 145-161.

- DíAz y DíAZ, Manuel (1996): «Tres compiladores latinos en el ambiente de Sancho IV», en Carlos Alvar/José Manuel Lucía Megías (eds.), La literatura en la época de Sancho IV, Alcalá de Henares, Universidad, 35-52.

- Domingues, José (2021): «La tradición medieval de las Siete Partidas en Portugal», en José Manuel Fradejas Rueda/Enrique Jerez Cabrero/Ricardo Pichel (eds.), Las Siete Partidas del Rey Sabio. Una aproximación desde la filología digital y material, Madrid/Frankfurt am Main, Iberoamericana/Vervuert, 103-116.

- Doubleday, Simon R. (2015): The Wise King: a Christian Prince, Muslim Spain, and the Birth of the Renaissance, New York, Basic Books.

- DuRany Castrillo, Mercedes (2009): «El convento de Santa Clara de Allariz (1282-1312)», en Raquel Casal/José Miguel Andrade/Roberto J. López (eds.), Galicia monástica. Estudos en lembranza da profesora María José Portela Silva, Santiago de Compostela, Universidade, 131-151.

- DuXFIELD, Polly (2018): Crónica particular de San Fernando Digitalv.1.0, Birmingham, University of Birmingham (https://estoria.bham.ac.uk/cpsf/) [última consulta: $15 / 07 / 2021]$.

- EGPA-lit = Pichel, Ricardo/Xavier Varela Barreiro (dirs.) (2019-): Escritorio GalegoPortugués Antigo: textos literarios, Santiago de Compostela, Universidade de Santiago de Compostela, Instituto da Lingua Galega (https://www.egpalit.org/) [última consulta: 15/07/2021].

- Fernández Fernández, Laura (2013): Arte y Ciencia en el scriptorium de Alfonso X el Sabio, El Puerto de Santa MaríA, Cátedra Alfonso X el Sabio/Secretariado de Publicaciones de la Universidad de Sevilla.

- FERnÁNDEZ FernáNDEZ, Laura (2021): «Folios reutilizados y proyectos en curso: imagen histórica e imagen jurídica en el proyecto político alfonsí», en Albert Mechthild/Ulrike Becker/Elmar Schmidt (eds.), Alfonso el Sabio y la conceptualización jurídica de la monarquía en las 'Siete Partidas'/Alfonso the Wise and the Juridical Conceptualization of Monarchy in the 'Siete Partidas', Göttingen/Bonn, V\&R Unipress/Bonn University Press, 73-114.

- Fernández Gallardo, Luis (2009): «La Crónica particular de San Fernando: sobre los orígenes de la crónica real castellana, I. Aspectos formales», Cahiers d'études hispaniques médiévales, 32, 245-265.

- Fernández Gallardo, Luis (2010): «La Crónica particular de San Fernando: sobre los orígenes de la crónica real castellana, II. Los contenidos», Cahiers d'études hispaniques médiévales, 33, 215-246. 
- FERnÁNDEZ-ORdóÑEZ, Inés (1992): La estorias de Alfonso el Sabio, Madrid, Istmo.

- FERnÁNDEZ-ORDóÑEZ, Inés (1993): Versión crítica de la estoria de España: estudio y edición desde Pelayo hasta Ordoño II, Madrid, Universidad Autónoma/Fundación Ramón Menéndez Pidal.

- FERNÁNDEZ-ORDÓÑEZ, Inés (2000a): «La transmisión textual de la Estoria de España y de las principales ‘Crónicas’ de ella derivadas», en Inés Fernández-Ordóñez/ Samuel G. Armistead (coords.), Alfonso X el Sabio y las crónicas de España, Valladolid, Universidad, 219-260.

- FERNÁNDEZ-ORDÓÑEZ, Inés (2000b): «Variación en el modelo historiográfico alfonsí en el siglo XIII: Las versiones de la Estoria de España», en George Martin (ed.), La historia alfonsí: el modelo y sus destinos (siglos XIII-XV), Madrid, Casa de Velázquez, 41-74.

- FERNÁNDEZ-ORDÓÑEZ, Inés (2000c): «El taller de las “estorias”», en Inés FernándezOrdóñez/Samuel G. Armistead (eds.), Alfonso X el Sabio y las crónicas de España, Valladolid, Centro para la Edición de los Clásicos Españoles, 61-82.

- FERnÁNDEZ-ORDÓÑEZ, Inés (2002a): «General Estoria», en Carlos Alvar/José Manuel Lucía Megías (coords.), Diccionario filológico de literatura medieval española: textos y transmisión, Madrid, Castalia, 42-54.

- FERnÁNDEZ-ORdóÑEZ, Inés (2002b): «Estoria de España», en Carlos Alvar/José Manuel Lucía Megías (coords.), Diccionario filológico de literatura medieval española: textos y transmisión, Madrid, Castalia, 54-80.

- Fernández Pomar, José María (1967): «Manuscritos del VI Condestable de Castilla en la Biblioteca Nacional», Helmantica. Revista de filología clásica y hebrea, 18:55$-57,89-108$.

- Ferreira, José de Azevedo (1980): Alphonse X. Primeyra Partida. Édition et Étude, Braga, Instituto Nacional de Investigação Cientifica (Textos de Linguística 3).

- FERREIRA, José de Azevedo (1984): «Subsídios para uma edição da Terceira Partida de Afonso X», Boletim de Filologia, 29, 101-118.

- Ferreira, Maria do Rosário (2005): A lenda dos Sete Infantes: Arqueologia de um destino épico medieval. Tese de doutoramento. Coimbra, Universidade.

- Ferreira, Maria do Rosário (2010): «D. Pedro de Barcelos e a representação do passado ibérico», en Maria do Rosário Ferreira (coord.), O Contexto Hispânico da Historiografia Portuguesa nos Séculos XIII e XIV. Em memória de Diego Catalán, Coimbra, Universidade, 81-106.

- Ferreira, Maria do Rosário (2012): «As traduções de castelhano para galego-português e as políticas da língua nos séculos XIII-XIV», e-Spania, 13 (https://doi. org/10.4000/e-spania.21021) [última consulta: 15/07/2021]. 
- FerReIRA, Maria do Rosário (2015): «Pedro de Barcelos: sangue, natura e a ordem do mundo», en José Carlos Ribeiro Miranda/Maria do Rosário Ferreira (orgs.), Natura e Natureza no Tempo de Afonso X, o Sábio, Porto, Húmus, 51-70.

- Ferreira, Maria do Rosário (2019): Pedro de Barcelos e a Escrita da História, Porto, Estratagias Criativas.

- FerReira, João Paulo Martins (2019): A nobreza galego-portuguesa da diocese de Tui (915-1381) (Anejos de Cuadernos de Estudios Gallegos XLVIII), Madrid/Santiago de Compostela, CSIC/Instituto de Estudios Gallegos Padre Sarmiento.

- Ferro Couselo, Xesús (1996 [1967]): A vida e a fala dos devanceiros: escolma de documentos en galego dos séculos XIII ao XVI. I. Terra de Ourense, Vigo, Galaxia/ Fundación Penzol, [edición facsimilar], 2 vols.

- Fidalgo, Elvira (2005): «Sobre las fuentes de los Miraglos de Santiago», Bulletin of Hispanic Studies, 82:3, 293-313.

- FidALGo, Elvira/Mercedes BrEa (2004): «Versiones iberorrománicas de los milagros de Santiago», en María Jesús Lacarra Ducay/Juan Manuel Cacho Blecua (eds.), Tipología de las formas narrativas breves románicas medievales (III), Zaragoza/ Granada, Universidad/Universidad, 183-211.

- Fidalgo, Elvira (ed.) (2020): Alfonso X el Sabio: cronista y protagonista de su tiempo, San Millán de la Cogolla, Cilengua.

- GARCIA, Charles (2008): «Violante Sánchez, fille de roi et filleule de reine», e-Spania, 5 (https://doi.org/10.4000/e-spania.11183) [última consulta: 15/07/2021].

- GARCía ÁlVAREZ, Rubén (1966): «Los Arias de Galicia y sus relaciones familiares con Fernando II de León y Alfonso I de Portugal», Brácara Augusta, 20, 1-19.

- García-Fernández, Miguel (2017): «Vivir y morir en femenino en la Galicia de los siglos XIV y XV», en Eduardo Pardo de Guevara y Valdés (ed.), Mujeres con poder en la Galicia Medieval (siglos XIII-XV): estudios, biografias y documentos (Anejos de Cuadernos de Estudios Gallegos XLIV), Madrid/Santiago de Compostela, CSIC/ Instituto de Estudios Gallegos Padre Sarmiento, 71-239.

- GARCíA-FERnÁNDEZ, Miguel (2021): «Mulleres nobres entre o reino de Galicia e a corte rexia en tempos de Afonso X: conexións familiares e vínculos culturais», en Mercedes Brea/Pilar Lorenzo Gradín (eds.), Afonso X e Galicia, Santiago de Compostela, Xunta de Galicia, 31-63.

- García Oro, José (1990): «La primitiva implantación de las clarisas en Galicia», en Santa Clara de Allariz. Historia y vida de un monasterio, Santiago de Compostela, Convento de San Francisco, 109-145.

- García Solalinde, Antonio (1930): Alfonso el Sabio. General Estoria, Madrid, Centro de Estudios Históricos. 
- Gómez Redondo, Fernando (1998): Historia de la prosa medieval castellana. I. La creación del discurso prosístico: en el entramado cortesano, Madrid, Cátedra.

- Gómez ReDOndo, Fernando (1999): Historia de la prosa medieval castellana. II. El desarrollo de los géneros. La ficción caballeresca y el orden religioso, Madrid, Cátedra.

- Gómez Redondo, Fernando (2007): Historia de la prosa medieval castellana. IV. El reinado de Enrique IV: el final de la Edad Media. Conclusiones. Guía de lectura. Apéndices. Índices, Madrid, Cátedra.

- GómEz REDONDO, Fernando (2009): «La literatura caballeresca castellana medieval: el Amadís primitivo», en José Manuel Lucía Megías (ed.), Amadís de Gaula 1508. Quinientos años de libros de caballerías, Madrid, Biblioteca Nacional de España/ Sociedad Estatal de Conmemoraciones Culturales, 53-79.

- González López, Emilio (1980): «Versión a nuestro idioma de la Crónica troyana de Fernán Martíns y Fernán Pérez de Andrade», La Voz de Galicia, 20/01/1980.

- Hijano Villegas, Manuel (2012): «La Crónica de Castilla: tradición e innovación», en Natalia Fernández Rodríguez/María Fernández Ferreiro (coords.), Literatura medieval y renacentista en España: líneas y pautas, Salamanca, Universidad/SEMYR, 645-654.

- Hijano Villegas, Manuel (2014): «Monumento inacabado: la Estoria de España de Alfonso VII a Fernando III», Cahiers d'études hispaniques medievales, 37, 13-44.

- Hijano Villegas, Manuel (2018): «Crónica particular de San Fernando: Composición y transmisión», en Francisco J. Hernández/Rocío Fernández Almeijeiras/Emma Falque (eds.), Medieval Studies in Honour of Peter Linehan, Firenze, SISMEL Edizioni del Galuzzo, 275-322.

- Hijano Villegas, Manuel (2020a): «Poética e ideología en la cronística postalfonsí», en Inés Fernández-Ordóñez (ed.), El legado de Ramón Menéndez Pidal (1869-1968) a principios del siglo XXI, Madrid, CSIC, vol. 2, 471-497.

- Hijano Villegas, Manuel (2020b): «Deseo narrativo en la cronística post-alfonsí», Bulletin of Hispanic Studies, 97:5, 465-478.

- HiLty, Gerold (1982): «A Versão portuguesa do Livro Cunprido», Biblos, 58, 207-267.

- JeRez Cabrero, Enrique (2020): «La primera sección del manuscrito escurialense K-II-3 de la Estoria de España», en Inés Fernández-Ordóñez (ed.), El legado de Ramón Menéndez Pidal (1869-1968) a principios del siglo XXI, Madrid, CSIC, vol. 2, 453-469.

- Leite, Mariana (2009): «Gil Vicente, Leitor de Afonso X: Sobre o Auto da Sibila Cassandra e a General Estória», en Maria do Rosário Ferreira/Ana Sofia Laranjinha/José Carlos Ribeiro Miranda (orgs.), Seminário Medieval 2007-2008, Porto, Estratagias Criativas, 41-60. 
- Leite, Mariana (2012): A General Estoria de Afonso X em Portugal: as múltiplas formas de receção do texto entre os séculos XIV e XVI. Tese de doutoramento inédita. Porto, Universidade.

- LeITE, Mariana (2017a): «La General Estoria entre dos lenguas: sobre las traducciones de la obra alfonsí al gallego-portugués», Atalaya, 17 (https://doi.org/10.4000/ atalaya.2810) [última consulta: 15/07/2021].

- LEITE, Mariana (2017b): «Tradução e tradição da General Estoria em Portugal: sobre as implicações do fragmento ANTT cx. 13, Maço 10 no 30», en José Carlos Ribeiro Miranda (org.), En Doiro antr'o Porto e Gaia. Estudos de Literatura Medieval Ibérica, Porto, Estratagias Criativas, 611-618.

- LeiTE, Mariana (2017c): «Entre galego-português e castelhano: sobre a marginalia da tradução dos Salmos no manuscrito R da General Estoria de Afonso X», en Marta Negro Romero et alii (eds.), Gallcecia. Estudos de lingüística portuguesa e galega, Santiago de Compostela, Universidade, 893-903 (http://doi.org/10.15304/ cc.2017.1080.52) [última consulta: 15/07/2021].

- Lilao Franca, Óscar/Carmen Castrillo GonzÁlez (1997-2002): Catálogo de manuscritos de la Biblioteca Universitaria de Salamanca, Salamanca, Universidad, 2 vols.

- Linehan, Peter (1993): History and the Historians of Medieval Spain, Oxford, Clarendon Press.

- LORENZO, Ramón (1975-77): La traducción gallega de la Crónica General y la Crónica de Castilla, Ourense, Instituto de Estudios Orensanos «Padre Feijoo», 2 vols.

- LoREnZo, Ramón (1982): «Correccións á edición da Historia Troyana de Parker», Verba. Anuario Galego de Filoloxía, 9, 253-290.

- LoREnzo, Ramón (1985): Crónica Troiana. Introducción e texto, A Coruña, Fundación Pedro Barrié de la Maza.

- LoREnzo, Ramón (1993): «Crónica Troiana», en Giulia Lanciani/Giusseppe Tavani (coords.): Dicionário de literatura medieval galega e portuguesa, Lisboa, Caminho, 192-193.

- LoREnZo, Ramón (1999): «A visión de Galicia na Crónica Xeral Calega e noutras Crónicas medievais», en Dieter Kremer (ed.), Actas do V Congreso I nternacional de Estudios Calegos (Universidade de Tréveris, 8-11 de outubro de 1997), Trier, GalicienZentrum der Universität Trier, vol. 2, 575-606.

- LoREnzo, Ramón (2000): «Prosa medieval», en Francisco Rodríguez Iglesias (dir.), Galicia. Literatura, Tomo XXX: A Idade Media, A Coruña, Hércules, 364-429.

- LoREnzo, Ramón (2002): «La interconexión de Castilla, Galicia y Portugal en la confección de las crónicas medievales y en la transmisión de textos literarios», Revista de Filología Románica, 19, 93-123 [https://revistas.ucm.es/index.php/RFRM/article/view/RFRM0202110093A] [última consulta: 15/07/2021]. 
- LoRENZO, Ramón (2013): «A visión de Santiago nalgunhas crónicas medievais», en Santiago López Martínez-Morás/Marina Meléndez Cabo/Gerardo Pérez Barcala (eds.), Identidade europea e intercambios culturales en el Camino de Santiago (Siglos $X I-X V)$, Santiago de Compostela, Universidade, 247-262.

- Lorenzo, Ramón/Xosé Luís Couceiro PÉRez (1999a): «Correccións á edición da General Estoria de Ramón Martínez López (I)», en Rosario Álvarez/Dolores Vilavedra (eds.), Cinguidos por unha arela común. Homenaxe ó profesor Xesús Alonso Montero, Santiago de Compostela, Universidade, vol. 1, 595-627.

- Lorenzo, Ramón/Xosé Luís Couceiro Pérez (1999b): «Correccións á edición da General Estoria de Ramón Martínez López (II)», en Xosé Luís Couceiro/Teresa García-Sabell Tormo/Manuel Míguez Ben/Emilio Montero Cartelle/Manuel Enrique Vázquez Buján/José María Viña Liste (coords.), Homenaxe ó profesor Camilo Flores, Santiago de Compostela, Universidade, 209-233.

- Lorenzo Gradín, Pilar/Susana Tavares Pedro (2017): O fragmento galego do Livro de Tristan. Edición paleográfica e crítica, Alessandria, Edizioni dell'Orso.

- Lorenzo Gradín, Pilar/José António Souto Cabo (coords.); Mariña Arbor Aldea/ Santiago Gutiérrez García, Santiago López Martínez-Morás e Gerardo PéreZ BARCALA (equipo de investigación) (2001): Livro de Tristán e Livro de Merlín. Estudio, edición, notas e glosario, Santiago de Compostela, Centro Ramón Piñeiro para a Investigación en Humanidades.

- Mariño Paz, Ramón (1998): Historia da lingua galega, Santiago de Compostela, Sotelo Blanco.

- Mariño Paz, Ramón (2008): Historia de la lengua gallega, München, Lincom Europa.

- Mariño PaZ, Ramón (2018): «Literatura en galego e mecenado na Idade Media», en Alexandre Rodríguez/Xosé Bieito Arias Freixedo (eds.), The Vindel Parchment and Martin Codax. The Golden Age of Medieval Galician Poetry/O Pergamiño Vindel e Martin Codax. O esplendor da poesía galega medieval, Amsterdam, John Benjamins, 103-117.

- Márquez Villanueva, Francisco (2004²): El concepto cultural alfonsí, Barcelona, Bellaterra.

- Martín-IgLesias, José Carlos (2016): «El corpus de textos sobre santo Domingo de Silos reunido por Bernardo de Brihuega en sus Vitae sanctorum (ca. 1270)», Revista de Estudios Latinos, 16, 131-153.

- MARTín-IgLeSIAS, José Carlos (2020): «Los manuscritos de las Vitae sanctorum de Bernardo de Brihuega conservados en la Biblioteca General Histórica de la Universidad de Salamanca», Evphrosyne, 48, 151-192 (https://doi.org/10.1484/ J.EUPHR.5.126061) [última consulta: 15/07/2021]. 
- MARTínez, H. Salvador (1998): «From Script to Print: Beyond Textual Criticism in Medieval Spanish Manuscript Culture», La corónica, 26:2, 173-194.

- MARTínez LóPEZ, Ramón (1963): General Estoria, versión gallega del siglo XIV. Ms. O.I.i del Escorial. Edición, introducción lingüística, notas y vocabulario, Oviedo, Universidad.

- Martins, Mário (1956): Estudos de Literatura Medieval, Braga, Livraria Cruz.

- Martins, Mário (1969): Estudos de Cultura Medieval, Braga, Verbo.

- Martins, Mário (1972): Estudos de Cultura Medieval II, Braga, Magnificat.

- Mattoso, José (1999): «A transmissão textual dos livros de linhagens», en Isabel Hub Faria (dir.), Lindley Cintra. Homenagen ao Homem, ao Mestre e ao Cidadão, Lisboa, Edições Cosmos, 565-584.

- MenÉndez PidaL, Ramón (1918 [1898]): «Traducción gallega de la Primera Crónica y de la Crónica de Castilla», en Crónicas Generales de España, Madrid, Catálogo de la Real Biblioteca, 149-153.

- MENÉndez Pidal, Gonzalo (1951): «Cómo trabajaron las escuelas alfonsíes», Nueva Revista de Filología Hispánica, V:4, 363-380.

- MenÉndez Pidal, Ramón (1955² [1906]): Primera crónica general de España que mandó componer Alfonso el Sabio y se continuaba bajo Sancho IV en 1289, Madrid, Gredos.

- Miranda, José Carlos Ribeiro (2009a): «A introdução à versão galego-portuguesa da Crónica de Castela (A2a): Fontes e estratagias», en Maria do Rosário Ferreira/ José Carlos Ribeiro Miranda/Ana Sofia Laranjinha (eds.), Seminário Medieval 20072008, Porto, Estratagias Creativas, 61-97.

- Miranda, José Carlos Ribeiro (2009b): «Na Génese da Primeira Crónica Portuguesa». Medievalista online, 5-6, 1-35 (https://core.ac.uk/download/pdf/302941179.pdf) [última consulta: 15/07/2021].

- Miranda, José Carlos Ribeiro (2010a): «Historiografia e genealogia na cultura portuguesa anterior ao Conde D. Pedro de Barcelos», en Maria do Rosário Ferreira (coord.), O Contexto Hispânico da Historiografia Portuguesa nos Séculos XIII e XIV. Em memória de Diego Catalán, Coimbra, Imprensa da Universidade de Coimbra, 53-80.

- Miranda, José Carlos Ribeiro (2010b): «Do Liber Regum ao Livro Velho de Linhagens», en Francisco Bautista Pérez/Jimena Gamba Corradine (eds.), Estudios sobre Edad Media, el Renacimiento y la Temprana Modernidad, San Millán de la Cogolla, SEMYR/Cilengua, 301-310.

- Miranda, José Carlos Ribeiro (2012): «A primitiva conclusão da versão galego-portuguesa da Crónica de castela (A2d)», Cahiers d'études hispaniques médiévales, 35, 123-140 (https://doi.org/10.3917/cehm.035.0123) [última consulta: 15/07/2021]. 
- Miranda, José Carlos Ribeiro (2015): «A Crónica de 1344 e a General Estoria: Hércules e a fundação da Espanha», en Marta Haro (dir.), Literatura y Ficción en la Edad Media Hispánica, València, PUV, 209-224.

- Monteagudo, Henrique (1995): «A Crónica galega dos reinos de León e Castela na historia e na historiografía galegas», en Trevor J. Dadson/R. J. Oakley/P. A. Odber de Baubeta (eds.), New frontiers in Hispanic and Luso-Brazilian scholarship. Como se fue el maestro: for Derek W. Lomax in memoriam, Lewiston, The Edwin Mellen Press, 33-55.

- Monteagudo, Henrique (2008): Letras primeiras. O Foral do Burgo de Caldelas, os primordios da lírica trobadoresca e a emerxencia do galego escrito, A Coruña, Fundación Pedro Barrié de la Maza.

- Monteagudo, Henrique (2019a): «Variación scriptolingüística e tradición manuscrita da lírica trobadoresca: As variables $<$ nh/n $>$ e $<$ ss/s $>$ », en Ernestina Carrilho/ Ana Maria Martins/Sandra Pereira/João Paulo Silvestre (orgs.), Estudos linguísticos e filológicos oferecidos a Ivo Castro, Lisboa, Universidade, Centro de Linguística, 859-959.

- Monteagudo, Henrique (2019b): «Variación e cambio lingüístico no galego-portugués (s. XIII - s. XIV): os clíticos me/mi e lle/lhi e outras formas en <-e> final», Boletín da Real Academia Galega, 380, 303-395 (https://doi.org/10.32766/brag.380.775) [última consulta: 15/07/2021].

- Moore, John K. (2008): Libro de los huéspedes (Escorial Ms. h.I.13). A Critical Edition, Tempe, Arizona Center for Medieval and Renaissance Studies.

- Morais-Barbosa, Jorge de (1958): Crónica de Castela (ms. 8817 da Biblioteca Nacional de Madrid). Elementos para o estudo linguístico. Tese de licenciatura dactilografada. Lisboa, Universidade, 3 vols.

- Morais-Barbosa, Jorge de (1960): «La langue de la Chronique de Castille (ms. 8817 de la Bibliothèque Nationale de Madrid», Boletim de Filologia, 19, 151-158.

- Moreira, Filipe Alves (2012): «Um novo fragmento da Crónica Portuguesa de Espanha e Portugal de 1341-1342 e sua relações com a historiografia alfonsina», en Seminário Medieval 2009-2011, Porto, Estratégias Criativas, [s.p.] (https://cutt.ly/ AhUz6YI) [última consulta: 15/07/2021].

- Moreira, Filipe Alves (2013): A Crónica de Portugal de 1419: Fontes, estratagias e posteridade, Lisboa, Fundação Calouste Gulbenkian/Fundação para a Ciência e a Tecnologia.

- Moreira, Filipe Alves / Arthur L.-F. Askins (2015): «A Crónica de 1344 para além de Pedro de Barcelos: perspetivas recentes e novidades», eHumanista, 64-79 (https://www.ehumanista.ucsb.edu/sites/secure.lsit.ucsb.edu.span.d7_eh/files/ 
sitefiles/ehumanista/volume31/ehum31.ms.moreira.askins.pdf) [última consulta: 15/07/2021].

- Noia Campos, María Camiño (1995): «Historia da traducción en Galicia no marco da cultura europea», Viceversa, 1, 13-62 (https://revistas.webs.uvigo.es/index.php/ viceversa/article/view/2216) [última consulta: 15/07/2021].

- Noia CAmpos, María Camiño (2004): «El ámbito de la cultura gallega», en Francisco Lafarga/Luis Pegenaute (eds.), Historia de la traducción en España, Salamanca, Ambos Mundos, 721-748.

- Norton, Frederick John (1973): «Lost Spanish Books in Fernando Colon’s Library Catalogues», en Royston Oscar Jones (ed.), Studies in Spanish Literature of the Golden Age presented to Edward M. Wilson, London, Tamesis, 161-171.

- Norton, Frederick John (1978): A Descriptive Catalogue of Printing in Spain and Portugal, 1501- 1520, Cambridge, Cambridge University Press.

- OsóRIo, Jorge A. (1993): «D. Dinis: o rei, a língua e o reino», Máthesis, 2, 17-36.

- PARdo De GueVARA y VALdÉs, Eduardo (2000): Los señores de Galicia. Tenentes y condes de Lemos en la Edad Media, A Coruña, Fundación Barrié de la Maza, 2 vols.

- PARdo DE Guevara y VAldÉs, Eduardo (2001): «Parentesco y nepotismo. Los arzobispos compostelanos y sus relaciones familiares en la Baja Edad Media», en Actas del Simposio Internacional «El Coro del Maestro Mateo», A Coruña, Fundación Pedro Barrié de la Maza, 67-70.

- Pardo de Guevara y Valdés, Eduardo (2011): «Las Armas de los Limia y sus Derivaciones (Siglos XIII-XV)», e-Spania, 11 (http://e-spania.revues.org/20540) [última consulta: 15/07/2021].

- PARdo DE GueVARA y VALDÉs, Eduardo (2012): De linajes, parentelas y grupos de poder. Aportaciones a la historia social de la nobleza bajomedieval gallega, Madrid, Fundación Cultural de la Nobleza Española.

- PARKer, Kelvin M. (1975): Historia Troyana, Santiago de Compostela, Instituto de Estudos Gallegos Padre Sarmiento-CISC.

- PAscual-Argente, Clara (2020): «De francés en castellano. La tradición manuscrita de la Crónica troyana de Alfonso XI», Troianalexandrina, 20, 23-58 (https://doi. org/10.1484/J.TROIA.5.122511) [última consulta: 15/07/2021].

- Pena, Xosé Ramón (2013): Historia da literatura galega. I. Das orixes a 1853, Vigo, Xerais.

- Peres Rodrigues, José Henrique (1999): «Alguns apontamentos sobre a traduçom galega da General Estoria do rei Afonso X, o Sábio», Revista de Letras da Universidade de Trás-os-Montes e Alto Douro, 4, 49-66. 
- PéRez Barcala, Gerardo (2019): «El Livro de Alveitaria del Cód. 2294 de la Biblioteca Nacional de Portugal: anotaciones para su historia y descripción», Revista de Literatura Medieval, 31, 179-200.

- Pérez Barcala, Gerardo (2020): «Las fuentes del Livro d'Alveitaria del Mestre Giraldo», en Manel Bellmunt Serrano/Joan Mahiques Climents (eds.), Literature, Science \& Religion. Textual Transmission and Translation in Medieval and Early Modern Europe, Kassel, Edition Reichenberger, 323-343.

- Pérez-EMbid Wamba, Javier (2002): Hagiología y sociedad en la España medieval. Castilla y León (siglos XI-XIII), Huelva, Universidad.

- Pérez Pascual, José Ignacio (1990): Crónica de 1404. Tese de doutoramento inédita. Salamanca, Universidad, 2 vols.

- Pérez Pascual, José Ignacio (1991a): «El castellano de la Crónica General de 1404», Verba. Anuario Galego de Filoloxía, 18, 201-219 (http://hdl.handle.net/10347/3155) [última consulta: 15/07/2021].

- Pérez Pascual, José Ignacio (1991b): «A narración das cruzadas na Crónica Xeral de 1404», en Mercedes Brea/Francisco Fernández Rei (coords.): Homenaxe ó profesor Constantino García, Santiago de Compostela, Universidade, vol. 2, 387-392 (http:// hdl.handle.net/10347/12544) [última consulta: 15/07/2021].

- Pérez Pascual, José Ignacio (1993): «Relaciones entre la Cronica de 1344 y la Cronica de 1404», en Aires A. Nascimento/Almeida Ribeiro (eds.), Actas do IV Congresso da AHLM, Lisboa, Cosmos, vol. 3, 167-171 (http://www.ahlm.es/IndicesActas/ ActasPdf/Actas4.3/23.pdf) [última consulta: 15/07/2021].

- Pérez Pascual, José Ignacio (1994): «O Corpus Pelagianum na Crónica Xeral de 1404», en Elvira Fidalgo/Pilar Lorenzo Gradín (coords.), Estudios galegos en homenaxe ó profesor Giuseppe Tavani, Santiago de Compostela, Centro Ramón Piñeiro para a Investigación en Humanidades, 249-256.

- Pérez PASCual, José Ignacio (2002): «Crónica de 1404», en Carlos Alvar/José Manuel Lucía Megías (coords.), Diccionario filológico de literatura medieval española: textos y transmisión, Madrid, Castalia, 325-327.

- Pichel, Ricardo (2012a): «A fortuna da Historia Troiana petrista (BMP ms. 558). Notas sobre a súa xénese, procedencia e vicisitudes», Madrygal. Revista de Estudios Gallegos, 15, 119-130 (https://doi.org/10.5209/rev_MADR.2012.v15.39200) [última consulta: 15/07/2021].

- Pichel, Ricardo (2012b): «Tradición, (re)tradución e reformulación na General Estoria e na Estoria de Troya afonsinas á luz dun testemuño indirecto do séc. XIV», e-Spania, 13 (https://doi.org/10.4000/e-spania.21124) [última consulta: 15/07/2021]. 
- Pichel, Ricardo (2013): A Historia Troiana (BMP MS. 558). Edición e estudo históricofilolóxico. Tese de doutoramento inédita. Santiago de Compostela, Universidade, 2 vols.

- Pichel, Ricardo (2014): «Nuno Freire de Andrade, Mestre de Cristo. Tradición e vínculos dos Andrade co reino portugués», Madrygal. Revista de Estudios Gallegos, 17, 99-113 (https://doi.org/10.5209/rev_MADR.2014.v17.45741) [última consulta: $15 / 07 / 2021]$.

- PICHEL, Ricardo (2016): «Lean por este libro que o acharam mais complidamente... Del Libro de Troya alfonsí a la Historia troyana de Pedro I», Troianalexandrina, 16, 55-180 (https://www.brepolsonline.net/doi/abs/10.1484/J.TROIA.5.112824) [última consulta: 15/07/2021].

- Pichel, Ricardo (2017a): «La Historia troyana de Pedro I y su proyección en la Galicia atlantista», La corónica, 45:2, 209-240 (https://muse.jhu.edu/article/669505) [última consulta: 15/07/2021].

- Pichel, Ricardo (2017b): «O casal Lima-Seixas no percurso da produción literaria galega a cabalo dos séculos XIV e XV», Alicerces. Revista de estudos sobre o Miño Medio, 3, 113-139.

- PICHEL, Ricardo (2018): «Sobre la recepción alfonsí de la Historia regum Britanniae: una versión primitiva de la Estoria de Bruto», Incipit (Buenos Aires), XXXVIII, 69106 (http://www.iibicrit-conicet.gov.ar/ojs/index.php/incipit/article/view/496) [última consulta: 15/07/2021].

- Pichel, Ricardo/Pablo Sánchez Ferro (2019): «O legado haxiográfico de Bernardo de Brihuega en Ourense», Fronda. Voandeira do Arquivo Histórico Provincial de Ourense, 82 (ano 13), 1-2 (https://www.anabad.org/wp-content/ uploads/2019/11/82-Brihuega.pdf) [última consulta: 15/07/2021].

- Pichel, Ricardo (2021a): «La recepción de las Siete Partidas en la Galicia bajomedieval», en José Manuel Fradejas Rueda/Enrique Jerez Cabrero/Ricardo Pichel (eds.), Las Siete Partidas del Rey Sabio. Una aproximación desde la filología digital y material, Madrid/Frankfurt am Main, Iberoamericana/Vervuert, 117-133.

- Pichel, Ricardo (2021b): «Las Vidas y pasiones de los apóstoles de Bernardo de Brihuega a la luz de un nuevo testimonio castellano», en Marina Serrano Marín/ Belén Almeida/Fernando Larraz (eds.), Babel a través del espejo. Homenaje a Joaquín Rubio Tovar, Alcalá de Henares, Universidad, 55-67.

- PICHEL, Ricardo (2021c, no prelo): «La traducción entre lenguas vernáculas en la Galicia medieval (ss. XIII-Xv)», en Francisco Lafarga/Luis Pegenaute (dirs.), Historia de la traducción en España [http://phte.upf.edu/hte/edad-media/] [última consulta: 15/07/2021]. 
- Pichel, Ricardo (2021d): «E aqui escripvo o que achey, e quen mays souver acreçente. La Crónica de 1404 revisitada: balance y nuevos enfoques de estudio», en Leyre Martín Aizpuru/Juan Miguel Valero Moreno (dirs.), La lengva de los copistas. Variación y modelos de la escritvra del texto en el español medieval, Salamanca, Universidad/SEMYR [en preparación].

- Pichel, Ricardo/Xavier VARela BarReiro (2017): «O fragmento galego-portugués do Livro de Tristam. Nova proposta cronolóxica e diatópica», Madrygal. Revista de Estudios Gallegos, 20, 159-214 (https://doi.org/10.5209/MADR.57636) [última consulta: $15 / 07 / 2021]$.

- Piel, Joseph/José MatToso (eds.) (1980): «Livro Velho de Linhagens», en Portugaliae Monumenta Historica. Nova Série. Vol. 1. Livros Velhos de Linhagens, Lisboa, Academia de Ciências de Lisboa, 21-60.

- Procter, Evelyn S. (2002 [1951]): Alfonso X de Castilla, patrono de las letras y del saber. [Tradución e notas de Manuel González Jiménez]. Murcia, Real Academia Alfonso X El Sabio.

- REI, António (2010): «A tradução do Livro de Rasis e a memória da Casa Senhorial dos Aboim-Portel», Cahiers d'études hispaniques médiévales, 33, 155-172.

- Río Riande, María Gimena del (2010): «El surgimiento de la prosa científica en Portugal: el Livro d'Alveitaria de Mestre Giralda», en Pierre Civil/Françoise Crémoux (coords.), Actas del XVI Congreso de la Asociación Internacional de Hispanistas. Nuevos caminos del hispanismo (París, del 9 al 13 de julio de 2007), Madrid/Frankfurt am Main, Iberoamericana/Vervuert (https://cvc.cervantes.es/ literatura/aih/pdf/16/aih_16_2_036.pdf) [última consulta: 15/07/2021].

- Rochwert-Zuili, Patricia (ed.) (2010): Crónica de Castilla, Paris, SEMH-Sorbonne (Les Livres d'e-Spania «Sources» 1) (http://e-spanialivres.revues.org/137) [última consulta: 15/07/2021].

- RodríGuEZ, José Luis (1999): «De castelhano para galego-português: as traduções medievais», en Rosario Álvarez Blanco/Dolores Vilavedra (coords.), Cinguidos por unha arela común. Homenaxe ó profesor Xesús Alonso Montero, Santiago de Compostela, Universidade, vol. 2, 1285-1299.

- Rodríguez, José Luis (2003 [1974]): «Crónicas galegas medievais», en Benxamín Casal Vila (dir.), Gran enciclopedia galega Silverio Cañada, Lugo/Pontevedra, El Progreso/El Diario de Pontevedra, vol. 12, 228-231.

- Rodríguez Porto, Rosa María (2012a): Thesaurum. La Crónica Troyana de Alfonso XI (Escorial, H. I. 6) y los libros iluminados de la monarquía castellana (1284-1369). Tese de doutoramento inédita. Santiago de Compostela, Universidade, 2 vols.

- Rodríguez Porto, Rosa María (2012b): «El Libro de las Dueñas y la Historia Troyana bilingüe (Santander, BMP, ms. 558). Palabras e imágenes para María Rosa Lida 
de Malkiel (1910-1962)», Troianalexandrina, 12, 9-62 (https://doi.org/10.1484/ J.TROIA.1.103037) [última consulta: 15/07/2021].

- Rodríguez Porto, Rosa María (2012c): «Inscribed/Effaced. The Estoria de Espanna after 1275», Hispanic Research Journal, 13:5, 387-406.

- Rodríguez-Velasco, Jesús (2010): «La urgente presencia de las Siete Partidas», La corónica, 38:2, 99-135 (https://doi.org/10.1353/cor.0.0067) [última consulta: $15 / 07 / 2021]$.

- SÁnchez-PRieto Borja, Pedro (2002): «Génesis y transmisión de los textos medievales castellanos», La corónica, 30:2, 47-104.

- Sánchez-Prieto Borja, Pedro (coord.) (2009a): General Estoria, Madrid, Fundación José Antonio de Castro, Biblioteca Castro, 10 vols.

- Sánchez-Prieto Borja, Pedro (2009b): General Estoria. Primera parte, Madrid, Fundación José Antonio de Castro, Biblioteca Castro, 2 vols.

- SÁnChEZ-PRIETo Borja, Pedro (2016): «Difusión del texto y criterio editorial: el caso de la General estoria de Alfonso X», en Arina Garone Gravier/Isabel Galina Russell/ Laurette Godinas (eds.), De la piedra al pixel: reflexiones en torno a las edades del libro, México, UNAM, 25-60.

- Sánchez-Prieto Borja, Pedro (2021): «Biblia y “materia bíblica” en la génesis de la historiografía universal alfonsí», en Marina Serrano Marín/Belén Almeida/ Fernando Larraz (eds.), Babel a través del espejo. Homenaje a Joaquín Rubio Tovar, Alcalá de Henares, Universidad, 69-83.

- SÁnchez-PRIETo Borja, Pedro/Belén ALmeIDa (2009): General Estoria. Quinta y sexta partes, Madrid, Fundación José Antonio de Castro, Biblioteca Castro, 2 vols.

- SNow, Joseph T. (2020): «Prólogo», en Elvira Fidalgo (ed.), Alfonso X el Sabio: cronista y protagonista de su tiempo, San Millán de la Cogolla, Cilengua, 11-24.

- Sobral, Cristina (2021): «Entre a corte e o mosteiro: traduzir a santidade nos sécs. XIII-XIV», en Ricardo Pichel (ed.), «Tenh'eu que mi fez el i mui gram bem». Estudos sobre cultura escrita medieval dedicados a Harvey L. Sharrer, Madrid, Sílex [no prelo].

- Sobral, Cristina/Esperança CARDEIRA (2018): «O Livro dos Mártires de Bernardo de Brihuega: dois séculos de leitura em português», Estudos de Lingüística Galega 10, 129-141 (http://dx.doi.org/10.15304/elg.10.4613) [última consulta: 15/07/2021].

- Sonsino, Ana/Marta Cruz/Cristina Sobral (2018): Edição semidiplomática do Livro dos Mártires, en Corpus de Textos Antigos, Lisboa, Centro de Linguística da Universidade de Lisboa (http://alfclul.clul.ul.pt/teitok/cta/index.php?action=file\&id=2265.xml) [última consulta: 15/07/2021].

- Sottomayor-Pizarro, José Augusto de (2012² [2008]): D. Dinis, Lisboa, Temas e Debates. 
- SotTomayor-PizarRo, José Augusto de (2011): «Os Limas: da Galiza a Giela (Séc. XII a XV)», en Actas do $2^{\circ}$ Congresso Internacional: Casa Nobre um Património para o Futuro, Arcos de Valdevez, Município de Arcos de Valdevez, 53-74.

- Sottomayor-Pizarro, José Augusto de (2015): «A Família Lima entre a Galiza e Portugal (Séculos XII a XVI)», en José Augusto de Sottomayor-Pizarro/Mário Jorge Barroca (eds.), Paço de Giela. História de um Monumento, Arcos de Valdevez, Município Arcos de Valdevez, 15-65.

- Sousa, Thomas Frederic (1964): A Linguistic Analysis of a Portion of the Galician Translation of the General Estoria by Alfonso X, el Sabio. Tese de doutoramento inédita. Madison, University of Wisconsin.

- Souto CABo, José António (1993): «Caracterizaçom dialectal da Galiza na idade média», en Gerold Hilty (coord.): XXe Congrès International de Linguistique et Philologie Romanes. Tome II, Section III. La fragmentation linguistique de la Romania (Université de Zurich, 6-11 avril 1992), Tübingen, Francke, vol. 2, 531-547.

- Souto CABo, José António (2012): Os cavaleiros que fizeram as cantigas. Aproximação às origens socioculturais da lírica galego-portuguesa, Niterói, Universidade Federal Fluminense.

- Souto Cabo, José António (2016): «A Crónica dos ministros gerais da Ordem dos Fraires Menores (BN 94 IL) e o seu antígrafo galego», en Alexandre Rodríguez Guerra (ed.), Lingüística histórica e dialextoloxía: coordenadas do cambio lingüístico, Vigo, Universidade (Monografías da Universidade de Vigo. Humanidades e ciencias xurídico-sociais 114), 273-298.

- Vaquero Díaz, María Beatriz/Francisco J. Pérez Rodríguez (2010): Colección documental del archivo de la Catedral de Ourense. Vol. I (888-1230), Vol. II (1231-1300), León, Centro de Estudios e Investigación «San Isidoro»/Caja España de Inversiones/Archivo Histórico Diocesano (Col. Fuentes y estudios de historia leonesa 131).

- VILA, Suso (2010): A Casa de Soutomaior (1147-1532), Noia, Toxosoutos.

- Zubillaga, Carina (2008): Antología castellana de relatos medievales (Ms. Esc. h-I-13), Buenos Aires, SECRIT.

- ZubiLlaga, Carina (2021): «Ecos de lectura y producción cultural castellana a comienzos del siglo XIV», Incipit, 40, 283-295.

- WARD, Aengus (ed.) (2016): Estoria de Espanna Digital v.1.0 (transcriptions and corrections by Fiona Maguire, Enrique Jerez Cabrero, Ricardo Pichel, Polly Duxfield, Christian Kusi Obodum, Marine Poirier, Aengus Ward, Bárbara Bordalejo, Nick Leonard, Avellana Ross, Silvia Yusta Fernández), Birmingham, University of Birmingham (https://estoria.bham.ac.uk/edition/) [última consulta: 15/07/2021]. 


\title{
As antigüidades da Gallaecia na obra historiográfica de Afonso X
}

\author{
Helena de Carlos Villamarín \\ Universidade de Santiago de Compostela
}

DOI: 10.17075/gtax.2021.009 



\section{INTRODUCIÓN}

$\mathrm{O}$ xeito en que os historiadores, como representantes ou cando menos cronistas das sociedades, configuran o seu pasado máis remoto é revelador das expectativas deses mesmos tecidos sociais, sexan estes agrupados como pobos, nacións, castas, familias ou dinastías. Hai agora case trinta anos que defendín a miña tese de doutoramento, un traballo de mocidade que rematou por ter forma de libro uns anos máis tarde ${ }^{1}$, mentres outros investigadores, paralelamente, se facían preguntas moi semellantes á que eu formulara como punto de partida² ${ }^{2}$ Como é obvio e propio de toda investigación rigorosa, eu mesma e, así, os outros estudosos que canda min se adentraron nos territorios do imaxinario colectivo primixenio servímonos de traballos previos dedicados a estas cuestións. Mais teño a sensación de que o tema se fixo aínda máis recorrente como motivo de investigación, tanto no referente á historiografía antiga, como á medieval, como mesmo á moderna e contemporánea, nos últimos vinte anos. Pode ser este un efecto expansivo e colateral da obra fundacional de Benedict Anderson ${ }^{3}$ ou propio dunha época obsesionada polas identidades colectivas. É tamén normal que, como investigadores dun pasado remoto, nos vexamos atraídos polo xeito en que os colectivos dese pasado imaxinaron a raíz da que derivaron, como foron os tempos fundacionais, baixo quen os viviron, quen marcou, en certo modo, os seus riscos definitorios. En definitiva, como quixeron presentarse perante outros grupos sociais.

É o meu propósito nas páxinas que seguen analizar e intentar entender a configuración que Afonso X fai da protohistoria da «Galizia» nas súas obras de historia, a Estoria de Espanna e a General Estoria, dous proxectos xerados en parte en paralelo, confeccionados emporiso en momentos distintos do tempo e pensados tamén con distintos propósitos, aínda que estes se poidan entender dun xeito

1 Dirixida polo profesor José Manuel Díaz de Bustamante, defendida co título de Las Antigüedades de España. Fundadores y reyes míticos en la literatura medieval o 16 de decembro de 1992. Foi logo publicada como libro, con algúns cambios, na prestixiosa colección do Centro Italiano di Studi sull’Alto Medioevo. Cf. De Carlos Villamarín (1996).

2 Precedente para min lamentablemente descoñecido, contemporáneo do meu traballo cando este tiña aínda só forma de tese, foi a obra de referencia sobre materia afonsina de Fernández Ordóñez (1992). Algúns dos temas abordados por min, e que son de grande interese para esta contribución, foran antes tratados por Estévez Sola (1990) e en paralelo ao meu traballo por González García (1997 e 1998).

3 Refírome evidentemente á xa clásica Imagined Communities: Reflections on the Origin and Spread of Nationalism, publicada por vez primeira en 1983 e traducida ao español en 1993. 
máis complementario que oposto (Catalán 1962, Rico 1984, Fernández Ordóñez 1992, Rodríguez Porto 2017). Por protohistoria entendo a anterior á romanización, ou cando menos ao relato xa organizado da presenza romana na Península, que no caso afonsino posúe un claro punto de inflexión coa entrada de Hispania na historia de Roma con motivo das guerras púnicas. Evidentemente, o que Afonso X dedique a esta zona da Península está en relación co relato establecido arredor do resto de Hispania. Sen caer na decepción que manifesta Ramón Lorenzo (1999) ao estudar as mencións a Galicia do Rei Sabio, é xusto tamén deixar claro desde un primeiro momento que non imos atopar neste caso un relato especialmente prolixo sobre a historia remota do noso país.

\section{PEGADAS DOS AUTORES TARDOANTIGOS}

A visión do que poderiamos denominar as «Antigüidades da Gallaecia» ${ }^{4}$ que se percibe na Estoria de Espanna de Afonso X emana en boa medida do seu modelo máis claro nestes aspectos, que é a Historia de rebus Hispaniae ou Historia Gothica de Rodrigo Ximénez de Rada (ca. 1246), pero ao tempo incorpora elementos que nos fan percibir o resultado como xa afastado desa fonte e, xa que logo, da tradición isidoriana. Non podemos esquecer que Isidoro de Sevilla, especialmente nas Etimoloxías ou Origines, se fai eco de noticias extractadas de Xustino, un autor do século III da nosa era que dedica aos Gallaeci unha parte proporcionalmente significativa do libro 44 das súas historias, pola súa vez epítome da obra de Pompeio Trogo (s. I), consagrado ao pasado prerromano da Península Ibérica, ou, para sermos máis precisos, de Hispania. Para sintetizar os elementos que configuran esa imaxe da Hispania primitiva dada por Xustino: a descrición laudatoria de Hispania e das súas xentes, cunha mención especial a Viriato $(44,1$ e 2); a riqueza en cabalos da Lusitania e da Gallaecia, que leva a falar da lenda de Teucro e as súas fundacións, entre as que se conta o soar dos galegos cuxa riqueza mineral comenta laudatoriamente (44, 3); Tartessos e os seus reis Gárgoris e Habis (44, 4, 1-14); Xerión, rei doutra parte de Hispania, cuxa riqueza en gandos atrae a Hércules (44, 4, 15-16); os cartaxineses como primeiros ocupantes pola forza «post regna deinde Hispaniae», as guerras púnicas, e a final pacificación e incorporación ao imperio de Roma por Augusto $(44,5)$. Este é un rico e completo esquema, no que podemos atopar un fío temático dun punto ao outro: de Viriato enlazamos coa Lusitania e dela coa Gallaecia, cuxas orixes se comentan. Ao falar da riqueza do seu terreo, pásase a tratar dos primeiros reis doutros lugares de Hispania, o cal conduce a Xerión e ao personaxe de Hércules. Desta deidade cóntase que foi venerada polos fenicios e que eles a trouxeron a Gades, que propicia a entrada dos cartaxineses en Hispania e a participación desta nas guerras púnicas. Pero dese

4 Sobre o concepto de Antiquitates, cf. De Carlos Villamarín (1996: 23-56). 
esquema só sobrevivirá no mundo medieval a laudatio Hispanie, da que non vou tratar aquí, e a figura de Xerión, polo que respecta ao pasado mítico.

Por resumir moito, un eco xa afastado destas noticias chega a Ximénez de Rada, e unha onda aínda máis feble deste esquema plásmase na Estoria de Espanna de Afonso X. Isto é perceptible na noticia que máis claramente se refire aos Gallaeci das transmitidas por Xustino, a do nóstos ou viaxe de regreso de Teucro desde a guerra de Troia ata o soar dos Gallaeci, dos que se presenta como fundador 5 . Esta noticia é aínda recollida por Isidoro de Sevilla nas súas Etimoloxías (9, 2, 104), pero xa non por Ximénez de Rada, quen vincula a orixe dos galegos aos gálatas compañeiros de Hércules (De rebus Hispaniae 1, 4, 29-35). Tampouco aparece na Estoria de Espanna afonsina, fiel aquí ao Toledano (Primera Crónica General 3: Menéndez Pidal 1906: 6): «e los otros que llamaron galacios poblaron Galizia, que antiguamientre solie seer desdell agua de Cea fastal puerto de Gaya [...] e poblaron una grand partida de Galizia que era yerma entre los dos rios que llaman Duero e Minno, e pusieron le nombre Portogal»; (Primera Crónica General 7: Menéndez Pidal 1906: 10): «E una gran partida de la gente que el (Hércules) traye fueron de Galacia, e mandolos poblar alii e por esso fue llamada aquella tierra Galizia». Omisión curiosa, se é que de omisión voluntaria se pode falar, cousa que creo que é posible. Non o sería tanto no caso de Ximénez de Rada. Que o bispo toledano non manexe a riquísima e case única información que sobre o pasado prerromano da Península, e por conseguinte da Gallaecia, proporciona o abreviador de Pompeio Trogo paréceme debido non á vontade de non facelo, senón talvez á imposibilidade de facelo. E iso porque é bastante probable que Ximénez de Rada non coñecese o texto de Xustino ${ }^{6}$. Malia que menciona entre as súas fontes a Pompeio Trogo, precisamente a cita dun autor cuxo texto está perdido e só é coñecido pola abreviación composta por Xustino, pode dar unha pista sobre o carácter secundario desta mención. Ximénez de Rada nomea entre as auctoritates utilizadas por el a Pompeio Trogo porque a súa nómina de autoridades é indirecta, é dicir, está tomada da súa fonte, un autor do século vi, Xordanes, quen menciona a Pompeio Trogo nos seus Getica 6, 48. Nesa mesma nómina Ximénez de Rada cualifica a Pompeio Trogo de «historiarum orientalium sollicitus supputator», algo así

5 Propiamente, o de Teucro non é un nóstos, xa que este concepto implica a idea de regreso ao lugar de partida, algo aplicable ao exemplo máis coñecido literariamente, o de Odiseo ou Ulises, que viaxa durante dez anos para regresar á súa Ítaca. O caso de Teucro en relación coa Gallaecia sería máis análogo ao de Eneas en relación co lugar onde máis tarde se edificará Roma: ningún dos dous heroes procede do sitio en que remata por asentarse, senón que ese establecemento obedece ao designio divino ou á casualidade. Con todo, a diferenza fundamental entre Teucro e Eneas é que, mentres o segundo é un heroe do bando troiano, Teucro, malia a súa liñaxe, tamén ligada á dinastía de Príamo, loita no bando dos gregos. Segundo Bracessi (1984: 15-16), non obstante, estes detalles esváense no marco ideolóxico e no esquema mítico da viaxe fundadora. Sobre o arqueiro Teucro e a súa caracterización como bastardo, medio irmán de Aiax Telamonio e responsable último da súa morte ante o pai, vid. Ebbott (2003), especialmente o capítulo 2: «Teucer, the Bastard Archer».

6 Que non o utilizara xa foi advertido por F. Rubio Álvarez (1956: 48), quen considera tamén que a nómina de fontes a puido tomar Afonso X de Ximénez de Rada. O padre Rubio non entra a considerar se o texto foi descoñecido ou simplemente omitido. 
como «coidadoso recortador de historias orientais $»^{7}$ (De rebus Hispaniae, Prologus, 70: Fernández Valverde 1987: 7), o cal dá a entender que o ten como unha autoridade para asuntos relacionados con Oriente, e desde logo non coa zona extrema do Occidente que é a Península Ibérica. As escasas ocasións en que nos seus textos Ximénez de Rada parece utilizar a Xustino, por exemplo, no episodio das amazonas, en realidade estase servindo doutra fonte, nese caso os Exordia Scithica ${ }^{8}$.

Que acontece na obra historiográfica de Afonso X con respecto a Xustino? O asunto resulta complexo e non moi claro. Por unha banda, a utilización dos Epitoma Historiarum Philippicarum de Pompeio Trogo na obra do Rei Sabio é ampla e diversa: claramente é unha fonte utilizada nas dúas obras afonsinas, por exemplo ao tratar a historia de Elisa/Dido (Primera Crónica General 49-60: Menéndez Pidal 1906: 31-44; General Estoria II, 1, capítulos 370-374 e II, 2, caps. 419-20), a raíña de Cartago, da que fala Xustino no libro $18^{9}$, e de xeito evidente así mesmo ao falar de Sicilia cando introduce o tema do Etna na General Estoria. Na cuarta parte da súa obra de historia universal, antes de narrar as guerras que atinxiron a illa na época de Artaxerxes Asuero, faise un «departimento» da terra de Sicilia (General Estoria Cuarta Parte, 2, 12: Orellana 2009: 179: «Departe la estoria en este logar d’aquella tierra e dize así»). Baixo la estoria decatámonos axiña de que se atopa o texto de Xustino 4, 1-2 (Seel 1985: 46-49) que Afonso segue con notable fidelidade. A lealdade do texto de Afonso X ao longo desta pasaxe ao seu modelo latino, «la estoria» ${ }^{10}$, só se ve truncada, ou modificada, en escasas malia que significativas ocasións, algunhas delas para seguir a Ovidio e os seus comentaristas ${ }^{11}$.

Se Xustino é utilizado nesta pasaxe, aínda que sen mención explícita ao seu nome, en cambio dista de ser un recurso para tomar noticias sobre a prehis-

7 A aposición utilizada polo Toledano para cualificar a Pompeio Trogo é curiosa. Recorda a Ovidio (Ex Ponto 2, 3, 18): «sollicitis supputat articulis», expresión empregada para medir o interese de alguén, «calcula con dedos solícitos». Supputare é un verbo empregado para a idea de contar, calcular, pero tamén para a de podar, recortar.

8 En concreto, nunha versión privativa dunha familia de códices que remontan probablemente a un antígrafo de área napolitana, como demostrei nun traballo recente, De Carlos Villamarín (2019).

9 A versión de Xustino desta historia, que se retrotrae ao historiador Timenio de Tauromene, foi estudada por Olga T. Impey en dous importantes traballos (Impey 1980 e 1982). Cf. así mesmo De Carlos Villamarín (2008).

10 En 15 (Orellana 2009: 184) refírese á mesma fonte como «aquella Estoria de Assiria», para narrar as guerras entre Catania e Siracusa, seguindo de novo a Xustino 4, 3, 4-7. Esta pasaxe das guerras aparece tamén de forma idéntica a Justino en Orosio, adv. pag. 2, 14, quen encabeza o seu relato desta parte coa frase: «Sicilia ab initio patria Cyclopum et post eos semper nutrix tyrannorum fuit».

11 Como acontece noutra mención que se fai á illa de Sicilia e aos seus tres promontorios ao tratar o mito de Proserpina (General Estoria, Primera parte, Génesis; Sánchez-Prieto Borja 2009: 404-405). Xa Irene Salvo García mostrou na súa tese de doutoramento (Salvo García 2012) que a pasaxe do mito de Proserpina da General Estoria é un resumo especialmente abreviado de dúas obras ovidianas, Fastos IV, 418-620, e Metamorfoses 5, 347 ss., que engade algúns detalles á anterior, como son precisamente os nomes dos tres promontorios. Malia que os mesmos afonsinos remiten a Eberardo de Béthune, autor do Graecismus, este non semella ter dado directamente a etimoloxía de Trinacria como tres montículos, aínda que pon o nome como exemplo de uso da palabra «akros» na acepción de monte (Graecismus, 8, 16: «Mons acros atque leuis, ceu Trinacris aut acrozymus»). A súa fonte é en realidade Arnulfo de Orléans. 
toria mítica da Península. Unha explicación pode ser que o texto de Xustino talvez circulou truncado, carente dese libro 44, último da obra, ou mesmo nunha sorte de escolma historiográfica dedicada aos imperios previos ao romano, xustificando así a denominación de historiador de asuntos orientais dada por Ximénez de Rada, ou de «aquella Estoria de Assiria» que din os afonsinos. Talvez, simplemente, Afonso X non quixo asumir ese relato, malia coñecelo. E mesmo quere diverxer del manifestamente, como acontece no tratamento do personaxe de Xerión, outro elemento do pasado mítico peninsular abordado por Xustino, pasado por Isidoro e chegado a Ximénez de Rada, que muda radicalmente mesmo na súa morfoloxía na obra afonsina, pois convértese nun monstro de sete cabezas, fronte ás tres que unanimemente lle asigna a tradición. Sobre este aspecto regresarei en breve. Polo de agora só quero comentar a estrañeza que me segue a causar a omisión das ricas informacións sobre a historia prerromana da Península de Xustino por parte dos colaboradores afonsinos. Se eles coñecían o texto, como demostran coñecer outras seccións del, por que non quixeron incorporalo? Máxime cando a actitude de Afonso X con respecto aos textos latinos é unha actitude humanista, que procura o texto para traducir, que o insire onde é pertinente ou mesmo lle busca o lugar para ser inserido. E en boa medida un dos sinais do cambio de rumbo das historias de España coa chegada do humanismo propiamente dito é xustamente esta, que a prehistoria mítica abandona non o molde, pero si a letra esculpida por Ximénez de Rada, e enche ese molde con datos tomados de Xustino, como sucede por exemplo na obra de Joan Margarit ou Rodrigo Sánchez de Arévalo, no século XV (Rubio Álvarez 1956: 49, De Carlos Villamarín 1995).

Quizais sexa pertinente mencionar, polo momento, a tamén sorprendente ausencia de referencias á obra de Isidoro de Sevilla que ofrece a obra historiográfica afonsina, xa destacada por Luis López Santos (1961). Aínda máis sorprendente é o feito de que a obra do bispo de Sevilla está presente e é utilizada polos afonsinos sen serlle a el atribuída. Os libros 14 e 15 das Etimoloxías de Isidoro aparecen entre os materiais usados nas historias afonsinas baixo o nome de Libro de las Provincias, tal como a crítica recoñece (Solalinde 1934, Lida de Malkiel 1958, González Rolán 1981, Sánchez Prieto Borja 2016). É dicir, cando Isidoro é utilizado non o é como auctoritas, senón baixo un título anónimo, pero en xeral non se recorre a el nin ás súas obras de xeito directo, cando menos en aparencia, nin é invocado polo seu nome agás para falar do seu papel como bispo ou como santo. Esta estraña circunstancia levou a Daniel Eisenberg (1973) a comentar: «A discussion of Alfonso's sources raises problems as well as solves them. How is it that Alfonso knew Isidore's Etymologies, the medieval work by which Spain was best known in Europe, only in a fragmentary version, with the wrong title and no author?». Segundo os estudosos citados, malia que cando menos un dos libros que figuran na listaxe de manuscritos tomados como empréstamo por parte de Afonso X ao mosteiro de Albelda en 1270, considerados por algúns como punto de partida para 
a confección da obra historiográfica ${ }^{12}$, é un exemplar das Etimoloxías (Beer 1894: 50-51, González Rolán 1981), en ningures, nin nas citas, nin mesmo nas fontes da General Estoria de Afonso X, se pode percibir unha alusión a Isidoro de Sevilla como auctoritas. Polo contrario, si hai algunhas mencións na Estoria de Espanna e na General Estoria a Esidro ou Eisidro, ou mesmo San Esidro, como santo. Segundo López Santos, o decrecente papel de Isidoro de Sevilla como autoridade literaria no medievo hispano foi en paralelo ao seu crecente significado e presenza nas fontes historiográficas como santo ${ }^{13}$.

Non se pode logo trazar unha presenza directa do autor visigodo, malia que, en cambio, si poidamos facelo das autoridades citadas por el e que os afonsinos usan de xeito directo, como é o caso de Plinio. É bastante probable que Isidoro e a súa obra fosen xa unha especie de reliquias dun mundo pasado e dun xeito de pensar pretérito para os intelectuais da época afonsina, e que o sabio visigodo fose recordado máis como o santo venerado no reino de León ${ }^{14}$ ca como a meirande autoridade do saber medieval, pero non por iso debemos pensar que a súa obra foi totalmente erradicada do escritorio afonsino. Ao meu xeito de ver, esta puido ser a ringleira sobre a que escribiron nalgúns momentos os colaboradores de Afonso X, a partir da que obtiveron a nómina de autoridades que, como Plinio, como Xustino, puideron logo consultar e traducir de xeito directo, e desde a que apreciaron a forza da etimoloxía como modo de coñecemento das cousas, aínda que a partires dese principio procurasen outras explicacións etimolóxicas desbotando as isidorianas.

\section{XERIÓN}

Quixera, polo de agora, achegarme a un dos personaxes máis fascinantes da secuencia de textos que levamos bosquexada na tradición historiográfica, o de Xerión. Como xa comentei, este personaxe aparece vinculado á historia de

12 Malia que con matices, xa que non hai unanimidade en considerar se este é realmente un punto de partida para a elaboración de materiais para ambas as obras ou habería que consideralo máis ben unha data tardía, cando en realidade habería dúas grandes etapas de elaboración de obras afonsinas, unha marcada polo ano 1250, coa que podería cadrar a confección da Estoria de Espanna, e outra polo 1270, que coincidiría coa redacción da General Estoria. Vid. Cárdenas (1997).

13 O papel de Isidoro como o santo máis prominente na chamada Reconquista cristiá da Península foi estudado coidadosamente e posta de relevo tamén a orixe e as relacións que manteñen entre si os diferentes textos que tratan de Isidoro como unha figura venerable e que tocan a devoción que se lle consagrou no reino de León (Martín 2005, Falque Rey 2015)..

14 Do que o propio Afonso evoca na Estoria de Espanna no importantísimo momento da entrada do seu pai Fernando III na súa amada cidade de Sevilla xusto o mesmo día do aniversario da translación de Isidoro a León, Estoria de Espanna 1125: Menéndez Pidal 1906: 767: «Capitulo de comma el rey don Fernando entro en Sseuilla et de comma fue refibido con grant profesion.; Dia era de la traslaçion de sant Esidro de Leon, arçobispo que fue de Seuilla-en la era de mill et dozientos et ochenta et seys, do andaua el anno de la Encarnaçion del Nuestro Sennor jeshu Cristo en mill et dozientos et quarenta et ocho-quando ese noble et bienauenturado rey don Fernando, de que la.estoria tantos bienes a contado, entro en esa dicha noble çipdat de Seuilla, capital de todo ese sennorio del Andalozia». 
Hispania ou, por mellor dicir, á súa protohistoria, en Xustino 44, 4, 15-16. Dísenos del que reinaba noutra parte de Hispania que tamén está formada por illas («In alia parte Hispaniae et quae ex insulis constat»), facendo alusión ao punto anterior, no que se trataba do reino primitivo de Tartessos (De Carlos Villamarín 1996: 80-92). Dísenos, así mesmo, que era o rei pacífico dun lugar próspero onde o gando se criaba vizosamente, ata o punto de que, por unha parte, a súa figura se evemeriza para facer da súa morfoloxía tripla encarnación de tres irmáns moi ben levados que gobernaban como un único rei, e, por outra parte, incorpórase Hércules ao relato, convertido nun depredador de gandos e riquezas (Xustino 44, 16, Seel 1985: 301):

Porro Geryonem ipsum non triplicis naturae, ut fabulis proditur, fuisse ferunt, sed tres fratres tantae concordiae extitisse, ut uno animo omnes regi viderentur, nec bellum Herculi sua sponte intulisse, sed cum armenta sua rapi vidissent, amissa bello repetisse [Ademais din que o mesmo Xerión non foi de natureza tripla, como se conta nos relatos, senón que existiron tres irmáns de tan grande entendemento que mesmo parecía que todos gobernaban cun único espírito, que non levaron a guerra a Hércules por vontade propia, senón que ao veren que lles roubaban os seus gandos, foron procurar coa guerra o que perderan].

Este Xerión visto como rei bo sometido ás razzias dun Hércules depredador coincide co Xerión do que nos fala Braccesi situado no Epiro, «ove la tradizione fa di Gerione un re indigeno» (Braccesi 1984: 24, De Carlos Villamarín 1996: 97, Chevallier 1976), e aseméllase moito ao Xerión divindade bondadosa e propiciatoria de oráculos situada en lugares como Abano, nos arredores de Padua, e Agirio, en Sicilia. Segundo Braccesi (1984: 24), ese culto a Xerión podería ser un eco da lembranza de depredacións de gando no seo dunha loita entre o elemento colonial pregrego, representado por Heracles, contra os reis indíxenas. A lenda de Xerión, vinculada á de Heracles en todos estes casos, expresaría a existencia dun substrato orixinario non grego (celta, para algúns estudosos, González García 1997: 18-48) que sería asimilado á lenda grega do Heracles clásico, pero co papel cambiado ${ }^{15}$, e falaría desde un punto de vista historicista dunha sorte de ruta prehistórica que uniría o norte do Adriático, por unha parte, con Sicilia, facendo un alto no Epiro, e, por outra, coa Península Ibérica, o cal se constataría en tempos posteriores coa introdución de lendas ligadas ás viaxes dalgúns heroes homéricos, nomeadamente Antenor e os Antenóridas, Diomedes, Anfíloco e Teucro ${ }^{16}$, relacionadas así mesmo con esta xeografía.

15 «per giustificare le razzie dell'elemento coloniale greco ai danni del indigeno, il dio, da divinità benefica, diviene demone mostruoso connesso con il regno delle tenebre» (Braccesi 1984: 24-25).

16 Ademais do expresado en De Carlos Villamarín (1992: 92-105), resulta fundamental Braccesi (1984: 33- 43: «Gli Antenoridi: dal Veneto all’Iberia»). 
Independentemente dos posibles contactos de época micénica e, máis tarde, de tempos coloniais atenienses e posteriormente romanos, entre estes lugares, interésame a certeza do que os textos comentan con respecto á figura de Xerión. O papel benéfico e a evemerización deste inicial monstro de tres cabezas mantense en Isidoro, quen utiliza case ao pé da letra a Xustino (Orig. 11, 3, 28: Oroz/ Casquero 1994: 52):

Dicuntur autem et alia hominum fabulosa portenta, quae non sunt, sed ficta in causis rerum interpretantur, ut Geryonem Hispaniae regem triplici forma proditum. Fuerunt enim tres fratres tantae concordiae ut in tribus corporibus quasi una anima esset [Pero cóntanse tamén outros prodixios fabulosos de homes, que non existen, pero interprétanse como ficcións nas causas das cousas, como o que se transmitiu de que Xerión, o rei de Hispania, tiña unha forma tripla. É que foron tres irmáns de tan grande entendemento que era como se houbese unha única alma en tres corpos].

Mantense, así mesmo, nel a indefinición do lugar xeográfico concreto co que se vincula a figura, ou máis ben, fronte a Xustino, pódese afirmar que Isidoro o vincula coa totalidade de Hispania. A interpretación evemerista de Xerión permanece en Ximénez de Rada, para quen el era o rei de tres provincias: Bética, Galicia e Lusitania (De rebus Hispaniae 1, 4, 19: Fernández Valverde 1987: 15):

Erat autem tunc temporis in Hesperia princeps quidam qui Gerion uocabatur et habundabat gregibus et armentis et habebat tria regna que nunc dicuntur Gallecia, Lusitania, Bethica: unde et iste Gerion cum esset alias fortis et ferox, triplex describitur fabulose [Había daquela en Hesperia un príncipe que se chamaba Xerión e abundaba en rabaños e gandos e tiña tres reinos que agora se chaman Galicia Lusitania e Bética: de onde tamén ese Xerión, que polo demais era forte e fero, se describe fabulosamente como triplo] ${ }^{17}$.

O cal coincide coa versión dada por Afonso X na General Estoria (II, 2; Fernández Ordóñez 1992: 131-132). E malia que aquí o Toledano o cualifíca de «ferox», tamén se mantén a idea non tanto de que Xerión fora un rei pacífico, como a de

17 Segundo Estévez Sola (1990), esta versión pola cal Xerión é cabeza de tres reinos procede do comentarista Iohannes Anglicus, quen di expresamente: «Gerionis caput est in triple regno/cuius diuicie preda fuere uiro», pero teño que advertir que xa en Servio, o famoso comentarista de Virxilio do século v (In Aen, 7, 662), Xerión goberna tres entidades xeográficas, aínda que estas se identifican coas Baleares: «Geryones rex fuit Hispaneae qui ideo trimembris fingitur, quia tribus insulis praefuit, quae adiacent Hispaniae: Baliaricae minori et maiori et Ebuso». 
que Hércules devastou a Península ao seu paso. En primeiro lugar, Xerión é vencido por Hércules nun lugar indefinido, talvez nalgunha desas provincias occidentais que gobernaba, pero esa vitoria fai entrar en escena a Galicia (De rebus Hispanie 1, 4, 29: Fernández Valverde 1987: 15 ):

Contra hunc pugnauit Hercules, et repetito bello ferocem uirtute domuit et prostrauit priuatum uita, patrimonio et armentis, optentamque partem illam Hesperie populis qui secum a Galacia uenerant captam tradidit habitandam; unde et a Galatis Galletia V $\underline{\text { a }}$ prouincia Hyspanie nomen accepit, licet ab aliquibus alia causa nominis assignetur [Contra este loitou Hércules, e repetida a guerra domou coa súa virtude ao fero e dobregouno, privado de vida, de patrimonio e de gandos, e entregou a parte aquela que obtivo de Hesperia, tras capturala, aos pobos que viñeran desde a terra dos gálatas para que a habitasen; de onde, a partir dos gálatas, Galicia, quinta provincia de Hispania, recibiu o seu nome, aínda que por parte dalgúns se lle asigne outro motivo ao nome].

Como xa adiantamos, Afonso X concorda ao pé da letra con Ximénez de Rada neste punto, ao atribuír a fundación de Galicia aos gálatas (Estoria de Espanna 7). E, como conclusión das incursións de Hércules en Hispania, e antes de deixar ao seu cargo a Hispán, o Toledano escribe (De rebus Hispaniae 1, 5, 46: Fernández Valverde 1987: 17):

Et optenta Hispania, immo uerius desolata, que a sui principio, quam primum Cetubeles habitarunt, satis prospera felicitate gaudebat, infelices populos, quos longa quies inhermes fecerat et ignauos, Grecorum iugo, qui naturaliter subditis sunt infesti, gladius Herculis subiugauit... [E obtida Hispania, ou máis ben asolada, a que desde a súa orixe, cando a habitaron os Cetubeles, gozaba dunha fecundidade abondo próspera, a espada de Hércules someteu ao xugo dos gregos, que de natural son crueis cos seus súbditos, a uns pobos desgraciados, aos que unha longa paz fixera inermes e preguiceiros].

Polo tanto, malia que Ximénez de Rada cualifica a Xerión como «ferox» e cre que esa ferocidade é vencida pola «virtus» de Hércules, considera que a ocupación de Hércules, e con el a «servitus» dos gregos baixo a que Hispania cae, e que continuará coa opresión dos romanos, é un feito lamentable, como expresa tamén repetidamente na súa Historia Romanorum, xa, por exemplo no seu Prologus (Fernández Valverde 1979-80: 159): 
Quia direptiones Herculis, quas gens misera pertulit Hesperorum, in superioribus capitulis declaraui, quae Romani, Vandali et Sueui, Alani et Silingui, et Arabes Mahometi, et qualiter Hispanias inuaserunt, et quae ei multiplicata supplicia addiderunt, prosequi dignum duxi... [Porque xa expliquei os saqueos de Hércules que soportou a pobre xente dos Hésperos en anteriores capítulos, considerei digno proseguir os dos romanos, vándalos e suevos, alanos e silingos, e os árabes de Mahoma, e como invadiron as Hispanias, e que castigos multiplicados engadiron a ese].

Baixo a concepción da historia do arcebispo de Toledo subxace con toda probabilidade un núcleo de historiografía «mozárabe» que se orixina na Península, xa visible na chamada Chronica Pseudoisidoriana, un texto datable no século XII (González Muñoz 2000), e que semella aínda máis perceptible en Afonso X, como veremos. Na mesma construción do personaxe de Xerión púidose superpoñer ao legado isidoriano a imaxe de Alión, presente na chamada Crónica del Moro Rasis (LII, Catalán/De Andrés 1975: 127), na que se fala da morte de «Alión a tres migeros de la çibdat que agora llaman la Curuña, a do el fizo el conçilio en Galizia» (Catalán 1975, De Carlos Villamarín 1996: 287-291, González García 1997: 112-124). Pero tamén é perceptible unha visión que eu mesma hai anos definira como «clasicista». A imaxe que Ximénez de Rada ofrece de Hércules, sobre os recordos isidorianos que sen dúbida alentan tamén a súa obra, un de cuxos referentes é a Historia Gothorum de Isidoro, torna de xeito obvio e confeso ás fontes literarias antigas, a Ovidio, a Virxilio ${ }^{18}$. Eu non descartaría que Ximénez de Rada estivese animado neste sentido polo coñecemento de primeira man dos clásicos que puido ter durante as súas estadías en Italia, onde tamén puido ser influído pola proliferación de voces cívicas na procura de orixes míticas vinculadas ao pasado glorioso e aos heroes fundadores das cidades e repúblicas italianas, especialmente as do Véneto e da Toscana, á imaxe e semellanza da mesma Roma (Benes 2011).

Sospeito que este camiño trazado polo arcebispo de Toledo contra 1246 (Jerez Cabrero 2003) foi continuado con meirande empeño, e nun sentido máis fondo, por Afonso X, a quen o seu labor na recollida e tradución de textos antigos pode facer análogo ao de calquera humanista mesmo posterior no tempo, como tentarei demostrar. Por outra banda, a Estoria de Espanna de Afonso X presenta algún elemento orixinal sobre as primeiras etapas da vida peninsular cuxa acción transcorre na actual Galicia, e máis concretamente vinculada á que moitas testemuñas presentan como a atracción sobranceira, protagonista de relatos máis ou menos fantásticos, visible en

18 As citas de Ximénez de Rada son literais: a Virxilio, Aen 7, 661-663; a Ovidio, Met. 9, 184-185 e Her. 9, 91-92. Curioso que estas últimas fontes, as ovidianas, foran traducidas practicamente na súa integridade ao castelán polo equipo afonsino para confeccionar as historias, sobre todo a General Estoria. 
documentos e en historias, o Faro da Coruña. Como construción na que alenta o carácter antigo e venerable podería pensarse que ocupa un papel análogo ao que na mesma obra afonsina ten o acueduto de Segovia; é dicir, a condición de monumento que causa tanta estrañeza como marabilla e que se relaciona con algún tipo de personaxe especial. Ximénez de Rada refírese ao monumento máis vagamente, como unhas torres, vinculándoo á presenza de Hércules «in finibus Hesperie» pero só o denomina «Gades Herculis», e vincula máis adiante a construción, ou reconstrución («extruxit»), desas torres «in pharo Gallecie et in Gadibus» ao delegado de Hércules en Hispania, Hispán (De rebus Hispaniae 1, 4, 16-19; 1, 7, 5-6). Afonso X aposta por atribuír claramente a construción do faro a Hércules, pero innova con respecto á súa fonte ao asociar este personaxe, asemade, á fundación da cidade da Coruña. Tamén ampliará as noticias do Toledano dándolle a Espán, convertido en sobriño de Hércules, a función de poñer un espello no cumio do faro, como veremos. Afonso X dota a Hércules dun protagonismo meirande do que lle outorgara o Toledano, e iso tanto na Estoria de Espanna como na General Estoria; as cales, por outra banda, non sempre concordan entre si, polo que é razoable pensar que ambas as dúas, sobre a base da historia de Ximénez de Rada, utilizaron cada unha pola súa conta o material de raíz hispanoarábiga que previamente os colaboradores afonsinos traduciran para ter ao dispor da confección dun e outro proxecto historiográfico (Fernández Ordóñez 1992: 120-138, 193-202).

Por unha banda, Afonso X na Estoria de Espanna introduce o personaxe de Xerión, segundo xa comentei, transformado en rei de sete provincias correspondentes ás súas sete cabezas lendarias (Primera Crónica General 7: Menéndez Pidal 1906: 9) e en concreto cualificado como:

un rey muy poderoso auie en Esperia que tenie la tierra desde Taio fasta Duero, e por que auie siete prouincias en su sennorio fue dicho en las fabliellas antiguas que auie siete cabeças; y este fue Gerion, y era gigante muy fuerte y muy liger, de guisa que por fuerça derecha auie conquista la tierra e auien le por fuerça a dar los omnes la meatad de quanto auien, tan bien de los fijos e de las fijas cuemo de lo al, e a los que no lo querien fazer mataualos. E por esto era muy mal quisto de todas las gentes, mas no osauan yr contra el por que no auie y qui los deffender...

Cabe recordar, que, en cambio, na General Estoria Xerión segue a ter tres cabezas, como na case unanimidade das fontes. Por momentos chego a sospeitar se non se fundirían na innovación da Estoria de Espanna afonsina elementos tomados dun curioso personaxe presente nun tamén curioso texto da tradición historiográfica hispana, vinculado expresamente a Galicia, a chamada «Historia de Octaviano e Septemsídero». Este texto, editado por Juan Gil (1971) e por Díaz y Díaz (1972-74 e 1985), 
está copiado no chamado Códice de Roda, o manuscrito da Real Academia da Historia 78 datado no século XI, que contén na súa primeira parte a obra de Orosio e, na segunda, unha serie de textos diversos, entre os que predominan os de corte historicista, ademais dun dossier de xenealoxías finalizado cunha imaxe da Epifanía, análogo ao que adoitan presentar os beatos e algunha biblia visigótica (De Carlos Villamarín 1996 e 2010). O texto que nos ocupa fala da loita entre Octaviano e Septemsídero; o primeiro é rei de Toledo e o segundo habita nun lugar indeterminado, pero relacionado con Galicia. Dise del que é «maritus de Iherie, pater de Bracaro et de Flavio et de Teoderico et de Galaa et de Gemulus et de Cesario, qui fecit Zesarea et Faro». Tras a loita e a inopinada vitoria de Septemsídero, este instálase coa familia en Lugo, e os fillos fanse fundadores epónimos de cidades da Gallaecia ${ }^{19}$ :

Bracarus Bracara, Flavius Flavias, Teudericus Tude super mare, Galaa portus Galee: Sequarius fuit mortuus in Tamare ibi dicunt portus Sequarii. Gemulus erat fortiosus, in singulas manus binas portavat columnas; ipse fecit bobata sci Petri et celbas super Aquas Caldas et ponte in Mineo. Et Cesarius super hinc resonat... [Brácaro Braga, Flavio Chaves, Teodorico Tui sobre o mar, Gala Portugal: Secuario foi morto no Tambre, no lugar que chaman Porto de Sigüeiro. Xemulo era ben forte, en cada man levaba dúas columnas; el fixo a bóveda de San Pedro e Celas sobre Caldas e unha ponte no Miño. E Cesáreo destaca por riba deste].

Resúltame curioso que a loita territorial, como na Estoria de Espanna, se resolva neste texto nun combate singular entre os reis. Pero tamén que Gemulus teña resonancias mesmo iconográficas con Hércules portando senllas columnas (Rodríguez Porto 2017), ou que se asocie a outro dos fillos de Septemsídero, Cesarius, co faro e, indirectamente, con Xulio César. Chama tamén poderosamente a atención que a muller de Septemsídero responda ao nome, de resonancias eponímicas, de Iheria, e que a filla de Hispán e muller de Pirus ou Piro, un dos primitivos reis da Península e epónimo dos montes Pirineos na Estoria de Espanna 8, se chame Liberia. Tampouco me parece a nómina de pobos que ocuparon Hispania segundo a Laus Spanie do folio 198r do Códice de Roda (De Carlos Villamarín 1996: 301-323) allea ao concepto dos «sennorios» da Península expresado na historia hispánica afonsina, é dicir, que Hispania se conciba como un soar que será sucesivamente dominado por diferentes «sennores», reinos ou pobos, sete no caso do texto citado do Códice de Roda. Cabe lembrar que este é

19 Remito o lector aos estudos citados para unha avaliación e posibles identificacións dos topónimos suxeridos no texto. A edición citada de Gil vén completada por un estudo de Isidoro Millán que incide nestes aspectos. 
aparentemente o principio vertebrador da Estoria de Espanna afonsina ${ }^{20}$. Sería prolixo tratar de todas estas cuestións, tan complexas, neste lugar, pero cando menos quero que quede apuntado para ulteriores investigacións. O Códice de Roda contén, como digo, as Historias adversus paganos de Orosio e materiais cuxa procedencia se podería asignar a moi distintos lugares da Península, sen que a eles sexan alleos os puntos de vista que poderían relacionalos con medios árabes. Que chegase a ser consultado polos colaboradores afonsinos, ou que estes coñecesen por outra vía os textos nel contidos, non me parece unha hipótese que poidamos desbotar.

\section{HÉRCULES}

É precisamente a tiranía exercida por este Xerión de sete cabezas, no que percibimos así mesmo trazas do mítico rei Minos de Creta (combatido, por certo, polo outro grande heroe vencedor de monstros, Teseo), quen atrae a un Hércules debuxado cos trazos da nobreza e da xustiza (Primera Crónica General 7: Menéndez Pidal 1906: 9-10):

[...] et cuando sopieron que Hercules uinie, enuiaron le dezir, que el, que tantos buenos fechos fiziera e tantos omnes sacara de premia e de mal sennorio, que acorriese a ellos, e quel darien toda la tierra. Quando esto oyo Hercules, plogol mucho e fuesse pora alla; ca maguer ell era del linage de los gigantes e muy fuerte, no era por esso omne cruo ni de mala sennoria, ante era muy piadoso a los buenos y muy brauo e fuert a los malos; e quando oyo las querellas daquellas yentes, doliose dellas e fuesse pora ellos. E quando Gerion lo sopo, fuesse con sus huestes pora aquel logar o fue despues poblada la cibdat que dizen Crunna, que era entonces yermo. Hercules enuio dezir a Gerion que las yentes no auien por que matarse ni por que lazrar, mas que lidiassen ellos amos un por otro; y el que uenciesse, que fuesse toda la tierra suya. E Gerion atreuiendose en su ualentia, e demas que era mayor que el, dixo quel plazie. E lidiaron tres dias que nos podien uencer; en cabo uencio Hercules e cortol la cabeça. E mando en aquel lugar fazer una torre muy grand; e fizo meter la cabeça de Gerion en el cimiento, e mando poblar y una grand cib-

20 A idea de que o principio estruturador da Estoria de Espanna é a sucesión de «sennoríos» foi formulada por Menéndez Pidal. No fondo podería resultar da incorporación e organización nun único texto das diferentes obras de Ximénez de Rada dedicadas non só aos godos, senón tamén aos romanos, vándalos, suevos e árabes; é dicir, aos pobos vinculados política e territorialmente con Hispania. Cf. Fernández Ordóñez (1992: 19-26). 
dat $^{21}$, e fazie escreuir los nombres de los omnes e de las mugeres que y uinien poblar, y el primero poblador que y uino fue una muger que auie nombre Crunna, e por essol puso assi nombre a la cibdat.

A torre será rematada por un sobriño de Hércules, o rei Espan, vinculado así mesmo coa construción do acueduto de Segovia e coa poboación e establecemento de monumentos en Cádiz, e encarnación do Hispán creado por Ximénez de Rada en De rebus Hispaniae 1, 7, malia que para o Toledano este personaxe non tivese vínculo familiar con Hércules. Segundo Afonso X (Primera Crónica General, 9: Menéndez Pidal 1096: 11):

Espan, sobrino dErcules, que finco por sennor en Espanna, anduuo por la tierra e fizo la poblar y endereçar, ca era muy maltrecha y destroyda por la grand guerra que fiziera Hercules; e com era omne sabio y entendido, soposse apoderar della, e poblo los puertos de la mar e otrossi logares en las montannas, por o entendio que podrie uenir danno dotras yentes de la tierra; e poblo muy grandes uillas y e buenas, e fizo y lauores marauillosas... E acabo la torre del Faro que començara Hercules, que es cabo a la Crunna; e com era omne muy sabidor, fizo fazer un grand espeio, que ueyen en el uenir las naues por el mar de muy luenne, e pusol en somo daquella torre, y esto fizo el por aguardar se dotras yentes sil uiniessen guerrear por mar.

O perfeccionamento por parte de Espán do faro coa incorporación do espello revelarase ben necesario no famoso episodio da invasión dos «almuiuces» que Afonso trata no capítulo 14 da Estoria de Espanna e que foi estudado en varias ocasións pola súa probable relación con lendas de orixe irlandesa ou xa filtradas pola visión hispanoarábiga (Wikander 1966, Fernández Ordóñez 1992: 198-202, González García 2012). A historia do espello preséntase xa antes, por exemplo no texto denominado Trezenzonii de solistitionis insula magna, unha pequena xoia datada no século XI, na que se atribúe tal marabilla ao farum Brecantium (Díaz y Díaz 1985), pero pode ter a súa base na famosa descrición de Hispania de Orosio (Historias adversus paganos 1, 2, 70-72) $)^{22}$, que chama tamén a atención pola relación que nela se establece entre os distintos ángulos da Hispania trigona, logo vinculados con construcións atribuídas

21 A letra cursiva é miña.

22 É preciso ter en conta que a obra de Orosio (s. v) foi traducida ao árabe no século x (Catalán 1975, Fernández Ordóñez 1992: 121) e pasou a incorporarse aos devanditos relatos e historias compostas na Península ou que circularon nela nun medio árabe, de onde as puideron tomar Ximénez de Rada e Afonso $\mathrm{X}$, sexa este por mediación de aquel, sexa, nalgunhas pasaxes, de xeito independente polo Rei Sabio. Inés Fernández Ordóñez (1992: 185-202) observa así mesmo que o detalle do espello do faro recorda extraordinariamente a descrición do faro de Alexandría feita na General Estoria I e baseada en al-Bakri, unha fonte hispanoarábiga recoñecida tamén para ambas as dúas obras históricas de Afonso X. 
a Hércules ou a personaxes relacionados con el, e que asimilan case desde sempre o extremo da Gallaecia con Gades ${ }^{23}$. Esta outra cidade marca tamén un fito na xeografía peninsular e nas andanzas de Hércules na visión de Afonso X, quen por riba introduce nas conquistas deste personaxe unha especial mención á súa amada cidade de Sevilla, noticia que recolle tamén na General Estoria (II, 2), aínda que pouco máis adiante a amplía atribuíndolle a Hércules, ademais, a construción de «una torre en que puso una imagen fecha por el saber de las estrellas, e tenie la mano tendida contra el mar». Na Estoria de Espanna este detalle desenvólvese para formar un relato máis minucioso (Primera Crónica General 6: Menéndez Pidal 1906: 8-9): «e porquel semeio que aquel logar era muy vicioso y estaua en el comienço doccident, fizo y una torre muy grand, e puso ensomo una ymagen de cobre bien fecha que cataua contra orient e tenie en la mano diestra una grand llaue en semeiante cuemo que querie abrir la puerta, e la mano siniestra tenie alçada e tenduda contra orient e auie escripto en la palma: estos son los moiones de Hercules...».

Tamén segundo a Estoria de Espanna, que novamente debe a súa información neste sentido a fontes hispanoárabes, Hércules é o que avista o lugar onde tempo máis tarde será fundada Sevilla e ante a profecía do seu «estrellero» Atlas de que sería outro grande home quen erixiría alí unha cidade, Hércules decide deixar nese lugar un monumento conmemorativo que, efectivamente, será atopado tempo máis tarde por Xulio César ${ }^{24}$. Este feito é lembrado na tradición manuscrita cando menos por unha miniatura (El Escorial, ms. Y.I.2, f. 5r) que reproduce o que o texto indica; é dicir, que o monumento é unha estatua erixida «sobre seis pilares de piedra y una losa de mármol» (Fernández Ordóñez 1992: 125, Rodríguez Porto 2017: 247-250) na que figura esta inscrición: «AQVI:SERA:POBLADA:LA:GRANT:CIBDAT:».

Ademais de lembrar case ao pé da letra a secuencia de feitos da construción do faro e da fundación e poboamento da cidade da Coruña por Hércules, utilizando unha variante desa mesma frase profética, e mando poblar y una grand cibdat, este relato que, sen atinxir directamente ás «Antigüidades da Gallaecia», axuda

23 Non podo deixar de evocar neste punto un texto de Xordanes no que se di que o promontorio da Gallaecia, neste caso comparado co de Lisboa, na medida en que ambos os dous son confundidos por algúns con illas do Océano, posúe un templo de Hércules (Getica 1, 7): «Et sunt iuxta fretum Gaditanum haut procul una Beata et alia quae dicitur Fortunata. Quamvis nonnulli et illa gemina Galliciae et Lysitaniae promuntoria in Oceani insulas ponant, in quarum una templum Herculis, in alia monumentum adhuc conspicitur Scipiones, tamen, quia extremitatem Galiciae terrae continent, ad terram magnam Europae potius quam ad Oceani pertinent insulas» [E hai a carón do mar de Gades, non lonxe, unha illa que chaman Feliz e outra que chaman Afortunada. Aínda que algúns poñan entre as illas do Océano aqueles dous promontorios xemelgos de Galicia e Lusitania, nun dos cales se ve aínda un templo de Hércules, no outro un monumento de Escipión, pero, como se estenden ata o extremo da terra de Galicia, pertencen á grande terra de Europa, máis ca ás illas do Océano].

24 Que o ciclo das andanzas e fundacións de Hércules é un elemento narrativo importante na concepción afonsina da historia peninsular vén destacado polo que nos deixa percibir o truncado ciclo de ilustracións dun dos manuscritos da redacción orixinaria da Estoria de Espanna, El Escorial ms. Y.I. 2 (Rodríguez Porto 2017). Nel pódese apreciar, así mesmo, unha ilustración de Hércules (f. 4r) que, a xuízo de Rodríguez Porto (2017: 243), «a sophisticated example of the rinascita dell'antico before the canonical Renaissance, is a case in point of this attitude towards ancient culture». 
a entender mellor o marco imaxinario no que esas se conciben, esta imaxe e o seu texto achegan unha información valiosísima. Este é un elemento de novo vinculado á convivencia co legado antigo na Península, algo xa perceptible na obra de Ximénez de Rada, pero tamén creo que a admiración e o crecente recoñecemento do seu pasado parecen especialmente evidentes conforme o rei vai coñecendo unha cidade como a Sevilla recentemente reconquistada. Pensamos moitas veces na fascinación que tivo que causar en tantos ollos a visión das construcións, monumentos e recordos dos moitos séculos de ocupación árabe nesa cidade, como no resto de Al-Andalus. Pero non debemos deixar de pensar no impacto que tivo que provocar coñecer tamén a presenza dos vestixios romanos que forzosamente tiveron que estar aínda presentes e vivos no territorio, moi en especial no urbano, e foron obxecto de constante reutilización mesmo para edificar palacios árabes (Rodríguez Porto 2017: 243). En definitiva, ao conquistar seu pai unha das grandes cidades de Al-Andalus, Afonso entra en contacto coa gran cidade da Bética, esa provincia que viu nacer a emperadores como Traxano, pero tamén a romanos distinguidos no cultivo das letras, nomeadamente a familia dos Anneos de Córdoba, un dos cales, Lucano, é profusamente utilizado na General Estoria. Cabería mesmo preguntarse se o relativo desleixo co que se trata a personalidade literaria de Isidoro de Sevilla, como antes vimos, podería deberse xustamente á toma de conciencia que Afonso $\mathrm{X}$ fai dos personaxes literarios romanos antigos, ao tempo que se redescobren as súas pegadas artísticas e visuais en Sevilla. Desde ese punto de vista, Isidoro válelle ao Rei Sabio como santo, pero non como figura literaria, eclipsado talvez polo recoñecemento de figuras que con certeza estaban representados en bustos e imaxes, e entre os cales tivo que figurar tamén Séneca, que, non o esquezamos, foi outro gran cultivador da imaxe de Hércules.

Pero é que, por outra banda, a ilustración que toma como motivo unha inscrición cuxo carácter é ademais profético revela un aspecto híbrido que a fai tan importante como, ao tempo, conmovedora. A miniatura imita os caracteres epigráficos e a disposición dunha inscrición romana, coa súa letra capital, cos seus puntos de separación, con todo o verismo, por así dicir, de quen quere reproducir algo que está á vista, pero está escrita en castelán. Curiosamente, tal como noutros casos Afonso $\mathrm{X}$ reproduce na súa obra poemas en latín, sen ir máis lonxe o que abre a Estoria de Espanna, nesta ocasión tanto o autor do texto como o seu fiel ilustrador traducen a suposta inscrición do latín que garantiría, coma quen di, un meirande realismo. Esta actitude lembra a que Roberto Weiss (1989: 168-194) evoca como propia dos primeiros humanistas italianos ${ }^{25}$, antes de que a epigrafía pase a ser considerada un obxecto de estudo en si mesma polo seu valor de fonte para a historia. Se a inscrición atribuída

25 O anónimo autor da Cronacha di Partenope pedíralle ao médico Niccolò di Deoprepio, procedente de Reggio Calabria, que lle traducise unha inscrición do grego ao latín posta no frontispicio do templo dos Dioscuros en Nápoles para inserila na súa obra. Isto sucede na primeira metade do século XIV. Segundo Weiss (1989: 32), «questa tradizione costituisce un punto di partenza: molto probabilmente infatti è la prima traduzione di un’epigrafe greca classica e per trovarne un’altra bisogna giungere al Quattrocento». 
a Hércules na Estoria de Espanna se traduce é porque non existe un distanciamento abondo con respecto a ela e o seu carácter de presunta pegada e testemuña, senón que se convive con ela dun xeito admirativo, pero natural, e así é tamén utilizada para apuntalar un relato en que Hércules se constitúe na peza lexitimadora dun dominio civilizador e precursor, profético e sempre vinculado á preexistencia, no mundo real, de monumentos romanos que son reinterpretados para dotalos de máis antigüidade e ao tempo dun enlace sinxelo co mesmo tempo dos romanos, como exemplifica a función de Xulio César en canto herdeiro das empresas hercúleas.

\section{EPÍLOGO}

A visión das «Antigüidades da Gallaecia» de Afonso X constata a progresiva desaparición do discurso derivado de Xustino arredor dos primeiros reis hispánicos, sobre o que prima o bosquexo un tanto parcial trazado por Ximénez de Rada, no que este lugar da Península ten certo papel aínda vinculado a Xerión, pero no que novos elementos, de probable procedencia arábiga, entran a configurar unha visión do pasado marcada pola existencia de monumentos, e entre eles o salientable faro da Coruña. Este, ao mesmo tempo, vaise unindo á figura de Hércules, de xeito aínda impreciso no Toledano, e claramente en Afonso X, sempre conservando por iso a relación con outro lugar da Península que xa chamara a atención dos xeógrafos antigos pola súa condición de extremo do mundo, Gades. O descubrimento por parte de Afonso X da Bética acentúa o desexo e a necesidade de dar explicación ao novo mundo que se abre ante el en forma de estatuas, inscricións e mais monumentos do rico pasado romano desta provincia. Con respecto a «Galizia», o faro ofrecerá enigmas que xa se atopan en textos anteriores cuxa pegada na obra de Afonso $\mathrm{X}$ dista de estar clara, pero que coinciden en atraer a atención cara a este monumento dos tempos pasados, así como en explicar talvez episodios históricos difíciles de situar pero que seguramente apelan a invasións marítimas, como dá a entender o capítulo dedicado aos «almuiuces». Afonso móvese, logo, entre o mundo das tradicións literarias e a experiencia dun universo novo e por descubrir, que virá na súa obra tamén da man doutras novas tradicións literarias, coa cantidade de textos que baixo a súa autoridade son procurados, lidos, traducidos e incorporados para enriquecer e acrecentar a súa portentosa obra historiográfica. A súa actitude, polo tanto, navega entre a prosecución de liñas literarias e documentais preexistentes, nomeadamente a de Ximénez de Rada, e o novo coñecemento de textos antigos, unha liña tamén marcada de xeito incipiente polo Toledano, que o Rei Sabio levará a un estado pioneiro na literatura europea, compartindo desde primeira hora e adiantándose, nalgún caso en medio século, a actitudes e a feitos que podemos percibir na Italia do primeiro humanismo. 


\section{REFERENCIAS BIBLIOGRÁFICAS}

- ANDERSOn, Benedict (1983): Imagined Communities: Reflections on the Origins and Spread of Nationalisms, London/New York, Verso.

- BEER, Rudolph (1894): Handschriftenschätze Spaniens, Wien, F. Tempsky.

- Benes, Carrie E. (2011): Urban Legends: Civic Identity and the Classical Past in Northern Italy (1250-1350), Pensilvania, Penn State University.

- BraCCesi, Lorenzo (1984): La leggenda di Antenore, da Troia a Padova, Padova, Signum Edizioni.

- CÁrdenas, Anthony J. (1997): «The Myth of Hercules in the Works of Alfonso X: Narration in the Estoria de España and in the General estoria», Bulletin of Hispanic Studies, 44, 5-20.

- Carlos Villamarín, Helena de (1995): «Mitos fundacionales de la Península Ibérica: entre la historiografía medieval y la del temprano humanismo», Euphrosyne, 23, 247-258.

- Carlos Villamarín, Helena de (1996): Las Antigüedades de Hispania, Spoleto, CISAM.

- CARlos Villamarín, Helena de (2008): «Interpreting the Past: Some Medieval Texts on Trojan Matter», The Journal of Medieval Latin, 18, 101-116.

- Carlos Villamarín, Helena de (2011): «El Códice de Roda como compilación de voluntad historiográfica», Edad Media. Revista de Historia, 12, 119-142.

- Carlos Villamarín, Helena de (2019): «Rodrigo Jiménez de Rada y la compilación historiográfica del códice de Bamberg Hist. 3», Traditio, 74, 249-270.

- Catalán, Diego (1962): De Alfonso X al conde de Barcelos. Cuatro estudios sobre el nacimiento de la historiografía romance en Castilla y Portugal, Madrid, Gredos.

- Catalán, Diego/Ma Soledad de Andrés (1975): Crónica del Moro Rasis, Madrid, Gredos.

- Chevallier, Raymond. (1976): «Les mythes ou le temps de la Protohistoire: l'exemple de l'Italie du Nord», en Aiôn. Le temps chez les Romains, Paris, Picard, 29-54.

- Díaz y Díaz, M. C. (1985): Visiones del más allá en Galicia en la Alta Edad Media, Santiago de Compostela, Bibliófilos Gallegos.

- DíAZ y Díaz, M. C. (1972-74): «Tres ciudades en el Códice de Roda: Babilonia, Nínive y Toledo», Archivo Español de Arqueología, 45-47, 125-130; 251-265.

- Еввотт, Mary (2003): Imagining Illegitimacy in Classical Greek Literature, Harvard University, Center for Hellenic Studies (http://nrs.harvard.edu/urn-3:hul.ebook:CHS_Ebbott.Imagining_Illegitimacy_in_Classical_Greek_Literature.2003) [última consulta: outubro de 2021]. 
- EISENBERG, Daniel (1973): «The General Estoria. Sources and Source Treatment», Zeitschrift für romanische Philologie, 89, 206-227.

- Estévez Sola, Juan Antonio (1990): «Aproximación a los orígenes míticos de España», Habis, 21, 139-152.

- Falque Rey, Emma (2014): «La translatio beati Isidori y el testimonio de Lucas de Tuy», Studium Legionense, 55, 149-180.

- FeRnándEZ ORDóÑEZ, Inés (1992): Las Estorias de Alfonso el Sabio, Madrid, Istmo.

- Fernández Valverde, Juan (ed.) (1979-80): «Roderici Ximenez de Rada Historia Romanorum», Habis, 10-11, 157-182.

- Fernández Valverde, Juan (ed.) (1987): Roderici Ximenez de Rada Historia de rebus Hispaniae sive Historia Gothica, Corpus Christianorum Continuatio Medievalis 72, Turnhout, Brepols.

- Gil FernándeZ, Juan (1971): «Textos olvidados del Códice de Roda», Habis, 2, 165-178.

- González García, Francisco Javier (1997): Hércules contra Gerión. Mitos y leyendas de la Torre de Hércules, vol. I, A Coruña, Vía Láctea Editorial.

- González García, Francisco Javier (1998): Hércules contra Gerión II. Mitos y leyendas de la Torre de Hércules, vol. II, A Coruña, Vía Láctea Editorial.

- GonZÁlez García, Francisco Javier (2012): «Las fuentes del relato de la invasión de los almujuces en la Estoria de Espanna de Alfonso X el Sabio», Mélanges de la Casa de Velázquez, 42:1, 185-203.

- GonzÁlez Muñoz, Fernando (ed.) (2000): La Chronica Gothorum Pseudoisidoriana (ms. Paris BN 6113). Edición crítica, traducción y estudio, Noia, Toxosoutos.

- GonZÁlez Rolán, Tomás (1981): «San Isidoro de Sevilla como fuente de Alfonso X el Sabio: un nuevo texto de las Etimologías (1. XIV) en la General Estoria (4a Parte)», Revista de Filología Española, 61-1/4, 225-234.

- ImPey, Olga Tudorica (1980): «Ovid, Alfonso X, and Juan Rodríguez del Padrón: two Castilian translations of the "Heroides" and the beginnings of Spanish sentimental prose», Bulletin of Hispanic Studies, 57, 4, 283-297.

- IMPEY, Olga Tudorica (1982): «En el crisol de la prosa literaria de Alfonso X: unas huellas de preocupación estilística en las versiones del relato de Dido», Bulletin Hispanique, 84, 5-23.

- JEREZ, Enrique (2003): «La Historia gothica del Toledano y la historiografía romance», Cahiers de linguistique et de civilisation hispaniques médiévales, 26, 223-239.

- Lida DE MalKIEL, María Rosa (1958): «La General Estoria. Notas literarias y filológicas 1», Romance Philology, 12, 2, 111-131. 
- LóPEZ SANTOS, Luis (1961): «Isidoro en la literatura medieval castellana», en Manuel C. Díaz y Díaz (ed.), Isidoriana, León, Centro de Estudios «San Isidoro» de León, 401-443.

- LoRENZo VÁzQuez, Ramón (1999): «A visión de Galicia na "Crónica Xeral Galega” e noutras "Crónicas" medievais», en Dieter Kremer (ed.), Actas do V Congreso Internacional de Estudios Galegos: Universidade de Tréveris 8-11 de outubro de 1997, vol. 2, Ediciós do Castro/Centro de Documentación de Galicia da Universidade de Trier, 575-606.

- MarTín, José Carlos (2005): «El corpus hagiográfico latino en torno a la figura de Isidoro de Sevilla en la Hispania tardoantigua y medieval (ss. VII-XIII)», Veleia, 22, 187-228.

- Menéndez Pidal, Ramón (ed.) (1906): Primera Crónica General, Estoria de España que mandó componer Alfonso el Sabio y se continuaba bajo Sancho IV en 1239, parte I: texto, Madrid, Bailly-Ballière e hijos editores.

- Millán GonZÁLEZ-PARDo, Isidoro (1971): «Nota adicional al trabajo del Profesor Juan Gil», Habis, 2, 179-182.

- Orellana, Raúl (2009): Alfonso X el Sabio General Estoria, Cuarta Parte, vol. 2, Madrid, Fundación José Antonio de Castro, en Pedro Sánchez-Prieto Borja (dir.), Alfonso X el Sabio, General Estoria, vol. 10, Madrid, Fundación José Antonio de Castro.

- Oroz Reta, José, Manuel. A. Marcos Casquero (1994): San Isidoro de Sevilla, Etimologías II, Madrid, BAC.

- Rico, Francisco (1984): Alfonso el Sabio y la General Estoria. Tres lecciones, Barcelona, Ariel.

- Rodríguez Porto, Rosa M. (2017): «The Pillars of Hercules: The Estoria de Espanna (Escorial, Y.I.2) as Universal Chronicle», en Michele Campopiano and Henry Bainton (eds.), Universal Chronicles in the High Middle Ages, York Medieval Press, 223-254.

- Rubio Álvarez, F. (1956): «Andanzas de Hércules por España, según la “General Estoria” de Alfonso el Sabio», Archivo Hispalense. Revista Histórica, Literaria y Artística, 24:75, 41-55.

- Salvo García, Irene (2012): Ovidio en la «General estoria» de Alfonso X. Tese de doutoramento. UAM.

- Sánchez-PRIETo Borja, Pedro (2009): Alfonso X el Sabio General Estoria, Primera parte, vol. 1, Madrid, Fundación Antonio de Castro.

- Sánchez-Prieto Borja, Pedro (2016): «Las maravillas del mundo en la General Estoria de Alfonso X», en Constance Carta/Sarah Finci/Dora Mancheva (eds.), Antes se agotan la mano y la pluma que su historia. Magis deficit manus et calamus 
quam eius hystoria. Homenaje a Carlos Alvar. Volumen I: Edad Media, San Millán de la Cogolla, Cilengua, 323-339.

- SeEL, Otto (1972): M. Iunianus Iustinus, Epitoma Historiarum Philippicarum Pompei Trogi, Leipzig, Teubner.

- Solalinde, Antonio G. (1934): «Fuentes de la General Estoria de Alfonso el Sabio», Revista de Filología Española, 19, 1-28.

- WeISS, Roberto (1989): La scoperta dell'Antichità classica nel Rinascimento, Padova, Editrice Antenore.

- WiKANDER, Stig (1966): «Los “Almuiuces” en la primera crónica general», Boletín de la Asociación Española de Orientalistas, 2, 109-116. 



\title{
Afonso o Sabio na lírica trobadoresca galego-portuguesa: da historia literaria á política cultural
}

\author{
Henrique Monteagudo \\ Instituto da Lingua Galega/Universidade de Santiago de Compostela
}

DOI: $10.17075 /$ gtax.2021.010 

Afonso o Sabio foi o promotor máis decisivo do emprego do castelán na documentación instrumental e do seu cultivo na prosa. A súa acción neste terreo foi da man do seu proxecto político de reforzo do poder da monarquía fronte á aristocracia e a igrexa1. Por outra banda, mostrou unha preferencia case exclusiva polo galego como lingua poética e foi un dos patrocinadores máis sobranceiros da lírica trobadoresca galego-portuguesa. Estas últimas facetas foron intensivamente estudadas nunha morea de traballos, parte dos cales serán citados ao longo da presenta achega, mais, aínda así, continúan sendo merecentes dunha reconsideración global desde o punto de vista da súa política cultural (Miranda 2012: 15-18). Desde a perspectiva inversa, o balance do papel do rei na evolución histórica da lírica galego-portuguesa raramente pasa dunha ben merecida - pero superficial- valorización encomiástica. Ao noso parecer, unha abordaxe que teña en conta o primeiro aspecto pode ser útil para equilibrar criticamente tal balance.

No presente contributo propómonos achegar elementos cara a este último obxectivo, coa plena consciencia de que para atinxilo cumpriría repensar unha serie de cuestións tanto do proxecto afonsino canto da historia daquel complexo fenómeno cultural. Entre estas, imos considerar, de xeito preliminar, as seguintes: a) a evolución do fenómeno trobadoresco durante o reinado de Afonso e por efecto das súas iniciativas nese terreo; b) a utilización da lírica trobadoresca ao servizo das políticas do rei; c) a significación, dentro do programa afonsino, das Cantigas de Santa María (CSM). Non pretendemos pechar ningunha destas cuestións, senón, ao contrario, abrilas ao debate, apoiándonos, loxicamente, nas valiosas propostas xa adiantadas neste sentido.

\section{O ASCENSO DA XOGRARÍA GALEGA NA CORTE DE AFONSO O SABIO}

Desde as súas orixes a finais do século XII, no noroeste da Península Ibérica existiu unha tradición de lírica trobadoresca autóctona que se expresou en

1 A bibliografía sobre este asunto é vastísima. Entre as mellores sínteses, pode verse Procter 2002: 13-18; Deyermond 1981: 154-173; Lapesa 1981: 237-247; Márquez Villanueva 1995 (especialmente, as pp. 35-42), e a panorámica de Fernández-Ordóñez 2013. 


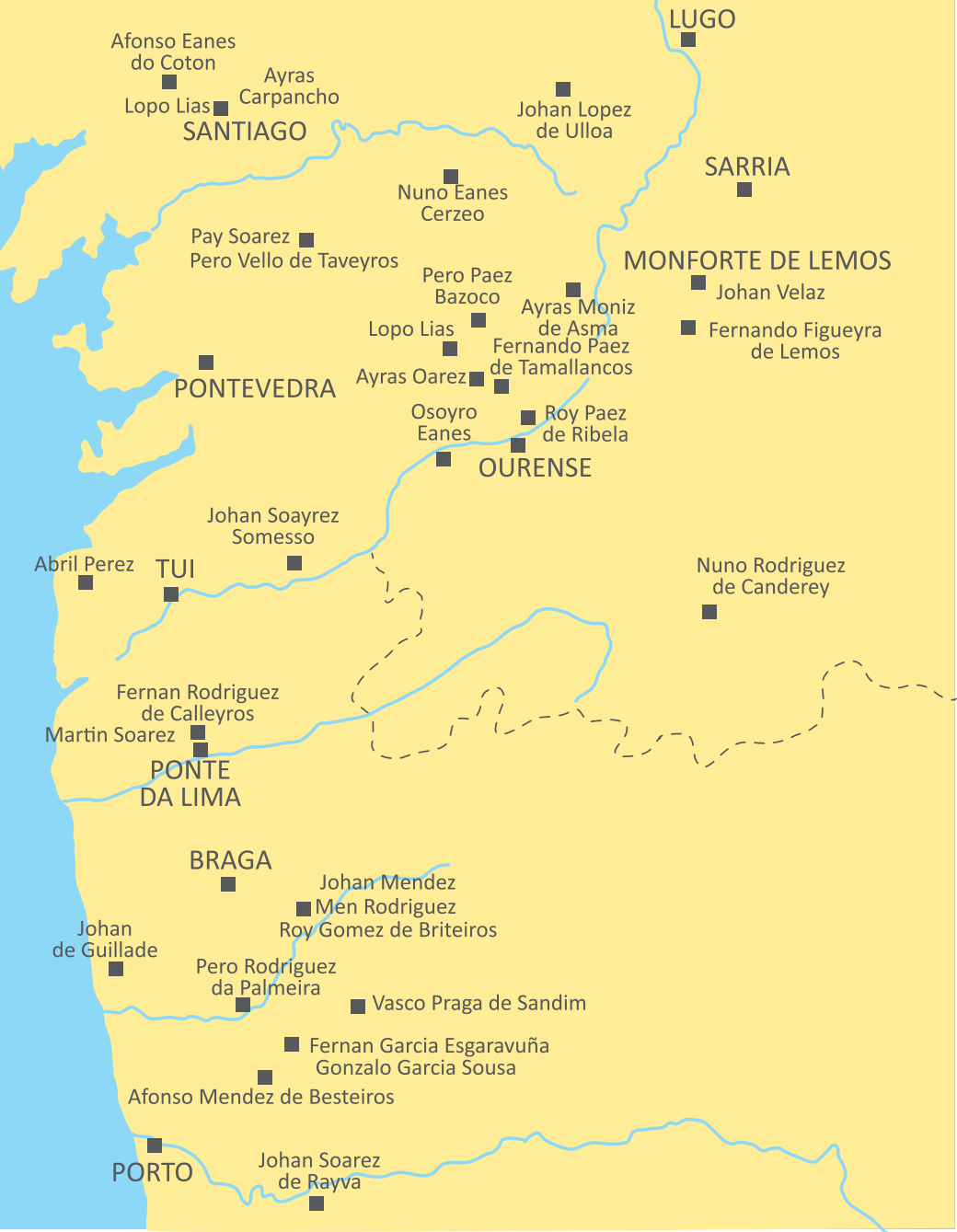

Mapa 1. Trobadores antigos. 
galego-portugués. Conforme o testemuño dos cancioneiros, as primeiras xeracións de trobadores, que floreceron entre 1175 ca. e 1225ca., estaban constituídas exclusivamente por nobres, entre os que se contan algúns magnates e unha maioría de cabaleiros de rango medio ou inferior, case todos orixinarios do occidente da Galecia (mapa n. $\left.{ }^{1}\right)^{2}$. A novidade foi acollida na corte de Afonso IX (derradeiro rei de León e Galicia, 1188-1230), o que parece que non aconteceu na corte real portuguesa. A segunda xeración trobadoresca, activa entre 1225 e 1240, estivo nutrida maiormente por «uma nobreza secundaria, de infanções e de simples cavaleiros», que producía os seus cantares «em regime de exclusividade» nos «paços de alguns magnates portugueses e galegos» (Oliveira/Miranda 1995: 500-501)². Deste xeito consolidábase

um processo de codificação literário-ideológica e um percurso de definição social e geográfica que irão, ao longo das décadas seguintes, identificar emblematicamente o galego-português e a poesia que nele se exprime com a proclamação por excelência da visão do mundo e da vivência aristocráticas não apenas portuguesa e galega, mas alastrando às terras vizinhas de Leão e Castela [...] onde a senhorialização territorial se afirmava mais forte e a curialização da nobreza se verificava menos eficaz do que no centro da península (Ferreira 2012: 6).

Fernando III, rei de Galicia e León desde 1230 (érao de Castela desde 1217) ata 1252, deparou unha acollida máis ben morna ao fenómeno trobadoresco na súa corte 4 . Pola contra, o seu primoxénito, o príncipe Afonso, xa na década de 1240, durante a súa etapa de infante, se arrodeou dun animado cortexo de trobadores, e durante o seu reinado (1252-1284) converteu a súa corte no centro máis importante do trobadorismo na península ibérica 5 . Segundo os cálculos de Oliveira, dos setenta e tres trobadores e xograres galego-portugueses que Tavani considera activos entre 1240 e 1280, polo menos corenta e seis pasaron por ela ${ }^{6}$. Entrementres, o seu xenro

2 Michaëlis 1990: II, 615-628; Tavani 1986: 249-255; Miranda 2004: 59-69, Oliveira 1995: 64-68 e Monteagudo 2008: 313-415 e 2014: 13-29, 36-40, 54-66 y 118-124. Oliveira/Miranda 1998, Miranda 2004: 13-57 e Oliveira 2001: 65-95 postulan que a primeira xeración floreceu nas cortes aristocráticas do centro-norte da Península, hipótese refutada directamente por Souto 2011a e 2012a e indirectamente por Monteagudo 2008: 341-359.

3 Oliveira 1995: 68-75 e 2001: 97-110.

4 Menéndez Pidal 1924: 186 e 191; Beltrán 2005: 39. Ambos os dous se refiren á lírica occitana, pero pretenden que este rei tivo interese na lírica galego-portuguesa. Secomasí, as páxinas que Menéndez Pidal dedica a esta (1924: 191-212), salvo no referente a Pero da Ponte, non mostran nada da súa suposta relación coa corte de Fernando III. Canto ao libro de Beltrán, o enteiro capítulo sobre «La corte de Fernando III» ten moi pouco que ver co tema enunciado. Pola súa banda, Alvar chega a suxerir que Fernando III é culpable do que denomina «fracaso lírico de Castilla» (1984: 6-7).

5 Sobre a corte de Afonso infante, véxase Alvar 1985 e, sobre todo, Oliveira 2010a e 2010b. Sobre a corte de Afonso como rei, véxase Alvar 1984; Beltrán 2005: 94-301; Oliveira 2010c e 2015.

6 Tavani 1986: 262; Oliveira 2010c: 69-72. 
Ferrol

- Fernando Esquio

Burgo do Faro

Pero Garcia d’Ambroa

Vasco Praga de Sandim

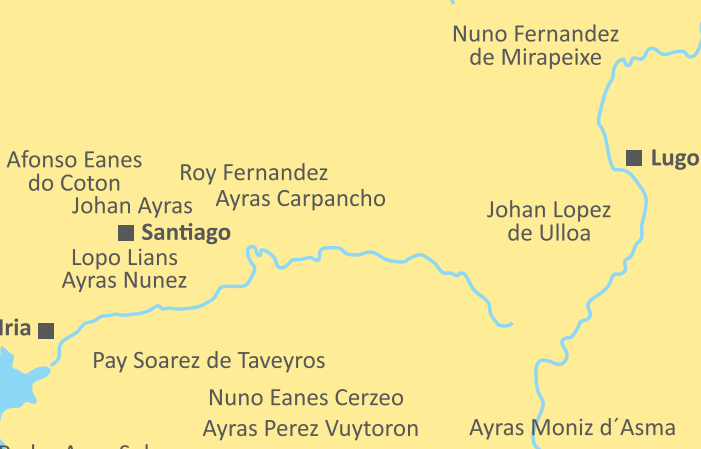

Pedro Anes Solaz

Pero Paez Bazaco

Fernando Figueyra de Lemos

Payo Gomez Chariño

- Monforte

Pontevedra Fernan Paez de Tamallancos

Roy Paez de Ribela Pero Vivyaez

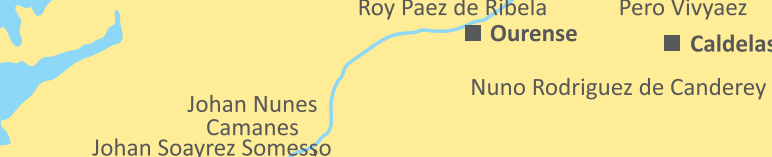

Johan Soayrez Somesso

[Gonçalo Tui Golparro Mendez d'Eixo]

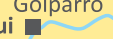

\section{Estevan}

Perez Froian

Ponte

Fernan Rodriguez de Calleyros

Johan Perez d'Aboim

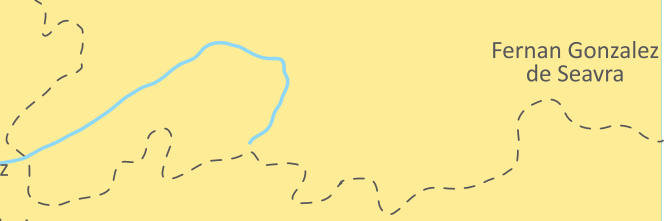

Fernan Fernandez Cogominho
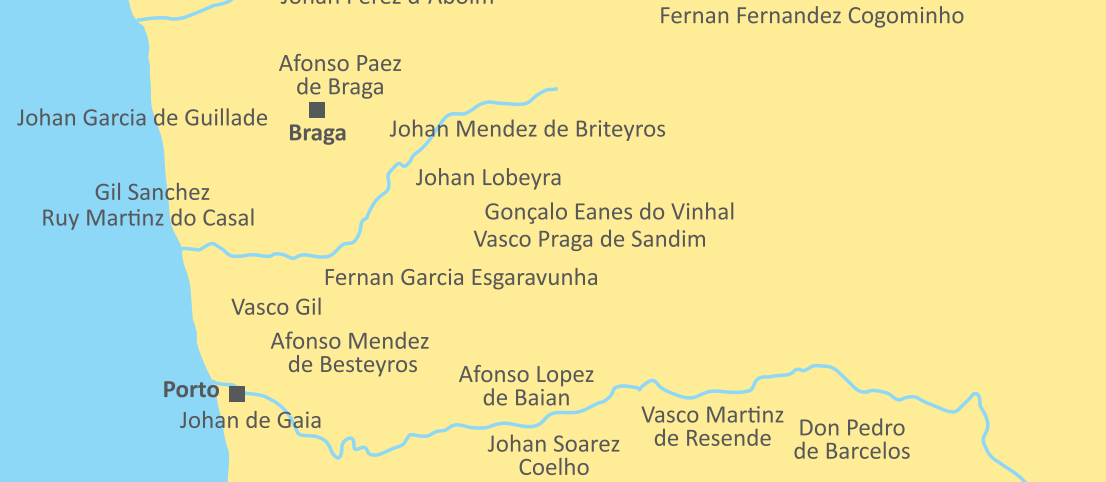

Mapa 2. Trobadores do noroeste. 
Afonso III o Bolonhês, rei de Portugal no período coetáneo (1248-1279), tamén ofreceu unha acollida cálida, aínda que menos efusiva, aos trobadores. Deste xeito, desde a metade do século XIII a lírica galego-portuguesa tendeu a orbitar á volta das cortes rexias, e non tanto arredor das cortes da media e pequena nobreza galaica e do noroeste peninsular en sentido largo ${ }^{7}$. De todos os xeitos, os seus cultivadores continuaron sendo na súa inmensa maioría orixinarios das terras da vella Galecia ata as últimas xeracións, activas na primeira metade do século XIV, cando a achega galega estiña ao paso que medra a do Portugal ao sur do Douro (mapa no 2 ).

A corte trobadoresca do Sabio foi máis nutrida, diversa e animada ca a do Bolonhês. En Portugal a tendencia centralizadora do padroado rexio traduciuse nun maior peso da aristocracia, nomeadamente da nobreza de corte. Alí salientaron trobadores como Afonso Lopez de Bayan, Johan Soarez Coello, Vasco Gil de Soverosa, Men Rodriguez de Briteyros ou Johan Perez de Avoyn (Oliveira 2009). Como consecuencia da acentuación do seu carácter aristocrático, en Portugal a lírica trobadoresca seguiu aferrada á cantiga de amor, calcada dos moldes occitanos. Unha das escasas novidades introducidas foi o cultivo da pastorela, un tipo de composición extremadamente convencional, de sabor distintivamente aristocrático, importado do norte de Francia (Gonçalves 2016: 441-453).

Na corte de Afonso o Sabio o panorama era máis heteroxéneo, pois, ademais da implicación do propio monarca, da participación de varios trobadores occitanos e dun importante séquito de cabaleiros galegos e portugueses, destacou a febril actividade dunha xograría maioritariamente galega e con forte presenza compostelá (mapa n.ㅇ 3) ${ }^{8}$. Desde a década de 1240, primeiro en territorio galego e despois na corte de Afonso o Sabio, a base social da lírica trobadoresca sufriu unha profunda transformación, ao entraren en xogo creadores cun perfil social ben diferente ao dos primeiros trobadores. Isto non deixou de ter efectos sobre a propia materia creativa. Da man da puxanza da xograría, en Galicia e na corte de Afonso, a canción de amor cedeu en importancia en relación tanto ao cantar satírico canto á cantiga de amigo, esta última vinculada a unha inveterada tradición literaria indíxena.

A puxanza da xograría galega prodúcese antes no propio territorio galego e aquí atinxe a súa expresión máis vistosa. Investigacións recentes están poñendo de vulto a capital achega do burgo de Compostela. Neste sentido, non pode deixar de chamar a atención a abraiante diversidade social do trobadorismo compostelán. Vencellados con Santiago, pola orixe ou a residencia, estiveron trobadores cabaleiros como Osoyro Eanes, Ayras Carpancho, Lopo Lias ou Afonso Eanes do Coton, clérigos como Ayras Nunez, Roy Fernandez, Martin Moxa, Sancho Sanchez ou Pae da Cana, segreis como Pero da Ponte e Bernal de Bonaval, xograres como Juyão Bolseyro

7 Oliveira 1985: 75-79; Ferreira 2012: 6.

8 Tavani 1986: 256-264; Oliveira 1989: 9, 29 e 32; Oliveira 1995: 75-79 e Oliveira 2010c: 68-72. Sobre un total de sesenta autores de naturalidade galega, este autor calcula que vinte e nove son xograres, vinte e sete trobadores e catro clérigos. Véxase tamén Oliveira 1995: 76-77 e Oliveira 2001: 178. 
Pedro Amigo de Sevilla

Pero d'Ambroa

Pero de Armea

Pero da Ponte Johan Ayras

Juyao Bolseyro

Bernal de Bonaval

Johan Romeu

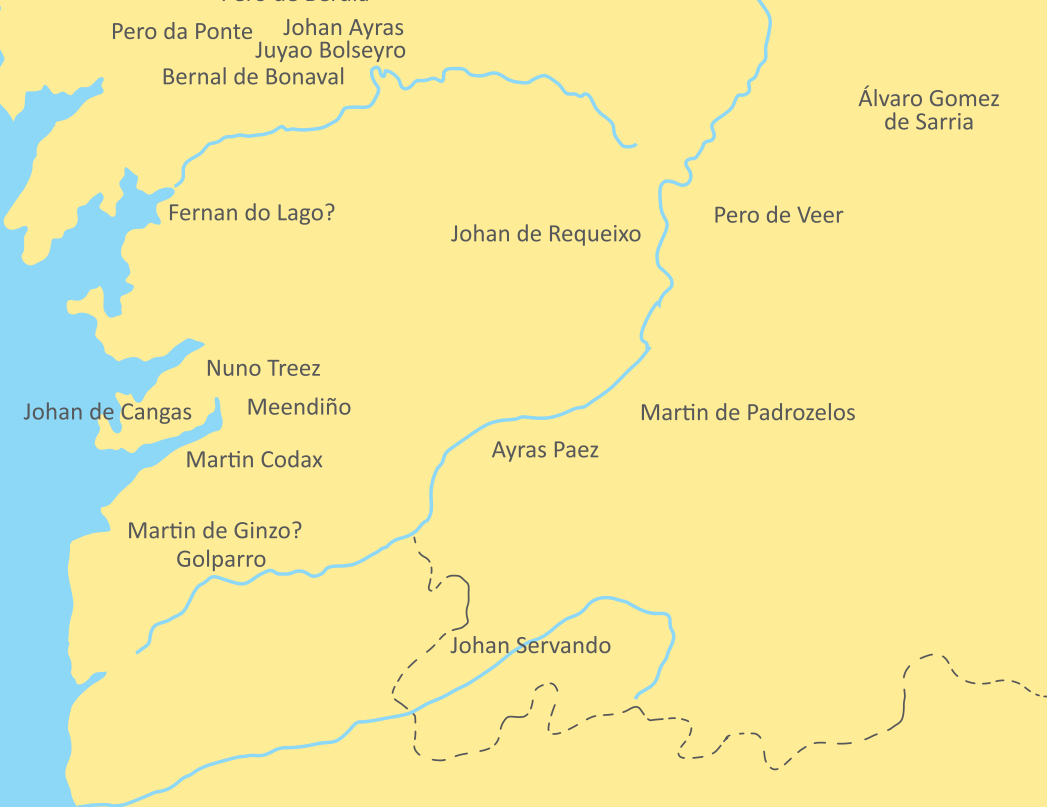

Mapa 3. Xograres galegos.

e Pero de Berdia e burgueses como Johan Ayras9. A devandita serie cobre todo o século XIII, desde os inicios ata o final: aos tres primeiros, os máis antigos, non se lles coñece contacto coas cortes reais (excepto talvez a Osoyro Eanes coa corte de Afonso de Galicia e León), pero boa parte dos demais pasaron pola corte do Sabio, algúns estiveron tamén na do seu fillo Sancho IV e o último incluso visitou a de don Denis. En todo

9 Lorenzo 1993, Vieira 1999, Souto/Vieira 2003, Souto 2011b e 2012b, Vieira, Morán e Souto 2012. Johan Ayras é o autor con máis composicións nos cancioneiros, despois de don Denis, con oitenta e unha cantigas. É extraordinario que un trobador identificado nos cancioneiros como «burgués de Santiago» chegase a producir e a reunir unha obra tan avultada. Sobre a directa conexión de Pae ou Pay da Cana con Afonso o Sabio, véxase o artigo de Francisco Hernández neste mesmo volume. 
caso, tal continuidade histórica e tal diversidade socio-cultural non se documenta en ningún outro centro do trobadorismo galego-portugués.

Á relación dos autores composteláns cómpre engadir dunha banda outros xograres galegos que destacaron na corte de Afonso e doutra, o tropel dos que probablemente exerceron fóra desta, dos cales a penas sabemos nada. No primeiro grupo salienta o trío procedente do arco ártabro, Pero de Anbrõa, Pero de Armea e Pedro Amigo de Sevilla, talvez os últimos representantes do círculo congregado ao redor da corte dos Traba, cuxo derradeiro gromo foi Rodrigo Gomez de Trastámara (morto en 1261), ben que o primeiro parece que estivo vencellado a outro nobre galego de grande relevo, Munio Fernandez de Rodeiro ${ }^{10}$. Por suposto, houbo máis xograres na corte de Afonso, como Johan Baveca ou Lourenço, de cuxa naturalidade galega non temos unha certeza absoluta.

O segundo grupo está constituído pola riola dos xograres cultivadores da cantiga da amigo paralelística, grupo a un tempo escuro pola humilde orixe social e a conseguinte falta de relevo histórico dos seus compoñentes, e brillante polo superior talento poético dalgúns dos seus nomes, como Martin Codax ou Meendiño. Se na corte de Afonso a preferencia pola cantiga satírica se converteu na principal novidade literaria, sen dúbida a innovación máis valiosa traída polos xograres veu da man da cantiga de amigo paralelística, soberbiamente cultivada polos xograres galegos que exerceron no ámbito local e que semella que non foi especialmente apreciada polo Rei Sabio.

De todos os xeitos, a promoción dos humildes xograres, de simples executantes das composicións elaboradas polos trobadores de rango aristocrático, a creadores das súas propias cancións, supuxo unha novidade revolucionaria, e Afonso o Sabio xogou nela un papel fundamental. Tratábase dun salto cualitativo no status socio-literario da xograría. Desde o inicio do cultivo da lírica trobadoresca víñase observando unha distinción estrita entre dúas categorías socio-culturais rixidamente xerarquizadas: trobadores e xograres. En principio, como observou Carolina Michaëlis, «segundo a theoria sustentada pela classe privilexiada, trobador era quem cultivava a poesía e a música, creando ou inventando obras novas, como dilettante, i. e., com inteira independencia; por gosto, sem ideia alguma de lucro». O trobador era un cabaleiro; pola contra, o xograr era un individuo da clase servil, cuxo «officio consistia em

10 Aínda está vivo o debate sobre a identidade de Pero Garcia de Anbrõa e Pedro de Anbrõa, ao primeiro dos cales, aparentemente un trobador que podería estar documentado antes de 1240, se atribúe nos cancioneiros unha cantiga de amor, mentres que o segundo, con toda seguranza un xograr ou segrel que estivo activo entre 1240 e 126 aproximadamente, aparece como autor de unha cantiga de amigo, unha tenzón e once cantigas satíricas (máis tres perdidas). Sobre isto véxase Souto 2006 e Ventura 2014. Sobre Pedro Amigo de Sevilla, véxase Beltrán 1993. Sobre Pero de Armea, Couceiro 1993. En todo caso, non nos cabe dúbida de que existiu un xograr ou segrel Pero de Anbrõa activo na corte de Afonso, e tamén parece claro que estes autores estiveron relacionados entre si. Sobre Munio Fernandez de Rodeiro e Rodrigo Gomez de Trastámara nos tempos de Afonso o Sabio, véxase o artigo de Francisco Hernández neste mesmo volume. 
tanger varios instrumentos de música e em cantar versos alheios» (Michaëlis 1990: II, 628-629).

A novidade quizais veu facilitada pola aparición previa dunha categoría intermedia, a de segrel. O debate sobre o significado deste termo no ambiente peninsular vén de lonxe, e bascula entre quen o entende como designación dunha categoría específica, híbrida, que se oporía tanto ao xograr - porque o segrel pertencía á nobreza ínfima e tiña competencia para trobar-coma a do trobador - porque recibía don pola súa actuación -, e quen o interpreta como a designación adoptada para os xograres aos que se recoñecía competencia para trobar ${ }^{11}$. Nos textos trobadorescos o termo aparece en poucas ocasións, case sempre empregado como sinónimo de xograr executante, non compositor (B 144, V 1021, B 1514, B 1515). Non obstante, tamén aparece aplicado a catro compositores: Pero da Ponte, Bernal de Bonaval, Pero de Anbrõa e Picandon. Curiosamente, os dous primeiros eran composteláns, o terceiro tamén era galego e o cuarto era un xograr ao servizo do trobador italiano Sordello.

Pero da Ponte, nunha tenzón co cabaleiro Afonso Eanes do Coton ${ }^{12}$, compostelán coma el (retéñase o dato), reivindícase como segrel e dá unha definición moi precisa do termo, que apuntala a primeira das dúas devanditas interpretacións, ben que restrinxe ese uso á «nossa terra» (Santiago? Galicia?): «en nossa terra, se Deus me perdon / a tod'o 'scudeiro que pede don / as mais das gentes lhe chaman segrel» [Anexo n.․ 16]. Ademais, Bernal de Bonaval é alcumado como segrel nunha tenzón que mantén con Abril Perez (B 1072, V 663) e nun maldizer que lle dirixe Ayras Perez Vuitoron (B 1475, V 1086); en ambas, o termo é empregado cunha clara connotación pexorativa. Tendo en conta a naturalidade dos poetas que acabamos de citar, se cadra o que aconteceu é que o termo adquiriu unha acepción particular no contexto galego.

En todo caso, unha proba de que estes segreis foron finalmente recoñecidos como trobadores de pleno dereito está na rúbrica que precede o cancioneiro dos xograres galegos incorporado á Compilación xeral da lírica trobadoresca, en que Bernal de Bonaval é cualificado como «primeyro trobador», o que implica que a designación de trobador non só se aplica a el, senón á totalidade dos autores incluídos neses cancioneiro (B 1062, V 653) ${ }^{13}$. Isto quer dicir que a denominación trobador xa non se refería á clase social, senón á competencia recoñecida na arte de trobar.

Este cambio non foi doadamente aceptado polos cabaleiros, que defendían o trobar como patrimonio exclusivo do seu estamento (Pidal 1924: 237-243). Non por casualidade, entre os temas preferidos das numerosas composicións satíricas do terceiro cuartel do século XIII salientan os ataques dos trobadores nobres con-

11 Resume a cuestión Oliveira 1993b, enviando a bibliografía máis relevante. Recentemente, retómaa Falcão 2019.

12 A tenzón era unha cantiga dialogada, tipicamente burlesca, composta por dous trobadores que compiten entre si en mordacidade e enxeño.

13 Sobre a xograría galega e o presunto Cancioneiro dos xograres galegos, véxase Oliveira 1987, 1989, 1994: 262-265 e 1998. 
tra os xograres. Aínda que o vituperio destes por parte aqueles é un tema recorrente na sátira trobadoresca, debe notarse que antes da puxanza da xograría o albo principal das invectivas eran as súas deficiencias como executantes. Por exemplo, o cabaleiro Martin Soarez búrlase do xograr Lopo nos termos seguintes: «Foy un dia Lopo jograr / a cas d'un infançon cantar; / e mandou-lh' ele por don dar / tres couces na garganta;/ e fuy-lh’ escass', a meu cuydar, /segundo com’el canta» (B1366 / V974). Durante o turbulento período de ascenso da xograría, os dardos apuntan tamén ás pretensións xograrescas de seren recoñecidos como trobadores. É ilustrativo o ataque do magnate Johan Perez de Avoyn contra o xograr Lourenço, un dos representantes máis significados da «nova» xograría (Falcão 2015): «Lourenço, soyas tu guarecer / como podias, per teu citolon, / ou ben ou mal, non ti digu' eu de non, / e vejo-te de trobar trameter;/ e quero-t’ eu desto desenganar: / ben tanto sabes tu que é trobar / ben quanto sab’ o asno de leer» (V1010).

O propio Afonso se burlou das pretensións dos segreis composteláns, personificadas en Pero da Ponte, en dúas célebres composicións: nunha acusouno de emborrachar a Afonso do Coton para asasinalo e roubarlle os seus cantares (B 485, V 68), noutra afeoulle: «vós non trobades come proençal, / mais come Bernaldo de Bonaval» (B 487, V 70) [véxase anexo n.o 14 e 15]. A crítica tense preguntado se o monarca non estará aquí singularizando un estilo de trobar especificamente compostelán, heterodoxo en relación cos modelos occitanos (Paredes 2010: 220-225 e 232-237).

Sexa como for, Afonso o Sabio acabou consagrando o recoñecemento dos xograres como trobadores mediante nun «decreto» poético, a Declaratio, promulgado en 1275 en resposta a unha Suplicatio do trobador occitano Guiraut Riquier. O rei sentencia que trobadores «son os que co corazón / saben tecer boas cobras / e facer danzas dobras, / fermosos sirventeses, / albas e tenzóns, / e compor letras e sons» ${ }^{14}$. Por parte, é probable que tamén favorecese a incorporación dos xograres aos cancioneiros, compilacións que inicialmente estaban reservadas aos cabaleiros. O primeiro paso nese sentido puido ser o acrecento do Cancioneiro da Ajuda, co engadido ao final de ciclos poéticos de autores coma Pero da Ponte, Roy Fernandez ou Martin Moxa $^{15}$. En definitiva, semella claro que a promoción da xograría resultaba congruente coa política decididamente anti-aristocrática do Rei Sabio. A súa utilización intensiva da lírica como arma de propaganda política apunta claramente no mesmo sentido, como veremos a seguir.

14 «so son aquel que.l cors / sabon de faire coblas / e de far dansas doblas / e sirventes valens / albas e partimens / e trobar motz e sos». A Suplicatio de Guiraut Riquier está editada por Alvar 1978: 133-156, a Declaratio de Afonso atópase na mesma obra, 178-189. A cita é das páxinas 188-189. Para a interpretación do decreto de Afonso, véxase Oliveira 1995: 36-41. Véxase tamén a tradución de Rodríguez Velasco 1999: 293-300.

15 O seu neto, o rei don Denis de Portugal, daría un paso máis nesa liña, decisivo, ao inserir un Cancioneiro de xograres galegos, individual e específico, no Cancioneiro xeral da lírica trobadoresca (Monteagudo 2019: 927-951). 


\section{AFONSO O SABIO E A LÍRICA TROBADORESCA: POESÍA E PROPAGANDA POLÍTICA}

Afonso foi el mesmo un trobador extraordinario, que compuxo corenta e catro cancións profanas ${ }^{16}$. Case todas elas teñen carácter satírico, coa nobreza e o clero como dianas das censuras máis furibundas, desde os cabaleiros desleais ata os coteifes covardes, e, por outra banda, desde o Papa ata o pornógrafo deán de Cádiz (Alvar 1984 e 1998). Unha preferencia tan marcada do rei pola cantiga satírica merece unha explicación: dunha banda pode responder a unha abordaxe predominantemente lúdica e política do seu cultivo; doutra, pode reflectir unha certa incomodidade ante a cantiga de amor, que tería adquirido carácter emblemático como expresión dos valores da aristocracia, constituíndo así unha especie de «bastião inexpugnável de uma cultura e de uma ordem que representavam um permanente desafio às instâncias de afirmação régia» (Ferreira 2012: 6).

Sexa como for, a vertente do uso político da lírica trobadoresca non só aparece na obra de Afonso, senón que foi cultivada por varios trobadores da súa corte, naturalmente, sempre ao seu favor. A corte lírica afonsina caracterízase por unha marcada predilección pola sátira, para a cal incluso se adaptou un novo tipo de cantiga, a tenzón. Aínda que abundan os estudos sobre episodios particulares e sobre composicións concretas, na nosa opinión falta unha visión xeral da faceta política da sátira trobadoresca ${ }^{17}$. Limitarémonos a esbozar algúns apuntamentos, enfocados cara aos litixios de Afonso cos dous poderes que combateu con máis teimosía: a igrexa, e, sobre todo, a nobreza.

O Rei Sabio tiña que ser bo coñecedor da vertente propagandística da lírica trobadoresca, amplamente explotada na lírica occitana. Carlos Alvar dá noticia de quince trobadores occitanos — sete dos cales visitaron a súa corte- que aludiron ao Sabio por un outro motivo nun total de sesenta composicións ${ }^{18}$. O mesmo estudoso propugna que, pola contra, os trobadores galego-portugueses ignoraron case totalmente os asuntos políticos ou se limitaron a tratalos de modo anecdótico (Alvar 1984: 19-20) ${ }^{19}$. A contrafío desta afirmación, o emprego da lírica como arma de propagan-

16 O inventario exacto do repertorio lírico profano de Afonso presenta algunhas dúbidas, xa que o número de tençons pode variar entre tres ou cinco, dependendo de se se identifica con el o interlocutor designado como «senhor» en cadansúa tençon con Pay Gomez Chariño (B1624/V1158) e Pero Garcia Burgales (B1383/V991). Véxase Alvar 1998: 17, e Oliveira 2013: 260-264. A transmisión deste repertorio foi azarosa, pois as súas composicións chegaron ás mans do seu bisneto, o conde Pedro de Barcelos, moito despois da súa morte, no segundo cuartel do século XIV, e en condicións bastante precarias. Foi don Pedro quen as integrou no Cancioneiro xeral da lírica.

17 Véxase Michaëlis 2004: 175-217; Tavani 1993; Lanciani/Tavani 1995: 105-118; Beltrán 2005: 123-232 e 2007: 13-52.

18 Como é de esperar, o asunto máis tratado nestas é a súa reclamación da coroa imperial. Véxase Alvar 1984 e 1977: 181-258, especialmente 257-258.

19 Este parecer aparece reiterado en Alvar 1998: 4-6. Concorda con el Lopes 1998: 263; Tavani 1993 é máis matizado. 
da política contaba con notables precedentes da tradición galego-portuguesa. Sen ir máis lonxe, o cantar que se considera máis antigo dos transmitidos polos cancioneiros é un sirventés político ${ }^{20}$. Esta vertente da lírica galego-portuguesa tivo que serlle familiar a Afonso ao menos desde os tempos da súa participación na guerra civil portuguesa. Este conflito estoupou co gallo da deposición de Sancho II e a designación do seu irmán Afonso, conde de Boulogne, como «protector do reino», decidida en 1245 polo Papa Inocencio IV a pedimento do episcopado portugués, coa complicidade de boa parte da nobreza. Destronado Sancho, o conde de Boulogne asumiría a coroa en 1248 -é o Afonso III O Bolonhês a que nos referimos atrás.

O noso Afonso, aínda infante, acudiu en apoio de Sancho II movido polo rexeitamento á inxerencia do Papado nun asunto político interno dun reino cristián (González Jiménez 1993: 22-24 e Mattoso 1987: 80-84). Recrutou un exército e penetrou en Portugal, pero finalmente tivo que se limitar a rescatar a Sancho para traelo ao exilio acompañado dun cortexo de nobres leais, moitos dos cales se converteron nos seus vasalos. Como consecuencia deste episodio varios dos trobadores portugueses desterrados instaláronse na corte afonsina e algúns deles convertéronse nos máis asiduos cultivadores da sátira política, como decontado veremos (Oliveira 2001: 113-122). Entre os nobres que acompañaron o infante na incursión en Portugal atopábanse trobadores galegos como Ayras Perez Vuytoron e xograres como Diego Pezello. Os cancioneiros recollen tres cantares ferozmente críticos con respecto á actuación do Bolonhês e os seus partidarios [Anexo n.ํ1, 2]. Nestas sátiras predominan dous temas que serán moi importantes no discurso satírico do noso Afonso: a deslealdade e a traizón ${ }^{21}$.

Ao longo das décadas seguintes non faltaron ocasións para que trobadores do seu séquito interviñesen a favor do soberano con motivo das súas desavinzas cos nobres. En total, non son menos de trinta as cantigas trobadorescas compostas na corte do Sabio que tocan directamente asuntos políticos, e máis dun terzo, concretamente once, foron compostas polo propio monarca ${ }^{22}$. Na súa maioría, trátase de cantigas de maldizer, o que significa que nelas a crítica é expresada de forma diáfana, mais entre elas hai tamén algunhas cantigas de escarnio ${ }^{23}$.

20 Trátase dunha cantiga composta polo trobador portugués Johan Soarez de Paiva con ocasión dun conflito na fronteira entre Navarra e Aragón, ocorrido por volta de 1196 (B 1330bis, V 937). Véxase Michaëlis 2004: 299-313 e López Aydillo 2008: 37-43.

21 O más brillante, sen dúbida, é a sátira de Ayras Perez Vuytoron (B 1477/V 1088). Véxase Michaëlis 1924, e Oliveira 1993a. Anos máis tarde, despois de vivir en carne propia rebelións contra el mesmo alentadas pola igrexa, Afonso lembrará a Sancho II nunha das composicións autobiográficas incluídas nas CSM: «nunca assi foi vendudo Rey don Sanch'en Portugal» (cantiga n.o 235, versos 57-58).

22 Alvar 1977: 181-258, especialmente 257-258.

23 A poética trobadoresca distinguía dous subxéneros de canción satírica: o escarnio e o maldizer. Nas cantigas de maldizer a crítica é expresada de forma ostensiva, directa e brutal. Ao contrario, a cantiga de escarnio disfraza o seu verdadeiro sentido mediante a aequivocatio, isto é, a ironía, a ambigüidade e o dobre sentido. As cantigas de escarnio cifran a súa mensaxe en chaves escuras, que esixen unha esexese especialmente enxeñosa (Liu 2004: 1-16). Afonso cultivou máis o maldizer ca o escarnio, mais outros trobadores da súa corte foron mestres requintados da aequivocatio, que adoito sementa de dúbidas calquera tentativa de interpretación (Lopes 1998: 103-117, 149-178; Alvar 1998: 7-8; Marcenaro 2010). 
O enfrontamento de Afonso co seu irmán Enrique, que se prolongou desde 1248 a 1258, deu azo para a composición dunha cantiga do propio rei (B 464) e dúas do portugués Gonçalo Eanes do Viñal que propalan a loia dos amores do príncipe coa súa madrasta, a raíña viúva Juana de Ponthieu [Anexo n.․ㅜ 12] ${ }^{24}$. Os enfrontamentos bélicos cos musulmáns na fronteira sur co gallo da revolta mudéxar (1263-1266), da incursión dos benimeríns (1275-1277) ou da campaña de represalia contra Granada (1280-81) motivaron a composición dunha serie de cantares de guerra en que Afonso fustriga da covardía dos coteifes que foxen ao primeiro embate e a deslealdade dos magnates que non acoden na súa axuda [Anexo n. 3, 4, 5, 6]. Os conflitos de Afonso coa Santa Sé, ben por culpa da frustración das súas aspiracións imperiais ou da lea que estalou ao redor da designación de arcebispo de Santiago (1266), están detrás da súa sátira contra o Papa [Anexo no 10]. Pola contra, o feito do imperio é obxecto dunha tenzón encomiástica entre Johan Vasquez de Talaveyra e Pedro Amigo de Sevilla [Anexo n. $\underline{0}$ 20].

A década dos setenta foi catastrófica para o monarca: revolta nobiliaria (1272), fin das aspiracións imperiais, invasión marinida, morte do infante Fernando de la Cerda (1275), preito sucesorio co futuro Sancho IV, execución do seu irmán Fadrique (1277)... Tres trobadores portugueses do seu cortexo dirixen as súas invectivas contra os magnates (ricos-homes) que se conxuraran contra o rei: Afonso Mendez de Besteyros [Anexo n.․ㅜ 10], Gil Perez Conde [Anexo n.ํㅗㅇ e Pero Gomez Barroso [Anexo n. 9$]^{25}$. A morte do infante don Manuel (1283), irmán menor do monarca e «príncipe dos traidores» que orquestraron a súa deposición en 1282 (Ballesteros 1984: 967), deu motivo para unha corrosiva sátira de Pero da Ponte [Anexo n.ํㅜ 13] ${ }^{26}$. A desolación da súa corte despois desta sucesión de desastres está expresivamente cantada nun texto de Gil Perez Conde [Anexo n.․ㅜ 18].

Este cantar suxire o ambiente depresivo en que un Afonso desenganado de vez puido compoñer os desconcertantes versos da inclasificable cantiga «Non me posso pagar tanto» [Anexo n.․19], en que vibra «com tons quase románticos o estado de espírito amargo de um protagonista decidido a abandonar o estado social privilexiado» (Bertolucci 1993: 39). Este «canto de desacougo» (Tavani 1986: 280), un dos máis célebres dos cancioneiros galego-portugueses, ten sido obxecto de interpretacións moi diversas, desde quen o le en termos autobiográficos ata quen, no extremo contrario, o considera un puro artificio, incluíndo quen pretende descifralo en chave onírica $^{27}$. Ao noso parecer, na cantiga o monarca expresa realmente os seus sentimen-

24 B1390/V999, V1008. Víñez 2004: 188-192 e 265-273; Lapa 1970: 64; Oliveira 2014: 14-15. Discútese o tema e a datación doutra cantiga de Afonso que podería estar relacionada co asunto: Lapa 1970: 65-67; Paredes 2010: 120-129; Mattoso 1985: 425-426; e Oliveira 2001: 118-119.

25 Véxase Beltrán 2007: 13-52. Este estudoso engade, ademais, unha composición de Pero da Ponte, «Mentre m’agora d'al non digo nada» (B1644, V 1178).

26 Lapa 1970: 549. A rúbrica da cantiga aclara:«Esta cantiga fez Pero da Ponte ao infante don Manuel».

27 Véxase Michaëlis 2004: 165-174; Lapa 1970: 13-16; Lanciani/Tavani 1995: 145-148; Lopes 1998: 170-173; Paredes 2001: 187-195, con remisión á bibliografía relevante; e Doubleday 2015: 178-179. 
tos, o cal resulta congruente co feito de que todos os seus outros cantares políticos teñen un contido manifestamente autobiográfico. Faino construíndo un artefacto literario preciosamente sofisticado, pero isto non lle resta sinceridade nin orixinalidade ao poema.

Do dito ata aquí pódense tirar tres conclusións. A sátira política é un dos motivos máis relevantes da produción trobadoresca de Afonso o Sabio e de varios trobadores da súa corte. Esta sátira é especialmente virulenta cando ataca os principais inimigos da política de reforzamento do poder real impulsada por Afonso con todo empeño. Está claro, pois, que o Rei Sabio non desdeñou colocar a lírica trobadoresca ao servizo dos seus intereses políticos. En definitiva, a política de Afonso con respecto á lírica trobadoresca galego-portuguesa foi coherente co seu proxecto global: ao converter a corte rexia no principal escenario daquela manifestación literaria, ao recoñecer aos xograres como trobadores, e ao involucrarse el mesmo como autor no movemento trobadoresco, o seu propósito era acabar co monopolio aristocrático sobre aquel fenómeno e aproveitar no seu beneficio o prestixio cultural de que gozaba. Vexamos se o proxecto de compilación das Cantigas de Santa María garda algunha relación con estes obxectivos.

\section{AFONSO O SABIO E AS CANTIGAS DE SANTA MARÍA, O SEU PROXECTO MÁIS PERSOAL}

O proxecto máis ambicioso de Afonso como cultivador da lírica en galego materializouse nas Cantigas de Santa María, unha das coleccións poético-musicais máis importantes da Idade Media europea. Esta magna obra foi composta seguindo «el método de producción de libros típicamente alfonsí, es decir, con la participación colectiva», isto é, «por una serie de equipos integrados y organizados en una «estructura de trabajo» que desarrolló una actividad de equipo controlada más o menos estrechamente por el rey» ${ }^{28}$. Con todo, un certo número de cantigas, especialmente as máis autobiográficas, foi atribuído á autoría persoal de Afonso. A xulgar polos códices sobreviventes, este magno proxecto materializouse en tres edicións diferentes, que en conxunto suman un total de 420 cantares $^{29}$.

A edición primitiva, probablemente encetada na segunda metade da década de 1250 e rematada antes de 1269, estaba composta de cen «cantares con sões

28 Monsalvo 2001: 224 e Martin 2001: 266. Véxase Martin 2001: 270-274 e Parkinson 2011: 83-85, 99. É tópico citar a explicación sobre o papel do monarca na elaboración das obras do seu taller que se ofrece na General Estoria: «El rey faze un libro non porque.l el escriva con sus manos, mas porque compone las razones d'el e las emienda, et yegua e enderesça, e muestra la manera de como se deve fazer, e des i escrivelas qui el manda, pero dezimos por esta razon que el rey faze el livro» (apud Martin 2001: 273).

29 Mettmann 1981: 28-31. Esta continúa sendo a edición de referencia do conxunto das CSM. 
saborosos», precedidos dunha «Intitulatio» non musicada que reivindica a autoría do monarca e un prólogo en que este lle ofrece o libro á Virxe e se declara o seu trobador, e seguidos dunha «Petiçon», a modo de epílogo, en que Afonso lle solicita a María que, como galardón pola súa ofrenda, interceda a prol do perdón dos seus pecados. Despois de confeccionado un primeiro códice, Afonso e o seu equipo continuaron axuntando milagres e compoñendo cancións e engadíronlle outras vinte e seis cantigas $^{30}$. Esta primeira colección foi transmitida nunha copia, códice To (Códice de Toledo), que é datada, dependendo dos estudosos, entre 1270 - data máis probable-e os inicios do século $\mathrm{XIV}^{31}$.

A edición máis ampla, probablemente iniciada na década de 1280 e acabada pouco antes do pasamento do monarca (1284), contén 415 cantares. Foi transmitida polo códice orixinal (E ou Códice dos Músicos), rematado dun xeito precipitado, talvez nos últimos meses de vida de Afonso, ou mesmo pouco despois do seu pasamento ${ }^{32}$. A edición de luxo, profusamente ilustrada, materializouse en dous tomos (Códice das Historias), dos cales só se completou o primeiro, con duascentas cantigas (T ou Códice Rico) 33. Stephen Parkinson, Martha Schaffer e Laura Fernández, entre outros, postulan que o Códice Rico representa unha edición inicialmente concibida como unha colección de 200 cantigas e que a súa duplicación se levaría a cabo mediante a produción dun novo volume, o Códice de Florencia. O feito de que o tomo que complementaría o Códice Rico, con duascentas cantigas máis, non chegase a ser finalizado (F ou Códice de Florencia), fai pensar que aínda se traballaba nel cando se produciu a morte do $\mathrm{re}^{34}$.

Como sinala Martha Schaffer, as tres edicións deben ser contempladas «as at least three significantly «distinct works, each of them takes a predecessor version as a point of departure», ou sexa, como distinct phases in the life of a major literary or artistic project», no cal «each manuscript or version represents a particular perspective» (2000: 186-197). A redacción primitiva, representada polo Códice de Toledo, parece responder a un propósito fundamentalmente devocional: a elaboración dun libro de cantares á Virxe para uso persoal do monarca. A edición de luxo, Códice das Historias, estaría concibida non só para uso do soberano, senón que os seus dous volumes, ricamente iluminados, «deben ser entendidos en su dimensión

30 Monteagudo 2003: XI. Son cinco cancións das festas de Santa María, outras cinco de festas de Xesucristo, e dezaseis cantigas máis de milagres e loor. Ningunha destas composicións figura no índice da obra, copiado ao comezo, entre a Intitulatio e o Prólogo, o que é indicativo de que son engadidos posteriores.

31 Edición facsímile: Afonso X O Sabio, Cantigas de Santa María; transcrición en Afonso o Sabio 2010. Discusión deste punto e defensa da datación tardía con argumentos paleográficos e codicolóxicos en Fernández Fernández 2011: 47-53 y 72-78; e 2016/2017: 85-86, 114-117.

32 Ademais do prólogo e a «Intitulatio» recolle 400 cantigas (das que se repiten sete), a pitiçon, unha nova cantiga de loor e doce festas da Virxe, dúas das cales son repetición de cantigas de loor. Véxase Mettmann 1981: I, 28-31. Reprodución fotográfica en branco e negro: Alfonso X el Sabio 1964.

33 Edición facsímile: Alfonso X el Sabio 2011. Fernández Fernández 2011: 47-53 e 2016/2017: 92-93.

34 Edición facsímile: Alfonso X el Sabio 1989. Transcrición paleográfica en Fidalgo/F ernández 2019. 
plenamente cortesana, como parte del patrimonio librario de la Corona» (Fernández Fernández 2011: 51).

A edición completa, Códice dos Músicos, outorga unha especial relevancia aos aspectos melódicos e, de acordo co seu carácter musical, contén un repertorio icónico menos ostentoso. Fernández Fernández sostén que esta recompilación «no debe ser entendida como la culminación del proyecto, sino como un manuscrito que asegurase la perduración del cancionero completo, posiblemente motivado por

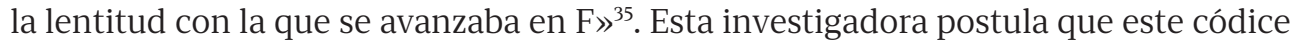
non se realizou con destino á corte, senón que foi pensado como unha peza de uso litúrxico para a Capela Real da Catedral de Sevilla, onde serviría á execución das cantigas durante as festas de santa María (Fernández Fernández 2011: 52-53).

Pola súa banda, Stephen Parkinson resume así a evolución do proxecto marial de Afonso:

The first collection begins as a personal mariale, a selection of mainly known pieces, and a personal act of devotion, inside troubadour culture [...] The increasing appreciation of the emblematic and exemplary function of a large collection of international and Iberian miracles, for political ends, emphasizing the monarch as the recipient of the favour of the Blessed Virgin who worked miracles throughout all the kingdoms of Iberia, leads to the consciously opulent outcome of the Códice de las Historias. (Parkinson 2011: 100)

A singularidade das Cantigas de Santa María dentro da oceánica obra afonsina foi destacada por unha pléiade de expertos. Así, Inés Fernández-Ordóñez chama a atención sobre o protagonismo outorgado ao rei como autor e actor tanto no texto coma nas imaxes dos códices iluminados, a un nivel que non ten parangón coas outras producións do obradoiro afonsino. Segundo esta investigadora, «las propiedades apotropaicas atribuidas al códice», «los tintes casi autobiográficos de texto e imagen», e o feito de que «el rey dispusiera su destino en forma testamentaria» manifestan a especialísima estima persoal que Afonso sentía por esta obra ${ }^{36}$. Por outra banda, esta mesma estudosa salienta tamén o parangón co conxunto da produción afonsina: a vontade autorial ao servizo dun proxecto político, o emprego exclusivo da lingua vulgar, o enciclopedismo didáctico e un afán de perfeccionamento constante, que produce varias versións da mesma obra. Movido pola súa insaciable curiosidade enciclopédica e un perfeccionismo enfermizo, o rei non deixaba de amorear información, de reformular os seus proxectos, de revisar e de reelaborar os textos para obter redaccións máis amplas e mellor acabadas, o que adoito provocou que algunhas ver-

35 Fernández Fernández 2016/2017: 105-106.

36 Fernández-Ordóñez 2011: 11-12; para as imaxes véxase Fernández Fernández 2011: 54-60. 
sións obras quedasen inconclusas ${ }^{37}$. Nese sentido, as CSM non son un caso illado, xa que se coñecen varias edicións, producidas baixo o seu mandato, dunha boa parte dos textos afonsinos.

\section{CANTIGAS, MILAGRES E SANTUARIOS NA POLÍTICA DE AFONSO}

Sen dúbida, a realización das CSM resultou custosísima, pois esixiu un xigantesco investimento de recursos financeiros, materiais e humanos (Schaffer 2000: 187). Alén dunha obvia motivación xenérica de «procura de prestixio e transcendencia», cómpre preguntarse polo sentido que Afonso imprimiu á súa empresa (Monsalvo 2001: 224). Antes de máis, semella claro que as CSM responden ás concepcións relixiosas do monarca. Neste sentido, a obra foi considerada a expresión de correntes renovadoras «orprendentemente avanzadas teológicamente y que, en algunos casos, rayaban la heterodoxia, o cuando menos, eran anti-conformistas con el pensamiento teológico tradicional» (Martínez 2003: 253). Concretamente, sinalouse que a colección se atopa imbuída dunha espiritualidade franciscana, que salienta a humanidade de Cristo e o papel da Virxe como co-redentora e mediadora.

Por outra banda, quíxose ver nas CSM unha manifestación artística «estrictamente civil», a plasmación dunha «visión laica de la cultura, aún en obras de alto contenido espiritual». Trataríase dunha espiritualidade vivida «al margen de las instituciones eclesiásticas»; de feito, «en las Cantigas Alfonso hace siempre de intermediario, sacerdote o maestro, entre María y el pueblo», papel que non se atribúe en ningún caso aos clérigos ${ }^{38}$. Nesta liña, Fernández-Ordóñez sinalou que «toda la concepción textual e iconográfica de las Cantigas minimiza el papel de la Iglesia y sus instituciones en la relación que los hombres establecen con la divinidad, en comparación con el ejercido por el rey» ${ }^{39}$. Por tanto, como di Georges Martin, nelas «es patente la voluntad de establecer una relación directa y personal del rey con el orbe espiritual que, apartando en cierto modo a la Iglesia, daba al monarca un papel destacado y casi sacerdotal» (Martin 2001: 284). Afonso preséntase como vicario de Deus, unha imaxe que reforzaba a autoridade do soberano no marco dunha nova ideoloxía do poder que resaltaba a hexemonía da monarquía (Doubleday 2005: 192).

Deste xeito, as interpretacións van esvarando das motivacións artísticas, sentimentais ou persoais de Afonso cara ao lugar das CSM no seu programa de goberno. En efecto, na liña apuntada polos xa citados Parkinson e Fernández-

37 Fernández-Ordóñez 2011: 13-14. Véxase también Martin 2001: 270-271.

38 Guerrero Lovillo, apud Martínez 2003: 248, 253.

39 Fernández Ordóñez 2011: 9. Para as imaxes, véxase Fernández Fernández 2011: 45. 
-Ordóñez, as CSM teñen sido consideradas un fiel reflexo non só da ideoloxía senón tamén do proxecto político do monarca. Jacques Le Goff chega a consideralas como «la plus grande entreprise d' exploitation politique du culte marial au Moyen Âge» (1990: 392), e para Martin, plasma a vontade de construír unha determinada imaxe pública do poder rexio e da súa persoa, o seu «yo tutelar y aglutinador», e constitúen «una auténtica proclamación política» (2001: 282 e 285). Igualmente, en consonancia co vasto programa científico e cultural emprendido por Afonso $\mathrm{X}$, tense subliñado que as CSM contribuirían á lexitimación sapiencial da realeza ${ }^{40}$. E, concretamente, as cantigas que narran milagres da Virxe que beneficiaban directamente a varios membros da familia real, nomeadamente a Fernando III e a súa dona a raíña Beatriz, foron relacionadas coa iniciativa de Afonso o Sabio de fundar unha capela real na catedral de Sevilla, a onde mandou trasladar os restos da súa nai e onde ergueu un mausoleo para o seu pai, establecendo un culto dinástico (Ferreira 2016: 307-308).

A colección marial de Afonso contén narracións amplamente difundidas en Europa e milagres relacionados con santuarios franceses que dispoñían das súas propias coleccións escritas, como Chartres, Soissons ou Rocamador. Por tanto, a súa realización requiriu un extenso traballo previo de documentación, materializado na recollida de numerosas fontes de todo tipo. Pero nas sucesivas edicións foron engadíronse relatos de milagres localizados en diversas rexións da Península, con especial predilección por Murcia e sobre todo por Andalucía, isto é, polos santuarios ergueitos e as poboacións fundadas polo propio Afonso nas terras que el mesmo conquistara. No total, inclúense máis de oitenta lendas marianas referidas a santuarios hispánicos, entre os cales o máis representado é o seu preferido, o Porto de Santa María, en Andalucía (24), seguido de Salas, en Aragón (22), Villasirga, na fronteira entre Castela e León (14), Terena, en Portugal (12) e Monserrat en Cataluña (6) ${ }^{41}$.

Desta maneira, as terras hispanas eran situadas na cartografía da ampla e prestixiosa tradición lírica mariana de modo a xerar «una tradición propia y autóctona» e así conseguir «una emancipación respecto de una tradición estándar» ${ }^{42}$. Neste sentido, tamén se contemplaron as CSM como «an attempt to promote the territorial power of Christianity in the newly conquered territories of western Andalusia» (Doubleday 2005: 190), isto é, «como parte del engranaje de recuperación y consolidación del territorio llevado a cabo por la Corona» (Fernández Fernández 2011: 45). Esta é a liña de interpretación que adopta Elvira Fidalgo, ao defender que a preeminencia outorgada aos santuarios marianos do sur da península, na nova España cristiá, obedecería ao «deseo del monarca de llamar la atención» sobre eses territorios, disputados cos musulmáns nuns casos, e con Portugal noutros. Canto á importancia dada a unha serie santuarios do norte, como Salas, Monserrat e sobre todo Villasirga, esta

40 Martin 2001: 273-274; Fernández-Ordóñez 2011: 8-9; Ayala Martínez 2011: 22.

41 Procter 2002: 39-43; Snow 2016/2017: 67-82; Fidalgo 2005: 157-170.

42 Monsalvo 2001: 224. Véxase tamén Martin 2001: 284. 
estudosa considera que a intención era promocionalos para que fixesen competencia á antiga, prestixiosa e aínda nutrida peregrinación a Compostela.

O obxectivo sería «desviar el importante flujo de peregrinos que iban a Santiago», ben para reforzar os centros de peregrinación do norte, ben para «aumentar el entusiasmo popular por las nuevas iglesias» do sur, «para repoblar nuevos territorios y crear nuevos asentamientos de población cristiana ${ }^{43}$. O problema desta caste de interpretacións, é que, como lembra Martin, «las Cantigas fueron destinadas al público de corte» (2001: 285). Concretamente, Kennedy suxire que o Códice Rico puido estar destinado a unha capela restrinxida para os membros da Orden de Santa María de España, creada polo rei, mentres que o Códice dos Músicos estaría destinado a un público cortesán máis amplo. En todo caso, «Alphonso’s intended readers were the courtiers and clerics who surrounded him», e as súas eran «works that present royal ideology to a literate, élite section of society, not to wider population» (Kennedy 2019: 28, 44, 151 e 218), e se nesta, como observa Ferreira, incluso tiveron unha recepción limitada, non se diga fóra dela (Ferreira 2016: 297-301 e 309-320; Kleine 2013: 30-36 refírese tamén á dificultade de comprensión por razón da lingua, Ferreira 2016: 324 descarta que existise tal dificultade). Por tanto, non puideron chegar, nin sequera en forma de afastado eco, a ese suposto público popular que debía dirixirse a aqueles santuarios favorecidos polo monarca. Esa limitación non é contraditoria co feito de que «the collection reflects an ambitious political and religious agenda, and that it was designed at the outset to have aural public impact both within and beyond the court», como acertadamente sinala Ferreira (2016: 320).

\section{A PEREGRINACIÓN XACOBEA NAS CANTIGAS. A LEA DO ARCEBISPADO DE SANTIAGO}

Sexa como for, é innegable que nas CSM latexa unha intención de parte de Afonso de «contra-programar» a peregrinación a Compostela, ou polo menos de eclipsar a celebridade deste santuario, enxalzando outros cultos rivais. Esta intención maniféstase de forma tanto implícita como explícita. En sete cantigas en que se fai referencia á peregrinación xacobea ou á cidade de Santiago, a mención do santuario do apóstolo brilla pola súa ausencia, e o mesmo acontece coas composicións localizadas en Galicia, que son unicamente sete, unha cifra moi baixa en comparanza con outras terras peninsulares ${ }^{44}$. Por exemplo, na cantiga $n^{\underline{0}} 184$ relátanse milagres

43 Fidalgo 2005: 170-176. As citas son das páxinas 172-173 e 176.

44 Procter 2002: 41; Fidalgo 2005: 154-156; Pousada 2010: 513-522. As cantigas localizadas en Galicia

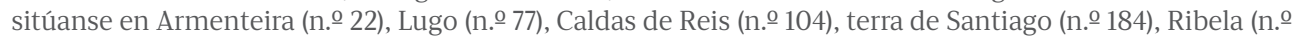
304), O Monte (n. 317) e O Viso (n. $\underline{0}$ 352). A cantiga n.. 103, que narra o milagre do monxe que botou trescentos anos escoitando o cantar do paxariño, non está situada explicitamente en Armenteira. 
de María na propia terra de Santiago, mentres que dous milagres que no Liber Sancti Jacobi son atribuídos ao Apóstolo en beneficio de cadanseu peregrino a Compostela, nas CSM son asignados á Virxe María, outorgando ao apóstolo un papel secundario (n. $\underline{0} 26$ e ก. $\underline{0} 175)$.

Pero noutras cantigas, como observa Fidalgo, máis valera o silencio ca a mala propaganda. Na cantiga no 218 , un peregrino alemán chega a Compostela pero non é curado por Santiago, senón pola Virxe de Villasirga na súa viaxe de volta. Noutra cantiga, a Virxe venerada neste mesmo santuario levántalle a penitencia a un romeu a Compostela (n. ㅇ 253). Á vista disto, non é de estrañar que na cantiga no 268 uns «romeus que de Santiago ían» aconsellasen a unha fidalga francesa que camiñaba en peregrinación a Compostela que se desviase do camiño para ir a Villasirga. A dona seguiu o consello e alí foi curada. Con estes antecedentes, tampouco sorprende que, segundo relata a cantiga n. $\underline{2} 278$, outra fidalga que viña curada da súa cegueira grazas á Virxe de Villasirga recomendase a un romeu que se dirixía a Santiago que se desviase a este santuario, polo visto máis milagreiro ca o apóstolo.

A publicidade negativa da peregrinación xacobea nas CSM ten sido obxecto de diversas lecturas. Para a maioría, a antipatía do rei é manifesta, ata o punto de falarse de «contra-propaganda»; só Montoya, sen moitos argumentos, refuga este tipo interpretacións como «gratuítas» (1991: 93). Un motivo da animadversión anti-santiaguista de Afonso que parece obvio é o seu prolongado litixio coa igrexa de Santiago. Desde os inicios do seu reinado, o monarca viuse obrigado a intervir en «muchos pleytos et demandas et querelas et contiendas» entre o clero catedralicio (arcebispo e cabido) e o concello. López Ferreiro tratou destas desavinzas, por suposto analizándoas desde unha posición favorable á igrexa, e apunta que «el astuto D. Alfonso X se aprovechó [...] para ingerirse en el señorío de la ciudad y nombrar Alcalde del Rey [...] Así iba D. Alfonso X preparando el terreno para dar el golpe á que le impulsaban los burgueses compostelanos ${ }^{45}$.

No medio dun clima de desconfianza do monarca cara ao Papado por causa do feito do Imperio, e no marco da súa política de afirmación do poder real, á morte do arcebispo Xoán Airas (1266), Afonso quixo impor como arcebispo de Compostela o cóengo Xoán Afonso, membro da familia real, pois era fillo bastardo do seu avó Afonso (López Ferreiro 1902: 227-232). O cabido compostelán dividiuse en dous bandos, a Santa Sé non aceptou o candidato proposto polo soberano e a prelatura quedou vouga ata 1267 , mentres o soberano se proclamaba protector de Santiago. Coa súa complicidade, os burgueses, en gráfica expresión de López Ferreiro, «se envalentonaron» e quixeron tomar as rendas da cidade. Nestas, o Papa designou arcebispo ao mitrado de Coimbra, Egas Fafez, quen, para complicar as cousas, finou antes de tomar pose. 
Entrementres, o Papado tamén quedaba vougo polo falecemento do Papa Clemente IV (1268), ata a proclamación de Gregorio X (1272). Así que sentou na cadeira de san Pedro, o novo Papa coutou de vez aspiracións imperiais de Afonso e pretendeu designar un arcebispo sen o acordo do rei (1273). Porén, en palabras de López Ferreiro, «alentados los burgueses compostelanos por la actitud más que equívoca del Rey D. Alfonso X, se negaron a reconocerlo por su Señor», mentres que o monarca lle esixía que lle prestase homenaxe (obriga que nunca tivera un arcebispo compostelán), se apropiaba da Pertiguería maior da terra de Santiago, tentaba privalo dos privilexios sobre os portos da diocese e se apoderaba das fortalezas nas terras da súa xurisdición. Finalmente, para fuxir da ira rexia, o arcebispo tivo que se exiliar, como fixeron moitos membros do cabido compostelán (López Ferreiro 1902: 239-248; véxase tamén o artigo de Francisco Hernández neste mesmo volume). Poida que o ambiente empezoñado destas encirradas liortas fose suficiente para explicar o nada disimulado anti-santiaguismo que destilan as Cantigas de Santa María.

\section{DISCUSIÓN E CONCLUSIÓNS: POR QUE TROBOU AFONSO O SABIO EN GALEGO?}

E con isto chegamos á cuestión da lingua. Visto o visto, non deixa de chocar que Afonso o Sabio escollese compoñer as CSM en galego, sendo unha obra que responde a motivacións, toca asuntos e ten propósitos alleos a Galicia e os galegos. Tense dito que o uso do romance en detrimento do latín, vinculado á orientación secularizadora do seu programa cultural fronte ao monopolio eclesiástico da cultura escrita, respondía a unha intención didáctica, isto é, ao desexo difundir determinados saberes ou de transmitir certas mensaxes nunha lingua comprensible a un público non alatinado: «o seu programa intelectual é didáctico e persegue o valor pedagóxico da utilidade inmediata» (Ayala Martínez 2011: 39). Mais este argumento non é suficiente para explicar o uso do galego nas CSM. Para Fernández-Ordóñez, as razóns disto foron máis ben de orde política:

Si toda la construcción política de Alfonso el Sabio propone a la monarquía castellano-leonesa como legítima aspirante al imperium peninsular, no hay que olvidar que ese edificio se levantaba tanto sobre el reino de Castilla como sobre el de León [...] En el paradigma cultural alfonsí el castellano como lengua de la cultura escrita en Castilla se flanquea del gallego como lengua de León, relevante testimonio de la voluntad integradora de la pluralidad lingüística de sus dominios. (2011: 12) 
Monsalvo Antón postula que Afonso tentou outorgar ao galego «en el marco protonacional del reino castellano-leonés» un papel de lingua cultural reservada á poesía lírica, comparable ao que o provenzal ocupaba entón no conxunto do arco mediterráneo. Por tanto, segundo este estudoso, o uso do galego nas cantigas afonsinas debe entenderse «en contraposición con el provenzal, como afirmación de una dignidad propiamente hispánica, y desde luego no en contraposición al castellano» (2001: 264).

Alén das anteriores interpretacións, non debe esquecerse a explicación defendida desde hai tempo por algúns estudosos. Afonso atopouse cunha situación na cal, desde un par de xeracións anteriores á súa, no centro e occidente da península, o cultivo do xénero lírico estaba asociado ao romance galego, grazas ao temperán impulso que lle deran algunhas familias da nobreza galaica. Isto dotárao duns recursos que os romances veciños tardarían en acadar. Formulouno con precisión Gerold Hilty ao sinalar que «Galicia se adelantó a Castilla en la creación del género de poesía amorosa y de escarnio en romance y, una vez constituido tal género, Castilla lo adoptó»; xa que o galego, sendo a lingua dun dos seus reinos, «se comprendía y ofrecía formas literarias que se podían aprovechar para la expresión de la lírica amatoria y sarcástica». Como advirte este estudoso, «no podemos enfocar esta situación desde una perspectiva moderna (nacionalista y regionalista) ni desde la perspectiva de la filología románica, que tiene que considerar el castellano y el galaico-portugués como dos lenguas románicas autónomas y distintas» (Hilty 2002). Por tanto, como sinala Ferreira, «Alfonso’s minstrels were expected to sing in Galician-Portuguese irrespective of the listener's mother tongue» (2016: 324).

En efecto, como xa salientara Tavani, ata os séculos XIII- XIV en varias áreas culturais de Europa, desde a Inglaterra anglo-normanda, ata Italia e a España cristiá, conviviron diversas tradicións literarias en réxime de simbiose. Nelas existiu unha asociación entre determinadas variedades lingüísticas e certos xéneros literarios análoga á que existía en toda Europa occidental entre os idiomas vulgares e o latín. Alleas á idea de unificación lingüística do territorio dun estado ao redor dun estándar nacional, as distintas tradicións literarias que xeraran cadansúa koiné para un xénero concreto (lírica, épica, narrativa) eran concibidas como mutuamente complementarias. Xa que logo, o galego-portugués non debe considerarse «a lingua poética dunha escola nacional, nin era considerada dun xeito tan restritivo por parte dos que a usaban», senón que, pola contra, asumiu a «función de vehículo expresivo dun xénero poético cultivado, degustado, imitado en toda a península centro-occidental, nun réxime de civilización literaria común» (Tavani 1986: 33-36).

O devandito é indubidable para a lírica trobadoresca profana. Canto ás CSM, aínda se pode argumentar dun xeito máis concreto. Davide Romano sinalou que para realizar as súas obras de «de sçiencias e de saberes», Afonso tivo que recorrer a persoal capacitado, que para o caso eran sabios xudeus especialistas nas materias 
tratadas e competentes en árabe e castelán, pero non en latín (Romano 1990: 682-695, Doubleday 2015: 62-64). Ora, para a realización das CSM cumpría dispor dun nutrido equipo de trobadores expertos cun completo dominio da gaya sciencia (Ferreira 2016: 320-323). Para tal, os artesáns que estaban ao alcance de Afonso eran na súa inmensa maioría galegos, capaces de aplicar ao seu idioma complexas técnicas compositivas como o cómputo silábico coas súas requintadas pautas e licenzas métricas, as regras da rima e da estrofa... O galego xa fora exercitado para estes mesteres, dispuña dun rico léxico e da necesaria flexibilidade sintáctica (Filgueira 1980: 1415). Non debe ser casualidade que o único nome que chegou a nós de colaboradores poéticos das CSM sexa o do clérigo e trobador compostelán Ayras Nunez (Mettmann 1971). Velaí unha serie de razóns, de carácter técnico e puramente práctico, para o uso do galego na composición das CSM.

Finalmente, á hora de xulgar a contribución de Afonso ao lirismo trobadoresco galego-portugués convén ter en conta a cautela expresada por Simon Doubleday (2005: 190) contra a «temptation to empathise excessively with courtly culture, and with a remarkably cultured king, in a way that distorts our understanding». Así, non pode deixar de verse na empresa mariana un propósito de reorientación da lírica galego-portuguesa en favor dun proxecto estritamente persoal do monarca. En certa maneira, tratouse dunha operación de expropiación dun patrimonio inmaterial - o capital simbólico adquirido polo galego- que viña sendo detido preferentemente pola nobreza galego-portuguesa e, subsidiariamente, pola nobreza leonesa e castelá. Conforme a opinión de José C. Miranda,

não é a língua que o leva para junto daqueles que a exercitavam, mas o contrário: é a necessidade [...] de estabelecer relações estreitas com o mundo senhorial do ocidente peninsular que leva Afonso a tornar-se trovador e, mais tarde, no seio do mundo trovadoresco, a procurar, pela palavra e pela acção, tornar-se a voz de comando desse mesmo mundo [...] o projecto de Afonso X no tocante ao galego-português e à sua quase exclusiva expressão trovadoresca revelou ser uma subtil operação de apropriação e de transfiguração monárquica de uma linguagem essencialmente vassálica e aristocrática, operação realizada ao longo de décadas. (Miranda 2012: 17)

Isto canxa perfectamente co empeño de Afonso por centralizar os saberes ao redor da coroa en canto tiña que ver coa «organización de su producción, al impulso económico que recibieron, al lugar que se les dio en la construcción del poder regio y de su imagen» (Martin 2001: 285). Mais, por outra banda, como subliña o mesmo estudoso, «tal vez la constante iniciativa cultural del rey haya debilitado en alguna medida la producción cultural fuera de la corte y de los talleres regios» (ibidem). É moi 
probable que o seu afán centralizador minguase a vitalidade da lírica trobadoresca galego-portuguesa, especialmente en terras galegas. Aquí, durante o reinado de Afonso, a lírica continuaba viva da man de humildes, pero soberbios, xograres, como Martin Codax e Mendiño, mais o certo é que a partir da década de 1280 practicamente non houbo remuda xeracional, e non se rexistran trobadores galegos activos despois dos primeiros anos dos século XIV. De 1300 ata 1350, só as cortes de don Denis e do seu fillo bastardo Pedro Afonso, Conde de Barcelos, darían acollida, ao sur do Miño, a unha manifestación cultural en constante refluxo (Tavani 264-273; Oliveira 1995: 79-86).

Así, o balance da súa achega á cultura expresada en lingua galega é mixto. A súa corte foi un escenario privilexiado para a lírica trobadoresca, que atraeu un importante grupo de trobadores e xograres. O monarca recoñeceu o estatuto artístico dos segundos, poñendo fin ao monopolio nobiliar desta manifestación cultural. Probablemente, promoveu a compilación do primeiro cancioneiro xeral da lírica trobadoresca galego-portuguesa, o arquetipo da tradición manuscrita sobrevivente. Neste cancioneiro acolleu non soamente as cantigas dos cabaleiros, como acontecera nas recollas previas, senón tamén dalgúns segreis e clérigos. Porén, os xograres continuaron excluídos del, e a súa incorporación ao ramo principal da tradición manuscrita tivo que agardar varias décadas, ata a confección dunha nova compilación xeral, hipoteticamente por iniciativa de don Denis (Monteagudo 2019: 932-951).

Canto ás Cantigas de Santa María, por moito que hoxe nos marabillemos pola súa opulencia e a súa calidade artística, e por moito que as estimemos como un testemuño sen par das artes, a cultura e a sociedade do seu tempo, a verdade é que acabaron por resultar un proxecto tan grandioso na súa concepción e espléndido na súa realización como estéril nos seus efectos (Filgueira 1985: 48-49; Tavani 1986: 58; Ferreira 2016: 297-298, 333-340). En definitiva, Afonso o Sabio foi un xenio paradoxal, foino en si e para si e foino tamén para Galicia, o seu idioma e a súa cultura. 


\section{REFERENCIAS BIBLIOGRÁFICAS}

- Afonso X o Sabio (2008): Cantigas de Santa Maria. Edición facsímile do Códice de Toledo (To). Biblioteca Nacional de Madrid (Ms 10.096), Santiago de Compostela, Consello da Cultura Galega.

- Afonso X o Sabio (2010): Cantigas de Santa Maria, Códice de Toledo (Transcrición de Marta Schaffer), Santiago de Compostela, Consello da Cultura Galega.

- Alfonso el Sabio (1964): La música de las Cantigas de Santa María de Alfonso el Sabio. I. Facsímil del códice j.b.2 de El Escorial, Barcelona, Diputación Provincial 7 Biblioteca Central.

- Alfonso X el Sabio (1989): Cantigas de Santa María. Tomo I. Edición facsímil del códice B.R. 20 de la Biblioteca Nazionale Centrale de Florencia: siglo XIII, Madrid, Edilán.

- Alfonso X el Sabio (2011): Las Cantigas de Santa María: Códice Rico, Ms. T-I-1, Real Biblioteca del Monasterio de San Lorenzo de El Escorial. Tomo I. Edición facsímil, Madrid, Patrimonio Nacional/Testimonio.

- Alvar, Carlos (1977): La poesía trovadoresca en España y Portugal, Madrid, Cupsa.

- Alvar, Carlos (1978): Textos trovadorescos sobre España y Portugal, Madrid, Cupsa.

- Alvar, Carlos (1984): «Poesía y política en la corte alfonsí», Cuadernos Hispano-Americanos, 410, 5-20.

- Alvar, Carlos (1985): «La cruzada de Jaén y la poesía gallego-portuguesa», en Vicente Beltrán (ed.), Actas del I Congreso de la Asociación Hispánica de Literatura Medieval, Barcelona, Promociones y Publicaciones Universitarias, 139-144.

- Alvar, Carlos (1986): «Las poesías de Pedro García de Ambroa», Studi Mediolatini e Volgari, 32, 11-40.

- Alvar, Carlos (1998): «Alfonso X, poeta profano. Temas poéticos. La corte poética del Rey», en Anton Touber (ed.), Le Rayonement des Troubadours, Actes du colloque de l'AIEO, Amsterdam/Atlanta, Rodopi, 3-17.

- Ayala Martínez, Carlos (2011): «El reinado de Alfonso X: la síntesis de una época», en Laura Fernández Fernández/Juan C. Ruiz Souza (eds.), Alfonso X el Sabio. Las Cantigas de Santa Maria. Códice Rico Ms T-I-1, Madrid, Patrimonio Nacional/ Testimonio, vol. 2, 17-42.

- Ballesteros Bereta, Antonio (1984): Alfonso X el Sabio, Barcelona, El Albir.

- Beltrán, Vicente (1993): «Pedr’Amigo de Sevilha», en Giulia Lanciani/Giuseppe Tavani (eds.), Dicionário da Literatura Medieval Galega e Portuguesa, Lisboa, Caminho, 519-520.

- BeLtRÁN, Vicente (2005): La corte de Babel. Lenguas, poética y política en la España del siglo XIII, Madrid, Gredos. 
- Beltrán, Vicente (2007): Poética, poesía y sociedad en la lírica medieval, Santiago de Compostela, Universidade.

- Bertoluci, Valeria (1993): «Alfonso X», en Giulia Lanciani/Giuseppe Tavani (eds.), Dicionário da Literatura Medieval Galega e Portuguesa, Lisboa, Caminho, 36-41.

- Brandẽo, António (1974): Monarquia Lusitana. Parte Quarta, Lisboa, Imprensa Nacional/Casa da Moeda.

- Couceiro, José L. (1993): «Pero d’Armea», en Giulia Lanciani/Giuseppe Tavani (eds.), Dicionário da Literatura Medieval Galega e Portuguesa, Lisboa, Caminho, 536-537.

- Deyermond, Alan D. (1981): Historia de la literatura española. 1. La Edad Media, Barcelona, Seix Barral.

- Doubleday, Simon (2005): «O que foi passar a serra: Frontier-crossing and the thirteenth-century nobility in the cantigas de escarnio e maldizer», en Martin Aurell (ed.), Le médiéviste et la monographie familiale: sources, méthodes et problematiques, Turnhout, Brepols, 189-200.

- Doubleday, Simon (2015): The Wise King. A Christian Prince, Muslim Spain, and the Birth of the Renaissance, New York, Basic Books.

- FALCÃo, Fernanda Scopel (2019): O trobar do segrel Lourenço nas tenções galego-portuguesas: uma retórica da impertinência. Tese de doutoramento inédita. Vitória, Universidade Federal do Espírito Santo.

- FALCÃo, Fernanda Scopel (2019): «Segréis, jograis-trovadores, doctores de trovar: especialização do ofício jogralesco e da convenção trovadoresca em solo ibérico», Roda da Fortuna, 8:1, 60-76.

- FERnÁndez FERnÁndEz, Laura (2011): «Este livro, com’achei, fez á onr'e á loor da Virgen Santa Maria: El proyecto de las Cantigas de Santa Maria en el marco del escritorio regio. Estado de la cuestión y nuevas reflexiones», en Laura Fernández Fernández/Juan C. Ruiz Souza (eds.), Alfonso X el Sabio. Las Cantigas de Santa Maria. Códice Rico Ms T-I-1, Madrid, Patrimonio Nacional/Testimonio, vol. 2, 43-78.

- FERnÁndez FERnÁndez, Laura (2016/2017): «Los manuscritos de las Cantigas de Santa María: definición material de un proyecto regio», Alcanate, X, 81-117.

- FERnÁndEZ-ORdóñEz, Inés (2011): «Prólogo. Las Cantigas de Santa María en el marco de las producciones alfonsíes: semejanzas y diferencias», en Laura Fernández Fernández/Juan C. Ruiz Souza (eds.), Alfonso X el Sabio. Las Cantigas de Santa Maria. Códice Rico Ms T-I-1, Madrid, Patrimonio Nacional/Testimonio Compañía Editorial, vol. 2, 7-15.

- FERNÁNDEZ-ORDÓÑEZ, Inés (2013): «Alfonso el Sabio en la historia del español», en Rafael Cano (ed.), Historia de la lengua española, Barcelona, Planeta, 381-422. 
- FerReira, Maria do Rosário (2012): «As traduções de castelhano para galego-português e as políticas da língua nos séculos XIII-XIV», e-Spania [En liña], consultado o 21 marzo de 2017. URL: http://e-spania.revues.org/21021; DOI: 10.4000/e-spania.21021.

- Ferreira, Manuel Pedro (2016): «The Medieval Fate of the Cantigas de Santa Maria: Iberian Politics Meets Song», Journal of the American Musicological Society, 69:2, 295-353.

- Fidalgo Francisco, Elvira (2005): «Peregrinación y política en las Cantigas de Santa Maria», en Elvira Fidalgo (ed.), Formas narrrativas breves en la Edad Media. Actas del IV Congreso, Santiago de Compostela, Universidade, 149-179.

- Fidalgo Francisco, Elvira/Fernández Guiadanes, Antonio (2019): O Códice de Florencia das Cantigas de Santa Maria (B.R. 20). Transcrición paleográfica, Santiago de Compostela, Xunta de Galicia.

- Filgueira Valverde, Xosé F. (1980): Afonso X e Galicia e unha escolma de cantigas, A Coruña, Real Academia Galega.

- Filgueira Valverde, Xosé F. (1985): «Introducción», en Alfonso X el Sabio, Cantigas de Santa María, Madrid, Castalia, 1985, XI-LXIII.

- Gonçalves, Elsa (2016): De Roma ata Lixboa. Estudos sobre os cancioneiros galego-portugueses, A Coruña, Real Academia Galega.

- GonZÁlez JiméneZ, Manuel (1993): Alfonso X el Sabio, 1252-1284, Palencia, La Olmeda.

- Hilty, Gerold (2002): «El plurilingüismo en la corte de Alfonso X el Sabio», en María T. Echenique Elizondo/Juan Sánchez Méndez (eds.), Actas del V Congreso Internacional de Historia de la Lengua Española. Vol. I, Madrid, Gredos, 207-220.

- KLeINE, Marina (2013): «El carácter propagandístico de las obras de Alfonso X», De Medio Aevo, 4:2, 1-42.

- Lanciani, Giulia/TaVani, Giuseppe (1995): As cantigas de escarnio, Vigo, Xerais.

- LaPa, Manuel Rodrigues (1970): Cantigas d'escarnho e de maldizer dos cancioneiros medievais galego-portugueses, Vigo, Galaxia.

- LAPESA, Rafael (1981): Historia de la lengua española, Madrid, Gredos.

- Le Goff, Jacques (1990): «Le roi, la Vierge et les images: le manuscrit des Cantigas de Santa Maria d'Alphonse X de Castille», en Paul de Clerk/Eric Palazzo (eds.), Rituels: Mélanges offerts à Pierre-Marie Gy, O.P., Paris, Cerf, 385-392.

- Liu, Benjamin (2004): Medieval Joke Poetry. The «Cantigas d'Escarnho e de Mal Dizer», Cambridge (Massachusetts)/London, Harvard University Department of Comparative Literature. 
- LOPES, Graça Videira (1998): A sátira nos cancioneiros galego-portugueses, Lisboa, Estampa.

- LÓPEZ AydiLlo, Eugenio (2008): Los cancioneros gallego-portugueses como fuentes históricas, Valladolid, Maxtor.

- López Ferreiro, Antonio (1902): Historia de la Santa A. M. Iglesia de Santiago de Compostela. Tomo V, Santiago, Imprenta del Seminario Conciliar Central.

- López FERreiro, Antonio (1975): Fueros municipales de Santiago y de su tierra, Madrid, Ediciones Castilla.

- Lorenzo VÁzQueZ, Ramón (1993): «Pero da Ponte», en Giulia Lanciani/Giuseppe Tavani (eds.), Dicionário da Literatura Medieval Galega e Portuguesa, Lisboa, Caminho, 537-539.

- Marcenaro, Simone (2010): L'equivocatio nella lirica galego-portoghese medievale, Alessandria, Edizioni dell'Orso.

- Márquez Villanueva, Francisco (1995): El concepto cultural alfonsí, Madrid, Fundación MAPFRE América.

- Marroni, Giovanna (1968): «Le poesie di Pedr'Amigo de Sevilha», Annali dell' Istituto Universitario Orientale. Sezione Romanza, 10, 189-339.

- MARTin, George (2001): «Los intelectuales y la corona: la obra histórica», en Manuel Rodríguez Llopis (ed.), Alfonso X y su época. El siglo del rey sabio, Barcelona, Carroggio, 259-286.

- Martínez, H. Salvador (2003): Alfonso X, el Sabio. Una biografía, Madrid, Polifemo.

- Mattoso, José (1985): Portugal Medieval. Novas interpretações, Lisboa, Imprensa Nacional/Casa da Moeda.

- Mattoso, José (1987): Fragmentos de uma composição medieval, Lisboa, Estampa.

- MenÉndez Pidal, Ramón (1924): Poesía juglaresca y juglares. Aspectos de la historia literaria y cultural de España, Madrid, Junta para la Ampliación de Estudios e Investigaciones Históricas/Centro de Estudios Históricos.

- Mettmann, Walter (1981): «Introdução», en Afonso X O Sábio, Cantigas de Santar Maria, Vigo, Xerais, vol. I, 16-36.

- Mettmann, Walter (1971): «Airas Nunes, Mitautor der “Cantigas de Santa Maria”», Iberorromania, 3, 8-10.

- Michä̈LIS DE VASCONCELlOS, Carolina (1924): «Em volta de Sancho II», Lusitânia, 2, 7-25.

- Michä̈lis de VAsconcellos, Carolina (1990): Cancioneiro da Ajuda. Reimpressão da edição de Halle (1904), acrescentada de um prefacio de Ivo Castro e do glossário das cantigas (Revista Lusitana, XXIII), 2 vols., Lisboa, Imprensa Nacional/Casa da Moeda. 
- MichaËLIs de Vasconcellos, Carolina (2004): Glosas marginais ao cancioneiro medieval portugués de Carolina Michaëlis de Vasconcelos, Coimbra, Universidade.

- Miranda, José C. (2004): Aurs mesclatz ab argen. Sobre a primeira geração de trovadores galego-portugueses, Porto, Guarecer.

- Miranda,JoséC. Ribeiro (2012): «Ogalego-portuguêse os seus detentores aolongo do século XIII», e-Spania [en liña], consultado o 21 de marzo 2021. URL: http://journals. openedition.org/e-spania/21084; DOI: https://doi.org/10.4000/e-spania.21084.

- Monsalvo AnTÓN, José M. (2001): «Renacimiento cultural y progreso científico en el ámbito europeo», en Manuel Rodríguez Llopis (ed.), Alfonso X y su época. El siglo del rey sabio, Barcelona, Carroggio, 195-234.

- Montoya Martínez, Jesús (1991): O cancioneiro marial de Afonso X, o Sabio, Santiago de Compostela, Universidade.

- Monteagudo, Henrique (2003): «Cantares con sões saborosos de cantar. Apuntamentos para un proemio», en Afonso X O Sabio, Cantigas de Santa Maria. Edición facsímile do Códice de Toledo (To), Santiago de Compostela, Consello da Cultura Galega, VII-XIII.

- Monteagudo, Henrique (2008): Letras primeiras. O foral do Burgo de Caldelas, os primordios da lírica trovadoresca e a emerxencia do galego escrito, A Coruña, Fundación Pedro Barrié de la Maza.

- Monteagudo, Henrique (2014): A nobreza miñota e a lírica trobadoresca na Galicia da primeira metade do século XIII: a personalidade histórica do trobador Johan Soayrez Somesso, os trobadores Afonso Soarez Sarraça e Estevan Fayan, Noia, Toxosoutos.

- Monteagudo, Henrique (2019): «Variación scriptolingüística e tradición manuscrita da lírica trobadoresca: As variables $<\mathrm{nh} / \mathrm{n}>\mathrm{e}<\mathrm{ss} / \mathrm{s}>$ », en Ernestina Carrilho/ Ana Maria Martins/Sandra Pereira/João Paulo Silvestre (eds.), Estudos lingüísticos e filológicos oferecidos a Ivo Castro, Lisboa, Centro de Lingüística da Universidade de Lisboa, 859-960.

- Oliveira, António Resende de (1987): «A cultura trovadoresca no Ocidente peninsular: trovadores e jograis galegos», Biblos, 63, 1-22.

- Oliveira, António Resende de (1989): «A Galiza e a cultura trovadoresca», Revista de História das Ideias, 11, 7-36.

- OliveIRA, António Resende de (1993a): «Airas Perez Vuitoron», en Giulia Lanciani/ Giuseppe Tavani (eds.), Dicionário da Literatura Medieval Galega e Portuguesa, Lisboa, Caminho, 28-29.

- Oliveira, António Resende de (1993b): «Segrel», en Giulia Lanciani/Giuseppe Tavani (eds.), Dicionário da Literatura Medieval Galega e Portuguesa, Lisboa, Caminho, 609-611. 
- Oliveira, António Resende de (1994): Depois do espectáculo trovadoresco. A estrutura dos cancioneiros peninsulares e as recolhas dos séculos XIII e XIV, Lisboa, Colibri.

- Oliveira, António Resende de (1995): Trobadores e xograres. Contexto histórico, Vigo, Xerais.

- Oliveira, António Resende de (1998): «Galicia trobadoresca», Anuario de Estudios Literarios Galegos, 207-229.

- Oliveira, António Resende de (2001): O trovador galego-português e o seu mundo, Lisboa, Editorial Notícias.

- Oliveira, António Resende de (2009): «Distracções e cultura», en Leontina Ventura, D. Afonso III, [S.l.], Círculo de Leitores, 270-317.

- Oliveira, António Resende de (2010a): «D. Afonso X, infante e trovador. I. Coordenadas de uma ligação à Galiza», Revista de Literatura Medieval, 22, 257-270.

- Oliveira, António Resende de (2010b): «D. Afonso X, infante e trovador. II. A produção trovadoresca», La parola del testo, 14, 7-19.

- Oliveira, António Resende de (2010c): «Na casa de Afonso X. O rei, a corte e os trovadores (abordagem preliminar)», Revista de História das Ideas, 31, 53-76.

- Oliveira, António Resende de (2013): «O Irrequieto Cancioneiro Profano do Rei Sábio», Revista Portuguesa de História, 44, 257-277.

- Oliveira, António Resende de (2014):. «A produção trovadoresca de Afonso X: 3. Os cantares de guerra», Revista de História das Ideas, 31, 9-29.

- Oliveira, António Resende de (2015): «A produção trovadoresca de Afonso X. 2. Entre trovadores e jograis galego-portugueses», La corónica, 43:2, 5-27.

- Oliveira, A. Resende de/José C. Miranda (1995): «A segunda geração de trovadores galego-portugueses: temas, formas, realidades», en Juan Paredes (ed.), Medioevo y literatura. Actas del V Congreso de la Asociación Hispánica Medieval, Granada, Universidad, vol. 3, 499-512.

- Oliveira, A. Resende de/José C. Miranda (1998): «Le surgissement de la culture troubadouresque dans l'Occident de la Péninsule ibérique (I). Compositeurs et cours», en Anton Touber (ed.), Le Rayonement des Troubadours, Actes du colloque de l'AIEO, Amsterdam/Atlata, Rodopi, 85-95.

- Paredes, Juan (2010): El cancionero profano de Alfonso X el Sabio, Santiago de Compostela, Universidade.

- Parkinson, Stephen (2011): «Alfonso X, miracle collector», en Laura Fernández Fernández/Juan C. Ruiz Souza (eds.), Alfonso X el Sabio. Las Cantigas de Santa Maria. Códice Rico Ms T-I-1, Madrid, Patrimonio Nacional/Testimonio Compañía Editorial, vol. 2, 79-100. 
- Pousada Cruz, Miguel A. (2010): «A contrapropaganda do Camiño de Santiago nas Cantigas de Santa María», en Esther Corral (ed.), In Marsupiis Peregrinorum. Circulación de textos e imágenes alrededor del Camino de Santiago en la Edad Media. Actas del Congreso Internacional, Firenze, Edizioni del Galluzzo, 509-525.

- Procter, Evelyn S. (2002): Alfonso X de Castilla, patrono de las letras y el saber, Murcia, Real Academia Alfonso X el Sabio.

- Río GRANDE, María G. del (2018): «Alacrán negro nen veiro». Simbología, metáfora y textualidad del escorpión en los textos alfonsíes», Letras, 78, 127-140.

- Rodríguez Velasco, Jesús D. (1999): Castigos para celosos, consejos para juglares, Madrid, Gredos.

- Romano, Davide (1990): «Le opere scientifiche di Alfonso X e l'intervento degli ebrei», en Oriente e Occidente nel Medioevo. Filosofia e scienze. Convegno Internazionale, 9-15 aprile 1969, Roma, Accademia Nazionale dei Lincei, 677-711.

- SCHAFFER, Martha (2000): «The Evolution of the Cantigas de Santa Maria: The Relationships between Manuscripts T, F and E», en Stephen Parkinson (ed.), Cobras e Son. Papers on the Text Music and Manuscripts of the Cantigas de Santa Maria, Oxford, Legenda, 186-213.

- SNow, Joseph T. (2016/2017): «La utilización política de la devoción mariana en el reinado de Alfonso X, el Sabio (1252-1284)», Alcanate, X, 61-85.

- Souto Cabo, José A. (2006): «Pedro Garcia de Ambroa e Pedro de Ambroa», Revista de Literatura Medieval, 18, 225-248.

- Souto CABo, José A. (2011a): «A emergência da lírica galego-portuguesa e os primeiros trovadores», A Trabe de Ouro, 87, 367-392.

- Souto Cabo, José A. (2011b): «Lopo Lias: entre Orzelhão e Compostela», Diacrítica, 25, 109-133.

- Souto Cabo, José A. (2012a): Os cavaleiros que fizeram as cantigas. Aproximação às origens socioculturais da lírica galego-portuguesa, Niteroi, Universidade Federal Fluminense.

- Souto Cabo, José A. (2012b): «En Santiago, seend’ albergado en mia pousada. Nótulas trovadorescas compostelanas», Verba, 39, 273-298.

- Souto Cabo, José António/Vieira, Yara Frateschi (2003): «Para um novo enquadramento histórico-literário de Airas Fernandes, dito 'Carpancho'», Revista de Literatura Medieval, 16, 221-277.

- TAVANI, Giuseppe (1986): A poesía lírica galego-portuguesa, Vigo, Galaxia.

- Tavani, Giuseppe (1993): «Sátira política», en Giulia Lanciani/Giuseppe Tavani (eds.), Dicionário da Literatura Medieval Galega e Portuguesa, Lisboa, Caminho, 608-609. 
- Ventura, Joaquim (2014): «A trindade de Pedro Garcia de Ambroa», Revista de Cancioneros, Impresos y Manuscritos, 3, 181-231.

- VIEIRA, Yara Frateschi (1999): En cas dona Maior. Os trovadores e a corte senhorial galega do século XIII, Santiago de Compostela, Laiovento.

- Vieira, Yara Frateschi/Isabel Morán Cabanas/José A. Souto Cabo (2012): O amor que eu levei de Santiago. Roteiro da lírica medieval galego-portuguesa, Noia, Toxosoutos.

- VíñEz SÁNCHEZ, Antonia (2004): El trovador Gonçal’Eanes Dovinhal. Estudio histórico y edición, Santiago de Compostela, Universidade. 



\section{ANEXO}

Cantigas satíricas de Afonso o Sabio e o seu círculo 

A seguir ofrécese unha escolma satíricas de cantigas de Afonso o Sabio e outros trobadores do seu séquito, con dúas modestas pretensións: acompañar o artigo, ofrecendo unha ilustración máis ampla dalgunhas das observacións que nel se conteñen, e ofrecer unha mostra da produción satírica de Afonso, enfocada cara aos temas considerados no dito artigo. A edición que se ofrece non ten outras pretensións que as divulgativas, aínda que non por iso está exenta de rigor filolóxico. Moitos dos textos presentan problemas de lectura moi difíciles. Tentamos resolvelos, mais, dado o propósito da edición, non nos detemos a ofrecer explicacións das solucións que adoptamos. As notas que acompañan non teñen máis finalidade que contextualizar os textos e facilitar a súa lectura. Por vía da regra, tomamos como referencia as lecturas que se ofrecen no projeto littera, a que remitimos para maiores explicacións e esclarecementos ${ }^{1}$. O glosario do espazo web Universo Cantigas dá precisa información sobre o significado concreto de cada termo².

\section{CRITERIOS DE EDICIÓN}

En xeral, respectouse a materialidade gráfica dos textos, pero aplicáronselles algunhas intervencións para facilitar a lectura:

Modernizouse a puntuación, a unión se separación de palabras e o uso de minúsculas e maiúsculas. As formas clíticas como os pronomes átonos aparecen separadas da palabra antecedente mediante un trazo: chorar-lh'-ey, querrey-vo-lh' eu, alhu-lo demandade, poi-lo ben faço, vende-la galdrapa.

Non se impuxeron acentos gráficos, salvo con valor diacrítico: é (verbo) / e (conxunción), én (pronome) / en (preposición).

Introducíronse distincións gráficas entre as vogais e consoantes $<\mathrm{u}>/<\mathrm{v}>\mathrm{e}<\mathrm{i}\rangle /<\mathrm{j}>\mathrm{e}$

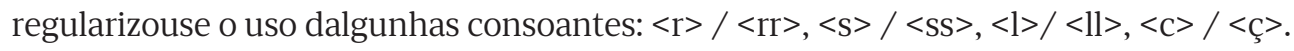
En posición final, xeneralizouse a grafía $<$ n $>$ para a consoante nasal.

$\mathrm{O}<\mathrm{h}>$ eliminouse cando non ten motivación etimolóxica ( $h u n>$ un), repúxose cando a ten (herdar, hoste, home), excepto no verbo aver e no adverbio e conxunción ora, e regularizouse para os pronomes medievais hy e $h u$ (estes últimos non levan $<\mathrm{h}->$ nas Cantigas de Santa María).

Regularizouse o uso de $<y>$ seguindo o criterio de frecuencia: úsase cando vai en ditongo en final de palabra (vay, rey, foy, muy), na secuencia -eyro / -eyra, cando representa a vogal tónica dun hiato (aynda, Raynha) e en familias léxicas ou variantes do mesmo vocábulo (rey / reyno, muy / muyto). Nas Cantigas de Santa María reprodúcense as grafías $<\mathrm{y}>/<\mathrm{i}>$ do códice.

1 Lopes, Graça Videira / Manuel Pedro Ferreira et alii (2011-): Cantigas medievais Galego Portuguesas. http://cantigas.fcsh.unl.pt

2 Ferreiro, Manuel (dir.) (2018-): Universo Cantigas. Edición crítica da poesía medieval galego-portuguesa, Universidade da Coruña. http://universocantigas.gal 
Todas as composicións de carácter satírico veñen transmitidas polos apógrafos italianos, copiados dunha compilación realizada en Portugal, polo que se emprega sistematicamente as grafías $<\mathrm{lh}>\mathrm{e}<\mathrm{nh}>$. Nas Cantigas de Santa María as grafías correspondentes son $<$ ll $>$ e $<$ nn $>$ ou $<\tilde{n}>$.

As palabras ou letras restituídas ou corrixidas van entre corchetes [ ], salvo nos caso dos refráns. Nas Cantigas de Santa María, o refrán non é reproducido despois de cada estrofa.

\section{O SIRVENTÉS POLÍTICO. CANTARES DE BATALLA I.1. A GUERRA CIVIL PORTUGUESA (1246-1248)}

\section{AYRAS PEREZ VUYTORON (B1477, V1088)}

Esta outra cantiga é de maldizer dos que deron os castelos como non devian al Rey don Afonso.

A lealdade de Bezerra, que pela Beyra muyto anda, ben é que a jur a tenhamos, pois que no-lo Papa manda.

Non ten Sueyro Bezerra que tort' é en vender Monsanto, ca diz que nunca Deus diss' a san Pedro mais de tanto: «Quem tu legares en terra erit ligatum in celo»; poren diz ca non é torto de vender hom'o castelo.

E poren diz que non fez torto o que vendeu Marialva, ca lhe diss' o arcebispo un vesso per que se salva: «Estote fortes in bello et pugnate cum serpente», poren diz que non é torto quen faz traiçon e mente.

O que vendeu Leyrea muyto ten que fez dereito, ca fez mandado do Papa e confirmou-lh' o esleito «Super istud caput meum et super ista mea capa» dade o castelo ao Conde, pois vo-lo manda o Papa.

O que vendeu Faria por remiir seus pecados, se mais tevesse, mais daria; e disseron dous prelados: «Tu autem, Domine, dimitte» aquel que se cofonde; ben esmolou en sa vida quen deu Santaren ao Conde.

Ofereçeu Martin Diaz aa cruz, que os cofonde, Covilhãa, e Pero Diaz Sortelha; e diss' o Conde: 
«Centuplum accipiatis» de mão do Padre Sancto.

Diz Fernan Diaz: «Ben m’est[e], por que oferi Monsanto».

[Pois non] ofereçeu Trancoso ao Conde Roy Bezerro, falou enton don Soeyro por sacar seu filho d' erro:

«Non potest filia mea sine patre suo facere quidquam»:

salvos son os traedores, pois ben hisopados fican!

O que ofereceu Sintra fez come bon cavaleyro, e disso-lhi o legado log'un vesso do Salteyro:

«Sagitte potentis acute», e foy hy ben acordado:

melhor é de seer traedor ca morrer escomungado.

E quando o Conde ao castelo chegou de Celorico, Pachec' enton o cuitelo tirou; et disse-lh'un bispo: «Mitte gladium in vagina», con el non nos empeescas.

Diz Pacheco: «Alhur, Conde, peede hu vos digam: Crescas!».

Maldisse don Ayras Soga ũa velha noutro dia; disse-lhi Pero Soarez un vesso per clerizia:

«Non vetula bombatricon scandit confusio ficum»; non foy Soeyro Bezerra alcaide de Celorico.

Salvos son os traedores quantos os castelos deron; mostraron-lhi en escrito [que foy ben quanto fezeron] «super ignem eternum et divinitatis opem»: salvo é quen trae castelo, a preito que o hisopen!

\section{Comentario}

Unha das sátiras máis célebres dos cancioneiros, datable por volta de 1247. Refírese a feitos históricos, censurando a traizón dos tenentes dun conxunto de castelos do centro de Portugal (a Beira), que foron entregados ao Conde de Bolonha (o «rey don Afonso» a que se refire a rúbrica explicativa), traizoando ao monarca lexítimo, Sancho II, e coa beizón do Papa e os bispos. Ayras Perez Vuytoron foi un cabaleiro galego que seguramente participou na hoste convocada polo infante Afonso para ir en axuda de Sancho II contra os rebeldes. A entrega do castelo de Monsanto por parte de Sueyro Bezerra é tomada como paradigma da deslealdade. En cada estrofa menciónase un ou dous castelos rendidos a traizón: Monsanto, Marialba, Leiria, Faria, Covilhãa, Sortelha, Trancoso, Sintra, Celorico. O Papa e os bispos encirraran a revolta nobiliar contra Sancho e beiceron a súa deposición, de xeito que a complicidade do clero cos revoltados exprésase na cantiga con cadanseu verso latino (ou macarrónico) por estrofa, en moitos casos citando versículos bíblicos ou frases dos oficios do ritual católico. 


\section{Notas}

ben é que a jur a tenhamos: é xusto que a consideremos de lei (legal)

418 Non ten Sueyro Bezerra que tort'é en vender Monsanto: Non pensa S. B. que hai delito en vender Monsanto «Quem tu legares en terra erit ligatum in celo»: «O que ti atares na terra será atado no ceo» poren diz ca non é torto de vender hom'o castelo: por tanto, di que non é delito vender o castelo ca lhe diss' o arcebispo un vesso per que se salva: xa que o arcebispo lle recitou un versículo que o salva «Estote fortes in bello et pugnate cum serpente»: «Sede fortes na batalla e loitade coa serpente» confirmou-lh' o esleito: confirmoullo o (bispo) elexido «Super istud caput meum et super ista mea capa»: «Sobre a miña cabeza e sobre a miña capa» remiir: redimir

«Tu autem, Domine, dimitte» aquel que se cofonde: «Ti, Señor, perdoa» aquel que se perde «Centuplum accipiatis»: «Recibideres o céntuplo» «Non potest filia mea sine patre suo facere quidquam»: «Non pode a miña filla facer nada sen o pai» hisopados: bendicidos e disso-lhi o legado log'un vesso do Salteyro: e díxolle o enviado do papa un verso do Libro dos Salmos «Sagitte potentis acute»: «Frechas potentes e afiadas» «Mitte gladium in vagina», con el non nos empeescas: «Mete a espada na vaíña, con el non nos incomodes Diz Pacheco: «Alhur, Conde, peede hu vos digam: Crescas!»: verso de difícil lectura e escura interpretación «Non vetula bombatricon scandit confusio ficum»: verso de difícil lectura e escura interpretación «super ignem eternum et divinitatis opem»: «por riba do lume eterno e do poder divino» salvo é quen trae castelo, a preito que o hisopen!: salvado queda o que traizoa o castelo, con tal de que o bendigan!

\section{DIEGO PEZELHO, JOGRAR (B1592, V1124)}

Meu Senhor arcebispo, and' eu escomungado

porque fiz lealdade: enganou-mi o pecado.

Soltade-m', ay Senhor,

e jurarey, mandado, que seja traedor.

Se traiçon fezesse nunca vo-la diria;

mais, pois fiz lealdade, vel por Santa Maria,

soltade-m', ay, Senhor,

e jurarey, mandado,

que seja traedor.

Per mia malaventura tivi ũu castelo en Sousa

e dey-o a seu don' e tenho que fiz gran cousa:

soltade-m', ay, senhor,

e jurarey, mandado,

que seja traedor.

Per meus negros pecados tive ũu castelo forte e dey-o a seu don' e ey medo da morte. 
soltade-m', ay, senhor,

e jurarey, mandado,

que seja traedor.

\section{Comentario}

Outra sátira, cargada de ironía, centrada nos mesmos feitos ca a anterior, e novamente poñendo en foco non só os traidores que entregaron os castelos, senón tamén a xerarquía eclesiástica que encirrou a rebelión dos nobres. A cantiga está posta en boca dun tenente leal ao rei (fixen lealdade, tiven un castelo en Sousa e deillo ao seu dono) que confesa o seu «pecado» (se traizón fixese, non me confesaría) e pide absolución ao arcebispo de Braga (soltade-me), xurando que se corrixirá e será un traidor. Diego Pezello é un xograr, probablemente galego e tal vez empregado de Airas Perez Vuitoron, que acompañou a hoste do infante Afonso na súa incursión en Portugal.

\section{I.2. AS CAMPAÑAS EN AL-ANDALUS}

\section{AFONSO O SABIO (B472)}

Pero que ey ora mengua de conpanha, nen Pero Garcia nen Pero d' Espanha

nen Pero Galego

non irá comego.

E ben vo-lo juro par Santa Maria:

que Pero d' Espanha nen Pero Garcia

nen Pero Galego

non iran cõmego.

Nunca cinga espada con bõa baynha,

se Pero d' Espanha nen Pero Galinha

nen Pero Galego

for ora cõmego.

Galego, Galego, outren irá comego!

\section{Comentario}

Primeira da serie de cantigas de Afonso contra os nobres que refugaron acompañalo coas súas hostes nas campañas militares en Andalucía, ben co gallo da revolta mudéxar de 1264 ou ben nas campañas da década seguinte. A acusación refírese xeneri- 
camente aos nobres galegos e «de Espanha», empregado o nome «Pero» (Pedro) nun sentido xeral, e deslizando unha acusación de covardía (Pero Galinha).

\section{Notas}

Pero que ey ora mengua de conpanha: Aínda que peciso reforzos. outren irá comego!: outro irá comigo!

\section{AFONSO X O SABIO (B491, V74)}

O genete

pois remete

seu alfaraz corredor:

estremece

e esmorece

o coteife con pavor.

Vi coteifes orpelados

estar muy mal espantados,

e genetes trosquiados

corrian-nos arredor;

tiinhan-nos mal aficados,

[e] perdian-na color.

Vi coteifes de gran brio

eno meyo do estio

estar tremendo sen frio

ant' os mouros d' Azamor;

e ia-se deles rio

que Auguadalquivir mayor.

Vi eu de coteifes azes

con infanções siguazes

muy peores ca rapazes;

e ouveron tal pavor

que os seus panos d' arrazes

tornaron doutra color.

Vi coteifes con arminhos, conhocedores de vinhos, que rapazes dos martinhos, que non tragian Senhor, 
saíron aos mesquinhos,

e fezeron todo peor.

Vi coteifes e cochões

con muy longos granhões

que as barvas dos cabrões:

ao son do atanbor

os deitavan dos arções

ant' os pees de seu Senhor.

\section{Comentario}

Vibrante sátira que fustiga a covardía dos coteifes (cabaleiros viláns) ante a cabalaría inimiga, os temibles genetes (da cabalería bereber), que cruzaron o Estreito de Xibraltar en auxilio do rei de Granada.

\section{Notas}

alfaraz: corcel árabe.

coteifes orpelados: soldados barbados?

genetes trosquiados: soldados rapados.

mal aficados: moi apertados.

Azamor: cidade da costa marroquina.

e ia-se deles rio...: íaselles un río maior ca do Guadalquivir, isto é, mexaban por eles (de terror).

infanções siguazes: cabaleiros nobres que ía detrás (?).

que os seus panos d' arrazes /...: os seus panos de Arrás quedaron sen cor (do medo).

conhocedores de vinhos: referencia escura difícil de interpretar.

rapazes dos martinhos: referencia escura.

con muy longos granhões: con longas greñas.

\section{AFONSO X O SABIO (B494, V77)}

O que foy passar a serra

e non quis servir a terra,

é ora, entrant' a guerra,

que faroneja?

Pois el agora tan muyto erra,

maldito seja!

O que levou os dinheyros

e non troux' os cavaleyros,

é por non ir nos primeyros

que faroneja? 
Pois que ven cõn-os prostumeyros,

maldito seja!

O que filhou gran soldada

e nunca fez cavalgada,

é por non ir a Graada

que faroneja?

Se é ricomẽ ou á mesnada,

maldito seja!

O que meteu na taleiga

pouc' aver e muyta meiga,

é por non entrar na Veiga

que faroneja?

Pois chus mol[e] é que manteiga,

maldito seja!

\section{Comentario}

Outra cantiga contra a falta de apoio dos nobres nas campañas bélicas do rei en Andalucía. Probablemente, neste caso refírese a un personaxe que o seu auditorio recoñecería, ou talvez a catro personaxes (un por estrofa) que serían notorios na época. Simon Doubleday propón datar a cantiga en 1274ca. e identificar o personaxe con Nuno Gonzalez de Lara, compañeiro desde a mocidade, do círculo de maior confianza do rei, que en 1271-72 liderou a rebelión dos nobres e buscou refuxio no reino de Granada (foy passar a serra). Os nobres, que nesa ocasión se aliaron co rei de Granada, entre outras cousas, reclamaban o pagamento dos seus servizos (soldada). A cantiga tamén podería referirse á campaña de represalia contra o rei de Granada de 1278, pola súa complicidade coa incursión dos benimeríns, e de aí a referencia á «Veiga» (de Granada). A chave da cantiga está no verbo faronejar, «quedar atrás, avanzar lentamente, con desidia». O verbo probablemente é derivado do adxectivo farón, aplicado ao animal (cabalo, burro,... ) que se nega a andar.

\section{Notas}

é ora, entrant' a guerra, / que faroneja?: é agora, cando comeza a guerra, cando queda atrás?

o que meteu na taleiga / ... o que meteu na alforxa pouco haber e moito conto.

Pois chus mole é que manteiga: pois é máis brando ca a manteiga (alusión á covardía). 
6. AFONSO O SABIO (B496/144b, V79)

Quen da guerra levou cavaleyros

e a sa terra foy guardar dinheyros,

non ven al mayo.

Quen de guerra se foy con maldade

e a sa terra foy comprar herdade,

non ven al mayo.

O que da guerra se foy con nemiga

pero non veo quand' é preitesia,

non ven al mayo.

O que tragia o pano de linho

pero non vẽo polo San Martinho,

non ven al mayo.

O que tragia o pendon sen cinco

e [e]no dedo sen pedra o vinco,

non ven al mayo.

O que tragia o pendon sen oyto

e a sa gente non dava pan coyto,

non ven al mayo.

O que tragia o pendon sen sete

e cinta ancha e muy gran topete,

non ven al mayo.

O que tragia o pendon sen tenda, per quant' agora sey de sa fazenda,

non ven al mayo.

O que con medo se foy dos martinhos

e a sa terra foy bever los vinhos,

non ven al mayo.

O que con medo fugiu da fronteyra

pero tragia pendon sen caldeyra,

non ven al mayo.

O que roub[ava] os mouros malditos

e a sa terra foi roubar cabritos,

non ven al mayo.

O que da guerra se foy con espanto

e a sa terra ar foy armar manto,

non ven al mayo.

O que da guerra se foy con gran medo

contra sa terra, espargendo vedo,

non ven al mayo. 
O que tragia pendon de cadarço, macar non vẽo en mes de março, non ven al mayo.

O que da guerra [se] foy recreudo, macar en Burgos fez pintar escudo, non ven al mayo.

\section{Comentario}

Outra cantiga máis da serie satírica contra os nobres que non acoden coas súas hostes ás campañas militares do rei en Andalucía. A chave aquí está no refrán, que fai referencia á convocatorias de reunión das tropas, que adoitaban realizarse no mes de maio, cando se iniciaba a temporada propicia para as hostilidades.

\section{Notas}

O que tragia o pendon sen cinco /...: o que traía o estandarte, pero sen nin tan sequera cinco combatentes, e no dedo o anel sen pedra (enténdase coma unha comparanza).

e a sa gente non dava pan coyto: e á súa hoste non lle daba pan cocido.

e cinta ancha e muy gran topete: modo de axeitar o cabelo da parte superior da cabeza típico dos nobres rurais. O que con medo se foy dos martinhos: o que se foi con medo dos combatentes mouros (?)

Pero tragia pendon sen caldeyra: o pendón sen a insignia que demostraba capacidade dos cabaleiros para contribuír cos seus medios á guerra.

contra sa terra, espargendo vedo: para a súa terra, morto de medo (escagarriado).

cadarço: seda basta.

recreudo: covarde.

macar en Burgos fez pintar escudo: probable alusión ás cortes de Burgos de 1272, onde os nobres impuxeron as súas demandas ao rei.

\section{AFONSO MENDEZ DE BESTEYROS (B1558)}

Don Foão, que eu sey que á preço de livão, vedes que fez ena guerra -daquesto soo certão: sol que viu os genetes, come boy que fer tavão, sacudiu-se e revolveu-se, alçou rab' e foy sa via a Portugal.

Don Foão, que eu sey que á preço de ligeyro, vedes que fez ena guerra -daquesto son verdadeyro: sol que viu os genetes, come bezerro tenreyro, sacudiu-se e revolveu-se, alçou rab’ e foy sa via a Portugal. 
Don Foão, que eu sey que á prez de liveldade, vedes que fezo na guerra - sabede-o por verdade: sol que viu os genetes, come can que sal de grade,

sacudiu-se e revolveu-se, al-

çou rab' e foy sa via a Portugal.

\section{Comentario}

Outra sátira máis contra a covardía dos nobres nas guerras andaluzas, neste caso dirixida a un nobre portugués, que non aparece identificado (don foão: «un tipo»). Afonso Mendez de Besteyros foi un cabaleiro portugués, partidario do deposto rei Sancho II; que ou ben se exiliou a Castela con Afonso o Sabio, ou ben estivo na súa corte.

\section{Notas}

á preço de livão / de ligeyro // prez de liveldade: ten sona de covarde. sol que viu os genetes: nada máis ver os xinetes (cabaleiros bereberes). come boy que fer tavão, / ...: como un boi picado por un tabán, ... alzou o rabo e liscou para Portugal. come can que sal de grade: coma o can que sae da gaiola.

\section{GIL PEREZ CONDE (B1516)}

Non troux' estes cavaleyros aqui este ricome nunca na guerra, que ora trage; son doutra terra, ca ja eu [en eles] mentes meti; nen seus numes non-os conhosco, ca lhis dissera «bon dia vosco!», mais nẽhun [deles] eu non conhoci.

Nen estas armas eu nunca lhas vi trajer na guerra, destes sinaes que ora trage non trouxe taes nosco na guerra quand' el Rey foy hy, nen outras; por que as ar faria, senon quae-las ante tragia? E ja sobr' esto con muytos departi.

Nen el enton non parecia assy na guerra, cordo como parece, ca nen cavalgada nen ensandece nunca fezeron en que el non foss' y; 
e as lazeyras per que passava, andand[o] aló, tan pouco dava por elas come se nunca foss' [y].

Nen custa nunca a receava; nen perda, nen med', alá hu andava... nunca de tal home falar oý.

\section{Comentario}

Gil Perez Conde é un cabaleiro portugués que estivo nas cortes de Afonso o Sabio e Sancho IV, autor dunha sobranceira obra satírica. Esta sátira hai que interpretala en chave irónica: o trobador marabíllase coa presenza dun nobre e a súa hoste, que se presentan cando non fan falla, pois non hai guerra, pero non acudiron cando era preciso ao campo de batalla.

\section{PERO GOMEZ BARROSO (B1443, V1054)}

Un ricome que oj' eu sey, que na guerra non foy aqui, ven muy sanhudo e diz assi como vos agora direy:

diz que ten terra qual pediu, mais, porque a nunca serviu, á muy gran querela del Rey. El vẽo, se Deus mi pardon, des que viu que era paz; ben lhi venha [hy], se ben faz, pero mostra el tal razon:

diz que ten terra qual pediu, mais, porque a nunca serviu, contra el Rey anda muy felon.

Pero na guerra non fez ben nen mal, que non quis hy viir con coyta del Rey non servir, pero mostra el ũa ren:

diz que ten terra qual pediu, mais, porque a nunca serviu, al Rey quer muy gran mal poren. 
Sanhudo ven contr' el Rey ja,

ca, hu foy mester, non chegou,

e mais de mil vezes jurou

que da terra non sairá;

diz que ten terra qual pediu,

mais, porque nunca a serviu,

al Rey poren gran mal querrá.

\section{Comentario}

Outra sátira anti-nobiliar dun trobador portugués exilado na corte afonsina despois da guerra civil portuguesa. De feito, participou na conquista de Sevilla e gañou un notable peso político ao lado de Afonso o Sabio, que lle encargou unha delicada misión negociadora como intermediario entre o monarca e os nobres revoltados contra el en alianza co rei de Granada, nun dos momentos máis criticos do reinado de Afonso. A cantiga, en chave de irónica paradoxa, censura un aristócrata (ricome) que non se presentou a auxiliar o monarca na guerra e despois preséntase enfadado (sanhudo), alegando que o rei lle concedeu a terra que el pedira e vén a queixárselle, porque non a serviu como debera.

\section{Notas}

que na guerra non foy aqui: que non se presentou cando a guerra.

ven muy sanhudo: vén moi airado.

El vẽo ... desque viu que era paz: presentouse cando chegou a paz.

ben lhi venha [hy], se ben faz / ...: que lle preste, se lle convén.

con coyta del Rey non servir: con afán de non servir ao Rei.

pero mostra el ũa ren: explica el o seguinte.

ca, hu foy mester, non chegou: porque, cando era necesario, non se presentou.

\section{DESAVINZAS CO PAPA E SÁTIRA DO CLERO}

10. AFONSO O SABIO (B463)

Se me graça fezesse este Papa de Roma!

Pois que er os panos da mia reposte toma,

que levass' el os cabos e dess' a mí a soma;

mais doutra guisa me foy el vende-la galdrapa.

Quisera eu assy ora deste nosso Papa

que me talhasse melhor aquesta capa. 
Se m’ el graça fezesse con os seus cardeaes, que lh' eu dess' e que mos talhasse iguaes; mais vedes en que vi en el maos sinaes, que do que me furtou, foy cobri-la sa capa.

Quisera eu assy ora deste nosso Papa

que me talhasse melhor aquesta capa.

Se con os cardeaes, con que faz seus conselhos, posesse que guardasse nós de maos trebelhos, fezera gran mercee, ca non furtar con elhos e os panos dos cristãos meter sô sa capa.

Quisera eu assy ora deste nosso Papa

que me talhasse melhor aquesta capa.

\section{Comentario}

Sátira do monarca contra o Papa, censurándoo porque lle rouba dereitos e bens que lle pertencen. A partir desta interpretación xeral da cantiga, que é bastante clara, a chave para a interpretación do seu texto concreto, bastante escuro para o lector actual, está no significado dos panos e da capa e todo o xogo cos duplos significados destes termos e doutros relacionados con eles, incluíndo frases feitas de significado que intuímos pero pouco claro para nós (vende-la galdrapa, talhar iguaes, talhar ũa capa, cobri-la sa capa, meter sô sa capa). Os panos fan referencia ás teas en xeral e ás vestimentas en particular. Son bastantes as cantigas satíricas que se refiren aos panos nos dous sentidos: por unha parte, como medio de pagamento (pois como tales eran usados naquel tempo), por outra parte, xogando cos distintos tipos de vestimenta como expresión do status social. Seguindo isto, probablemente co pano de fondo da disputa sobre a coroa imperial, a que Afonso aspirou e o Papa acabou por negar (1272), coñécese que na Afonso acusa o Papa de apropiarse de haberes ou dereitos que lle corresponden como monarca (talvez aludindo tamén á designación dos bispos, cuestión candente polo conflito sobre o arcebispado de Compostela), e mesmo de apropiarse de bens de todos os cristiáns, quizais aludindo aos tributo que cobraba a Igrexa e que en parte eran desviados a Roma.

\section{Notas}

Pois que er os panos da mia reposte toma / ...: visto que as roupas do meu vestiario colle que levass' el os cabos e dess' a mí a soma: que quedase el coas pezas de menor valor e me deixase a min as mellores

doutra guisa me foy el vende-la galdrapa: doutro xeito me vendeu el o pano; a galdrapa era un manto que se colocaba na garupa da cabalgadura, debaixo da sela de montar; a expresión empregada parece ten un sentido de «enganar».

que me talhasse melhor aquesta capa: que me cortase mellor esta capa; que me arranxase mellor este negocio 
que lh' eu dess' e que mos talhasse iguaaes: que eu llos dese e mos cortase polo mesmo padrón; o sentido pode ser «que aceptase os prelados da miña preferencia»

mais vedes en que vi en el maos sinaes / ...: mais reparade en que eu notei os seus maos modos, as súas avesas intencións.

que do que me furtou, foy cobri-la sa capa: que foi cubrir a súa capa do que me furtou; o sentido pode ser «que se foi vestir co que me roubou», «que se aproveitou ou alardeou do que me quitou» (a coroa imperial?).

posesse que guardasse nós de maos trebelhos: se dedicasen a protexernos de maos pasos

ca non furtar con elhos /...: e non roubar con eles (os cardeais) e meter os bens dos cristiáns nos seus petos (sô sa capa).

\section{AFONSO X O SABIO (B493, V76)}

Ao dayan de Calez eu achei livros que lhi levavan de Berger; e o que os tragia preguntey por eles, e respondeu-m’ el: «Senher, con estes livros que vós veedes dous e con-os outros que ele ten dos sous, fod' el per eles quanto foder quer.

E aynda vos end' eu mais direy: macar na Ley muyt'á leer [mester], por quanto eu [de] sa fazenda sey, con-os livros que ten, non á molher a que non faça que semelhen grous os corvos, e as aguias babous, per força de foder, se x' el quiser.

Ca non á mais, na arte do foder, do que nos livros que el ten jaz; e el á tal sabor de os leer, que nunca noite nen dia al faz; e sabe d' arte do foder tan ben, que con-os seus livros d' artes, que el ten, fod' el as mouras cada que lhi praz.

E mais vos contarey de seu saber, que con-os livros que el ten faz: manda-os ante sy todos trager, e pois que fode per eles assaz, se molher acha que o demo ten, 
assy a fode per arte e per sén, que saca dela o demo malvaz.

E, con tod' esto, aynda faz al con-os livros que ten, per bõa fe:

Se acha molher que aja mal deste fogo que de san Marçal é, assy [a] vay per foder encantar que, fodendo, lhi faz ben semelhar que é geada ou nev' e non al.

\section{Comentario}

Vituperio xocoso do deán da catedral de Cádiz, afeccionado á literatura pornográfica e asiduo practicante do sexo e a maxia. A cidade de Cádiz foi conquistada e refundada por Afonso o Sabio en 1262, pouco despois da toma de Alcanatif, que foi rebautizada como Puerto de Santa María (1260). Pouco despois, a cidade pasou a ser sede episcopal. Está documentado un deán de Cádiz, Roy Diaz, que tal vez tivo algún desencontro co rei que provocou esta sátira subida de ton, en que a imaxe do clero non sae moi ben parada.

\section{Notas}

dos sous: dos seus

macar na Ley muyt'á leer [mester]: aínda que lle cómper estudar moito as leis (canónicas)

a que non faça que semelhen grous /...: a que non faga que lle semellen os corvos grous e as enguías vermes da seda (isto é, que non faga alucinar).

do que nos livros que el ten jaz: do que se contén nos libros que el ten.

e pois que fode per eles assaz: e despois de que fode grazas a eles dabondo

per arte e per sén: con arte e con saber

Se acha molher que aja mal /...: se atopa unha muller que padeza do fogo de san Marzal, encántaa mediante o sexo, e faille crer que é xeada ou neve e non outra cousa. Clara referencia a prácticas de maxia: o fogo de San Marçal era unha designación popular da eripsela, unha doenza infecciosa da pel, que provocaba unha intensa sensación de frío, seguida de grandes calores. Na cantiga n.ํㅗ1 das CSM esta doenza é descrita en pormenor.

\section{LEAS NA FAMILIA REAL}

\section{GONÇALO EANES DO VIÑAL (V1008)}

Esta cantiga fez don Gonçal'Anes do Vinhal ao infante don Anrique porque dizian que era entendedor da Raynha dona Joana, sa madrasta, e esto foy quando o el rey don Afonso pos fora da terra. 
Sey eu, donas, que deitad' é d' aqui, do reyno, ja meu amigu' e non sey como lhi vay, mais quer' ir a el rey,

chorar-lh'-ey muyto e direy-lh' assy:

«Por Deus, senhor, que vos tan bon rey fez,

perdoad' a meu amigu' esta vez».

Porque o amo tan de coraçon, como nunc' amou amigo molher,

irey ali hu el rey estever,

chorando dos olhos, direy-lh' enton:

«Por Deus senhor, que vos tan bon rey fez,

perdoad' a meu amigu' esta vez».

$\mathrm{E}$, pois que me non val rogar a Deus,

nen os santos non me queren oyr,

irey a el rey mercee pedir

e direy, chorando dos olhos meus:

«Por Deus, senhor, que vos tan bon rey fez,

perdoad' a meu amigu' esta vez,

e por Deus, que vos deu honr' e bondade

a don Anris esta vez [perdoade]».

\section{Comentario}

Gonçalo Eanes do Viñal foi un trobador portugués que fixo unha meteórica carreira na corte de Afonso o Sabio, con quen participou en campañas militares xa nos tempos en que este, aínda infante, conquistou Murcia (1243). Debeu de servir ao monarca en difíciles misións, porque recibiu un importante señorío en Aguilar (Andalucía). Compuxo dúas cantigas relacionadas coas desavinzas entre Afonso e o seu irmán o príncipe Enrique, que acabou sendo expulsado dos reinos (el rey don Afonso o puxo fóra da terra). Ambas teñen forma de cantiga de amigo; nesta, posta en voz de dona Johana de Ponthieu, segunda esposa e viúva de Fernando III; preséntase a Enrique como amante (entendedor) da súa madrasta, quen lle implora ao rei que lle levante o castigo do desterro.

\section{PERO DA PONTE (B1655, V1189)}

Esta cantiga fez Pero da Ponte ao infante don Manuel, que se começa «Mort’é don Martin Marcos», e na cobra segunda o poden entender. 
Mort' é Don Martin Marcos, ay Deus, se é verdade?

Sey ca se el é morto, morta é torpidade, morta é bavequia e morta neiciidade, morta é covardia e morta é maldade.

Se Don Martinh' é morto, sen prez e sen bondade, oy-mais, maos costumes, outro senhor catade; mais non-o acharedes de Roma ata Cidade; se tal senhor queredes, alhu-lo demandade.

Pero un cavaleyro sey eu, par caridade, que vos ajudari' a tolher del soydade; mais [queredes] que vos diga ende ben verdade?: non est rey nen conde, mais é-x' outra podestade, que non direy, que direy, que non direy...

\section{Comentario}

Sátira do segrel compostelán Pero da Ponte contra o infante don Manuel, fillo de Afonso o Sabio, quen se puxera de parte do seu irmán, o futuro rei Sancho IV, no preito sucesorio que este mantivo co monarca. Este preito estoupou a finais da década de 1270 e desembocou na rebelión aberta de Sancho e na deposición de Afonso, quen viviu os dous últimos anos do seu reinado retirado e illado en Sevilla, mentres o seu fillo tomaba as rendas do goberno. A sátira toma forma de parodia dun pranto ou elexía fúnebre - tipo de composición en que Pero da Ponte era especialista- e constitúe unha execración do infante Manuel por persoa interposta, un tal Martin Marcos, cuxa morte da pé para un implacable retrato moral do infante rebelde.

\section{Notas}

morta é bavequia e morta neiciidade: morta é a estupidez e a necidade. sen prez: sen honra.

oy-mais, maos costumes, outro senhor catade: de hoxe en diante, maos costumes, procurade outro señor. alhu-lo demandade: ídeo procurar a outra parte. 


\section{POLÉMICAS SOCIO-LITERARIAS}

14. AFONSO X O SABIO (B485, V68)

Pero da Pont' á feito gran pecado

de seus cantares, que el foy furtar

a Coton, que, quanto el lazerado

ouve gran tempo, el x'os quer lograr,

e doutros muytos que non sey contar,

por que oj' anda vistido e onrado.

E poren foy Coton mal dia nado, pois Pero da Ponte herda seu trobar;

e muy mais lhi valera que trobado

nunca ouvess' el, assy Deus m’ ampar, pois que se de quant' el foy lazerar serve don Pedro e non lhi dá en grado.

E con dereito seer enforcado deve Don Pedro, por que foy filhar a Coton, pois lo ouve soterrado, seus cantares, e non quis ende dar ũu soldo pera sa alma quitar sequer do que lhi avia emprestado.

E porend' é gran traedor provado, de que se ja nunca pode salvar, come quen a seu amigo jurado, bevendo con ele, o foy matar: todo po-los cantares del levar, come é que oj' anda arrufado?

E pois non á quen-no poren retar queyra, seerá oy-mais por min retado.

\section{Comentario}

Sátira de Afonso o Sabio contra o segrel Pero da Ponte, ao que acusa, humoristicamente, de que emborrachou, asasinou e enterrou o trobador Afonso Eanes do Coton para apoderarse das súas cantigas. O rei sentencia que Pero da Ponte debe ser aforcado, porque despois de cometer o crime, nin sequera deu unha esmola pola alma do asasinado. 


\section{Notas}

á feito gran pecado: cometeu un gran pecado.

434 quanto el lazerado / ouve gran tempo: todo o que el traballou durante moito tempo.

el x'os quer lograr: quere aproveitalo para si.

E poren foy Coton mal dia nado: por iso, Coton naceu en mal día.

pois que se de quant' el foy lazerar / ...: pois de todo o que el traballou se lucra don Pedro (da Ponte) e non llo agradece.

e non quis ende dar /...: de todo o que se aproveitou da Ponte, non quixo nin sequera dar unha moeda pola alma de Afonso do Coton.

de que se ja nunca pode salvar: nunca poderá salvarse disto.

come é que oj' anda arrufado: como agora anda fardando.

seerá oy-mais por min retado: será retado por min de hoxe en diante.

\section{AFONSO X O SABIO (B487, V70)}

Pero da Ponte, paro-vos sinal

per ante o Demo do fogo infernal,

porque con Deus, o padre 'spirital,

minguar quisestes, mal per descreestes.

E ben vej' ora que trobar vos fal,

pois vós tan louca razon cometestes.

E pois razon atan descomunal

fostes filhar, e que tan pouco val,

pesar-mi-á en se vos pois a ben sal

ante o Diaboo, a que obedecestes.

E ben vej' ora que trobar vos fal,

pois vós tan louca razon cometestes.

Vós non trobades come proençal,

mais come Bernardo de Bonaval;

e por ende non é trobar natural,

pois que o del e do Dem' aprendestes.

E ben vej' ora que trobar vos fal,

pois vós tan louca razon cometestes.

E poren, don Pedr' en Vila Real,

en maao ponto vós tanto bevestes.

\section{Comentario}

Nova sátira xocosa contra o segrel cortesán Pero da Ponte. Se na anterior é acusado de asasinar e roubar a Afonso Eanes do Coton, nesta é imputado por ser autor dunha composición demoníaca, pero non está claro se ten este carácter polo seu contido relixioso 
(o cal parece improbable) ou é simplemente unha maneira figurada de descualificala hiperbolicamente. En todo caso, a afirmación «vós non trobades come proençal / mais come Bernardo de Bonaval» parece unha censura contra o desvío dos trobadores galegos (ou dos segreis composteláns?) respecto aos moldes occitanos.

\section{Notas}

paro-vos sinal: notifícovos, cítovos perante o demo; trátase dunha expresión xurídica minguar quisestes, mal per descreestes: quixestes faltar, e del renegastes.

E ben vej' ora que trobar vos fal: agora comprobo que non sodes capaz de trobar. pois vós tan louca razon cometestes: pois emprendestes tal loucura.

E pois razon atan descomunal / fostes filhar: xa que vos deu por cometer unha tolería tan enorme, pesar-mi-á en se vos pois a ben sal: hame de amolar se safades ben desta ante o demo.

e por ende non é trobar natural: e por isto non é trobar como é debido.

en Vila Real: pode referirse a Ciudad Real, localidade rebautizada como Vila Real por Afonso en 1255, ou a outra vila de reguengo, como Allariz ou Ribadavia.

\section{AFONSO EANES DO COTON / PERO DA PONTE (B969, V556)}

Pero da Ponte e Afons' Eanes fezeron esta tenzon

-Pero da Pont', en un vosso cantar

que vós ogano fezestes d' amor, fostes-vos hy escudeyro chamar.

E dized' ora tant', ay, trobador: pois vos escudeyro chamastes hy, por que vos queixades ora de min, por meus panos, que vos non quero dar?

-Afons' Anes, se vos én pesar, tornade-vos a vosso fiador; e de m'eu hy escudeyro chamar, e por que non, pois escudeyro for? E se peç' algo, vedes quant' á hy: non podemos todos guarir assy come vós, que guarides per lidar.

-Pero da Ponte, quen a mí veer desta razon ou doutra cometer, querrey-vo-lh' eu responder, se souber, como trobador deve responder: en nossa terra, se Deus me perdon, 
a todo escudeyro que pede don

as mais das gentes lhe chaman segrel.

-Afons' Anes, est' é meu mester,

e per esto dev' eu guarecer

e per servir donas quanto poder;

mais [hy] ũa ren vos quero dizer:

en pedir algo non digu' eu de non

a quen entendo que faço razon,

e alá lide quen lidar souber.

-Pero da Ponte, se Deus vos perdon, non faledes mais en armas, ca non

vos está ben, esto sabe quen-quer.

-Afons' Anes, filharey eu don,

é verdad', e vós, ay cor de leon?

E faça quis-cada-quen seu mester.

\section{Comentario}

Debate poético (tenzón) entre o trobador galego Afonso Eanes do Coton e o segrel Pero da Ponte, os dous involucrados nunha cantiga satírica de Afonso o Sabio. O interesante do texto é o debate sobre a definición dos respectivos status socioculturais, o do cabaleiro trobador e do escudeiro segrel. Afonso do Coton pregúntalle a Pero da Ponte por que se queixa de que el non o retribúa polo seu oficio (era moi común pagar con panos), tendo en conta de que se reivindica como escudeiro e trobador, por tanto, cultivador desinteresado da arte do trobar. Pero da Ponte respóndelle que el non vive da guerra, coma Afonso do Coton (guarides por lidar). Afonso replica que un escudeiro que troba a cambio de paga (escudeiro que pede don) «en nossa terra» (Galicia? a terra de Santiago? España?) é denominado segrel. Pero da Ponte continúa reivindicando o seu dereito a ser retribuído polo seu trobar. Afonso remate rogándolle ironicamente que non fale de armas, que non lle acae, e no retruque final, Pero da Ponte búrlase de Afonso alcumándoo humoristicamente de Cor de León (corazón de León).

\section{Notas}

por que vos queixades ora de min / ...: por que vos queixades de que non vos pague cos meus panos? se vos én pesar / tornade-vos a vosso fiador: se vos amola, queixádevos a quen volos fiou (insinuando que os panos de Coton son de fiado).

E se peç' algo, vedes quant'á hy: se pido algo a cambio de trobar, explico por que o fago.

non podemos todos guarir assy: non todos podemos gañar a vida así.

come vós, que guarides per lidar: coma vós, que vivides de facer a guerra.

desta razon ou doutra cometer: atacáronme con estes ou con outros argumentos. 
a todo escudeyro que pede don: a todo escudeiro que pide paga. esto sabe quen-quer: isto sábeo todo o mundo.

filharey eu don: recibirei pagamento.

E faça quis-cada-quen seu mester: e cada un faga o que lle pete.

\section{JOHAN PEREZ DE AVOYN CON LOURENÇO (V1010)}

-Lourenço, soýas tu guarecer

como podias, per teu citolon,

ou ben ou mal, non ti digu' eu de non,

e vejo-te de trobar trameter;

e quero-t' eu desto desenganar:

ben tanto sabes tu que é trobar

ben quanto sab' o asno de leer.

-Johan d' Avoyn, ja me cometer

veeron muytos por esta razon

que mi dizian, se Deus mi perdon,

que non sabia 'n trobar entender,

e veeron poren comigu' entençar,

e figi-os eu vençudos ficar

e cuydo-vos deste preito vençer.

-Lourenço, serias muy sabedor,

se me vencesses de trobar nen d' al,

ca ben sey eu quen troba ben ou mal,

que non sabe mais nẽhun trobador;

e por aquesto te desenganey;

e vês, Lourenço, onde cho direy:

quita-te sempre do que teu non for.

- Johan d' Avoyn, por Nostro Senhor,

por que leixarey eu trobar atal

que muy ben faç' e que muyto mi val?

Des hy ar gradece-mi-o mia senhor,

porque o faç'; e, pois eu tod' est' ey,

o trobar nunca o eu leixarey,

poi-lo ben faç' e ey hy gran sabor.

\section{Comentario}

Tenzón satírica entre o trobador portugués Johan Perez de Avoyn, un dos magnates máis sobranceiros da corte de Afonso III O Bolonhês, e o xogral Lourenço, un dos máis 
produtivos e polémicos dos representados nos cancioneiros. Johan de Avoyn, en ton humorístico, concede que Lourenço viva do seu oficio como executante (guarecer per teu citolon), pero pretende disuadilo de que se dedique a trobar. Lourenço, en ton desafiante gábase da súa competencia no trobar (que muy ben o faço), e advirte que non vai deixar, porque lle gusta (ey hy gran sabor) e porque llo agradece a súa dona.

\author{
Notas \\ soýas tu guarecer: antes gañabas a vida, como podías, co teu citolón; nótese o aumentativo de cítola \\ e vejo-te de trobar trameter: vexo que te entremetes no trobar \\ ja me cometer / veeron muytos: xa me viñeron atacar moitos \\ e veeron poren comigu' entençar: viñeron por iso a disputar en tenzón \\ e figi-os eu vençudos ficar: deixeinos vencidos \\ e cuydo-vos deste preito vençer: coido que vos vou vencer nesta discusión \\ se me vencesses de trobar nen d' al: se me vencess en trobar ou noutra cousa \\ e vês, Lourenço, onde cho direy /...: polo que eu cho direi \\ Des hy ar gradeçe-mi-o mia senhor: ademais, agradécemo a miña señor \\ poi-lo ben faç' e ey hy gran sabor: xa que o fago ben e gústame moito
}

\title{
V. TRISTURA NA CORTE E FUXIDA DO MUNDO
}

18. GIL PEREZ CONDE (B1525)

Non é Amor en cas del Rey, ca o non pod' om' y achar aa cea nen ao jantar; a estas oras o busquey nas pousadas dos privados; preguntey a seus prelados por Amor, e non-o achey.

Tẽen que o non sab’ el Rey que Amor aqui non chegou, que tant' ogano del levou e non vẽo; ben-o busquey nas tendas dos infanções e nas dos de criações, e hy dizen todos «non sey».

Perdud' é Amor con el Rey, porque nunca en hoste ven, pero xe del[e] algo ten.

Direy-vos eu hu o busquey: 
antr' estes freyres tempreyros,

ca ja os espitaleyros

por Amor non preguntarey.

\section{Comentario}

Esta cantiga de Gil Perez Conde, trobador portugués activo nas corte de Afonso o Sabio e Sancho IV, semella reflectir o ambiente tenso e depresivo da corte do primeiro nos seus últimos anos, cando o seu propio fillo Sancho se rebelara contra el. A referencia final aos Templarios é significativa, pois foi a única orde militar que se mantivo fiel ao monarca ata os seus derradeiros días. Nesta cantiga, Amor debe ser entendido non no sentido erótico, senón no de solidariedade e e concordia.

\section{Notas}

ca o non pod' om' y achar: non se pode atopar alí

Tẽen que o non sab' el Rey: coidan que non sabe o rei

Infanções: infanzóns, cabaleiros nobres

Criações: cabaleiros novos, criados na corte.

Hu o busquey: onde o busquei.

Antr' estes freyres tempreyros / ca ja os espitaleyros /...: entre os freires templarios (da Orde do Temple), porque aos hospitalarios (da Orde do Hospital) / por Amor non preguntarei.

\section{AFONSO O SABIO (B480, V63)}

Non me posso pagar tanto

do canto

das aves nen de seu son,

nen d' amor nen de misson

nen d' armas, ca ey espanto,

por quanto

muy perigoosas son,

-come dun bõo galeon,

que mi alongue muyt' aginha

deste demo da canpinha,

hu os alacrães som;

ca dentro no coraçon

senti deles a espinha!

E juro par Deus lo santo

que manto

non tragerey nen granhon,

nen terrey d' amor razon 
nen d' armas, porque quebranto

e chanto

440 ven delas toda sazon;

mais tragerey un dormon

e irey pela marinha

vendendo azeit' e farinha;

e fugirey do poçon

do alacran, ca eu non

lhi sey outra meezinha.

Nen de lançar a tavolado

pagado

non sõo, se Deus m' ampar,

a treo, nen de bafordar;

e andar de noute armado,

sen grado

o faço e a roldar;

ca mais me pago do mar

que de seer cavaleyro;

ca eu foy ja marinheyro

e quero-m' oy-mais gardar

do alacran, e tornar

ao que me foy primeyro.

E direy-vos ũu recado:

pecado

ja me non pod' enganar

que me faça ja falar

en armas, ca non m’é dado

-doado

m’é de as eu razõar,

pois las non ey a provar-;

ante quer' andar sinlheyro

e ir come mercadeyro

algũa terra buscar,

hu me non possan culpar

alacran negro nen veyro.

\section{Comentario}

Este é unha das cantigas máis célebres dos cancioneiros galego-portugueses. Orixinal e desconcertante, traballada sobre os tópicos do «contemptus mundi» e da «fuga 
mundi», o poema ten sido obxecto de interpretacións moi diversas, desde quen o le en termos autobiográficos ata quen, no extremo contrario, o considera un puro artificio (edición, comentario e discusión en Paredes 2010: 187-195, con remisión á bibliografía máis importante; véxase tamén del Río Grande 2018). A voz poética do rei expresa o seu desengano e o desexo de abandonar a vida que leva, propia dun cabaleiro: renuncia ao amor e ás armas e anuncia a súa decisión de fuxir por mar para vivir como mercadeiro, vendendo aceite e fariña. A chave da composición está no motivo que o apuxa a tan drástica decisión: librarse dos alacráns que o rodean e do seu veneno, unha referencia a penas encuberta á deslealdade e traizón, probablemente dos nobres e de varios dos seus familiares.

\section{Notas}

Non me posso pagar tanto: Xa non me podo deleitar.

nen de misson: nin de campañas militares.

ca ey espanto: pois téñolles medo.

que mi alongue muyt' aginha: que me aparte axiña

nen granhon: nin barba (que adoitaban levar os cabaleiros).

nen terrey d' amor razon: nin falarei de amor

chanto: pranto.

toda sazon: sempre.

mais tragerey un dormon: levarei unha barca.

e fugirey do poçon: fuxirei do veneno.

Nen de lançar a tavolado: Tampouco me apetece lanzar ao taboado (entretemento militar).

a treo, nen de bafordar: practicar o bafordo (un exercicio de armas); a treo é forma restaurada.

e andar de noute armado /...: andar de noite armado, a facer roldas, fágoo a contragusto. oy-mais: de hoxe en diante.

tornar / ao que me foy primeyro: volver ao que fun primeiramente.

E direy-vos ũu recado /...: Dareivos unha expliacación: o pecado xa non me pode enganar para facerme falar de armas, pois non me toca- éme de balde falar delas, pois nunca as vou probar.

ante quer' andar sinlheyro: prefiro andar solitario

hu me non possan culpar /...: onde non me poida trabar, alacrán negro nin pinto. 


\section{GABANZA DO REI E DO SEU «FEITO DO IMPERIO»}

20. JOHAN VASQUIZ DE TALAVEYRA/PEDRO AMIGO DE SEVILLA (B1550)

-Ay Pedr’ Amigo, vós que vos tẽedes

por trobador, agora o verey

eno que vos ora preguntarey

e no recado que mi tornaredes:

Nós, que avemos muy bon Rey por senhor

e no-lo alhur fazen enperador,

dizede-mi ora quant' y entendedes.

-Johan Vaasquiz, pois me cometedes, direy-vos eu quant' y entend' e sey: pois nós avemos aquel melhor Rey que no mund'á, ¿por que non entendedes que o seu prez e o seu valor todo noss' est, poys enperador for? O demo lev' o que vos hy perdedes!

-Ay Pedr' Amigo, eu non perderia en quant' el Rey podesse mais aver en bõa terra e en gran poder, ca quant' el mais ouvesse, mais valria. Mais perde o Reyn' e vos perdedes hy, os que sen el ficaredes aqui, pois que s' el for d' Espanha sa via.

-Johan Vaasquiz, eu ben cuidaria que o Reyno non á por que perder por el Rey nosso senhor mais valer, ca Rey do mund' é. Se se vay sa via valrá el mais, e ar nós per el hy.

Demais quis Deus que ten seu filh' aqui, que se s' el for, aqui nos leixaria.

-Ay Pedr' Amigo, pois vos ja venci desta tençon que vosco cometi, nunca ar migo filhedes perfia.

-Johan Vaasquiz, sey que non é assy desta tençon, ca errastes vos hy e diss' eu ben quanto dizer devia. 


\section{Comentario}

Gabanza do rei Afonso e do seu «feito do Imperio» tecida en forma de tenzón entre dous trobadores que frecuentaron a súa corte: o castelán Johan Vasquiz e o galego Pedro Amigo de Sevilla, probablemente composta pouco antes da viaxe do monarca a Beaucaire para entrevistarse co Papa nunha derradeira tentativa, fanada, de conseguir o apoio deste para a súa ambición imperial.

\section{Notas}

no-lo alhur fazen enperador: e nolo fan emperador outrures, noutra terra (alhur). quant' y entend' e sey: canto entedo e sei do assunto $(y)$.

ca quant' el mais ouvesse, mais valria: canto o rey máis tivese, máis valería.

Se se vay sa via / valrá el mais, e ar nós per el hy: se marcha, valerá el mais e, e nós tamén por el.

desta tençon que vosco cometi /...: xa que vos vencín nesta tenzón que fixen convosvo, nunca máis discutades comigo.

Ca errastes vos hy: porque vos errastes no asunto (ao afirmar que o reino e os súbditos perdían coa marcha do rei).

\section{UNHA AUTOBIOGRAFÍA POÉTICA E POLÍTICA}

\section{CANTIGAS DE SANTA MARÍA, CÓDICE DOS MÚSICOS, N. 235}

Esta é como Santa Maria deu saude al Rey don Afonso

quando foi en Valadolide enfermo que foi juygado por morto.

Como gradecer ben-feito / é cousa que muito val, assi quen non-o gradece / faz falsidad' e gran mal.

E daquest' un gran miragre / vos direi desta razon, que avẽo a don Afonso / de Castel' e de Leon Rei, e da Andaluzia / dos mais reinos que y son; e, por Deus, parad'y mentes /e non cuidedes en al.

Aqueste Santa Maria / mui de coraçon de pran loava mais doutra cousa, / e non prendia afan en servi-la noit' e dia, / rogando seu bon talan que morress' en seu serviço, / poi-lo seu ben nunca fal.

E desto que lle pedia / tan muito a aficou por esto, que ũa noite / en soños llo otorgou, ond' ele foi muit' alegre,/ tanto que s' el espertou, e loou porend' a Virgen,/ a Señor espirital. 
Pois passou per muitas coitas / e delas vos contarei: Ũa vez dos ricos-homes/ que, segundo que eu sei, se juraron contra ele / todos que non fosse Rey, seend' os mais seus parentes, / que divid' é natural,

E demais, sen tod' aquesto, / fazendo-lles muito ben, o que lle pouco gracian / e non tiỹan en ren; mais conortou-o a Virgẽ / dizendo: «Non dês poren nulla cousa, ca seu feito / destes é muy desleal.

Mas eu o desfarei todo / o que eles van ordir, que aquelo que desejan / nunca o possan conprir; ca meu fillo Jesu-Cristo / sabor á de se servir, e d'oi-mais mui ben te guarda / de gran pecado mortal».

Tod' aquesto fez a Virgẽ, / ca deles ben o vingou; e despois, quand' en Requena / este Rey mal enfermou, u cuidavan que morrese, / daquel mal ben o sãou; fez por el este miragre / que foi começ' e sinal Dos bẽes que lle fezera / e lle queria fazer. E depois, quando da terra / sayu e que foi veer o Papa que enton era, / foi tan mal adoecer que o teveron per morto / dest' anfermidad' atal.

E pois a Monpisler vẽo / e tan mal adoeceu que quantos fisicos eran, / cada ũu ben creeu que sen duvida mort' era; / mas ben o per guareceu a Virgen Santa Maria, / como Señor mui leal. E feze-ll' en poucos dias / que podesse cavalgar e que tornass' a sa terra / por en ela ben sãar; e passou per Cataloña, / en que ouve de fillar jornadas grandes no dia, / como quen and' a jornal. E pois entrou en Castela, / vẽeron todos aly, toda-las gentes da terra, / que lle dizian assy: «Sennor, tan bon dia vosco». / Mas depois, creed' a my, nunca assi foi vendudo / Rey don Sanch’ en Portugal,

Ca os mais dos ricos-omes / se juraron, per com' eu sei, por deitaren do reyno / e que ficasse por seu, que x'o entre si partissen; / mas de fazer lles foi greu, ca Deus lo alçou na cima / e eles baixou no val. 
E depois, quand' en Bitoira / morou un an' e un mes, jazendo mui mal doente, / contra el o Rey frances se moveu con mui gran gente; / mas depois foi mais cortes,

ca Deus desfez o seu feito / com' agua desfaz o sal.

E depois de muitos maes / o sãou, grandes e greus, que ouve pois en Castela, / u quis o Fillo de Deus que fillasse gran vingança / daqueles que eran seus ẽemigos e pois dele. / E ben com' ard' estadal

Ardeu a carne daqueles / que non querian moller; os outros pera o demo / foron e, se Deus quiser, assi yrá tod' aquele / que atal feito fezer, e do mal que lles én veña, / a mi mui pouco m’ incal.

E pois sayr de Castela, / el Rey con mui gran sabor ouve d' ir aa fronteira; / mas a mui bõa Sennor non quis que enton y fosse / se non sãasse mellor; porend' en todo o corpo / lle deu febre gẽeral.

E con est' anfermidade / das outras sãar o fez; e u cuidavan que morto / era, foi-se dessa vez dereit' a Valedolide, / u a Sennor mui de prez o guariu do que ficara. / Mas ante quis que en tal

Ponto vẽess' a seu feito, / que non ouvess' y joyz que de vida o julgasse, / e a Sant' Anperadriz lle fez ben sentir a morte; / mais eno dia fiiz de Pasqua quis que vivesse, / $\mathrm{u}$ fazen o ciro pasqual.

E ar foy-o conortando, / ca maltreit' era assaz, e de todas sas doores / o livrou ben e en paz, tragendo per el sas mãos, / e non tiinna enfaz e parecia mas crara / que é rubi nen crestal.

E tod' aquesto foi feito / dia de Pascua a luz per ela e per seu Fillo, / aquel que seve na cruz que tragia nos seus braços, / que pera nos sempr' aduz a sa merce' e sa graça / no perigo temporal.

Tod' aquesto faz a Virgen, / de certo creed' a min, pera dar-nos bõa vida / aqui e pois bõa fin; e porende a loemos / que nos meta no jardin de seu fill' e que nos guarde / do mui gran fog' yfernal. 
Como gradecer ben-feito / é cousa que muyto val, assi quen non-o gradece / faz falsidad' e gran mal.

\section{Comentario}

Nas Cantigas de Santa María atópanse unha serie de composicións que teñen un carácter autobiográfico, ou ben que contan episodios da vida de familiares de Afonso o Sabio. Unha das máis notables, e talvez a que ten un contido político máis explícito, é a que se reproduce aquí. Só figura nun dos códices, o máis amplo (E). A composición foi obxecto dun minucioso estudo sobre os feitos históricos que nela se relatan (Kinkade 1992). Este investigador subliña que a orde cronolóxica en que se presentan os acontecementos que máis relevantes da súa vida entre 1269 e 1279, o período talvez máis crucial do seu reinado, durante o cal se sucederon unha serie de infortunios para Afonso o Sabio: a traizón dos seus familiares, as conspiracións, revoltas e abandono das obrigas feudais de moitos dos aristócratas máis empoleirados dos seus reinos (os ricos-omes), unha sucesión de cinco terribles doenzas, a renuncia da súa reclamación do trono do Sacro Imperio por causa da oposición do Papa. Neses anos tamén se produciron as mortes do seu primoxénito e herdeiro, Fernando, e da súa filla Leonor, que son evocadas indirectamente («depois de muitos maes [...] grandes e greus»).

Tamén hai unha referencia a un acontecemento atroz, que foi a condena á morte que Afonso impuxo ao seu propio irmán, Fradique (esganado) e ao seu cuñado Simon Ruiz de los Cameros, queimado vivo (1277), condena que na cantiga se motiva pola acusación de manteren relacións homosexuais: «E ben com’ ard’ estadal / Ardeu a carne daqueles / que non querian moller», aínda que a realidade histórica parece máis complexa (Kinkade 1992: 315-318). Significativamente, lémbrase tamén a traizón que padecera o rei de Portugal, Sancho II, quen Afonso, aínda infante, tentara apoiar, sen suceso, fronte á rebelión dos nobres alentada pola Igrexa e encabezada polo seu propio irmán. Como o propio Kinkade indica, as palabras chave desta composición son traizón e ingratitude, ás que se podería engadir deslealdade.

\section{Notas}

foi juygado: foi xulgado, foi tido.

parad'y mentes /e non cuidedes en al: estade atentos e non pensedes noutra cousa.

de pran: realmente.

e non prendia afan: non se cansaba.

seu bon talan: con toda a alma.

poi-lo seu ben nunca fal: o ben da Virxe nunca falla.

tan muito a aficou: tanto lle insistiu.

que divid' é natural: os seus parentes están naturalmente obrigados (en débeda) con el.

o que lle pouco gracian / e non tiỹan en ren: pouco llo agradecían e non o tiñan en conta.

Non dês poren / nulla cousa: Non te preocupes por isto, non lle deas importancia. 
ordir: urdir.

sabor á de se servir: gústalle axudar.

d'oi-mais: desde agora.

u cuidavan que morrese: onde coidaron que ía morrer.

en que ouve de fillar: onde tivo que facer

por deitaren do reyno / e que ficasse por seu: os ricos-omes conxuráronse para expulsalo do reino e apoderarse deste.

de fazer lles foi greu: foilles imposible.

u quis o Fillo de Deus: onde quixo o Fillo de Deus.

E ben com' ard' estadal: así como arde un estadal.

e do mal que lles én veña, /...: do mal que lles veña (aos que van ao inferno) a min tanto me ten.

o guariu do que ficara: o curou do mal que lle quedara.

que non ouvess' y joyz /...: que non houbese xuíz que xulgase a súa vida (que non morrese).

u fazen o ciro pasqual: o día de Pascua, cando se acende o cirio pascual.

E ar foy-o conortando, / ...: e tamén o foi confortando, porque estaba moi maltreito.

e non tiinna enfaz: que non levaba veo (que lle cubrise a cara).

que seve na cruz: que estivo na cruz.

que pera nos sempr' aduz: que nos trae para sempre. 

Este libro saíu do prelo o día 23 de novembro de 2021, cando se cumpren 800 anos do nacemento de Afonso X. 






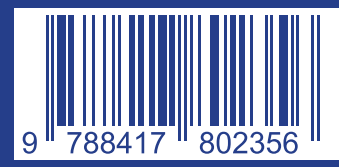

No ano 2021 cúmprense 800 anos do nacemento dun dos reis máis famosos, complexos e interesantes do noso pasado medieval: Afonso X (1221-1284). O Consello da Cultura Galega non podía quedar á marxe desta efeméride e, xunto a outras iniciativas, encargou a un grupo de historiadores, filólogos e historiadores da arte un volume en que se abordase a relación que o Rei Sabio tivo co reino de Galicia, coa súa cultura e coa súa lingua.

O mesmo monarca que foi quen de situar ao galego nun dos seus cumios literarios, coas Cantigas de Santa María ou coa súa lírica satírica, foi sinalado, entre outras cousas, como inimigo da Igrexa de Santiago, pouco entusiasta do fenómeno xacobeo, responsable do comezo da marxinalidade política de Galicia no conxunto da Coroa de Castela ou pouco proclive ao contacto coa nobreza e a Igrexa dun país que, por outra parte, nunca pisou durante o seu reinado.

Cal foi, en realidade, a relación de Afonso con Galicia e co galego? Neste volume preténdese dar unha resposta actual, poliédrica e afastada dos tópicos que máis recorrentemente condicionaron o estudo dun tema tan relevante. Malia a evidente predilección de Afonso X polos territorios do sur, sinaladamente Sevilla, este libro evidencia que Galicia seguiu a ser un dos reinos máis importantes para a Coroa, mesmo no plano financeiro. Ou que o cultivo literario da lingua galega foi en moitas ocasións, á marxe das claves afectivas ou persoais que contribúan a explicar o seu emprego, un recurso político habilmente empregado polo Sabio para promover os seus intereses e atacar os seus adversarios. Sen esquecer a importancia que os portos galegos tiveron na política afonsina ou as súas accións urbanizadoras no noso territorio.

Xa que logo, cómpre repensar o tópico da marxinalidade de Galicia nos tempos de Afonso o Sabio. 